FACULDADE DE ARQUITETURA E URBANISMO UNIVERSIDADE DE SÃO PAULO

TESE DE DOUTORADO

\title{
PADRÕES DE OCUPAÇÃO DO SOLO E MICROCLIMAS URBANOS NA REGIÃO DE CLIMA TROPICAL CONTINENTAL
}

Denise Helena Silva Duarte

Orientador: Prof. Dr. Geraldo Gomes Serra

São Paulo, outubro de 2000 


\title{
PADRÕES DE OCUPAÇÃO DO SOLO E MICROCLIMAS URBANOS NA REGIÃO DE CLIMA TROPICAL CONTINENTAL
}

\author{
Denise Helena Silva Duarte \\ Orientador: Prof. Dr. Geraldo Gomes Serra
}

Tese apresentada à Faculdade de Arquitetura e Urbanismo da Universidade de São Paulo como parte dos requisitos para a obtenção do título de Doutor em Arquitetura. 
"Para os ocidentalistas, do que o Brasil necessitava era do que um deles, regozijado com a violenta destruição das gelosias nos sobrados do Rio de Janeiro, em 1809, chamava expressivamente de 'desassombramento'. Desassombramento através do vidro inglês nas casas e nas carruagens ainda orientalmente revestidas de gelosias e cortinas: as casas de 'grades de xadrez' (...) Desassombramento nas cidades, através de ruas largas como as do Ocidente que substituíssem os becos orientalmente estreitos do Rio de Janeiro, de Salvador, do Recife, de São Luís do Maranhão, de São Paulo, de Olinda, de todos os burgos antigos do País. (...) Sob vários aspectos, o que havia já entre nós de imitado, assimilado ou adotado do Oriente representava uma já profunda e, às vezes, saudável adaptação do homem ao trópico, que aquele 'desassombramento' rompeu ou interrompeu quase de repente. Pois não se vence o trópico sem de algum modo ensombra-lo à moda dos árabes ou dos orientais. Sem ruas estreitas. Sem xales, panos da Costa, guardasóis orientalmente vastos para as caminhadas sob o sol dos dias mais quentes. Sem sombras de grandes árvores asiáticas e africanas, como a mangueira, a jaqueira, a gameleira, em volta das casas, nas praças e à beira das estradas. Sem telha côncava nos edifícios. Sem largos beirais arrebitados nas pontas em cornos de lua. Sem casas de telhado acachapado no estilo dos pagodes da China. Sem varanda ou copiar, à moda indiana, ou dos bangalôs da Índia, nas habitações rústicas. Sem cortinas, sem rótulas ou sem gelosias nas casas ou sobrados de cidade. Sem esteiras dentro das casas, forrando o chão. Sem colchas da índia nas camas dos ricos. Sem refrescos de tamarindo, de limão, de água de côco, nas horas de calor mais ardente. Sem muito azeite, muito cravo, muita pimenta, muito açafrão avermelhando a comida, avivando- $a$, requeimando-a para melhor despertar o paladar um tanto indolente das pessoas amolecidas pelo calor. E esses valores orientais, o Brasil assimilara-os através do português, do mouro, do judeu, do negro. $O$ Brasil fizera-os valores seus. Ao findar o século XVIII eram valores brasileiros. Ligavam amorosamente o homem e a sua casa à América tropical. Não podiam deixar de afetar a mentalidade ou o espírito dos homens, certo como é que o hábito tende a fazer o monge: tanto o hábitotrajo como o hábito-costume. ” 


\section{As Cidades e o Céu}

Ândria foi construída com tal arte que cada uma de suas ruas segue a órbita de um planeta $e$ os edifícios e os lugares públicos repetem a ordem das constelações e a localização dos astros mais luminosos: Antares, Alpheratz, Capela, as Cefeídas. O calendário da cidade é regulado de modo que trabalhos e ofícios e cerimônias se disponham num mapa que corresponde ao firmamento daquela data: assim, os dias na terra e as noites no céu se espelham.

Mediante minuciosa regulamentação, a vida da cidade flui com a calma do movimento dos corpos celestes e adquire a necessidade dos fenômenos não sujeitos ao arbítrio humano. Aos cidadãos de Ândria, louvando-lhes a laboriosa fabricação e bem-estar do espírito, fui levado a declarar.

- Compreendo bem como vocês, sentindo-se parte de um céu imutável, engrenagens de um meticuloso mecanismo, evitem fazer em sua cidade e em seus costumes a mais ligeira mudança. Ândria é a única cidade que conheço à qual convém permanecer imóvel no tempo.

Olharam-se pasmos.

- Mas por que? E quem disse? - E conduziram-me até uma rua suspensa recentemente aberta sobre um bosque de bambus, um teatro de sombras em construção no lugar do canil municipal, agora transferido para os pavilhões do antigo lazareto, abolido por estarem curados os últimos empestados, e, recém-inaugurados, um porto fluvial, uma estátua de Talete, um tobogã.

- E essas inovações não perturbam o ritmo astral da cidade? - perguntei.

- A correspondência entre a nossa cidade e o céu é tão perfeita - responderam - que cada mudança em Ândria comporta alguma novidade nas estrelas. - Os astrônomos perscrutam com os telescópios depois de cada mudança que acontece em Ândria e assinalam a explosão de uma nova, ou a passagem do laranja para o amarelo de um ponto remoto do firmamento, a expansão de uma nebulosa, a curvatura de uma espiral da Via Láctea. Cada mudança implica uma cadeia de outras mudanças, tanto em Ândria como nas estrelas: a cidade e o céu nunca permanecem iguais.

Do caráter dos habitantes de Ândria, duas virtudes merecem ser recordadas: a confiança em si mesmos e a prudência. Convictos de que cada inovação na cidade influi no desenho do céu, antes de qualquer decisão calculam os riscos e as vantagens para eles e a para o resto da cidade e dos mundos. 


\section{Agradecimentos}

Ao Prof. Dr. Geraldo Gomes Serra, pela seriedade do seu trabalho de orientação, pela atenção que dedica aos seus alunos, sempre atento à formação desses pesquisadores

À Fapesp, pelo apoio concedido a esta pesquisa, e também pelas críticas, sugestões e comentários do ilustre assessor

Aos colegas do Departamento de Tecnologia da Arquitetura e do Urbanismo da FAU/USP, em especial à Silvana Marques, Liliana Alves e Maria Lúcia Vieira

Aos professores do grupo de conforto ambiental da FAU/USP, em especial à nossa coordenadora, Prof. Dra. Anésia Barros Frota

Ao Núcleo de Pesquisa em Tecnologia da Arquitetura e do Urbanismo - NUTAU, em especial à Maria Cristina Luchesi de Mello e Carlos Eduardo

Ao Laboratório de Climatologia da Universidade Federal de Mato Grosso - UFMT, sob a coordenação da Prof. Dra. Gilda Maitelli, aos seus alunos da disciplina de Climatologia do Curso de Geografia do ano de 1998, à equipe da Estação Climatológica Mestre Bombled, em especial ao estagiário Gérson, e à Prof. Luciane Durante, do Departamento de Arquitetura e Urbanismo, pelo apoio ao trabalho de medições microclimáticas

Ao Prof. Dr. Pedro Leite da Silva Dias, Prof. Dr. Artêmio Foulari e o meteorologista Demerval Soares Moreira, do Departamento de Ciências Atmosféricas do Instituto Astronômico e Geofísico da USP - IAG/USP, pelo apoio na interpretação dos dados climáticos

À Prof. Dra. Magda Lombardo, do Departamento de Geografia da FFLCH/USP, pelos comentários e sugestões

Ao Prof. Dr. Baruch Givoni, da Universidade da Califórnia - UCLA, e Prof. Dr. Jorge Gil Saraiva, do Laboratório Nacional de Engenharia Civil - LNEC/Lisboa, pelas críticas, comentários e sugestões

Ao Prof. Dr. Leonardo Bittencourt, da Universidade Federal de Alagoas, e Prof. Dr. Francisco Gonçalves da Silva, da Universidade Federal da Paraíba, pelos comentários e sugestões 
Ao Prof. Dr. Carlos Alberto de Bragança Pereira, Prof. Dra. Júlia Soler e à estagiária Regina, do Centro de Estatística Aplicada do Instituto de Matemática e Estatística da USP - CEA/USP e ao Prof. Dr. Nilton Ricoy Torres do Departamento de Tecnologia da Arquitetura da FAU/USP, pelas consultas em estatística

Aos pesquisadores do Instituto Nacional de Pesquisas Espaciais - INPE, Dr. Alberto Setzer e a Arq. Madalena Niero Pereira, pela orientação sobre o uso de sensoriamento remoto

A Pascal Govery e Vincent Dubrueil, do Laboratoire COSTEL - Climat et Occupation $d u$ Sol par Teledetection, do Departamento de Geografia da Universidade Rennes 2, França, pelo tratamento das imagens de satélite

Ao Instituto de Planejamento e Desenvolvimento Urbano - IPDU, da Prefeitura Municipal de Cuiabá, em especial ao Arq. José Antonio Lemos dos Santos e à Arq.Maristela Mitiko, pelo apoio durante a coleta de dados

À Secretaria de Finanças da Prefeitura Municipal de Cuiabá, pela cessão de dados do Cadastro Imobiliário

À equipe do Horto Florestal de Cuiabá, sob a coordenação do Eng. Archimedes Pereira Lima Neto, ao CREA-MT e aos alunos Augusto e João Paulo, que cederam espaço para a instalação dos instrumentos

Ao Prof. Lenine Povoas e à Prof. Dunga Rodrigues, pelas aulas de história

Ao Prof. Dr. Ualfrido Del Carlo, pelas muitas aulas que presenciei

Ao Prof. Dr. Marcelo de Andrade Roméro, por ter acreditado neste trabalho quando ele era apenas uma vaga idéia

Às amigas Joana Carla Soares Gonçalves e Roberta Consentino Kronka, pelo apoio e companheirismo ao longo deste trabalho

Aos meus pais, Dalva e Antonio, por estarem sempre presentes

Ao meu amor, Júlio César Calsinski, por fazer parte da minha vida 


\section{RESUMO}

O objeto deste trabalho são os microclimas urbanos nas cidades brasileiras na região de Clima Tropical Continental. Partindo do princípio que há uma correlação entre microclimas urbanos e ocupação do solo, o objetivo é medir numericamente a correlação entre a temperatura do ar e algumas variáveis familiares ao planejamento, e que podem ser regulamentadas pela legislação municipal, a fim de orientar as medidas necessárias para amenizar o rigor climático nas cidades da região.

Faz-se uma descrição qualitativa e quantitativa das variáveis urbanísticas envolvidas, bem como medições de temperatura e umidade do ar em diferentes estações e horários.

Os resultados mostram que as variáveis taxa de ocupação e coeficiente de aproveitamento mantém correlação positiva com a temperatura do ar, e refletem uma maior influência da densidade construída sobre o período noturno, o que concorda com a teoria existente. Já com as variáveis arborização e água a correlação foi negativa em relação à temperatura do ar, em todos os horários.

Ao final propõe-se um índice em função das variáveis urbanísticas utilizadas, visando subsidiar futuros trabalhos na determinação da proporção ideal entre densidade construída, arborização e água. 


\section{ABSTRACT}

The subject of this thesis is the urban microclimate in cities of the Brazilian Continental Tropical Region. According to the principle that there is a correlation between urban microclimates and urban occupation, the objective is to numerically measure the correlation between air temperature and variables which are familiar to urban planning strategies. These variables can be controlled by municipal regulations, aiming to guide the procedures to ameliorate the urban harsh climate in that region.

Qualitative and quantitative descriptions of the urban variables are made, as air temperature and humidity measurements registered along the day for the two main seasons.

The results show that with variables related to building density, the correlation was positive when referred to air temperature, and reflected the greater influence of building density at night, what is in accord with the existing theory. On the other hand, using trees and water, the correlation was negative, when related to air temperature, in all periods.

At the end, this work suggests an index using urban variables, aiming to support future studies in determining the ideal proportion among building density, trees and water in urban environments. 


\section{SUMÁRIO}

PARTE 1

\section{Introdução e quadro teórico referencial}

1. INTRODUÇÃO.

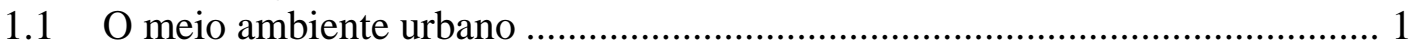

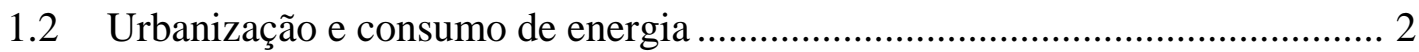

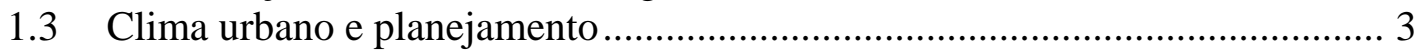

1.4 A questão ambiental no Brasil....................................................................... 7

1.5 Aplicação do conhecimento e formas de intervenção ..................................... 8

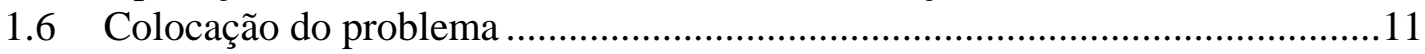

1.7 Descrição circunstanciada do objeto e do objetivo ........................................14

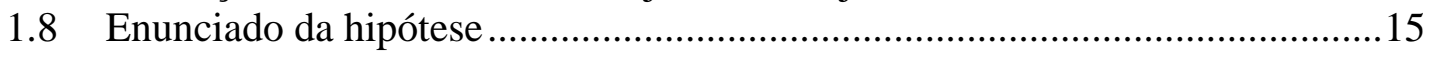

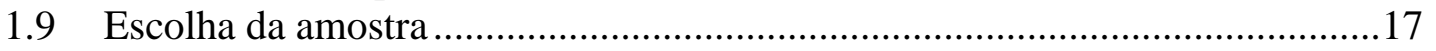

1.10 Construção do modelo e descrição das variáveis envolvidas ............................18

2. ESTADO DA ARTE NAS PESQUISAS ENVOLVENDO CLIMA URBANO E PLANEJAMENTO …............................................................................33

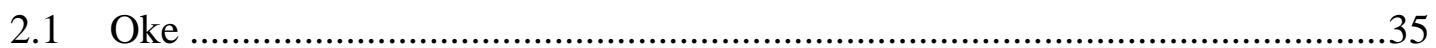

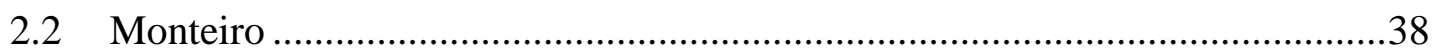

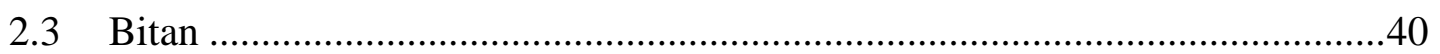

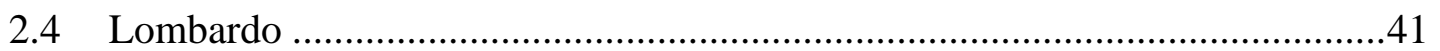

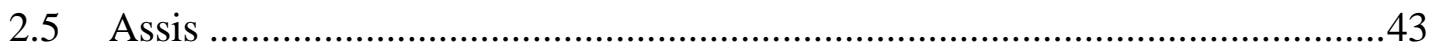

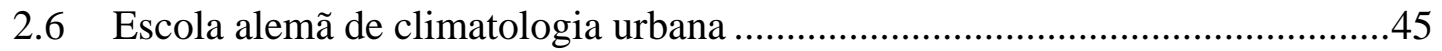

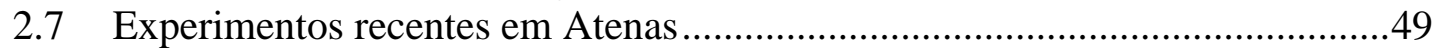

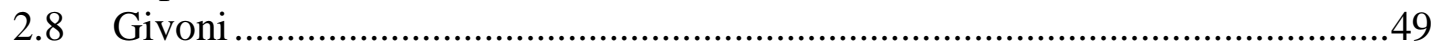

2.9 Estudos recentes de ventilação urbana .......................................................52

3. EXEMPLOS DE ADAPTAÇÃO AO CLIMA ..........................................59

3.1 Exemplos históricos de adaptação ao clima ...................................................59

3.2 Exemplos recentes de adaptação ao clima nos recintos das exposições

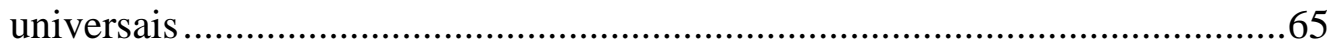

3.2.1 Tratamento bioclimático da Expo'92 em Sevilha ...............................65

3.2.1.1 Tratamento das coberturas ...........................................................69

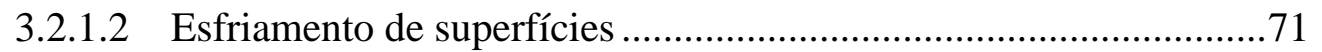

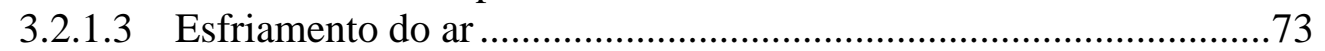

3.2.2 Tratamento bioclimático da Expo’98 em Lisboa .................................74

3.3 Exemplos de adaptação ao clima nas capitais planejadas ...............................78

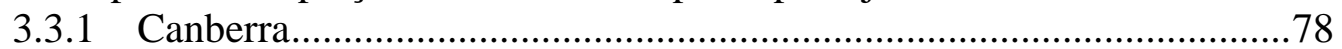

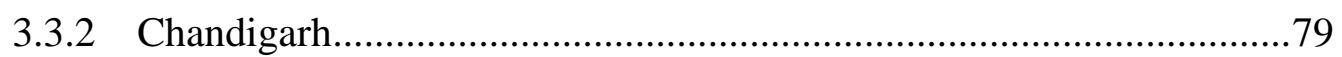

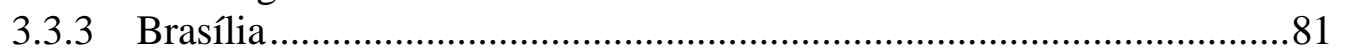

4. O PAPEL DA ARBORIZAÇÃO E DOS CORPOS D’ÁGUA EM ÁREAS URBANAS ...........................................................................................................87

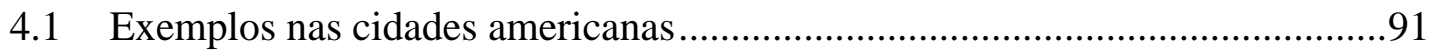

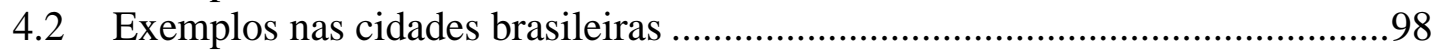


PARTE 2

Levantamento de dados secundários para caracterização da área de estudo

5. CONDIÇÕES AMBIENTAIS NA REGIÃO EM ESTUDO.........................107

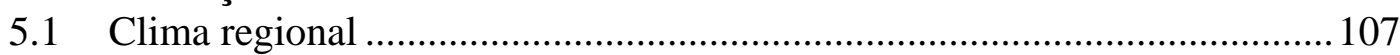

5.1.1 Características físicas da região.......................................................109

5.1.2 Classificações climáticas ..................................................................112

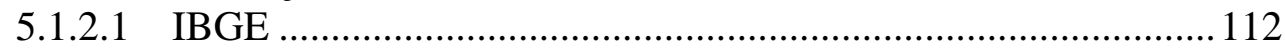

5.1.2.2 Köppen .............................................................................112

5.1.2.3 Thornthwaite ............................................................................... 114

5.1.3 Características climáticas .................................................................115

5.2 Clima urbano na cidade de Cuiabá................................................................119

5.2.1 Registro de dados climáticos ..........................................................119

5.2.2 Alterações no clima provocadas pela urbanização ............................119

6. A URBANIZAÇÃO NA REGIÃO DA AMOSTRA ESCOLHIDA ..........127

6.1 A evolução urbana de Cuiabá........................................................................127

6.1.1 Ciclo da Mineração..........................................................................127

6.1.2 Ciclo da Sedimentação Administrativa ............................................132

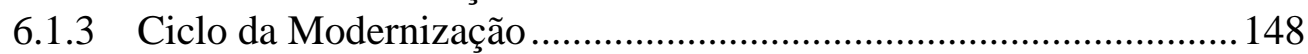

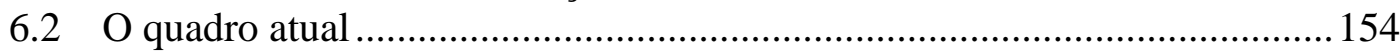

\section{PARTE 3}

\section{Levantamento de dados primários para descrição qualitativa e quantitativa dos sete casos estudados}

7. USO E OCUPAÇÃO DO SOLO NA REGIÃO EM ESTUDO.....................159

7.1 Análise da evolução da mancha urbana através de imagens de satélite .......159

7.2 Levantamento de vegetação e corpos d'água significativos..........................162

7.2.1 Áreas protegidas pela legislação municipal........................................162

7.2.1.1 Mata Ciliar do Rio Cuiabá …………………...............................163

7.2.1.2 Mata Ciliar do Córrego do Barbado...............................................165

7.2.1.3 Parque Antônio Pires de Campos...................................................165

7.2.1.4 Horto Florestal e Rio Coxipó ………………………………….....165

7.2.1.5 Mata da Mãe Bonifácia ..............................................................165

7.2.2 Outros espaços significativos ..........................................................167

7.2.2.1 Campus da Universidade Federal de Mato Grosso ......................167

7.2.2.2 Morro do Seminário ..................................................................167

7.2.2.3 Arborização de rua .....................................................................167

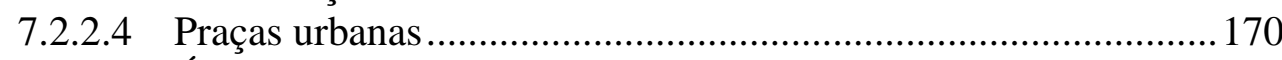

7.2.2.5 Áreas do Projeto CURA nos bairros Araés, Lixeira e Quilombo

7.2.2.6 Quintais remanescentes no centro da cidade e nos bairros mais

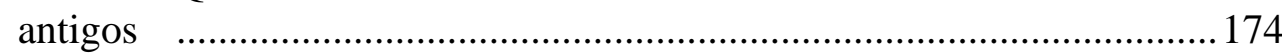

7.2.3 Conclusões do levantamento ............................................................175 
7.3 Descrição qualitativa dos sete casos estudados .........................................176

7.3.1 Morro da Luz ................................................................................ 176

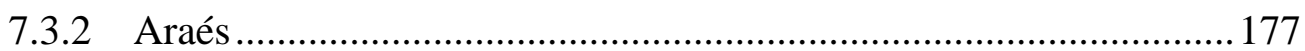

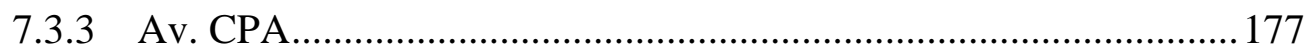

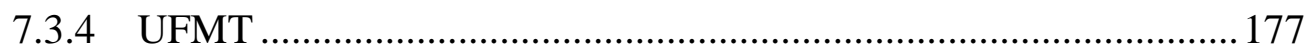

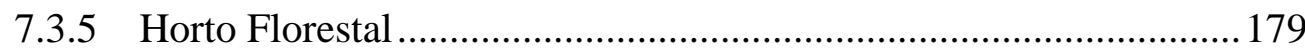

7.3.6 Pascoal Ramos ......................................................................... 179

7.4 Quantificação de variáveis urbanísticas nos sete casos estudados ............... 180

8. MEDIÇÕES DE PARÂMETROS MICROCLIMÁTICOS NA REGIÃO EM

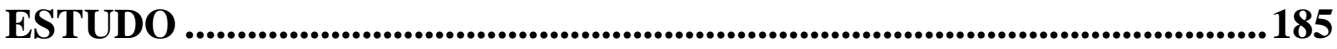

8.1 Variáveis microclimáticas medidas e calculadas .....................................187

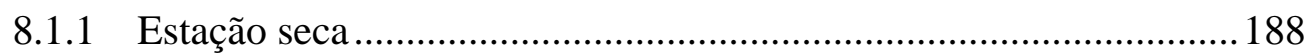

8.1.1.1 Análise dos dados e observações pertinentes............................197

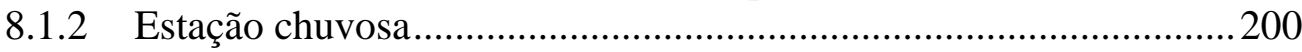

8.1.2.1 Análise dos dados e observações pertinentes ...........................................207

\section{PARTE 4}

\section{Análise dos resultados e conclusões}

\section{COMPROVAÇÃO DA TESE E ANÁLISE DOS RESULTADOS}

9.1 Correlação entre os postos de medição ....................................................2211

9.2 Classificação das condições de conforto nos casos estudados .....................211

9.3 Comprovação da tese..........................................................................213

9.4 Proposta de um parâmetro relacionando densidade construída, arborização e superfícies d’água em áreas urbanizadas ..................................................219

9.4.1 Exemplo de aplicação do índice para os sete casos estudados em

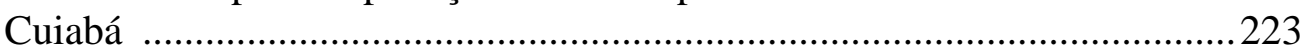

9.4.2 Utilidade, implementação e determinação do índice ideal .............. 226

\section{CONSIDERAÇÕES FINAIS E CONCLUSÕES}

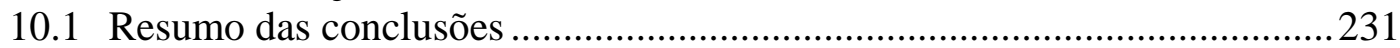

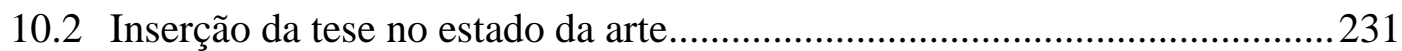

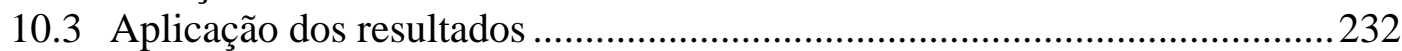

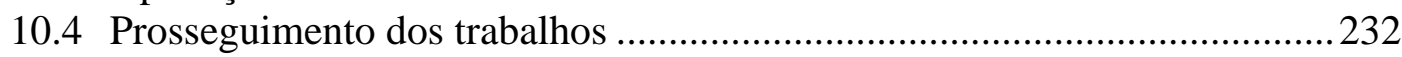

10.5 Necessidade de revisão das leis de uso do solo e dos códigos de obras para incorporar o conhecimento já existente sobre clima urbano .......................234

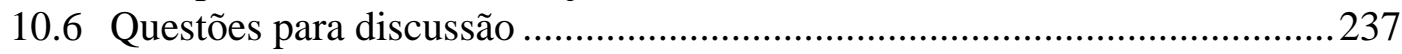

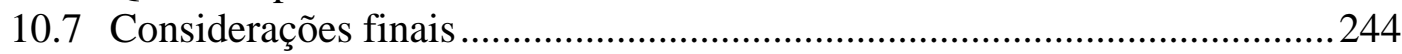

\section{ANEXOS}

Anexo 1 - Dados climáticos do aglomerado Cuiabá/Várzea Grande....................249

Anexo 2 - Fotos aéreas dos casos estudados ......................................................225

BIBLIOGRAFIA REFERENCIADA E CONSULTADA................................263 


\section{LISTA DE FIGURAS}

\section{Capítulo 1}

Fig. 1.1 - Temperaturas máximas anuais em Los Angeles..................................... 13

Fig. 1.2 - Esquema metodológico........................................................................ 26

\section{Capítulo 3}

Fig. 3.1 - O uso de vegetação e água criando um microclima diferenciado nos jardins do Alhambra.

Fig. 3.2 - O uso da água nos Jardins do Generalife, melhorando as condições higrotérmicas locais.

Fig. 3.3 - O uso de vegetação proporcionando sombreamento para os pedestres nos Jardins do Generalife, reduzindo os ganhos térmicos por radiação solar.

Fig. 3.4 - Um dos muitos pueblos blancos na Andaluzia, compactos e com os edifícios caiados anualmente para melhor adaptação ao clima quente e seco.

Fig. 3.5 - O correto uso de vegetação em Sevilha. À esquerda, fazendo a transição exterior/interior nos Reales Alcázares e, à direita, promovendo sombra em um restaurante no Barrio de Santa Cruz.

Fig. 3.6 - Arcadas para sombreamento e o uso da água para aumentar a umidade do ar na Plaza de España, em Sevilha.

Fig. 3.7 - Uso de vegetação e de aspersão de água para a criação de um microclima ameno na Estación Atocha, em Madrid.

Fig. 3.8 - Arcadas no entorno da Piazza di San Marco, em Veneza....................... 65

Fig. 3.9 - Barreira de árvores e fontes d'água usadas para o semi-confinamento de uma área de espetáculos no recinto da Expo’92.

Fig. 3.10 - Teto verde e aspersão de água usadas para o semi-confinamento de uma zona de descanso no recinto da Expo'92.

Fig. 3.11 - Detalhe da cobertura dupla com câmara de ar ventilada usada no recinto da Expo'92.

Fig. 3.12 - Cobertura de bambu proporcionando sombreamento para os visitantes nas filas de espera dos pavilhões da Expo'98.

Fig. 3.13 - O uso de espelhos d'água e vegetação nos jardins da Expo'98 criando praças molhadas para os pedestres.

Fig. 3.14 - Praça molhada com a cascata de 4m de altura ao fundo. ........................ 77

Fig. 3.15 - A cascata e o sistema de aspersão de água a partir do piso, umidificando o ar.

Fig. 3.16 - Uso de vegetação e espelhos d'água em um dos seis trechos dos Jardins Garcia de Horta no recinto da Expo'98.

Fig. 3.17 - O Lago Griffin e os jardins nas suas margens no ambiente árido de Canberra.

\section{Capítulo 4}

Fig. 4.1 - Vista do Central Park.

Fig. 4.2 - Vista do Paley Park na direção da Rua 53. 
Fig. 4.3 - Imagem termal de Washington mostrando os pontos mais aquecidos em vermelho e os menos aquecidos em verde

Fig. 4.4 - Urban Solar Oasis, projeto de Jeffrey Cook para Phoenix, em 1987 ..... 96

Fig. 4.5 - Vista de Curitiba em abril de 2000 com um dos corredores de adensamento ao fundo e as áreas verdes distribuídas por toda a cidade. 100

Fig. 4.6 - Parque do Ingá; reserva florestal mantida desde o traçado inicial da cidade de Maringá.

Fig. 4.7 - Maringá com o verde distribuído por toda a cidade. .............................. 102

Fig. 4.8 - Vista parcial da Lagoa Rodrigo de Freitas. ................................................ 103

Fig. 4.9 - Ausência de áreas verdes no Centro de São Paulo. ................................. 103

\section{Capítulo 5}

Fig. 5.1 - Unidades climáticas do Brasil.................................................................. 107

Fig. 5.2 - Localização dos postos do INMET na região Centro-Oeste..................... 108

Fig. 5.3 - Relevo. Região Centro-Oeste. ................................................................ 109

Fig. 5.4 - Hidrografia. Região Centro-Oeste. ........................................................... 110

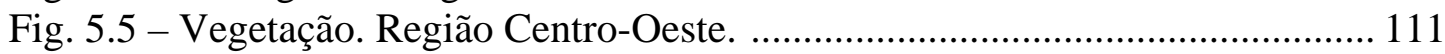

Fig. 5.6 - Tipologia Climática. Região Centro-Oeste. .......................................... 115

Fig. 5.7- Temperatura Média do Ano. Região Centro-Oeste. .................................. 116

Fig. 5.8 - Altura Média da Precipitação Anual. Região Centro-Oeste. .................... 117

Fig. 5.9 - Representação esquemática, adaptada para Cuiabá, das variações da temperatura do ar e da localização da ilha de calor associada ao uso do solo urbano.

Fig. 5.10 - Médias mensais horárias de velocidade do vento (m/s), do período de 1970-1992.

Fig. 5.11 - Uso do solo urbano e a formação de ilhas de calor. Isotermas. .............. 123

Fig. 5.12 - Uso do solo urbano e a formação de ilhas de calor. Isoigras. ................. 124

\section{Capítulo 6}

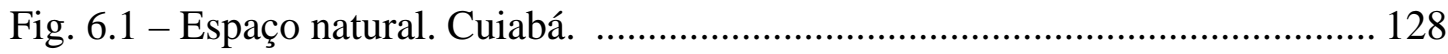

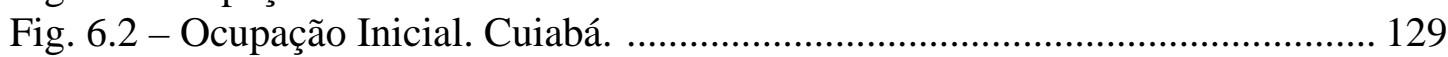

Fig. 6.3 - Prospecto da Villa do Bom Jesus de Cuiabá, de 1790 ................................ 130

Fig. 6.4 - Plano da Villa do Cuiabá, de autor não identificado. .............................. 130

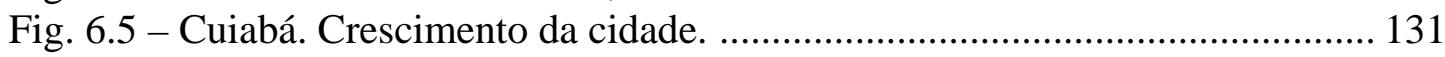

Fig. 6.6 - Primeira casa construída em Cuiabá, em 1720. ..................................... 133

Fig. 6.7 - Vista de larga extensão da Chapada e um dos vales que comunicam o Planalto de Guimarães com a Depressão Cuiabana ................................. 133

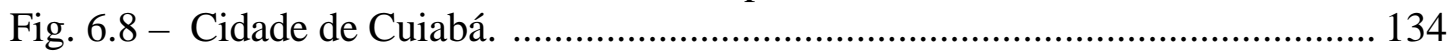

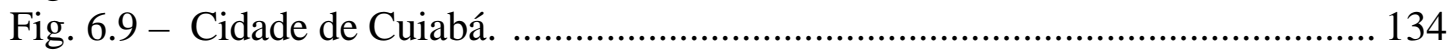

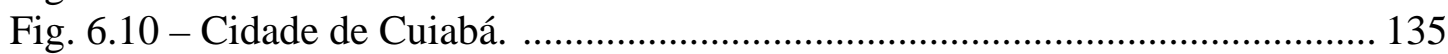

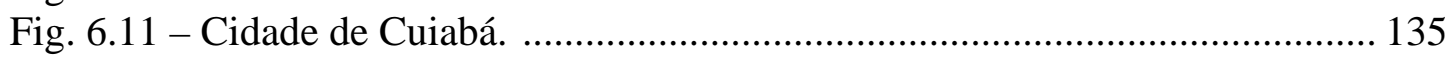

Fig. 6.12 - Vista panorâmica de Cuiabá no início do século. .................................... 136

Fig. 6.13 - Porto de Corumbá no início do século XX. ......................................... 138

Fig. 6.14 - Casas populares, já demolidas, próximas à ponte sobre o Rio Coxipó .. 141

Fig. 6.15 - Vista da Praça da República no início do século; hoje uma das principais da cidade. 
Fig. 6.16- Rua 13 de Junho, antiga Rua Bela do Juiz.

Fig. 6.17 - Vista de uma aldeia portuguesa, na região de Castro Verde. .................. 144

Fig. 6.18 - Típico sobrado português. ................................................................... 144

Fig. 6.19 - Transição entre o exterior e o interior em uma casa lusitana na região

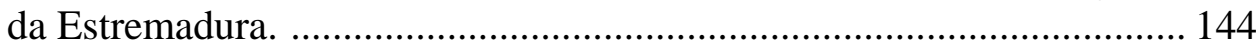

Fig. 6.20 - Zona Residencial Oriental. Ruas tortuosas e estreitas. .......................... 146

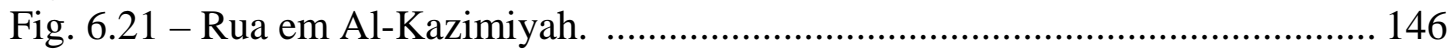

Fig. 6.22 - Esquadrias encontradas em Cuiabá. Década de 70. ............................. 147

Fig. 6.23 - Esquadria encontrada em Cuiabá. Década de 70. ................................. 147

Fig. 6.24 - Vista do centro antigo da cidade em janeiro de 1995............................ 149

Fig. 6.25 - Rua Galdino Pimentel, conhecida como Rua de Baixo, no centro antigo de Cuiabá. .................................................................................... 150

Fig. 6.26 - Rua Campo Grande, no centro antigo de Cuiabá. ................................. 150

Fig. 6.27 - Entroncamento da Rua do Meio com a Travessa 21 de Abril, conhecida como Beco Torto, no centro antigo de Cuiabá. .................... 150

Fig. 6.28 - Bairro Araés antes e depois da intervenção do CURA. ......................... 151

Fig. 6.29 - Vista da Av. do CPA em 1980, próximo ao viaduto da Av. Miguel Sutil, no sentido Centro-CPA. ............................................................... 153

Fig. 6.30 - Vista do CPA em 1980 no sentido CPA-Centro.................................... 153

Fig. 6.31 - Vista da Av. Rubens de Mendonça em 1997. ......................................... 153

\section{Capítulo 7}

Fig. 7.1 - Imagem do Landsat de setembro de 1984, formada pela combinação das bandas 3, 4 e 5 .

Fig. 7.2 - Imagem do Landsat de novembro de 1997, formada pela combinação das bandas 3, 4 e 5.

Fig. 7.3 - Esgoto sendo lançado no Rio Cuiabá, próximo à Ponte Júlio Müller. ..... 164

Fig. 7.4 - Av. Beira-Rio, às margens do Rio Cuiabá. .............................................. 164

Fig. 7.5 - Córrego do Barbado no cruzamento com a Av. Beira-Rio, a poucos metros do Rio Cuiabá. .......................................................................... 164

Fig. 7.6 - Morro da Luz visto a partir do centro da cidade. .................................... 166

Fig. 7.7 - Rio Coxipó ao longo do Horto Florestal. .................................................. 166

Fig. 7.8 - Mata da Mãe Bonifácia. ......................................................................... 166

Fig. 7.9 - Vista do trecho inicial do Córrego da Prainha. ....................................... 168

Fig. 7.10 - Vista de um dos estacionamentos no campus universitário. .................... 168

Fig. 7.11 - Morro do Seminário, na área central da cidade. ................................... 168

Fig. 7.12 - Trecho arborizado da Av. Presidente Marques. .................................... 169

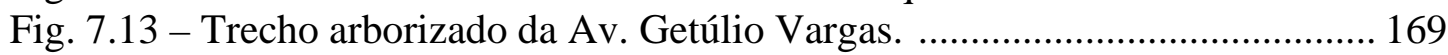

Fig. 7.14 - Trecho arborizado da Av. Coronel Escolástico. .................................... 169

Fig. 7.15- Ambiente inóspito para o pedestre na Av. da Prainha. ............................ 170

Fig. 7.16 - Praça Alencastro, em frente à Prefeitura Municipal de Cuiabá, ainda

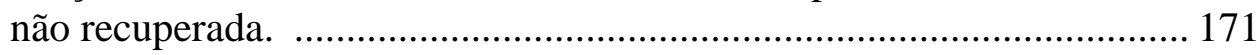

Fig. 7.17 - Praça da República, mantida por uma loja de departamentos. ............... 171

Fig. 7.18 - Praça Ipiranga. ..................................................................................... 171

Fig. 7.19 - Praça 8 de Abril (Praça do Chopão), antigo ponto de prostituição.

Atualmente é mantida pelos comerciantes das proximidades. ................ 172

Fig. 7.20 - Praça Clóvis Cardoso, na época em reforma, na Av. Isaac Povoas. ...... 172 
Fig. 7.21 - Praça Rachid Jaudy, na Av. Generoso Ponce, mantida por uma

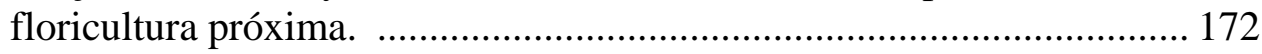

Fig. 7.22 - Praça Santos Dumont, na Av. Getúlio Vargas. ..................................... 173

Fig. 7.23 - Área verde ao longo do Córrego do Caixão, no Quilombo. ................... 173

Fig. 7.24 - Área de lazer abandonada no Centro Esportivo do Araés, área do

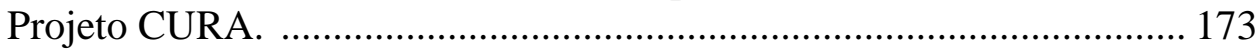

Fig. 7.25 - Quintal remanescente na área central da cidade. ................................. 175

Fig. 7.26 - Quintal remanescente na área central da cidade. ................................. 175

Fig. 7.27 - Alta densidade de ocupação no centro antigo ........................................ 178

Fig. 7.28 - Araés visto do alto em 1997. Ao fundo a ocupação vertical al longo da Av. CPA.

Fig. 7.29 - Vista da Avenida no sentido Centro-CPA, próximo ao viaduto da Av. Miguel Sutil, em agosto de 1998. ........................................................ 178

Fig. 7.30 - Campus da UFMT, a aproximadamente 3Km da área central. .............. 179

Fig. 7.31 - Acesso ao Horto Florestal, a aproximadamente 5Km da área central.... 179

Fig. 7.32 - Bairro Pascoal Ramos, a mais de 15 Km do centro de Cuiabá. .............. 180

Fig. 7.33 - Entorno do INMET, no município vizinho de Várzea Grande, às margens do Rio Cuiabá, a 3,5Km da área central de Cuiabá. ................ 180

Fig. 7.34 - Proporções entre superfícies d’água, verde, vazios, ruas e projeção construída em cada um dos pontos escolhidos.

\section{Capítulo 8}

Fig. 8.1 - Abrigo meteorológico padrão na Estação Climatológica Mestre Bombled, no campus da UFMT. ......................................................... 186

Fig. 8.2 - Abrigo meteorológico simplificado utilizado para as medições. ............. 186

Fig. 8.3 - Imagem do satélite GOES-8 às 15h (horário de Brasília) do dia 26/08/1998, mostrando a chegada da frente fria.

Fig. 8.4 - Imagem do satélite GOES-8 às 12h15 (horário de Brasília) do dia 26/08/1998 mostrando a frente fria sobre a região de Cuiabá.

Fig. 8.5 - Temperatura de bulbo seco em 23/08/98, com medições horárias das $8 \mathrm{~h}$ às $20 \mathrm{~h}$.

Fig. 8.6 - Umidade relativa do ar em 23/08/98, com medições horárias das 8h às 20h......

Fig. 8.7 - Umidade absoluta do ar em 23/08/98, com medições horárias das 8h às 20h.

Fig. 8.8 - Temperatura de bulbo seco em 24/08/98, com leituras às 8h, 14h e 20h.192

Fig. 8.9 - Umidade relativa do ar em 24/08/98, com medições às 8h, 14h e 20h. .. 192

Fig. 8.10 - Umidade absoluta do ar em 24/08/98, com medições às 8h, 14h e 20h. 192

Fig. 8.11 - Temperatura de bulbo seco em 25/08/98, um dia típico da estação quente e seca dentro do período de medições, com leituras às 8h, 14h e $20 \mathrm{~h}$.

Fig. 8.12 - Umidade relativa do ar em 25/08/98, com medições às 8h, 14h e 20h. . 193

Fig. 8.13 - Umidade absoluta do ar em 25/08/98, com medições às 8h, 14h e 20h. 193

Fig. 8.14 - Temperatura de bulbo seco em 26/08/98, no primeiro dia da frente fria, com leituras às $8 \mathrm{~h}, 14 \mathrm{~h}$ e $20 \mathrm{~h}$.

Fig. 8.15 - Umidade relativa do ar em 26/08/98, com medições às 8h, 14h e 20h. 194

Fig. 8.16 - Umidade absoluta do ar em 26/08/98, com medições às 8h, 14h e 20h. 194 
Fig. 8.17 - Temperatura de bulbo seco em 27/08/98, no segundo dia da frente fria, com leituras às $8 \mathrm{~h}, 14 \mathrm{~h}$ e $20 \mathrm{~h}$.

Fig. 8.18 - Umidade relativa do ar em 27/08/98, com medições às 8h, 14h e 20h. . 195

Fig. 8.19 - Umidade absoluta do ar em 27/08/98, com medições às 8h, 14h e 20h. 195

Fig. 8.20 - Temperatura de bulbo seco em 28/08/98, saindo da frente fria, com leituras às $8 \mathrm{~h}, 14 \mathrm{~h}$ e $20 \mathrm{~h}$.

Fig. 8.21 - Umidade relativa do ar em 28/08/98, com medições às 8h, 14h e 20h. . 196

Fig. 8.22 - Umidade absoluta do ar em 28/08/98, com medições às 8h, 14h e 20h. 196

Fig. 8.23 - Temperatura média dos seis dias, por faixa de horário, na estação seca.197

Fig. 8.24 - Média das temperaturas registradas por posto nos seis dias de medição.

Fig. 8.25 - Temperatura de bulbo seco em 23/08/98 nas três estações próximas ao centro.

Fig. 8.26 - Umidade absoluta média dos seis dias, por faixa de horário, na estação seca.

Fig. 8.27 - Média das umidades absolutas registradas por posto nos seis dias de medição.

Fig. 8.28 - Temperatura de bulbo seco em 29/01/99, com leituras às 8h,14h e 20h. 201

Fig. 8.29 - Umidade relativa do ar em 29/01/99, com medições às 8h,14h e 20h. .. 201

Fig. 8.30 - Umidade absoluta do ar em 29/01/99, com leituras às 8h, 14h e 20h. ... 201

Fig. 8.31 - Temperatura de bulbo seco em 30/01/99, com leituras às 8h,14h e 20h.202

Fig. 8.32 - Umidade relativa do ar em 30/01/99, com medições às 8h,14h e 20h. .. 202

Fig. 8.33- Umidade absoluta do ar em 30/01/99, com leituras às 8h, 14h e 20h. .... 202

Fig. 8.34 - Temperatura de bulbo seco em 31/01/99, com leituras horárias das $8 \mathrm{~h}$ às $20 \mathrm{~h}$.

Fig. 8.35 - Umidade relativa do ar em 31/01/99, com medições horárias das 8h às 20h.

Fig. 8.36 - Umidade absoluta do ar em 31/01/99, com medições horárias das 8h às $20 \mathrm{~h}$.

Fig. 8.37 - Temperatura de bulbo seco em 01/02/99, com leituras às 8h,14h e 20h.204

Fig. 8.38 - Umidade relativa do ar em 01/02/99, com medições às 8h,14h e 20h. .. 204

Fig. 8.39 - Umidade absoluta do ar em 01/02/99, com leituras às 8h, 14h e 20h. ... 204

Fig. 8.40 - Temperatura de bulbo seco em 02/02/99, com leituras às 8h,14h e 20h. 205

Fig. 8.41 - Umidade relativa do ar em 02/02/99, com medições às 8h,14h e 20h. .. 205

Fig. 8.42 - Umidade absoluta do ar em 02/02/99, com medições às 8h,14h e 20h. . 205

Fig. 8.43 - Temperatura de bulbo seco em 03/02/99, com leituras às 8h,14h e 20h. 206

Fig. 8.44 - Umidade relativa do ar em 03/02/99, com medições às 8h,14h e 20h. .. 206

Fig. 8.45 - Umidade absoluta do ar em 03/02/99, com medições às 8h,14h e 20h. . 206

Fig. 8.46 - Temperatura média por faixa de horário na estação chuvosa................. 207

Fig. 8.47 - Média das temperaturas registradas por posto nos seis dias de medição.

Fig. 8.48 - Umidade absoluta média por faixa de horário na estação chuvosa. ....... 208

Fig. 8.49 - Média das umidades absolutas registradas por posto nos seis dias de medição.

Fig. 8.50 - Piranômetro modelo Ranger II Plus utilizado para as medições de temperatura superficial sobre pavimentos.

Fig. 8.51- Temperatura superficial dos pavimentos ao sol e à sombra. 209 


\section{Capítulo 9}

Fig. 9.1 - Temperatura média e diferenças médias de temperatura (considerando as estações seca e chuvosa) em relação ao caso mais crítico (Morro da Luz).

Fig. 9.2 - Taxa de ocupação e coeficiente de aproveitamento líquidos versus temperatura média durante as estações seca e chuvosa.

Fig. 9.3 - Taxa de ocupação, coeficiente de aproveitamento, percentagem de superfícies d’água e de arborização brutos versus temperatura média durante as estações seca e chuvosa.

Fig. 9.4 - Gráfico de dispersão com a função linear que relaciona as variáveis envolvidas e o coeficiente de correlação $(r=0,98)$ entre temperatura do ar e coeficiente de aproveitamento bruto às 8 h, em 23/08/98, durante a estação seca.

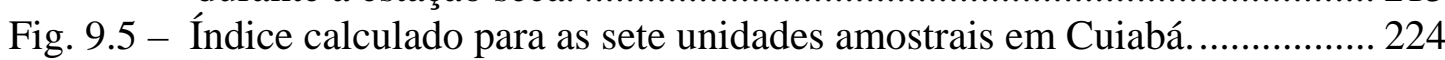

Fig. 9.6 - Índice calculado para os bairros Lixeira, Poção e Bandeirantes............... 226

Fig. 9.7 - Áreas verdes em centro de quarteirão no bairro da Lixeira. ................... 226

\section{ANEXO 1}

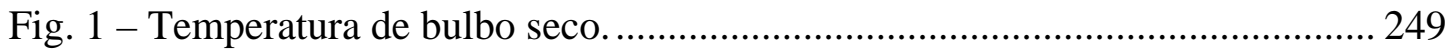

Fig. 2 - Amplitude térmica média mensal. ........................................................... 250

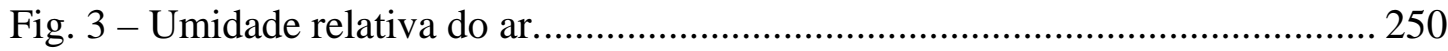

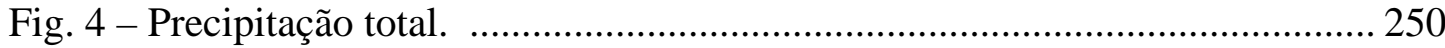

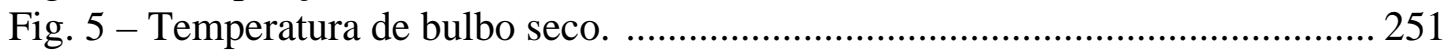

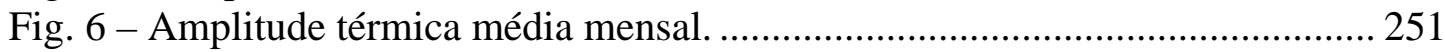

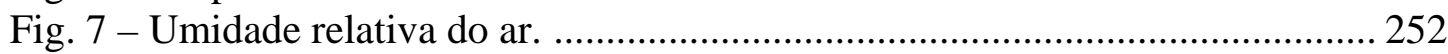

Fig. 8 - Precipitação total. ................................................................................... 252

Fig. 9 - Médias mensais horárias de velocidade do vento $(\mathrm{m} / \mathrm{s})$, do período de 1970- 1992.

\section{ANEXO 2}

Fig. 1 - Foto aérea do Horto Florestal com a demarcação da área quantificada no entorno do posto.

Fig. 2 - Foto aérea do Pascoal Ramos com a demarcação da área quantificada no entorno do posto. ....................................................................................... 256

Fig. 3 - Foto aérea do Araés e da Av. do CPA com a demarcação da área quantificada no entorno dos postos.

Fig. 4 - Foto aérea do Morro da Luz com a demarcação da área quantificada no entorno do posto.

Fig. 5 - Foto aérea da UFMT com a demarcação da área quantificada no entorno do posto.

Fig. 6 - Foto aérea do INMET com a demarcação da área quantificada no entorno do posto.

Fig. 7 - Foto aérea dos bairros Lixeira, Poção e Bandeirantes, com a demarcação da área quantificada. 


\section{LISTA DE TABELAS}

\section{Capítulo 1}

Tabela 1.1 - Taxa média geométrica de crescimento anual.

\section{Capítulo 5}

Tabela 5.1 - Postos do INMET na região Centro-Oeste...................................... 108

Tabela 5.2 - Variações anuais nos valores de temperatura do ar. ........................ 120

\section{Capítulo 7}

Tabela 7.1 - Índices levantados em área de área $\left(\mathrm{m}^{2}\right)$ no entorno de cada ponto de

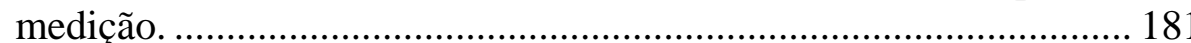

Tabela 7.2 - Índices levantados em \% no entorno de cada ponto de medição. ..... 181

Tabela 7.3 - Taxas de ocupação e coeficientes de aproveitamento líquidos e brutos no entorno de cada ponto de medição.

\section{Capítulo 8}

Tabela 8.1 - Temperaturas mínimas e máximas absolutas registradas na estação do

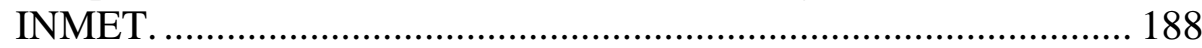

Tabela 8.2 - Direção e velocidade do vento registrados na estação do INMET durante a estação seca.

Tabela 8.3 - Temperatura média do dia, classificação dos postos e variação percentual da temperatura na escala Celsius em relação ao posto de maior temperatura média..

Tabela 8.4 - Temperaturas mínimas e máximas absolutas registradas na estação do

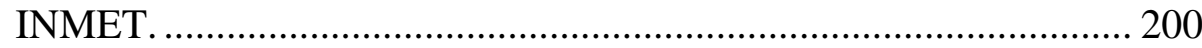

Tabela 8.5 - Direção e velocidade do vento registrados na estação do INMET. .. 200

Tabela 8.6 - Temperatura média do dia, classificação dos postos e variação percentual da temperatura na escala Celsius em relação ao posto de maior temperatura média.

\section{Capítulo 9}

Tabela 9.1 - Coeficientes de correlação (r) entre as temperaturas médias, em relação ao caso de referência, no Horto Florestal........................................... 211

Tabela 9.2 - Coeficientes de correlação (r) na estação seca. .................................. 216

Tabela 9.3 - Coeficientes de correlação (r) na estação chuvosa. ........................... 216

Tabela 9.4 - Equações de regressão linear para a estação seca. ............................ 217

Tabela 9.5 - Equações de regressão linear para a estação chuvosa........................ 218

\section{ANEXO 1}

Tabela 1 - Normais climatológicas 1961-1990. ..................................................... 249

Tabela 2 - Médias mensais 1985-1994.................................................................... 251

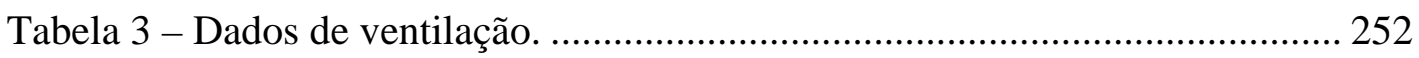


PARTE 1

Introdução e quadro teórico referencial 


\section{INTRODUÇÃO}

\subsection{O meio ambiente urbano}

Neste fim de século, muitas cidades são vistas como símbolos de crise ambiental. Os problemas relacionados ao meio ambiente urbano são os mais variados: excesso de ruído, emissão de poluentes no ar e na água, escassez de recursos energéticos e de água, falta de tratamento adequado de resíduos, alterações no regime de chuvas e de ventos, formação de ilhas de calor, ilhas secas, ilhas de frio, inversão térmica gerando problemas de saúde na população, aumento do consumo de energia para condicionamento artificial e transporte, etc.

É clara a necessidade de desenvolver novas estratégias de planejamento que permitam a continuidade do crescimento das áreas urbanas de forma que a população possa viver num ambiente mais equilibrado. Para tanto é preciso integrar uma série de fatores em busca da sustentabilidade urbana em todos os níveis de planejamento, fatores que envolvem não só a sustentabilidade ecológica mas também a sustentabilidade social, como foi intensamente debatido na IV International Ecocity Conference, realizada em Curitiba, em abril de 2000.

Entidades como a Ecocity Builders ${ }^{1}$, ou o movimento chamado New Urbanism ${ }^{2}$ têm divulgado esse novo campo de pesquisa e atuação dos planejadores urbanos. As propostas de soluções são muitas; o desafio maior parece ser o de encontrar um ponto de equilíbrio entre uma ordem urbanística ideal e a implementação e gestão dessas novas idéias.

Dentre as questões relacionadas ao meio ambiente urbano um dos pontos a serem resolvidos são as alterações climáticas, que provocam mudanças no regime de chuvas e fluxo de ventos, geram ilhas de calor e de frio, provocando um aumento no consumo de energia para climatização artificial dos edifícios, além de desconforto para a população, o que chamou a atenção de entidades como a World Meteorological Organization - WMO. Dentre os objetivos estabelecidos no Fourth WMO Long-Term Plan 1996-2005 ${ }^{3}$ estão os chamados serviços meteorológicos especializados, que incluem, entre outros, o atendimento às necessidades do planejamento do uso do solo e energia. O World Climate Programme presta assistência na aplicação de informações climáticas e do conhecimento para benefícios econômicos e sociais, visando o desenvolvimento sustentável e a implementação da Agenda 21. A WMO também dá indicações para integrar o clima

\footnotetext{
${ }^{1}$ http://www.preservenet.com/EcoBuild.html.

Ecocity Builders: "a membership non-profit organization dedicated to rebuilding our cities, towns and villages in balance with nature. (...) Ecocity Builders is the group that explores this new field in theory (...) while organizing original local projects in the East San Francisco Bay Area"

${ }^{2}$ http://www.cnu.org/newurbanism.html.

New Urbanism "seeks to reintegrate the components of modern life - housing, workplace, shopping and recreation - into compact, pedestrian-friendly, mixed-use neighborhoods linked by transit and set in a larger regional open space framework. The New Urbanism is an alternative to suburban sprawl, a form of low-density development that consists of large, single-use "pods"-office parks, housing subdivisions, apartment complexes, shopping centers - all of which must be accessed by private automobile"

${ }^{3} \mathrm{http}: / /$ www.wmo.ch/web-em/wmo831.html
} 
nas questões urbanas; alerta que a ineficiente utilização das fontes de energia urbana, desde o transporte até o desenho urbano inadequado, figura entre as principais causas do aumento global dos gases do efeito estufa, que é o fator que mais contribui para o aquecimento do planeta. A WMO tem um histórico de colaboração com a Organização Mundial da Saúde sobre a relação entre os assentamentos humanos e a saúde, incluindo a climatologia urbana e o ambiente construído. Durante o evento WMO Technical Conference on Tropical Urban Climates (1994), a colaboração entre as partes envolvidas foi uma das recomendações da sessão "Clima Urbano, Conforto e Saúde”. Foram sugeridas estreitas colaborações com o PLEA ${ }^{4}$ - Passive and Low Energy Architecture, com a ISES - International Society for Solar Energy e com a UIA - International Union of Architects.

Em 1996 a WMO co-patrocinou o ICUC, Internacional Conference on Urban Climatology em Essen, Alemanha. Em junho de 2000 começou a se formar uma associação internacional para tratar de climatologia urbana a partir da consolidação das ICUC. Segundo Tim OKE, ${ }^{5}$ professor da University of British Columbia, em Vancouver, Canadá, "several very successful international conferences on urban climate have been held since the late 1960s. One set was organized by the WMO (also WHO and sometimes with CIB) in Brussels, Moscow and Mexico City. A second set was run by IFHP in Herzliya-on-sea and Karlsruhe. The two merged to hold joint International Conferences on Urban Climatology (ICUC) together with other occasional cosponsors (e.g. AMS, ISB) in Kyoto (1989), Dahka (1993), Essen (1996) and Sydney (1999). In Sydney there was a general consensus that ICUC should be constituted as a more formal entity than it currently is, but that it should be a loosely structured organization without expensive trappings. In order to move this notion forward it was decided in Sydney, to form an interim board to create the organization.” Dentre os vários tópicos propostos estão os fenômenos climáticos que acontecem nas micro-escalas, como em edifícios, canyons urbanos, ruas, parques etc., e a melhoria das condições de clima urbano pelo planejamento e desenho urbanos.

\subsection{Urbanização e consumo de energia}

O número de habitantes em áreas urbanas subiu de 600 milhões em 1890 para 2 bilhões em 1986, e se esta tendência continuar, mais da metade da população mundial vai viver nas cidades até o final do ano 2000, e em 2010 esse número deve chegar a $80 \%$ da população mundial. Nos Estados Unidos estima-se que $90 \%$ da população viva nas cidades ou nos seus arredores. Há 100 anos apenas 1\% da população vivia nas cidades e em 1950 menos de 30\% da população era urbana. Atualmente pelo menos 170 cidades têm mais de 1 milhão de habitantes cada. A situação é ainda mais dramática nos países em desenvolvimento; 23 das 34 cidades com mais de 5 milhões de habitantes estão nos países em desenvolvimento. Quando

\footnotetext{
${ }^{4}$ http://www.arct.cam.ac.uk/plea2000

O PLEA é uma entidade que divulga a responsabilidade ambiental e ecológica na arquitetura e planejamento, que estimula o compromisso entre desenvolvimento, documentação e difusão dos princípios do design bioclimático e a aplicação de condicionamento passivo, em benefício dos assentamentos humanos sustentáveis, e a próxima conferência, em novembro de 2001, será realizada no Brasil.

${ }^{5}$ informação via e-mail.
} 
se fala em aumento populacional em áreas urbanas não se pode deixar de pensar no aumento da demanda energética correspondente. Áreas urbanas submetidas a condições de stress térmico usam muito mais energia para condicionamento artificial no verão e/ou aquecimento no inverno, e esses custos podem ser reduzidos através de uma visão ampla do planejamento climático das cidades; "an increase of the urban population by $1 \%$, increases the energy consumption by 2.25 , i.e., the rate of change in energy use is twice the rate of change in urbanization. These data show clearly the impact that urbanization may have on energy use. (SANTAMOURIS, 1998, p.147)

De acordo com a Energy Efficiency and Renewable Energy Network - EREN, do U.S. Department of Energy - $\mathrm{DOE}^{6}$, "temperature increases in urban areas dramatically impact cooling costs. In cities with populations of more than 100.000 , peak utility cooling demand increases $1.5 \%$ to $2 \%$ for every $0.6^{\circ} \mathrm{C}\left(1^{\circ} \mathrm{F}\right)$ the temperature rises. Urban temperatures across the United States have raised an average of $1.1^{\circ}$ to $2.2^{\circ} \mathrm{C}\left(2^{\circ}\right.$ to $\left.4^{\circ} \mathrm{F}\right)$ in the last 40 years, which means your city is probably paying a premium to keep cool in the summer. In Washington, D.C., for example, air conditioners typically run for about 1300 hours each year. This costs ratepayers about \$40,000 for each hour of operation, or about \$52 million a year!”

O governo americano divulgou, em fevereiro de 2000, o President Clinton FY2001 Climate Change Budget. ${ }^{7}$ Dentre outras medidas estão o incentivo para a geração de energia limpa e os incentivos fiscais para edifícios energeticamente eficientes, no qual consumidores podem receber um crédito de US $\$ 1,000$ a US $\$ 2,000$ pela compra de uma casa com baixo consumo de energia, além de $20 \%$ de crédito para a compra de produtos e/ou equipamentos domésticos e ainda US\$1,000 a US\$2,000 de crédito para a instalação de um sistema de energia solar. Também foi divulgada uma parceria entre governo e indústria chamada PATH - Partnership for Advancing Technology in Housing, a fim de melhorar a eficiência energética de novas habitações em mais de $50 \%$ e para se chegar a um retrofit de 15 milhões de casas existentes para torná-las 30\% mais eficientes em 10 anos. O programa do U.S. Department of Energy chamado Rebuild America, que busca uma maior eficiência energética na renovação de edifícios, já tem parcerias em quase todo os Estados Unidos, e tem alcançado uma redução de 20 a 30\% no consumo de energia em pequenos edifícios comerciais, escolas, residências e órgãos públicos. ${ }^{8}$

\subsection{Clima urbano e planejamento}

Além das questões relacionadas ao consumo de energia é consenso entre os pesquisadores a grande responsabilidade do planejamento e dos projetos urbanos e de edificações no controle da qualidade do clima da cidade, com repercussões diretas sobre a qualidade de vida urbana (ASSIS, 1990). Para BITAN (1992, p.313), "the main question of today's urban planners must be: what should be the future urban planning strategy and buildings methods which will, on the one hand, enable the continuation of the growth of the urban areas and their activities and, on the other hand, enable its population to live and act in a good climate and environment?"

\footnotetext{
${ }^{6}$ http://www.eren.doe.gov

${ }^{7}$ http://www.whitehouse.gov

${ }^{8}$ http://www.eren.doe.gov/buildings/rebuild/
} 
Para EVANS e SCHILLER (1996, p.363) “planners require answers to a complex combination of questions: What are the characteristics of the existing microclimates that should be preserved when urban growth is needed? What are the possible effects of alternative planning proposals on the future urban thermal environment? What are the possible and desirable microclimate modifications that the planners should aim to achieve through planned urban growth? Finally, how can the urban thermal environment be protected or improved within the limits imposed by political, economic, social and legal restraints?”

Até pouco tempo os principais esforços na área da chamada arquitetura bioclimática estavam voltados para o desempenho higrotérmico dos edifícios, e pouco tinha sido feito visando uma adequação climática do espaço urbano e a melhoria das condições de conforto nos espaços públicos, apesar dos princípios já largamente difundidos pela da Carta de Atenas, da obrigatoriedade do planejamento regional e urbano, da submissão da propriedade privada do solo urbano aos interesses coletivos, da limitação do tamanho e da densidade das cidades, da edificação concentrada, porém adequadamente relacionada com amplas áreas de vegetação, da separação da circulação de veículos e de pedestres, etc.

Segundo HOUGH (1998), o condicionamento artificial dos edifícios teve efeitos marcantes nas cidades modernas. A vida urbana se converteu em uma série de experiências condicionadas artificialmente, com moradia, espaços de trabalhos e veículos isolados do exterior. Liberando os edifícios das preocupações climáticas, o condicionamento artificial permitiu o desenvolvimento de mega-estruturas cujo aquecimento, refrigeração, umidade e iluminação dependem totalmente de sistemas mecânicos. Isso fez com que as cidades dessem as costas ao meio exterior, tornandose cada vez mais um lugar contaminado, varrido por ventos de inverno ou sufocados pelo calor do verão. A preocupação exclusiva com o microclima interior nega o papel climático ao espaço exterior, e os microclimas urbanos cada vez mais insalubres geram maior confiança nos microclimas interiores controlados.

LE CORBUSIER (1993) afirma que não se pode enfrentar um problema de urbanismo sem se reportar constantemente aos elementos constitutivos da região, à influência do meio, à situação geográfica e topográfica, ao clima. "O espírito da cidade formou-se no decorrer dos anos; simples construções adquiriram um valor eterno na medida em que simbolizam a alma coletiva; constituem o arcabouço de uma tradição que, sem querer limitar a amplitude dos progressos futuros, condiciona a formação do indivíduo, assim como o clima, a região, a raça, o costume. Por ser uma 'pequena pátria', a cidade comporta um valor moral que pesa e que está indissoluvelmente ligado a ela. (...) Quanto mais a cidade cresce, menos as 'condições naturais' são nela respeitadas. Por 'condições naturais' entende-se a presença, em proporção suficiente, de certos elementos indispensáveis aos seres vivos: sol, espaço, vegetação. Uma expansão sem controle privou as cidades desses alimentos fundamentais de ordem psicológica e fisiológica. O indivíduo que perde contato com a natureza é diminuído e paga caro, com a doença e a decadência, uma ruptura que enfraquece seu corpo e arruína sua sensibilidade, corrompida pelas alegrias ilusórias da cidade."

Ainda segundo CORBUSIER (1993), é urgente e necessário modificar certos usos, tornando acessível a todos, por meio da legislação, um certo nível de bem-estar. É 
preciso impedir, por uma rigorosa regulamentação urbana, que famílias inteiras sejam privadas de luz, de ar e de espaço, determinando a maneira como o solo deve ser ocupado, estabelecendo a relação entre a superfície construída e as áreas livres ou plantadas, estabelecendo locais para as moradias e seus diversos prolongamentos, etc. Assim se construiria a cidade daí em diante com toda a segurança e, dentro dos limites das regras estabelecidas por um estatuto do solo, seria dada toda a liberdade à iniciativa privada e à imaginação do artista. "Há ainda superfícies livres no interior de algumas cidades. Elas são a sobrevivência, miraculosa em nossa época, de reservas constituídas no passado: parques rodeando residências principescas, jardins adjacentes a casas burguesas, passeios sombreados ocupando a área de uma muralha militar derrubada. Os dois últimos séculos consumiram com voracidade essas reservas, autênticos pulmões da cidade, cobrindo-os de imóveis, colocando alvenaria no lugar da relva e das árvores. Outrora os espaços livres não tinham outra razão de ser senão o prazer de alguns privilegiados. Não interviera ainda o ponto de vista social, que dá hoje um sentido novo à sua destinação. Eles podem ser os prolongamentos diretos ou indiretos da moradia; diretos se cercam a própria habitação, indiretos se estão concentrados em algumas grandes superfícies menos imediatamente próximas. Em ambos os casos, sua destinação será a mesma: acolher as atividades coletivas da juventude, propiciar um espaço favorável às distrações, aos passeios ou aos jogos das horas de lazer." Para Corbusier, "a textura do tecido urbano deverá mudar; as aglomerações tenderão a tornar-se cidades verdes. Contrariamente ao que ocorre nas cidades-jardins, as superfícies verdes não serão compartimentadas em pequenos elementos de uso privado, mas consagradas ao desenvolvimento das atividades comuns que formam o prolongamento da moradia."

Diversas tentativas de se controlar o ambiente urbano - especialmente em cidades de clima rigoroso - foram apresentadas, por exemplo, pelos projetos ousados de R. BUCKMINSTER FÜLLER (1985), que buscavam tornar a sua idéia de Spaceship Earth uma realidade. Há também um projeto de SÉRGIO BERNARDES para o Hotel Tropical de Manaus de 1967 (1967/68); tratava-se de um hotel de turismo internacional nos arredores de Manaus, em plena floresta amazônica, com uma cúpula protetora refletora, criando um ambiente interno climatizado.

Há também projetos mais realistas, como expostos por J. L. FLEURY DE OLIVEIRA (1984), que relata um sistema integrado de pesquisa científica e tecnológica para a cidade laboratório de Humboldt, em Aripuanã-MT. Humboldt foi planejada para a pesquisa do modelo de desenvolvimento urbano adaptado às condições do meio tropical úmido. As pesquisas em Humboldt visavam a adaptação, inovação e criação de tecnologia amazônica nos setores da engenharia civil, da arquitetura e do urbanismo. Nesse projeto, a cidade pluvial deveria surgir baseada na definição da habitação pluvial. A vida urbana nas zonas de clareira era muito prejudicada pelo excesso de radiação solar no período seco ou pelo excesso de precipitação no período chuvoso. Daí a necessidade de se projetar grandes áreas cobertas contínuas, substituindo a sombra natural da cobertura florestal derrubada.

FLEURY (1989) também relata o modelo do prof. Spencer M. P. Nogueira para uma ocupação climática da Amazônia, com uma "malha agro-urbana interflorestal" formada por células e comunidades básicas sobre palafitas, interligadas por passarelas elevadas de madeira. $\mathrm{O}$ assentamento sobre palafitas garante algumas condições de segurança e conforto, tais como a proteção contra insetos e 
alagamentos. Nesse projeto, todo o processo construtivo e os materiais propostos fazem parte do repertório local.

Para a construção de novas cidades, o planejamento do clima urbano deve começar com a seleção do sítio. Quando as condições naturais não são favoráveis, a criação de um microclima apropriado é essencial para incentivar (ou até mesmo possibilitar) o uso de áreas externas em cidades de clima rigoroso, seja ele muito frio ou muito quente. Nos últimos anos diversos trabalhos foram publicados relatando as preocupações de arquitetos em países de clima frio, como no Canadá, por exemplo. Para PRESSMAN (1996, p.521-529) “The main principles to be incorporated in exemplary 'winter city' design should be contact with nature, year-round usability, user participation, cultural continuity, and the creation of comfortable microclimatic conditions throughout much of the city's open spaces. Creating optimum conditions for human well-being, habitation, work and intellectual development in each of the four seasons is vital under harsh environments. Adopting a climatesensitive approach to planning policy and urban design can render everyday life stressful, especially during the lengthy winter periods found in many northern latitude and high altitude settings. (...) climate-responsive approaches and energyefficient policies will generate a combined effect toward improving liveability, from the urban development perspective, if these are carefully integrated at the micro and meso-scales. (...) New cold-climate design standards will be essential.” No Canadá, o rigor climático está no inverno, quando as temperaturas atingem valores de até $15^{\circ} \mathrm{C}$ ou $-20^{\circ} \mathrm{C}$. No verão, todos querem andar ao ar livre. No inverno, entretanto, as condições externas são tão rigorosas que a tendência a permanecer em recintos fechados é muito grande. Em Montreal se constrói cada vez mais debaixo da terra por causa do frio; são construídos verdadeiros shoppings nos pátios do metrô ligados aos subsolos dos edifícios. Cada estação de metrô é interligada com os andares térreos de diversos edifícios circundantes, os quais, em geral, têm amplas galerias comerciais. Essas interligações são sempre maiores do que o simples deslocamento de passageiros exigiria, exatamente para poder abrigar outras lojas. Dessa forma, vão surgindo espaços desse tipo por todo o centro da cidade.

A preocupação em se planejar proteção total ou parcial para pedestres incentivando a criação de conexões entre edifícios via galerias, arcadas, passagens sombreadas, etc. é comum às cidades de clima rigoroso mas, com frequência, regulamentações desnecessárias inviabilizam essas inovações. Os projetistas deveriam ser encorajados a planejar esses espaços em troca de ganhos na área construída, descontos em impostos para o proprietário, etc. Esses ganhos poderiam incentivar o uso de elementos construtivos que contribuem para a melhoria das condições de conforto. SCHILLER e EVANS (1994, p.358) comentam os códigos de edificações: "The restrictive nature of the code often leads to an emphasis on what is not permitted, rather than on what type of development is desirable. It may avoid the worst abuses but does not ensure good solutions to the often conflicting requirements of urban development. Specific limitations may appear arbitrary without a clear justification, while the often inflexible application of code may prevent alternative proposals which achieve the planners original objectives at lower cost or with improved quality of urban design. This inflexibility is especially undesirable in a situation of rapid development." 
Em 1997 o Núcleo de Meio Ambiente do IBAM - Instituto Brasileiro de Administração Municipal, em convênio com a Eletrobrás, através do PROCEL Programa Nacional de Conservação de Energia, divulgou o Modelo para Elaboração de Código de Obras e Edificações (BAHIA, 1997). Face à escassez de recursos energéticos o PROCEL incentiva o combate ao desperdício e, dentro do Subprograma de Edificações prega que, tão importante quanto tornar mais eficientes os prédios existentes, é conscientizar as pessoas que podem influenciar no planejamento de uma cidade, na concepção de projetos e na construção de prédios eficientes. No modelo do projeto de lei são inseridas diversas questões relacionadas ao conforto ambiental e à conservação de energia, tais como o uso de cobertura vegetal para amenizar extremos climáticos ou a construção de marquises, beirais, varandas, brises e cobogós para proteção solar do edifício e redução da carga térmica, sem prejuízo da ventilação.

Segundo SPIRN (1995) poucas cidades se adaptaram engenhosamente à natureza: Stuttgart empregou seus espaços livres na canalização de ar fresco e limpo para o centro congestionado; Woodlands, no Texas, aproveita espaços livres públicos e privados como um sistema de drenagem de águas pluviais, que absorvem as águas das cheias e previnem enchentes mais abaixo; Boston, onde as várzeas à montante da cidade foram compradas para o armazenamento das águas das cheias a uma fração do custo de uma nova barragem; Denver, cujas praças retêm as águas pluviais para prevenir enchentes; Zurique e Frankfurt, que administram suas florestas urbanas para a produção de madeira, bem como para a recreação; Filadélfia, que transformou resíduos sólidos em uma ampla gama de produtos úteis; Manhattan, onde um pequeno espaço como o Paley Park oferece um recanto calmo e fresco; Delft, na Holanda, onde nos parques se explora tanto a produção de energia quanto a beleza da paisagem. Cada uma dessas cidades tratou de uma maneira abrangente pelo menos um de seus problemas urbanos. Para a resolução desses problemas, as soluções nem sempre precisam ser abrangentes, mas o entendimento do problema, sim. Acredita-se que mudanças idealizadas através de pequenos projetos são mais viáveis. Quando coordenadas, essas mudanças podem ter um efeito de longo alcance.

\subsection{A questão ambiental no Brasil}

No Brasil a institucionalização da questão ambiental ocorreu no início da década de 70. Em 1973 foi criada a Secretaria Especial do Meio Ambiente - SEMA. A emergência de movimentos sociais urbanos e ambientais acelerou o aprimoramento das políticas urbanas e ambientais, principalmente na década de 80 , quando o país retornou ao regime democrático. Ao contrário do que ocorreu na maioria dos países desenvolvidos, onde as bases de infra-estrutura para o desenvolvimento urbano foram financiadas previamente pela iniciativa privada, no Brasil coube ao Estado a criação das condições gerais para o desenvolvimento urbano, já em meio ao processo descontrolado de urbanização. O ambientalismo no Brasil estruturou-se constituído por associações ambientalistas por um lado e por agências estatais de meio ambiente por outro, relacionando-se de maneira às vezes complementar, às vezes contraditória. Na fase ambientalista, a eficácia das lutas ecológicas foi muito baixa em termos de ganhos reais, mas foi significativa do ponto de vista da conscientização da população. A degradação ambiental não foi detida e, muito menos, revertida, mas a percepção da degradação aumentou na sociedade. O movimento ecológico difundiu- 
se e cresceu em capacidade de organização e atuação. A imagem de movimento exótico cedeu lugar ao reconhecimento de sua importância no cenário de luta e crítica ao regime vigente (MENEZES, 1996).

Um novo impulso foi dado em 1981, com a criação da lei que estabeleceu a Política Nacional de Meio Ambiente, regulamentada em 1983. Nela se considerou, pela primeira vez, a conciliação do desenvolvimento econômico com a preservação ambiental. Entre os instrumentos jurídicos inovadores destacam-se o Zoneamento Ambiental, a Avaliação de Impacto Ambiental e o Cadastro Técnico Federal de Atividades e Instrumentos de Defesa Ambiental. Criou-se o Sistema Nacional de Meio Ambiente - SISNAMA, integrado por um órgão colegiado - o Conselho Nacional de Meio Ambiente - CONAMA - e por órgãos executivos das esferas federal e estadual. Ao CONAMA coube a responsabilidade de formular a política ambiental do país. Em 1985 foi criado o Ministério do Desenvolvimento Urbano e Meio Ambiente, incorporando a estrutura do BNH. Dois anos depois esse ministério foi transformado em pasta de Habitação, Urbanismo e Meio Ambiente; no final do governo Sarney, o ministério foi extinto, e a SEMA voltou ao Ministério do Interior. Em 1989 foi criado o Instituto Brasileiro de Meio Ambiente e Recursos Naturais Renováveis - IBAMA, pela fusão da SEMA com agências federais. Um ano depois, já no governo Collor, foi criada a Secretaria do Meio Ambiente da Presidência da República (SEMAM-PR), à qual o Ibama ficou subordinado (MENEZES, 1996).

Em termos ambientais, a Constituição brasileira de 1988 é considerada uma das mais avançadas e inovadoras no mundo. O Brasil foi o primeiro país a consagrar a obrigatoriedade da Avaliação de Impacto Ambiental, na sua Constituição. Pela primeira vez também se determinou constitucionalmente a obrigatoriedade do Plano Diretor para cidades com mais de 20.000 habitantes. A discussão sobre o papel do município na gestão ambiental urbana intensificou-se a partir de 1988. Ambientalistas e governantes perceberam que na esfera municipal estão as maiores condições para a contenção, prevenção e solução da maioria dos problemas ambientais. Até meados da década de 80 a maioria dos ambientalistas era alheia ao problema do desenvolvimento: ecologia e economia eram vistas como realidades antagônicas. O reconhecimento dos elos essenciais entre meio ambiente e desenvolvimento já havia sido enfatizado na Primeira Conferência das Nações Unidas sobre Meio Ambiente, em Estocolmo, no ano de 1972; porém, foi o relatório da Comissão Mundial sobre Meio Ambiente e Desenvolvimento (1991) - Nosso Futuro Comum, que deu novo impulso à tomada de consciência da interdependência entre ecologia e economia, lançando o pressuposto básico do desenvolvimento sustentável (MENEZES, 1996). Em 1992 o governo brasileiro sediou a Conferência das Nações Unidas sobre Meio Ambiente e Desenvolvimento, fundamentada no princípio do desenvolvimento sustentável. Novo avanço foi dado em 1998, quando entrou em vigor a Lei n. ${ }^{0}$ 9.605, chamada Lei de Crimes Ambientais, que determina punições aos crimes contra a fauna e a flora, o ordenamento urbano e o patrimônio cultural, e ao causador de poluição.

\subsection{Aplicação do conhecimento e formas de intervenção}

As questões ambientais são um produto das aglomerações. Segundo as premissas de YEANG (1995, p.42) para uma visão ecológica do design, "people are part of a closed system, and the processes of the natural environment, being unitary, must be 
considered as part of the design and planning process. There are interrelationships between the man-made and the natural environment, and any changes to part of the system affect the entire system."

Abordando a água como limite ao desenvolvimento, SERRA (2000) afirma que a principal causa do desmatamento e os maiores consumidores de água do planeta não são as mega-cidades, e sim, a agricultura, que é responsável por mais de $60 \%$ da retirada de água dos mananciais, e que provoca poluição dos aquíferos por defensivos e fertilizantes na maior parte dos rios do Estado de São Paulo. Fazendo uma diferenciação bastante clara entre escassez e falta d'água, Serra conclui que a disponibilidade de água em São Paulo não é ruim, mas problemas como a ocupação irregular no entorno dos reservatórios precisam ser repensados: da forma como está, a ocupação acaba sendo induzida pela lei que a proíbe, mas ela poderia ser regulamentada.

O homem sempre busca alterar o meio ambiente em função das necessidades humanas socialmente definidas; essas alterações mal conduzidas são a causa de muitos dos problemas no meio ambiente urbano, mas deve-se deixar claro que a urbanização não é um mal em si. A questão é que nos países em desenvolvimento ela se conjuga com altos índices de pobreza. A ocupação de áreas urbanas ambientalmente mais frágeis como mangues, várzeas, fundos de vale, aterros, lixões e áreas de mananciais, aliada a um aumento descontrolado das atividades econômicas, é a expressão mais contundente dos efeitos dessa conjugação (MENEZES, 1996). Segundo ROGERS (1997), "while the need for cities and the inevitability of their continued growth will not diminish, city living per se need not lead to civilisation's self-destruction. I passionately believe that the arts of architecture and city lanning could be evolved to provide crucial tools for safeguarding our future, creating cities that provide sustainable and ciilising environments."

A infra-estrutura é o principal meio de controlar o meio ambiente urbano, mas as determinações têm que ser locais. Para tanto, há a necessidade do entendimento do sítio natural antes do urbanismo, fazendo-se uma leitura ecológica da forma ${ }^{9}$ urbana, principalmente das áreas ambientalmente mais frágeis que, muitas vezes, não são

\footnotetext{
${ }^{9}$ As expressões estrutura, geometria da malha e tecido urbanos são usadas por diferentes autores, muitas vezes sem definição precisa. Quando citados neste trabalho manteve-se o termo, porém, grifado. Adota-se, neste caso, as expressões espaço natural, espaço construído e forma urbana definidos por SERRA (1987).

Espaço natural - é a paisagem primitiva; é o espaço físico antes que nele sejam introduzidas adaptações pelo homem (p.32, 52). A forma do espaço natural é descrita por um conjunto de variáveis tais como relevo, hidrografia, clima, materiais de construção disponíveis, fertilidade do solo, existência de minérios, ocorrência de água, etc. (p.84)

Espaço construído - são adaptações no espaço natural que vão sendo construídas; a cada momento novas decisões vão sendo tomadas, tendo em vista não apenas o espaço natural e suas características, mas também as localizações e formatos já decididos para as aglomerações anteriores. A cada nova decisão, os parâmetros serão cada vez mais aqueles da própria aglomeração e cada vez menos aqueles do espaço natural, que, na verdade, vai sendo constantemente modificado (p.85).

Forma urbana - é a disposição no espaço das várias partes da aglomeração urbana e o conjunto das relações espaciais que estas mantém entre si e com o todo, como percebida pelo seu contorno, cor e textura (p.99).
} 
pensadas em termos urbanos. Deve-se ter em mente que o espaço natural não é uma folha em branco: clima, relevo, hidrografia e demais fatores naturais devem ser considerados no desenho urbano e deve-se tirar proveito deles para melhorar a qualidade do produto final, que é a cidade. Em cidades de clima rigoroso, por exemplo, não posso mudar o clima regional, mas posso utilizar dispositivos microclimáticos para criar espaços mais agradáveis. Sob a pressão da ocupação são rápidos o desaparecimento de espaços catalisadores de atividades urbanas e o surgimento de áreas degradadas pela ocupação inadequada, tais como os movimentos de terra desnecessários que acontecem na abertura de novos loteamentos, contribuindo para a desertificação do solo e tornando a recuperação bem mais difícil. Fatos como esses podem trazer à cidade mudanças progressivas e irreversíveis, contrapondo crescimento e decadência.

Nas questões que envolvem clima urbano e planejamento, apesar de todo o conhecimento já produzido, falta aproximação entre as partes envolvidas; há um distanciamento entre as duas áreas: climatologias por um lado, arquitetos e planejadores de outro. Climatologistas urbanos demonstram interesse em estudos para cidades de clima tropical, em países em desenvolvimento, e também lamentam a lacuna de interação com o planejamento; para a climatologia essa linha de pesquisa já tem um histórico razoavelmente longo. Ela foi intensificada a partir da década de 1970 com os estudos de Landsberg, Oke, Chandler, Borstein e seus seguidores. Já a integração com o planejamento é um pouco mais recente, com as experiências da escola alemã de planejamento, e depois com estudos na África do Sul.

Um dos maiores obstáculos para a integração entre a climatologia urbana, as questões energéticas, as ações de planejamento e desenho urbano é a complexidade da modelagem. Cada uma dessas áreas tem suas limitações: o trabalho do climatologista não chega ao planejamento urbano porque ele não tem ferramentas para isso; no máximo chega a algumas recomendações gerais; o arquiteto, por sua vez, não domina a modelagem matemática usada pelos climatologistas. Alguns modelos matemáticos são formulados na climatologia urbana para o balanço de energia, mas não são facilmente aplicáveis ao planejamento; muitos desses modelos dizem respeito à camada limite urbana, e não consideram o referencial humano. Já os arquitetos e planejadores urbanos vivem em função de modelos concretos, não têm familiaridade com regras gerais; estas precisam ser traduzidas para uma linguagem mais voltada para a aplicação prática desse conhecimento.

Falta uma linguagem comum, que contribua para que a somatória desse conhecimento resulte em propostas concretas de planejamento e desenho urbano adequadas ao clima, e com isso seja possível alcançar as vantagens que um padrão de ocupação mais adequado pode trazer, principalmente a redução no consumo de energia e o conforto para os moradores. Um bom exemplo de integração é o que aconteceu na EXPO'92, em Sevilha, quando previamente foi formada uma equipe multidisciplinar de especialistas para testar diferentes soluções e orientar o trabalho dos muitos arquitetos que planejaram o recinto da exposição com enorme sucesso sob condições climáticas tão adversas. ${ }^{10}$

\footnotetext{
${ }^{10}$ ver capítulo 3 .
} 
As características do clima urbano, suas causas e efeitos, já são bem conhecidos, mas esse conhecimento raramente é aplicado. Cada cidade é composta por um mosaico de microclimas diferentes; os mesmos fenômenos que caracterizam o mesoclima urbano existem em miniatura por toda a cidade, como pequenas ilhas de calor, bolsões de poluição atmosférica e diferenças locais no fluxo dos ventos. É imperativo manipular o clima da cidade para a saúde, o conforto e a conservação de energia, ainda que os arquitetos e urbanistas das cidades modernas raramente o façam. $\mathrm{O}$ sucesso ou o fracasso dos espaços públicos urbanos tem muito a ver com o conforto, o que é, para muitos, uma preocupação menor. Existem outras exigências igualmente importantes para os projetistas, tanto funcionais como estéticas, mas se um lugar é desconfortável, esse desconforto pode acabar com todas as outras considerações (SPIRN, 1995).

\subsection{Colocação do Problema}

Parte-se de um princípio largamente aceito pela comunidade científica de que há uma correlação entre microclimas urbanos e algumas variáveis relacionadas ao uso e ocupação do solo. Já existe uma fundamentação teórica e dados empíricos suficientemente claros para afirmar que o espaço construído é um dos fatores que contribuem para a criação de microclimas diferenciados em relação ao clima regional, em alguns casos, inconvenientes ou desconfortáveis para o ser humano, conforme já foi demonstrado em estudos anteriores sobre a existência de ilhas de calor, de ilhas secas ou dos desconfortos relacionados à circulação de ventos em ambientes urbanos, por exemplo.

Teoricamente esse processo é reversível, ou pelo menos pode ser alterado ou controlado até certo ponto pelas ações de planejamento e desenho urbano. Pode-se até restaurar ou amenizar as condições ambientais indesejadas retirando-se a causa, em última instância demolindo a cidade, ou partes dela. Em Nova Iorque, por exemplo, para a construção do Central Park, mais de 340ha, boa parte deles já ocupados, foram desapropriados ${ }^{11}$; no centro de Maringá, planejada na década de 1940, uma densa área verde foi preservada no centro da então futura cidade, com a vegetação original do lugar. ${ }^{12}$

Através de um conjunto de medidas relacionadas ao planejamento da cidade e ao tratamento dos espaços públicos é possível criar um microclima mais ameno em regiões de clima rigoroso, ou até mesmo criar um microclima que nunca existiu nas condições naturais. De acordo com GIVONI (1989, p.6-8, 6-9) "It is possible to infer from theoretical considerations, as well as from actual measurements in and around buildings, that in hot-and-dry regions it might be possible to plan cities so that the ambient daytime air temperatures would be lower than those of the surrounding country. The main planning approach by which such a modification of the urban temperature seems possible is a combination of urban density, building heights and an average albedo of the whole area of the towns which will reduce significantly the solar radiation absorbed in the urban fabric."

\footnotetext{
${ }^{11}$ ver capítulo 4.

12 ver capítulo 4 .
} 
Em muitas cidades brasileiras na região de clima tropical continental não seria suficiente restaurar condições anteriores à urbanização porque, na verdade elas nunca foram boas, o clima regional já era rigoroso antes da urbanização. Num caso crítico como este o desafio para o planejador urbano é criar novas condições que nunca existiram, claro que não na cidade como um todo, como se ela fosse climatizada à maneira das cidades visionárias protegidas por um domo climatizado, mas numa sucessão de pequenos espaços com certo grau de confinamento, onde a alteração das condições climáticas seja possível. Para YANNAS (1998, p.42), "urban tissue is not homogenous, either along a horizontal section from centre to outskirts, or vertically from ground to the urban canopy, and that generalised models would be of limited value. Secondly, the existence of such differences suggests that pockets of improved microclimate can be created by appropriate interventions, thus starting a reversal of the heat island effect." Alterações como estas já foram feitas, por exemplo, no recinto da exposição universal de 1992, durante o rigoroso verão sevilhano ${ }^{13}$, cujas condições climáticas são bastante parecidas com as da estação seca na região de clima tropical continental no Brasil.

Para ROSENFELD et al. (1995, p.260) "Urban air temperatures can also be reduced substantially through a combination of albedo modification and tree planting. (...) This regional oasis effect is evident in the weather records of cities built in arid environments." Em Sacramento, Califórnia, após um extensivo programa de arborização urbana, os espaços tratados dentro da cidade têm melhores condições de conforto higrotérmico do que fora, sob a influência das condições naturais. ${ }^{14}$

Estudos do Heat Island Group, vinculado ao Lawrence Berkeley Laboratory, e do U.S. Department of Energy também demonstraram que o aumento de temperatura em áreas urbanas não segue necessariamente um aumento de população. A região onde hoje se situa Los Angeles era semidesértica em 1880, e as temperaturas máximas anuais giravam em torno de $38,9^{\circ} \mathrm{C}\left(102^{\circ} \mathrm{F}\right)$. Com a irrigação nas áreas de cultivo, em 50 anos as temperaturas no verão caíram cerca de $2,8^{\circ} \mathrm{C}\left(5^{\circ} \mathrm{F}\right)$. Após a urbanização, a partir dos anos 1940, as áreas verdes foram substituídas por pavimentos e massa edificada; em 50 anos as temperaturas no verão voltaram aos níveis de 1880 e ainda estão subindo à razão de $0,56^{\circ} \mathrm{C}\left(1^{\circ} \mathrm{F}\right)$ a cada dez anos (fig.1.1). "But with white roofs, concrete-colored pavements, and about 10 million new shade trees, Los Angeles could be cooler than the semidesert that surrounds it, instead of hotter. (...) In our own simulation, we raise the city albedo - the reflected fraction of incident solar heat - by a modest 7.5 percent and cover 5 percent of its area with 10 million trees. (...) In devising our "cool communities" strategy, we have focused our attention on helping Los Angeles - the smog capital of the United States - though its elements could be applied in other cities as well. Computer modeling of Los Angeles' heat island bears out what Mediterranean architects have known for thousands of years. Together, the planting of trees and the lightening of roofs and pavement could lower the average summer afternoon temperature in the Los Angeles heat island by $5^{\circ} \mathrm{F}$, cutting the need for air conditioning by 18 percent and significantly lowering the levels of smog." (ROSENFELD at al., [s.d])

\footnotetext{
${ }^{13}$ ver capítulo 3.

${ }^{14}$ ver capítulo 4.
} 


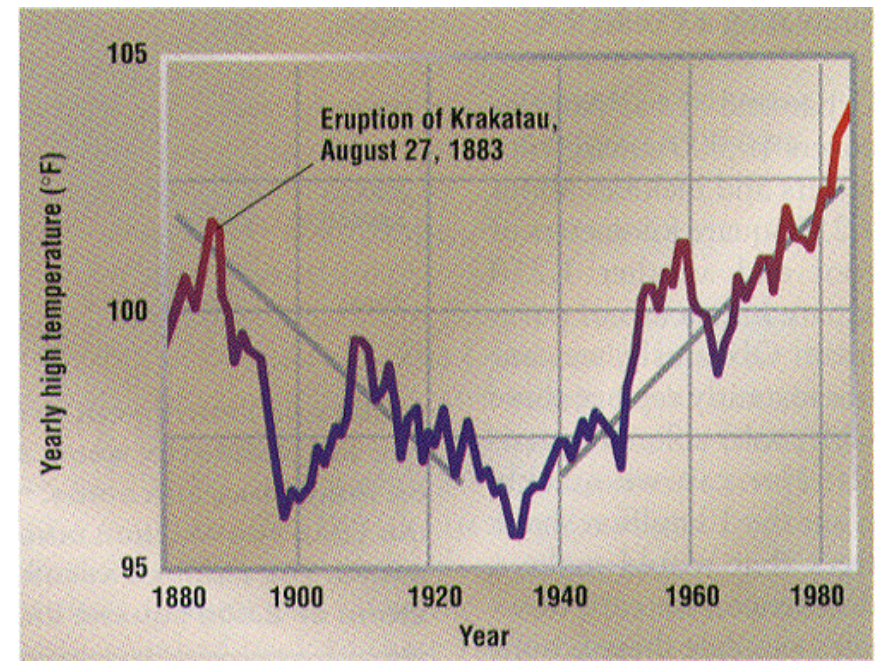

Figura 1.1 - Temperaturas máximas anuais em Los Angeles. (fonte: Heat Island Group. http://eetd.lbl.gov/heatislands/)

SAILOR (1995) também simulou alterações no albedo e na percentagem de cobertura vegetal de Los Angeles e demonstrou que, apenas com o albedo seria possível uma redução da temperatura na área central de $1,4^{\circ} \mathrm{C}$; no caso da cobertura vegetal a redução seria de $1,3^{\circ} \mathrm{C}$. Novas simulações do efeito combinado das duas estratégias resultaram em ganhos quase em dobro; e segundo o autor "a single degree Celsius reduction in summertime afternoon air temperatures corresponds to a $2 \%$ energy savings for the Los Angeles basin."

Estudos de JAUREGUI, GODINEZ e CRUZ (1992) em Guadalajara, México, detectaram um efeito de oásis na área central no período da tarde, na estação seca, e os autores atribuem esse efeito ao fato da cidade atuar como uma fonte de umidade em relação aos arredores, apesar de que no período noturno a diferença de temperatura entre centro e periferia segue o modelo já conhecido da ilha de calor, ou seja, com o centro mais aquecido que a periferia da cidade. O mesmo fenômeno foi observado na Cidade do México por JAUREGUI (1986). PEARLMUTTER, BITAN e BERLINER (1999), fazendo uma análise microclimática em canyons urbanos em Israel, também confirmaram que durante o dia, sob condições extremas de stress térmico em um clima desértico, o canyon urbano compacto era uma verdadeira ilha fria, principalmente devido ao sombreamento proporcionado pelos edifícios.

Um outro ponto a ser equacionado é a intervenção em climas compostos, que muitas vezes apresentam requisitos contraditórios para diferentes estações do ano. Foram encontradas algumas recomendações de GIVONI (1989, p.8-1, 8-3) que se encaixam nas condições de clima tropical continental de muitas cidades brasileiras, com duas estações do ano termicamente estressantes: uma quente e seca (com temperaturas mais amenas no período noturno) e outra quente e úmida. "High temperatures, low humidity and intense sunshine are prevalent during the dry-season. Winds are often dust-laden. The climate in this season is very similar to that prevailing in the hot-dry regions. (...) Somewhat lower temperatures (still too high from the human comfort aspect), high humidity, cloudy skies and heavy rain occur during the hot-humid season... (...) The winter is mild, with plenty of sunshine and comfortable temperatures. (...) The design guidelines however should lead to indoor and outdoor optimal conditions year around... Protection from the intense solar radiation is of 
primary importance both indoors and outdoors, to prevent overheating of pedestrians in streets and to minimize the elevation of the indoor temperature. (...) Although the average solar radiation is weaker in the hot-humid season than in the hot-dry one, it can add significantly to psychological heat stress and buildings heat load. When the sky is clear, in days or hours between the cloudy periods, solar intensity can be very high. Therefore solar protection is important both outdoors and indoors in this season as well."

Sob essas condições climáticas, presentes em muitas cidades brasileiras de clima tropical continental, para se chegar a um microclima desejado GIVONI (1994, p.242243) coloca o sombreamento como pré-requisito para os espaços externos antes de qualquer outra medida, porque a proteção à radiação solar tem um grande efeito psicológico na redução do stress térmico. Se as superfícies sombreadas também forem úmidas, natural ou artificialmente, a sua temperatura cai para a temperatura de bulbo úmido que, na estação seca, pode ser significativamente menor do que a temperatura do ar. Sendo assim, para as cidades na região de clima tropical continental no Brasil, parte-se dos seguintes princípios:

- o primeiro recurso para promover conforto térmico em espaços externos é criar sombra de boa qualidade, ou seja, que apresente transmissividade nula e ausência de sobreaquecimento sobre a mesma; isso incentiva o uso de determinados espaços, favorece o percurso a pé nas áreas residenciais, de comércio e serviços, o que de início nos leva a pensar em arborização em larga escala. Da mesma forma que foi pensado para Chandigarh ${ }^{15}$, o ideal seria criar caminhos para que o pedestre pudesse percorrer toda a cidade sob um teto verde, protegido da intensa radiação solar;

- além da vegetação arbórea formando um teto natural deve-se pensar também na adoção de arcadas ou galerias para sombreamento e proteção das fortes chuvas de novembro a março, possibilitando e incentivando o uso das áreas de comércio e serviços mesmo durante a estação chuvosa;

- com o rápido crescimento das cidades e o aumento da densidade ocupacional pretendido por muitos planos diretores nas cidades brasileiras (como São Paulo, Curitiba e Cuiabá, por exemplo), deve-se compensar a alta densidade pretendida e a verticalização da ocupação com elementos que proporcionem amenidade climática para o pedestre, talvez com uma seqüência de áreas verdes para minimizar a intensidade da ilha de calor.

\subsection{Descrição circunstanciada do objeto e do objetivo}

O objeto deste trabalho são os microclimas urbanos nas cidades brasileiras da região de Clima Tropical Continental, em particular as situadas nas depressões geográficas, com escassa ventilação.

A construção do objeto-modelo foi fundamentada em uma pesquisa envolvendo o conhecimento do meio físico, particularmente as condições climáticas na região estudada, e os fatos históricos sobre a ocupação urbana, fazendo um levantamento de

\footnotetext{
${ }^{15}$ ver capítulo 3.
} 
dados primários com medições de microclimas urbanos e com a caracterização qualitativa e quantitativa de padrões típicos de ocupação local.

O objetivo é medir a correlação numérica entre algumas variáveis de uso e ocupação do solo urbano e a variável temperatura do ar, a fim de orientar qual o conjunto de medidas necessárias para amenizar as condições climáticas nas cidades brasileiras na região de clima tropical continental, que predomina no Centro-Oeste do Brasil.

O modelo utilizado para o estabelecimento de tal correlação é universalmente válido para cidades em regiões continentais, com diferentes tipos de clima e padrões de ocupação urbana. Já o grau de correlação e o conjunto de medidas resultantes ficam restritos às cidades sob as mesmas condições climáticas, além da necessidade de se integrar às tradições culturais locais.

\subsection{Enunciado da hipótese}

Em estudos internacionais ${ }^{16}$ já foi provado que é possível introduzir modificações no espaço urbano que modifiquem a temperatura, a umidade do ar e a ventilação, amenizando condições climáticas extremas. Os mouros já faziam isso há séculos na Andaluzia, intuitivamente, por tentativa e erro. ${ }^{17}$ Porém, embora se afirme que é possível melhorar os microclimas urbanos manipulando uso e ocupação do solo, o grau de correlação entre a temperatura do ar e algumas variáveis diretamente aplicáveis ao planejamento não foi estabelecido. Seguindo um dos caminhos que KUHN (1994, p.45-55) usa para explicar o que motiva o cientista a perseguir suas escolhas até chegar a uma conclusão, esta tese busca realizar um trabalho empírico para articular a teoria ao paradigma, resolvendo algumas de suas ambiguidades residuais e permitindo a solução de problemas para os quais ela anteriormente só tinha chamado a atenção.

Os modelos de clima urbano existentes ${ }^{18}$ geralmente tratam da cidade como um todo para prever a intensidade máxima da ilha de calor (que não é objeto desta pesquisa) em função:

- do tamanho da cidade, usando o parâmetro população, às vezes com a interferência da velocidade regional de vento;

- da relação H/W (height/width) ou do fator de céu visível (sky view factor) nos canyons urbanos;

- ou ainda do balanço de energia, com variáveis familiares aos climatologistas, mas não diretamente aplicáveis ao planejamento urbano.

Parte-se do princípio já aceito pela comunidade científica de que há uma correlação entre microclimas urbanos e condições de uso e ocupação do solo. O que a tese está fazendo pela primeira vez é estabelecer uma correlação numérica entre a temperatura do ar e alguns parâmetros de uso e ocupação do solo, não para a cidade como um todo, mas em diferentes pontos do espaço construído que são representativos dos

\footnotetext{
${ }^{16}$ ver capítulo 3 sobre o tratamento dos espaços abertos da EXPO’92, em Sevilha.

${ }^{17}$ ver capítulo 3.

${ }^{18}$ ver capítulo 2.
} 
diferentes padrões de ocupação, usando variáveis de planejamento que podem ser regulamentadas pela legislação municipal.

A inovação também está no modelo de pesquisa para sistematizar essa correlação e no uso de variáveis familiares ao planejador urbano e que podem ser regulamentadas. Com o estabelecimento do grau de correlação entre a temperatura do ar e cada parâmetro relacionado à ocupação urbana, pode-se saber qual a associação de cada um deles com a temperatura e quais os seus períodos de maior influência, pois os fenômenos climáticos urbanos são diferentes para o período diurno e noturno; a ilha de calor é um fenômeno tipicamente noturno, mas é preciso investigar melhor o stress térmico que acontece durante o dia.

Os resultados podem ser utilizados no planejamento de novas áreas de ocupação para que elas respondam melhor às condições do clima. As conclusões podem trazer informações para subsidiar códigos de obras, leis de uso do solo, o planejamento de cidades novas ou de novos bairros, o assentamento de conjuntos habitacionais que se multiplicam na periferia, geralmente sem nenhuma preocupação com questões de conforto higrotérmico, arrasando terrenos sem respeitar a topografia e sem preservar a vegetação existente.

O estabelecimento de tal correlação já foi tentado por SAMPAIO (1981), cujo objetivo era sistematizar metodologicamente um caminho que permitisse aferir e explicitar possíveis correlações entre as variáveis uso do solo e as ilhas de calor para o caso de Salvador, verificando a existência da correlação e determinando o grau de associação entre as variáveis. Sampaio usou como variável dependente a temperatura do ar e como variáveis independentes o uso do solo e as condições do meio físico. Quantificou densidade populacional, taxa de ocupação, volume edificado, coeficiente de aproveitamento, área de vias e área edificada por habitante. Escolheu como pontos amostrais áreas significativas em termos de arranjo espacial, sendo cinco delas construídas e outras três livres. De hora em hora foram feitas três leituras em cada ponto, em intervalos de cinco minutos, a uma altura de $0,80 \mathrm{~m}$ do solo, das 6 às $18 \mathrm{~h}$, em um único dia. Pelos resultados encontrados, Sampaio concluiu que a intensidade de uso do solo não poderia ser apontada como tendo uma correlação linear com a variação de temperatura na cidade de Salvador, invalidando a hipótese inicial em termos de significação numérica; o autor afirma ainda que Salvador não se encaixa no modelo de OKE (1973a) para relacionar a intensidade da ilha de calor à população. Apesar disso, Sampaio conseguiu comprovar contrastes entre áreas edificadas e áreas livres nas temperaturas máximas e médias.

O resultado do trabalho de Sampaio mostra a dificuldade de se isolar a variável uso do solo para demonstrar a ocorrência da ilha de calor. Na época o autor não conseguiu comprovar a hipótese para o caso de Salvador com os dados de microclimas urbanos medidos e os índices urbanísticos utilizados, talvez por condições climáticas atípicas durante o curto período de medições, por ter medido somente no período diurno e, principalmente, pelo fato de que cidades litorâneas, sujeitas a ventos de grande intensidade que aumentam as trocas térmicas por convecção, são menos sujeitas à influência da forma urbana (SERRA, 1987) sobre a temperatura do ar, o que não acontece em cidades tropicais continentais, sob condições de céu claro e calmaria. Com o aumento da velocidade do vento diminui a 
tendência da temperatura na zona urbana ser superior à dos arredores (GIVONI, 1998, p.257).

Como subproduto da tese foi proposto um índice relacionando a massa edificada com a área de arborização e superfícies d'água que, após ser testado em outras cidades e validado, pode ser usado para ajustar a proporção recomendada entre o espaço construído e os elementos naturais em cidades existentes ou para o planejamento de novas áreas de ocupação, bairro a bairro.

\subsection{Escolha da amostra}

Desde a década de 1970 o Centro-Oeste é a segunda região que mais cresce no país e onde está surgindo um dos mercados de mais rápida expansão no Brasil. Todos os estados da região e o Distrito Federal apresentaram altas taxas de crescimento populacional nas últimas décadas, principalmente em função de fluxos migratórios (tab.1.1). O crescimento foi ainda mais impulsivo em Mato Grosso. Ocupando 10,5\% do território nacional o estado tem sofrido mudanças profundas. Em 1970, seis em cada dez habitantes moravam na zona rural. O quadro hoje se inverteu: sete em cada dez moram na cidade (CENTRO-OESTE EM EXAME, 1998).

Tabela 1.1 - Taxa média geométrica de crescimento anual. (fonte: IBGE)

\begin{tabular}{|c|c|c|c|}
\hline & $\mathbf{1 9 7 0 / 8 0}$ & $\mathbf{1 9 8 1 / 9 1}$ & $\mathbf{1 9 9 1 / 9 6}$ \\
\hline MS & 3.2 & 2.4 & 1.63 \\
\hline MT & 6.62 & 5.35 & 2.01 \\
\hline GO & 2.78 & 2.34 & 2.4 \\
\hline DF & 8.13 & 2.81 & 2.66 \\
\hline
\end{tabular}

Dentro da região de clima tropical continental, que predomina no Centro-Oeste do Brasil, optou-se por trabalhar como amostra com as condições ambientais da cidade de Cuiabá pelos seguintes motivos:

- localização em área tropical continental, sem influência marítima, onde já foi detectada a influência do uso do solo urbano na ocorrência de ilhas de calor no trabalho de MAITELLI (1994);

- o fato da zona urbana estar situada em uma depressão geográfica faz com que a frequência e a velocidade média dos ventos seja extremamente baixa, minimizando o efeito das trocas térmicas por convecção e ressaltando ainda mais a influência do espaço construído sobre a temperatura do ar, o que acaba gerando condições praticamente ideais para este tipo de experimento;

- a continuidade de trabalhos anteriores da candidata e do orientador na cidade, fazendo a análise em um espaço bastante conhecido;

- o porte médio da cidade e suas altas taxas de crescimento. Pelas projeções do IBGE, em 1999 o município de Cuiabá tinha 453.813 habitantes e o município vizinho de Várzea Grande, 214.435 habitantes, totalizando 668.248 habitantes em um aglomerado urbano;

- em Cuiabá encontram-se amostras de desenho urbano acompanhando cada período de sua história, gerando uma grande variedade de padrões de ocupação. É um exemplo de cidade do período colonial que foi se 
modernizando e se adaptando às suas novas funções, ao contrário de outras antigas capitais de estado como Ouro Preto e Goiás Velho, por exemplo, que foram substituídas por novas capitais planejadas - Belo Horizonte e Goiânia respectivamente.

\subsection{Construção do modelo e descrição das variáveis envolvidas}

Estando claro o objetivo da pesquisa pode se especificar as condições para o processo de construção do modelo em questão. Para ECHENIQUE (1975, p.235, 237, 241), "un modelo es una representación de una realidad, donde la representación se hace a través de la expresión de ciertas características relevantes de la realidad observada y donde la realidad consiste en los objetos o sistemas que existen, han existido o puedan existir. (...) El propósito principal de un modelo es proporcionar un cuadro simplificado e inteligible de la realidad para poder comprenderla mejor. Debe ser posible manipular un modelo para poder proponer mejoras en la realidad. (...) deberá existir un objeto o sistema a ser investigado, una intención, claramente expresada, por la cual realizar una selección, un proceso de observación y abstracción, un proceso de traducción mediante los medios de representación, y un proceso de prueba y establecimiento de conclusiones."

Segundo BUNGE (1974, p.22, 221), a construção do modelo é uma atividade criadora que põe em jogo os conhecimentos, as preferências e até a paixão intelectual do pesquisador. Deve-se partir de um objeto concreto, construir um objeto-modelo e finalmente chegar ao modelo teórico; essa sequência particulariza a teoria, mas a torna verificável. Antes de aplicar hipóteses é preciso construir o objeto-modelo, que por sua vez é um modelo conceitual do sistema em causa e não um modelo qualquer, mas um modelo construído com conceitos encontrados nas próprias hipóteses.

Qualquer representação esquemática de um objeto pode ser denominada objetomodelo e a representação é sempre parcial, reducionista. Citando SERRA (1997), ao referir-se a esta tese em particular, "neste momento Cuiabá deve transferir-se para a sua mesa; se o objeto-modelo estiver insuficiente você deve voltar ao real $e$ realimentá-lo.” Depois se estabelece um esquema idealizado ou o modelo teórico do sistema; se não há modelo teórico, não há predição científica. Para BUNGE (1974) o modelo nunca é mais nem menos do que uma representação idealizada, aproximada, em termos teóricos, das feições salientes do sistema em causa.

Segundo DANTAS (1981, p.9), todo modelo, implícita ou explicitamente, contém uma teoria. Para BUNGE (1974, p.34), a fim de se obter um modelo teórico, o objeto modelo deve ser expandido e engastado em uma moldura teórica; um modelo teórico de um objeto concreto certamente não corresponde à complexidade de seu referente, mas em qualquer caso é muito mais rico que o despido objeto-modelo, que é apenas uma lista de características do objeto concreto.

No modelo como teoria a ênfase é a redução do objeto, quando tudo se passa como se..., e uma enorme quantidade de informações vai se transformando em qualidade de dados para o trabalho.

$\mathrm{Na}$ construção dos modelos são necessárias algumas simplificações, ao mesmo tempo em que é preciso garantir coerência, precisão e comprobabilidade da teoria; essas são condições essenciais para que algo seja uma teoria científica. De acordo 
com BUNGE, (1974, p.128, 123-124), "simplicidade lógica é desejável enquanto não envolve perda de precisão, escopo e profundidade (...) somente serão admitidas na ciência aquelas simplificações que tornam a teoria mais manejável, mais coerente, ou melhor, comprovável; nenhuma simplificação será aceitável se esta cortar severamente qualquer destas características ou a profundidade, o poder explanatório ou o poder preditivo da teoria.(...) o que se quer é a economia e não a pobreza (...) não se requer uma simples eliminação de complexidades, mas uma redução cautelosa de redundâncias, uma simplificação em alguns aspectos sofisticados, sob a condição de não diminuir a verdade.”

Para DANTAS (1981), a primeira noção de modelo é um fato que é produzido ou reproduzido em laboratório e submetido a uma observação empírica, com a qual vai se rejeitar, reformular, esclarecer ou redefinir uma teoria. Mas como se elabora o conhecimento quando o fato não é reproduzível em laboratório, como por exemplo, no estudo de fenômenos sociais?

Problema semelhante também é encontrado nas pesquisas em arquitetura e urbanismo. A dificuldade fica evidente quando se compara o contraste entre as ciências nas quais se pode ensaiar (na química, por exemplo) e as que vivem da observação (como a astronomia); pesquisas em urbanismo são baseadas fundamentalmente em observações, pela dificuldade ou até impossibilidade da realização de ensaios em alguns casos.

De acordo com DANTAS (1981, p.3,8) “o papel científico do planejamento urbano deve propiciar a formulação de teorias sobre a cidade, teorias estas que expressariam o conhecimento sobre o objeto da arte aplicada e da política, permitindo a contínua avaliação das intervenções adotadas ou daquelas recomendadas." Dantas também critica a utilização de teorias importadas na construção de modelos urbanos, em função de suas deficiências face à realidade brasileira: "a avaliação de teorias sobre a cidade, através de sua verificação empírica, constitui uma forma de desenvolver o planejamento urbano enquanto ciência (...) tal verificação pressupõe um método e um instrumento de análise. (...) Os modelos urbanos constituem uma representação de fenômenos que caracterizam a cidade. A modelagem, procedimento através do qual se elabora modelos, compreende uma análise sistemática de fatos reais: identificação e mensuração de elementos que constituem estes fatos e, identificação e mensuração das relações entre tais elementos."

De acordo com SERRA (1997), a busca do rigor faz com que, muitas vezes, adote-se uma simbolização matemática sem que, na verdade, exista qualquer possibilidade de expressão matemática dos conceitos em discussão; em muitas pesquisas, por modelos matemáticos não se chega a lugar algum. Para NOVAES (1982, p.10), o instrumental matemático se adapta apenas a uma pequena fração do universo de conceitos e fatores no ambiente urbano.

Partindo de uma visão sistêmica, cada edifício ou grupo de edifícios, com suas áreas verdes e praças circundantes, cada parque, cada rua e estrada deve ser projetado não só como um sistema em si mesmo, mas como parte de um bairro maior, que é um subsistema da cidade, e como uma pequena peça do ecossistema metropolitano (SPIRN, 1995, p.271). Nesta tese vai se utilizar um modelo reducionista para tratar 
da correlação entre algumas variáveis do planejamento relacionadas ao conforto térmico em áreas urbanas.

Define-se como variável resposta (variável dependente) a temperatura do ar, mas a umidade também foi registrada em todas as observações para um melhor entendimento do contexto climático em cada unidade observacional. As variáveis direção e velocidade do vento foram consideradas com algumas restrições pelos seguintes motivos:

- em Cuiabá a ventilação é extremamente baixa por causa da configuração geográfica de depressão da zona urbana, com velocidade do vento pouco superior a $1 \mathrm{~m} / \mathrm{s}$ durante boa parte do tempo ${ }^{19}$, o que não justificaria a inclusão de mais um conjunto de equipamentos para registrar valores tão baixos. Na dissertação de ASSIS (1990) a influência dessa variável também foi considerada pouco significativa na escala mesoclimática para Belo Horizonte, em função das baixas velocidades de vento na região, da ordem de $1,4 \mathrm{~m} / \mathrm{s}$;

- o vento vai se tornando menos eficiente para reduzir o stress térmico quando a temperatura do ar atinge a temperatura da pele, por volta dos $35^{\circ} \mathrm{C}$, o que também é freqüente na região em boa parte do ano;

- as duas estações meteorológicas de apoio fornecem esses dados e ambas estão localizadas em zonas urbanas, uma no campus da UFMT - Universidade Federal de Mato Grosso, a aproximadamente 3Km da área central de Cuiabá, e a outra no INMET - Instituto Nacional de Meteoologia, no município vizinho de Várzea Grande, a aproximadamente $1 \mathrm{Km}$ após a travessia da Ponte Júlio Müller sobre o Rio Cuiabá, e a 3,5Km do centro de Cuiabá.

Quanto à escolha das variáveis urbanísticas levou-se em consideração algumas definições: para SERRA (1987) o espaço natural pode ser descrito por um conjunto de variáveis como relevo, hidrografia, pedologia, flora, clima, etc., e a forma urbana pode ser definida como a disposição, no espaço, das várias partes do aglomerado urbano. ASSIS (2000, p.13) pergunta qual seria o conjunto de variáveis para a descrição do espaço urbano e, mais especificamente, da forma urbana, de modo que se possa compreender melhor a inter-relação da cidade com o clima?

Para YANNAS (1998), em estudos mais abrangentes de meio ambiente urbano, deve-se considerar e trabalhar os seguintes parâmetros:

- built form, density and type to influence airflow, view of sun and sky, and exposed surface area

- street canyon width-to-height ratio and orientation, to influence warming-up and cooling processes, thermal and visual comfort conditions, and pollution dispersal

- building design to influence building heat gains and losses, albedo and thermal capacity of external surfaces, use of transitional spaces

- urban materials and surface finishes to influence absorption, heat storage, and emissivity

\footnotetext{
${ }^{19}$ ver capítulo 5 .
} 
- vegetation and bodies of water to influence evapotranspiration and evaporative cooling processes on building surfaces and/or on open spaces

- traffic reduction, diversion, rerouting to reduce air and noise pollution, and heat discharges

Algumas variáveis foram apontadas por GIVONI (1986, p.488-489) como elementos que afetam o microclima urbano, as condições de conforto e a demanda de energia dos edifícios, assim como o potencial para utilização de energia solar. O autor definiu essas variáveis como:

- size and density of the built-up area

- layout and width of streets, their orientation and relation to the prevailing winds

- $\quad$ patterns of the sub-division and the shape, size and orientation of the building lots

- the height, shape and relative location of buildings

- shading conditions along streets and in parking areas”

Para ASSIS (1997, p. 34-35) as características descritivas da forma urbana relacionadas ao balanço energético da camada limite urbana são o uso do solo, a geometria da malha (dimensões, distribuição, volumetria e distância entre os edifícios) e a tipologia da ocupação (edifícios, ruas, áreas verdes, etc.). O tipo de fachadas e as propriedades térmicas dos materiais constituintes determinam as condições de troca térmica entre o ambiente exterior e interior. Outros parâmetros envolvidos são a orientação solar do espaço construído e sua permeabilidade ao vento. Para Assis a morfologia urbana, as propriedades térmicas dos materiais das superfícies e a proporção entre área verde e área construída são os principais fatores ligados à cidade responsáveis pela mudança climática e geração da ilha de calor.

Segundo ASSIS (2000, p.59), a partir do experimento de OKE (1980/1981), que demonstrou que a geometria urbana e as propriedades térmicas das superfícies são as características mais relevantes que governam as variáveis responsáveis pelas diferenças no balaço de energia radiante e nas taxas de resfriamento entre os meios urbano e rural, um crescente número de pesquisadores começou a verificar que a geometria urbana constitui, de fato, uma das causas primárias da mudança climática local, não apenas restrita ao fenômeno noturno da ilha de calor. Já as áreas verdes e os corpos d'água devem ser considerados nas trocas de calor latente e na transformação da energia absorvida; em áreas urbanas este fator pode sofrer uma grande diminuição em relação às trocas de calor sensível devido à impermeabilização do solo, canalização de águas superficiais e diminuição da cobertura vegetal.

Cidades litorâneas ou próximas a grandes corpos d’água, com ventos de grande intensidade que promovem continuamente trocas por convecção, estão menos sujeitas à influência da forma urbana sobre a temperatura do ar (ASSIS, 2000). Em estudo de caso para Maceió BARBIRATO e MATTOS (1999) concluíram que embora a malha urbana interfira na modificação do clima local, em valores absolutos as diversas tipologias urbanas mostraram poucas diferenças na temperatura do ar. ELIASSON (1990/91) realizou medições na escala urbana e na escala da rua, nos chamados canyons urbanos, em Göteborg, Suécia, e os resultados mostraram uma variação de temperatura do ar menor do que a esperada. A temperatura superficial 
variou alguns graus em diferentes geometrias urbanas, mas a temperatura do ar variou muito pouco, sugerindo que a geometria teria pouca influência sobre os padrões de temperatura do ar. Neste estudo somente a temperatura superficial mostrou ter uma relação estatisticamente significativa com o fator de visão de céu para a cidade em estudo.

O mesmo não acontece em áreas urbanas em regiões continentais, conforme já demonstrado nos estudos de LOMBARDO (1985) para São Paulo, ASSIS (1990, 1997 e 2000) para Belo Horizonte e MAITELLI (1994) para Cuiabá.

EMMANUEL (1993), em estudo para climas equatoriais, afirma que a geometria urbana é um dos fatores mais importantes da mudança climática, pelo menos em micro-escala. Estabelece como instrumentos principais de projeto a massa edificada e a vegetação, com o uso da água proposto para melhorar a ventilação de resfriamento noturno. $\mathrm{O}$ autor propõe a manipulação da geometria para explorar o potencial de sombreamento das massas edificadas, visando a redução da radiação solar nos ambientes externos durante o dia, e o seu equilíbrio com os elementos naturais.

MIZUNO et al. (1990/91), da Universidade de Osaka, Japão, estudaram os efeitos do uso do solo na distribuição horizontal das temperaturas em ambientes urbanos. Fazendo experimentos no recinto da EXPO'70 concluíram que, em ordem decrescente, os seguintes fatores contribuem para o aumento da temperatura do ar: superfícies construídas, grama, corpos d’água e árvores, e que somente uma superfície gramada, sem o fator sombreamento provocado pelas árvores, não contribui muito para a redução das temperaturas. Em outro local, um centro urbano de 150.000 habitantes as seguintes variáveis contribuem, em ordem decrescente, para o aumento da temperatura: pavimentação, edifícios, áreas verdes e superfícies d'água. Os autores também concluíram que o raio de influência das condições de uso do solo ao redor de um ponto varia de $50 \mathrm{~m}$ a $200 \mathrm{~m}$ em uma escala local, e fica em torno de $1,5 \mathrm{Km}$ na escala urbana.

ASSIS (2000, p.61), visando uma abordagem mais prática de projeto urbano, sugere que alguns atributos relativos ao formato, rugosidade e porosidade da massa edificada poderiam ser reunidos, diminuindo o número de variáveis. OKE (1980/81, p.48), ao propor uma parametrização para a acumulação de calor nas áreas urbanas, experimentou uma classificação de uso do solo em quatro categorias, mas depois concluiu que esse grau de detalhamento era desnecessário, injustificado, e que somente duas categorias eram necessárias: as áreas verdes e a área edificada.

Os modelos existentes que tratam da ilha de calor como fenômeno noturno geralmente prevêem a intensidade máxima da ilha de calor, em função da população, posteriormente englobando a velocidade de vento regional (OKE, 1982), ou ainda em função da relação H/W (height/width) entre a altura dos edifícios e a distância entre eles ou a variante fator de céu visível (sky view factor), conforme OKE (1981). Esses modelos expressam a hipótese de que a ilha de calor urbana é causada principalmente pela redução da perda do calor radiante acumulado durante o dia para o céu no período noturno, devido à visão restrita do ceú. GIVONI $(1998$, p.252) diz que a perda total de energia radiante a partir da zona urbana é mais ou menos a mesma se comparada a uma área rural; a diferença é que, em áreas urbanas, a maior parte da radiação é emitida a partir das coberturas e fechamentos verticais dos pavimentos mais altos dos edifícios, e o resfriamento ao nível da rua é parcial. 
O fator de visão de céu pode ser entendido como uma das variáveis que descrevem a geometria urbana, do ponto de vista do balanço energético das superfícies, mas sem descrever a forma dos edifícios. Na área central de São Francisco, Califórnia, TAHA (1988) investigou qual a correlação entre a temperatura do ar noturna, medida a 1,5m do chão em noites de céu claro e com velocidade do vento inferior a $1 \mathrm{~m} / \mathrm{s}$, e o fator de céu visível. "Although ground surface temperature is more sensitive to the sky view factor variation than is air temperature, the present investigation has focused on the latter because of its more direct relevance to city-wide building energy use." Taha levanta outras variáveis implícitas ao fator de céu visível: quando esse valor é baixo, isso significa que "wind velocity is reduced within the urban canopy layer (except for funneling effects), thermal mass per unit area is increased (and therefore the volumetric heat capacity $\rho C$ ), the mixing with the upper boundary layer is more restricted, and so forth." Os resultados demonstraram que há uma correlação moderada entre as variáveis (de $r=-0,30$ a $r=-0,86$ ), considerando todos os pontos estudados, e que essa correlação é bastante alta em alguns locais específicos. Taha lembra que a posição geográfica de São Francisco não apresenta condições ideais para a ocorrência da ilha de calor, que os dados foram coletados em uma estação amena, e que os resultados podem ser diferentes para outras estações do ano.

GOLDREICH (1992) questiona se uma cidade pequena, mas com o mesmo fator de céu visível de uma cidade grande, teria a mesma intensidade da ilha de calor, e cita uma informação verbal do próprio Oke dizendo que sim, desde que os fatores climáticos sejam os mesmos e que a área central tenha pelo menos $0,5 \mathrm{Km}$ sob as mesmas condições de ocupação em todas as direções.

Modelos baseados no fator de visão de céu caracterizam o fenômeno de aquecimento noturno; porém, GIVONI (1998, p.254) alerta para o fato de que o que acontece no período diurno pode ser completamente diferente. Quanto mais altos os edifícios e menores as distâncias entre eles, menos radiação solar atinge o solo durante o dia.

Comentando os modelos existentes, GIVONI (1998, p.281-282) acha conveniente substituir o parâmetro população por densidade construída, por esta apresentar uma relação causal mais forte com o aquecimento urbano. A densidade de diferentes áreas construídas na cidade afeta os microclimas pontualmente e, pelo seu efeito cumulativo, determina a modificação do clima regional pela urbanização. Para o autor, a fração de solo coberta pelos edifícios é um fator relevante para se avaliar o efeito climático da urbanização. Estudos de SHARLIM e HOFFMAN (1984) em Tel Aviv estabeleceram vários índices; os mais significativos foram a razão entre a área do envelope dos edifícios em relação à área total e a razão entre a área permanentemente sombreada ao redor dos edifícios em relação à área total. Outros índices incluíam área construída, área pavimentada, área verde e população estimada, mas o seu efeito foi considerado estatisticamente não significativo.

Finalmente, nesta tese foram definidas como variáveis explicativas (variáveis independentes) a taxa de ocupação e o coeficiente de aproveitamento do solo líquidos e brutos (que de certa forma descrevem a variável densidade construída recomendada por Givoni), a área de espelho dos corpos d'água e a área da projeção horizontal das copas das árvores, e todas elas podem ser quantificadas, além dos três horários do dia nos quais são realizadas as medições, às 8h, 14h e 20h. 
Descreve-se o método utilizado e o modelo da tese, passo a passo, e apresenta-se um fluxograma (fig.1.2) resumindo o esquema metodológico:

1. construção do quadro teórico referencial.

2. colocação do problema, definição do objeto, objetivo e enunciado da hipótese.

3. escolha da amostra e conhecimento do meio, através de uma pesquisa de caráter histórico e ambiental da região em estudo.

4. escolheu-se criteriosamente sete casos (sete locais de estudo) com diferentes padrões de ocupação na zona urbana da cidade de Cuiabá, fazendo-se um levantamento das condições ambientais em cada um deles. Foi usada uma amostragem intencional, em que o pesquisador deliberadamente escolhe certos elementos para pertencer à amostra, por julgar tais elementos representativos da população (COSTA NETO, 1977). Sendo assim, os dados não são considerados como amostras, e sim, como observações pontuais. O número de unidades observacionais ficou condicionado à limitação no número de instrumentos e de pessoas disponíveis para o trabalho de campo.

5. desses sete locais, dois correspondem ao entorno das estações meteorológicas do INMET - Instituto Nacional de Meteorologia, e da UFMT - Universidade Federal de Mato Grosso. Os demais foram escolhidos criteriosamente de forma que representassem as condições ambientais naturais da região (quase sem intervenções urbanas próximas, como o Horto Florestal), os locais com pequena intervenção urbana (como o bairro Pascoal Ramos, na periferia da cidade), e três bairros totalmente urbanizados, próximos à área central de Cuiabá, mas com padrões urbanos bastante diversos por causa de seus distintos períodos de ocupação e crescimento. São estes: o centro antigo, próximo ao Morro da Luz, o entorno da Av. do CPA e o bairro Araés.

6. o trabalho de campo foi feito em duas etapas visando, por um lado, a descrição qualitativa e quantitativa da taxa de ocupação líquida e bruta, do coeficiente de aproveitamento líquido e bruto, das superfícies d’água e da arborização (levantamento A). Por outro, a obtenção da temperatura e da umidade do ar nas duas estações do ano mais significativas para o clima da região (levantamento B) em cada um dos sete locais escolhidos.
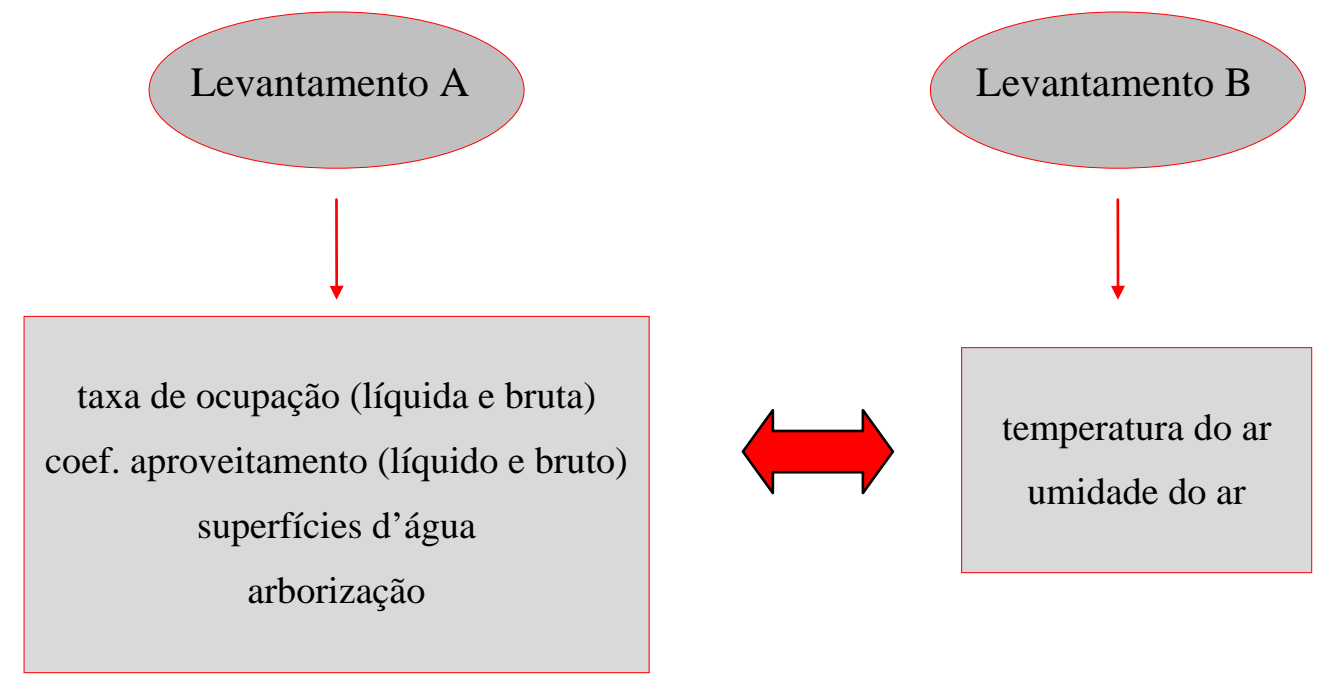

temperatura do ar umidade do ar 
7. o levantamento A foi feito em duas etapas. Na primeira cada um dos sete sítios é descrito qualitativamente. Para a descrição qualitativa foi feita uma pesquisa de caráter ambiental, utilizando fotos de satélite, fotos aéreas e pesquisa de rua para caracterização e documentação fotográfica dos pontos estudados. Na segunda etapa, nos mesmos locais descreve-se quantitativamente a taxa de ocupação (\%), o coeficiente de aproveitamento, a área ocupada por superfícies d'água ( $\mathrm{m}^{2}$ ) e por arborização (área da projeção horizontal das copas das árvores em $\mathrm{m}^{2}$ ). ${ }^{20}$ Os índices quantificados são ordenados em planilhas e gráficos.

8. para o levantamento B foram feitas medições de temperatura e umidade do ar nos sete locais escolhidos, nas escalas horizontal e temporal. A escala horizontal representa as flutuações registradas ao mesmo tempo em diferentes pontos, e a escala temporal representa as flutuações no mesmo ponto em diferentes momentos. ${ }^{21}$ Essas medições foram feitas em duas estações significativas para o clima da região: estação seca e estação chuvosa.

9. como resultado temos medições de 2 parâmetros (temperatura e umidade do ar) para 7 casos, em duas estações do ano, além dos dados sobre ventilação fornecidos pelas estações de apoio. Foram seis dias consecutivos de medições em cada estação, sendo um dia com leituras de hora em hora, das 8h às 20h e, nos outros cinco, leituras em três horários que coincidem com os utilizados pelas estações meteorológicas oficiais: 8h, 14h e 20h, sendo estas o $9^{\circ}$ Distrito de Meteorologia do INMET - Instituto Nacional de Meteorologia, e a Estação Climatológica Mestre Bombled, no campus da Universidade Federal de Mato Grosso. No total foram feitas 392 observações para cada parâmetro: temperatura e umidade do ar.

10. os sete casos foram classificados segundo a qualidade dos microclimas encontrados (neste caso os locais com menor temperatura do ar), fazendo-se uma análise do contexto urbano em que cada unidade observacional se insere.

11. para cada leitura às $8 \mathrm{~h}, 14 \mathrm{~h}$ e $20 \mathrm{~h}$ fez-se um teste de correlação entre a variação horizontal da temperatura do ar e cada uma das seis variáveis de ocupação separadamente, totalizando 216 testes. Dessa forma foi possível saber se há correlação entre elas, em que horários a correlação é mais ou menos acentuada, o grau e o sinal da correlação, comprovando a hipótese.

12. ao final, como um subproduto da tese, foi proposto um índice em função das variáveis de ocupação utilizadas neste estudo, visando subsidiar futuros trabalhos na determinação da proporção recomendada (do ponto de vista do conforto higrotérmico urbano) entre a densidade de ocupação e os elementos naturais (vegetação e água), para as cidades da região de clima tropical continental.

\footnotetext{
${ }^{20}$ MIZUNO et al. (1990/91), da Universidade de Osaka, Japão, estudaram os efeitos do uso do solo na distribuição horizontal das temperaturas em ambientes urbanos e concluíram que somente uma superfície gramada, sem o fator sombreamento provocado pelas árvores, não contribui muito para a redução das temperaturas.

${ }^{21}$ Para GIVONI (1998, p.265), do ponto de vista do desenho urbano a escala horizontal é a mais relevante, porque é a mais afetada pela geometria dos edifícios, pela orientação das ruas, pela existência de edifícios altos, etc.
} 


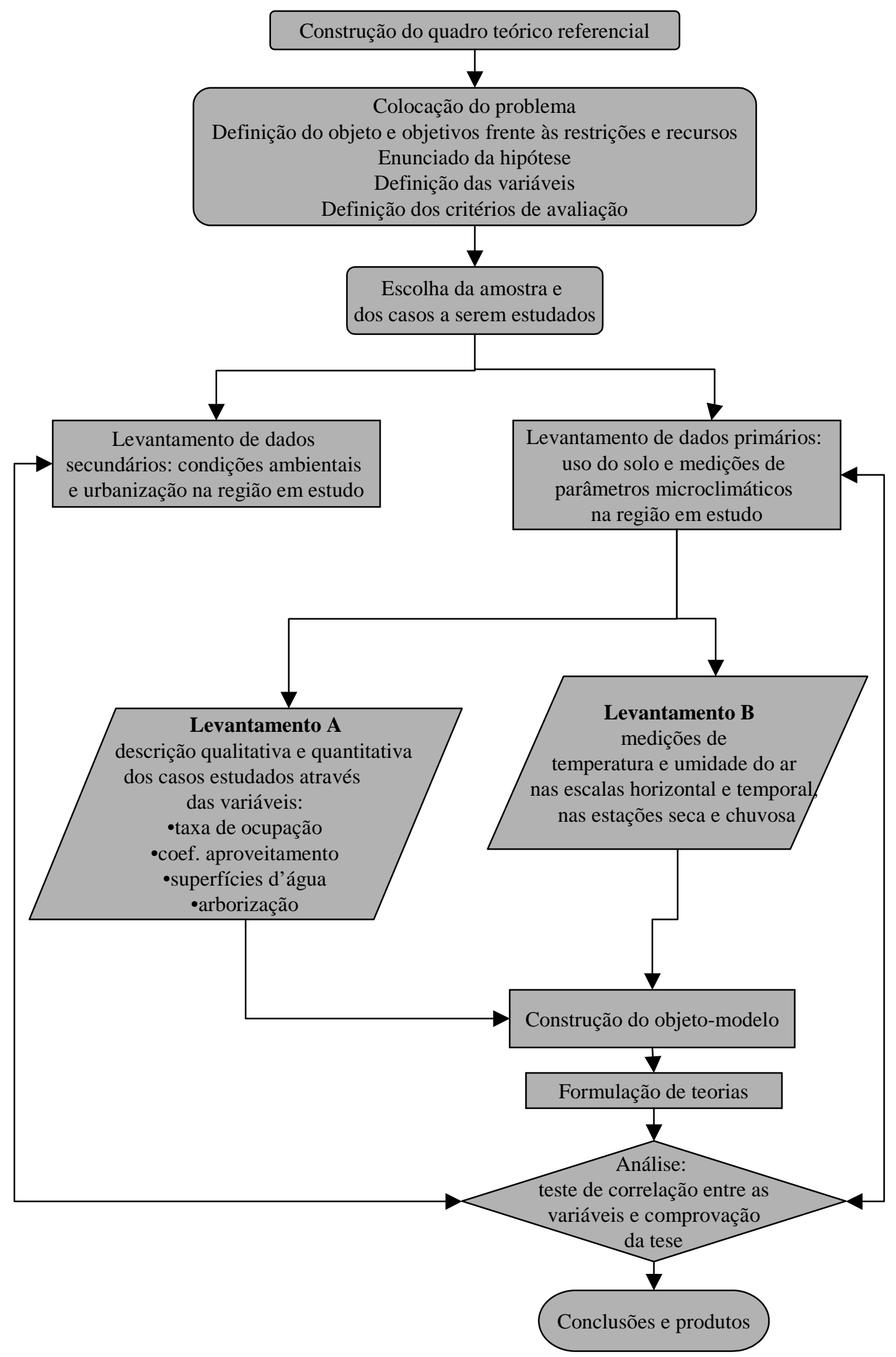

Figura 1.2 - Esquema metodológico. 
Os mais recentes estudos nessa área, como o de OKE et al. (1999), ainda não conseguiram equacionar totalmente o balanço de energia em áreas urbanas, e concluíram que os efeitos combinados das características da superfície, tais como a disponibilidade de água e as propriedades térmicas dos materiais, interagem de maneira bastante complexa, e vão demandar tempo e novos estudos para serem equacionados.

Também ainda não se dispõe de uma equação matemática de fácil aplicação ao planejamento urbano, mas já foi possível levantar uma tendência para a correlação entre temperatura do ar e as condições de ocupação, e dar prosseguimento ao estudo em trabalho posterior.

Acredita-se que o estabelecimento desses padrões ideais de ocupação exija profunda revisão dos códigos de edificações, bem como dos planos diretores municipais, do ponto de vista ambiental e energético.

Para se chegar a essas melhorias também é necessário o envolvimento da população na busca de soluções para os problemas locais, estimulando a participação dos moradores; acredita-se que os problemas ambientais não podem resolvidos somente através do Estado; é imprescindível a atuação consciente e responsável da comunidade (como já acontece em algumas cidades, como Curitiba, por exemplo) e para isso pode-se começar pelos pequenos problemas do entorno mais imediato, ligados aos usos e costumes, à cultura local. As medidas propostas devem considerar e otimizar a participação da comunidade em um compromisso coletivo no qual o modelo de gestão de desenvolvimento local seja aberto, flexível, capaz de incorporar novos fatores e corrigir distorções, reformulando-se continuamente, em favor de uma utilidade social.

É preciso deixar claro que o resultado final não é um projeto para a região de Cuiabá, porque a cidade foi usada apenas como amostra dentro do universo das cidades brasileiras da região de clima tropical continental e, sendo assim, o método utilizado pode ser aplicado para qualquer cidade sob as mesmas condições climáticas.

Trata-se de um estudo interdisciplinar, com um trabalho conjunto entre arquitetura e urbanismo, geografia, climatologia e história, quando foi possível experimentar todo o tipo de dificuldade para o entendimento entre as partes. Contou-se com o apoio do Laboratório de Climatologia da UFMT - Universidade Federal de Mato Grosso, com pesquisadores e meteorologistas do IAG-USP - Instituto Astronômico e Geofísico da Universidade de São Paulo, com os arquitetos e planejadores do IPDU - Instituto de Planejamento e Desenvolvimento Urbano da Prefeitura Municipal de Cuiabá, com a equipe do Horto Florestal de Cuiabá e com historiadores locais. Esses vínculos foram sendo estabelecidos ao longo de anos de trabalho, desde a pesquisa para dissertação de mestrado da autora (DUARTE, 1995) e para a tese de doutoramento de MAITELLI (1994), que mapeou as ilhas de calor e ilhas secas na cidade. Este estudo tenta construir um elo de ligação entre as diversas áreas envolvidas fazendo um trabalho de campo que o planejador urbano geralmente não tem. Os geógrafos também sentem falta dessa cooperação, pois não entendem por que as cidades e os edifícios e são construídos de maneira inadequada, sendo que o conhecimento sobre microclimas urbanos já tem um histórico razoável.

Ao longo de todo o trabalho a tese buscou uma linguagem comum entre as áreas envolvidas que possa ser utilizada no planejamento urbano. Como não havia nenhum 
modelo preestabelecido, a cada passo foi preciso buscar qual a maneira de se coletar informações, como trabalhar com elas, como integrar conhecimentos de áreas afins em busca de um objetivo comum.

\section{Referências Bibliográficas}

1. ASSIS, Eleonora Sad de. Mecanismos de desenho urbano apropriados ‘a atenuação da ilha de calor urbana: análise de desempenho de áreas verdes em clima tropical. Rio de Janeiro, 1990. Dissertação (Mestrado em Arquitetura) - Faculdade de Arquitetura e Urbanismo, Universidade Federal do Rio de Janeiro.

2. ASSIS, Eleonora Sad de. Bases teóricas para a Aplicação da climatologia ao planejamento urbano. In: IV Encontro Nacional de Conforto no Ambiente Construído, 1997, Salvador. Anais. Salvador: FAUUFBA/LACAM-ANTAC, 1997. p.134-139.

3. ASSIS, Eleonora e FROTA, Anésia. Urban bioclimatic design strategies for a tropical city. In: Atmospheric Environment, Oxford, v.33, n.24-25, p.41354142, 1999.

4. ASSIS, Eleonora Sad de. Impacto da forma urbana na mudança climática: método para previsão do comportamento térmico e melhoria de desempenho do ambiente urbano. São Paulo, 2000. Tese (Doutorado em Arquitetura) Faculdade de Arquitetura e Urbanismo, Universidade de São Paulo.

5. BAHIA, Sérgio Rodrigues (coord.) Modelo para Elaboração de Código de Obras e Edificações. Rio de Janeiro: IBAM/DUMA, 1997. (Núcleo de Meio Ambiente do IBAM - Instituto Brasileiro de Administração Municipal, em convênio com a Eletrobrás através do Programa Nacional de Conservação de Energia - PROCEL).

6. BARBIRATO, Gianna, MATTOS, Arthur. Microclimas Urbanos em Maceió. In: V Encontro Nacional de Conforto no Ambiente Construído e II Encontro Latino-Americano de Conforto no Ambiente Construído - ENCAC, 1999, Fortaleza. Caderno de Resumos. Fortaleza: ANTAC, 1999.

7. BARBIRATO, Gianna, MATTOS, Arthur. O uso da modelagem climática no planejamento dos espaços urbanos. In: V Encontro Nacional de Conforto no Ambiente Construído e II Encontro Latino-Americano de Conforto no Ambiente Construído - ENCAC, 1999, Fortaleza. Caderno de Resumos. Fortaleza: ANTAC, 1999.

8. BITAN, Arieh. The high climatic quality city of the future. Atmospheric Environment, Oxford, v.26B, n.3, p.313-329, 1992.

9. BUCKMINSTER FÜLLER. The Artifacts of R. Buckminster Füller. Vol.4: The Geodesic Revolution, Part 2, 1960-1983. New York, London: Garland, 1985.

10. BUNGE, Mario. Teoria e Realidade. São Paulo: Perspectiva, 1974.

11. Centro de Estatística Aplicada do Instituto de Matemática e Estatística da Universidade de São Paulo - CEA/IMEUSP. Relatório de Consulta. 
12. CENTRO-OESTE EM EXAME. A conquista do oeste. São Paulo: Exame, n.20, ed. 671, 23 set. 1998.

13. COMISSÃO MUNDIAL SOBRE MEIO AMBIENTE E DESENVOLVIMENTO. Nosso Futuro Comum. 2.ed. Rio de Janeiro: FGV, 1991.

14. COSTA NETO, Pedro L. de O. Estatística. São Paulo: Edgard Blücher, 1977.

15. DANTAS, Jorge. Modelos Urbanos. Um enfoque científico no planejamento urbano. São Paulo, 1981. Tese (Livre-docência) - Faculdade de Arquitetura e Urbanismo, Universidade de São Paulo.

16. DUARTE, Denise. O clima como parâmetro de projeto para a região de Cuiabá. São Carlos, 1995. Dissertação (Mestrado em Arquitetura) - Escola de Engenharia de São Carlos, Universidade de São Paulo.

17. ECHENIQUE, Marcial. Modelos: una discusión. In: Martin, L. et al. La Estructura del Espácio Urbano. Barcelona: Gustavo Gili, 1975.

18. ELIASSON, Ingegärd. Urban geometry, surface temperature and air temperature. Energy and Buildings, n.15-16, 1990/91, p.141-145.

19. EMMANUEL, Rohinton. A Hypothetical 'shadow umbrella' for thermal comfort enhancements in the equatorial urban outdoors. Architectural Science Review, n.36, 1993. p.173-184.

20. EVANS, M., SCHILLER, S. Application of microclimate studies in town planning: a new capital city, an existing urban district and urban river front development. In: Atmospheric Environment, Oxford, v.30, n.3, p. 361-364, 1996.

21. FLEURY DE OLIVEIRA, José Luiz Ferreira. Amazônia: Condicionantes da Ocupação e Assentamentos Humanos. São Paulo, 1984. Dissertação (Mestrado) - Faculdade de Arquitetura e Urbanismo, Universidade de São Paulo.

22. FLEURY DE OLIVEIRA, José Luiz Ferreira. Amazônia: Proposta para uma Ecoarquitetura. São Paulo, 1989. Tese (Doutoramento) - Faculdade de Arquitetura e Urbanismo, Universidade de São Paulo.

23. GIVONI, Baruch. Design for climate in hot, dry cities. In: URBAN CLIMATOLOGY AND ITS APPLICATIONS WITH SPECIAL REGARD TO TROPICAL AREAS. Mexico D.F., 26-30 November 1984. Proceedings. OKE, T. (ed.) Urban Climatology and its Applications with Special Regard to Tropical Areas. Geneva: WMO n.652, 1986, p.487-513.

24. GIVONI, Baruch. Urban Design in Different Climates. Geneve: WCAP-10, WMO/TD n.346, 1989.

25. GIVONI, Baruch. Passive and Low Energy Cooling of Buildings. New York: John Wiley \& Sons, 1994.

26. GIVONI, Baruch. Climate Considerations in Building and Urban Design. New York: John Wiley \& Sons, 1998. 
27. GOLDREICH, Yair. Urban climate studies in Johannesburg, a sub-tropical city located on a ridge - a review. Atmospheric Environment, v.26B, n.3, p.407420, 1992.

28. HOUGH, Michael. Naturaleza y ciudad. Barcelona: Gustavo Gili, 1998.

29. IV INTERNATIONAL ECOCITY CONFERENCE. Curitiba, abril de 2000.

30. JAUREGUI, E. The urban climate of Mexico City. In: URBAN CLIMATOLOGY AND ITS APPLICATIONS WITH SPECIAL REGARD TO TROPICAL AREAS. Mexico D.F., 26-30 November 1984. Proceedings. OKE, T. (ed.) Urban Climatology and its Applications with Special Regard to Tropical Areas. Geneva: WMO n.652, 1986, p.63-86.

31. JAUREGUI, E., GODINEZ, L., CRUZ, F. Aspects of heat-island development in Guadalajara, Mexico. Atmospheric Environment, v.26B, n.3, p.391-396, 1992.

32. KUHN, Thomas S. A Estrutura das Revoluções Científicas. 3.ed. São Paulo: Perspectiva, 1994.

33. LE CORBUSIER. A Carta de Atenas. São Paulo: Hucitec/EDUSP, 1993.

34. LOMBARDO, Magda. Ilha de calor nas metrópoles. São Paulo: Hucitec, 1985.

35. GOLDREICH, Yair. Urban climate studies in Johannesburg, a sub-tropical city located on a ridge - a review. Atmospheric Environment, v.26B, n.3, p.407420, 1992.

36. MAITELLI, Gilda. Abordagem tridimensional de clima urbano em área tropical continental: o exemplo de Cuiabá - MT. São Paulo, 1994. Tese (Doutoramento em Geografia). São Paulo: FFLCH, Universidade de São Paulo.

37. MENEZES, Claudino Luiz. Desenvolvimento Urbano e Meio Ambiente. A experiência de Curitiba. Campinas: Papirus, 1996.

38. MIZUNO M. et al. Effects of land use on urban horizontal atmospheric temperature distributions. Energy and Buildings, n.15-16, 1990/91, p.165176.

39. NOVAES, Antonio G. Modelos em Planejamento Urbano, Regional e de Transportes. São Paulo: Edgard Blücher, 1982.

40. Novos Hotéis no Estado do Amazonas. ABA, n.1, p.132-135, 1967/68.

41. OKE, T.R. City size and the urban heat island. Atmospheric Environment, v.7, 1973a, p.769-779.

42. OKE, T.R., KALANDA, B.D., STEYN, D.G. Parametrization of heat storage in urban areas. Urban Ecoclogy, Netherlands, v.5, 1980/1981, p.45-54.

43. OKE, T. R. The energetic basis of the urban heat island. Quarterly Journal of the Royal Meteorology Society, v.108, n.455, p.1-24, jan.1982.

44. OKE, T. R. et al. The energy balance of central Mexico City during the dry season. Atmospheric Environment, v.33, 1999, p.3919-3930. 
45. PEARLMUTTER, D., BITAN A., e BERLINER, P. Microclimatic analysis of 'compact' urban canyons in an arid zone. Atmospheric Environment, Oxford, v.33, p.4143-4150, 1999.

46. PRESSMAN, Norman E. P. Sustainable winter cities: future directions for planning, policy and design. Atmospheric Environment, Oxford, v.30, n.3, p.521-529, 1996.

47. ROGERS, Richard. Cities for a small planet. London: Faber and Faber, 1997.

48. ROSENFELD, Arthur et al. Mitigation of urban heat islands: materials, utility programs, updates. Energy and Buildings, v.22, p.255-265, 1995.

49. ROSENFELD, Arthur et al. Painting the Town White and Green. LBL. Heat Island Group. [s.d.] In: http://eetd.lbl.gov/HeatIsland/PUBS/PAINTING

50. SAILOR, David. Simulated urban climate response to modifications in surface albedo and vegetative cover. Journal of Applied Meteorology, v.34, p.16941701, 1995.

51. SAMPAIO, Antonio Heliodorio Lima. Correlações entre o uso do solo e ilhas de calor no ambiente urbano: o caso de Salvador. São Paulo, 1981. Dissertação (Mestrado em Geografia), Faculdade de Filosofia, Letras e Ciências Humanas, Universidade de São Paulo.

52. SANTAMOURIS, Matheos. The Athens urban climate experiment. In: Environmentally Friendly Cities. Proceedings of PLEA'98. Lisbon: James and James, 1998, p.147-152.

53. SCHILLER, S, EVANS, M. Climate responsive urban development in tropical cities: training and practice. In: TECHNICAL CONFERENCE OF TROPICAL URBAN CLIMATES. Dhaka, mar./apr.1993. Report. [Geneve]: WMO/TD n.647, 1994, p.377-390. p.357-364.

54. SERRA, Geraldo Gomes. O espaço natural e a forma urbana. São Paulo: Nobel, 1987.

55. SERRA, Geraldo Gomes. AUT 802 - Modelos. Notas de aula. São Paulo: FAUUSP, 1997.

56. SERRA, Geraldo G. São Paulo: water as a limit do development. Anais do Seminário 2000 do World Federation of Scientists, Erice, Itália. WFS, 2000.

57. SHARLIM, N., HOFFMAN, M.E. The urban complex as a factor in the airtemperature pattern in a Mediterranean coastal region. Energy and Buildings, n.7, 1984, p.149-158.

58. SPIRN, Anne Whiston. O jardim de granito. São Paulo: EDUSP, 1995.

59. TAHA, Haider. Night Time Air Temperature and the Sky-View Factor: A Case Study in San Francisco, California. Lawrence Berkeley Laboratory, Berkeley CA, LBL- 24009, 1988.

60. WORLD METEOROLOGICAL ORGANIZATION. Fourth WMO Long-Term Plan 1996-2005. Summary of Objectives, Policies and Strategy. Geneva: WMO n.831, 1996. 
61. WORLD METEOROLOGICAL ORGANIZATION. Technical Conference on Tropical Urban Climates, 1993, Dhaka. Report. Geneva: WCASP-30, WMO/TD n647, 1994.

62. YANNAS, Simos. Living with the city. Urban design and Environmental Sustainability. In: Environmentally Friendly Cities. Proceedings of PLEA'98. Lisbon: James and James, 1998, p.41-48.

63. YEANG, Ken. Designing with nature. The ecological basis for architectural design. New York: McGraw-Hill, 1995. 


\section{ESTADO DA ARTE NAS PESQUISAS ENVOLVENDO CLIMA URBANO E PLANEJAMENTO}

Nessa linha de pesquisa há uma série de dificuldades a serem vencidas: cabe lembrar que estimativas das condições microclimáticas devem se basear em dados que nem sempre estão disponíveis para o planejador urbano. Além do grande número de variáveis envolvidas, esses dados devem ser coletados durante um bom período de tempo, dependendo das finalidades da pesquisa. Muitas vezes essa coleta pode ser demorada e dispendiosa.

Fazendo-se uma revisão na literatura existente, percebe-se que a combinação de diferentes técnicas de pesquisa pode gerar bons resultados nos estudos que envolvem o meio ambiente urbano, pelo menos enquanto não se dispõe de uma ferramenta única que englobe todas as variáveis em questão. Trabalha-se com a combinação de mapas, imagens de satélite, fotografias aéreas, fotografias no nível da rua, etc., além da coleta de dados climáticos e microclimáticos.

As técnicas de sensoriamento remoto vêm sendo utilizadas com cautela porque ainda apresentam restrições. Hoje já se sabe da limitação do uso de imagens de satélite nos estudos de clima urbano porque alguns materiais apresentam indistintamente a mesma resposta espectral. Inicialmente se pensava em utilizar imagens de bandas termais para o acompanhamento das ilhas de calor, mas já se sabe que isso ainda não é totalmente possível. As leituras registradas pelo satélite correspondem às temperaturas superficiais, e não à temperatura do ar. Para estudos em superfícies homogêneas como, por exemplo, para se acompanhar as variações de temperatura da água do mar, as imagens da banda termal podem ser bastante úteis, mas para superfícies heterogêneas, como a superfície do solo urbano, as distorções podem ser consideráveis, tornando o conhecimento da área estudada imprescindível; além disso, a eventual presença de nuvens é um complicador para essas medições. Portanto, uma imagem termal para estudo das ilhas de calor só seria utilizada com estas ressalvas. Segundo os pesquisadores entrevistados no INPE - Instituto Nacional de Pesquisas Espaciais, o estudo das ilhas de calor utilizando-se somente as imagens de satélite da banda termal ainda não é totalmente viável; seria necessário se utilizar simultaneamente outros métodos de coleta de dados para calibrar as leituras. O pesquisador Dr. Alberto Setzer ${ }^{1}$ citou o exemplo de um trabalho que vem se desenvolvendo desde 1985 para o monitoramento de queimadas, através da análise de imagens quase diárias da banda termal do satélite NOAA; ele afirma que ainda não é possível precisar a temperatura atingida de fato nesses locais. Porém, as imagens termais podem ter outras aplicações; nas imagens geradas na faixa do infravermelho próximo, em torno de $1.500 \mathrm{~nm}$, pode-se detectar algum efeito de temperatura; essa imagem termal pode ser até mais útil do que uma imagem do canal visível para se detectar a presença de vegetação, por exemplo, pelas diferenças de temperaturas superficiais em relação a um entorno construído. "Satellite remote sensing should never be evaluated and applied in isolation, without comparison to other mapping techniques and sources of information, such as aerial photos or sample surveys which have unique and complementing advantages. (...) Reference

\footnotetext{
${ }^{1}$ informação verbal, 1997.
} 
data are always needed to some extent in the analyses of remote sensing images. These reference data can be in the form of maps, air photos or air reconnaissance, although normally some fieldwork on the ground is also necessary. They are to help identify the features shown in the image and to verify the reliability of interpretations. (...) In the urban context, the term base-maps is normally applied to large-scale maps in the range of 1:500 to 1:2500. Mapping at these scales can be achieved only by aerial photography or terrestrial surveying. For thematic maps from 1:10.000 to 1:50.000 satellite imagery can be considered for creating or updating base-maps. (...) A higher level of technology does not necessarily mean that better results will be produced. On the contrary, in most cases visual interpretation of satellite images is better than computer-based processing for urban applications." (PAULSSON, [s.d.], p.10, 14)

Fazendo-se as ressalvas necessárias, para TSO (1996, p.519), “through remote sensing techniques it is now possible to have a snapshot of the thermal condition of an area, down to the details of $30 \mathrm{~m}$ pixels on a processed image. Despite the lack of a continuous temporal assessment and the fact that surface temperatures rather than air temperatures are deduced, remote sensing can be a potentially powerful diagnostic tool to gauge the thermal condition, particularly in the urbanised or urbanising areas." Para QUATTROCHI e RIDD (1988, p.20) “a number of investigators have provided evidence using thermal infrared remote sensor data, that urban areas are strong daytime longwave radiators. (...) Other researchers have used remote sensing data to observe nightime longwave radiation characteristics of cities."

Com todos os avanços ainda é difícil encontrar softwares para simulação de condições ambientais urbanas, talvez devido à dificuldade de se tratar em conjunto a contribuição de inúmeras variáveis. Para TSO (1996, p.519), “a successful model should also be able to predict the effect of green areas and tree-planting programmes, thus providing an important simulation software at the disposal of the town planners. With continuing progress, it should be possible to estimate the effect of a particular mix of buildings and green spaces to the neighbourhood in question. It may be possible for the environment regulatory bodies to design more specific guidelines or standards that large building projects should adhere to, in order that the projects will not bring about an overall excessive increase in outdoor temperatures. It is also noteworthy that, to be useful, it may not be necessary for the diagnostic and prognostic tools to be highly accurate in the absolute sense. What is sufficient is that the tools should be able to detect and predict incremental effects to the environment, and standards could then be made relative to the existing conditions."

Estudos de adequação climática voltados para a arquitetura geralmente vão do clima regional ao edifício, sem passar pela análise climática da cidade onde ele se insere. De acordo com MONTEIRO (1990, p.107) que fomenta a prática interdisciplinar, "entre a região e o edifício há um sensível hiato posto que a variação do 'local' dentro do quadro regional é considerável. (...) Da mesma forma o subsídio da observação do 'posto meteorológico padrão' para a escala do edifício requer também alguma consideração.” 
Do ponto de vista do climatologista, o principal interesse é estudar o impacto da área urbana na atmosfera. Para o planejamento urbano e o projeto de edifícios o interesse maior está na direção oposta, ou seja, estudar os impactos da atmosfera urbana nos aspectos funcionais, econômicos e de segurança do ambiente edificado na saúde e bem-estar de seus ocupantes. Tendo identificado tais impactos, o que nem sempre se constitui em tarefa fácil, o próximo passo é desenvolver métodos para modificá-los. Pode-se obter algum sucesso por meio de um raciocínio qualitativo à base de experiência no trato do clima e na observação de princípios gerais. Porém, o que realmente é necessário é uma metodologia quantitativa, utilizando modelos de inputoutput, incorporando o sistema afetado por este clima (TAESLER, 1986, p.201 e MONTEIRO, 1990, p.100).

De acordo com a revisão de Monteiro (1976), o primeiro de estudo de clima urbano surgiu em Londres, no início da era industrial, com a obra do climatologista amador Luke Howard, em 1833, que analisou contrastes meteorológicos em Londres, entre a metrópole e o entorno. Os estudos se multiplicaram nas cidades industrializadas da Europa Ocidental e depois na América do Norte. Mais tarde vieram os estudos de Mumford, professor de Planejamento Urbano na Universidade da Pensilvânia, Filadélfia, sobre a história natural da urbanização, e de Landsberg, na época chefe do Serviço de Climatologia do U.S. Weather Bureau e professor de Meteorologia nas Universidades da Pensilvânia e de Chicago, sobre o clima das cidades. Depois do pioneiro Landsberg, que fez parte da equipe de Albert Mayer para o planejamento original de Chandigarh, destacaram-se o meteorologista americano Robert Borstein, da San Jose State University, Califórnia, e Roger Taesler, meteorologista sueco.

No Department of Physical Geography, na Göteborg University, Suécia, pesquisas em clima urbano vêm sendo feitas desde os anos 70, com apoio do Swedish Council for Building Research (UPMANIS, 2000). Em Johannesburg, na África do Sul, também já são quase três décadas de estudos de clima urbano na cidade (GOLDREICH, 1992).

JAUREGUI (1994, p.377-390) faz uma revisão do desenvolvimento da climatologia urbana em regiões tropicais e subtropicais no mundo; segundo o autor, apesar dos estudos anteriores, somente nos anos 70 surgiram os primeiros trabalhos descrevendo efeitos urbanos em cidades tropicais, incluindo aí os estudos de Monteiro e Tarifa no Brasil, para a cidade de Marabá, no Pará. Nos anos 80 aconteceram três importantes conferências sobre climatologia urbana aplicada às regiões tropicais que aproximaram as pesquisas na área vindas de diversas partes do mundo, eventos que se tornaram mais freqüentes nos anos 90. BORNSTEIN (1986, p.237-276) faz uma revisão dos modelos de clima urbano existentes, comentando a sua natureza, limitações e aplicações. Dentre os modelos para a chamada urban canopy layer (camada até o nível das coberturas dos edifícios) Bornstein classifica os modelos três categorias: os estatísticos, os que se referem às trocas de energia nos canyons urbanos e os modelos em túnel de vento.

Segue um relato dos últimos avanços feitos pelos principais autores.

\subsection{Oke}

Prof. Tim R. Oke, do Departamento de Geografia da University of British Columbia, Vancouver, Canadá, desenvolveu o modelo de climatologia urbana que toma por 
base o conceito de ilha de calor urbana. Em OKE (1973), o autor apresenta o modelo que relaciona a intensidade da ilha de calor à população, baseado em estudos para as cidades européias e norte-americanas. OKE $(1981,1982)$ demonstrou que a geometria urbana e as propriedades térmicas das superfícies construídas têm mais influência na magnitude e na configuração da ilha de calor do que o vento ou a densidade da população, apresentando um novo modelo que relaciona a intensidade da ilha de calor com o fator de céu visível ou com a relação H/W (altura/largura) nos canyons urbanos. Oke também comenta que, para uma dada população, as cidades européias têm uma geometria mais aberta quando comparadas às cidades norteamericanas, que geralmente apresentam canyons urbanos mais profundos.

O modelo matemático da ilha de calor urbana considera a escala tridimensional do clima, e faz a diferenciação entre duas camadas distintas (OKE, 1976): a chamada UCL - urban canopy layer, que se estende do solo até o nível médio das coberturas, e a UBL - urban boundary layer, a camada limite interna em uma mesoescala, cujas características são determinadas, pelo menos parcialmente, pela presença da malha urbana.

Segundo ASSIS (1997, p.135), o modelo de Oke é mais comprometido com a compreensão do fenômeno meteorológico e sua modelagem do que com uma perspectiva de intervenção humana, daí a sua dificuldade essencial de apropriação dentro de uma prática de planejamento e de projeto urbano. Sua grande contribuição foi a consolidação de que o clima da cidade é produto de um fenômeno de transformação de energia a partir da interação entre o ar atmosférico e o ambiente urbano construído. Oke explicou a diferença entre os processos térmicos rural e urbano, e colocou em evidência a geometria urbana e a inércia térmica dos materiais de construção no processo de mudança climática causado pelos assentamentos urbanos. Atualmente é a mesma perspectiva adotada por KATZSCHNER (1997) ao propor uma estrutura de integração entre as escalas climáticas e as do planejamento urbano como meio de viabilizar a tradução dos aspectos do clima urbano para uma linguagem de planejamento.

OKE (1984, p.1) fala na lacuna entre clima urbano e planejamento devido à complexidade do tema, à sua interdisciplinaridade e à falta de diálogo entre os envolvidos, dificultando a transferência de conhecimento sobre climatologia urbana em ferramentas práticas de planejamento. Nessa época já havia o consenso que "climate has an important role to play in settlement design and must be included as an integral part of the education of every urban planner. (...) On the other hand, the second part of the consensus is that, with a few notable exceptions, very little use is being made of the available urban climate knowledge and expertise in the planning process." Para esse entendimento Oke conclui que falta habilidade em demonstrar a importância da informação climática para o planejamento e falta o poder preditivo para antecipar o impacto climático das alternativas de projeto. Oke classifica os métodos de pesquisa na área em:

- empíricos, que estão fundamentados em condições reais, mas sua validade se restringe àquela base de dados; "They are linked by the common feature of reliance upon an empirical data base. Dependence upon observed input is both strength and weakness. On the other hand it means they are founded on 
'real world' conditions, on the other it often restricts the method to the specific location where the data were gathered". (OKE, 1984, p.4)

- modelos físicos escalares, que permitem recriar as condições locais e predizer o que ocorrerá com a implantação de estruturas planejadas, usados principalmente para simular os fluxos de ar para ventilação e a dispersão de poluentes através de áreas urbanas e no entorno dos edifícios, usando túneis de vento; "scale models have also been used to simulate shadow patterns and heat loading on building arrays using an appropriately oriented light source. The effects of urban geometry on canyon nocturnal cooling also have been investigated.” (OKE, 1984, p.4-5) Segundo Oke há experiências para simular:

o padrões de sombra e de carga térmica em arranjos de edifícios (OLGYAY \& OLGYAY, 1963)

o efeitos da geometria urbana no resfriamento noturno (OKE, 1981) ou em experimentos quase controlados no exterior simulando a ilha de calor urbana (DAVIS \& PEARSON, 1970)

o os efeitos da mudança de rugosidade superficial (LETTAU, 1970)

o efeitos da geometria urbana sobre o albedo (AINDA, 1982)

- modelos numéricos que não consideram o referencial humano, sendo que a maioria deles trata das condições climáticas acima da camada limite (urban boundary layer), e não das condições para o planejamento (urban canopy layer), abaixo do nível das coberturas.

Analisando os modelos disponíveis, OKE (1984, p.5-6) lista as principais questões trazidas pelos planejadores urbanos:

- Is there an optimum proportion of the city devoted to vegetation?

- Is there an optimum arrangement of such green space?

- Is there a preferred orientation for roads and buildings to maximize solar radiation influences?

- Are there optimal height/width ratios for street canyons to maximize energy conservation or pollutant dispersal?"

OKE (1984) menciona os resultados obtidos em cidades planejadas nas quais foram consideradas as determinações climáticas e que, mesmo assim, não se viram livres desses problemas ${ }^{2}$; o autor cita também as cidades idealizadas por LANDSBERG (1973) e PAGE (1980), visões futuristas que incluem cidades totalmente climatizadas em domos, cidades subterrâneas e comunidades espaciais. O autor alerta para a falta de regulamentação de um procedimento padrão para medições de clima urbano, sem a qual não é possível estabelecer uma base de comparação dos dados e aponta a necessidade do estabelecimento de hipóteses mais gerais ao invés da descrição de estudos de caso.

Em OKE, TAESLER e OLSSON (1990/91), os autores apresentam o programa TRUCE - The Tropical Urban Climate Experiment, da WMO - World Meteorological Organization. O objetivo é contribuir para o entendimento dos mecanismos de controle da modificação da atmosfera das cidades tropicais e fornecer

\footnotetext{
${ }^{2}$ ver capítulo 3 .
} 
uma base melhor para o planejamento e previsão ambiental, incluindo estudos de observação e modelagem. Os autores afirmam que para cada grau Celsius no aumento da temperatura média diária em Los Angeles há um aumento de \$20M/ano nos gastos com ar-condicionado. Por causa disso o U.S. Department of Energy lançou um manual mostrando como a ilha de calor pode ser minimizada com medidas simples, como o plantio de vegetação adequada e o uso de superfícies com cores mais claras.

Em sua publicação mais recente, OKE et al. (1999) realizaram medições do balanço de energia na Cidade do México, na estação seca, em uma área densamente construída. Os resultados mostraram um ambiente dominado pelo calor sensível, e em particular que armazena grandes quantidades de calor no espaço construído durante o dia, liberando-o durante a noite. A evaporação é mínima em todos os horários. Os autores esperavam poder aplicar as mesmas relações já encontradas em áreas menos urbanizadas, mas não foi o que encontraram; "It appears that the competing effects of surface characteristics such as water availability, active surface area and thermal properties of the materials interact in a complex manner that will take time to unravel."

\subsection{Monteiro}

O Prof. Dr. Carlos Augusto de Figueiredo Monteiro, do Departamento de Geografia da FFLCH/USP - Faculdade de Filosofia, Letras e Ciências Humanas da Universidade de São Paulo e professor visitante no Departamento de Geociências da UFSC - Universidade Federal de Santa Catarina, foi colaborador em diversos projetos de planejamento urbano, trabalho que despertou acolhida e interesse entre arquitetos, urbanistas e paisagistas, como Jorge Wilheim, que freqüentou um de seus cursos de Climatologia Urbana na pós-graduação. Monteiro colaborou com Joaquim Guedes na implantação de uma nova cidade no Pará, e também no trabalho da arquiteta e paisagista Rosa Kliass. MONTEIRO (1976, p.132-133) comenta a internacionalização da arquitetura e diz que "de duas, uma: ou essas edificações dispõem de uma tecnologia de conforto tão especializada a ponto de anular completamente a realidade climática, ou há lugares onde o grau de desconforto é enorme. (...) Penso, sobretudo, na Amazônia, em plena fase de ocupação e implantação urbana. Se criarmos cidades padronizadas universalmente, teremos que ter os recursos e as técnicas para anular a natureza ou pagaremos alto preço pelo desconforto criado."

Para MONTEIRO (1976, p.124), como toda organização complexa, o clima da cidade admite uma visão sistêmica, com vários graus de hierarquia funcional, e diferentes níveis de resolução. O modelo para o ‘sistema clima urbano’ de Monteiro aborda três questões básicas:

- conforto térmico (resolução termodinâmica)

- qualidade do ar (resolução físico-química)

- impacto meteórico (precipitações)

De acordo com Monteiro a pesquisa do clima da cidade implica obrigatoriamente em observação fixa permanente, bem como em trabalho de campo com observações móveis e episódicas. O trabalho de SEZERINO e MONTEIRO (1990) na caracterização do campo térmico na cidade de Florianópolis estabeleceu de um método para medições de clima urbano utilizando um psicrômetro em abrigos 
meteorológicos simplificados, baseados nos utilizados pelo Prof. Tarifa no Laboratório de Climatologia da USP. Inicialmente foi feita uma seqüência de $24 \mathrm{~h}$ de medições em 20 pontos da cidade, com leituras de três em três horas, referenciadas às leituras da estação meteorológica local. Para os autores a extensão da validade das observações ao redor do ponto é função da homogeneidade morfológica de cada área, levando-se em conta as condições topográficas, de vegetação e tipologia edificada. No segundo experimento os pontos de observação foram concentrados em uma área menor, no centro da cidade, combinados com observações verticais. Esses primeiros experimentos estão dentro da chamada urban canopy layer, definida por Oke.

Segundo MONTEIRO (1990) o ideal seria fazer medições nas quatro estações do ano por vários anos seguidos, abrangendo uma amostragem expressiva, e que um experimento inicial deve conter, no mínimo, dois eventos em estações opostas. A duração mínima deve ser de 24h, e as leituras devem ser referenciadas à estação meteorológica padrão da cidade. Monteiro diz que se pode utilizar aparelhagem simples, desde que seja respeitada a homogeneidade do equipamento em todos os pontos de medição. Deve-se também fazer observações sob as condições atmosféricas e observações sobre a forma urbana. O autor lembra que número de pontos de medição significa número de aparelhos e de pessoas capacitadas para efetuar o trabalho de campo, e que a padronização do registro é tão importante quanto o treinamento da equipe.

Para Monteiro a distribuição dos pontos de observação é uma decisão do pesquisador e deve ser norteada pela percepção do clima urbano. A escolha dos pontos deve recair sobre a melhor forma de expressar a natureza ou o caráter da cidade estudada, baseada no conhecimento do local, em um mapa do sítio e uma carta de uso do solo, assim como do conhecimento do crescimento vertical e da variação espacial da cobertura do solo. Os padrões de homogeneidade para se estabelecer a validade dos registros no entorno de cada ponto podem ser estabelecidos através da análise de fotos aéreas e controle de campo.

Para o autor cada ponto expressa - no momento em que foi registrado - o comportamento da atmosfera, englobando as componentes da atmosfera regional e aquelas advindas da resposta local, ao mesmo tempo em que deve refletir algo do contexto mesoclimático e, sobretudo, está intimamente comprometido com as condições microclimáticas criadas pela forma urbana.

Para ASSIS (1997) a definição de campo térmico urbano apresentada por Monteiro soa melhor para o conforto ambiental na escala urbana, pela possibilidade de relacionar as características da forma urbana que condicionam o clima local às configurações do campo térmico urbano, nas suas dimensões temporais e espaciais. Para Assis a proposta de Monteiro parece convergente à experiência alemã de planejar com o clima que toma um caráter operacional para o processo de projeto urbano a partir da consolidação do conceito de clima urbano ideal. Desse conceito derivam os dois atributos principais do clima urbano utilizados pela escola alemã de climatologia urbana: qualidade do ar e condições bioclimáticas de conforto térmico humano.

Porém, tanto o modelo conceitual de Monteiro quanto o modelo matemático de Oke são modelos sistêmicos e de balanço de energia, difíceis de serem aplicados ao planejamento urbano. 


\subsection{Bitan}

Inicialmente BITAN (1984), do Departamento de Geografia da Universidade de Tel Aviv, e ASSIF publicam um atlas de planejamento climático de Israel, dividindo a região em pequenas áreas climáticas homogêneas; os dados climáticos são representados graficamente por tabelas e figuras, num esforço para se chegar a uma linguagem comum entre climatologistas e planejadores.

Em outra publicação BITAN (1988) afirma que os fatores climatológicos devem ser integrados em todos os níveis de planejamento, do regional ao projeto urbano e do edifício e enfatiza dois princípios para sua metodologia:

- deve ter um caráter universal, para que possa usada em qualquer lugar

- deve ter a possibilidade de ser usada separadamente para cada estágio do processo de planejamento

Bitan identifica cinco estágios (partindo dos requisitos dos usuários, da localização, do tamanho e das funções da área a ser planejada) para orientar a coleta de dados climáticos, medições, processamento e análise que, por sua vez, subsidiarão a determinação de critérios e recomendações ao planejamento e projeto urbano e de edificações. Para Bitan a representação dos dados deve incluir desenhos, mapas, gráficos, diagramas, tabelas que possam facilitar o entendimento e o uso dos dados climáticos. O estágio mais importante do processo é quando o levantamento anterior é integrado a cada etapa do planejamento regional, de assentamento rural ou urbano, ou de edifícios. Em áreas urbanas o entendimento do clima determina a escolha do local, o layout do assentamento, a localização das funções e usos do solo na cidade, as distâncias de percurso para os pedestres, e a redução dos aspectos negativos do clima envolvendo o desenho urbano e o paisagismo no processo de planejamento.

O próximo passo é "the stage which the principles and details of the climatological planning of a certain project are presented to the planner. At this stage, which should be as early as possible in the planning process, the planner, architect or decision-maker has been taught about the advantages of climatological input from the qualitative, as well as the quantitative points of view. This means that the applied climatologist must show that, on one hand, in most cases climatological planning does not increase building costs, and, on the other hand, there is the possibility of large savings in air-conditioning, heating, and sometimes also in lighting costs. Above all, a correct climatological planning improves the quality of life." (BITAN 1988, p.9) Deste estágio em diante o climatologista deve acompanhar a execução do projeto checando o desempenho de suas recomendações. Depois do projeto acabado o objetivo é comprovar o desempenho das soluções adotadas através de medições e observar as reações da população envolvida.

Para ASSIS (1997, p.136) o método de BITAN é mais adequado para o planejamento de cidades novas, e não aborda a gestão de qualidade ambiental urbana que o processo de planejamento deve prever.

Em BITAN (1990/91), o autor faz um estudo de reabilitação climática para uma idade histórica em Israel, de clima rigoroso na região quente e árida. Esse trabalho é parte do desenvolvimento de um plano geral para a cidade buscando reintegrar o projeto adequado ao clima em todos os níveis: na escala urbana, na escala dos bairros e dos edifícios. O autor conclui que as principais estratégias são a redução da 
radiação solar, o aumento do albedo e sombreamento com árvores de copas largas dos dois lados das ruas e em parques, playgrounds e praças públicas, ou ainda com arcadas, pérgolas, e centros comerciais cobertos.

BITAN (1992) apresenta um conceito abrangente de planejamento urbano climático e ambiental, ressaltando que a qualidade climática é tão importante quanto a qualidade do ar nas áreas urbanas.

Em PEARLMUTTER, BITAN e BERLINER (1999) os autores afirmam que, ainda que as modificações trazidas pelas superfícies urbanas sejam bem conhecidas, faltam análises em micro-escalas de condições de conforto térmico que possam ser aplicadas no desenho urbano. Uma grande quantidade de dados empíricos coletados em canyons urbanos no árido sul de Israel foram integrados a um modelo de balanço de energia representando as trocas térmicas entre o pedestre e o canyon urbano. Os resultados sugeriram que, no verão, o sobreaquecimento no canyon é principalmente um fenômeno noturno, e que durante o dia, nas horas de stress térmico pelo calor em um clima desértico, o canyon compacto é na verdade uma ilha fria, principalmente devido ao sombreamento. No inverno a forma compacta é um pouco mais aquecida, e o fator determinante é a proteção dos fortes ventos durante a noite. Os autores criticam o modelo de cidade-jardim usado em muitos assentamentos em Israel, com grandes espaços abertos, e edifícios isolados na paisagem, climaticamente inapropriados para a região.

\subsection{Lombardo}

A Prof. Dra. Magda Adelaide Lombardo, do Departamento de Geografia da Faculdade de Filosofia, Letras e Ciências Humanas da Universidade de São Paulo, que vem orientando e colaborando em diversas pesquisas na área da arquitetura e do urbanismo, comprovou a existência de uma alta correlação entre os tipos de uso do solo urbano e a variação das temperaturas superficiais na cidade de São Paulo. Assim, as altas temperaturas são verificadas em áreas de crescimento vertical intenso, densidade demográfica acima de trezentos habitantes por hectare e pouca quantidade de vegetação, principalmente nos setores industriais e residenciais. Já as regiões com maior concentração de espaços livres, com vegetação ou nas proximidades de reservatórios d’água, as temperaturas sofrem declínios acentuados, porque a maior quantidade de vegetação implica em mudança no balanço de energia. Lombardo integrou ao trabalho de campo à análise de imagens de sensoriamento remoto, desenvolvendo um algoritmo para o cálculo das temperaturas superficiais dos alvos em função da distância que chega ao satélite e da estimativa das emissividades superficiais. Através da interpretação das imagens termais do satélite NOAA e usando o algoritmo, a autora verificou a ocorrência de áreas mais frias nos parques, reservas florestais e reservatórios d'água, enquanto no centro da cidade e áreas densamente ocupadas, as temperaturas superficiais eram mais elevadas. Para o trabalho de campo foram instalados 38 pares psicrométricos distribuídos pela cidade, além de um transecto móvel equipado para medições da temperatura do ar, umidade e vento. Lombardo registrou diferenças de $10^{\circ} \mathrm{C}$ em estado de calmaria na cidade de São Paulo. A autora mapeou a existência de áreas verdes na cidade, encontrando uma cobertura vegetal de $70 \%$ no Morumbi, e de apenas $3 \%$ na área central (LOMBARDO, 1985). 
Em uma mesa redonda realizada durante o IV ENCAC - Encontro Nacional de Conforto no Ambiente Construído, LOMBARDO (1997) reforçou a relação entre climatologia e conforto; porém, apesar das mais de 30 pesquisas em clima urbano no Brasil, poucas saíram das prateleiras. Surgiram alguns métodos bons para diagnósticos, mas difíceis de serem aplicados ao planejamento. Nos estudos de clima urbano é preciso observar a escala regional, a cidade, o bairro, o cotidiano das pessoas; a autora afirmou que ainda falta um consenso sobre como fazer as medidas, como integrar escalas diferentes, quais os instrumentos a serem utilizados para pesquisa, etc. Segundo Lombardo, para o planejamento seria de enorme utilidade a antecipação de cenários na ocupação da periferia, mas ainda não se conseguiu superar totalmente a lacuna na integração de conhecimentos; de um lado tem-se a informação sobre o clima e de outro a atividade de planejamento, com um vazio entre eles. O grande desafio hoje é como transformar os dados de clima urbano em critérios de ocupação, em índices urbanísticos, etc.

A tese de livre-docência de Lombardo (1995) discute as categorias de análise e de métodos dos diversos campos da geografia física quanto à temática ambiental, procurando fornecer subsídios ao planejamento urbano. Posteriormente, fazendo essa ponte com o planejamento Lombardo orientou o trabalho de SANTANA (1997), relacionando o desenho urbano ao clima de Fortaleza, com o objetivo de detectar a relação entre uso do solo, forma urbana e diferenças de temperatura do ar, aliados à perda de qualidade ambiental e descaracterização da paisagem urbana, desenvolvendo uma metodologia de avaliação do comportamento térmico dos espaços microclimáticos e a ligação destes com a morfologia do desenho urbano e conforto térmico humano. Santana verificou que, durante o dia, as temperaturas do ar mais elevadas foram registradas nas zonas de maior densidade de edificações, pessoas e veículos, com sombreamento reduzido e pouca vegetação, embora as áreas verticalizadas tenham apresentado temperaturas mais amenas no período da manhã, por apresentar mais massa edificada, necessitando de mais tempo para se aquecer. As temperaturas do ar mais baixas foram encontradas à beira-mar e em zonas com presença de corpos d’água e vegetação significativa, que se comportam como estabilizadores das variações de temperatura. Santana recomenda recuos entre os edifícios que favoreçam a circulação dos ventos, a arborização dos passeios, principalmente a oeste, a inserção de praças arborizadas entre as quadras densamente edificadas e a criação de parques urbanos. Reforça as recomendações para a criação de sombras, para a manutenção da ventilação e a adoção de critérios na escolha dos materiais urbanos.

No curso de atualização de Clima Urbano durante o V ENCAC, LOMBARDO (1999) reforçou o caráter tridimensional dos estudos de clima urbano, e a dificuldade de se trabalhar com a dimensão vertical, considerando as alterações provocadas pelo processo de urbanização. Também enfatizou a necessidade de estudos para diferentes realidades climáticas e do entendimento dos dados locais dentro do contexto regional. Lombardo citou como exemplo as ações de planejamento em Sacramento, Califórnia, onde um extensivo programa de arborização urbana conseguir criar condições de conforto térmico na zona urbana que não existiam nas condições naturais, fazendo com que o microclima na cidade fosse mais agradável do que no entorno. 


\subsection{Assis}

ASSIS (1990) apresenta um método para o processamento de dados climáticos a fim de se determinar o comportamento médio do campo térmico urbano durante os períodos críticos de verão e inverno, usando a rede de estações meteorológicas locais. Com a identificação da tipologia de uso e ocupação do solo, Assis elaborou um mapa base de classes predominantes de uso e densidade habitacional de ocupação do solo urbano em Belo Horizonte. Esse estudo mostrou um comportamento diferenciado na evolução das temperaturas máximas e mínimas como função do uso do solo, tanto no verão como no inverno. ASSIS conclui que, em Belo Horizonte, na faixa de 130 a 150 hab/ha, o impacto da ocupação horizontal é maior do que o vertical, principalmente no verão, em função da menor área impermeabilizada, da existência de vegetação mais significativa e das superfícies sombreadas em função da verticalização. A tendência para uma maior elevação das temperaturas durante o dia foi observada nas áreas com gabaritos baixos, com pouca cobertura vegetal e alta densidade de ocupação. As áreas verticalizadas tendem a ser mais quentes durante a noite, tanto no verão como no inverno. O estudo mostrou que com uma densidade populacional de 130-150 hab/ha, com cobertura vegetal de apenas 3\%, o impacto de áreas ocupadas horizontalmente no conforto térmico é maior do que em áreas verticalizadas, principalmente no verão. Nas áreas verticais de mesma densidade, o índice de vegetação varia de 3 a 50\% em Belo Horizonte.

Assis considera que, pelo menos nas regiões tropicais, além do estudo da ilha de calor urbana como fenômeno tipicamente noturno, é muito importante a sua abordagem no período diurno, para o estabelecimento de diretrizes de planejamento urbano para o controle das condições térmicas.

ASSIS (1997, p.134-139) levanta o problema de integração entre as escalas de abordagem do clima e do planejamento urbano, de seus meios de representação, bem como o comprometimento das bases conceituais da abordagem sobre clima urbano com a visão sistêmica, os limites operacionais dos modelos para aplicação ao planejamento urbano e os limites da representação do fenômeno climático, ou seja, da ainda incipiente cartografia do clima urbano, em conter informações úteis para o projeto da cidade.

Assis discute as bases teóricas para a aplicação da climatologia ao planejamento urbano com enfoque em três questões, buscando identificar alguns caminhos possíveis para a integração disciplinar:

- o problema da base teórica para a abordagem da climatologia no planejamento urbano. Os modelos conhecidos do clima urbano desenvolveram-se a partir da perspectiva sistêmica, que tem origem comum à do pensamento racionalista das teorias ecológica e funcionalista sobre o espaço e a cidade. A visão sistêmica tem sido criticada por sua falta de perspectiva histórica e por sua dificuldade de tratar os valores humanos, sendo apontada como fator de fragmentação social e empobrecimento das relações cidadãs, quando apropriada pela prática do planejamento urbano.

- as escalas de abordagem na climatologia e no planejamento urbano. As escalas climáticas são um assunto polêmico na climatologia geográfica, havendo grandes divergências nas taxonomias propostas pelos diversos autores. Essa questão é de fundamental importância para a própria definição e 
abrangência do clima urbano, além de suas implicações sobre as metodologias, pois se observa que certos tipos de dados, conjunto de procedimentos e de técnicas são mais apropriados a determinadas escalas de estudo. Por outro lado, am planejamento urbano a questão das escalas e de sua integração também carece de consenso.

- o problema do desenvolvimento de uma representação climatológica útil ao planejamento e projeto urbanos, o que implicou na necessidade de uma discussão sobre o conceito de 'forma urbana' e de seus atributos relacionados ao clima, para identificar as principais variáveis integradoras que orientariam a geração de um tipo de representação do clima urbano comprometida com o referencial humano e com uma perspectiva de intervenção, através do plano, com vistas à gestão de qualidade física do ambiente urbano. Foi feito um levantamento de índices de conforto térmico urbano, buscando analisar a viabilidade de utilização como referencial do desempenho térmico do recinto. A maior parte dos esforços de representação dos elementos e da dinâmica do clima urbano tem sido desenvolvida com o intuito de descrevê-lo, mais do que fornecer subsídios para o planejamento e o projeto urbano. Assis cita a representação de SEZERINO \& MONTEIRO (1990) na qual a simples plotagem das variáveis do clima sobre a malha urbana em projeção horizontal ou em corte vertical não traz informações diretamente aplicáveis ao processo de planejamento e projeto. É possível extrair informações sobre o impacto das estruturas urbanas sobre a mudança climática, cruzando dados climáticos com uma classificação de uso do solo, densidade de ocupação e tipologia predominante de edificação (ASSIS, 1990), além de integrar dados de sensoriamento remoto em canal termal que auxiliam na percepção de áreas relativamente mais quentes e mais frias da área urbana.

ASSIS (1997, p.137) conclui que existe um grande potencial de integração entre os conceitos e modelos de clima urbano, mas que muito ainda precisa ser feito na análise de experiências e contribuições diversas que possam servir de subsídio à busca da compatibilização entre as escalas de abordagem e à geração de modos de representação úteis ao planejamento e ao projeto urbanos. Apesar dos limites da visão sistêmica é possível admitir sua aplicação restrita a fenômenos específicos, perdendo seu status de paradigma central nas explicações das relações complexas que produzem a organização sócio-espacial.

Segundo ASSIS (1997), a visão sistêmica é o marco teórico de dois modelos conceituais de clima urbano: o modelo verbal proposto por Monteiro e o modelo matemático proposto por Oke. São modelos tipicamente do balanço de energia, unidimensionais e, portanto, ainda incipientes para aplicação ao projeto urbano. Modelos meteorológicos, embora mais desenvolvidos do que o de modelo verbal de Monteiro, são mais difíceis de ser apropriados, por não considerarem o referencial humano. ASSIS analisa contribuições para o desenvolvimento de uma metodologia para análise de desempenho térmico do recinto urbano através de técnicas de:

- simulação em modelos físicos

- critérios e procedimentos para a garantia de condições adequadas de insolação e iluminação natural no ambiente urbano, que dão base às relações geométricas de distância e volumetria das edificações conhecidas como 
'envelope solar' e 'envelope de iluminação'. Assis propõe a integração destes critérios gerando um conceito novo de 'envelope luminoso solar', como base para a determinação das distâncias e volumetria dos edifícios.

A tese de ASSIS (2000) parte da hipótese de que é possível alcançar e preservar boas condições climáticas nos recintos urbanos, especialmente com relação ao conforto térmico, através do planejamento e de seus instrumentos regulamentadores, analisando a variável geometria da malha urbana. A hipótese verificada é a de que uma melhor relação formal de arranjo entre as edificações de um determinado lugar, do ponto de vista térmico, pode ser obtida a parir de critérios de acesso e controle da insolação e iluminação natural para a economia de energia.

ASSIS e FROTA (1999) e ASSIS (2000) apresentam uma estratégia de desenho urbano que leva em conta as variações climáticas, usando os dados disponíveis e simulações físicas do campo térmico em áreas urbanas, para analisar a influência das formas urbanas (uso do solo, tipologia e configuração dos edifícios) nas mudanças climáticas. Foram utilizados modelos físicos escalares do ambiente rural (solo natural) e urbano (com as intervenções em uma área de Belo Horizonte) para estudar sua perda radiante de calor após o pôr-do-sol em uma noite calma e sem nuvens, condições preferenciais para a ocorrência das ilhas de calor. Os modelos foram ensaiados em uma câmara fria e os sensores foram calibrados para reproduzir as experiências descritas por OKE (1981). Os resultados mostraram que a área construída permaneceu mais aquecida do que áreas abertas e que grandes áreas livres inseridas em áreas verticalizadas reduziram o efeito da ilha de calor. Os resultados indicam que, para as condições climáticas da cidade de Belo Horizonte, a alta densidade dos assentamentos, tanto nas áreas horizontais como verticais, não é adequada. As grandes áreas verdes devem ser inseridas na zona urbana para um melhor aproveitamento do seu potencial de resfriamento em climas tropicais.

\subsection{Escola alemã de climatologia urbana}

Na Alemanha os estudos de clima urbano já têm tradição em Frankfurt, Stuttgart, Hanover, e Kassel. Desde 1976 a Alemanha incluiu nas suas regulamentações de planejamento e construção a questão do clima urbano. Em 1977 foi divulgada a primeira seqüência da Cartilha Urbanística do Clima ${ }^{3}$, a partir da qual a noção de clima urbano como fator de planejamento passou por um notável desenvolvimento. De acordo com BAUMÜLLER, (1986, p.455-460), "since this time it has been necessary to take the atmospheric environment into consideration in the development plan of a city. The change of the skyline which takes place in the building of a city influences the interaction between the ground and the atmosphere in a threedimensional way. This is an important point of view because planners mainly think in two dimensions.(...) Stuttgart's practices can very well serve as a model for other cities in the Federal Republic of Germany and elsewhere. This kind of awareness of climatological needs is rather the exception than the rule." Em Frankfurt, uma das muitas cidades européias que há muito reconheceram o valor da arborização urbana para melhorar a qualidade do ar, plantaram-se quatro fileiras de árvores de cada lado das ruas principais da cidade. (SPIRN, 1995, p.86)

\footnotetext{
3 Título original STÄDTEBAULICHE KLIMAFIBEL. Hinweise für die Bauleitplanung - folge 2. Stuttgart, 1995. Tradução do Arq. Francisco A. Gonçalves da Silva, 1998.
} 
Antes de outras cidades Stuttgart envolveu climatologistas nas equipes de planejamento urbano, talvez pelo fato de que a qualidade do ar não era boa, as condições geográficas eram desfavoráveis e a velocidade do vento de cerca de $2 \mathrm{~m} / \mathrm{s}$, sendo que as inversões térmicas ocorriam com freqüência. Desde 1951 uma agência foi instituída para tratar dos problemas relativos à qualidade do ar, clima e ruído. A agência faz medições desses parâmetros, interpreta os resultados e orienta os planejadores. Em Stuttgart, por mais de três décadas, climatologistas, urbanistas, paisagistas e arquitetos trabalharam juntos na implementação de um grande plano para melhorar a qualidade do ar da cidade. Estudos identificaram encostas desocupadas acima da cidade como a principal fonte de ar limpo e fresco que flui à noite colina abaixo, em direção ao centro. Na época em que foi descoberto seu papel crucial na ventilação da cidade, as colinas arborizadas estavam sendo rapidamente convertidas em bairros residenciais. Por causa de sua importância para toda a comunidade, a cidade restringiu a ocupação dessas colinas, incorporando-as a um sistema radial de espaços livres, que se estende dos limites rurais ao centro da cidade. O uso do solo nesses canais de ar fresco é estritamente controlado; 100m é a largura mínima para esses canais de ar, que são plantados com grama e árvores. Em Stuttgart o tráfego foi banido das ruas centrais pouco ventiladas. Algumas ruas foram alargadas na área central para melhorar a circulação de ar. Outras medidas, tais como o uso de jardins suspensos e de telhados planos com lâmina d'água, foram introduzidas para reduzir a absorção de calor pelos edifícios. A cidade implantou parques sombreados arborizados ligados aos canais de fluxo de ar a fim de refrescar as regiões vizinhas e filtrar o ar. Tais esforços melhoraram o microclima no centro de Stuttgart. (SPIRN, 1995, p.96-99)

A experiência alemã é uma das mais desenvolvidas nessa área, e ultimamente vem sendo divulgada no Brasil pelo Prof. Dr. Lutz Katzschner, do Departamento de Planejamento Urbano de Kassel, que tem 200.000 habitantes. Ao contrário do método de Oke, que é vinculado à parte física, mas não considera a cidade construída, o método proposto por KATZSCHNER (1997) trabalha sobre a cidade construída, resultando em ações mais voltadas para a melhoria da qualidade ambiental de cidades existentes.

Durante o IV ENCAC, Salvador, em 1997, Katzschner ofereceu um curso que teve por objetivo mostrar uma forma de abordagem da climatologia urbana como subsídio para o planejamento e abordou:

- tratamento de dados climatológicos

- parâmetros relevantes para a construção de edificações nas cidades e para a expansão urbana

- técnicas de aplicação do conhecimento em climatologia no projeto da edificação e no desenvolvimento urbano

Para Katzschner são três os aspectos que influenciam o clima urbano:

- ventilação e balanço de energia

- topografia do sítio

- estrutura urbana

Segundo KATZSCHNER (1997, p.49) "Urban climate studies are more and more used as tool for urban planning and architecture. The main aspects are the air 
pollution complex and the thermal comfort complex, which both have to be considered in planning. (...) In many countries clean air programs define limits for air pollution concentrations, which have to be respected. For the thermal conditions no limits exist so that qualities can be described through bioclimatic complex values based on the heat balance of man as the PMV or PET. But as these values give rare information about the dynamic situation within the Urban Canopy Layer it seems sometimes easier to develop a more qualitative description, which can be used by planners. For city planners it is sometimes difficult to get data for emission concentrations or the bioclimatic complex values. Also they need a single climate map with all information."

Segundo Katzschner, para caracterizar o clima urbano é necessário identificar os efeitos da área edificada e das áreas verdes em geral e a tipologia da área edificada (densidade, número de pavimentos, etc.).

No caso alemão os planos são desenvolvidos por bairros, com a participação de climatologistas desde a fase de concepção. As áreas apropriadas ou não para o adensamento, verticalização, áreas verdes, etc., são localizadas e dimensionadas em função do mapeamento da circulação do ar e das ilhas de calor urbanas.

Para KATZSCHNER (1997, p.49), “To implement air quality as well as the thermal comfort conditions for city planning it is important to have a urban climate description in a spacial variation. All meteorological data have to be oriented towards a qualitative classification of concrete areas. (...) This qualitative description of urban climate qualities demand to translate the meteorological data into planning criteria and link them also with the planning aims. The meteorological data can be got by measurements, theoretical approaches or numerical simulations."

É importante circular pela cidade e observar os locais mais adequados para as medições. As imagens de satélite, por registrarem as temperaturas superficiais, não mostram a dinâmica dos fluxos de ar gerados pelas diferenças entre áreas verdes e áreas construídas. Para KATZSCHNER (1997, p.50-52) o primeiro passo é uma análise geográfica de mapas de uso do solo, estruturas, alturas construídas, vegetação e sistemas de drenagem. Este diagnóstico pode ser combinado com resultados de medições de clima urbano, gerando um mapeamento de padrões climáticos que inclui todos os fatores em um único sistema de classificação climática. Katzschner também apresenta uma classificação dos fatores que influenciam o clima urbano baseada em condições de taxa de ocupação, altura e densidade dos edifícios e fator de rugosidade, o que leva a uma classificação em termos da intensidade da ilha de calor, de padrões de qualidade do ar e condições microclimáticas.

É preciso também encontrar o ponto de equilíbrio entre precisão e utilidade dos dados. O autor sugere medições simples se não há equipamentos mais sofisticados disponíveis; o mais importante é traduzir os dados brutos para facilitar o trabalho de planejamento;“...urban climate knowledge can only be integrated in the planning process if the link between planning and climatology is closed. This should be done by translating climatological data into urban planning instruments. These instrument is a climatological classification system, which implements planning advices. So to every city structure a climatic orientated quality can be defined. This aerial pattern enables planners to compare different city structures in dependence urban climate." (KATZSCHNER, 1997, p.58) 
O segundo passo é o desenvolvimento de uma proposta de planejamento orientada climaticamente com diferentes categorias:

- áreas que devem ser protegidas ou melhoradas por razões climáticas;

- áreas importantes para o microclima urbano, para as condições de conforto térmico e para o desenvolvimento de circulações térmicas induzidas;

- áreas que apresentam más condições climáticas com recomendações para melhorias.

Dependendo da tipologia e do arranjo urbano uma variável climática pode ter maior ou menor importância e dependendo da condicionante climática (necessidade de ventilação, de conservação de energia, etc.) é melhor construir em altura com maiores afastamentos ou com gabaritos mais baixos com maior adensamento (KATZSCHNER, 1997).

Nos últimos anos pode-se dizer que cresce o número de planejadores 'verdes' em Frankfurt, o mapeamento climático é levado em consideração nas decisões políticas e é usado pelo governo municipal para que o planejamento de novas áreas não atrapalhe as vias aéreas de circulação de ventos.

Em Kassel, por exemplo, o vento é necessário para dispersar a poluição, mas não por exigência de conforto. Na cidade de Kassel 20 pessoas trabalharam durante um ano usando dois furgões equipados para medidas móveis computadorizadas em transectos e mais 4 a 6 bicicletas para a amostragem de microclimas. Também foram feitas medidas verticais instalando os equipamentos em torres ou usando balões meteorológicos. Através das medidas temporais é possível calcular a taxa de resfriamento de cada área urbana. Durante o V ENCAC, Fortaleza, 1999, Katzschner $^{4}$ relatou os resultados dos sobrevôos em Kassel com câmeras infravermelhas para registrar as diferenças de temperaturas nas superfícies urbanas, a fim de se determinar a influência dos materiais no aquecimento urbano.

Cruzando os dados climáticos medidos com uma prévia classificação do uso do solo, densidade de ocupação, tipologia da edificação e de superfície do solo é possível elaborar uma carta-síntese da dinâmica climática, que é a base para as recomendações de melhorias nas ocupações existentes.

Seguindo o método de Katzschner, foi feito um estudo de caso para Salvador investigando as condições de ventilação urbana através do estudo da maquete da cidade e de trabalho de campo para aplicação de índices de conforto térmico em recintos urbanos. Foi estabelecido um plano de medições no qual estão sendo feitas três medições por dia, por pelo menos três dias, em períodos do ano significativos para a caracterização da variação sazonal. As áreas urbanas a serem amostradas devem ser descritas, mapeadas e fotografadas para caracterizar cada ponto da amostra.

Numa primeira aproximação a estrutura urbana pode receber uma classificação preliminar, como por exemplo, áreas de edifícios altos, áreas de edifícios baixos, áreas cobertas por vegetação, caracterizada em sua densidade de construção e tipo de revestimento superficial predominante. Através dessas características as áreas podem ser classificadas por meio de um índice de rugosidade que, por sua vez, relaciona

\footnotetext{
${ }^{4}$ informação verbal.
} 
uma dada tipologia de assentamento urbano a um certo comportamento climático amostrado.

A avaliação das condições bioclimáticas é feita pela aplicação de um índice de conforto térmico. A escola alemã adaptou o modelo de Fanger para condições exteriores, gerando um modelo de balanço energético homem-ambiente que pode ser aplicado em recintos urbanos.

\subsection{Experimentos recentes em Atenas}

Experimentos em clima urbano vêm sendo feitos em Atenas desde 1996 como parte do projeto POLIS da European Commission, divulgados principalmente pelo Prof. Matheos SANTAMOURIS (1998, p.147-152) "The aim of the experiment was to investigate the temperature distribution in the major's Athens region and evaluate the impact of heat island on the energy performance of buildings." Até 1998 quase quarenta estações de medição foram instaladas para monitorar os principais parâmetros climáticos. O experimento permitiu identificar uma ilha de calor de intensidade máxima de $15^{\circ} \mathrm{C}$. O impacto da ilha de calor no consumo de energia dos edifícios também vem sendo avaliado e chegou-se à conclusão de que os edifícios na região central de Atenas consomem quase o dobro de energia para suprir suas necessidades de resfriamento quando comparados com outros edifícios mais afastados. Ao mesmo tempo a eficiência dos equipamentos de ar condicionado diminuiu em $25 \%$ por causa do aumento de temperatura.

Foram registradas grandes diferenças de temperatura entre a zona urbana e as estações de referência durante o verão 1996-97. Diferenças de temperatura superiores a $18^{\circ} \mathrm{C}$ foram encontradas durante o dia em particular entre a estação próxima à maior concentração de tráfego e a de referência. De acordo com SANTAMOURIS (1998, p.149), "the highest the temperature in the urban stations the highest the temperature difference. This is mainly due to the thermal balance of the urban region where heat inputs are added mainly from the traffic increasing thus local temperatures, something that does not happens to the surrounding suburban reference region. As function of the urban layout, traffic load, anthropogenic heat and the overall balance of each particular area, temperature differences during the daytime varies from 0 to $18^{\circ} \mathrm{C}$. A mean temperature difference is close to $7-8^{\circ} \mathrm{C}$. (...) During the night period the central Athens region is to about $3^{\circ} \mathrm{C}$ warmer than the reference suburban stations. Differences up to $5^{\circ} \mathrm{C}$ have been also recorded in many stations."

Em uma publicação anterior SANTAMOURIS (1997, p.15-24) faz uma revisão das últimas pesquisas na área, com os resultados referentes ao papel que o albedo da superfície, as áreas verdes e o desenho das vias desempenham na configuração do microclima urbano.

\subsection{Givoni}

Em 1989 foi divulgado pela WMO - World Meteorological Organization o documento Urban Design in Different Climates, da autoria de Baruch GIVONI ${ }^{5}$. O autor aponta a contradição entre exigências para manter um microclima adequado no

\footnotetext{
${ }^{5}$ Versão resumida publicada em GIVONI (1991).
} 
interior dos edifícios e aqueles necessários aos espaços exteriores, como por exemplo, o uso de cores claras nas fachadas para reduzir os ganhos de calor versus a necessidade de reduzir o ofuscamento nas ruas. "A lot of research has been done on human responses to the thermal environment and human comfort, as functions of the ambient climatic conditions. Most of this research was done in relation to the indoor thermal environment and only relatively few studies have dealt with human responses and specially comfort, outdoors. In dealing with urban design, as distinct from building design, the main interest is in comfort an stress as they are experienced by people working outdoors, pedestrians in the streets, people staying in public parks, etc." (GIVONI, 1989, p.1-6)

Sobre as técnicas de pesquisa GIVONI (1989, p.2-9) lembra que os efeitos de detalhes específicos de desenho urbano em variáveis climáticas têm sido estudados por vários pesquisadores, experimentalmente ou por simulação matemática. "An alternative approach to the study of the impact of design on the urban climate and its modification is to study the effect of specific urban design features on specific elements of the urban climate. Some of these effects can be studied in a laboratory setup, either analytically, experimentally, by computer simulation or numerical calculations." Givoni chama atenção para a distinção entre os modelos matemáticos na camada-limite urbana e na camada no nível das coberturas.

Givoni é um dos poucos autores a abordar as dificuldades de se trabalhar em climas compostos com mais de uma estação termicamente estressante, e menciona o caso do clima de monções, com duas estações quentes que provocam stress térmico: uma quente e seca, outra quente e úmida, como na região Centro-Oeste do Brasil. O autor também lembra que "at temperatures below $33^{\circ} \mathrm{C}$ (under sedentary activity), increasing air velocity reduces the heat sensation due to the higher convective heat loss from the body and lowering of the skin temperature. At temperatures between about $33^{\circ} \mathrm{C}$ and $37^{\circ} \mathrm{C}$ air velocity does not affect significantly the thermal sensation. At environmental temperatures above about $37^{\circ} \mathrm{C}$ increased air velocity actually increases the thermal sensation of heat although it still reduces the skin wetness and so might be desirable." (GIVONI, 1989, p.1-8)

Para GIVONI (1989), através de um conjunto de medidas ou de ações relacionadas ao planejamento da cidade e ao tratamento dos espaços públicos é possível criar um microclima que nunca existiu nas condições naturais. Em áreas densamente ocupadas a maior parte das trocas por radiação se dá nas superfícies das coberturas e não ao nível do solo ou nos fechamentos verticais. Garantindo que as coberturas tenham cores claras é possível se chegar a um balanço de radiação negativa: a perda de radiação de ondas longas pode exceder substancialmente a radiação solar absorvida, mesmo num dia claro de verão. Sob essas condições a temperatura média das coberturas vai ser menor do que a temperatura do ar regional. Como o ar frio é mais denso que o ar aquecido, ele desce para as ruas da cidade; se esta é de grandes proporções e com ocupação densa, pode-se dizer que é possível alcançar uma temperatura do ar durante o dia no nível da rua menor do que no entorno não construído.

Em relação à largura das ruas, as mais estreitas proporcionam maior sombreamento para os pedestres nas calçadas; no entanto, a sombra pode ser obtida mesmo em ruas mais largas, com a adoção de alguns dispositivos nos edifícios ou pela vegetação, o 
que se torna imprescindível em determinados tipos de clima nas largas avenidas necessárias ao escoamento do tráfego. "In a hot-dry region the provision of shade in the streets in summer is one of the major design means for minimizing the heat stress of people walking in the street.(...) The orientation of the streets also determines in practice the orientation of the individual lots into which the area is subdivided and consequently it greatly affects the orientation of the buildings. (...)Protection against sun for pedestrians on the sidewalks is very desirable in hot dry regions. It can be provided by buildings with overhanging roofs, or colonnades in which the ground floor is set back from the edge of the road, with the upper stories jutting out, supported by pillars (or other means)." (GIVONI, 1989, p.6-18,20) Além disso, por causa do período chuvoso, deve-se sempre levar em consideração no projeto de edifícios e de espaços urbanos a mobilidade dos usuários durante as chuvas quase diárias em alguns locais, a necessidade de aumentar a absorção de água das chuvas e aumentar o período de drenagem. Como boa parte da superfície urbana não está sujeita a tráfego pesado, como estacionamentos, as áreas para pedestres podem ser cobertas com pavimento permeável, como blocos vazados, brita, etc, com vegetação rasteira. Uma camada de areia e pedregulho sob os blocos pode aumentar a área de infiltração acima da superfície dura, aumentando a grau de absorção de água no solo (GIVONI, 1989, p.7-9)

Givoni lembra que há melhor ventilação nas ruas quando elas são paralelas ou inclinadas em até certo ponto na direção dos ventos predominantes durante o período da tarde, quando a temperatura do ar atinge seu máximo. Porém, é imprescindível se estudar o não comprometimento da ventilação dos edifícios, especialmente em climas quentes e úmidos; a melhor posição pode ser induzida pela divisão dos lotes. Com a orientação oblíqua ao vento predominante o vento penetra na cidade e os edifícios ficam expostos à pressão positiva e negativa, forçando a circulação (GIVONI, 1989, p.7-12) "This street orientation thus provides a good potential for natural ventilation of the buildings while at the same time provides also good ventilation in the streets. It is desirable mainly in high density residential zones."

Givoni aborda a compatibilidade entre verticalização, alta densidade ocupacional e manutenção da ventilação em áreas urbanas: "In neighborhoods with high rise apartment buildings, higher overall urban densities (total Floor Area Ratio) can be maintained with adequate potential for natural ventilation. Reasonable distances between the building blocks should be insured, and long buildings should not form 'walls' perpendicular to the wind direction. The wind can then 'negotiate' between the buildings so that the potential for natural ventilation exists. (...) In a planned neighborhood the distances between buildings are often controlled by setback regulations. Such regulations are tools for preventing harmful consequences of the economic pressure to increase urban density beyond certain limits. From the climatic viewpoint the distances between buildings affect the solar and wind exposure of the walls. The actual effect depends on the direction (orientation) of the space between the buildings. However often setback regulations do not take into account the orientation of the building." (GIVONI, 1989, p.6-11)

Quanto mais altos os edifícios e menor a distância entre eles, menor a quantidade de radiação solar que atinge as ruas e demais áreas entre os edifícios. Isso deve ser contrabalançado com as vantagens de se ter mais área exposta de solo natural para absorção de água da chuva, ventilação no nível da rua, etc. Givoni lembra também 
que "the higher and more dense the built-up area is, the slower is the rate of nighttime cooling off. This is one of the major factors causing the urban 'heat island'..." (GIVONI, 1989, p.2-5) Dentre outros fatores, a necessidade de se reduzir os custos com infra-estrutura urbana leva aos incentivos para aumentar a densidade de ocupação nas cidades. "Thus the reality of modern urbanization leads to higher densities than is the case in traditional settlements but, with suitable urban and building's design details, this should and could be accomplished with minimum worsening of the environmental quality. An urban configuration to be avoided as much as possible in hot humid regions is that of high long buildings, of the same height, perpendicular to the prevailing wind direction. (...) An urban profile of variable buildings, where buildings of different heights are placed next to each other, and when the long facades of the buildings are oblique to the wind, enhances the urban ventilation. (...) ...the best urban climate conditions exists in a hot humid climate when that density is obtained with high narrow buildings ("towers"), placed as far apart from each other as is consistent with the given density.(...) Encouraging urban development with buildings of different height next to each other, thus improves the urban ventilation.(...) When high narrow buildings are placed relatively far apart, they do not reduce the air speed near the ground level.(...) In fact such buildings can increase appreciably the low level air speed, thus improving the ventilation potential for lower buildings between them in the streets." (GIVONI, 1989, p.7-12,13,17)

Em seu último livro, comentando os modelos de clima urbano existentes, GIVONI (1998, p.281-282) acha conveniente substituir o parâmetro população por densidade construída, por esta apresentar uma relação causal mais forte com o aquecimento urbano. A densidade de diferentes áreas construídas na cidade afeta os microclimas pontualmente e, pelo seu efeito cumulativo, determina a modificação do clima regional pela urbanização. Para o autor, a fração de solo coberta pelos edifícios é um fator relevante para se avaliar o efeito climático da urbanização.

\subsection{Estudos recentes de ventilação urbana}

Nos estudos de ventilação urbana há uma grande dificuldade de simulação por causa da complexidade do traçado. Porém, é possível simular setores da cidade que têm algum padrão de homogeneidade; é possível modelar partes, mas não a cidade inteira.

BITTENCOURT et al.(1997 e 2000) apresentam um estudo relacionando taxa de ocupação e número de pavimentos no potencial de ventilação natural dos ambientes internos e externos. Os autores estudam duas alternativas de implantação de um edifício em lote típico da orla marítima de Maceió e concluem que a elevação no número de pavimentos combinada à redução da taxa de ocupação do lote permitiria uma melhor distribuição do fluxo de ar nos ambientes internos e externos. A legislação em vigor limita o número de pavimentos permitido para as construções na orla, sendo permitidos seis pavimentos na primeira quadra, sete pavimentos na segunda, e assim sucessivamente, pretendendo-se um escalonamento na altura das edificações. Na prática esse escalonamento vem ocorrendo apenas até a $3^{\text {a }}$ quadra. A partir daí a opção predominante dos construtores é pelo edifício de oito andares, que oferece a melhor relação entre taxa de ocupação e coeficiente de aproveitamento. A legislação também prevê recuos progressivos de acordo com o número de 
pavimentos de uma edificação. A fim de contrabalançar a limitação relativa ao número de pavimentos, os empreendedores tentam obter o maior número possível de unidades habitacionais por andar, o que tem induzido os projetistas a comprometer a qualidade do conforto ambiental, uma vez que são forçados a optar por orientações desfavoráveis em relação aos ventos dominantes em algumas unidades habitacionais.

Os autores recomendam uma redução na taxa de ocupação de 50\% para $25 \%$, a ampliação no número de pavimentos para 12 andares, a manutenção do coeficiente de aproveitamento 4 e o uso de pilotis completamente vazado, sendo permitido como área fechada somente a caixa de elevadores e a escada. Para o caso de Maceió as simulações também indicam que é mais importante para a melhor ventilação do espaço construído o predomínio do fator recuo sobre o fator altura, contrariando a legislação em vigor. Os maiores recuos laterais, além de possibilitar melhor ventilação natural em ambientes externos e internos, garantem maior privacidade no interior dos apartamentos.

A tese de SILVA (1999), O vento como ferramenta no desenho do ambiente construído. Uma aplicação ao nordeste do Brasil, traz uma metodologia que permite avaliar as condições de ventilação natural urbana. Os resultados podem abranger desde a obtenção de padrões gerais de ventos no nível do solo até a medição de perfis de velocidade em diferentes locais, tornando possível a avaliação das condições de ventilação externa, das condições de conforto para pedestres, dos níveis de poluição e dispersão de gases, do fluxo de calor de e para prédios através de seus envelopes, ou da medição das pressões do vento sobre prédios, à computação de taxas de corrente, permitindo, desse modo, a avaliação das ações do vento, tanto em termos de cargas de desenho e cobertura, taxas de ventilação natural, conforto e qualidade do ar interior, assim como equilíbrios energéticos, tendo por objetivo o uso racional de energia. Silva faz uma aplicação a João Pessoa para demonstração do seu potencial de análise de condições reais, em diferentes locais, e como uma ferramenta de desenho urbano e de futuras instalações humanas.

Silva ensaia uma maquete da área de estudo simulando a situação de ocupação existente e, posteriormente, simulando o total aproveitamento da área permitido pela legislação em vigor em João Pessoa. Foi utilizada a técnica de figuras de erosão que permite para cada situação uma visão qualitativa do conjunto e a quantificação das velocidades do vento especialmente reduzidas ou elevadas em pontos distintos no nível do solo. Ao todo foram 24 ensaios no túnel de vento, sendo 12 de erosão e 12 de camada-limite atmosférica em 7 padrões diferentes de ocupação do solo. Silva constatou que o planejamento do clima de vento na cidade possibilita identificação e a previsão de alterações no padrão de ocupação do solo. A interação entre vento e as modificações feitas na superfície de determinada área ditam o sistema de ventilação resultante dessa interação, seja em situações planejadas ou em casos de ocupações já existentes. O planejamento, a verificação e o aumento da eficácia do aproveitamento do vento no ambiente construído mostraram-se possíveis tanto no que se refere à caracterização dos ventos através de observações meteorológicas tratadas com modelos numéricos, quanto à sua aplicação à área da cidade de João Pessoa.

Pode-se avaliar condições do vento tanto em termos de carga, de conforto, segurança, taxas de ventilação natural, incluindo transporte e dispersão de poluentes, quanto da integridade física das pessoas em ambientes externos, de qualidade do ar interior e 
equilíbrios energéticos, objetivando um planejamento consciente dos consumos energéticos e da qualidade de vida.

Na tentativa de resumir o estado da arte nas pesquisas envolvendo clima urbano e planejamento, as principais conclusões são:

- o desafio hoje é transformar dados de clima urbano em critérios de ocupação, em índices urbanísticos, etc. Apesar das mais de 30 pesquisas em clima urbano no Brasil, poucas saíram das prateleiras. Surgiram alguns métodos bons para diagnósticos, mas difíceis de serem aplicados ao planejamento. $\mathrm{O}$ que realmente falta é uma metodologia quantitativa, utilizando modelos de input-output, incorporando todo o sistema. Por ora a combinação de diferentes técnicas de pesquisa pode gerar bons resultados, pelo menos enquanto não se dispõe de uma ferramenta única que englobe todas as variáveis em questão.

- falta um consenso sobre como fazer as medidas, como integrar escalas diferentes, quais os instrumentos a serem utilizados, etc.

- as últimas medições do balanço de energia em áreas densamente ocupadas demonstraram que não se pode aplicar as mesmas relações já encontradas em áreas menos urbanizadas, pois as variáveis parecem interagir de maneira bem mais complexa.

- os modelos baseados nos canyons urbanos mostraram resultados diferentes para condições diurnas e noturnas, que podem ser contraditórias.

- é conveniente substituir o parâmetro população usado em alguns modelos de ilha de calor por densidade construída, por esta apresentar uma relação causal mais forte com o aquecimento urbano.

- resultados de sobrevôos com câmeras infravermelhas a fim de se determinar a influência dos materiais no aquecimento urbano já demonstraram claras diferenças de desempenho térmico entre superfícies naturais e construídas.

- pode haver compatibilidade entre verticalização, alta densidade ocupacional e manutenção da ventilação em áreas urbanas.

- sob determinadas condições é possível criar microclimas urbanos que nunca existiram nas condições naturais, os chamados oásis urbanos.

\section{Referências Bibliográficas}

1. ASSIS, Eleonora Sad de. Mecanismos de desenho urbano apropriados ‘a atenuação da ilha de calor urbana: análise de desempenho de áreas verdes em clima tropical. Rio de Janeiro, 1990. Dissertação (Mestrado em Arquitetura) - Faculdade de Arquitetura e Urbanismo, Universidade Federal do Rio de Janeiro.

2. ASSIS, Eleonora Sad de. Bases teóricas para a aplicação da climatologia ao planejamento urbano. IV Encontro Nacional de Conforto no Ambiente 
Construído, 1997, Salvador. Anais. Salvador: FAUUFBA/LACAM-ANTAC, 1997. p.134-139.

3. ASSIS, Eleonora e FROTA, Anésia. Urban bioclimatic design strategies for a tropical city. Atmospheric Environment, Oxford, v.33, n.24-25, p.4135-4142, 1999.

4. ASSIS, Eleonora Sad de. Impacto da forma urbana na mudança climática: método para previsão do comportamento térmico e melhoria de desempenho do ambiente urbano. São Paulo, 2000. Tese (Doutorado em Arquitetura) Faculdade de Arquitetura e Urbanismo, Universidade de São Paulo.

5. AVISSAR, Roni. Potential effects of vegetation on the urban thermal environment. Atmospheric Environment, Oxford, v.30, n.3, p.437-448, 1996.

6. BAUMÜLLER, J. The introduction of climatology into the administration and development of planning in the city of Stuttgart. In: URBAN CLIMATOLOGY AND ITS APPLICATIONS WITH SPECIAL REGARD TO TROPICAL AREAS. Mexico D.F., 26-30 November 1984. Proceedings. OKE, T. (ed.) Urban Climatology and its Applications with Special Regard to Tropical Areas. Geneva: WMO n.652, 1986, p. 455-460.

7. BITAN, Arieh \& ASSIF, Shamai. Climatic Data Analysis and its use and representation for planners. Energy and Buildings, Netherlands, n.7, p.11-22, 1984.

8. BITAN, Arieh. The methodology of applied climatology in planning and building. Energy and Buildings, Netherlands, n.11, p.1-10, 1988.

9. BITAN, Arieh. Bet She'an Master Plan - Climatic Rehabilitation of an Ancient Historic City. Energy and Buildings, Netherlands, n.15-16, p.23-33, 1990/1991.

10. BITAN, Arieh. The high climatic quality city of the future. Atmospheric Environment, Oxford, v.26B, n.3, p.313-329, 1992.

11. BITTENCOURT, Leonardo Salazar et al. A influência da relação entre taxa de ocupação $\mathrm{x} \mathrm{n}^{\circ}$ de pavimentos no potencial de ventilação natural dos ambientes internos e externos. In: IV Encontro Nacional de Conforto no Ambiente Construído, 1997, Salvador. Anais. Salvador: FAUUFBA/LACAM-ANTAC, 1997. p.102-106.

12. BITTENCOURT Leonardo Salazar et al. O efeito da verticalização das edificações na ventilação natural do tecido urbano: o caso da orla marítima de Maceió. In: VIII ENTAC, 2000, Salvador. Anais em CD-ROM. Salvador: ANTAC, 2000.

13. BORNSTEIN, R. D. Urban climate models: nature, limitations and applications. In: URBAN CLIMATOLOGY AND ITS APPLICATIONS WITH SPECIAL REGARD TO TROPICAL AREAS. Mexico D.F., 26-30 November 1984. Proceedings. OKE, T. (ed.) Urban Climatology and its Applications with Special Regard to Tropical Areas. Geneva: WMO n.652, 1986, p.237-276. 
14. Cartilha Urbanística do Clima. Título original STÄDTEBAULICHE KLIMAFIBEL. Hinweise für die Bauleitplanung - folge 2. Stuttgart, 1995. Tradução do Arq. Francisco A. Gonçalves da Silva, 1998.

15. GIVONI, Baruch. Urban Design in Different Climates. Geneva: WMO Technical Document n.346, 1989.

16. GIVONI, Baruch. Climate Considerations in Building and Urban Design. New York: John Wiley \& Sons, 1998.

17. GOLDREICH, Yair. Urban climate studies in Johannesburg, a sub-tropical city located on a ridge - a review. Atmospheric Environment, v.26B, n.3, p.407420, 1992.

18. JAUREGUI, Emesto. Overview of papers on urban climate in tropical/subtropical areas. In: TECHNICAL CONFERENCE OF TROPICAL URBAN CLIMATES. Dhaka, mar./apr.1993. Report. [Geneva]: WMO/TD n.647, 1994, p.377-390.

19. KATZSCHNER, Lutz. Urban climate studies as tools for urban planning and architecture. In: IV Encontro Nacional de Conforto no Ambiente Construído, 1997, Salvador. Anais. Salvador: FAUUFBA/LACAM-ANTAC, 1997, p.4958.

20. LANDSBERG, Helmut. The meteorologically utopian city. Bulletin of American Meteorological Society. v.54, n.2, p.86-89, feb. 1973.

21. LOMBARDO, Magda. Ilha de calor nas metrópoles. São Paulo: Hucitec, 1985.

22. LOMBARDO, Magda. O clima e a cidade. In: IV Encontro Nacional de Conforto no Ambiente Construído, 1997, Salvador. Anais. Salvador: FAUUFBA/ LACAM-ANTAC, 1997. p.59-62.

23. LOMBARDO, Magda. Clima Urbano. Notas de aula. Fortaleza, 1999.

24. LOMBARDO, Magda. Qualidade Ambiental e Planejamento Urbano: considerações e métodos. São Paulo, 1995. Tese (Livre-docência). Faculdade de Filosofia, Letras e Ciências Humanas - Departamento de Geografia, Universidade de São Paulo.

25. MONTEIRO, Carlos A. F. Teoria e Clima Urbano. São Paulo: Universidade de São Paulo, 1976. Série Teses e Monografias, n.25.

26. MONTEIRO, Carlos A. F. A cidade como processo derivador ambiental e estrutura geradora de um clima urbano. Geosul, Florianópolis, n.9, p.80-114, 1990.

27. MONTEIRO, Carlos A. F. Adentrar a cidade para tomar-lhe a temperatura. Geosul, Florianópolis, n.9, p.61-79, 1990.

28. MONTEIRO, Carlos A. F. Cidade e ambiente atmosférico. Geosul, Florianópolis, n.9, p.115-123, 1990.

29. MONTEIRO, Carlos A. F. Por um suporte teórico e prático para estimular estudos geográficos do clima urbano do Brasil. Geosul, Florianópolis, n.9, p.7-19, 1990. 
30. OKE, Tim R. City size and the urban heat island. Atmospheric Environment, v.7, p.769-779, 1973.

31. OKE, Tim R. The distinction between canopy and boundary-layer urban heat islands. Atmosphere, v.14, n.4, p.269-277, 1976.

32. OKE, Tim R. Canyon Geometry and the nocturnal urban heat island: comparison of scale model and field observations. Journal of Climatology, v.1, p.237254, 1981.

33. OKE, Tim R. The energetic basis of the urban heat island. Quarterly Journal of the Royal Meteorology Society, v.108, n.455, p.1-24, jan.1982.

34. OKE, Tim R. Towards a prescription for the greater use of climatic principles in settlement planning. Energy and Buildings, Netherlands, n.7, p.1-10, 1984.

35. OKE, TAESLER e OLSSON. The Tropical Urban Climate Experiment (TRUCE). Building and Environment, Netherlands, v.15-15, p.67-73, 1990/91.

36. OKE, T. R. et al. The energy balance of central Mexico City during the dry season. Atmospheric Environment, v.33, 1999, p.3919-3930.

37. PAGE, J. K. Climate Considerations and Energy Conservation. In: BACH, W., PANKRATH, J., WILLIAMS J. (ed.). Interactions of climate and energy. Dordrecht: Reidel, 1980. p.73-88.

38. PAULSSON, Bengt. Remote Sensing - an operational tool for urban planning in developing countries. In: Cities of the world as seen from space. Hong Kong: Geocarto International Centre, [s.d.], p.10, 14.

39. PEARLMUTTER D., BITAN A. \& BERLINER, P. Microclimatic analyses of compact urban canyons in an arid zone. Atmospheric Environment, Oxford, v.33, n.24-25, p.4143-4150, 1999.

40. QUATTROCHI, Dale \& RIDD, Merryll. Analysis of vegetation within a semiarid urban environment using high spatial resolution airborne thermal infrared remote sensing data. Atmospheric Environment, Oxford, v.32, n.1, p.19-33, 1998.

41. SANTAMOURIS, Matheos. Energy and indoor climate in urban environments recent trends. In: IV Encontro Nacional de Conforto no Ambiente Construído, 1997, Salvador. Anais. Salvador: FAUUFBA/LACAM-ANTAC, 1997. p.1524.

42. SANTAMOURIS, Matheos. The Athens urban climate experiment. In: Environmentally Friendly Cities. Proceedings of PLEA'98. Lisbon: James and James, 1998, p.147-152.

43. SANTANA, Andrea. O desenho urbano e a climatologia em Fortaleza. São Paulo, 1997. Dissertação (Mestrado em Geografia) - Faculdade de Filosofia, Letras e Ciências Humanas, Universidade de São Paulo.

44. SEZERINO, Maria Lurdes e MONTEIRO, Carlos A. F. O campo térmico da cidade de Florianópolis. Geosul, Florianópolis, n.9, p.20-60, 1990. 
45. SILVA, Francisco A. Gonçalves da. O vento como ferramenta no desenho do ambiente construído. Uma aplicação do nordeste do Brasil. São Paulo, 1999. Tese (Doutorado) - Faculdade de Arquitetura e Urbanismo, Universidade de São Paulo.

46. TAESLER, Roger. Urban climatological methods and data. In: URBAN CLIMATOLOGY AND ITS APPLICATIONS WITH SPECIAL REGARD TO TROPICAL AREAS. Mexico D.F., 26-30 November 1984. Proceedings. OKE, T. (ed.) Urban Climatology and its Applications with Special Regard to Tropical Areas. Geneva: WMO n.652, 1986, p.199-236.

47. TSO, C. P. A survey of urban heat island studies in two tropical cities. Atmospheric Environment, Oxford, v.30, n.3, p.507-519, 1996.

48. UPMANIS, Hillevi. The park has its own climate. Swedish Building Research, n.2, p.8-10, 2000. 


\section{EXEMPLOS DE ADAPTAÇÃO AO CLIMA}

\subsection{Exemplos históricos de adaptação ao clima}

Vitrúvio (1997. p.17, 25, 140), por volta do ano 700, já alertava que “Antes de echar los cimientos de las murallas de una ciudad habrá de escogerse un lugar de aire sanísimos. Este lugar habrá de ser alto, de temperatura templada, no expuesto a las brumas ni a las heladas, ni al calor ni al frío. (...) Una vez acabado el recinto amurallado, resta por hacer la distribución del área o solar en el interior, y las adecuadas vías de acceso a las plazas, las calles y los callejones, conforme a la región del cielo que sea más ventajosa. Será acertada la disposición si prudentemente se procura evitar que enfilen directamente con las calles los vientos; los cuales, si son fríos, molestan; si cálidos, vician; si húmedos, dañan.(...) Los edificios particulares estarán bien dispuestos si desde el principio se ha tenido en cuenta la orientación y el clima en que se van a construir; porque está fuera de duda que habrán de ser diferentes las edificaciones que se hagan en Egipto de las que se efectúen en España; distintas las que se hagan en el Ponto de las que se efectúen en Roma; ya puesto que una parte de la Tierra está bajo la influencia inmediata de su proximidad al Sol, otra por su distancia de él, y otra por su posición intermedia entre ambas resulta templada."

Leon Battista ALBERTI (1991, p.169, 184), em seu tratado De Re Aedificatoria editado pela primeira vez em 1485, ao falar sobre a implantação de novas cidades, diz que "seguramente hay que meditar una y otra vez en qué lugar emplazarla, con qué orientación y de qué perímetro.” Mais adiante lembra o trecho em que Cornelio Tacito, em Nero and the Burning of Rome, "escribe (...) que Roma, a consecuencia de haber prolongado Nerón la longitud de sus calles, se volvió más calurosa y, por esa razón, menos saludable. Mientras que en otras partes el ambiente umbroso, en las calles estrechas, hace que el clima sea más crudo, en ese sitio ello no sucede: en efecto, durante el invierno reciben la luz del sol de modo permanente."

Em 1573 o rei Felipe II promulgava as Ordenanzas de descubrimiento, nueva población y pacificación de las Indias (1973), que regulamentavam a ocupação das colônias espanholas. Para a escolha do lugar recomendava sítios sem excesso de calor ou frio, " $y$ haueindo de declinar es mejor que sea frío (...) no se elijan en lugares muy altos porque son molestados de los vientos y es dificultoso el servicio y acarreto ni en lugares muy baxos porque suelen ser enfermos elijan en lugares medianamente levantados que gozen de los ayres libres (...) las calles en lugares fríos sean anchas y en los calientes sean angostas pero para defensa adonde hay caballos son mejores anchas."

No continente americano a preocupação com o clima é mencionada desde a implantação das primeiras cidades na época da colonização. Para HOLANDA (1995, p.95-98) um zelo minucioso e previdente dirigiu a fundação das cidades espanholas na América, reflexo da determinação em assegurar o predomínio militar, econômico e político da metrópole sobre as terras conquistadas, mediante a criação de grandes núcleos de povoação estáveis e bem ordenados. O próprio traçado dos centros urbanos na América espanhola denuncia o esforço determinado de vencer e retificar a fantasia caprichosa da paisagem agreste; é um ato claro da vontade humana. As 
ruas não se deixam modelar pela sinuosidade e pelas asperezas do terreno, mas são voluntariamente retas. O plano regular não nasce nem ao menos de uma idéia religiosa, foi simplesmente um triunfo da aspiração de ordenar e dominar o mundo conquistado. O traço retilíneo, em que se exprime a direção da vontade a um fim previsto e eleito, manifesta bem essa deliberação. E não é por acaso que ele impera decididamente em todas essas cidades espanholas, as primeiras 'cidades abstratas' que edificaram os europeus em nosso continente. No plano das cidades hispanoamericanas o que se exprime é a idéia de que o homem pode intervir arbitrariamente, e com sucesso, no curso das coisas e de que a história não somente acontece, mas pode ser dirigida e até fabricada.

Nas regiões da América que couberam aos castelhanos o clima geralmente não oferecia grandes problemas. Boa parte dessas terras estava situada fora da zona tropical e a grandes altitudes. Atraídos pela amenidade do clima nos altiplanos das proximidades da costa ocidental, foi neles que fizeram os castelhanos seus primeiros assentamentos. Mesmo na cidade de Quito, em pleno equador, o espanhol encontrou uma temperatura amena. A altitude permitiu aos europeus, mesmo na zona tórrida, desfrutar um clima semelhante ao que lhes é habitual em seu país. Ao contrário da colonização portuguesa, que foi antes de tudo litorânea e tropical, a castelhana parece fugir deliberadamente da marinha, preferindo as terras do interior e os planaltos. Existem, aliás, nas ordenanças, recomendações explícitas nesse sentido (HOLANDA, 1995, p.99).

O traçado geométrico nunca alcançou entre as terras de colonização portuguesa a importância que teve entre as cidades espanholas; o desenvolvimento tardio dos centros urbanos repeliu esse esquema inicial e obedeceu às sugestões topográficas. A rotina norteou os portugueses; eles preferiram agir por experiências sucessivas, nem sempre coordenadas umas às outras, a traçar de antemão um plano para segui-lo até o fim. "Raros os estabelecimentos fundados por eles no Brasil que não tenham mudado uma, duas ou mais vezes de sítio, e a presença da clássica vila velha ao lado de centros urbanos de origem colonial é persistente testemunho dessa atitude tateante $e$ perdulária. (...) A cidade que os portugueses construíram na América não é produto mental, não chega a contradizer o quadro da natureza, e sua silhueta se enlaça na linha da paisagem. Nenhum rigor, nenhum método, nenhuma previdência, sempre esse significativo abandono que exprime a palavra 'desleixo" (HOLANDA, 1995, p.109, 110)

Para BRUAND (1991), enquanto os hispânicos esforçavam-se para criar conjuntos urbanos disciplinados, com planos regulares em xadrez, os portugueses se deixavam guiar pela natureza, explorando a topografia e deixando que as aglomerações crescessem livremente, sem nenhum esquema pré-concebido, aproveitando as condições locais. Traços de adaptação ao clima também são relatados por FREYRE (1990, p.205,105), como os valorizados recantos cheios de sombra na arquitetura colonial, sob os parreirais, onde se podia merendar nos dias de calor; " $a$ arquitetura patriarcal dos portugueses, na sua adaptação ao Brasil, teve de resolver o problema de excesso de luminosidade e de calor. O que os portugueses em parte conseguiram, valendo-se da experiência adquirida por eles na Ásia e na África. (...) Aos mouros se deve atribuir o gosto pelas fontes, tão comuns nos jardins e nos pátios dos sobrados do Recife, pelos chafarizes e pelas bicas onde a pequena burguesia de Salvador ia de 
noite refrescar-se, tomar banho, lavar os pés”, segundo Freyre, influência do mouro através do português.

E os mouros já haviam deixado marcas dessa adaptação nas cidades da Andaluzia, no sul da Espanha, que traduzem com maestria, unindo técnica e beleza, a adaptação da ocupação ao clima. Há exemplos fantásticos na implantação das cidades, nos espaços públicos, nas construções milenares e nos hábitos do povo, que nas cidades pequenas não dispensam a siesta durante as horas de calor escaldante, quando os serviços fecham para o almoço e só reabrem no final da tarde.

No ano 711d.C os muçulmanos invadiram a Espanha, a qual chamavam de $A l$ Andaluz. A atual Andaluzia foi a região da Espanha onde os mouros permaneceram por mais tempo e deixaram suas construções mais grandiosas. Os principais monumentos mouriscos estão em Granada, Córdoba e Sevilha. É surpreendente a arquitetura mourisca produzida no reino násrida de Granada, cujo apogeu está no Alhambra que, com seu exterior austero, não dá idéia ao visitante do seu interior com salões suntuosos, ricamente decorados, pátios e jardins.

Os reflexos na água, combinados com jogos de luz e sombra, eram centrais na arquitetura mourisca; juntamente com o uso de vegetação e do sombreamento criaram espaços ao ar livre com um microclima diferenciado em relação à aridez local, aumentando a umidade do ar, reduzindo ganhos térmicos pela radiação solar e diminuindo a temperatura do ar (fig.3.1). Belíssimos exemplos também são encontrados nos Jardins do Generalife, em Granada (fig.3.2 e 3.3), antiga propriedade de campo dos reis násridas e nos jardins dos Reales Alcázares, em Sevilha, com fontes e terraços densamente arborizados, proporcionando aos visitantes um refúgio do calor intenso. O nome Generalife (Yannat al Arif) tem várias interpretações; uma delas é o jardim do paraíso elevado, e é exatamente essa a sensação que se tem nesses jardins que começaram a ser construídos no século XIII.

A arquitetura moura do norte da África, que influenciou a arquitetura espanhola chegando às colônias na América Latina, produziu ótimos exemplos de ocupação urbana com a preocupação de garantir condições de conforto térmico (para não dizer de sobrevivência) em regiões de clima rigoroso no sul da Espanha, de clima quente e seco, onde chove pouco ou quase nada. Nos pueblos blancos da Andaluzia (fig.3.4), compactos para que os edifícios sombreiem uns aos outros, e com ruas estreitas protegendo os pedestres, as casas de barro cozido são caiadas regularmente para refletir o sol intenso. Em povos primitivos as casas são escavadas nas pedras, protegendo os ocupantes das variações extremas de temperatura. Nos labirintos de ruas estreitas, repletos de becos, praças escondidas e pátios floridos nos antigos guetos judaicos as construções também são sempre dotadas de paredes grossas, com poucas e pequenas aberturas que garantem o interior mais fresco.

O uso de água para resfriamento evaporativo e de vegetação para sombreamento no casco histórico de Sevilha são surpreendentes. Pelas ruelas e becos do bairro de Santa Cruz o visitante se depara com recantos inusitados onde esses elementos são aproveitados ao máximo; qualquer espaço, por menor que seja, próximo à sombra e à água, torna-se um ponto de atração para turistas e moradores (fig.3.5); só assim é possível passar tantas horas ao ar livre sob o calor escaldante do verão sevilhano. 


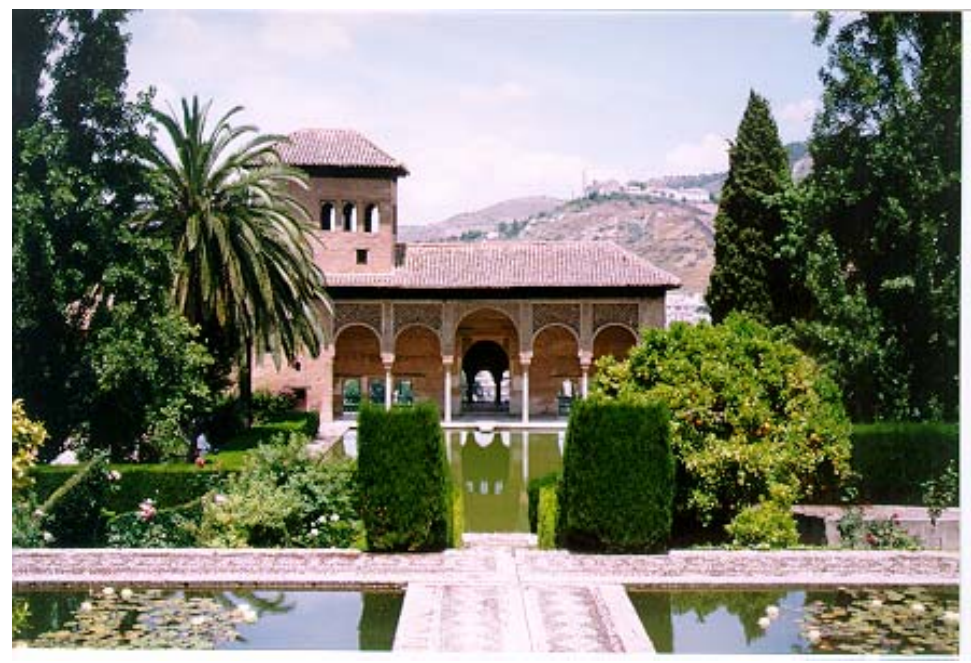

Figura 3.1 - O uso de vegetação e água criando um microclima diferenciado nos jardins do Alhambra. (foto: D. Duarte)

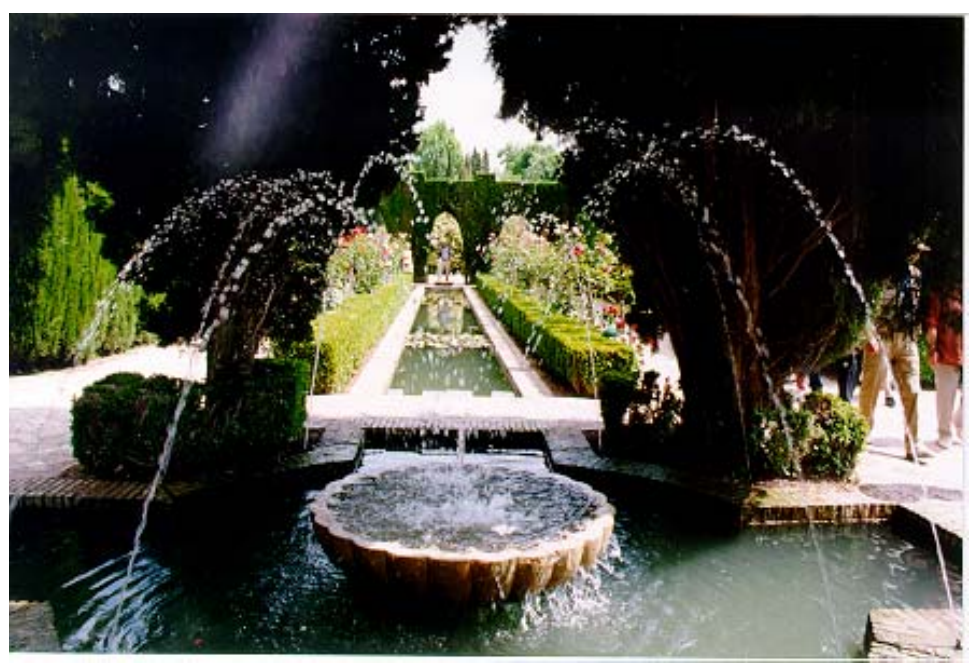

Figura 3.2 - O uso da água nos Jardins do Generalife, melhorando as condições higrotérmicas locais. (foto: D. Duarte)

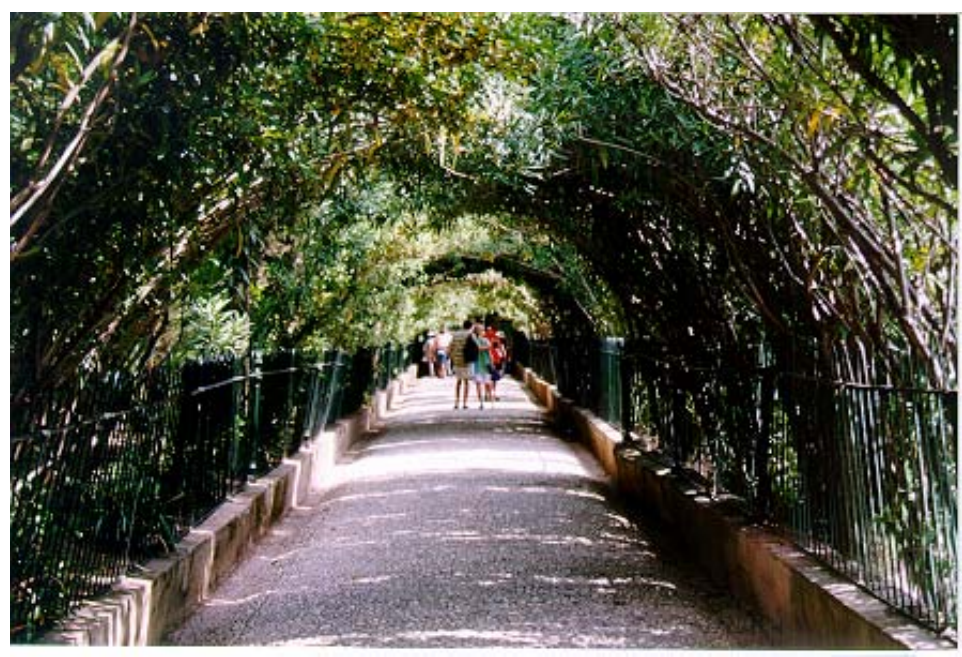

Figura 3.3 - O uso de vegetação proporcionando sombreamento para os pedestres nos Jardins do Generalife, reduzindo os ganhos térmicos por radiação solar. (foto: D. Duarte) 


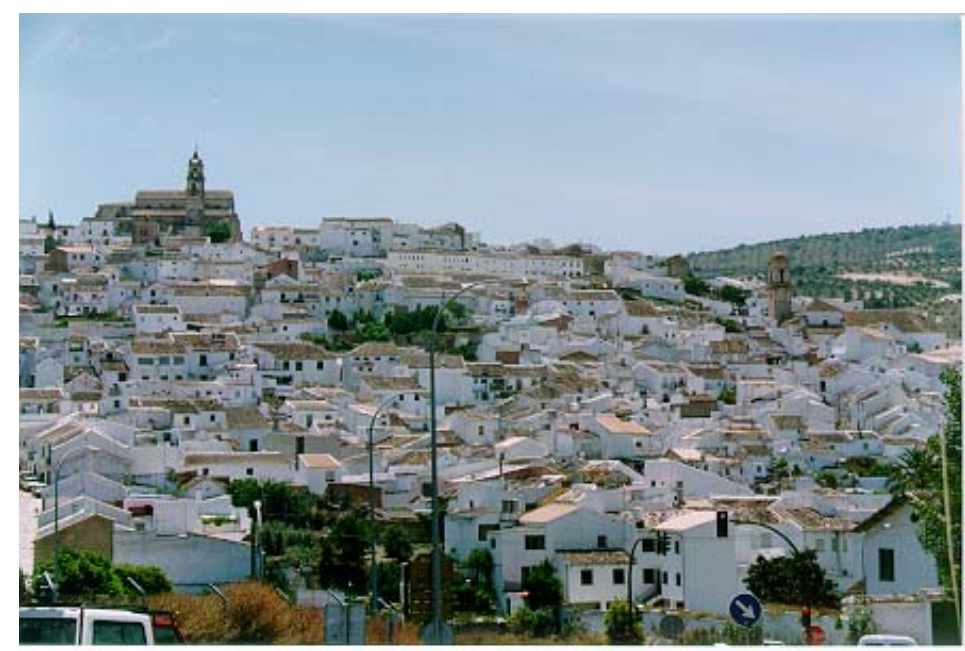

Figura 3.4 - Um dos muitos pueblos blancos na Andaluzia, compactos e com os edifícios caiados anualmente para melhor adaptação ao clima quente e seco. (foto: D. Duarte)
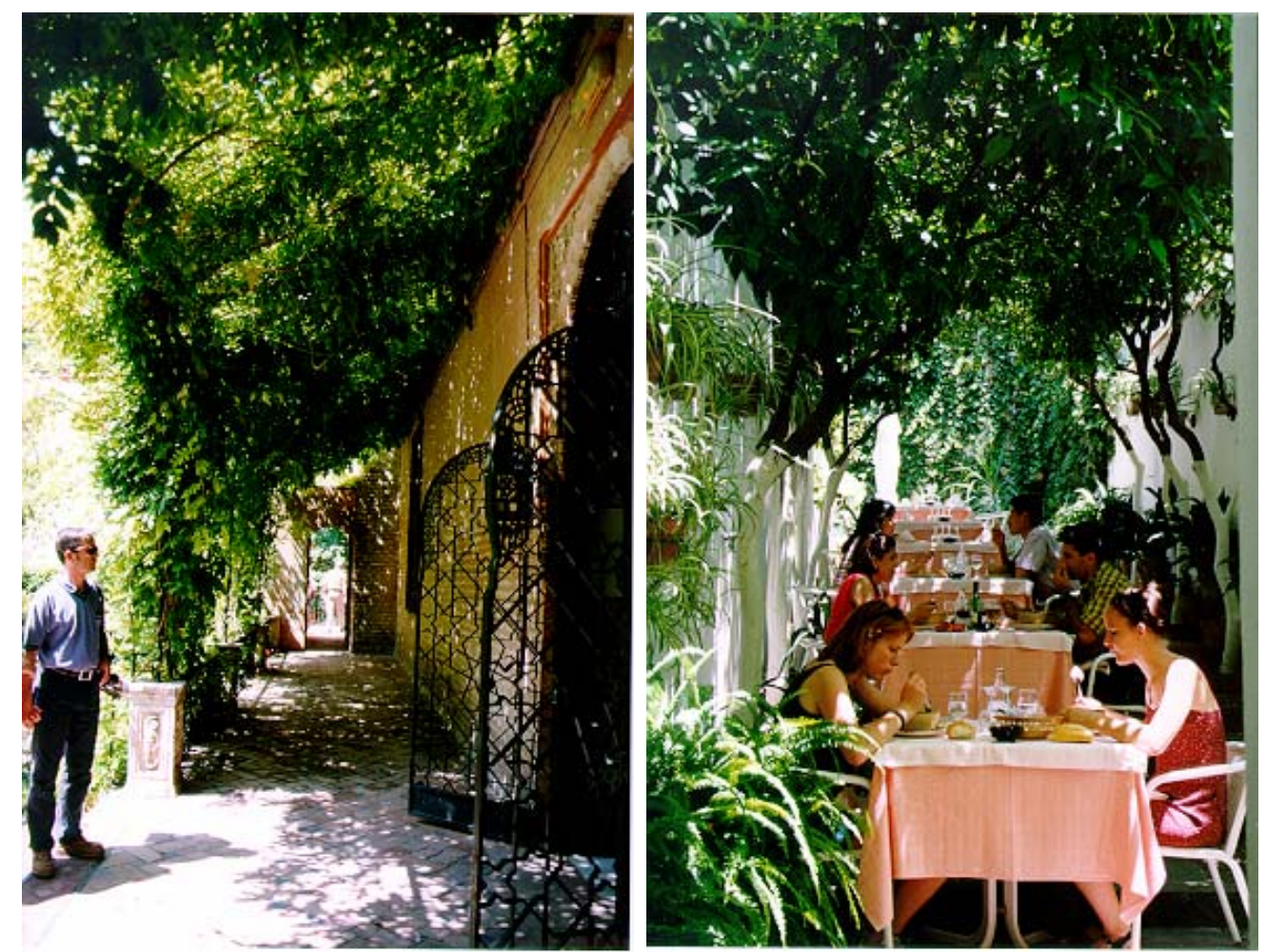

Figura 3.5 - O correto uso de vegetação em Sevilha. À esquerda, fazendo a transição exterior/interior nos Reales Alcázares e, à direita, promovendo sombra em um restaurante no Barrio de Santa Cruz.

(foto: D.Duarte)

Além dos edifícios e espaços públicos criados no período da dominação moura, Sevilha conta com exemplos mais recentes de adaptação ao clima tais como a belíssima Plaza de España (fig.3.6), construída para a Exposição Ibero-Americana de 1929, e o recinto da Expo'92, na Isla de la Cartuja, hoje um complexo com centro de convenções, museus e áreas de lazer, ambos usando as lições deixadas pelos mouros, com arcadas para sombreamento, fazendo uso da água e da vegetação para a criação de espaços de amenidade climática frente às condições ambientais locais. 


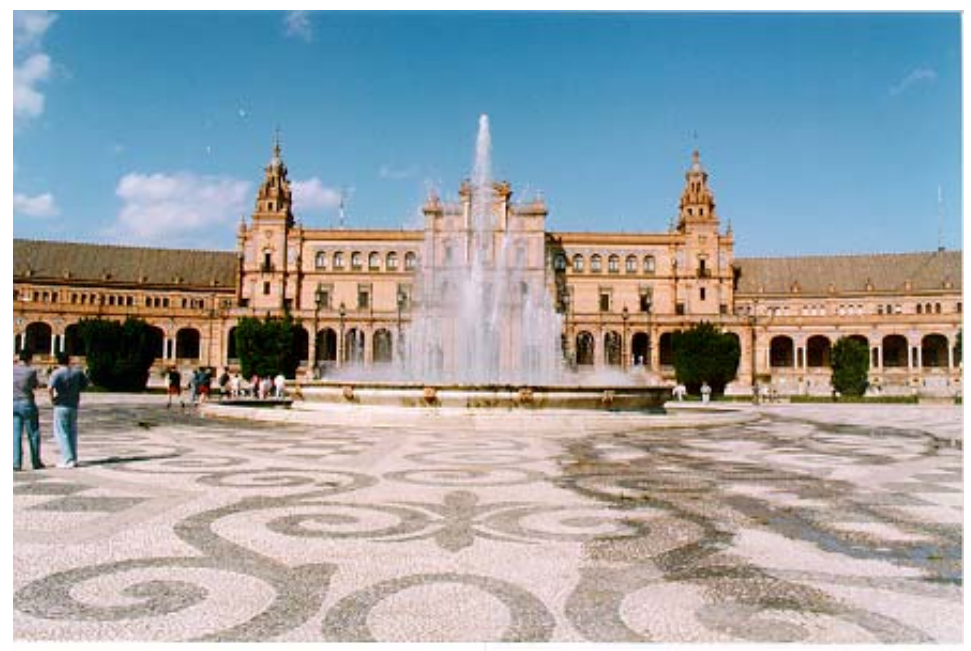

Figura 3.6 - Arcadas para sombreamento e o uso da água para aumentar a umidade do ar na Plaza de España, em Sevilha. (foto: D. Duarte)

Exemplos igualmente interessantes do uso da água para amenizar condições climáticas são encontrados em Roma, que tem água corrente nas fontes espalhadas por toda a cidade, em Madri, também nas fontes e no interior da belíssima estação Atocha (fig.3.7), que cria condições higrotérmicas bem mais amenas do que as condições naturais locais, ou ainda em Bologna, com suas arcadas sombreando os caminhos para pedestres.

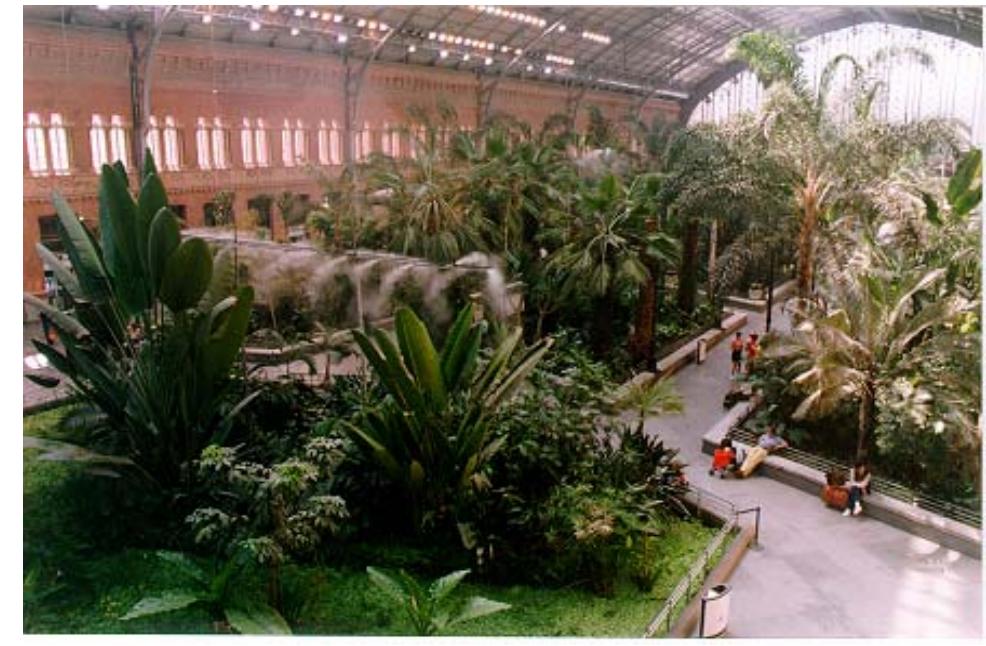

Figura 3.7 - Uso de vegetação e de aspersão de água para a criação de um microclima ameno na Estación Atocha, em Madrid. (foto: D. Duarte)

Cook (1991) lembra os exemplos da Plaza Mayor, em Madrid, e da Piazza di San Marco, em Veneza (fig.3.8) que, apesar de não terem sido intencionalmente planejadas segundo critérios bioclimáticos, têm o que o autor chama de ramificações bioclimáticas. Cook comenta que, apesar de serem dois dos espaços urbanos mais admirados do mundo, e de todo o efeito hipnótico desses espaços sobre as pessoas, geralmente ninguém se dá conta do por que eles são tão confortáveis, tão aconchegantes. Convém lembrar que nenhum desses dois exemplos tem vegetação, e a atratividade acontece por outros fatores, como o sombreamento proporcionado pelas arcadas ao redor da praça. Cook conclui que o conceito de cidade bioclimática 
ainda está se desenvolvendo. A analogia que alguns autores fazem entre a concepção bioclimática para o edifício e para a escala urbana é inadequada, não só por razões técnicas, mas também pelos critérios usados para a criação dos espaços, que são diferentes. Para Cook, "perhaps the next generation of passive researchers will exercise as much thoroughness in examining urban prototypes and public outdoor spaces, as the past generation has devoted to the closed rooms of private one family houses. The world would be the richer."

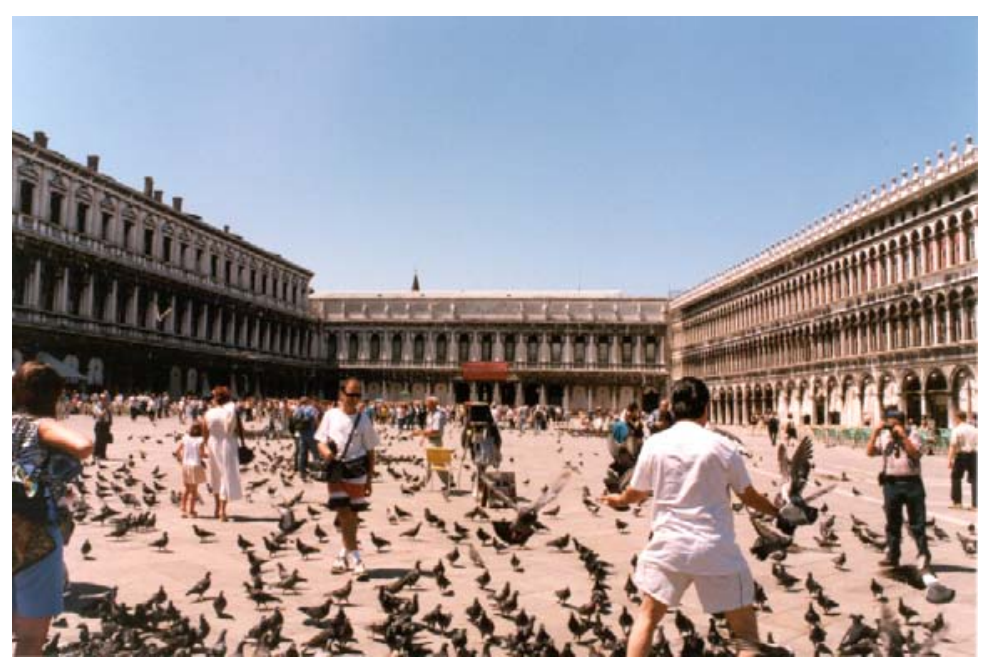

Figura 3.8 - Arcadas no entorno da Piazza di San Marco, em Veneza. (foto: D. Duarte)

\subsection{Exemplos recentes de adaptação ao clima nos recintos das exposições universais}

\subsubsection{Tratamento Bioclimático da Expo'92 em Sevilha}

O tratamento climático dos espaços abertos e semi-confinados na Expo'92 foi, sem dúvida, um dos pontos altos da Exposição Universal celebrada em Sevilha no ano de 1992. Na época não havia realização precedente, nem base metodológica em que se basear. As soluções remetiam à tradição ainda presente nas cidades da Andaluzia em amenizar o rigor do clima. O trabalho, iniciado em 1987, desenvolveu uma tecnologia específica para aplicação ao projeto energeticamente racional da envoltória dos edifícios e para o uso de técnicas naturais de resfriamento. Englobando ferramentas da matemática, da física e da experimentação, provou-se que é possível condicionar os espaços abertos com o uso de técnicas naturais de resfriamento.

Os espaços abertos na Expo eram espaços habitados, independente dos pavilhões, onde se levou em conta o aspecto psicológico associado à sensação de conforto. Os espaços abertos deram identidade ao recinto, e foram tratados não como espaços residuais, mas com personalidade própria, devido ao desejo de ressaltar a tradição sevilhana e mediterrânea de viver ao ar livre. As ruas, praças e edifícios históricos mostram numerosas técnicas de amenização do rigor do clima andaluz.

A maior parte das soluções propostas se baseia nos mesmos recursos que, por intuição, foram empregados por seus antepassados. Em uma primeira etapa se tratou de separar nas soluções tradicionais o que era fundamental do que era acessório, seja 
estético ou por limitação tecnológica da época. Depois se tratou de reunir e melhorar os conceitos fundamentais com o suporte das tecnologias atuais. A dimensão dos espaços públicos e a intensidade de tratamento motivado pelo rigor do clima durante o verão em Sevilha fizeram dos espaços abertos da Expo'92 uma instalação singular. Não existiam precedentes que contemplassem a diversidade e a amplitude das técnicas naturais de esfriamento incorporadas para conseguir a habitabilidade dos espaços públicos. "Así por ejemplo, no es posible diseñar los espacios abiertos de Expo'92 a semejanza de las calles peatonales del casco antiguo sevillano, donde la sombra y el confinamiento surgen como resultado de los propios edificios." (GUERRA MACHO et.al., 1994, p.5)

Em um espaço interior o conceito de conforto está estreitamente ligado ao conceito de temperatura do ar, sendo esta a variável fundamental a considerar. Já em espaços abertos existem outros fatores que contribuem de maneira mais significativa do que a temperatura. Em um espaço aberto a radiação solar recebida diretamente pelo ocupante é o ganho de calor fundamental, e que é desprezível no espaço interior. A temperatura das superfícies circundantes é praticamente igual à temperatura do ar no espaço interior, podendo apresentar diferenças significativas no caso de espaços abertos. Outra diferença está no fato de que na climatização interna se deve evitar as correntes de ar enquanto que em um espaço aberto é tolerável e até desejável o estabelecimento de velocidades de ar relativamente altas que melhoram a efetividade da sudoração. "El objetivo en espacios abiertos es más atemperar, dulcificar, y atenuar el rigor climático exterior que el alcanzar un grado de confort equiparable al de recintos confinados." (ALVAREZ DOMINGUEZ, 1992, p.12-14)

O conforto em espaços abertos depende de uma série de variáveis das quais a temperatura do ar é só uma delas e não a mais importante. O número de variáveis a tratar em cada caso e a intensidade da manipulação dependem de muitos fatores, entre os quais:

- características do espaço a tratar (geometria, dimensões, orientação, grau de confinamento)

- efetividade e custo das possibilidades técnicas a empregar

- possibilidade de integração dessas técnicas no espaço sem distorcer seu objetivo estético

Em um espaço fechado a concepção da envoltória é o fator determinante da demanda energética. Já em espaços abertos os elementos estruturais, arquitetônicos e urbanísticos que conformam esses espaços são ao mesmo tempo os componentes tecnológicos da instalação de climatização. Coberturas, lâminas d’água, pavimentos, vegetação, confinamento, etc., são ao mesmo tempo elementos arquitetônicos e soluções de climatização natural. Para a equipe da Expo'92 era inviável o tratamento térmico dos espaços abertos sem uma participação da engenharia desde as primeiras etapas de desenho arquitetônico.

O recinto da exposição foi planejado para o clima rigoroso de Sevilha, seco e com temperaturas superiores a $38^{\circ} \mathrm{C}$ durante boa parte do tempo no verão, chegando a $42,9^{\circ} \mathrm{C}$ em dias extremos, e amplitude térmica média de $18^{\circ} \mathrm{C}$, que chega a $22^{\circ} \mathrm{C}$ ou $23^{\circ} \mathrm{C}$ nos dias mais quentes. A radiação solar alcança valores muito elevados, próximos aos máximos esperados em função da latitude do lugar. 
Nessas condições a habitabilidade dos espaços abertos depende do alcance de níveis aceitáveis de conforto. A idéia não era alcançar nos espaços abertos da Expo as mesmas condições de um espaço interior climatizado. Se o objetivo fosse esse, não teria solução. Devido às grandes dimensões seria economicamente inviável climatizar os espaços abertos mediante técnicas convencionais. O acondicionamento integral não seria tecnicamente possível nem economicamente viável.

O objetivo final era dispor de ferramentas de cálculo que permitissem caracterizar os parâmetros básicos de cada sistema, definir a faixa ótima de variação de cada uma das variáveis de projeto, quantificar a contribuição de cada sistema para melhoria das condições de conforto e finalmente dimensionar os sistemas de acondicionamento.

O projeto das avenidas foi desenvolvido por sete equipes multidisciplinares, diferenciando as zonas de passagem das de permanência - pensadas para o descanso, para a contemplação de espetáculos rápidos, etc. - e das adjacentes. As zonas de permanência receberam uma alta intensidade de condicionamento, que por sua vez foi médio nas zonas de passagem e baixo nas zonas adjacentes. Mas na totalidade das zonas de passagem e permanência se instaram sistemas de proteção solar.

A funcionalidade dos espaços abertos assim como o tempo de permanência médio dos visitantes nesses espaços determina a intensidade de condicionamento requerido para cada um deles, sendo que diferentes combinações desses recursos podem originar o mesmo nível de conforto. O objetivo final é conhecer, dentro de um conjunto de alternativas, qual delas apresenta um maior nível de conforto.

No trabalho de modelagem o objetivo era expressar a realidade física por meio de equações para prever o comportamento que teriam os componentes e sistemas em qualquer situação (ALVAREZ DOMINGUEZ, 1992, p.15); foram feitos ensaios de laboratório que requeriam a construção de uma planta piloto em escala real e paralelamente se projetou uma instalação experimental contendo diferentes versões dos elementos mais significativos, para prever como se comportaria cada um dos componentes em diversas situações variando tanto as alternativas de projeto como os dados climáticos. Isso levou a equipe a estabelecer quais eram as variáveis mais importantes em cada componente e quais eram as secundárias. O sistema de aquisição de dados funcionou durante o período da exposição, de 20 de abril a 12 de outubro de 1992; foram coletados 15.264 valores por dia, para se saber se o conforto foi alcançado ou não e a que custo.

Para o clima de Sevilha, no verão, às $14 \mathrm{~h}, 55 \%$ dos ganhos de calor diz respeito aos ganhos por radiação direta e difusa (ALVAREZ DOMINGUEZ, 1992, p.29) Em função disso, os critérios de acondicionamento são:

- reduzir a radiação solar;

- reduzir o efeito de radiação de onda longa recebida por outras superfícies mais aquecidas, invertendo inclusive o sinal da troca radiante e convertendo-o em perda de calor;

- reduzir os ganhos por convecção e converte-los em perdas de calor sempre que possível.

Com base nesses critérios básicos de acondicionamento foram definidas as seguintes estratégias (ALVAREZ DOMINGUEZ, 1992, p.30): 
- bloquear a radiação solar direta e difusa;

- obstruir a radiação solar refletida;

- reduzir a temperatura das superfícies circundantes;

- reduzir a temperatura do ar;

- fomentar o movimento do ar ou aumentar sua velocidade para potencializar o efeito da redução de temperatura.

Dentre os critérios estabelecidos a obstrução da radiação solar direta é o início de qualquer estratégia de acondicionamento, e a redução da temperatura do ar é o último recurso a empregar, dadas as magnitudes relativas com que contribuem para o balanço térmico. No tratamento de espaços exteriores a fração convectiva não é o parâmetro determinante e, portanto, as técnicas para se alcançar uma redução de temperatura só devem ser aplicadas depois de se haver esgotado as opções restantes (ALVAREZ DOMINGUEZ, 1992, p.28). A sequência de tratamento era:

- proporcionar sombra de boa qualidade, com baixa transmissividade;

- para complementar o tratamento onde necessário se avalia em primeiro lugar a contribuição devida ao possível tratamento (esfriamento, neste caso) de superfícies verticais e horizontais utilizando elementos contíguos, tais como lâminas d’água, cascatas, etc.;

- $\quad$ se a contribuição das superfícies frias não permite obter o condicionamento necessário, estuda-se o esfriamento do ar.

O procedimento é fixar o nível de conforto requerido para o espaço e representar as possíveis combinações dos diferentes parâmetros que dão esse nível de conforto em um gráfico; isso permite escolher a combinação mais acertada dos parâmetros, otimizando o desenho final. Diferentes combinações de parâmetros dão lugar a um comportamento global aceitável.

Em espaços fechados pode-se garantir o conforto atuando quase exclusivamente sobre as condições higrotérmicas do ar, enquanto que em espaços exteriores outras variáveis devem ser consideradas. Em espaços fechados as trocas radiantes, tanto de ondas curtas como longas, têm uma intensidade menor em comparação com outros fluxos de calor. Já no acondicionamento de espaços abertos este efeito não só está sempre presente como sua quantidade é percentualmente a maior de todos os ganhos. Portanto o bloqueio efetivo da radiação é a medida mais eficaz, a ponto de não ser efetivo implementar técnica adicional alguma sem haver eliminado previamente o intercâmbio radiante em uma porcentagem significativa (ALVAREZ DOMINGUEZ, 1992, p.27). Sempre que o ocupante estiver rodeado de superfícies com temperatura da ordem da exterior, como no caso da cobertura, ou ainda inferior, como no caso das lâminas d’água e do pavimento, o balanço radiante é favorável do ponto de vista do conforto térmico.

Para um possível esfriamento do ar o grande inconveniente é que um espaço aberto por definição, ainda que seja semi-confinado por barreiras de água, vegetação ou outra forma de sombreamento, permite o fluir do ar exterior e, portanto, mescla o ar tratado com o não tratado. Além disso, o caudal de ar exterior que flui por esse espaço semi-confinado pode ser grande o suficiente para que o resultado do tratamento do ar seja desprezível. Para reduzir a entrada do ar exterior em espaços semi-abertos há que se aumentar o nível de confinamento da zona, protegendo-a dos ventos dominantes com o uso de árvores, arbustos, barreiras d’água, edifícios 
próximos, etc. Nos espaços semi-confinados do recinto da Expo'92 (fig.3.9 e 3.10), a separação interior/exterior foi alcançada com barreiras de árvores, água pulverizada e fontes que faziam um pré-condicionamento do ar externo que entrava nos espaços de uso público, evitando a entrada de ar quente e seco, característico das condições climáticas locais.

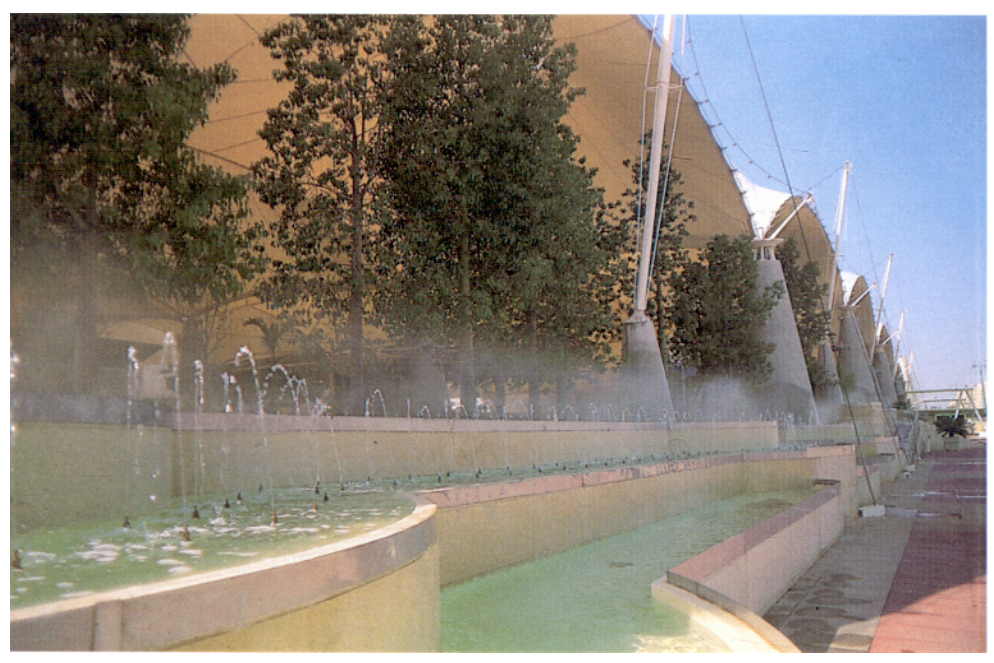

Figura 3.9 - Barreira de árvores e fontes d’água usadas para o semi-confinamento de uma área de espetáculos no recinto da Expo’92. (fonte: Guerra Macho et al. Control climático..., p.21)

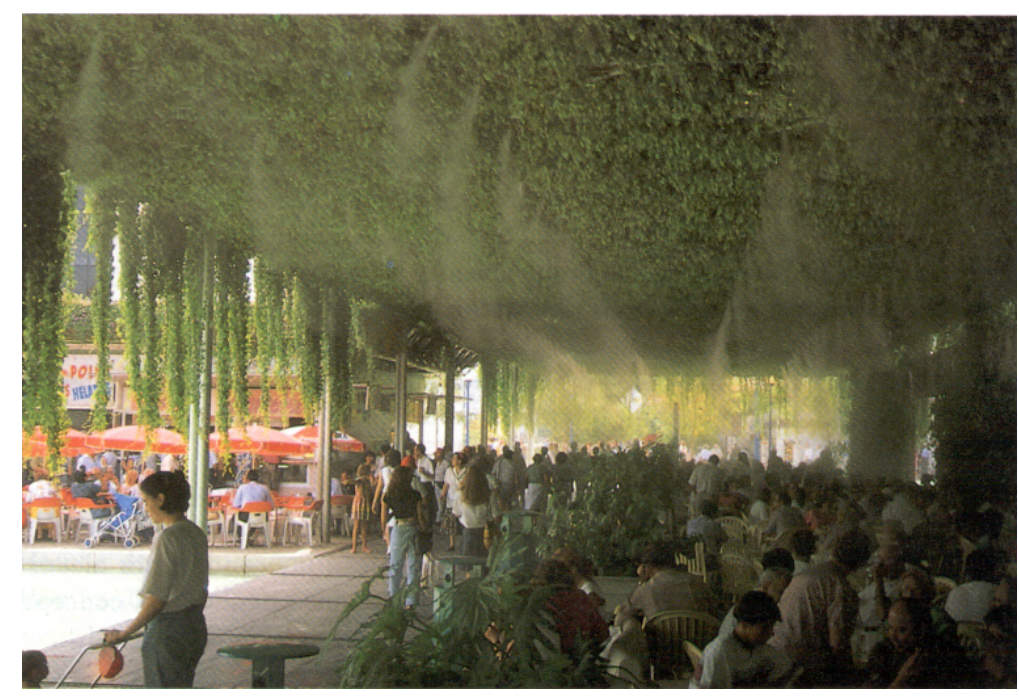

Figura 3.10 - Teto verde e aspersão de água usadas para o semi-confinamento de uma zona de descanso no recinto da Expo’92. (fonte: Guerra Macho et al. Control climático..., p.122)

\subsubsection{Tratamento das coberturas}

Sabendo-se da importância da temperatura da cobertura sobre o conforto do ocupante, o primeiro critério para o acondicionamento de um espaço aberto é impedir que a radiação solar alcance os usuários, já que é o ganho mais importante, não se esquecendo da qualidade da sombra produzida.

Uma cobertura mal projetada pode gerar um problema praticamente impossível de se compensar com o emprego de outras técnicas de acondicionamento. As coberturas simples não são, em muitos casos, as mais adequadas e nem as mais baratas. Já as 
coberturas duplas e múltiplas podem competir favoravelmente com a simples devido à sua melhor relação desempenho/custo.

A transmissividade de uma cobertura simples depende fortemente do material utilizado; já em coberturas duplas (fig.3.11) é conveniente que a câmara de ar entre elas seja ventilada. Isto pode ser alcançado inclinando-se as coberturas e colocando aberturas nos pontos altos, ou simplesmente usando como capa superior uma cobertura com aberturas que favoreçam a saída de ar quente por toda a superfície. Nas coberturas duplas, o comportamento global é menos dependente da cor do que nas simples; portanto a sujidade e a possível degradação são mais admissíveis, o que permite o uso de materiais de menor qualidade ou mais baratos. A influência da sujidade é alta para as coberturas simples, média para as duplas e muito baixa ou nula para as abertas múltiplas.
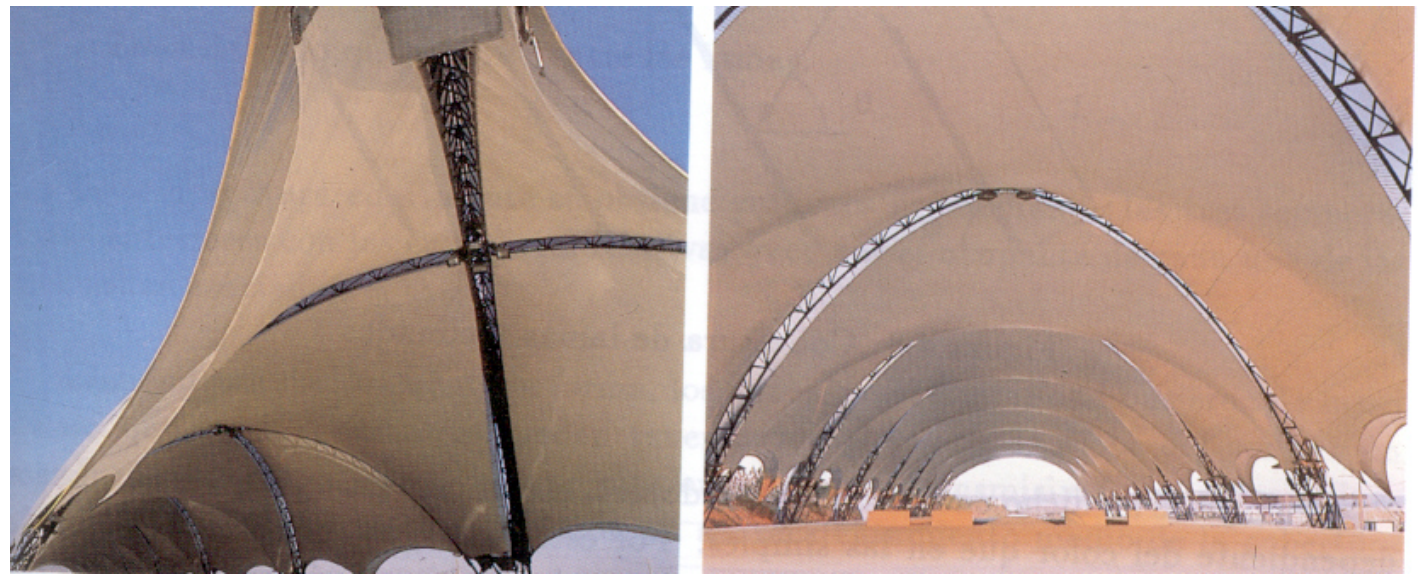

Figura 3.11 - Detalhe da cobertura dupla com câmara de ar ventilada usada no recinto da Expo’92. (fonte: Alvarez Dominguez, Servando. Control climático..., p.89)

Coberturas tendem a se aquecer por causa da radiação solar absorvida. O desconforto é proporcional ao fator de forma entre a cobertura e o ocupante. Nesses casos deve-se reduzir a temperatura superficial da cobertura mediante um sistema de rega. Nesse caso a água pode ser utilizada sob a forma de uma película contínua ou descontínua. Na Expo'92, para se evitar o sobreaquecimento das coberturas, que poderia chegar a $10^{\circ} \mathrm{C}$, foi previsto um sistema de rega cujo principal problema era assegurar uma distribuição uniforme da água impulsionada. A uniformidade é difícil porque apareceram caminhos preferenciais, tendo que se recorrer a sistemas de pulverização. Houve também certa dificuldade em se conseguir uma manutenção adequada dos aspersores, e não se conseguia de forma permanente que a cobertura estivesse uniformemente molhada.

De acordo com ALVAREZ DOMINGUEZ (1992, p.110), o uso de lâminas d’água pode ser extraordinariamente efetivo e alcançar reduções de temperatura da ordem de $12^{\circ} \mathrm{C}$ para coberturas de cor clara e de $20^{\circ} \mathrm{C}$ para coberturas de cor média em comparação com as mesmas coberturas secas. Porém, a quantidade de água a ser utilizada é grande e, para que a eficácia se conserve, a temperatura da água deve se manter baixa. Já com uma rega descontínua a redução de temperatura superficial é menor, em torno de 4 a $7^{\circ} \mathrm{C}$ menor do que a temperatura exterior nas horas extremas. Em compensação o consumo é reduzido em mais de 99\%, já que basta proporcionar 
em cada instante a água que se evapora com o uso de aspersores que liberam água na quantidade certa para a evaporação.

A evaporação da água pode reduzir teoricamente a temperatura do ar até a temperatura de bulbo úmido. A instalação de rega da cobertura permitiu manter uma temperatura superficial da cobertura nas horas mais quentes do dia por volta de $7^{\circ} \mathrm{C}$ inferior à temperatura ambiente exterior. Em relação à cobertura sem rega, a redução de temperatura foi de quase $20^{\circ} \mathrm{C}$, melhorando sensivelmente as condições de conforto.

Na Expo’92 também foram instalados $50.000 \mathrm{~m}^{2}$ de pérgolas vegetais, que oferecem uma proteção solar compatível com a visão de céu e da paisagem, o que elimina qualquer sensação de enclausuramento, mesmo nas de baixa altura. Do ponto de vista do conforto essas coberturas podem ter um comportamento excelente, já que podem combinar transmissividades baixas, inferiores a 5\%, com um sobreaquecimento médio da cobertura menor do que $2^{\circ} \mathrm{C}$ (ALVAREZ DOMINGUEZ, 1992, p.91). Uma cobertura vegetal de qualidade bloqueia totalmente a radiação e não se sobreaquece, ou seja, apresenta transmissividade nula e ausência de sobreaquecimento sobre a mesma, com absorção de $50 \%$ e refletividade de $30 \%$. A pérgola Expo foi pensada para incorporar a vegetação à própria estrutura de sombra com o qual se reduz sensivelmente sua necessidade de crescimento. A estrutura de sombra na zona central das avenidas se conseguiu fundamentalmente por árvores.

\subsubsection{Esfriamento de superfícies}

Seguindo a seqüência de tratamento, o segundo recurso é o esfriamento das superfícies para:

- melhorar as condições de conforto dos ocupantes reduzindo, anulando, ou até invertendo as trocas radiantes desfavoráveis de ondas longas;

- contribuir para o esfriamento direto da temperatura do ar;

- contribuir para o esfriamento indireto da temperatura do ar.

O esfriamento de superfícies leva à obtenção de baixas temperaturas em coberturas, pavimentos de zonas ocupadas, superfícies horizontais e verticais adjacentes a essas zonas. Em solos e pavimentos, para que uma determinada atuação sobre o terreno (materiais especiais, uso de grama, etc.) se traduza em um efeito significativo sobre o ar ambiente é necessário que essas atuação se produza de modo uniforme em uma extensão de várias centenas de metros. A grama é ideal para ser usada em espaços adjacentes às zonas ocupadas; seu efeito benéfico é tanto maior quanto menor é a dimensão relativa da zona ocupada, por ser maior a fração de grama 'vista' pelos ocupantes.

Vale lembrar que não é viável o esfriamento direto do ar mediante um esfriamento das superfícies (ALVAREZ DOMINGUEZ, 1992, p.105). O esfriamento de superfícies deve atuar em:

- zonas de sombra ocupadas durante as horas centrais do dia;

- zonas não ocupadas expostas ao sol imediatamente adjacentes às anteriores;

- zonas expostas ao sol durante as horas centrais e ocupação prevista unicamente para a noite. 
Quanto ao uso de espelhos d'água, de acordo com GUERRA MACHO et.al. (1994, p.106), o efeito sobre o ocupante é, de certa maneira, proporcional a como a pessoa vê a lâmina d’água, ou seja, depende do fator de forma ocupante/superfície da água. Assim é importante facilitar a circulação dos visitantes pelas zonas próximas à lâmina d'água que, ao sol, mantém uma temperatura inferior a de um pavimento convencional. Apesar de sua elevada capacidade de absorção, a energia absorvida se evacua em grande parte pela evaporação de uma fração pequena do volume d'água. Esse processo é melhorado com a instalação de aspersores que aumentam a superfície de troca de calor água/ar e, portanto, a taxa de evaporação. A temperatura mínima alcançável por uma lâmina d’água é, teoricamente, a temperatura de bulbo úmido. Tanques com aspersores permitem manter a temperatura da água inferior à temperatura do ar ambiente. Além disso a água em movimento produz um efeito psicológico favorável sobre os usuários, o que foi comprovado pela utilização intensiva dos visitantes da Expo.

As lâminas d'água utilizadas na Expo têm profundidade da ordem de $50 \mathrm{~cm}$ ou mais, e podem ter sistemas de jatos d'água ou aspersores incorporados. Funcionam por dois motivos: por sua capacidade de manter a temperatura da água inferior à do ar ambiente e por sua baixa refletividade. De acordo com ALVAREZ DOMINGUEZ (1992, p.112), apesar da radiação solar absorvida por uma lâmina d'água ser considerável, com valores de até $80 \%$, esta absorção não origina uma elevação de temperatura da água, devido à evaporação e à inércia térmica da massa de água.

Pode-se utilizar os espelhos d'água:

- sob a forma de lâminas horizontais situadas em zonas expostas ao sol adjacentes a zonas de passagem ou permanência, o que combina duas vantagens, baixa temperatura superficial e baixa refletividade. A refletividade é função do ângulo de incidência da radiação solar, sendo menor (da ordem de 3\%) quando o sol está alto, ou seja, nos momentos mais desfavoráveis;

- sob a forma de cascata e paredes de água internas ou próximas às zonas ocupadas.

No uso de cortinas d'água o objetivo é similar ao dos espelhos d'água: melhorar a sensação de conforto através da troca de calor que se estabelece entre o ocupante e a superfície da cortina d'água que se encontra a uma temperatura mais baixa. As superfícies verticais frias são mais eficientes que as horizontais do ponto de vista das trocas radiantes, já que têm um fator de forma ocupante/superfície muito mais elevado. Além disso há uma melhoria no confinamento da zona e um certo prétratamento do ar quando a parede de água se situa entre os ocupantes e a direção predominante do vento. Uma vantagem adicional é que o próprio movimento da água mantém a temperatura da água mais baixa do que se ela estivesse parada; produz-se um arrasto de ar frio da cortina em direção às zonas próximas que pode modificar sensivelmente a temperatura do ar nas proximidades. Em barreiras úmidas se cria uma cortina de água que esfria o ar que a atravessa segundo a direção dos ventos dominantes. Na Expo'92 foram utilizadas cortinas de água de até $200 \mathrm{~m}$ de comprimento e $1,5 \mathrm{~m}$ de altura, e também uma parede de vidro ondulada de $6 \mathrm{~m}$ de altura por onde cai a água. 


\subsubsection{Esfriamento do ar}

As estratégias anteriores não afetam por princípio a temperatura do ar, ou seja, o objetivo é atuar sobre a troca radiante entre o indivíduo e o entorno. Quando o nível de conforto alcançado em uma zona não é o desejado, o terceiro recurso disponível para melhorar as condições de conforto é esfriar o ar contido na zona considerada. Como já foi dito, para esfriar o ar o grande inconveniente é que mesmo um espaço semi-confinado por definição permite a entrada do ar exterior e, portanto, mescla o ar tratado com o não tratado.

Outro problema é a grande quantidade de ar tratado necessário para manter a zona em condições melhores do que o entorno. Produzem-se movimentos naturais que rapidamente tendem a misturar o ar esfriado da zona tratada com o ar ambiente mais aquecido, prejudicando o resultado desejado. Isso pode minimizado com um confinamento sem perder o caráter de espaço aberto, por exemplo, colocando barreiras naturais ou com o rebaixamento da zona tratada em relação aos seus arredores para criar um volume de ar frio independente e estável. Assim mesmo há trocas entre o ar tratado e não tratado, obrigando o uso de sistemas de esfriamento superdimensionados em relação às exigências usuais dos espaços fechados. Em espaços semiconfinados há que se considerar o efeito psicológico: se a temperatura exterior beira os $40^{\circ} \mathrm{C}$ e a do espaço semiconfinado fica em torno de $30^{\circ} \mathrm{C}$, há sensação de alívio frente às condições exteriores.

O esfriamento do ar pode ser sensível ou latente:

- sensível, reduzindo a temperatura do ar sem adição de umidade. Só pode ser realizado por contato direto com uma superfície mais fria. Esse esfriamento por técnicas convencionais é economicamente inviável. Na EXPO as técnicas consideradas foram a utilização de condutos enterrados, com o uso do terreno como sumidouro da evacuação de calor (que acabaram não sendo utilizados), ou UTAs (unidades de tratamento de ar) alimentadas por água resfriada;

- latente ou evaporativo, também chamado de umidificação adiabática, que consiste em colocar em contato ar e água, esfriando-se o ar mediante a absorção de calor para a evaporação da umidade, resultando em ar mais frio e mais úmido. O termo adiabático significa que não há entrada de energia no sistema, pois o esfriamento sensível do ar é conseguido à custa da energia latente de vaporização da água. Este sistema possibilita um esfriamento do ar com baixo custo, pois a energia extraída é gratuita e só se supõe uma pequena perda de água por evaporação. $\mathrm{O}$ aumento de umidade do ar não chega a ser crítico para o conforto, a não ser que venha acompanhado de altas temperaturas. Para garantir o contato necessário entre ar e água há duas soluções: manter molhada uma superfície sólida com grande área de contato ou conseguir que a água forme a área de contato dividindo-a em múltiplas gotas finas, por aspersão.

De acordo com ALVAREZ DOMINGUEZ (1992, p.133), as unidades de tratamento de ar sensíveis ou latentes são indicadas para condicionar zonas de permanência de tamanho reduzido ou as em que pode haver uma alta concentração de visitantes ou ainda em zonas muito confinadas, como terraços de restaurantes ou zonas destinadas a espetáculos. 
O esfriamento do ar pode se dar com ou sem aumento da umidade absoluta do ar. No caso de esfriamento latente o limite alcançado para a temperatura do ar é a temperatura de bulbo úmido, que depende da temperatura de bulbo seco e da umidade relativa. Com aspersores se reduz a temperatura do ar mediante resfriamento evaporativo, adicionando umidade ao ar diretamente no espaço a ser condicionado. As gotas se evaporam tirando o calor necessário do ar circundante que, ao esfriar-se, cai por gravidade. Um sistema com aspersores é mais efetivo quanto maior é a taxa de água evaporada em relação a que é lançada. Para isso é importante que a área de transferência entre a gota e o ar seja elevada, o que leva à escolha de um sistema em que o tamanho da gotas seja pequeno, da ordem de micras. Se a água não evapora em sua totalidade provoca um consumo de água desnecessário e pode molhar os ocupantes.

Os sistemas de aspersão podem ser incorporados a:

- torres frias;

- aspersores em árvores ou pérgulas, que podem ser utilizados para acondicionar grandes áreas, com uma distribuição de ar frio muito regular se as árvores forem dispostas uniformemente;

- barreiras úmidas que fazem com que o vento, antes de entrar na zona a ser tratada, coloque-se em contato com água aspergida que por sua vez, ao se evaporar, resulte em um pré-esfriamento do vento. As barreiras úmidas necessitam de vento para funcionar, sendo inúteis em casos sem vento ou se ele não vem na direção esperada.

\subsubsection{Tratamento bioclimático na Expo'98 em Lisboa}

Na Exposição Mundial de Lisboa foi colocado em prática o maior e mais completo projeto de reconversão urbana da história de Portugal (EXPO’98). Na zona oriental de Lisboa, uma vasta área degradada e poluída - com instalações industriais antiquadas, depósitos petrolíferos, velhos armazéns militares, um matadouro obsoleto e até uma lixeira a céu aberto - deveria dar lugar a um novo conceito de ocupação do espaço que permitisse, no futuro, devolver à cidade de Lisboa uma importante faixa de território situada à beira do Rio Tejo.

O projeto teve por objetivo criar uma nova centralidade na área metropolitana de Lisboa e oferecer uma elevada qualidade de vida urbana conjugando habitação, escritórios, comércio e lazer com condições de circulação, estacionamentos, serviços, etc. Foi privilegiada e relação com o rio, aproveitando-se $5 \mathrm{Km}$ de suas margens.

A área de intervenção apresentava um avançado estado de degradação ambiental, como resultado de uma ocupação predominantemente industrial, caracterizada pela ausência de legislação ambiental e de critérios de ordenamento, e do uso do solo sem controle de ocupações clandestinas. O projeto de intervenção teve como objetivo principal oferecer aos futuros usuários um ambiente urbanístico, paisagístico e ambiental favorável ao reencontro com a natureza ao longo do rio. Foram privilegiados os percursos para pedestres, com a criação de grandes parques de estacionamento e incentivando o uso do transporte público na ligação com a cidade de Lisboa. 
Esse projeto único estendeu-se por uma área de 330ha, fazendo renascer uma importante zona de Lisboa. A vasta extensão abrangida está completamente liberta de tudo o que antes ali existia, e traz algumas das mais avançadas infra-estruturas, tais como a rede de telecomunicações em fibra ótica, um sistema de frio e calor para a climatização dos edifícios e a coleta automática de lixo, sonhos de qualquer urbanista.

A estratégia ambiental foi incorporada desde o início do projeto, adotando padrões de proteção ao meio ambiente que respondessem às necessidades dos próximos 50 anos. A primeira contribuição da Expo'98 foi a limpeza de uma enorme área que era ocupada por estruturas industriais obsoletas, depósitos de material militar e das empresas petrolíferas. Resolvidos os erros do passado, passou-se a pensar no futuro.

Também foi feita a reciclagem de materiais tanto nas fases de demolição como de construção, e a mistura de solos e materiais já existentes na zona de intervenção para preparar terra vegetal, necessária ao desenvolvimento das 30.000 árvores, das quais cerca de 500 já existentes foram transplantadas.

Segundo os promotores do evento, toda a infra-estrutura da Expo'98 permite significativas poupanças de energia, como a rede de frio e calor para aquecimento e resfriamento dos edifícios, que substitui com vantagem da ordem de $30 \%$ os tradicionais aparelhos de ar-condicionado de janela que, na área da Expo, são proibidos. O objetivo é conseguir uma redução entre $50 \%$ a $60 \%$ do consumo face aos sistemas tradicionais.

Houve uma tomada de consciência dos promotores privados para a necessidade da adoção, desde a fase inicial dos seus projetos, de estratégias tecnológicas que evitassem o desperdício de energia. A idéia era racionalizar o consumo, tanto na concepção de edifícios como na exploração de um sistema centralizado de distribuição de frio e calor. Esse sistema, que utiliza gás natural como combustível, vai assegurar o fornecimento de água quente e fria para satisfazer as necessidades de climatização dos edifícios da zona de intervenção com uma enorme rentabilidade energética, se comparada aos sistemas clássicos normalmente utilizados para esse fim.

Centrando-se na idéia de equilíbrio entre a qualidade de vida e o meio ambiente, a Expo'98 proporcionou aos seus residentes um porto de recreio. Promovendo a ligação com o rio, foi construído um passeio ribeirinho totalmente arborizado que oferece uma ampla variedade de equipamentos de descanso e lazer. A urbanização da zona de intervenção da Expo'98 pretendeu valorizar a relação da cidade com o rio, recuperar o ambiente e a paisagem, assegurar a integração deste espaço na cidade, tendo por alicerce a concepção do espaço físico e dos edifícios para a realização da exposição mundial de 1998 e a criação de um espaço urbano singular e multifuncional. Serão 30.000 árvores, 110ha de áreas verdes, 80ha de parques urbanos e 12.000 habitações para 25.000 habitantes até o ano de 2009.

Segundo os promotores do evento, o recinto da Expo’98 não pretende isolar-se; ao contrário, quer devolver o rio à cidade. Tentou-se fazer a ligação entre a zona histórica da cidade e este espaço moderno com um traçado generoso de avenidas e com muito verde. Próximo ao parque urbano, com uma área superior a 80ha, a Vila Expo terá uma localização privilegiada com uma excelente vista panorâmica sobre esta zona verde. 
O desenho da área de intervenção leva em conta as características geográficas e, principalmente, climáticas da região, prevendo a necessidade de sombra e proteção contra os ventos. Diversas técnicas foram aplicadas no tratamento paisagístico usando água, vegetação e materiais simples como bambu para sombreamento nas áreas ocupadas (fig.3.12), amenizando o calor do verão para os visitantes.

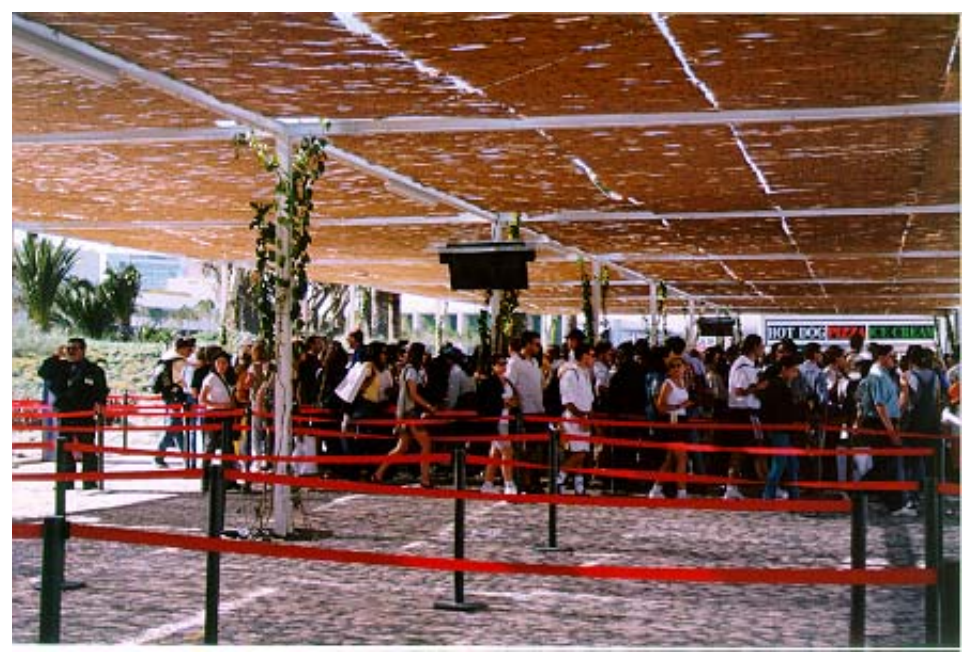

Figura 3.12 - Cobertura de bambu proporcionando sombreamento para os visitantes nas filas de espera dos pavilhões da Expo'98. (foto: D. Duarte)

A presença de água e áreas verdes é um dos elementos principais do recinto da Expo'98. Em toda a área surgem elementos associados à água, como pequenos tanques com plantas aquáticas, bicas, fontes, etc. São praças molhadas, que podem ser atravessadas pelo pedestre (fig.3.13), e zonas de descanso onde a água tem um tratamento de caráter lúdico, relaxante. Outra atração é a cascata (fig.3.14 e 3.15), um pórtico com $4 \mathrm{~m}$ de altura onde pequenos tubos projetam a água a $4 \mathrm{~m}$ de distância. Há também um enorme jardim com seis trechos de $25 \mathrm{~m}$ de largura cada (fig.3.16), com plantas que recriam o ambiente vegetal de diferentes lugares percorridos pelos portugueses, totalizando cerca de 400 espécies doadas pelos países que aderiram ao projeto. Essas áreas verdes são um verdadeiro pavilhão a céu aberto e celebram as trocas botânicas como parte da aventura dos descobrimentos.

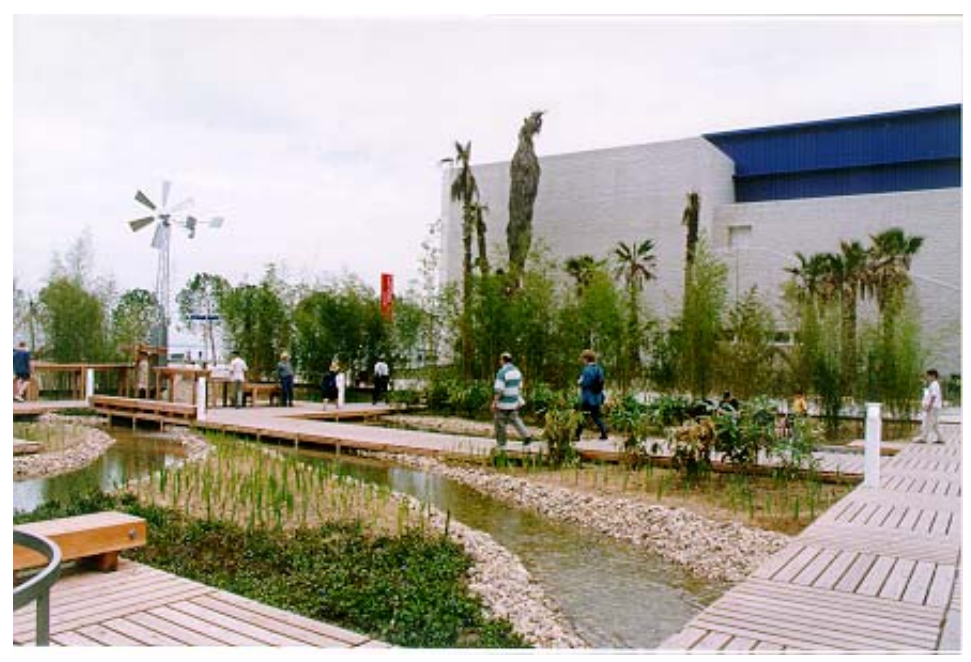

Figura 3.13 - O uso de espelhos d’água e vegetação nos jardins da Expo’98 criando praças molhadas para os pedestres. (foto: D. Duarte) 


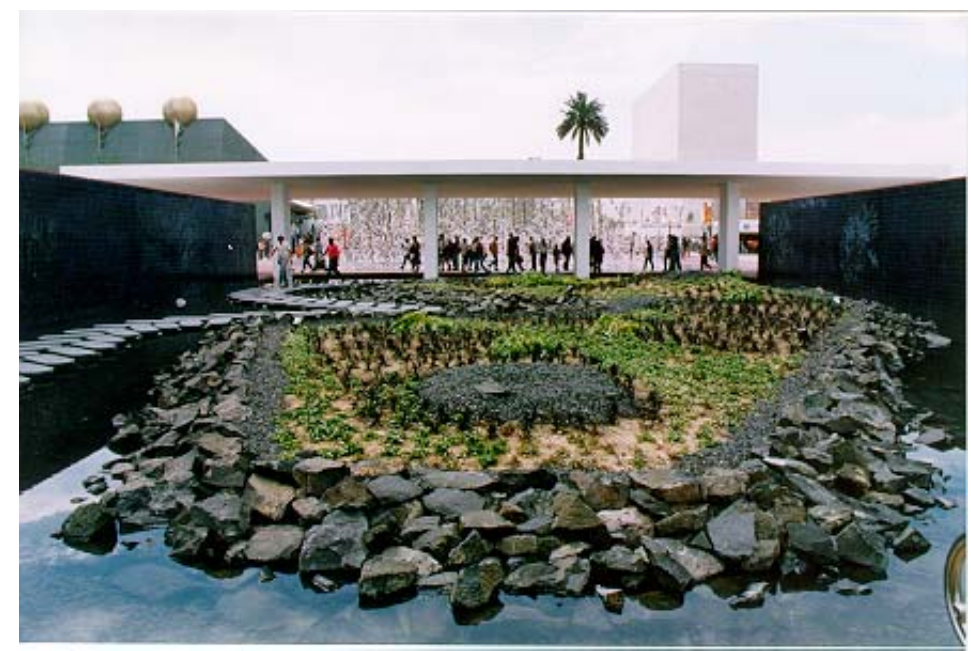

Figura 3.14 - Praça molhada com a cascata de 4m de altura ao fundo. (foto: D. Duarte)

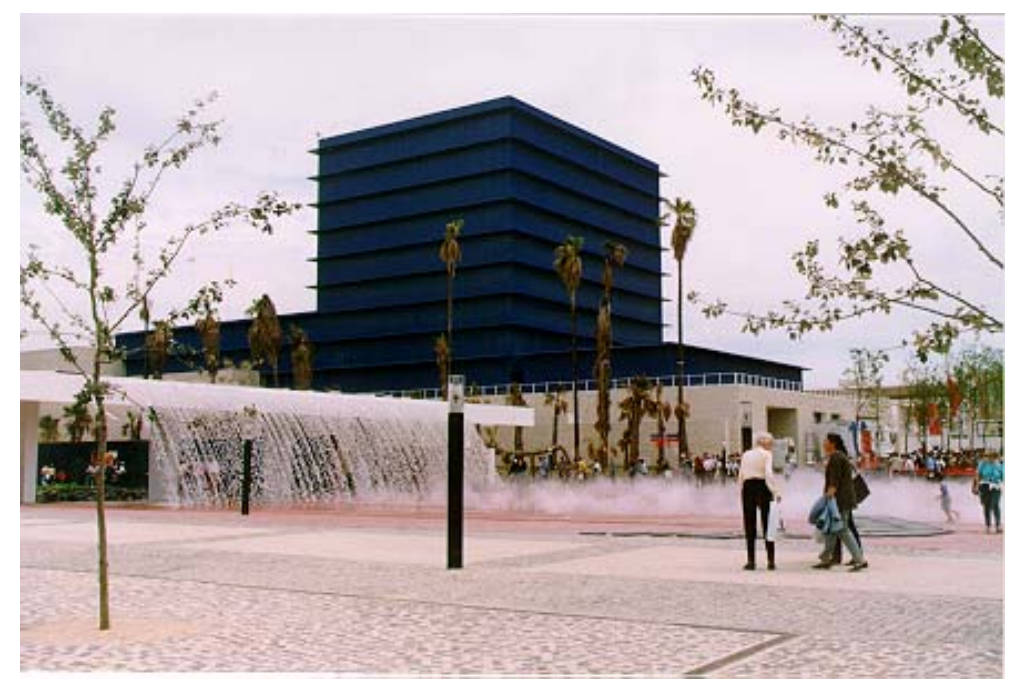

Figura 3.15 - A cascata e o sistema de aspersão de água a partir do piso, umidificando o ar. (foto: D. Duarte)

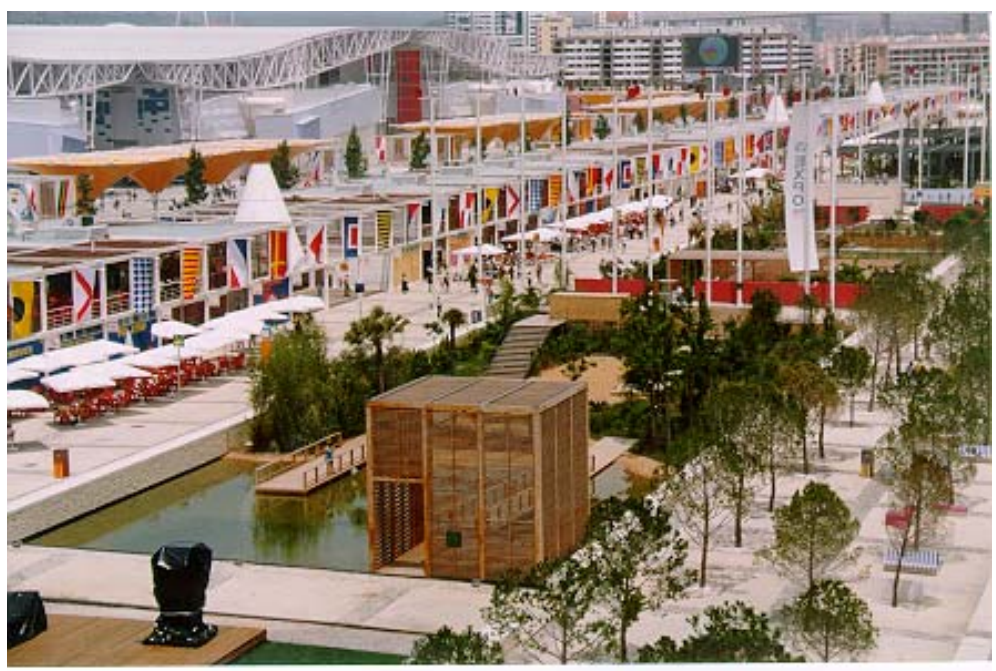

Figura 3.16 - Uso de vegetação e espelhos d’água em um dos seis trechos dos Jardins Garcia de Horta no recinto da Expo'98. (foto: D. Duarte) 
O uso de tecnologias passivas e de baixo consumo energético para o aproveitamento do vento, da energia solar e da temperatura da água para resfriamento dos edifícios garantiram, em média, uma redução de $50 \%$ no gasto de energia e 18 mil toneladas de $\mathrm{CO}_{2}$ a menos por ano, se comparados à construção tradicional portuguesa (GONÇALVES, 1998).

\subsection{Exemplos de adaptação ao clima nas capitais planejadas}

O projeto para Canberra é o primeiro dos três para as grandes capitais planejadas do século, porém, os princípios do urbanismo do século XX, tais como foram expressos em 1943, na Carta de Atenas (LE CORBUSIER, 1993), foram raramente evidenciados na escala de uma capital; as únicas exceções notáveis são as de Chandigarh, onde Le Corbusier, nomeado conselheiro do governo de Punjab para assuntos de arquitetura em 1950, trabalhou durante vários anos em colaboração com Pierre Jeannneret, Maxwell Fry e Jane Drew e, principalmente, Brasília, no centro de um distrito federal, a partir de 1956. Quando do tombamento de Brasília pela UNESCO - Organização das Nações Unidas para a Educação, a Ciência e a Cultura, um dos defensores disse que a questão era proteger uma obra singular, moderna, a única cidade construída neste século a partir do nada para ser a capital de um país, constituindo-se assim em magnífico exemplo histórico.

\subsubsection{Canberra}

Em 1911 o governo australiano, na época localizado em Melbourne, decidiu que Canberra seria o melhor lugar para a nova capital, a cerca de $300 \mathrm{Km}$ a sudeste de Sydney. Assim como Brasília, Canberra ${ }^{1}$ foi construída para ser a capital do país e sede do governo, constituindo um distrito federal.

Na Austrália mais de $70 \%$ do continente é árido; as chuvas são poucas e imprevisíveis em boa parte do país nas áreas ocupadas pelo deserto. Na porção sul os verões são quentes e o inverno ameno. Ao norte as variações climáticas diminuem e no litoral norte só há duas estações, a seca e a chuvosa. Em Canberra a precipitação mensal está entre 40 e $50 \mathrm{~mm}$ de chuva, com amplitude térmica por volta de $15^{\circ} \mathrm{C}$. Canberra é uma cidade rural, cercada de eucaliptos, e sua população é inferior a 500.000 habitantes.

Em 1912 o arquiteto paisagista americano Walter Burley Griffin venceu o concurso internacional para o projeto da cidade. Sua proposta era a de uma cidade-jardim com lagos, avenidas e desníveis partindo de um ponto central, a Parliament House. Canberra era uma fazenda de criação de ovelhas às margens do Rio Molonglo, que foi represado em 1963 para a construção de um lago artificial (fig.3.17). A água era um elemento essencial no projeto de Griffin para Canberra. O lago em si já é uma atração, cercado de jardins e ciclovias, onde os moradores costumam caminhar e fazer passeios em suas margens. Ele imaginou uma cidade ampla, moderna, sem construções altas e com o centro e os principais edifícios concentrados ao redor do lago.

A arborização teve espaço ao longo das avenidas e das áreas livres planejadas por Griffin. O reflorestamento das montanhas ao redor da cidade foi prioridade já em

\footnotetext{
${ }^{1}$ http://www.act.gov.au/CanberraStrategy/contents.htm
} 
1911, e o plantio em larga escala de árvores nativas e arbustos foi feito antes mesmo da construção da nova capital. Griffin usou os elementos da topografia local para estruturar a cidade e definir a área central. Também foram demarcados parques urbanos e um horto para produção de mudas. Mesmo após o crescimento da cidade, quando a mancha urbana se estendeu além dos limites do plano original de Griffin, Canberra manteve suas características originais. Os espaços abertos, a arborização de rua, a proteção dos cursos d'água, a conservação dos jardins individuais criaram um clima de amenidade. A zona urbana é vinculada ao National Capital Open Space System, que incorpora reservas ambientais, florestas e mananciais que foram demarcados para conservação. A visão de Griffin dos edifícios incorporados à paisagem foi de fundamental importância para se chegar à atmosfera única de Canberra. Para se manter essas características no futuro, o desafio é a manutenção desses espaços.

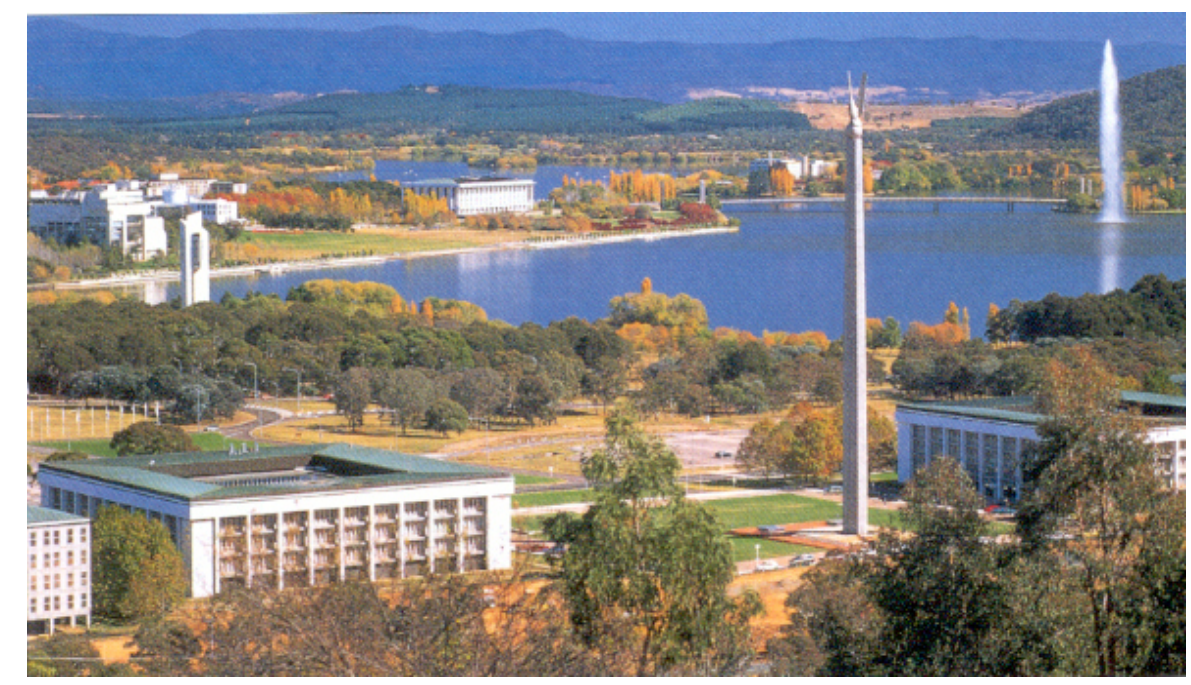

Figura 3.17 - O Lago Griffin e os jardins nas suas margens no ambiente árido de Canberra. (fonte: Austrália. Guia Visual, p.16)

\subsubsection{Chandigarh}

O segundo exemplo é o de Centre Ville de Chandigarh ${ }^{2}$, India, planejada em 1950, construída em 1968. No final dos anos 40, o arquiteto americano Albert Mayer foi escolhido pelo governo indiano para planejar Chandigarh; para a equipe foram também chamados outros especialistas como o climatologista Landsberg e Matthew Nowicki. O projeto original foi influenciado pelas idéias de Howard de contrabalançar as desvantagens da expansão das cidades industriais pela criação de cidades limitadas em tamanho e envoltas em cinturões verdes, com as vantagens do campo e da cidade. No plano de Mayer os elementos do sítio e os costumes da população local determinaram o caráter da cidade. Mayer acreditava que as ruas indianas eram apropriadas para um lugar com forte insolação e que mesmo os menores pátios internos promoviam frescor e dignidade às habitações. Seus desenhos indicavam ruas curvas, pátios e uma seqüência de espaços abertos e fechados, com

\footnotetext{
${ }^{2}$ http://chandigarh.nic.in.
} 
amplo uso de água e verde entremeando os edifícios. Em 1950 Nowicki faleceu em um acidente de avião, Mayer sentiu que não poderia continuar o projeto sozinho e se demitiu.

Para assumir o projeto foi chamado Le Corbusier, cujas idéias eram diferentes das de Mayer. Em quatro dias Corbusier e sua equipe redesenharam a cidade, conservando algumas das idéias originais. Enquanto Mayer preferia o padrão sinuoso para as ruas, ao invés de adotar a rigidez do padrão geométrico, Corbusier era contrário à solidificação do acidental. Para Corbusier a linha reta era a conexão lógica entre dois pontos.

De acordo com o Estatuto da Terra de Le Corbusier para Chandigarh, 'care of the body and spirit' é uma das quatro funções básicas da cidade. Cerca de 800 ha de áreas verdes foram distribuídos em aproximadamente $114 \mathrm{Km}$. Três áreas são diferenciadas pela arborização: as vias principais, os espaços no entorno dos principais edifícios, parques e áreas especiais. Corbusier classificou a arborização em função da espécie e da cor para identificação da hierarquização do sistema viário. Corbusier incorporou ao rígido traçado um sistema de parques integrados a cinturões verdes de um lado da cidade a outro, permitindo uma vista desobstruída das montanhas.

A arborização é parte integral do plano da cidade. Árvores foram plantadas ao longo das vias, nos parques, ao redor dos centros comerciais e em áreas residenciais para suavizar o clima rigoroso da região. Chandigarh fica entre 304 e 365m de altitude, com precipitação média de $1.114 \mathrm{~mm}$ anuais. No inverno, de novembro a janeiro, a temperatura varia de $4^{\circ} \mathrm{C}$ a $14^{\circ} \mathrm{C}$; no verão, de abril a julho, entre $37^{\circ} \mathrm{C}$ e $44^{\circ} \mathrm{C}$. Um parque linear de $8 \mathrm{Km}$, conhecido como Leisure Valley corta a cidade no sentido NE para SW. Caminhos para pedestres e ciclovias permitem às pessoas percorrer a cidade sob a sombra das árvores, e os setores desenhados por Corbusier são integrados por áreas verdes orientadas na direção das montanhas.

Em 1952 foi criado o um cinturão verde ao redor de Chandigarh para regulamentar qualquer assentamento a $16 \mathrm{Km}$ dos seus limites, proibindo a criação de qualquer outra vila ou cidade e a instalação de qualquer estabelecimento comercial ou industrial. A idéia era garantir que Chandigarh seria sempre circundada pelo campo. Le Corbusier acreditava que "The sun, space and verdure are the ancient influences, which have fashioned our body and spirit. Isolated from their natural environment, all organisms perish, some slowly, some quickly, and man is no exception to this general rule. Our towns have snatched men from essential conditions, starved them, embittered them, crushed them, and even sterilised them.... Unless the conditions of nature are re-established in man's life, he cannot be healthy in body and spirit..." $\mathrm{A}$ idéia de Le Corbusier das 24 Solar Hours foi ponto de partida para este projeto. Foi feito um estudo do movimento solar e foram explorados diversos tipos de proteção para sombreamento; Corbusier afirmava que "one can control the sun on the four cardinal points of an edifice and that one can play with it even in a torrid country and obtain lower temperatures."

\footnotetext{
${ }^{3}$ http://chandigarh.nic.in.
} 


\subsubsection{Brasília}

A idéia de fundar uma capital no centro do Brasil é antiga, tendo sido expressa em diversas ocasiões desde o fim do século XVII. Na visão de Dom Bosco ${ }^{4}$, em 1883, "Entre os paralelos 15 e 20, no lugar onde se formará um lago, nascerá uma grande civilização, e isso acontecerá na terceira geração. Aqui será a terra prometida.” Em 1922, quando da comemoração do Centenário da Independência, a escolha da região Centro-Oeste como local da futura capital foi simbolizada pela Pedra Fundamental, erguida perto de Planaltina, a alguns quilômetros a nordeste da atual Brasília. Uma nova Capital seria construída para o Brasil partindo do nada. Para a escolha do sítio da nova capital no planalto central foi elaborado o relatório Belcher que, segundo MONTEIRO (1990, p.137), é um documento que fornecia excelentes elementos geomorfológicos e biogeográficos, quais os quais ele chegou a trabalhar em sua temporada na Universidade de Brasília.

Assim como Chandigarh a população prevista para Brasília era de 500.000 habitantes; em ambos os projetos os arquitetos puderam desenvolver seu trabalho com total liberdade e os projetos são praticamente contemporâneos. Na concepção de Brasília Lúcio Costa conciliou sua formação acadêmica tradicional com os princípios da Carta de Atenas: a setorização, a separação da circulação de pedestres das vias de tráfego de veículos, a eliminação da rua tradicional como estruturadora do espaço urbano e o conceito da unidade de vizinhança (GOROVITZ, 1985). Em Brasília, na concepção original de Lúcio Costa ${ }^{5}$, a escala residencial com a proposta inovadora da superquadra, a serenidade urbana assegurada pelo gabarito uniforme de seis pavimentos, o chão livre e accessível a todos através do uso generalizado dos pilotis e o franco predomínio do verde trouxe consigo o embrião de uma nova maneira de viver, própria de Brasília e inteiramente diversa das demais cidades brasileiras.

As extensas áreas livres, a serem densamente arborizadas ou guardando a cobertura vegetal nativa, diretamente contíguas às áreas edificadas, marcam a presença da escala bucólica, que intervém no ritmo e na harmonia dos espaços urbanos e se faz sentir na passagem sem transição do ocupado para o não ocupado, delimitando a cidade por áreas livres arborizadas.

Toda a estrutura residencial do Plano Piloto é baseada nas superquadras, que têm cerca de 200 x 200 metros cada. Os blocos de apartamentos são dispostos de maneira diversa, mas obedecem a um padrão geral: máximo de três andares nas quadras 400, máximo de seis nas quadras 200, 100 e 300, com vegetação e iluminação natural abundantes. As superquadras são separadas por vias transversais onde funciona o comércio local destinado a servir aos moradores. Cada conjunto de oito superquadras constitui uma unidade de vizinhança, com espaços reservados para áreas de esporte, templos e postos policiais. As superquadras residenciais se integram à escala monumental não apenas pelo gabarito das edificações como pela definição geométrica do território de cada quadra através da arborização densa da faixa verde que a delimita e lhe confere o uso de pátio interno urbano. ${ }^{6}$

\footnotetext{
${ }^{4}$ www.guiabrasilia.com.br

${ }^{5}$ COE - Código de Obras e Edificações de Brasília, em www.guiabrasilia.com.br

${ }^{6}$ www.guiabrasilia.com.br
} 
No centro a densidade de ocupação é maior e os gabaritos mais altos, à exceção dos dois setores de diversões. O plano-piloto optou por concentrar a população próxima ao centro através da criação de áreas de vizinhança que só admitem habitação multifamiliar, mas não da forma tradicional. A proposta de Brasília mudou a imagem de morar em apartamento, e isto porque morar em apartamento na superquadra significa dispor de chão livre e de gramados contíguos à casa, numa escala em que um lote individual normal não tem possibilidade de oferecer. E prevaleceu a idéia de distribuir a ocupação residencial em áreas definidas para apartamentos (superquadras) e para casas isoladas, estas mais afastadas do centro.

Da proposta do plano-piloto resultou a incorporação à cidade do imenso céu do planalto, como parte integrante e onipresente da própria concepção urbana; segundo Lúcio Costa os vazios são por ele preenchidos; a cidade é deliberadamente aberta aos 360 graus do horizonte que a circunda. Na implantação de Brasília, assim como Canberra, foi criado um grande lago (fig.3.18 e 3.19). O Plano-piloto (fig.3.20) refuga a imagem tradicional no Brasil da barreira edificada ao longo da água; a orla do lago se pretendeu de livre acesso a todos, apenas privatizada no caso dos clubes.

De acordo com o COE - Código de Obras e Edificações de Brasília, complementar e preservar as características originais da cidade significa, dentre outras providências, manter os gabaritos vigentes nos dois eixos e em seu entorno direto, permanecendo não edificáveis as áreas livres contíguas, e baixas a densidades, com gabaritos igualmente baixos, nas áreas onde já está prevista a ocupação entre a cidade e a orla do lago.

Segundo o Código, Brasília deverá manter-se diferente de todas as demais cidades do país: não terá apartamentos de moradia em edifícios altos; o gabarito residencial não deverá ultrapassar os seis pavimentos iniciais, sempre soltos do chão. Este será o traço diferenciador: o gabarito alto no centro comercial, mas deliberadamente contido nas áreas residenciais, a fim de restabelecer, em ambiente moderno, escala humana mais próxima da nossa vida doméstica e familiar tradicional. Deve-se também garantir a estrutura das unidades de vizinhança do Eixo Rodoviário Residencial, mantendo a entrada única nas superquadras, a interrupção das vias que lhes dão acesso para evitar o tráfego de passagem, bem como ocupando devidamente as entrequadras não comerciais com instalações para esporte e recreio e demais equipamentos de interesse comunitário, sobretudo escolas públicas destinadas ao ensino médio. Deve-se proibir a vedação das áreas cobertas de acesso aos prédios (pilotis) e dos estacionamentos, sejam eles cobertos ou não.

De acordo com a classificação de Köppen, o clima do DF se enquadra entre os tipos tropical de savana e temperado chuvoso de inverno seco. Existem duas estações bem definidas: uma chuvosa e quente, que normalmente se prolonga de outubro a abril, e outra fria e seca, em geral de maio a setembro. A temperatura média é de $20,5^{\circ} \mathrm{C}$; a máxima absoluta é de $35^{\circ} \mathrm{C}$ e a mínima absoluta é de $2^{\circ} \mathrm{C}$. A umidade relativa do ar é baixa, variando entre $25 \%$ no inverno e $68 \%$ no verão. O mês mais seco do ano é setembro, com precipitação pluviométrica média de $75 \mathrm{~mm}$, e o mais chuvoso é dezembro, com precipitação de $875 \mathrm{~mm}$. A precipitação pluviométrica anual é de $1.925 \mathrm{~mm}$. 


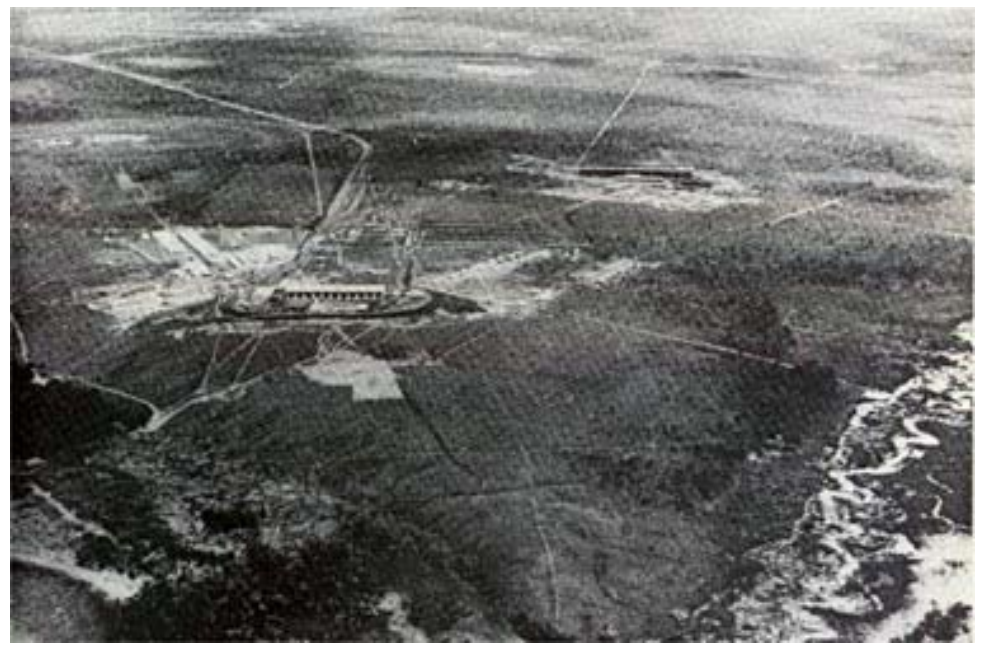

Figura 3.18 - Palácio da Alvorada e Vale do Paranoá (futuro lago), em 1958. (fonte: Guia de Brasília)

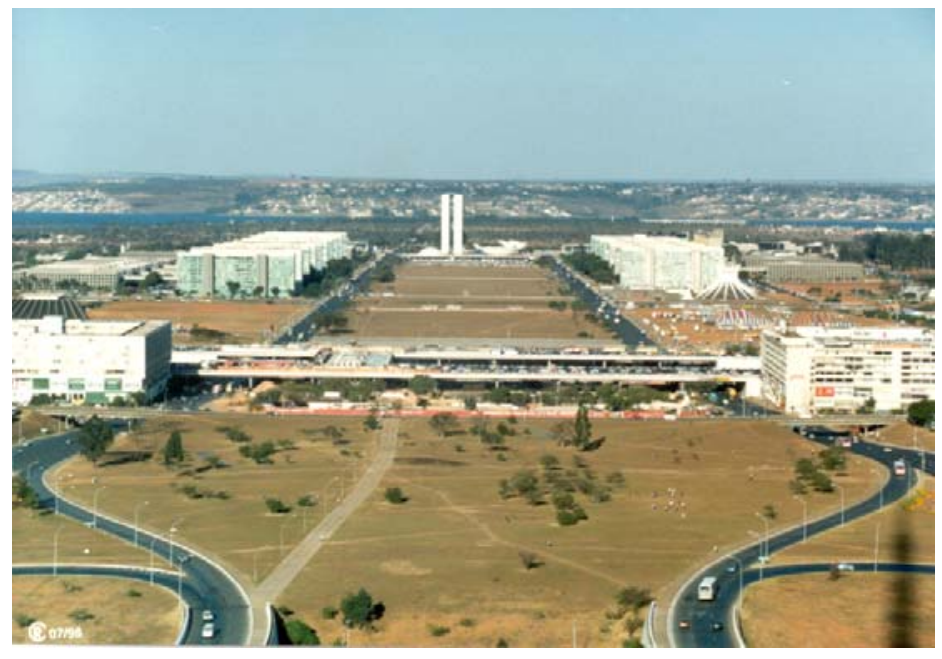

Figura 3.19 - O solo árido de Brasília, com o Lago Paranoá ao fundo. (foto: J. Calsinski)
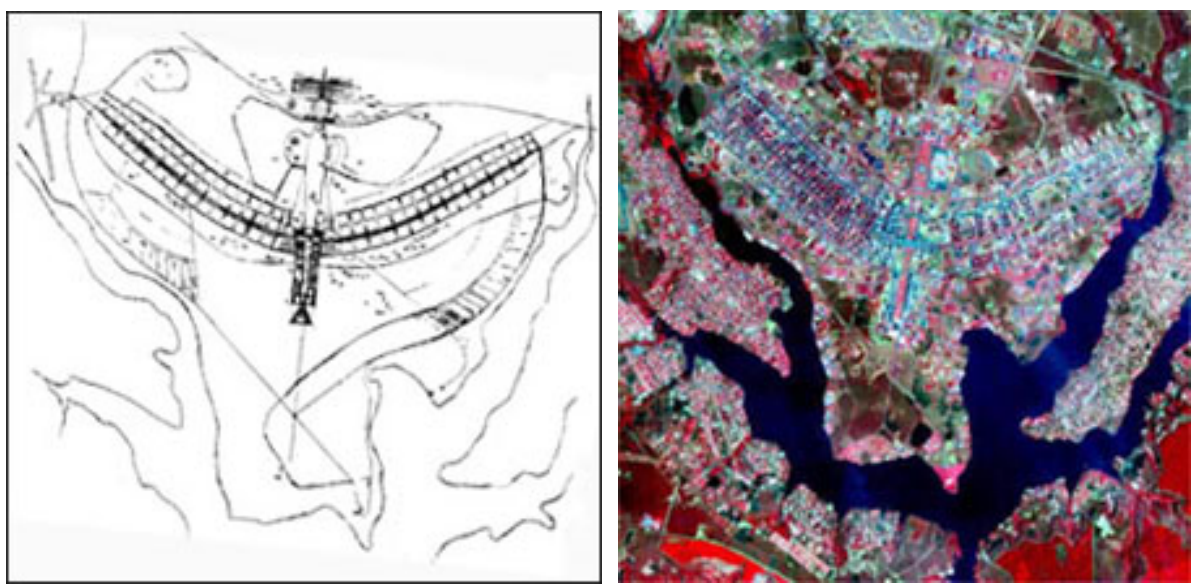

Figura 3.20 - Esboço original do projeto do Plano Piloto de Brasília: Lúcio Costa, 1957, e imagem de satélite da cidade de Brasília. INPE: Landsat ,1985. (fonte: GDF/SETUR/SEBRAE - CODEPLAN no www.guiabrasilia.com.br) 
No depoimento de Günter Weimer sobre a época da construção de Brasília (TOLEDO, 1999) ele diz que o local era um imenso canteiro de obras, sem um mínimo de áreas verdes. O pouco de cerrado que não havia sido removido pela terraplanagem estava queimado por longa estiagem. Qualquer lufada de vento levantava imensas nuvens de pó. Weimer fala sobre sua convivência com o Eng. Eustáquio Toledo Filho, politécnico, que foi professor da Universidade de Brasília. Segundo Weimer, Eustáquio afirmava que Brasília estava sendo construída sobre premissas equivocadas, com altos investimentos em grandes centrais de ar condicionado, quando o clima local permitia quase sempre estar na zona de conforto, excetuando-se a baixa umidade, que poderia ser equacionada.

ROMERO (1999) faz um diagnóstico das alterações climáticas em Brasília, na periferia do plano-piloto. De acordo com a autora, a degradação do meio ambiente da periferia, em consequência da ausência de planejamento urbano adequado e sustentável, pode ser caracterizado através de cinco grandes categorias: desestruturação da paisagem, inadequação da infra-estrutura, carência de vegetação, excesso de radiação e reflexão. Romero critica o superdimensionamento do sistema viário que privilegia carros em prejuízo dos pedestres, a relação entre largura e altura dos canyons urbanos e a falta de vegetação não permitida pelas estreitas calçadas. A resolução destas questões, que evitaria a excessiva exposição à radiação solar e propiciaria sombra, dificilmente é encontrada na periferia do plano-piloto. Sombra e vegetação não são pensadas como elemento de composição, e ficam como elementos residuais sem desempenhar nenhum papel na ambientação dos espaços. Segundo a autora, nas cidades da periferia do plano-piloto a concepção espacial se parece com um grande espaço aberto contínuo onde se instalam edifícios como sólidos independentes. Trata-se de uma estrutura de sólidos que reduz a rua a um papel secundário, de fundo, sem características de volume aparente. As funções de circular, de viver, de se reunir, desaparecem: a rua passa a ser somente via, delimitada sobre o terreno. A análise de Romero é feita em 4 escalas: na grande dimensão das estruturas urbanas, na escala do sítio, na dimensão pontual do lugar e na escala dos edifícios. Romero conclui que mesmo numa cidade planejada como Brasília, os espaços urbanos que a compõem apresentam dentro de um mesmo setor os mais variados aspectos que precisam de uma abordagem diferenciada. De acordo com BRUAND (1991) Lúcio Costa não tinha planos para as cidades satélites; eles foram elaborados posteriormente como meros paliativos.

\section{Referências Bibliográficas}

1. ALBERTI, Leon Battista. De Re Aedificatoria. Madri: Akal, 1991.

2. ALVAREZ DOMINGUEZ, Servando et al. Control Climático em Espacios Abiertos. El Proyecto EXPO'92. Sevilha: CIEMAT, 1992.

3. BRUAND, Yves. Arquitetura Contemporânea no Brasil. 2.ed. São Paulo: Perspectiva, 1991.

4. COOK, Jeffrey. Searching for the Bioclimatic City. In: Architecture and Urban Space. Proceedings of the Ninth International PLEA Conference, Seville: Kluwer, September 1991, p.7-16. 
5. Energy and environment in cities. A global strategy for EXPO'98 Lisbon. Principles and tools. [Lisboa]: [1998].

6. EXPO’98 Lisboa. Guia Oficial. [Lisboa]: [1998].

7. FREYRE, Gilberto. Sobrados e Mucambos. 8ed. Rio de Janeiro: Record, 1990.

8. GONÇALVES, Joana C. S. Expo’98. Rotas para o próximo milênio. AU, São Paulo, n.79, p.32-41, ago/set. 1998.

9. GOROVITZ, Matheus. Brasília, uma questão de escala. São Paulo: Projeto, 1985.

10. GUERRA MACHO, José J. et al. Control Climático em Espacios Abiertos. Evaluación del Proyecto EXPO’92. Sevilha: CIEMAT, 1994.

11. HOLANDA, Ségio Buarque de. Raízes do Brasil. 26.ed. São Paulo: Companhia das Letras, 1995.

12. LE CORBUSIER. A Carta de Atenas. São Paulo: Hucitec/EDUSP, 1993. (Estudos Urbanos. Série Arte e Vida Urbana)

13. MONTEIRO, Carlos A. F. Entrevista com o Prof. Carlos Augusto de Figueiredo Monteiro. Geosul, Florianópolis, n.9, p.124-139, 1990.

14. Ordenanzas de descubrimiento, nueva población y pacificación de las Indias, dadas por Felipe II en 1573. Madrid: Instituto de Cultura Hispánica, 1973.

15. ROMERO, Marta Adriana Bustos. Viabilidade Ambiental de Urbanização do Distrito Federal. Analise das constantes morfológicas. Brasília: UNB/FAU, Relatório Final de Projeto de Pesquisa CNPq, 1999.

16. TOLEDO, Eustáquio. Ventilação Natural das Habitações. Maceió: EDUFAL, 1999.

17. VITRUVIO, Marco Lucio. Los Diez Libros de Arquitectura. Barcelona: Iberia, 1997. 


\section{O PAPEL DA ARBORIZAÇÃO E DOS CORPOS D’ÁGUA EM ÁREAS URBANAS}

Muitas são as funções da vegetação em espaços urbanos; nas cidades de clima rigoroso, com altas temperaturas ao longo de todo o ano, a busca da amenidade climática talvez seja a maior delas. A vegetação torna-se fundamental para o bemestar dos pedestres, proporcionando-lhes o sombreamento necessário nos espaços públicos. Além disso, a vegetação deve ser encarada como uma ferramenta para o planejamento ambiental também do ponto de vista visual, de controle de ruído, de contenção de encostas, de melhoria da qualidade do ar, etc.

Na Suécia, pesquisas da Göteborg University em clima urbano têm enfatizado os efeitos climáticos dos parques urbanos, mostrando que eles criam um microclima próprio e que influenciam o seu entorno de diversas maneiras. Segundo UPMANIS (2000), grandes parques podem ser até $5,9^{\circ} \mathrm{C}$ mais frios do que o seu entorno, especialmente durante a noite, e que pequenos parques podem ser até $2^{\circ} \mathrm{C}$ mais frescos que o entorno construído. Além disso, durante a noite, a diferença de temperatura entre parque e espaço construído dá origem a pequenos fluxos de vento localizados, que tornam-se importantes para o fornecimento de ar fresco do parque em direção à cidade.

Para SPIRN (1995) o efeito climático de um parque sombreado estende-se às ruas adjacentes. Uma rua arborizada vizinha ao parque parece mais fria no verão do que uma rua sem arborização duas quadras adiante. Um parque ajardinado também tem ar mais puro do que a cidade em volta, em parte porque o parque não é uma fonte emissora de poluentes, mas também porque as folhas filtram a poeira do ar. Hoje são mais comuns os parques pavimentados, com pouca ou nenhuma vegetação; a diferença entre esses parques e a cidade à sua volta é muito pequena, tanto nos aspectos climáticos como estéticos. A conquista da melhor qualidade do ar não pode depender apenas do controle das emissões, mas deve ser coordenada com um projeto urbanístico que viabilize a dispersão e a filtragem dos poluentes e melhore o clima geral.

Para GIVONI (1991, p.294) a influência de parques urbanos e espaços abertos no clima urbano se estende somente a uma curta distância nos arredores densamente construídos. Por essa razão, a contribuição dos parques é principalmente proporcionar áreas ao ar livre para descanso e lazer, com clima agradável para os visitantes ou para os que moram ou trabalham nos seus arredores. "It seems that the size of a park, beyond a given limit, makes little difference in the climatic conditions in it and in the range of its effects. Thus, the division of the entire space allocated for parks into a large number of small parks, spread over the whole urban area, will have a greater effect on the overall urban climate, than would the creation of a small number of large parks. (...) As the effect of public green areas on the climatic conditions around buildings in the built-up sections of a city, away from the green areas, is rather limited, their effect on ambient conditions around buildings and the energy demand for heating and air-conditioning, is also limited. In this respect, the effect of vegetation in private lots around buildings can be more significant." Do ponto de vista da poluição do ar Givoni também afirma que é preferível espaçar as árvores e os parques urbanos por toda a cidade do que concentrá-los em alguns 
pontos. Estudos de HONJO e TAKAKURA (1990/91), da Universidade de Tóquio, usando modelos numéricos para estimar os efeitos de resfriamento das áreas verdes nos arredores também concluíram que pequenas áreas verdes inseridas no ambiente urbano são mais eficientes.

Outro ponto a ser abordado é a função social dos parques urbanos, especialmente em áreas habitacionais de baixa renda. "While the living conditions in low-income areas are much inferior to those of the high-income areas, the public parks can provide to the low-income residents opportunities for recreation and entertainment within an area with environmental quality equal to those of other urban residents. (...) under favourable circumstances and appropriate physical design details, the parks may help in creating a feeling of a 'community' in the neighbourhood. " (GIVONI, 1991, p.295-296)

Espaços sombreados e com maior umidade nos parques, ao longo das ruas e caminhos para pedestres minimizam o stress térmico e o desconforto. Mesmo na estação seca, desde que as áreas verdes recebam manutenção adequada, funcionam como oásis, proporcionando sombra e frescor em contraste com o exterior tórrido. $\mathrm{Na}$ estação chuvosa, além do sombreamento, é importante não bloquear os ventos dominantes; isso pode ser alcançado escolhendo-se adequadamente as espécies a serem plantadas, optando-se por árvores de copas altas e largas, de troncos desnudos, que não impedem a ventilação no nível do corpo dos usuários, conciliando assim o mesmo espaço para uso em duas estações diferentes, com exigências diferentes. Para GIVONI (1991, p.298), “a combination of grasses, low flower beds and shade trees with high trunks is thus the most appropriate plants combination in parks in this climate." Nesse período a manutenção é um pouco mais fácil e menos dispendiosa do que na seca, já que não é necessária a irrigação.

Givoni enfatiza as inúmeras vantagens no uso de vegetação nas regiões ou estações secas: "In the open areas between buildings, on public as well as on private land, planting trees should be encouraged as much as water availability and financial resources enable. Solar radiation absorbed in leaves of vegetation increases the evaporation rate instead of raising the temperature. The resulting elevated humidity, in an arid region, can be welcomed from the comfort view point. Thus, large coverage of the land surface by a combination of white roof and trees can result in significant lowering of the urban temperatures in hot-dry regions. (...) instead of raising the temperature of the leaves the energy is mostly 'spent' in the process of evapotranspiration of water from the leaves. Thus an increase in the humidity takes place instead of an elevation of temperature. (...)In the open country a significant part of the absorbed solar radiation is transformed into latent heat in the process of evapotranspiration from the leaves of trees, shrubs, grass, etc. Only the remaining part is converted into sensible heat and results in temperature elevation. In an urban area, on the other hand, most of the absorbed solar radiation is converted ultimately into sensible heat, which raises the air temperature and contributes to the heat island effect." (GIVONI, 1989, p.2-3, 2-6, 6-9)

São muitos os estudos para se avaliar o impacto da vegetação no ambiente térmico urbano. Para AVISSAR (1996, p.447) "Since vegetation can substantially affect the wind, temperature, moisture and precipitation regime of urban areas, it has very important practical consequences, e.g. heating and cooling requirements of 
buildings, dispersion and concentration of pollutants, and urban weather. Thus, if planned carefully, it seems that vegetation could be used to mitigate some of the anthropogenic effects generated by the development of urban areas." Para EVANS e SCHILLER (1996, p.451-452) "Vegetation is considered as a design variable which acts as an indirect modifier of indoor conditions as well as an environmental moderator of urban spaces at different scales. The conventional approach to landscape design emphasizes the formal and visual aspects of outdoor space, at the expense of environmental and microclimatic values."

Para SAILOR (1998, p.43) aumentar o albedo ou a vegetação urbana pode significar um impacto no clima regional, causando um efeito indireto para o resfriamento de toda a cidade. Os resultados indicam um potencial para reduzir as temperaturas de pico no verão em Los Angeles em mais de $1,3^{\circ} \mathrm{C}$ através da implementação de $14 \%$ na cobertura vegetal. Estudos através de simulações para cidades hipotéticas em diversas latitudes e sujeitas a diferentes tipos de clima mostraram que pode se esperar uma economia de 5\% na energia usada para resfriamento com um aumento de 6,5\% da cobertura vegetal. Sailor afirma que um programa de plantio mais agressivo poderia dobrar essa economia. Para a EREN ${ }^{1}$ - Energy Efficiency and Renewable Energy Network do U.S. Department of Energy - DOE, "The energy savings can be significant. In the United States, the annual effect of properly positioned trees is a savings averaging about $20 \%$ to $25 \%$ of residential energy costs, compared with the costs for the same house in an unsheltered area."

A maior contribuição da vegetação é a sombra para os pedestres, mas outras vantagens em áreas urbanas também são significativas. GIVONI (1991) cita diversos estudos experimentais nos quais é demonstrado que em um dia quente de verão, a temperatura médias das paredes sombreadas por uma combinação de árvores e arbustos é reduzida de $13,5^{\circ} \mathrm{C}$ a $15,5^{\circ} \mathrm{C}$, e que trepadeiras reduzem a temperatura superficial dos fechamentos em $10^{\circ} \mathrm{C}$ a $12^{\circ} \mathrm{C}$.

Em muitas cidades brasileiras, o traçado urbano prioriza a edificação, e as áreas verdes ficam restritas a locais de dimensões reduzidas e formas irregulares, justamente as sobras dos espaços construídos, o que faz com que a distribuição das áreas verdes nem sempre esteja de acordo com as necessidades da população. Considera-se área verde qualquer área, urbana ou rural, de propriedade pública ou privada, que apresente algum tipo de vegetação com dimensões vertical e horizontal significativas e que seja utilizada com objetivos sociais, científicos ou culturais. As dimensões variam; o que caracteriza o espaço é o contraste com o entorno edificado. Tão importantes quanto a disponibilidade das áreas verdes são a sua distribuição e a qualidade dos espaços produzidos, em função das vantagens sociais que a população usufrui. De acordo com GONÇALVES (1994) se por um lado o loteador tem algum interesse no melhor aproveitamento do solo em termos de área construída, a administração pública corrobora esse interesse, à medida que quanto maior a área construída, maior a arrecadação de impostos e menores os custos de manutenção pela redução no número de áreas verdes. Além disso, os bicos de quadra destinados às áreas verdes atendem, na melhor das hipóteses, a uma porcentagem de área verde por habitante, mas não às funções a que se destinam esses equipamentos.

\footnotetext{
${ }^{1}$ http://www.eren.doe.gov
} 
A arborização urbana é frequentemente comprometida por pragas, eliminada para novas obras e, por inadequação das espécies plantadas, entra em conflito com os equipamentos urbanos como calçadas, rede aérea de fios e cabos, dutos e galerias subterrâneas, aumentando os custos de manutenção e reparos nesses equipamentos; de acordo com a Secretaria Municipal do Verde e do Meio Ambiente da Prefeitura Municipal de São Paulo (SÃO PAULO, 1993) os problemas decorrentes da interferência das árvores na rede elétrica são um dos principais entraves à arborização de vias públicas; espécies com caule e ramos quebradiços são muito vulneráveis a chuvas e ventos fortes, colocando em risco a segurança de pedestres, veículos e construções; a própria largura das calçadas, quando estreitas, são um empecilho à convivência entre as árvores de rua e a circulação de pedestres; nas calçadas também são comuns os problemas com espécies que apresentam raízes superficiais, que danificam o pavimento. Outro ponto crítico nos programas de arborização pública é a própria sobrevivência das mudas plantadas, que varia de $20 \%$ a 30\%, comprometendo os objetivos de qualquer programa.

Do ponto de vista da manutenção, é mais fácil manter grandes árvores em menor número do que vice-versa. Do ponto de vista do conforto também, pois o sombreamento é muito mais eficiente. Por estranho que pareça o efeito das árvores é mais sentido na sua ausência; se há árvores as pessoas não se dão conta, mas se faltam árvores, sim.

De acordo com SPIRN (1995) a vida média de uma árvore plantada junto às ruas é de aproximadamente dez anos. A popularidade da árvore de rua aumentou com o rápido crescimento urbano; à medida que as cidades se tornaram mais densas e foram separadas de sua área rural as árvores de rua tornaram-se cada vez mais comuns. $\mathrm{Na}$ maioria das vezes a vegetação urbana é exposta a condições desfavoráveis: muita ou pouca água, temperaturas muito elevadas ou muito baixas, atmosfera, água e solo contaminados, pragas e doenças. Uma calçada não oferece o espaço, os nutrientes ou a água de que uma árvore necessita para crescer; um canteiro elevado, suficiente apenas para uma árvore, é um dos piores ambientes urbanos, fato que é atestado pela grande quantidade de canteiros de concreto vazios, cheios de lixo, espalhados pelas praças. Os canteiros maiores, para acomodar várias árvores apresentam menos problemas de variação de temperatura e de ressecamento que afetam os pequenos canteiros individuais. Na escolha das espécies uma boa medida é selecionar árvores cujo ambiente nativo seja rigoroso, similar ao de uma rua na cidade, que hoje é um dos ambientes urbanos menos saudáveis.

De um modo geral, quanto mais hostil é um ambiente, maior é o custo de manutenção das plantas, mas as flores, os arbustos e as árvores que crescem como mato em terrenos baldios desafiam esta norma, e pequenas florestas urbanas sobrevivem, muitas vezes com uma aparência exuberante. Até o momento o jardim urbano selvagem não teve muita aceitação junto à população; para muitos, é um sinal de terra abandonada. Num parque ou junto a um curso d'água na periferia da cidade, um campo de flores silvestres parece natural; transportado para o centro e circundado por ruas e edifícios, a mesma área parece abandonada (SPIRN, 1995). Porém, essas comunidades de plantas nativas requerem uma manutenção mínima, colocam as cidades no seu contexto regional e as diferenciam de outras cidades, em vez de separá-las da paisagem circundante. 


\subsection{Exemplos nas cidades americanas}

O Central Park ${ }^{2}$ (fig.4.1) foi o primeiro parque público nos Estados Unidos; os defensores da idéia admiravam os espaços públicos de Londres e Paris e achavam que Nova Iorque precisava de um local assim. Em Londres o Hyde Park, antigo campo de caça real, foi aberto ao público já em 1637. Após três anos de debates sobre a localização do Central Park e os custos envolvidos, em 1853 a cidade de Nova Iorque adquiriu mais de 700 acres de terra no centro de Manhattan. Em 1863 a área foi expandida para 843 acres (mais de 340ha).

A construção do Central Park foi o maior projeto público de Nova Iorque no século XIX. Mais de 270.000 árvores e arbustos foram plantados. O parque foi aberto ao público no inverno de 1859. Por volta de 1865 o parque já recebia mais de 7 milhões de visitantes por ano. As regras de uso eram muito restritas no começo; só mais tarde o espaço foi liberado para um uso mais democrático pela classe trabalhadora. Debates acerca das modificações no plano original e usos continuam até hoje. Nos anos 60 eventos como concertos de rock já eram bem-vindos. Entretanto, nos ano 70, cortes severos nas verbas públicas comprometeram a manutenção do parque. Nos anos 80 a Central Park Conservancy, uma organização privada, encarregou-se da restauração do plano original. Por volta de 1990 a organização contribuiu com mais da metade do orçamento para a manutenção do parque e teve papel importante nas decisões sobre o seu futuro.

O Paley Park (fig.4.2), de 1967, também em Nova Iorque, é um refúgio nas ruas movimentadas e barulhentas. Num dia abafado, quente e úmido de verão este pequeno parque $(12,80 \times 30,48 \mathrm{~m})$ é surpreendentemente fresco. Uma cascata forma a parede de fundo. O som calmante e torrencial mascara o ruído da rua. A água espirra no calçamento e resfria o ar quando se evapora. O Paley Park é bastante copiado. É um excelente exemplo de como uma drástica mudança no microclima urbano pode ser conseguida num espaço bem pequeno. Abrigos como esses podem ser colocados em toda a cidade, integrados em praças e parques (SPIRN, 1995, p.90-91).

Estudos de QUATTROCHI e RIDD (1988, p.32) utilizando técnicas de sensoriamento remoto demonstraram que "urban vegetation has a considerable range of long wave thermal energy responses, and illustrates the benefits of maintaining and enhancing the urban forest in reducing heat into the urban atmosphere." Quattrochi é um geólogo da NASA's Global Hydrology and Climate Center, em Huntsville, Alabama, e trabalha usando a tecnologia chamada Airborne Thermal and Land Application Sensor (ATLAS), que usa uma câmera instalada em um avião Lear 23 jet que capta imagens infravermelhas de alta resolução da energia emitida pela superfície (fig.4.3). ATLAS registra seis canais visíveis, sendo dois em infravermelho próximo (logo além de 700nm onde a visão humana termina) e seis na banda termal infravermelha $(8.000$ a $14.000 \mathrm{~nm})$ que mostram a energia radiante. Além do ATLAS são utilizados outros instrumentos como sensores instalados em satélites meteorológicos e medidas de campo. O ATLAS tem uma resolução de $10 \mathrm{~m}$, o que significa que um pequeno edifício será representado por um ou dois pixels na imagem. Para melhor compreensão, os dados coletados estão sendo superpostos em mapas topográficos para gerar imagens em 3D.

\footnotetext{
${ }^{2}$ http://www.centralpark.org
} 


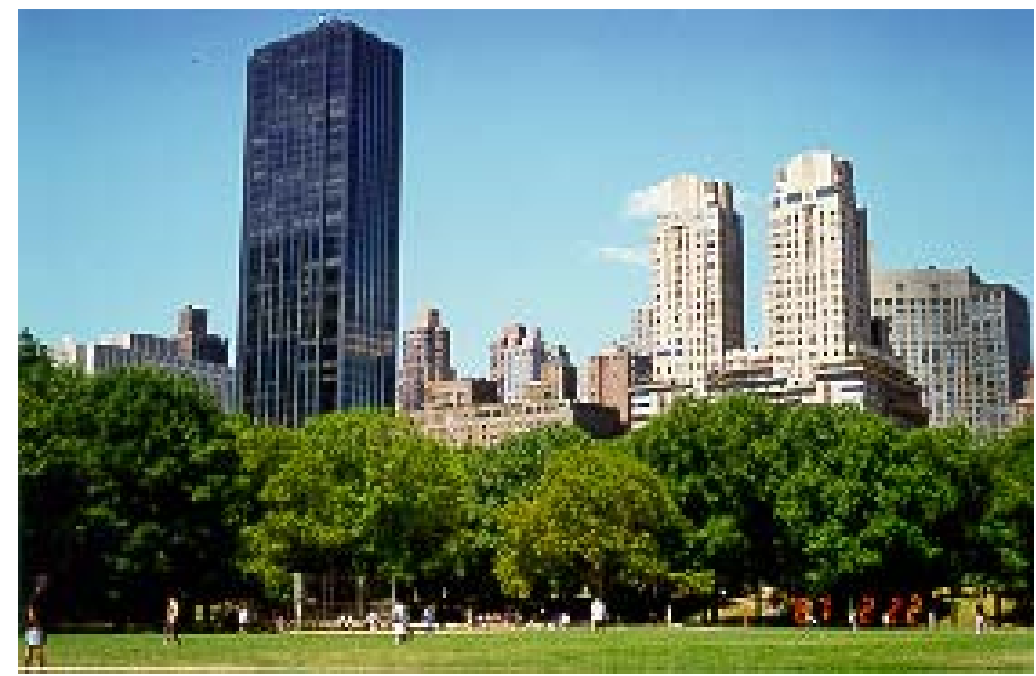

Figura 4.1- Vista do Central Park. (foto: J.Gonçalves)

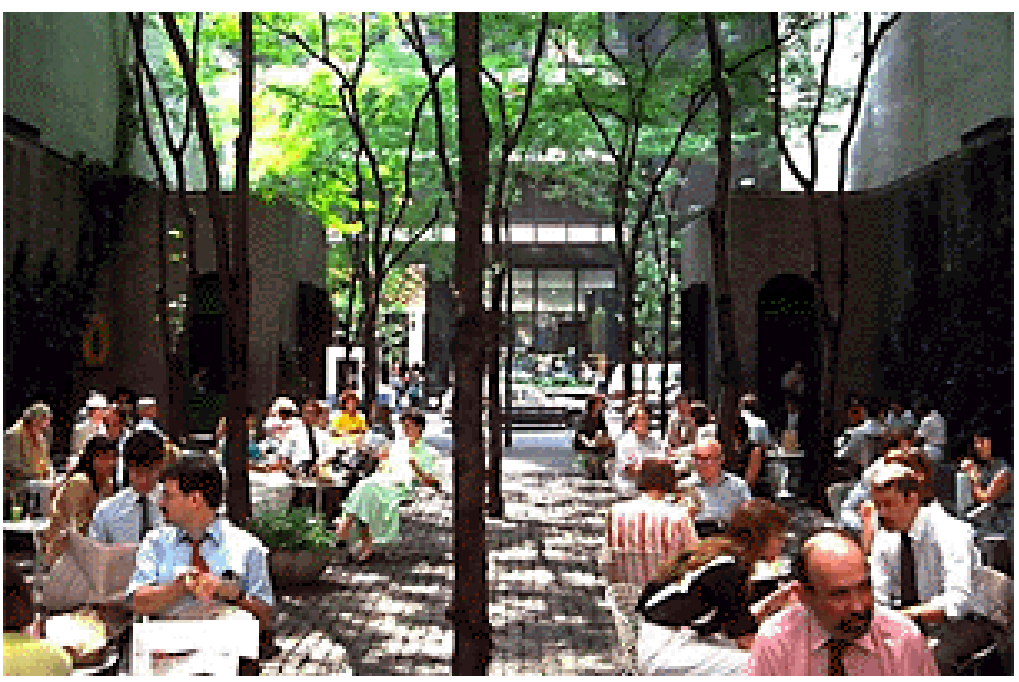

Figura 4.2 - - Vista do Paley Park na direção da Rua 53. (fonte: University of Virginia web page)

Essa tecnologia é a mesma utilizada para estudar as superfícies de Marte e Júpiter. As imagens mostram qual a quantidade de radiação é liberada ou refletida por qualquer edifício ou superfície com mais de $10 \mathrm{~m}^{2}$. Os dados são analisados por Haider Taha, um climatologista do LBL - Lawrence Berkeley Laboratory, que com essas informações pode simular a substituição de cores nas superfícies, o aumento ou a diminuição da massa vegetal, etc. Quattrochi, Taha e mais seis cientistas da NASA, do LBL e de outras universidades americanas fazem parte do Urban Heat Island Pilot Project ${ }^{3}$ (UHIPP), patrocinado pela Environmental Protection Agency. Esses vôos já foram realizados em Atlanta (Geórgia), Baton Rouge (Louisiana), Salt Lake City (Utah) e Sacramento (Califórnia). Os cientistas da NASA trabalham com um planejador urbano, Maury Estes, para se certificar de que os dados coletados pelo programa sejam traduzidos em ferramentas úteis para planejadores, arquitetos, legisladores e cidadãos comuns.

\footnotetext{
${ }^{3}$ http://eetd.lbl.gov/heatisland/
} 


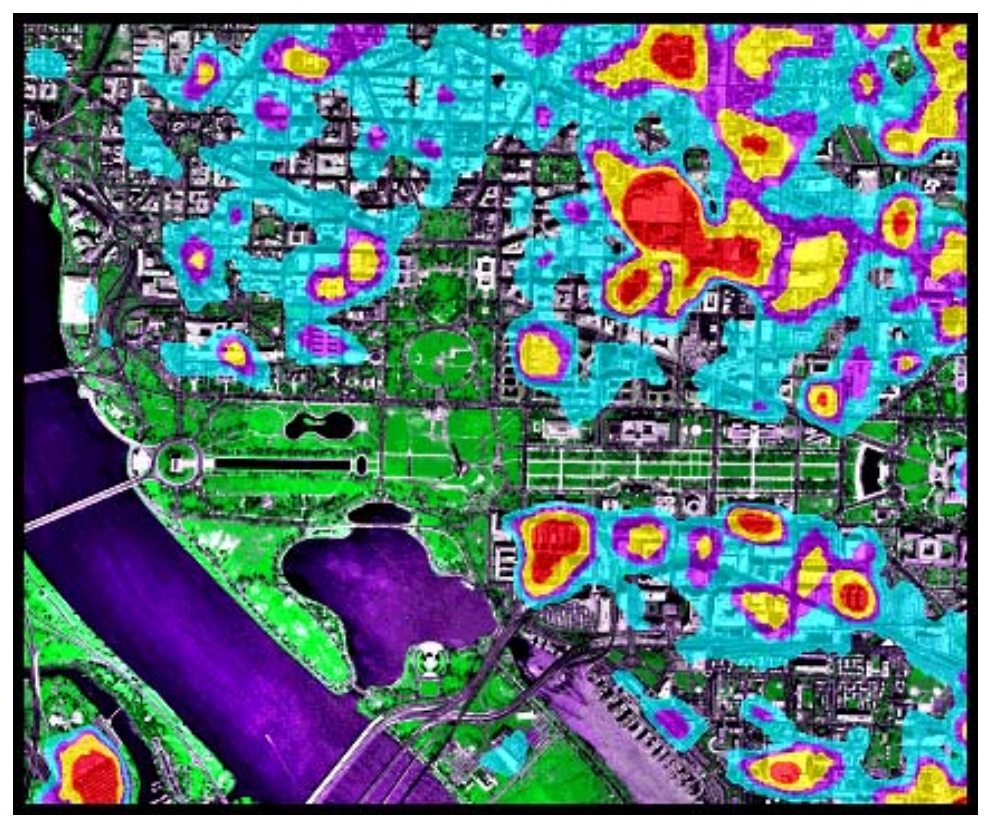

Figura 4.3 - Imagem termal de Washington mostrando os pontos mais aquecidos em vermelho e os menos aquecidos em verde (fonte: Rosenfeld et al. Painting the town white - and green)

Jeff Luvall, pesquisador no Marshall Space Flight Center da NASA ${ }^{4}$, explica o fenômeno de forma bastante simples: "While UHIPP is quite complex, at its core is the fact that the evaporation of water absorbs a lot a heat. Plants, and trees in particular, evaporate large amounts of water from their leaves. The energy required to evaporate water is taken from the air and from the sunlight intercepted by the leaves, thus cooling the air. Trees are also very effective in shading the ground, thus preventing the heating of the surface by sunlight. On the other hand, asphalt, concrete, and other manmade materials are very effective at absorbing light and reradiating it as infrared radiation that raises the temperature of the air. In turn, that makes air conditioning systems work harder, even after sunset. As a result, utility bills go up and heat stress as a result of increased heat over the city can affect human health. Atop all that, depending on meteorological conditions, the hot air will form a dome or bubble over the city which is several degrees warmer that the surrounding countryside."

Para a Environmental Protection Agency - EPA ${ }^{5}$, principal financiadora do projeto, o UHIPP "is finding ways to cool the city and thereby reduce ozone pollution problems. (...) NASA and EPA are working with the Pilot Cities to develop 'Actions Plans' that will: 1) categorize land use across the city; 2) estimate the areas of maximum potential for reflective surfaces and urban forestation; 3) identify which organizations within the city or a given community would be appropriate in helping to implement the mitigation measures; and 4) outline and prioritise policy levers and potential programs that offer the largest cooling potential at the least cost. (...) We want to get the data out to city planners as soon as possible. (...) Feeling cooler is a nice feeling, but city planners need hard data to help justify changes in how things are done. Thus, UHIPP is providing a series of demonstrations."

\footnotetext{
${ }^{4}$ http://www.ssl.msfc.nasa.gov/newhomw/headlines

${ }^{5}$ http://www.epa.gov
} 
Em Sacramento e Baton Rouge os planejadores urbanos estão usando os resultados em benefício dos seus respectivos programas de arborização urbana. Escolhendo áreas estratégicas para a plantação de árvores e incentivando o uso de cores mais claras e refletoras nas superfícies, os pesquisadores acreditam poder diminuir as temperaturas na cidade. Dados coletados pelo ATLAS mostraram que, enquanto a temperatura superficial em um pátio de estacionamento chegava a quase $50^{\circ} \mathrm{C}$, em árvores próximas dentro do mesmo pátio a temperatura registrada era de $32^{\circ} \mathrm{C}$. Os pesquisadores esperam que os resultados sejam incorporados à legislação municipal de Atlanta para incentivar o plantio de árvores e o uso de cores mais claras e refletoras nas superfícies. Para o pesquisador QUATTROCHI ${ }^{6}$ "planting trees to shade the city and installing highly reflective roofing material are seen as measures that are politically palatable as opposed to passing more restrictive air quality legislation." Os cientistas do LBL também estão trabalhando em softwares para que planejadores urbanos possam prever os efeitos das ilhas de calor nas cidades e tomar as precauções necessárias.

Um exemplo bem sucedido é o programa Sacramento Shade, na cidade de Sacramento $^{7}$, Califórnia, o maior programa americano de plantio de árvores para redução das cargas para resfriamento de edifícios, relatado por HILDEBRANDT e SARKOVICH (1998, p.85-94). Em 1990, as entidades Sacramento Municipal Utility District e Sacramento Tree Foundation estabeleceram uma parceria conhecida como Sacramento Shade para plantar 500.000 árvores até o ano 2.000 a fim de reduzir o consumo de energia usado para o resfriamento durante o verão. Esta iniciativa obteve enorme sucesso; até 1995 mais de 200.000 árvores já tinham sido plantadas pela comunidade. Nesse programa os consumidores de energia elétrica recebem uma muda gratuita juntamente com a responsabilidade de trabalhar em conjunto com a Tree Foundation, que por sua vez ensina os princípios básicos e a melhor maneira de aproveitar a sombra de árvores ainda jovens para o sombreamento de seus edifícios durante o verão. Essa iniciativa se tornou um modelo para outros programas de plantação de árvores e ganhou diversos prêmios. O principal objetivo era plantar árvores nos lugares certos para reduzir o consumo de energia, mas muitos outros benefícios indiretos do plantio de árvores, tais como a melhoria da qualidade do ar, o resfriamento da cidade, a mitigação dos efeitos da ilha de calor, também foram considerados. Em Sacramento as árvores formam uma verdadeira cobertura vegetal, que do alto parece uma floresta urbana. Para participar do programa o morador deixa seu nome e telefone no SMUD's Conservation Department, e um funcionário entra em contato com o interessado para orientá-lo sobre como tirar máximo proveito da arborização para baixar seu consumo de energia, escolhendo as melhores espécies e fornecendo quantas mudas forem necessárias. Além de Sacramento, toda a baía de San Francisco conta com um planejamento ambiental conhecido como Green City Program (BERG, 1990).

Além dos benefícios físicos, uma cidade arborizada torna-se mais atraente e influencia no estado de espírito das pessoas, além de valorizar comercialmente as áreas arborizadas. Para SUMMIT e SOMMER (1998, p.3-4), "generally, people who either planted their own tree or participated in a tree planting program (or did both) were more satisfied with the tree and its planting, more likely to think the tree had

\footnotetext{
${ }^{6}$ http://www.ssl.msfc.nasa.gov/newhomw/headlines

${ }^{7}$ http://www.smud.org
} 
improved the yard and neighbourhood, and less likely to want the tree removed or to wish for a different tree. (...) The tree planting bring neighbours together for an environmental act, whether that is their reason for participating or not."

Estudos de SHEETS e MANZER (1991) na área de psicologia ambiental demonstraram que a presença de vegetação na cidade afeta as reações emocionais das pessoas; elas ficam mais amigáveis, mais cooperativas, menos deprimidas. A vegetação também influencia a qualidade de vida urbana, sugerindo um ambiente melhor, mais seguro e mais limpo para se viver. Estudos de HULL (1992) demonstraram que há uma melhora significativa no humor das pessoas já nos primeiros 30 minutos em que freqüentam um parque urbano. $\mathrm{O}$ autor sugere que mesmo um contato breve com locais arborizados contribui para o bem-estar das pessoas, e alerta para os desdobramentos que isso pode ter em ambientes de escritórios, hospitais, escolas e em outros lugares onde as pessoas podem ficar estressadas ou mal humoradas.

Jeffrey COOK (1991), da Arizona State University, no texto Searching for the Bioclimatic City, lembra que corpos d'água ou grandes massas de vegetação estão entre as intervenções mais eficientes para modificação do clima, e que o tratamento de ruas e avenidas são um dos componentes bioclimáticos mais interessantes. Em climas áridos as possibilidades de intervenção são ainda maiores; Cook cita o caso de Phoenix, Arizona, onde em um dia de verão pode-se alcançar $9^{\circ} \mathrm{C}$ de diferença entre um pátio de estacionamento pavimentado e uma área verde próxima irrigada. Em seu projeto Urban Solar Oasis COOK (1999) ${ }^{8}$ propôs iniciar uma metamorfose em Phoenix, contruindo uma praça sobre uma área de estacionamento pavimentada de 90x100m, buscando demonstrar que estratégias bioclimáticas podem ser aplicadas em qualquer lugar; "the four primary design elements were living trees, a sunken garden, a great tensile shade structure, and a series of 'cool towers' evaporatively driven down draft chimneys." O resfriamento necessário para o verão é equilibrado com a necessidade de acesso solar no inverno, calculando-se a exposição ao sol e o sombreamento em todas a estações do ano e horários do dia, tirando proveito de uma grande cobertura tensionada. Células fotovoltaicas aproveitam a energia solar para gerar eletricidade para as fontes e para a iluminação da praça. Segundo Cook, "properly modified, the power of the sun nourishes and sustains all life.(..) Simultaneous with the practical goal of making this space functional and pleasant would be its educational demonstration to transform other public spaces into resource enhancing and energy harvesting oppurtunities. The ethic of a nonmechanical bases for the comfort and aesthetic design for outdoor spaces illustrates sustainibility at an urban scale." Jardins e 10 torres de $18 \mathrm{~m}$ de altura com aspersão de água para resfriamento completam o tratamento. $\mathrm{O}$ sombreador existente no topo de cada torre funciona como um coletor de água de chuva. As torres foram dimensionadas para liberar ar tratado a $27^{\circ} \mathrm{C}$ de temperatura a uma velocidade de $7,6 \mathrm{~m} / \mathrm{minuto}$ quando a temperatura ambiente é de $41^{\circ} \mathrm{C}$. A torre principal, com $30 \mathrm{~m}$ de altura e diâmetro de $7,5 \mathrm{~m}$ produziria $14.000 \mathrm{~m}^{3}$ de ar tratado por minuto sob temperatura ambiente de $41^{\circ} \mathrm{C}$ (fig.4.4).

\footnotetext{
${ }^{8}$ http://www.public.asu.edu/ alexis68
} 


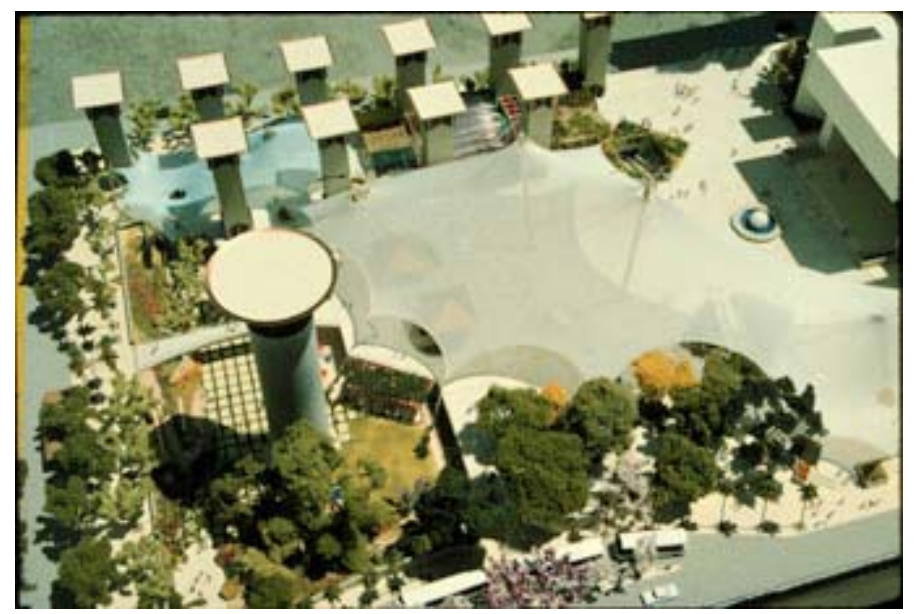

Figura 4.4 - Urban Solar Oasis, projeto de Jeffrey Cook para Phoenix, em 1987. (fonte: http://www.public.asu.edu/ alexis68)

Boston é outro bom exemplo; a cidade evoluiu a partir de um deserto há apenas três séculos e meio. Nesse tempo o espaço natural transformou-se a ponto de estar irreconhecível, numa natureza caracteristicamente urbana. Os colonizadores trouxeram árvores frutíferas e ornamentais da Europa e em 1728 a primeira fileira de árvores foi plantada como uma alameda de sombreamento. Entre 1880 e 1895 os habitantes fizeram novas grandes plantações na cidade. Essa paisagem construída pelo homem foi modelada por exércitos de cavalos e trabalhadores, como parte de um movimento mais amplo nas cidades norte-americanas e européias, nas quais grandes e bucólicos parques foram criados para a crescente população urbana. Esses parques bucólicos, projetados como uma forma idealizada de natureza derivada das propriedades rurais inglesas, requeriam uma enorme manutenção. Hoje muitos deles estão em declínio e em péssimas condições, necessitando de renovação. Em 1890 um habitante de Boston podia caminhar por toda a cidade sob as árvores, por um sistema integrado de vias e parques, da autoria de Olmsted. Hoje o chamado Emerald Necklace está descaracterizado, suas alamedas cortadas por elevados, com trilhas convertidas em passagens para automóveis e os parques em declínio. As faixas foram alargadas e convertidas em pistas em resposta à demanda por mais estradas para ligar o centro ao subúrbio. (SPIRN, 1995, p.29, 42, 190) Nos últimos anos Boston vem trabalhando em um novo plano para a área central ${ }^{9}$ removendo elevados, e visando restaurar a reputação de cidade planejada para pedestres e ciclistas.

Seattle que, segundo RUANO (1999), era a cidade mais habitável nos Estados Unidos em 1975, em 1994 aprovou um plano abrangente chamado Toward a Sustainable Seattle 1994-2014, ${ }^{10}$ estabelecendo políticas de planejamento e elaborando um conjunto de indicadores de sustentabilidade. As idéias para o plano foram desenvolvidas ao longo de 5 anos, através de discussões e debates de técnicos com a comunidade.

Outro exemplo é Dayton, Ohio; de acordo com SPIRN (1995, p.93), através de uma engenhosa administração de fundos federais, verbas de fundações privadas, do conhecimento de estudantes e professores de várias universidades americanas e da

\footnotetext{
9 http://www.ci.boston.ma.us/environment/transportation.asp

${ }^{10}$ http://www.ci.seattle.wa.us/planning
} 
disposição de muitos moradores da cidade em ceder seu tempo, Dayton reuniu uma quantidade impressionante de projetos relacionados ao clima urbano. Em Dayton os ventos são um problema nas praças e calçadas situadas na base dos edifícios altos. Pela primeira vez foi estudada uma maquete de toda uma área central em um túnel de vento com o propósito de desenvolver um plano abrangente que pudesse resolver os problemas do vento no nível do solo. Como muitas cidades americanas, Dayton tem ruas largas e muitos espaços abertos próximos ao centro. Uma vez que nem todas as seis faixas eram utilizadas para acomodar o tráfego propôs-se que os canteiros centrais e as calçadas fossem ampliadas e arborizadas. Em 1980 o serviço florestal dos Estados Unidos forneceu a Dayton um climatologista que estudou o clima e a qualidade do ar da cidade e avaliou suas necessidades. A fim de coletar mais dados sobre a temperatura local o escritório de administração municipal, através de apelos na televisão, organizou um exército de voluntários na cidade para recolher os dados de temperatura em dias e horários pré-determinados. Outras cidades americanas como Cincinnati, Buffalo e Lafayete, em Indiana, inspiraram-se no exemplo de Dayton e implementaram programas similares. (SPIRN, 1995, p.95-96)

Outra estratégia foi colocada em prática em Denver. De acordo com SPIRN (1995, p.179), a administração exige que edifícios novos ou reformados retenham as águas pluviais no local, formando uma combinação de telhados, praças e estacionamentos para armazenar a água da chuva. Muitos desses modelos são aplicáveis a todas as cidades, não apenas àquelas com climas áridos e semi-áridos ou com várzeas densamente ocupadas. Os códigos de obras em muitas cidades americanas exigem que os telhados sejam projetados para resistir ao equivalente a $150 \mathrm{~mm}$ de água por um certo período de tempo.

No caso de Davis, Califórnia, a cidade inovou numa legislação para a conservação de energia incluindo um novo código de obras, normas que incentivam o uso da energia solar e o desenvolvimento de alternativas de transporte para o automóvel particular. A cidade se concentrou na construção dos edifícios e no transporte desde que uma pesquisa demonstrou que os automóveis representam $50 \%$ de todo o consumo de energia, e o aquecimento e refrigeração das edificações, outros 25\%. O novo código de obras regulamenta tanto a localização como o projeto dos novos edifícios, incluindo a orientação solar, a quantidade de aberturas, as cores dos telhados e paredes e o sombreamento das fachadas. Antes desse código a maioria das casas era construída com um sistema de condicionamento de ar. Com a melhoria dos projetos, muitos moradores agora consideram o ar-condicionado desnecessário. Segundo SPIRN (1995, p.99-100), a experiência foi altamente bem sucedida. O General Plan $^{11}$ da cidade de Davis está disponível na internet; o plano contém as políticas e os programas que vão conduzir a cidade até o ano 2010, e abre o diálogo entre a equipe de planejamento e a comunidade.

Tucson, Arizona, é outra cidade americana tirando proveito da arborização urbana para amenizar o calor no verão, na proporção de uma árvore para cada habitante. A proposta é não só pela economia de energia, mas também para melhorar a qualidade de vida da comunidade. O programa Trees for Tucson, ${ }^{12}$ "an offshot of Tucson Clean and Beautitiful, Inc., a nonprofit organization funded by government and

\footnotetext{
${ }^{11}$ http://www.city.davis.ca.us/city/genplan/

${ }^{12}$ http://www.eren.doe.gov
} 
private grants and donations”, incentiva o plantio de fornece informações para proprietários, associações de moradores e escolas sobre espécies que necessitam de pouca água, apropriadas ao clima local, aumentando a conscientização da comunidade sobre as questões ambientais locais. Os envolvidos participam de workshops duas vezes ao ano que ensinam técnicas de plantio, poda, fertilização, cuidados com insetos e doenças, além de seminários específicos para paisagistas, professores, que enfatizam a informação sobre o uso de árvores para reduzir os gastos com resfriamento.

Segundo a EREN" 13 "the effects of evapotranspiration are more difficult to quantify, but researchers using computer simulations estimate that planting a total of three trees per house on the south, east, and west sides would result in cooling energy reductions of 30\% in Sacramento, California, 17\% in Phoenix, Arizona, and 23\% in Lake Charles, Louisiana. Shading accounts for about 10\% to 35\% of these savings, and the remainder...results from lower temperatures caused by evapotranspiration." Conhecendo as dificuldades de manutenção de árvores em áreas urbana, a EREN lembra que "Unlike forest trees, city trees demand work. They grow in conditions far more cramped, dirty, impoverished, hot and windy than wild trees do. In a forest, fallen trees and leaves enrich the soil. In the city, soil is packed by traffic and washed by oil runoff. City trees breathe car exhaust and stand in the heat reflected off buildings and streets. (...) Trees in a forest may live hundred of years, but a city tree typically lives only a few decades. (...) The problem is worse in the city, because in the county, many main streets were not built with trees in mind - or lost many trees when roads were widened...There is little county tree stewardship beyond trimming of branches that block roads; most of the estimated 4.3 million trees outside the city area privately owned."

\subsection{Exemplos nas cidades brasileiras}

No início da República, em 1894, Belo Horizonte inaugurou no Brasil a experiência de cidades totalmente planejadas. Idealizada por Aarão Reis, sua trama regular, quadrada, com largas avenidas diagonais se opôs ao desenho da colonial Ouro Preto, a antiga capital, localizada em uma região montanhosa de difícil acesso, na encosta de um vale escarpado. Segundo BRUAND (1991) a localização da nova capital foi escolhida com muito bom senso, pois está situada quase no centro geográfico do Estado e a apenas $100 \mathrm{Km}$ de Ouro Preto. A altitude de $800 \mathrm{~m}$ e as condições climáticas excelentes para um país tropical também eram favoráveis.

Na nova capital as normas para os bairros residenciais estabeleceram, para os lotes de aproximadamente $1.000 \mathrm{~m}^{2}$, edificações de no máximo três andares, que deveriam se destinar ao uso exclusivamente residencial, com amplos recuos frontais, delimitados por cercas vivas ou gradis, mantendo canteiros arborizados e gramados nos passeios públicos. Atualmente o gabarito ainda é mantido, mas os edifícios abrigam empresas de serviços. ${ }^{14}$

Em Belo Horizonte são $32 \mathrm{~m}^{2}$ de área verde por habitante distribuídas em parques e ao longo das largas avenidas. Alguns jardins públicos e praças previstas no projeto de Aarão Reis nunca foram executados. Com o Projeto 100 mil Árvores em Belo

\footnotetext{
${ }^{13} \mathrm{http}: / / \mathrm{www}$. eren.doe.gov

${ }^{14}$ Exposição $3^{\text {a }}$ Bienal Internacional de Arquitetura, 1997.
} 
Horizonte uma parceria entre Prefeitura e empresas privadas possibilita o aumento e a manutenção da arborização urbana. A partir de uma licitação, a empresa recebe o direito de explorar comercialmente um espaço de propaganda em cada muda plantada. Os bons resultados do Programa têm levado a Prefeitura a usar o mesmo modelo de edital de licitação para instalação e manutenção de cestas de lixo em vias públicas ${ }^{15}$.

Em 1990 uma pesquisa da Population Crisis Commitee, de Washington, elegeu Belo Horizonte como a cidade de melhor qualidade de vida na América Latina, e a $45^{\text {a }}$ numa lista de 100 grandes cidades no mundo inteiro. Em outra pesquisa da consultoria Trevisan, Belo Horizonte foi eleita a segunda melhor cidade brasileira pra se viver, ficando atrás apenas de Porto Alegre. Hoje um dos maiores desafios da capital mineira é tentar desfazer o que parecia uma solução há 100 anos, quando a cidade foi planejada com um traçado xadrez, no qual ruas e avenidas convergem todas para o centro. Por essa razão estima-se que 50\% dos veículos que passam diariamente no centro não precisariam trafegar pela região, usada apenas como passagem $^{16}$. Planejada para abrigar 200.000 habitantes no seu centenário, em 1997 esse número chegou a 2.100.000 habitantes.

Em Goiás o êxito da experiência em Belo Horizonte e a semelhança de condições com a antiga capital, Goiás Velho, surgida no período da mineração - levou à repetição da experiência mineira quatro décadas depois. O plano de Atílio Correia Lima, de 1934, previu a implantação da cidade a pouco mais de $100 \mathrm{Km}$ da antiga capital, em um terreno com declividade de 1 a $2 \%$, em local de clima agradável e com 34,6\% de áreas livres, das quais 162 ha destinados a parques e jardins. O zoneamento foi claramente imposto, separando o centro administrativo, o setor comercial e o habitacional, e circundando a cidade por cinturões verdes. A cidade foi planejada para comportar inicialmente 50.000 habitantes.

O urbanista determinou, no plano original, a criação de vários parques e áreas verdes, totalizando $32,5 \mathrm{~m}^{2}$ por habitante. O projeto do arquiteto Atílio Correia Lima usou os eixos clássicos que se cruzam onde se localiza o centro comercial e o jardim central. O setor de habitações tem ruas curvas de distribuição e vias sem saída em cul-de-sac, com exuberante vegetação, com uma interpretação do arquiteto do modelo de cidadejardim. Esse setor é integrado ao traçado geral da cidade, no qual ruas curvas e retilíneas convivem de forma harmoniosa. ${ }^{17}$ Alguns dos elementos do projeto original foram alterados, com a supressão do jardim central, a modificação do setor de habitações e a falta de continuidade do desenho urbano inicial.

De acordo com MARTINS Jr. (1996, p.72), Goiânia possui condições para instalar um modelo de cidade ecologicamente equilibrada. Curitiba, que não teve planejamento original, gastou bilhões com desapropriações em áreas de nascentes e em margens de córregos para a implantação de seus parques lineares. Hoje, Curitiba colhe em triplo o que investiu; a cidade abre portas junto aos organismos da ONU Organização das Nações Unidas para o financiamento do desenvolvimento sustentável, às vezes até a fundo perdido. Tudo isso graças a um planejamento ambiental inteligente realizado em Curitiba à frente dos destinos do povo paranaense

\footnotetext{
${ }^{15}$ http://www.bsi.com.br/unilivre/centro/experiências

${ }^{16}$ Revista Veja, 10 de dezembro de 1997.

${ }^{17}$ Exposição na $3^{\mathrm{a}}$ Bienal Internacional de Arquitetura, 1997.
} 
e curitibano, que rendeu também a manutenção da equipe do arquiteto e Governador do Estado Jaime Lerner.

Curitiba, ${ }^{18}$ citada por urbanistas do mundo inteiro como cidade-modelo, segue o princípio de que a ocupação e os usos da cidade devem ser induzidos, de modo que o adensamento populacional seja compatível com a infra-estrutura disponível. Curitiba é atualmente a cidade brasileira com maior área verde por habitante (fig.4.5); em 20 anos Curitiba aumentou sua área verde por habitante de $0,5 \mathrm{~m}^{2}$ para $52 \mathrm{~m}^{2}$. A cidade possui 26 parques com um total de 20 milhões de $\mathrm{m}^{2}$ de áreas verdes públicas freqüentados por mais de 150 mil pessoas nos finais de semana.

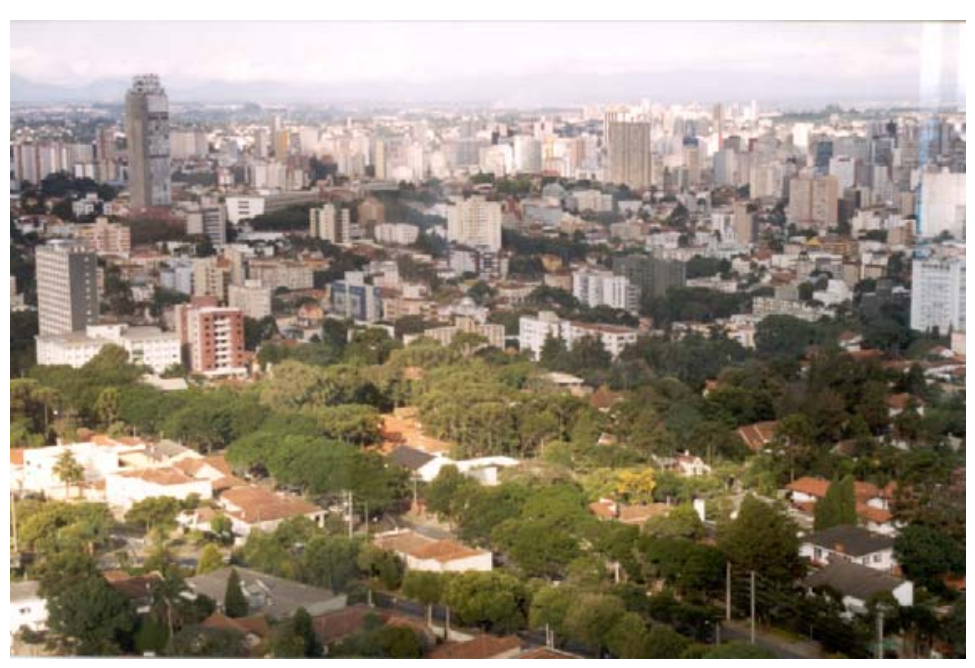

Figura 4.5 - Vista de Curitiba em abril de 2000 com um dos corredores de adensamento ao fundo e as áreas verdes distribuídas por toda a cidade. (foto: D. Duarte)

Nas áreas com bosques cadastrados é estimulada a preservação através de incentivos fiscais e construtivos, admitindo-se a edificação com parâmetros superiores em altura. Foram instituídos alguns benefícios como a isenção ou redução do imposto imobiliário, proporcionalmente à faixa de cobertura florestal, e o estabelecimento de condições especiais de aproveitamento para os terrenos integrantes do Setor Especial de Áreas Verdes. As condições são regulamentadas por decreto que estabelece que as edificações podem ter altura superior à da zona do entorno com redução da taxa de utilização do terreno, garantindo a adequada preservação das áreas verdes. Em áreas maiores e com cobertura vegetal relevante, essa ocupação pode ser ainda mais incentivada em altura, neste caso condicionada ao recolhimento de recursos aos Fundos Municipais de Meio Ambiente e da Ação Social ou à doação de parte da área verde ao município, necessária para a criação de novos parques ou incorporação aos já existentes.

Essas opções de lazer significam qualidade de vida e equilíbrio da cidade com seu meio ambiente. A maioria dos parques de Curitiba são lineares, implantados ao longo dos rios e em fundos de vale. Funcionam como uma barreira para impedir a ocupação indevida nessas áreas, sujeitas a enchentes, e para livrar rios e córregos do risco de se tornarem depósitos de lixo. Os lagos dos parques servem para conter as enchentes e funcionam como reguladores de vazão das águas em épocas de chuva.

\footnotetext{
${ }^{18}$ Dados do IPPUC em www.curitiba.pr.gov.br
} 
A Lei de Zoneamento e Uso do Solo de Curitiba - parte do Plano Diretor aprovado em 1966 e que há 33 anos norteia o crescimento da cidade - foi revista recentemente e em 04 de abril de 2000 a nova lei entrou em vigor. Essa revisão incluiu a implementação de novos instrumentos de planejamento para estabelecer parcerias da iniciativa privada com o poder público, o aproveitamento da infra-estrutura já instalada para incentivar o adensamento em áreas que comportam maior verticalização e a criação de novas unidades de conservação, parques, praças e espaços públicos.

As alterações propostas são o resultado de um trabalho que durou mais de dois anos. Um grupo de técnicos realizou os estudos visando detectar os conflitos na legislação em vigor e propor soluções. Dentre as propostas estavam a criação de novos eixos de adensamento, a ampliação do mecanismo de solo-criado e de transferência de potencial construtivo, criação de novas unidades de conservação e maior área de afastamento para as edificações, evitando a formação de áreas de sombra e melhorando as condições de insolação e ventilação em regiões da cidade onde há adensamento excessivo. MENEZES (1996) descreve a experiência de Curitiba em desenvolvimento urbano e meio ambiente e atribui esse sucesso à humanização da cidade, à concepção de cidade como uma causa partilhada, envolvendo a população em campanhas e programas de arborização e limpeza pública. Uma nova cultura passou a ganhar forma entre os curitibanos; a população passou a assumir a cidade, envolvendo-se na conservação de sua qualidade de vida.

Um outro caso interessante é o projeto do engenheiro civil Jorge de Macedo Vieira para a então nova cidade de Maringá, com um desenho urbano fortemente influenciado pelo ideário de cidade-jardim; como ele próprio sugere ao comentar seus parques (fig.4.6) para Maringá ${ }^{19}$ : "eu projetei aqueles parques com o seguinte sentimento: de mostrar às gerações que viessem depois, quando a cidade estivesse construída, o que era Maringá antes (...) era uma mata virgem.” Maringá, fundada pela Companhia Melhoramentos Norte do Paraná, foi traçada obedecendo ao projeto urbanístico de Jorge de Macedo Vieira que demarcou as amplas ruas, avenidas e praças, considerando ao máximo as características topográficas do sítio e revelando a preocupação com a preservação da vegetação nativa. A cidade previa abrigar uma população total de 200.000 habitantes; atualmente são 300.000.

Jorge de Macedo Vieira foi responsável por projetos como o Jardim América em São Paulo e Águas de São Pedro, na região de Piracicaba. Contratado pela Cia. Melhoramentos Norte do Paraná Vieira criou um projeto considerado na época, 1945, como um dos mais arrojados e modernos, seguindo a orientação da companhia que exigia largas avenidas, muitas praças e áreas verdes. A grande preocupação da Cia. Melhoramentos ao encomendar o projeto urbanístico era conjugar o plano urbano à topografia da região.

Preocupada com a questão ambiental que a derrubada da mata fatalmente abalaria, a Cia. solicitou ao Eng.Vieira que fizesse constar no desenho original de Maringá três áreas que hoje formam um verdadeiro pulmão verde. Ao todo Maringá possui praças, bosques e um horto florestal, num total de cerca de 160.000 árvores. O projeto se preocupou primeiro em formar canteiros dentro do horto para acomodar as diversas mudas que vieram principalmente de São Paulo, encomendadas pela Cia.

\footnotetext{
${ }^{19}$ Exposição na $4{ }^{\mathrm{a}}$ Bienal Internacional de Arquitetura, 1999/2000.
} 
Melhoramentos para serem plantadas na cidade. Para cada rua, avenida ou praça era escolhida uma espécie, de tal maneira que Maringá tem árvores floridas durante todo o ano (fig.4.7). Maringá apresenta uma das maiores concentrações de área verde por habitante e é recoberta por um verdadeiro teto natural.

Algumas cidades no interior de São Paulo, como Rio Claro e Santa Bárbara d’Oeste, por exemplo, têm grandes árvores nas áreas centrais, que funcionam como verdadeiros tetos naturais. Pirassununga também já teve um enorme teto de ficus na praça central, que foi cortado por causa de insetos.

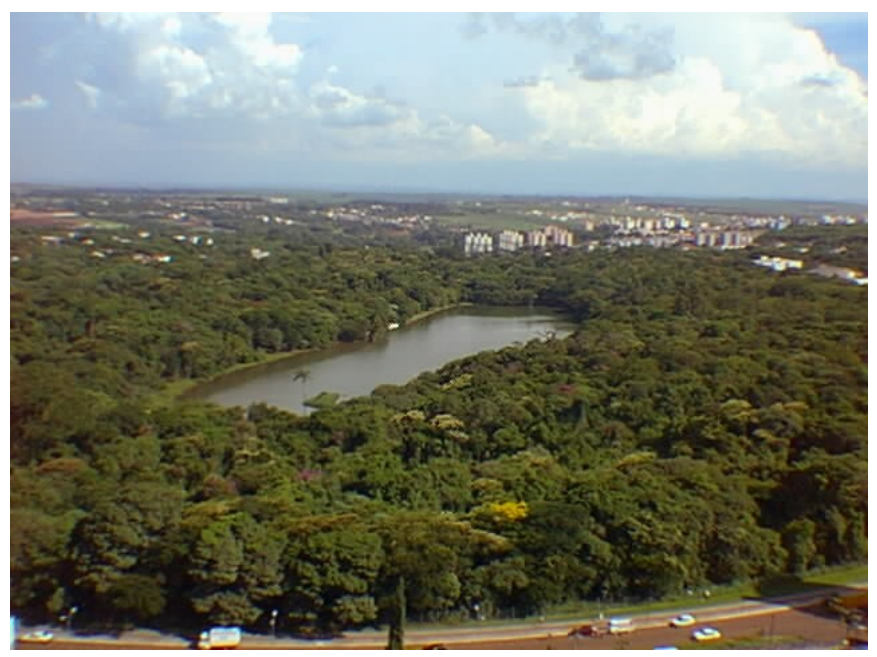

Figura 4.6 - Parque do Ingá; reserva florestal mantida desde o traçado inicial da cidade de Maringá. (fonte: www.maringa.pr.gov.br)

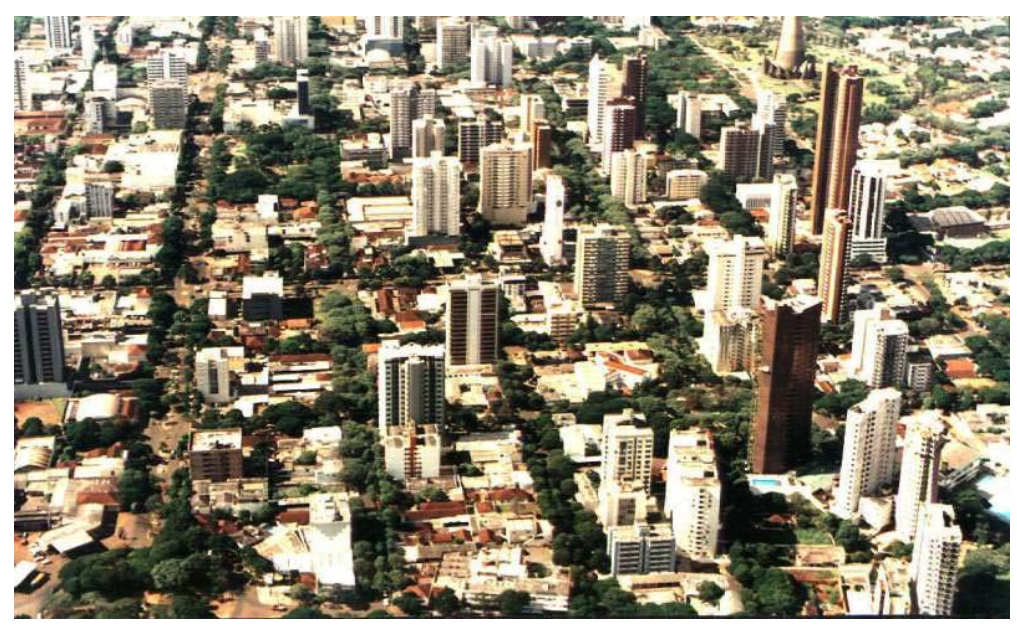

Figura 4.7 -Maringá com o verde distribuído por toda a cidade. (fonte: www.maringa.pr.gov.br)

No Rio de Janeiro, apesar das altas temperaturas, o verde ainda presente nos morros e principalmente na Floresta da Tijuca, além de espaços de amenidade climática como a Lagoa Rodrigo de Freitas (fig.4.8) e o Aterro do Flamengo, contribuem para a melhoria das condições de conforto para o pedestre. Outro recurso eficiente é o sombreamento proporcionado pelas galerias no centro da cidade, principalmente ao longo da Av. Getúlio Vargas, recurso presente também em outros espaços públicos criados no pilotis do MEC e no aeroporto Santos Dumont. 


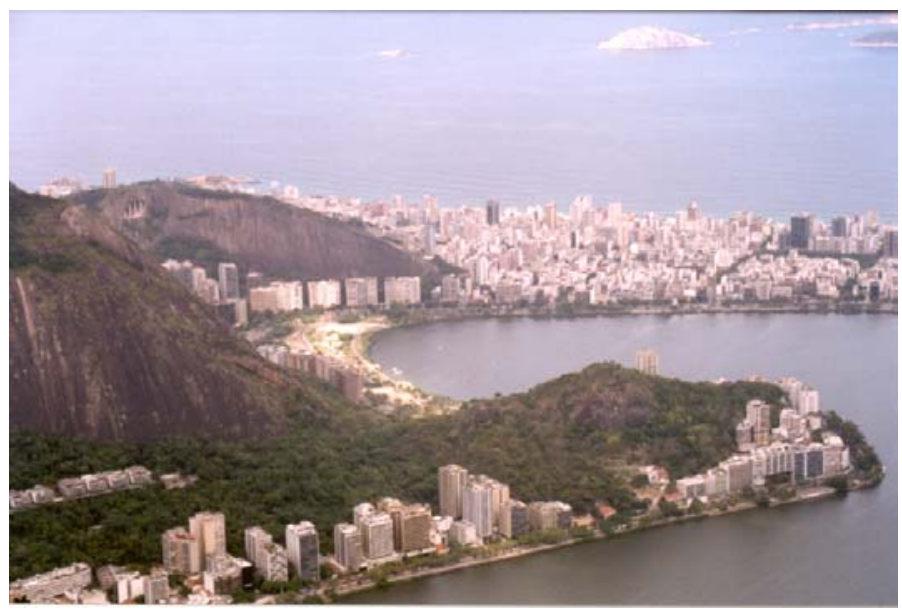

Figura 4.8 - Vista parcial da Lagoa Rodrigo de Freitas. (foto: D. Duarte)

No caso de São Paulo, sobre a expansão urbana da cidade, KLIASS (1994) comenta o início da urbanização das várzeas: a cidade que até então se desenvolvia a partir de seu núcleo central, ao longo dos caminhos de meia encosta e espigões, passa a ocupar as áreas de várzea e os terraços fluviais, onde se instalaram as ferrovias. Nestes espaços, até então poupados à urbanização, localizavam-se as indústrias e junto a elas os bairros operários. A criação de áreas verdes não entrou na implantação de nenhuma das grandes intervenções urbanas da cidade: nem nos seus planos viários, nem nas suas 'não-soluções' de saneamento básico. Se por um lado as marginais do Tietê e Pinheiros acabaram por inviabilizar a criação de parques de várzea e o sistema de esgoto destruiu o potencial de aproveitamento das represas como área de recreação, seria de se esperar que pelo menos essas intervenções viárias tivessem respeitado as áreas verdes existentes.

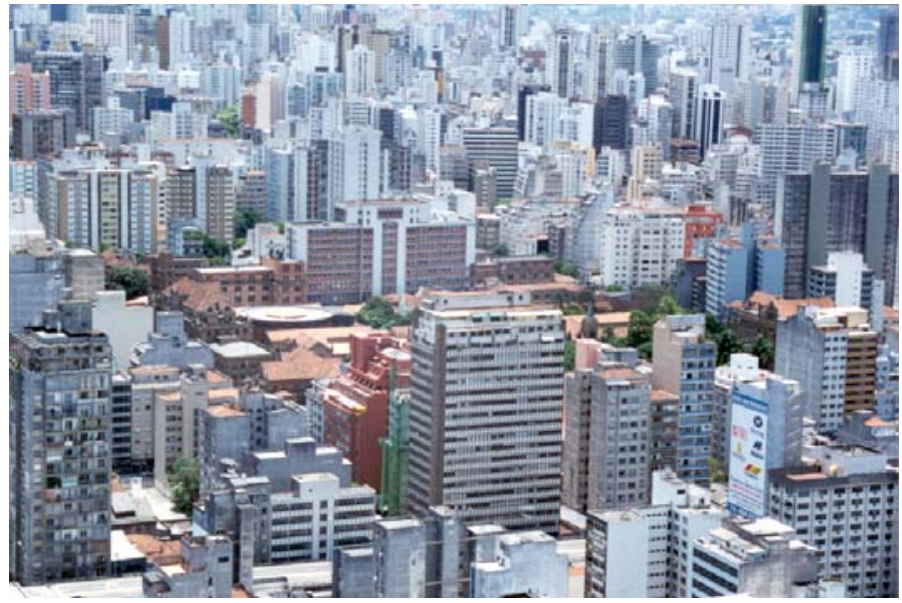

Figura 4.9 - Ausência de áreas verdes no Centro de São Paulo. (foto: J. Calsinki)

De 1967 a 1969, na gestão Faria lima, desenvolveu-se sob contrato com a Prefeitura o Plano de Áreas Verdes de Recreação do Município de São Paulo, elaborado por Rosa Grena Kliass e Miranda Martinelli Magnoli tendo como colaboradoras as arquitetas Edith de Oliveira e Maria Madalena Ré. O município foi dividido em 25 zonas e para cada uma das zonas foram feitas propostas de áreas verdes de recreação nas categorias de Parques de Vizinhança, Parques de Bairro, Parques Setoriais e 
Parques Metropolitanos. Segundo KLIASS (1994, p.31)“a inserção do Parque Urbano na vida das cidades decorreu da necessidade, de um lado, de equipá-la de forma a atender às atividades de lazer e recreação, decorrência do novo ritmo introduzido pelo tempo artificial - o tempo da cidade industrial - em contraposição ao tempo natural, inerente à vida rural. Por outro lado, da necessidade de introduzir espaços com características amenizadoras das estruturas urbanas, contrapondo-as às massas edificadas, espaços estes tratados com elementos naturais, principalmente vegetação.(...) Nas últimas duas décadas, a crescente preocupação com os aspectos de meio ambiente e de preservação do patrimônio paisagístico têm contribuído para revigorar as propostas de valorização das áreas verdes nos centros urbanos, dando ênfase na manutenção de áreas naturais ou de criação de áreas de recomposição da paisagem com elementos naturais."

Ainda segundo Kliass a segunda forma de apropriação dos fundos de vale e várzeas, no início deste século, foi seu aproveitamento como áreas verdes. No entanto, as amplas várzeas do Tietê e do Pinheiros persistiram como vazios urbanos até há bem pouco tempo. A sua utilização como parques lineares como resultado de ocupação urbana de propósitos múltiplos, seja engenharia sanitária, engenharia viária, ou valorização de terras lindeiras, teria concedido à cidade uma paisagem urbana de grande qualidade, suprindo a demanda de parques e certamente amenizando as questões de conforto ambiental. Outros locais com potencial paisagístico são as margens das represas. Apesar delas terem sido utilizadas para fins recreativos e de lazer, e de às suas margens se estabelecerem áreas de clubes particulares, as represas não foram aproveitadas como parques na cidade. No caso de São Paulo deu-se a perda do potencial de áreas verdes com a apropriação inadequada aos seus fundos de vale e principalmente das amplas várzeas em posições estratégicas do ponto de vista ambiental e urbano. Teria sido possível, e não foram poucas as recomendações constantes em estudos e planos, a implementação de propostas de parques quando da execução de grandes obras de infra-estrutura, como foi o caso da regularização dos rios Tietê e Pinheiros, da instalação do metrô e da cirurgia urbana que resultou no seu sistema viário.

Para Kliass, desde os primórdios da absorção do parque como fato urbano, uma das razões invocadas para sua criação era a valorização do seu entorno, quer pela amenização das condições de urbanização, quer pelo aumento do seu valor imobiliário. Apesar de ser de amplo conhecimento do mercado de imóveis de São Paulo, esse fato, fartamente utilizado mercadologicamente quando se trata de vender imóveis junto a parques já existentes, não chegou a gerar modificação das tendências que acabaram por configurar o quadro atual. Qual a causa para a não adoção do projeto paisagístico global para os parques urbanos em São Paulo? Kliass acredita que, em parte seja pela não valorização do projeto paisagístico, que decorre em grande parte da fragilidade da categoria profissional que somente ultimamente inicia a sua estruturação, mas também devido à organização administrativa que não tem condições de absorver projetos de profissionais externos.

Segundo Kliass a cidade de São Paulo deixou escapar a ocasião de, em momento crítico, proceder à reserva de áreas de parques para sua posterior implantação (fig.4.9), o que poderia ter garantido a seus cidadãos uma melhor qualidade de vida urbana. É preciso que as cidades brasileiras sejam alertadas para esse perigo e que a questão da reserva de áreas verdes para futuros parques urbanos, constitua elemento 
estruturante dos planos diretores que venham a ser elaborados. Que estes mesmos planos se alimentem necessariamente de estudos ambientais nos quais a questão do potencial paisagístico receba especial atenção. Para que esses procedimentos se efetivem é preciso que se disponha de recursos humanos capazes de desempenhar as funções que as tarefas exigirão. Para tal é necessário preparar arquitetos paisagistas para atuar na concepção e gerenciamento dos Sistemas de Áreas Verdes e elaborar os projetos dos parques urbanos.

Para Kliass algumas medidas imediatas deveriam ser tomadas. A primeira é a preservação dos últimos sítios com potencial para parques urbanos, matéria relativamente fácil pela escassez de casos. Dever-se-á também a curto prazo estabelecer política de incentivo a projetos que dotem a cidade de grandes áreas verdes públicas, seja pela preservação de áreas verdes ainda remanescentes, seja pela criação das mesmas pelo remanejamento de áreas já ocupadas. Em São Paulo, perdida a grande oportunidade de aproveitamento das grandes várzeas do Tietê e Pinheiros, a cidade deverá, no entanto, ir buscar na sua estrutura e em sua dinâmica de desenvolvimento, um projeto que a médio e longo prazo, dependendo das necessidades do mercado, das condições econômicas gerais e da estrutura organizacional que para tal propósito se monte, possa se transformar em tema urbanístico e paisagístico da maior importância para a qualidade de vida na cidade.

\section{Referências Bibliográficas}

1. AVISSAR, Roni. Potential effects of vegetation on the urban thermal environment. Atmospheric Environment, Oxford, v.30, n.3, p.437-448, 1996.

2. BERG, Peter et al. A green city program for the San Francisco bay area and beyond. San Francisco: Planet Drum Foundation/Wingbow, 1990.

3. BRUAND, Yves. Arquitetura Contemporânea no Brasil. 2.ed. São Paulo: Perspectiva, 1991.

4. COOK, Jeffrey. Searching for the Bioclimatic City. In: Architecture and Urban Space. Proceedings of the Ninth International PLEA Conference, Seville: Kluwer, September 1991, p.7-16.

5. COOK, Jeffrey. Urban Solar Oasis. Bioclimatic design strategies. ENEA/ ECO, Projects for Sustainable Development. Supplement to l'Arca. Milan and Rome, Italy, the Premier issue of ECO, p.6-9, 1999.

6. EVANS \& SCHILLER. Training Architects and Planners to Design with Urban Microclimates. In: Atmospheric Environment, Oxford, v.30, n.3, p 449-454, 1996.

7. GIVONI, Baruch. Impact of planted areas on urban environmental quality: a review. Atmospheric Environment, Oxford, v.25B, n.3, p.289-199, 1991.

8. GIVONI, Baruch. Urban Design in Different Climates. Geneve: WMO Technical Document n.346, 1989.

9. GONÇALVES, Wantuelfer. Padrões de Assentamento de Áreas Verdes Municipais - uma visão crítica. São Paulo: FAUUSP, 1994. Tese (Doutoramento). Faculdade de Arquitetura e Urbanismo, Universidade de São Paulo. 
10. HILDEBRANDT, Eric W. \& SARKOVICH, Misha. Assessing the costeffectiveness of SMUD's Shade Tree Program. Atmospheric Environment, Oxford, v.32, n.1, p.85-94, 1998.

11. HONJO, T., TAKAKURA, T. Simulation of thermal effects of urban green Areas on their surrounding areas. Energy and Buildings, Netherlands, n.15-16, 1990/91, p.443-446.

12. HULL, R. B. Brief encounters with urban forests produce moods that matter. Journal of Arboriculture, v.18, n.6, p.322-324, Nov. 1992.

13. KLIASS, Rosa G. Parques Urbanos de São Paulo. São Paulo: Pini, 1994.

14. MARTINS Jr., Osmar Pires. Uma Cidade Ecologicamente Correta. Goiânia: AB, 1996.

15. MENEZES, Claudino Luiz. Desenvolvimento Urbano e Meio Ambiente. A experiência de Curitiba. Campinas: Papirus, 1996.

16. QUATTROCHI, Dale \& RIDD, Merryll. Analysis of vegetation within a semiarid urban environment using high spatial resolution airborne thermal infrared remote sensing data. Atmospheric Environment, Oxford, v.32, n.1, p.19-33, 1998.

17. ROSENFELD et al. Painting the town white- and green. In: http://eetd.lbl.gov/HeatIsland/PUBS/PAINTING

18. RUANO, Miguel. Ecourbanismo. Entornos humanos sostenibles: 60 proyectos. Barcelona: Gustavo Gili, 1999.

19. SÃO PAULO. Prefeitura Municipal de São Paulo. A Questão Ambiental Urbana: Cidade de São Paulo. São Paulo: Prefeitura Municipal de São Paulo/SVMA, 1993.

20. SÃO PAULO. Programa um milhão de árvores. Educação Ambiental. Secretaria Municipal do Verde e do Meio Ambiente: DEAPLA, 1997.

21. SAILOR, David J. Simulations of annual degree day impacts of urban vegetative augmentation. In: Atmospheric Environment, Oxford, v.32, n.1, p.43-52, 1998.

22. SHEETS, Virgil L., MANZER, Chris D. Affect, cognition, and urban vegetation. Some effects of adding trees along city streets. Environment and Behavior, v.23, n.3, p.285-304, May 1991.

23. SPIRN, Anne Whiston. O jardim de granito. São Paulo: EDUSP, 1995.

24. SUMMIT, Joshua \& SOMMER, Robert. Urban tree-planting programs - a model for encouraging environmentally protective behavior. In: Atmospheric Environment, Oxford, v.32, n.1, p.1-5, 1998.

25. UPMANIS, Hillevi. The park has its own climate. Swedish Building Research, n.2, p.8-10, 2000. 


\section{PARTE 2}

Levantamento de dados secundários para caracterização da área de estudo 


\section{CONDIÇÕES AMBIENTAIS NA REGIÃO DE CLIMA TROPICAL CONTINENTAL}

\subsection{Clima regional}

No Brasil, o Clima Tropical Continental predomina na região Centro-Oeste (fig.5.1), e são poucas as cidades na região que dispõem de dados climáticos (ver fig.5.2 e tab.5.1). Comparando-se com outras regiões, como o sudeste, por exemplo, o número de postos existentes é bastante reduzido, principalmente no estado de Mato Grosso. As principais fontes são os postos do Instituto Nacional de Meteorologia e algumas estações do Ministério da Aeronáutica nos aeroportos ${ }^{1}$.

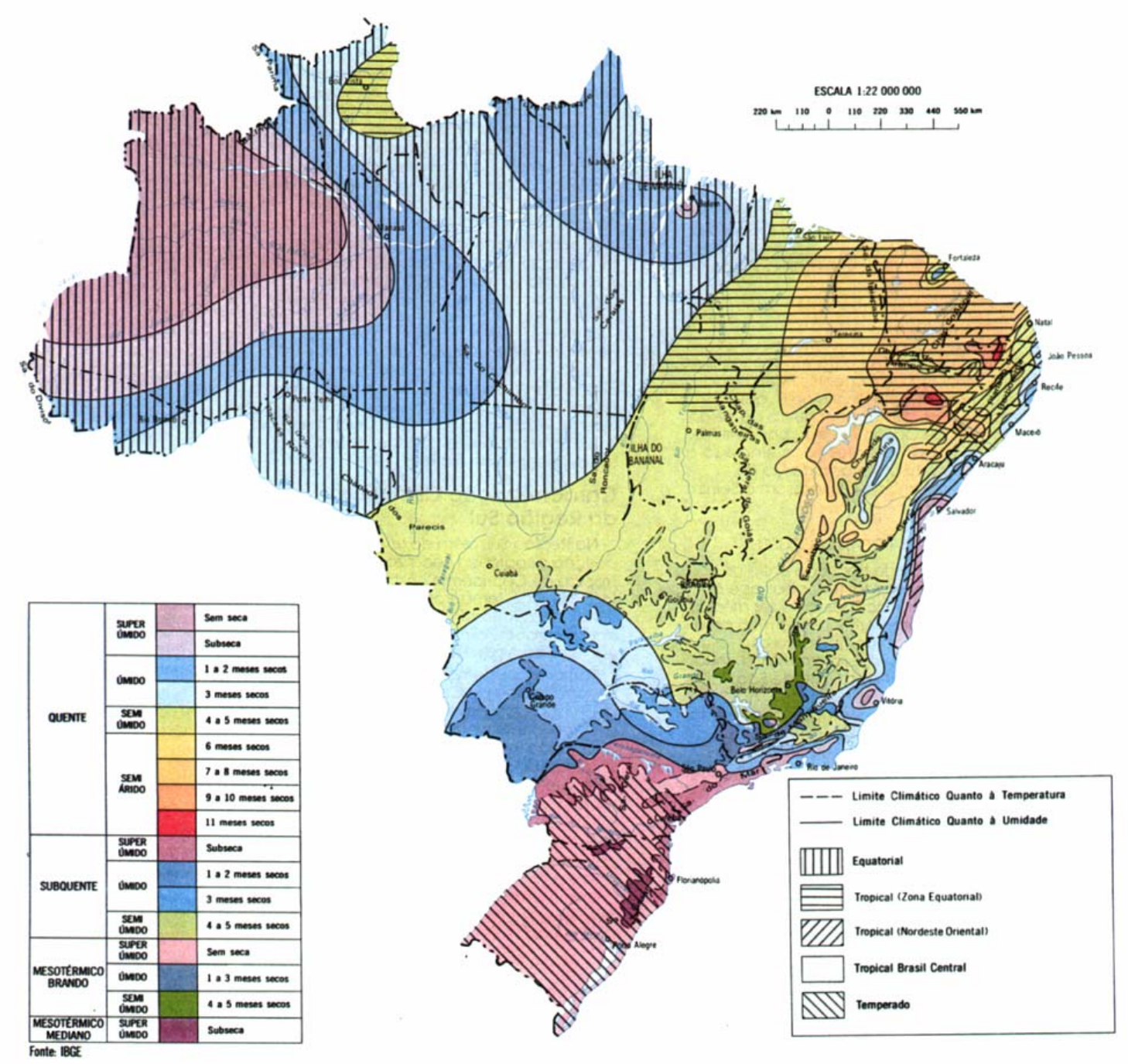

Figura 5.1 - Unidades climáticas do Brasil. (fonte: IBGE. Anuário Estatístico)

\footnotetext{
${ }^{1}$ ver anexo 1.
} 


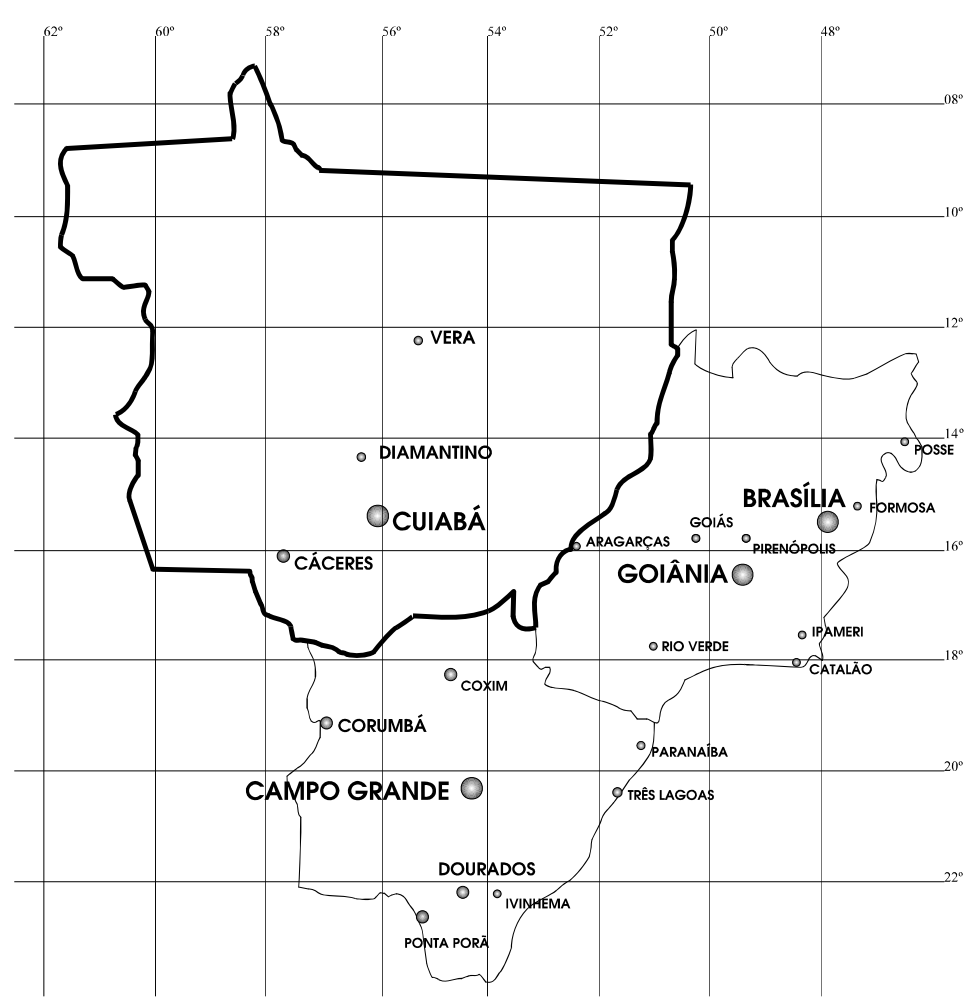

Figura 5.2 - Localização dos postos do INMET na região Centro-Oeste.

Tabela 5.1 - Postos do INMET na região Centro-Oeste.

\begin{tabular}{|l|l|l|l|l|l|}
\hline MUNICíPIO & ESTADO & LATITUDE & LONGITUDE & $\begin{array}{l}\text { ALTIT. } \\
\text { POSTO }\end{array}$ & $\begin{array}{l}\text { PERÍODO } \\
\text { MEDIÇÕES }\end{array}$ \\
\hline Cuiabá & MT & 15.33 & 56.07 & 151.34 & $61 / 90$ \\
Cáceres & MT & 16.03 & 57.41 & 118 & $71 / 90$ \\
Diamantino & MT & 14.24 & 56.27 & 286.3 & $62 / 90$ \\
Vera & MT & 12.12 & 56.30 & 415 & $73 / 90$ \\
Aragarças & GO & 15.54 & 52.14 & 345 & $68 / 90$ \\
Catalão & GO & 18.11 & 47.57 & 840.47 & $61 / 90$ \\
Formosa & GO & 15.32 & 47.20 & 912 & $61 / 90$ \\
Ipameri & GO & 17.43 & 48.10 & 772.99 & $77 / 90$ \\
Goiânia & GO & 16.40 & 49.15 & 741.48 & $61 / 90$ \\
Goiás & GO & 15.55 & 50.08 & 512.22 & $61 / 90$ \\
Pirenópolis & GO & 15.15 & 48.58 & 740 & $76 / 90$ \\
Posse & GO & 14.06 & 46.22 & 825.64 & $76 / 90$ \\
Rio Verde & GO & 17.48 & 50.55 & 745.54 & $72 / 87$ \\
Brasília & DF & 15.47 & 47.56 & 1159.54 & $63 / 90$ \\
Campo Grande & MS & 20.27 & 54.37 & 530 & $61 / 90$ \\
Corumbá & MS & 19.05 & 57.3 & 130 & $75 / 90$ \\
Coxim & MS & 18.3 & 54.46 & 287 & $73 / 90$ \\
Dourados & MS & 22.14 & 54.59 & 452 & $72 / 90$ \\
Ivinhema & MS & 22.19 & 53.56 & 369.20 & $73 / 90$ \\
Paranaíba & MS & 19.42 & 51.11 & 331.25 & $71 / 90$ \\
$\begin{array}{l}\text { Ponta Porã } \\
\text { Três Lagoas }\end{array}$ \\
(fonte: Brasil. Ministério da Agricultura e Reforma Agrária. INMET. Normais Climatológicas $1961-1990)$. & $61 / 90$ \\
\end{tabular}




\subsubsection{Características físicas da região}

O Centro-Oeste ocupa $1.604 .852 \mathrm{Km}^{2}$, que equivalem a $18,86 \%$ do território nacional. Compreende os estados de Goiás, Mato Grosso do Sul, Mato Grosso e o Distrito Federal. As diversas formações do relevo e a grande extensão latitudinal conferem à região uma diversificação térmica só superada pela região sudeste. São vastas superfícies baixas, com menos de $200 \mathrm{~m}$, extensas chapadas sedimentares, de 700m a 900m e as elevadas superfícies cristalinas, de 900m a 1200m (fig.5.3). Já o mecanismo atmosférico, que determina um ritmo sazonal de precipitação, com máximas no verão e mínimas no inverno, garante uma certa homogeneidade à região (NIMER, 1979).

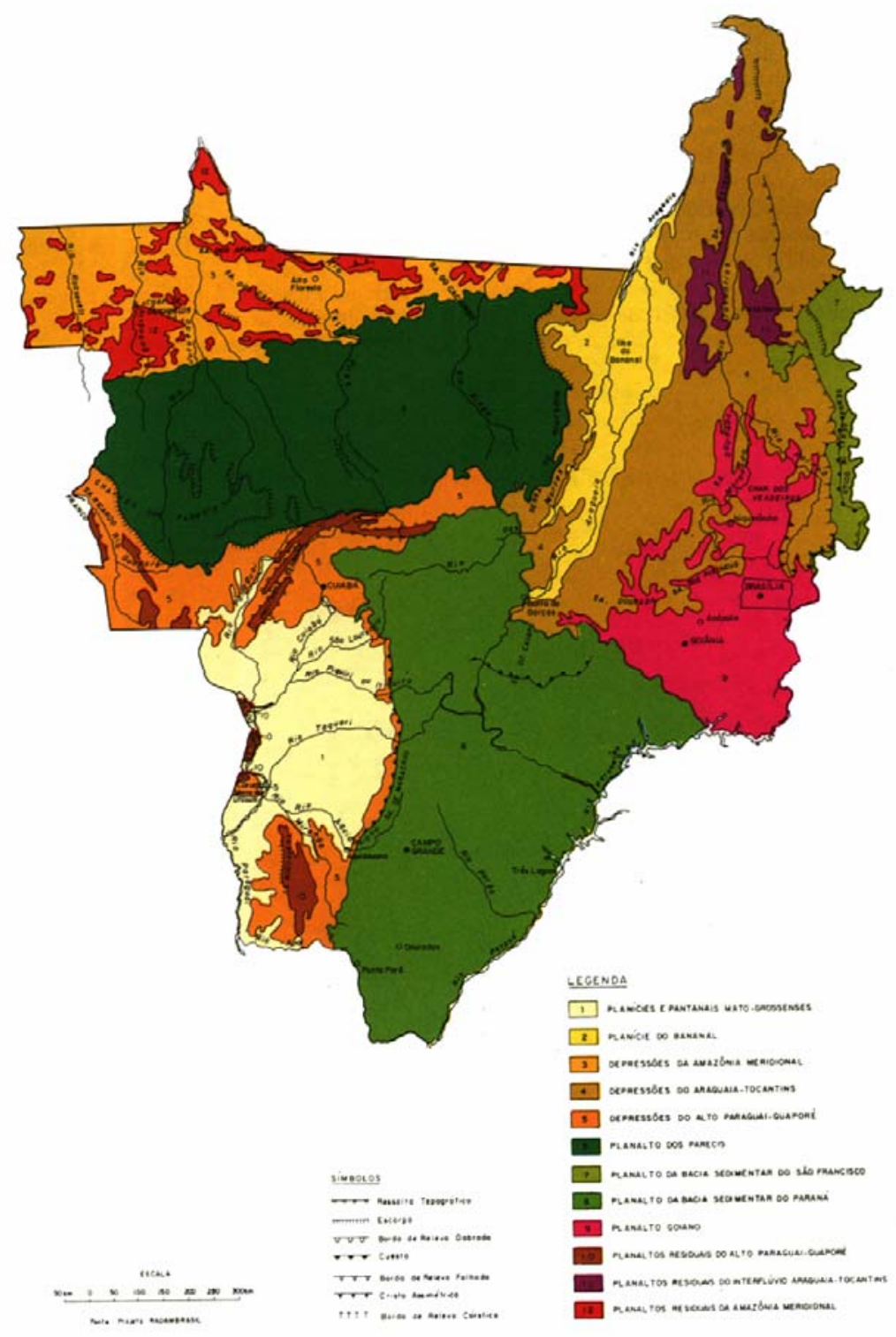

Figura 5.3 - Relevo. Região Centro-Oeste. (fonte: IBGE. Geografia do Brasil v.1.p. 55) ${ }^{2}$

\footnotetext{
${ }^{2}$ Os mapas do IBGE aqui apresentados são anteriores à divisão territorial do estado de Goiás, cujo norte é hoje o estado de Tocantins, e que não mais pertence à região Centro-Oeste.
} 
O relevo caracteriza-se pela predominância do extenso Planalto Central, com terrenos antigos e fortemente aplainados pela erosão, que deram origem aos chapadões, como dos Parecis e dos Guimarães. A parte oeste de Mato Grosso do Sul e sudoeste de Mato Grosso é ocupada pela depressão do pantanal mato-grossense, que é cortada pelo rio Paraguai, cujas cheias inundam a depressão (fig.5.4). A vegetação é típica do cerrado na maior parte da região, e complexa no pantanal, que possui uma formação mista, com espécies típicas de floresta, cerrado, campos gerais e caatinga (fig.5.5); no inverno e na primavera permanece seca; no verão e no outono é inundada pela cheia dos rios, cujo escoamento é dificultado pela baixa declividade do terreno (NIMER, 1979).

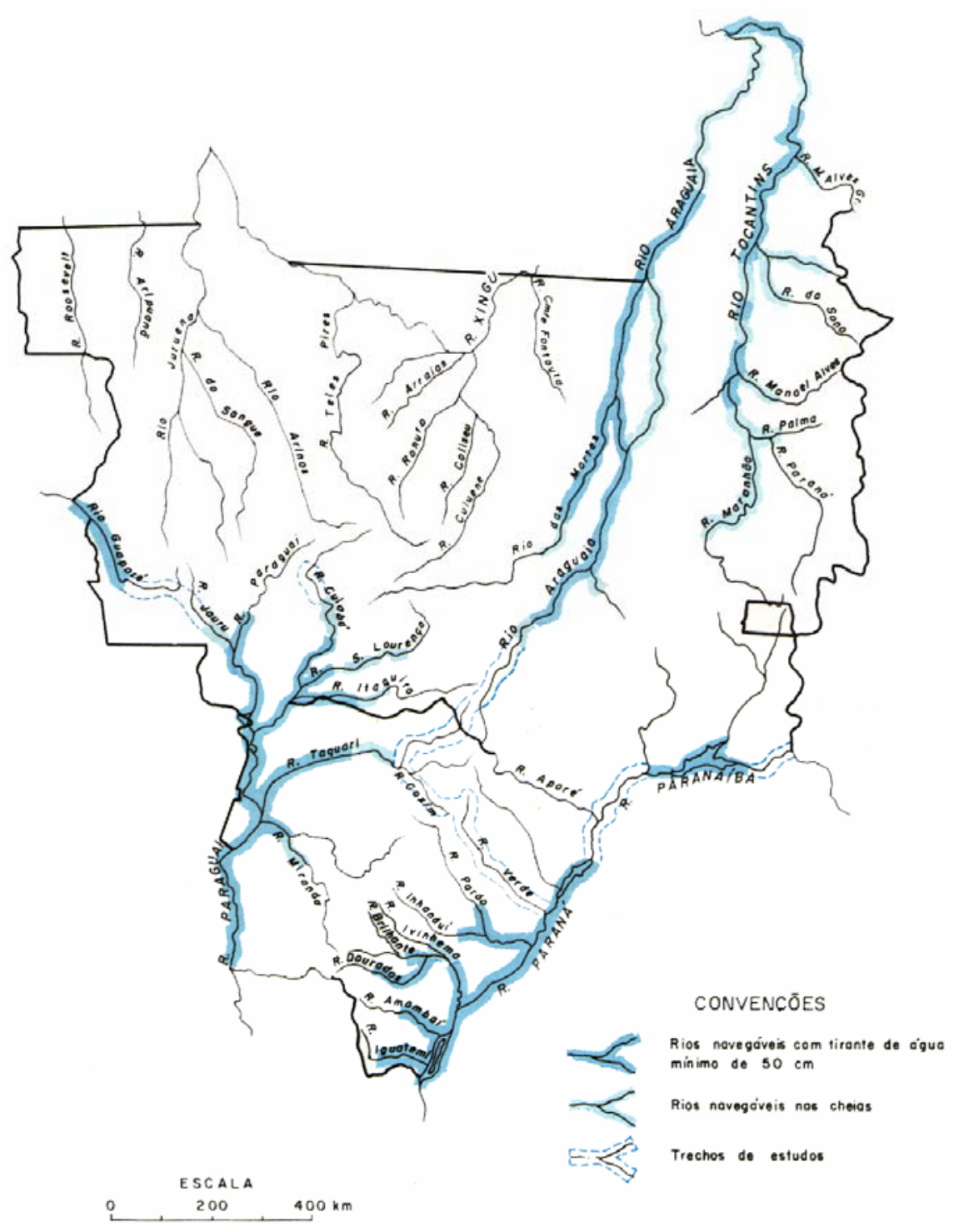

Figura 5.4 - Hidrografia. Região Centro-Oeste. (fonte: IBGE. Geografia do Brasil v.1.p.55) 
Mato Grosso ocupa uma área de $881.001 \mathrm{Km}^{2}$. Situa-se entre os paralelos $7^{\circ} 20^{\prime} 39^{\prime}$ e $18^{\circ} 10^{\prime} 00^{\prime}$ de latitude sul e os meridianos de $50^{\circ} 13^{\prime} 48^{\prime \prime}$ e $61^{\circ} 31^{\prime} 00^{\prime \prime}$ a oeste de Greenwich. Está contido na Zona Intertropical, ficando relativamente próximo ao Equador. Por essa razão não há grandes diferenças entre as estações, e a temperatura é bastante alta durante boa parte do ano. Tem como limites os estados do Amazonas e Pará ao norte, Tocantins e Goiás ao leste, Mato Grosso do Sul ao sul, Rondônia e também a Bolívia a oeste. É banhado principalmente pelos rios Juruena, Teles Pires, Xingu, Araguaia, Paraguai, Piqueri, São Lourenço, das Mortes, e Cuiabá.

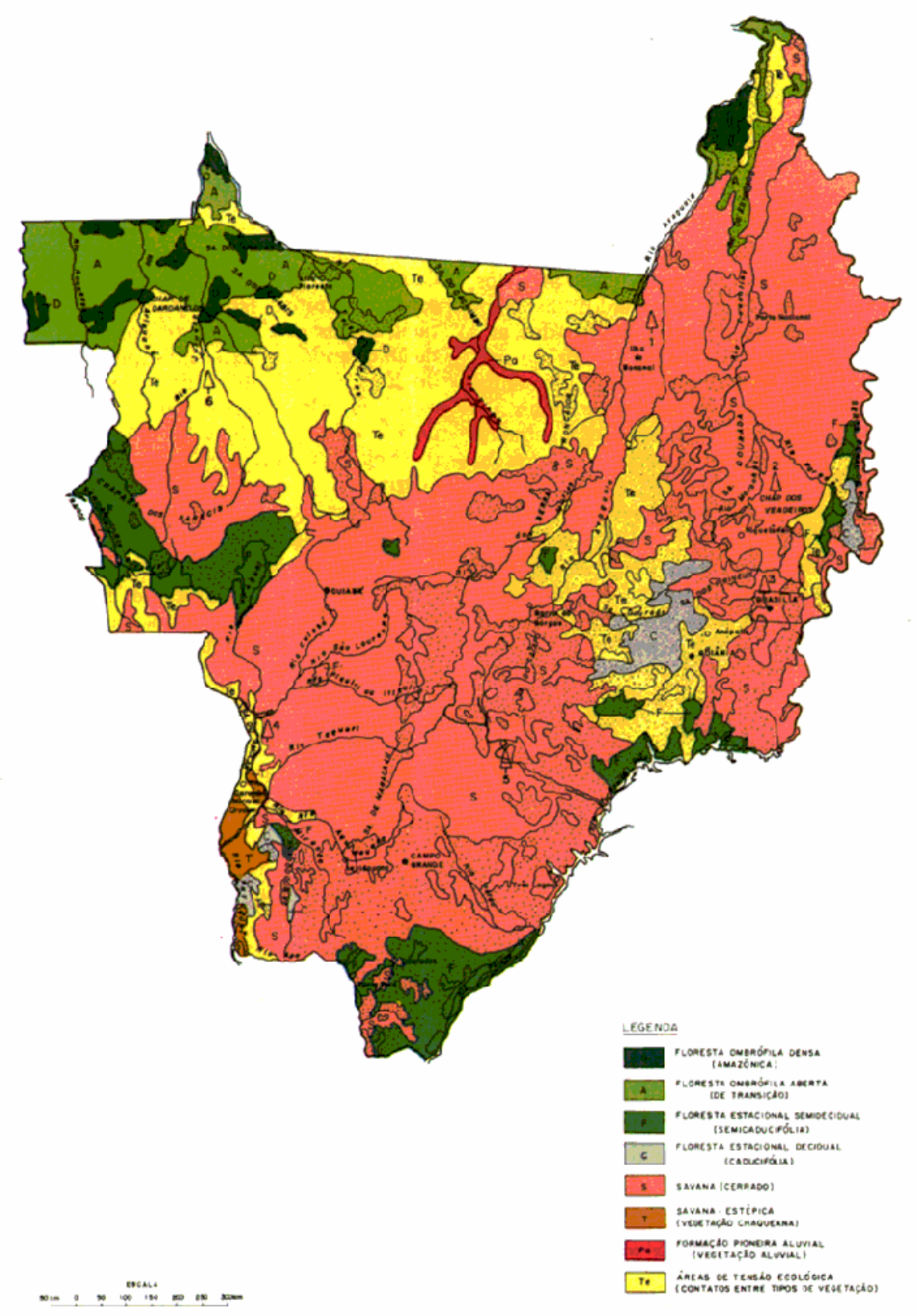

Figura 5.5 - Vegetação. Região Centro-Oeste. (fonte: IBGE. Geografia do Brasil v.1.p.118) 
Em Mato Grosso o relevo é modesto, formado por planícies entremeadas por morros. O principal rio é o Cuiabá, pertencente à Bacia Platina. A cobertura vegetal apresenta três formações principais: floresta, cerrado e complexo do Pantanal. Cerca de $43 \%$ do Mato Grosso está recoberto por vegetação não florestal, com predomínio do cerrado, com árvores baixas, de menos de $10 \mathrm{~m}$ de altura e menos numerosas do que os arbustos. Sua estrutura compreende dois extratos: o superior, formado por árvores e arbustos, e o inferior, composto por uma cobertura descontínua de gramíneas e ervas. As árvores têm troncos e galhos retorcidos, de caule grosso e casca espessa.

É marcante o caráter de continentalidade da região. Cuiabá localiza-se a $15^{\circ} 33^{\prime}$ de latitude sul e $56^{\circ} 07^{\prime}$ de longitude oeste, e é o Centro Geodésico da América do Sul, com altitude média inferior a 200m. O município possui área de $12.790 \mathrm{Km}^{2}$; tem como limites os municípios de Chapada dos Guimarães e Rosário Oeste ao norte, Campo Verde a leste, Santo Antônio do Leverger ao sul, Acorizal e Várzea Grande a oeste, e situa-se a $1.133 \mathrm{Km}$ de Brasília.

\subsubsection{Classificações climáticas}

As classificações climáticas auxiliam a estabelecer as generalidades das regiões climáticas, que são qualquer porção da superfície da Terra com elementos climáticos e características similares. As numerosas regiões climáticas podem ser agrupadas nos principais tipos climáticos. Utilizam-se, neste trabalho, as classificações do IBGE, Köppen e Trewartha.

\subsubsection{IBGE}

Segundo o IBGE (1994, p.108), a região tem clima quente semi-úmido, na faixa Tropical Brasil Central, com 4 a 5 meses secos. Na primavera-verão são comuns as temperaturas elevadas. As máximas de setembro e outubro (meses mais quentes) oscilam entre $30^{\circ} \mathrm{C}$ e $36^{\circ} \mathrm{C}$. O inverno é uma estação amena, embora ocorram com frequência temperaturas baixas, em razão da invasão do ar polar - as chamadas friagens - muito comuns nessa época do ano, e que geralmente não se mantêm por mais de dois dias.

A distribuição sazonal de chuvas é tipicamente tropical, com máxima no verão e mínima no inverno. Mais de $70 \%$ do total de chuvas acumuladas durante o ano se precipitam de novembro a março. O inverno é excessivamente seco, principalmente o mês de julho.

\subsubsection{Köppen}

Classificação publicada pela primeira vez em 1918, pelo Dr. Wladimir Köppen, da Universidade de Graz, na Áustria. É baseada nas médias anuais e mensais de temperatura e precipitação. A classificação de Köppen é o sistema mais empregado, baseado na observação do crescimento das plantas. Dois elementos principais determinam a cobertura vegetal:

- temperatura - que define as espécies possíveis;

- chuva - que permitirá ou não a sua existência, pois a escassez de água e a secura do ar só admitem vegetação sobre fontes subterrâneas, os oásis, ou então resistentes à seca, quando dotadas de espinhos e reservas de água. 
Para Köppen, a vegetação nativa é a melhor expressão da totalidade de um clima, e as plantas são instrumentos meteorológicos capazes de medir todos os elementos climáticos integrados. Por esse motivo, muitos limites climáticos são definidos em função da vegetação. "El calor influye en la vegetación sobre todo mediante la existencia o la ausencia de determinados géneros o asociaciones de vegetales, por la riqueza de sus formas o por la exuberancia de su desarrollo, y mucho menos, en cambio, mediante el carácter de la vegetación en general. Sólo donde el calor no basta para que prospere una vegetación arbórea o donde la falta de calor hace desaparecer cualquier clase de vegetación, el aspecto del paisaje llega a sufrir una transformación de los órganos vegetales a las temperaturas se notan poco en el paisaje.” (KÖPPEN, 1948, p.153-155)

Segundo TREWARTHA (1954,p.226), existem algumas críticas a essa classificação. Porém, ela tem seus méritos como estratégia de ensino, e é largamente aceita nos Estados Unidos e no exterior. As principais críticas são:

- a escassez de observações meteorológicas em grandes partes do mundo faz com que uma classificação climática com limites bastante rígidos seja insatisfatória, gerando algumas incoerências;

- alguns limites climáticos foram estabelecidos considerando-se a paisagem natural, outros foram estabelecidos arbitrariamente;

- fórmulas desenvolvidas para climas em terras baixas foram utilizadas para altitudes maiores.

Köppen adota uma nomenclatura simbólica para designar tipos climáticos, através de uma combinação de letras com sentido bastante preciso. São cinco zonas fundamentais de clima que, partindo do equador em direção aos pólos, agrupam-se da seguinte maneira:
A $\rightarrow$ zona tropical chuvosa, sem inverno;
$\mathrm{B} \rightarrow$ duas zonas secas;
$\mathrm{C} \rightarrow$ duas zonas temperadas, sem uma capa de neve regular;
$\mathrm{D} \rightarrow$ uma zona boreal de neve e bosque, com verão e inverno, em que ambas as estações se apresentam de forma perfeitamente marcada (esta zona não existe no hemisfério austral);
$\mathrm{E} \rightarrow$ duas zonas polares com clima de neve e fora do limite de vegetação arbórea.

Na zona tropical A pode-se encontrar:

- abundantes chuvas em todos os meses, principalmente no Equador;

- temporadas de seca mais ou menos bem marcadas.

Como nesta zona todos os meses apresentam mais ou menos as mesmas temperaturas, o único fator decisivo com respeito à vegetação é o grau de intensidade das temporadas de seca e os meses em que elas ocorrem. Para uma denominação mais precisa são utilizados os índices $f$ para indicar clima de selva, com chuva contínua durante todo o ano e $w$ para clima de savana, onde as chuvas são periódicas 
e o inverno é seco. Os índices $i, g, g^{\prime}, m$, w’ e w” também são utilizados para indicar pequenas variações de temperatura, vento, umidade e frequência de chuvas.

Segundo Köppen, o clima da região é do tipo $A w$, tropical com verão úmido e inverno seco. O tipo Aw tem estação seca no inverno, e as chuvas só ocorrem quando o sol alcança maior altura sobre a região. Conforme a latitude pode haver também uma pequena seca no verão, chamada de veranico. A variabilidade das precipitações é sempre acentuada, havendo anos de escassez e outros de inundações. Dada a regular distância do equador, $A w$ apresenta maior amplitude anual de temperatura que o tipo $A f$, em média $12^{\circ} \mathrm{C}$, e as temperaturas mais elevadas ocorrem antes do rigor do verão, por este ser chuvoso. A vegetação, afetada pela seca, limita-se a bosques ralos ou gramíneas.

\subsubsection{Thornthwaite}

A classificação de Thornthwaite emprega três índices climáticos - eficiência da precipitação, concentração sazonal de chuvas e eficiência térmica - para diferenciar e localizar limites climáticos. Esses limites são determinados comparando-se precipitação e evapotranspiração, independentemente da vegetação, tipo e uso do solo. Ao contrário de Köppen, aqui a vegetação é considerada apenas como um mecanismo físico pelo qual a água é transportada do solo para a atmosfera. Thornthwaite também emprega uma combinação de letras para designar tipos climáticos:

Segundo a eficiência da precipitação:

$$
\begin{aligned}
& \mathrm{A} \rightarrow \text { chuvoso } \\
& \mathrm{B} \rightarrow \text { úmido } \\
& \mathrm{C} \rightarrow \text { subúmido } \\
& \mathrm{D} \rightarrow \text { semi-árido } \\
& \mathrm{E} \rightarrow \text { árido }
\end{aligned}
$$

Segundo a temperatura: $\quad \mathrm{A}^{\prime} \rightarrow$ tropical

$$
\begin{aligned}
& \mathrm{B}^{\prime} \rightarrow \text { mesotérmico } \\
& \mathrm{C}^{\prime} \rightarrow \text { microtérmico }
\end{aligned}
$$$$
D^{\prime} \rightarrow \text { taiga }
$$$$
\mathrm{E}^{\prime} \rightarrow \text { tundra }
$$$$
\mathrm{F}^{\prime} \rightarrow \text { gelo permanente }
$$

Segundo a distribuição sazonal da precipitação:

$r \rightarrow$ precipitação em todas as estações

$\mathrm{w} \rightarrow$ precipitação deficiente no inverno

$\mathrm{d} \rightarrow$ precipitação deficiente em todas as estações

$\mathrm{s} \rightarrow$ precipitação deficiente no verão

Segundo esta classificação, a região tem clima subúmido tropical, com precipitação deficiente durante o inverno, tipo $C A^{\prime}$ w, com vegetação característica de pastagem (TREWARTHA, 1957, p.227). 


\subsubsection{Características climáticas}

Segundo o IBGE (1988, p.31), o clima quente domina a região Centro-Oeste (fig.5.6). Sua característica mais marcante é a frequência quase que diária de temperaturas altas, sobretudo em Mato Grosso e Goiás, onde nos meses mais quentes, setembro e outubro, podem ocorrer máximas superiores a $40^{\circ} \mathrm{C}$. A maior parte da região não tem sequer um mês com temperatura média inferior a $20^{\circ} \mathrm{C}$ e as temperaturas médias anuais são, em geral, elevadas (fig. 5.7).

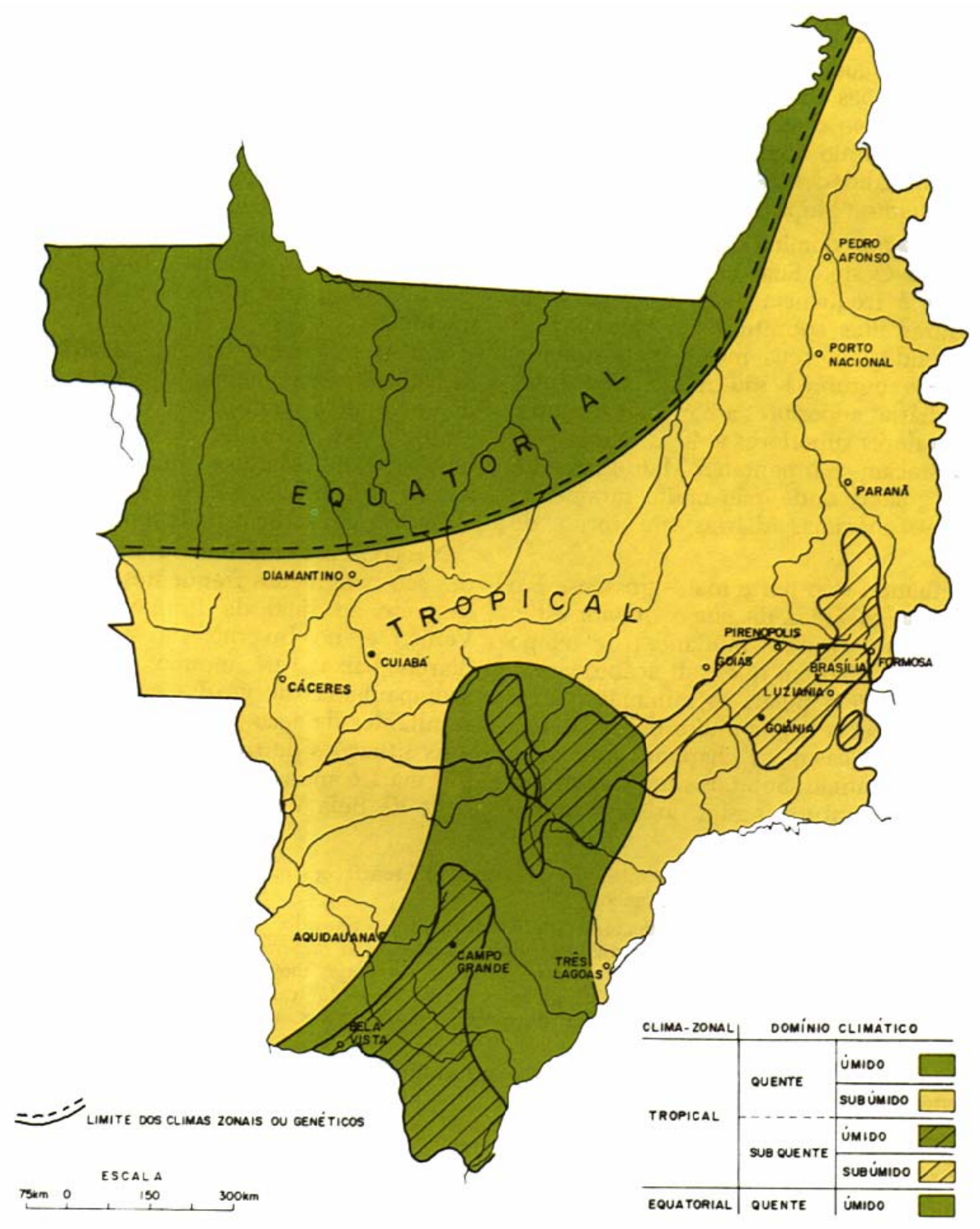

Figura 5.6 - Tipologia Climática. Região Centro-Oeste. (fonte: IBGE. Geografia do Brasil v.1.p.32)

Outra característica importante é o ritmo sazonal de precipitação bastante marcado, com uma nítida estação seca, no período de inverno. As temperaturas são constantemente altas, com pequenas diferenças durante o ano. O mês mais quente 
(setembro ou outubro) pode vir antes do período chuvoso (outubro a março), no qual as nuvens e precipitações mais pesadas tendem a baixar a temperatura. Geralmente pode-se identificar três períodos distintos em função da temperatura:

- estação seca e mais fresca, no inverno;

- estação seca e a mais quente, um pouco antes das chuvas;

- estação úmida e quente, durante as chuvas, no verão.

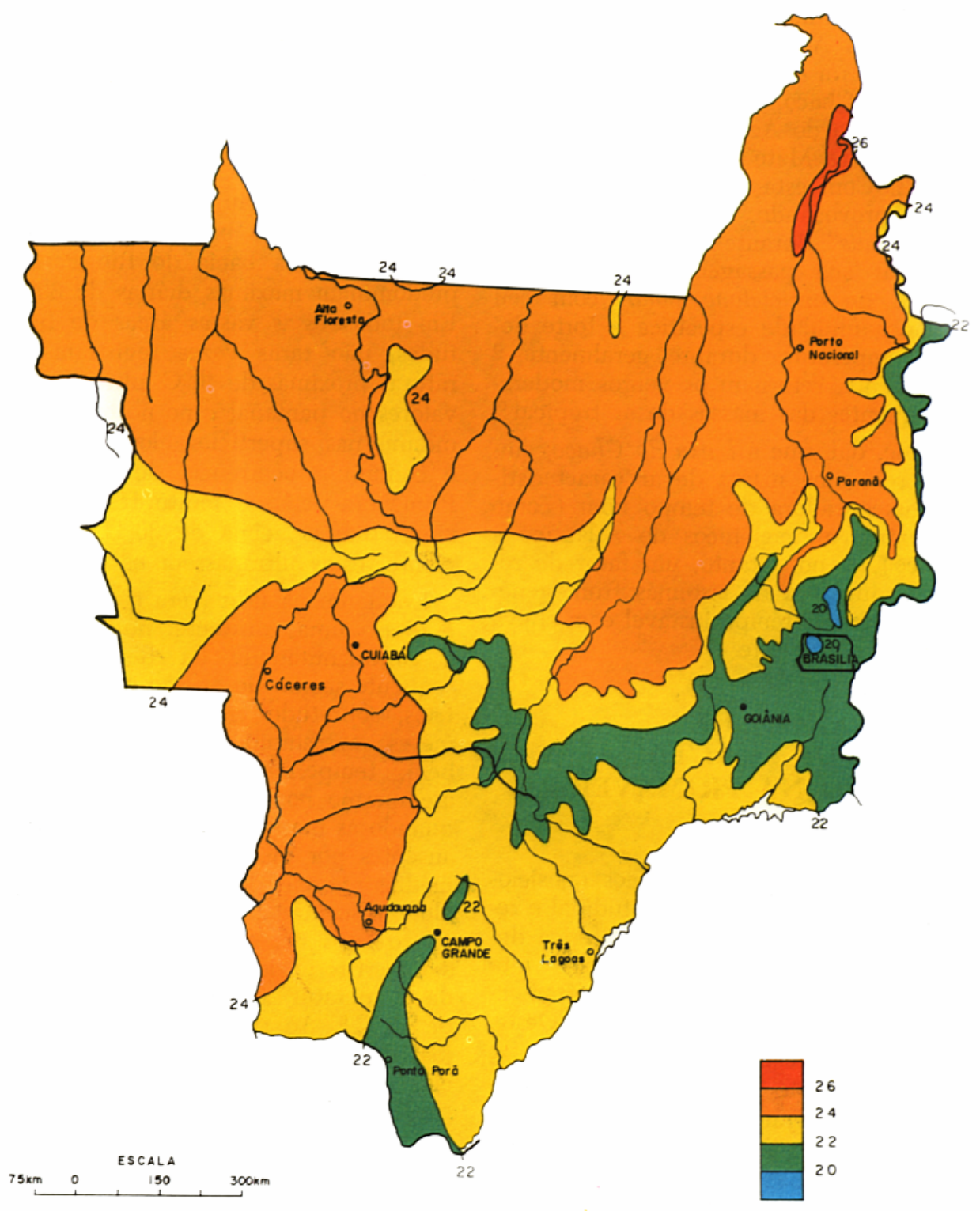

Figura 5.7 - Temperatura Média do Ano. Região Centro-Oeste. (fonte: IBGE. Geografia do Brasil. v.1.p.26)

Segundo o IBGE (1988, p.25), na primavera, é comum ocorrer um forte calor em toda a região Centro-Oeste, principalmente no norte de Goiás e Mato Grosso. Essas 
altas temperaturas da primavera-verão podem ser atribuídas à ação da Massa Tropical Continental (CAMPELO Jr. et al, 1991, p.549).

No começo das chuvas, as temperaturas assemelham-se às do tipo climático $A f$ (clima tropical chuvoso, sem estação seca) e Am (clima tropical chuvoso, com pequena estação seca), que predominam no norte do Mato Grosso e na região amazônica. A amplitude térmica diária diminui e, apesar do calor não ser tão intenso como na estação quente e seca, as altas taxas de umidade do ar fazem com que o ambiente pareça mais abafado, aumentando a sensação de desconforto.

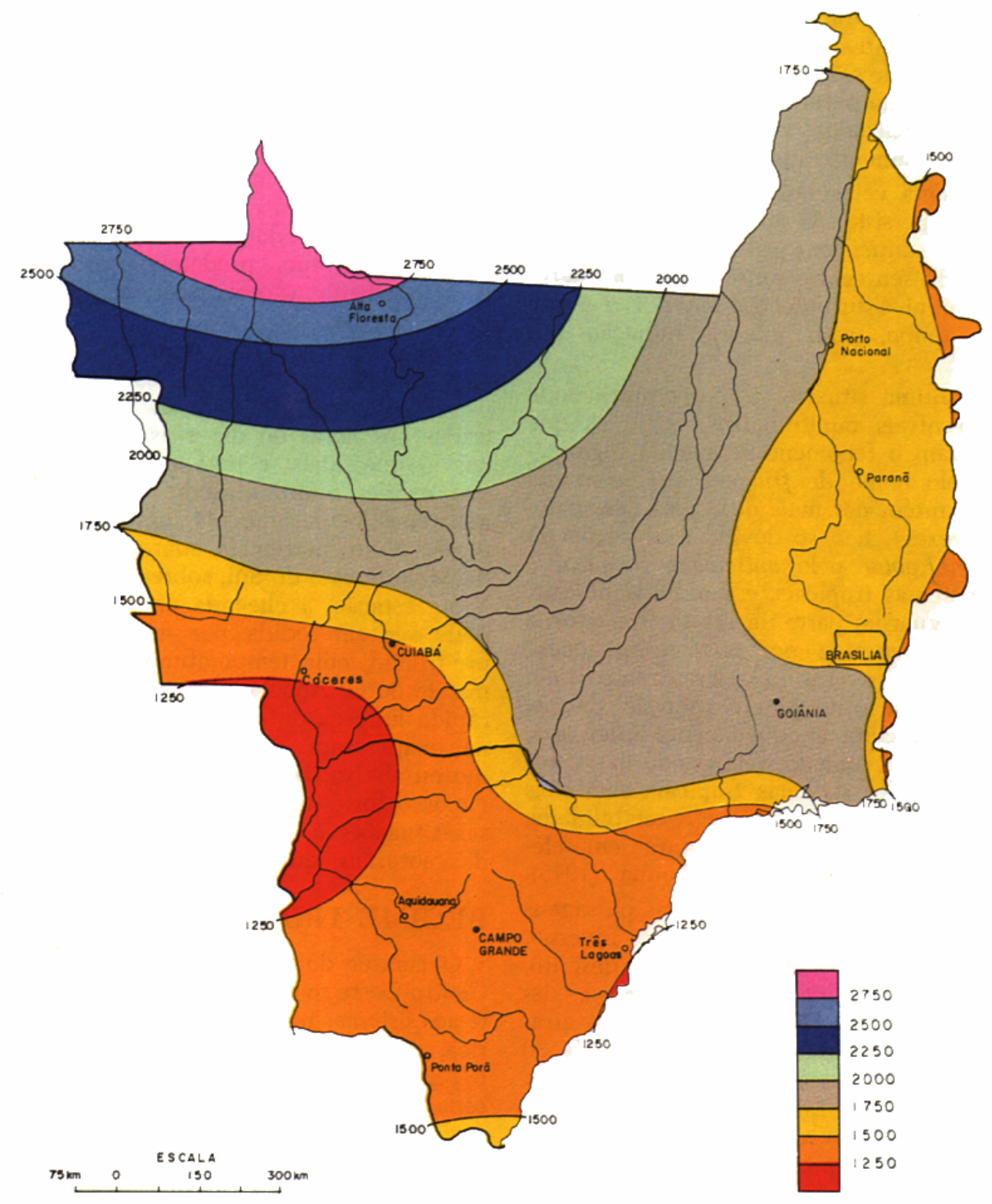

Figura 5.8- Altura Média da Precipitação Anual. Região Centro-Oeste. (fonte: IBGE. Geografia do Brasil. v.1.p.28)

A temperatura também tende a subir logo após o período chuvoso, em função do céu se apresentar mais claro e a atmosfera, mais seca. Porém, durante a noite, nesse mesmo período, a perda de calor para atmosfera é um pouco maior, tornando as noites mais agradáveis. No inverno a temperatura continua alta, mas, como a 
umidade do ar é baixa, o calor não é tão opressivo, e as noites tornam-se mais amenas.

Como a temperatura não varia muito, a precipitação torna-se o elemento fundamental para diferenciar os tipos climáticos nas baixas latitudes (fig.5.8). O regime de chuvas em toda a região Centro-Oeste deve-se quase que exclusivamente aos sistemas regionais de circulação atmosférica. A influência do relevo é de tão pouca importância que não chega a interferir nas tendências gerais determinadas pelos fatores dinâmicos. De maneira geral, as precipitações máximas ocorrem durante o verão, e as mínimas, no inverno, com baixos índices nos meses de junho, julho e agosto. Em quase toda a região Centro-Oeste, mais de $70 \%$ do total de chuvas acumuladas durante o ano precipitam-se de novembro a março, com trimestre mais chuvoso em janeiro-feveiro-março, ao norte; dezembro-janeiro-fevereiro, no centro; e novembro-dezembro-fevereiro, no sul. Na estação chuvosa ocorrem violentas tempestades, provocando inundações, entremeadas por períodos de transição sob o calor do sol intenso.

O inverno é seco, porém, a estação seca, apesar dos baixos índices de umidade do ar, torna-se bem-vinda depois do calor úmido e abafado do período chuvoso. A paisagem torna-se ressecada e o ar recebe a poeira e a fumaça das queimadas. $\mathrm{O}$ trimestre mais seco é junho-julho-agosto, e o mês que o antecede, maio, e o que o sucede, agosto, são muito pouco chuvosos.

Apesar de boa parte da região não apresentar um mês sequer com temperatura média inferior a $20^{\circ} \mathrm{C}$, em Cuiabá ocorrem, em média, 17 dias por ano com temperatura média inferior a $20^{\circ} \mathrm{C}$ e apenas 8 dias por ano com temperatura média inferior a $18^{\circ} \mathrm{C}$, no período de maio a setembro (CAMPELO Jr. et al 1991, p.550).

No inverno frentes frias podem chegar até a região, provocando o fenômeno conhecido localmente como friagem, e que se caracteriza por uma queda brusca e rápida da temperatura, provocada por penetração dos ventos frios da massa polar atlântica, que avança pela vertente leste dos Andes argentinos e bolivianos e atinge o Centro-Oeste. "São ondas de frio, que chegam repentinamente, permanecem por alguns dias e se esvaem, até que venha outra, numa frequência de 4 a 6 por ano, quando muito. Nos intervalos há sempre dias não muito quentes e noites frescas.”(PÓVOAS, 1983, p.43)

Segundo o IBGE (1988, p.27), a frequência mensal da friagem é muito rara em abril, costuma tornar-se presente em maio e atinge seu máximo normalmente em julho, no rigor do inverno, decaindo, a seguir, até setembro ou outubro. A frequência média das friagens é de três por ano, mas em certos anos não se dá nenhuma, enquanto em outros são sentidas cinco ou mais invasões.

As ondas de frio que atingem a região geralmente não são as mesmas que chegam aos estados do sul do país, porque estas, desviadas quase sempre para nordeste, pelo relevo litorâneo, desfazem-se sobre o Oceano Atlântico. "As que chegam a Cuiabá vêm diretamente de Buenos Aires e Assunção, trazidas pelo vento sul que encana no corredor formado pela planície do Pantanal, entre as barreiras do planalto brasileiro de um lado e dos contrafortes dos Andes, de outro. Quando intensas, chegam à Cidade Verde exatamente quatro dias depois que as temperaturas registraram suas marcas mais baixas na capital argentina.(...) Costumava-se dizer, 
outrora, em Cuiabá, que a noite de São João era a mais fria do ano. E geralmente era. Naquela época o frio vinha com um pouco de garoa, no estilo do inverno paulistano, e muita cerração. Todavia a expansão da área construída da cidade contribuiu para modificar isso. Isso e muita cousa mais...” (PÓVOAS, 1983, p.43).

\subsection{Clima urbano na cidade de Cuiabá}

Este item enfatiza as alterações no clima provocadas pela urbanização, os fatores agravantes provocados pelas características de depressão geográfica em áreas urbanas, e apresenta resultados de outros estudos mostrando o mapeamento das ilhas de calor e ilhas secas já detectadas na cidade de Cuiabá, relacionando-as com uso e ocupação do solo urbano. Conforme justificativas para a escolha da amostra, ${ }^{3}$ vai se detalhar as condições de clima urbano em Cuiabá ${ }^{4}$ dentro do universo das cidades brasileiras na região de clima tropical continental. Do mesmo modo as demais cidades da região e as novas que ainda estão por vir podem sofrer os mesmos problemas ambientais no futuro.

\subsubsection{Registro de dados climáticos}

Em Cuiabá as pesquisas meteorológicas são feitas desde 1901 pelo Observatório Meteorológico Dom Bosco, fundado e mantido pelos padres salesianos. Em 1911 o Observatório integrou-se ao INEMET - Instituto Nacional de Meteorologia, e continuou sendo operado pelos salesianos até 1966. Com o fechamento do Observatório a 31 de dezembro desse mesmo ano, o arquivo existente foi transferido para o $9^{\circ}$ Distrito de Meteorologia, e as medições passaram a ser feitas pelo INEMET, atual DNMET - Departamento Nacional de Meteorologia, do Ministério da Agricultura e Reforma Agrária. O posto localiza-se no município vizinho de Várzea Grande, a menos de $1 \mathrm{Km}$ após a travessia da ponte sobre o Rio Cuiabá.

De 1901 a 1940, os instrumentos ficaram no pátio do Colégio São Gonçalo, em solo gramado, sem obstáculos próximos, na área central da cidade. De 1941 a 1966, ficaram instalados no terraço, acima do telhado do mesmo Colégio. A partir de 1967 o arquivo foi transferido para o Distrito de Meteorologia do INMET; os dados de 1967 a 1969 não estão disponíveis. Em 1970 houve o reinício das medições, quando os instrumentos foram mudados de lugar mais duas vezes, mas sob condições ambientais semelhantes. A partir de 1978 as medições passaram a ser feitas no $9^{\circ}$ Distrito de Meteorologia, em Várzea Grande. As médias mensais e anuais até 1966 foram registradas nos quatro volumes do livro de Jorge BOMBLED ([s.d.]), Meio Século de Meteorologia, o principal responsável pela coleta e registro desses dados na época.

\subsubsection{Alterações no clima provocadas pela urbanização}

A cidade modifica o clima através das alterações em sua superfície, produzindo aumento de calor, modificações no fluxo de vento, diminuição da umidade relativa, e diminuição da infiltração da água das chuvas, em função do aumento da superfície impermeável formada pela pavimentação e área construída. Isso ocorre porque a

\footnotetext{
${ }^{3}$ ver capítulo 1.

${ }^{4}$ ver dados climáticos no anexo 1.
} 
substituição dos materiais naturais pelos materiais urbanos provoca mudanças nos processos de absorção, transmissão e reflexão, e nas características da atmosfera local.

A temperatura nas cidades é, em geral, $0,5^{\circ} \mathrm{C}$ a $1,0^{\circ} \mathrm{C}$ superior à do campo, com uma diferença maior pela manhã e à noite, e menor à tarde, mas sempre mais intensa no verão. Também, como o resfriamento oriundo da radiação à noite é maior no campo, a amplitude térmica diária torna-se menor nas cidades. Nas áreas urbanas a umidade é em média menor que nos campos em volta, parte devido ao revestimento do solo, que impede a evaporação, e parte pela maior temperatura.

A variação diária da umidade é geralmente inversa da variação apresentada pela temperatura, mas com uma amplitude semelhante. Assim, o máximo da umidade ocorre no nascer do sol, e o mínimo às $14 \mathrm{~h}$, com amplitude menor no inverno, e maior no verão. Nos vales, o acúmulo de nevoeiro da manhã confirma o máximo neste período.

Para a análise das alterações climáticas na cidade de Cuiabá adota-se aqui a periodização usada por MAITELLI (1994), em função da mudança de local de exposição dos instrumentos e da disponibilidade dos dados: 1920-1940, 1941-1966 e 1970-1992. O período de 1970-1992 (e que continua até os dias atuais) corresponde à urbanização mais intensa, no qual, segundo Maitelli, a temperatura mínima média (que sob condições atmosféricas estáveis acontece no período noturno) aumentou cerca de $0,073^{\circ} \mathrm{C} /$ ano (tab.5.2). Esse é o período que mais interessa aos propósitos desta tese.

Tabela 5.2 - Variações anuais nos valores de temperatura do ar. (fonte: Maitelli, 1994)

\begin{tabular}{|l|l|l|l|}
\hline & $1920-1940$ & $1941-1966$ & $1970-1992$ \\
\hline t máx. média anual & $+0,072^{\circ} \mathrm{C} /$ ano & $-0,04{ }^{\circ} \mathrm{C} /$ ano & $-0,01^{\circ} \mathrm{C} /$ ano \\
\hline t média média anual & $-0,03^{\circ} \mathrm{C} /$ ano & $+0,02^{\circ} \mathrm{C} / \mathrm{ano}$ & $-0,001^{\circ} \mathrm{C} / \mathrm{ano}$ \\
\hline t mín. média anual & $-0,021^{\circ} \mathrm{C} /$ ano & $+0,044^{\circ} \mathrm{C} / \mathrm{ano}$ & $+0,073^{\circ} \mathrm{C} /$ ano \\
\hline
\end{tabular}

Pesquisando-se a história da urbanização na amostra, percebe-se a correlação entre a urbanização mais intensa e o aumento da temperatura mínima média anual, principalmente a partir da década de 70. MAITELLI (1994) demonstra que o crescimento urbano influenciou o aumento da temperatura mínima média, com uma elevação de $0.073^{\circ} \mathrm{C}$ por ano no período de 1970 a 1992, época que coincide com um crescimento populacional mais intenso. Entretanto, não foram observados aumentos na temperatura média das médias e média das máximas nesse mesmo período. A influência da urbanização sobre o acréscimo nas temperaturas médias mínimas, provavelmente, está relacionada ao armazenamento de calor no espaço construído durante o período diurno e a sua liberação no período noturno.

Em Cuiabá, houve uma acentuada concentração de edifícios altos, nos últimos anos, no centro da cidade. Essas construções absorvem e armazenam parte da energia calorífica que, à noite, é emitida para o ar atmosférico, além de alterar o fluxo natural do vento, que dispersaria o calor. A superfície do solo urbano é quase inteiramente 
formada por materiais impermeáveis e nas áreas centrais já ocorre a diminuição de vegetação nas vias públicas e nos quintais.

A explosão populacional que se intensificou a partir da década de 70 provocou uma série de alterações na estrutura da paisagem e uso do solo urbano. O crescimento vertical vem ocorrendo de forma concentrada na parte noroeste do núcleo central e a nordeste da cidade, numa distância de aproximadamente $800 \mathrm{~m}$ da área comercial. Nos loteamentos recentes, principalmente nos bairros de casas populares, ocorrem as menores densidades de vegetação, e as áreas periféricas são dominadas pelo cerrado. A modificação dos parâmetros da superfície e da atmosfera pela urbanização dá origem à formação das chamadas ilhas de calor (fig.5.9), já caracterizadas para Cuiabá na tese de doutoramento de MAITEELI (1994).

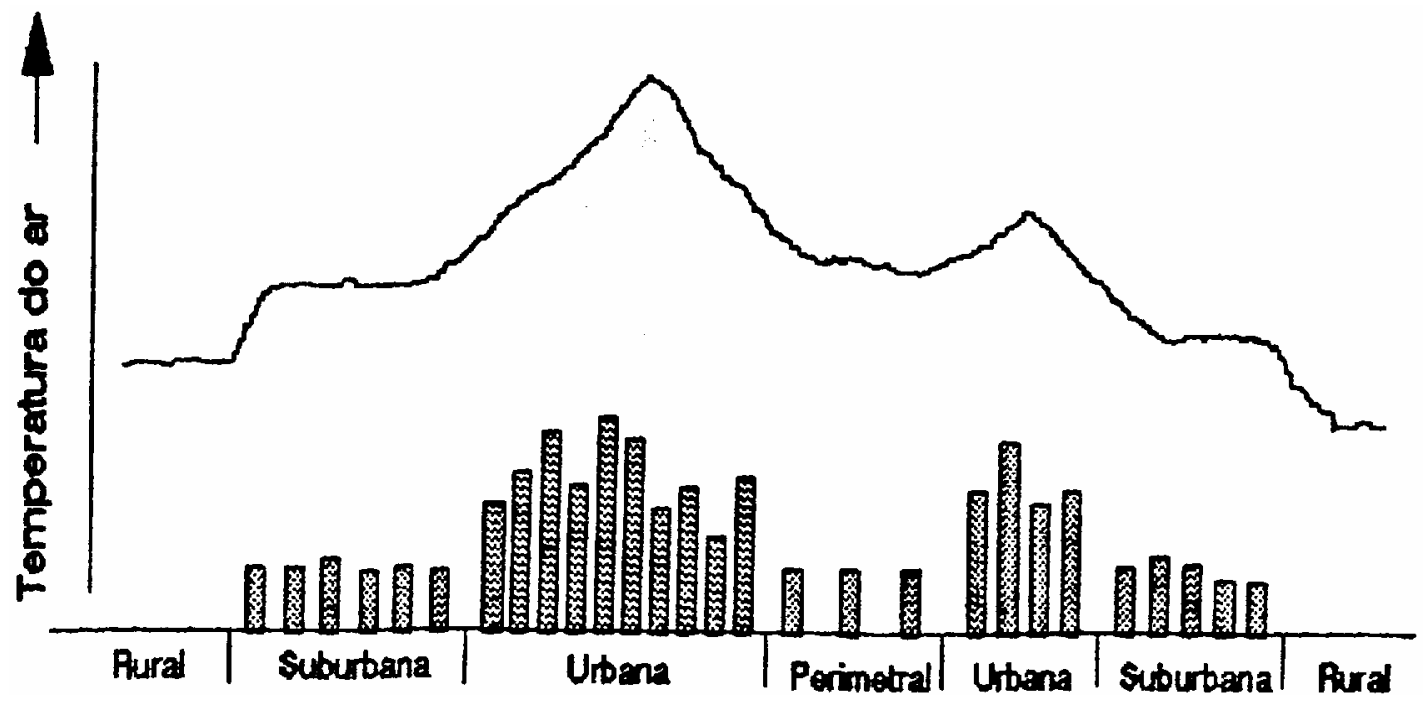

Figura 5.9- Representação esquemática, adaptada para Cuiabá, das variações da temperatura do ar e da localização da ilha de calor associada ao uso do solo urbano. (fonte: Maitelli, 1994, p.40)

A intensidade da ilha de calor urbana é definida como a maior diferença entre os valores de temperatura do ar de uma área urbana e seus arredores. A intensidade da ilha de calor está relacionada ao tamanho da cidade - tendo como parâmetro a população - à geometria das ruas e dos prédios das áreas centrais - variáveis mais recentemente representadas pelo fator de visão de céu.

Além disso, é importante considerar as características do clima local, que podem favorecer a formação de ilhas de calor e influenciar sua intensidade, e Cuiabá apresenta características marcantes de continentalidade, de depressão geográfica e ventilação fraca. A máxima intensidade da ilha de calor ocorre, geralmente, em condições de céu claro e com vento calmo. A intensidade diminui e torna-se mínima sob condições de instabilidade do ar.

A estação seca em Cuiabá caracteriza-se pela maior estabilidade do tempo, vento fraco e moderado, com noites claras e céu limpo. O sítio urbano apresenta topografia suave e está circundado por chapadões, o que confere à área urbana as características de depressão. Devido a este fator, a ventilação é fraca, com velocidade média do vento pouco superior a $1 \mathrm{~m} / \mathrm{s}$ por volta das 20:00h (fig.5.10). As maiores velocidades médias do vento são observadas por volta das 14:00h, com valores de até $2.6 \mathrm{~m} / \mathrm{s}$ no 
início da estação chuvosa (MAITELLI, 1994). Em regiões continentais as calmarias são freqüentes, intensificando o stress térmico causado pela combinação de altas temperaturas e umidade durante a estação chuvosa.

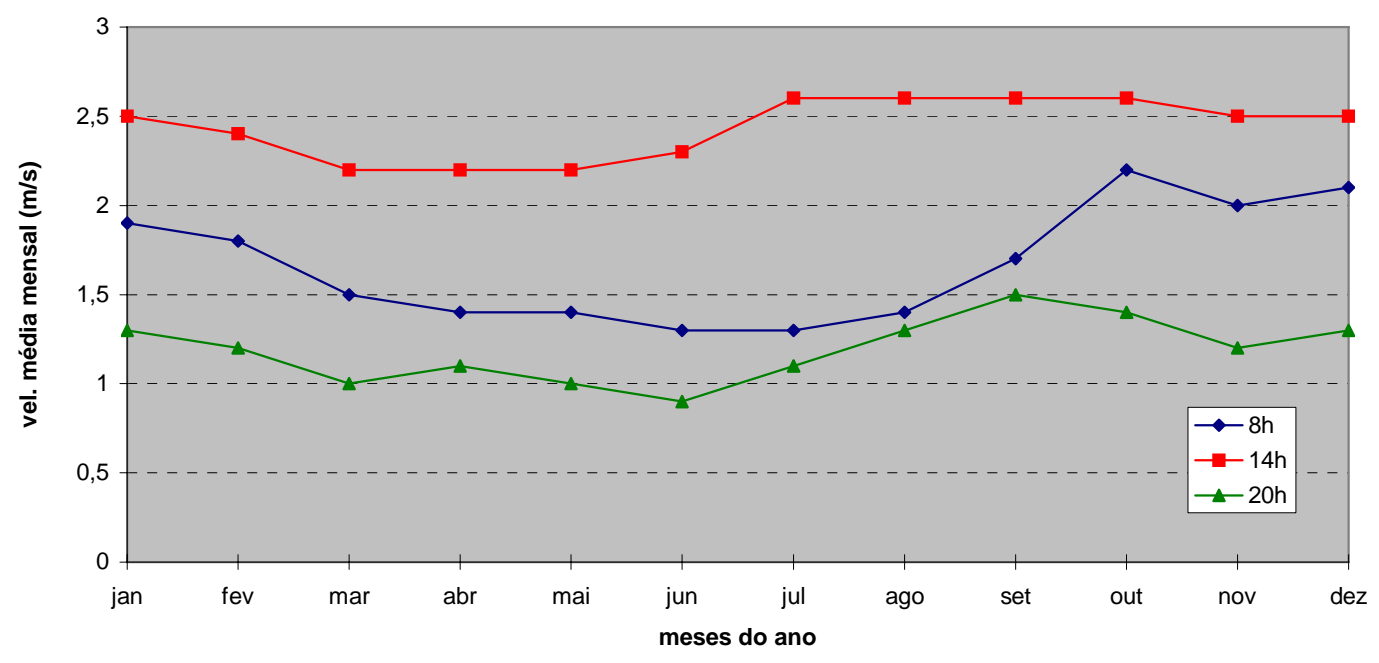

Figura 5.10 - Médias mensais horárias de velocidade do vento (m/s), do período de 1970-1992. (fonte: dados do INMET apud Maitelli, 1994)

Na tese de MAITELLI (1994) foi feito um mapeamento de temperatura e umidade do ar combinando medições em pontos fixos e transectos móveis. Em Cuiabá, a intensidade média da ilha de calor foi de $3,8^{\circ} \mathrm{C}$ no período noturno da estação seca, com máximos de até $5^{\circ} \mathrm{C}$, sob condições de tempo estável, céu limpo e calmaria, e de $1,8^{\circ} \mathrm{C}$ no período chuvoso, com valores máximos de até $2,3^{\circ} \mathrm{C}$. Medições realizadas por MAITELLI demonstraram que o distrito comercial, no centro da cidade, é a área mais aquecida (fig.5.11). A umidade relativa do ar variou inversamente em relação à temperatura do ar. As ilhas de calor apresentam-se associadas a verdadeiras 'ilhas secas’ e o ar das áreas centrais era, muitas vezes, até 22\% mais seco do que nos arredores, principalmente à noite, na estação seca (fig.5.12). Os meses mais secos são junho, julho e agosto, que apresentam condições mais freqüentes de estabilidade do ar, o que favorece a ocorrência da ilha de calor.

Na área de crescimento vertical recente, próxima ao distrito comercial, observa-se uma segunda ilha de calor em formação que, embora de menor intensidade, com acréscimo de temperatura em torno de $2^{\circ} \mathrm{C}$ em relação à área suburbana, reflete as características do uso do solo, com a concentração de edifícios, avenidas pavimentadas e tráfego intenso.

Maitelli recomenda o acompanhamento do desenvolvimento das ilhas de calor, a realização de um projeto de arborização de espaços públicos e privados e a divulgação das informações sobre o uso do solo para melhorar as condições climáticas e de conforto ambiental, já que atualmente a população não é orientada para isso. Também critica as técnicas construtivas 'importadas' utilizadas na cidade e que são inadequadas ao clima da região. ${ }^{5}$

\footnotetext{
${ }^{5}$ informação verbal, 1994.
} 


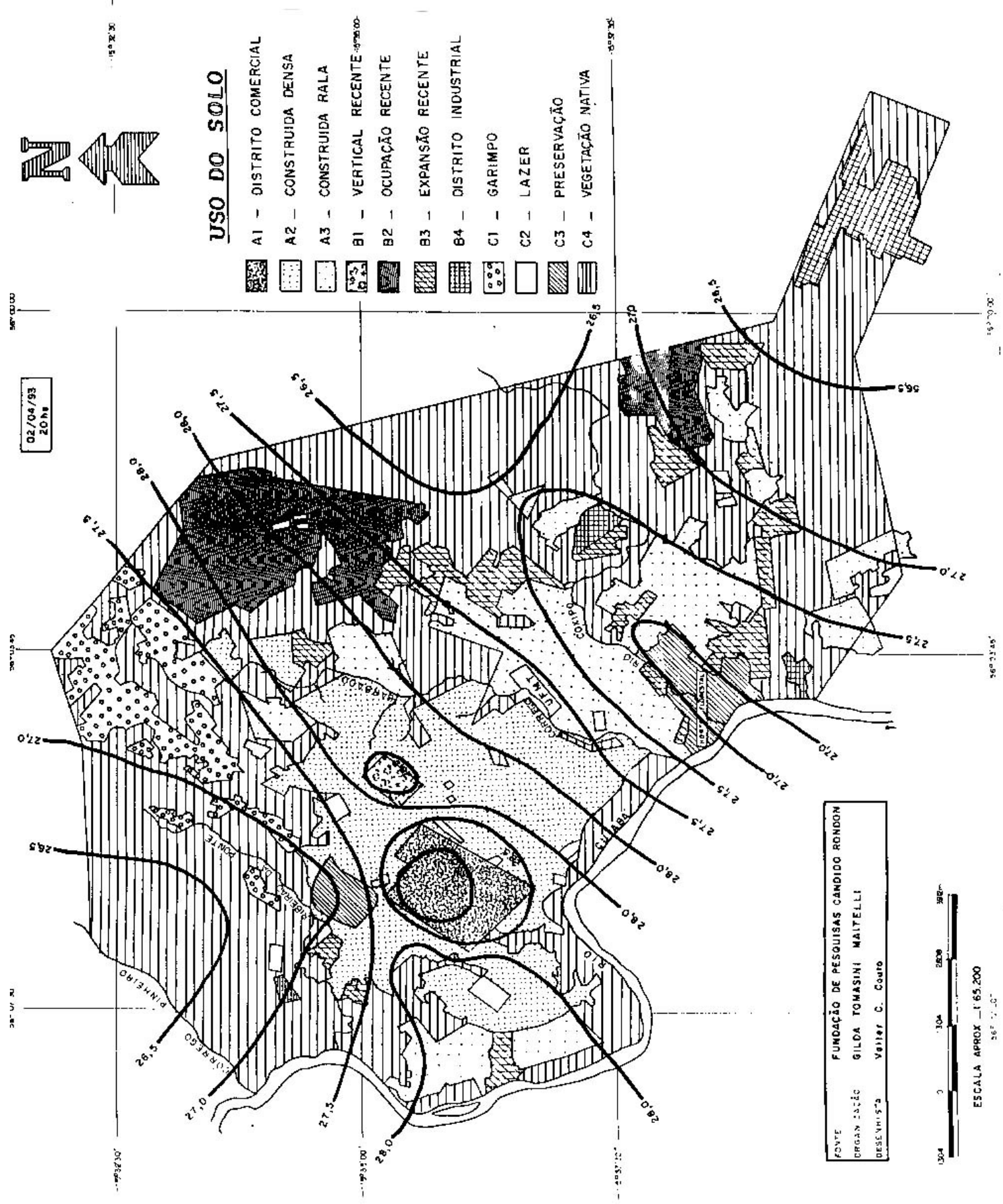

Figura 5.11 - Uso do solo urbano e a formação de ilhas de calor. Isotermas. (fonte: Maitelli, 1994) 


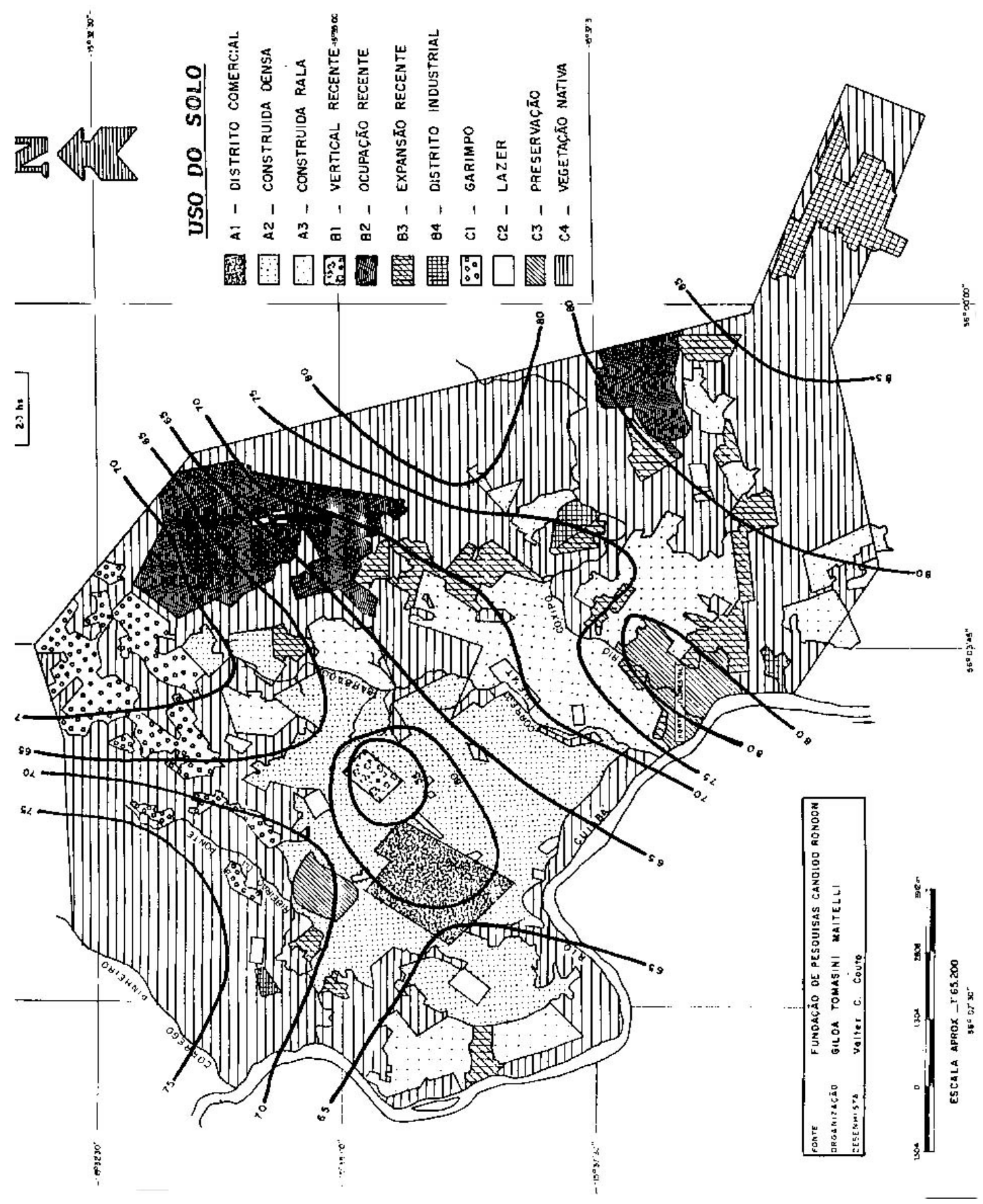

Figura 5.12- Uso do solo urbano e a formação de ilhas de calor. Isoigras. (fonte: Maitelli, 1994) 


\section{Referências Bibliográficas}

1. BOMBLED, Jorge. Meio Século de Meteorologia. Cuiabá: Centro de Ciências Agrárias/UFMT, [s.d.]. v. II e III.

2. BRASIL. Ministério da Agricultura e da Reforma Agrária. Normais Climatológicas 1961-1990. Brasília: INMET, [s.d.].

3. CAMPELO Jr. et al. Caracterização Macroclimática de Cuiabá. In: $3^{\circ}$ Encontro Nacional de Estudos sobre o Meio Ambiente, Londrina 1991. Anais. Londrina, v.1, Comunicações, p.542-552.

4. IBGE. Anuário Estatístico do Brasil 1993. Rio de Janeiro, v.52, p.1-1119, 1994.

5. IBGE. Geografia do Brasil. Rio de Janeiro: IBGE, Fundação Instituto Brasileiro de Geografia e Estatística, 1988. 5v. V. 1: Região Centro-Oeste.

6. KÖPPEN, Wilhelm. Climatologia. México: Fondo de Cultura Económica, 1948.

7. MAITELLI, Gilda T. Uma Abordagem Tridimensional de Clima Urbano em Área Tropical Continental: o exemplo de Cuiabá - MT. São Paulo, FFLCH USP,1994. Tese (Doutorado em Geografia). Faculdade de Filosofia, Letras e Ciências Humanas, Universidade de São Paulo, 1994.

8. NIMER, Edmon. Climatologia do Brasil. Rio de Janeiro: IBGE/SUPREN, 1979 (Série Recursos Naturais e Meio Ambiente, n.4).

9. PÓVOAS, Lenine C. Cuiabá de Outrora. Cuiabá: Resenha Tributária, 1983.

10. TREWARTHA, Glenn. An Introduction to Climate. 3.ed. New York: McGrawHill, 1954. 


\section{A URBANIZAÇÃO NA REGIÃO DA AMOSTRA ESCOLHIDA}

Para se compreender a organização urbana do Centro-Oeste nos dias atuais é necessário recorrer ao tempo do Brasil colônia, entender o posicionamento do Brasil no contexto mundial; deve-se penetrar no espírito da colonização, integrante de um processo muito mais amplo, o da constituição do modo de produção em sua fase comercial capitalista. A interioridade do Centro-Oeste, acrescida do fato da ocupação inicial da região ter se baseado em imperativos ocasionais, tais como o extrativismo mineral e vegetal, impedia, de saída, o florescimento e a permanência de centros urbanos de maiores dimensões, como também da vida urbana de modo geral. A situação urbana era caracterizada pela precariedade, que veio se prolongando até um tempo não muito remoto (IBGE, 1988, p.191).

\subsection{A evolução urbana de Cuiabá}

Cuiabá desenvolveu-se com a mineração, num processo descontínuo, espacialmente desarticulado. Para uma melhor compreensão do processo de evolução urbana, utiliza-se a periodização de FREIRE (1988, p.18) que, em função dos aspectos que caracterizam diferentes momentos do desenho urbano e da arquitetura, distingue três ciclos de produção do espaço, na história urbana de Cuiabá:

- o Ciclo da Mineração, que se estende desde a fundação da cidade, em 1719, até 1820, quando Cuiabá passa, de fato, a sediar a capital da Província de Mato Grosso;

- o Ciclo da Sedimentação Administrativa, que vai de 1820 a 1968, quando dinamitaram a Catedral do Senhor Bom Jesus de Cuiabá, o mais importante monumento barroco do Centro-Oeste. Este fato coincide com a abertura do portal mato-grossense da Amazônia para o avanço das fronteiras, mediando a expansão capitalista para as imensas áreas do norte do Estado;

- o Ciclo da Modernização, incrementado a partir de 1968 quando efetivamente se inicia a diversificação das funções urbanas da cidade, sob a pressão das frentes pioneiras.

\subsubsection{Ciclo da Mineração}

Segundo o IBGE (1988, p.244), em fins do século XVII e início do século XVIII, o mercantilismo português teve repercussões espaciais nos remotos espaços do Oeste brasileiro, através do bandeirismo paulista. Nesse período, com a mineração do ouro, foram surgindo núcleos de população que originaram cidades como Goiás, Vila Bela e Cuiabá.

Cuiabá surgiu a partir da descoberta do ouro no vale do córrego da Prainha (fig.6.1). O primeiro paulista a alcançar as beiradas do Rio Cuiabá foi Antonio Pires de Campos, e este não estava em busca do ouro, mas do gentio coxiponé, que vivia naquelas paragens. O segundo foi Pascoal Moreira Cabral que, indo também à caça de índios, deparou-se casualmente em 1718 com granetes de ouro cravados nas barrancas do rio Coxipó-Mirim; reuniu os companheiros e levantou arraial no lugar onde mais tarde se ergueu a capela de São Gonçalo. Em 1722 um feliz acaso revelou 
aos aventureiros as riquíssimas aluviões de um sítio próximo ao do Coxipó-Miriam, precisamente o lugar onde hoje se ergue a cidade de Cuiabá, no qual índios do sorocabano Miguel Sutil, que tendo saído para buscar mel, voltaram trazendo ouro as 120 oitavas que originaram a famosa Lavra do Sutil, em Cuiabá. Contam-se às centenas e aos milhares as pessoas - paulistas e emboabas - que, logo nos primeiros anos da exploração, chegaram ao arraial cuiabano (HOLANDA, 1994, p.50, $140-$ 142), onde depois cresceu a vila, e finalmente a cidade.

Ali se ergueram as primeiras construções (fig.6.2), provavelmente próximas ao Morro do Rosário. Estabeleceram-se ali não apenas a produção, mas também as residências, não havendo, em um primeiro momento, uma diferenciação no uso do espaço. Mais tarde as pequenas elevações existentes foram ocupadas pelas construções simbólicas, como as igrejas e os edifícios públicos, enquanto que as residências ficaram nas baixadas. "As eventuais adaptações do espaço natural no sítio de Cuiabá, promovidas pelo indígena, não foram suficientemente perenes ou grandes para que deixassem marca ou memória. Dessa forma, o processo de adaptação do espaço e da sua aglomeração inicia-se com a chegada dos paulistas." A implantação inicial da estrutura urbana aconteceu entre os anos de 1720 e 1730, já profundamente marcada pela forma do seu espaço natural. "Não houve, todavia, qualquer traçado prévio, tendo a estrutura inicial se implantado de acordo com a lógica das relações funcionais entre as atividades e o sítio. “ (SERRA, 1987, p.191195) "O ouro definiu um desenho típico das cidades mineradoras do século XVIII. (...) A facilidade de ocupação dos terrenos localizados à margem direita do Prainha e a efervescência do ouro fácil direcionaram o crescimento da Vila Real do Bom Jesus, conquistando ao arvoredo e mato cerrado o espaço de seu sítio urbano, ocupando as margens do riacho, subindo e descendo morros e encostas." (FREIRE, 1992, p.17) ${ }^{1}$

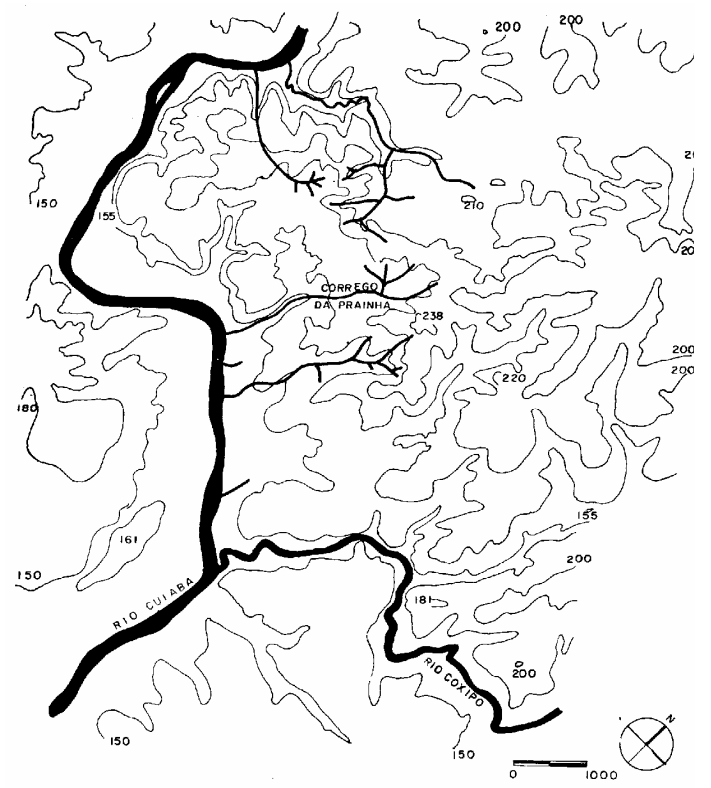

Figura 6.1- Espaço natural. Cuiabá. (fonte: Serra, G. O Espaço Natural e a Forma Urbana, p. 183).

\footnotetext{
${ }^{1}$ Vila Real do Senhor Bom Jesus de Cuiabá.
} 


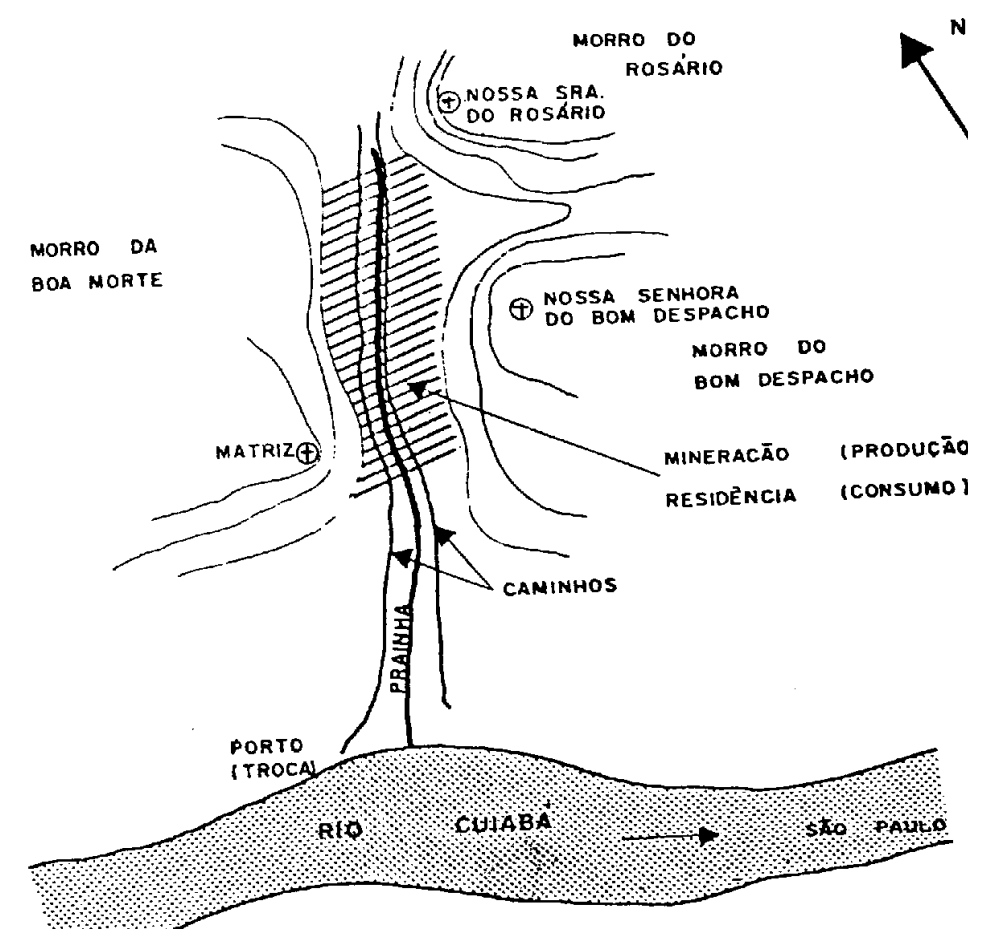

Figura 6.2- Ocupação Inicial. Cuiabá. (fonte: Serra, G. O Espaço Natural e a Forma Urbana, p. 186)

De lá só se exportava ouro, e muito pouco se produzia. Nas frotas de comércio ia o bastante para que não morressem de fome os moradores de Cuiabá, e depois de Vila Bela e de outras localidades nascidas da expansão cuiabana e à medida que se empobreciam as antigas jazidas (HOLANDA, 1994, p.147). Porém, com o esgotamento rápido das minas de ouro acaba a justificativa para a existência da cidade ao final do século XVIII; Cuiabá era uma cidade fantasma, em vias de desaparecimento.

De acordo com AZEVEDO (1953, p.26-27), “apenas dois anos decorridos de sua elevação à categoria de vila, Cuiabá entrou em lastimável decadência. Mais de mil pessoas abandonaram-na, tomando o rumo de Goiás; suas casas de telha não chegavam a 10; 'eram tudo misérias, queixas e lamentos', pois não produziam as roças e quem escapava das doenças, morria de fome: 'tudo era gemer, chorar, morrer'. A instalação da nova capitania, com sede na Vila Bela da Santíssima Trindade de Mato Grosso (1752), nas lindes remotas do Guaporé, significou novo golpe ao aglomerado que nascera sob tão bons auspícios. Mais gente abandonou a vila, que, por essa época, não teria mais do que seis ruas. Por tudo isso, a Cuiabá setecentista cresceu lentamente e não guardou em seu solo os benefícios que a riqueza poderia ter-lhe proporcionado, ao contrário do que aconteceu com as vilas de Minas Gerais. Salvo o ouro que ficou nos altares de algumas de suas velhas igrejas, nenhum outro elemento testemunha aquele período de riqueza que caracterizou os primeiros anos de vida do núcleo cuiabano. Assim sendo, é muito provável que a fisionomia urbana de Cuiabá no primeiro quartel do século XIX correspondesse, em linhas gerais, à da vila do século XVIII. (...) Por outro lado, Cuiabá conseguira transformar-se num entreposto comercial, abastecendo, modestamente embora, tanto a zona norte (Rosário, Diamantino) como a região de Livramento. Tais fatos explicam sua elevação à categoria de cidade em 1818 (...) a população do distrito pouco ultrapassaria 2.000 habitantes.” 
De acordo com FURTADO (1995, p.84), não se havendo criado nas regiões mineradoras formas permanentes de atividades econômicas, com exceção de alguma agricultura de subsistência, era natural que, com o declínio da produção de ouro, viesse uma rápida decadência. Todo o sistema ia se atrofiando, perdendo vitalidade, desagregando-se numa economia de subsistência.

Em Imagens de Vilas e Cidades do Brasil Colonial, de Nestor Goulart REIS (2000), constam mapas e desenhos de Cuiabá da segunda metade do século XVIII (fig.6.3 e $6.4)$

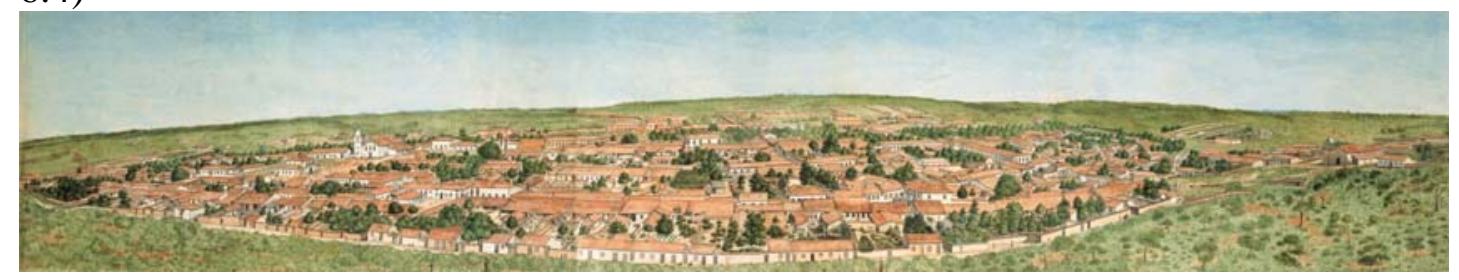

Figura 6.3 - Prospecto da Villa do Bom Jesus de Cuiabá, de 1790, autor não identificado. Esse desenho faz parte da série elaborada durante a chamada "Viagem Filosófica" dirigida pelo naturalista

Alexandre Rodrigues Ferreira, nascido no Brasil e formado em Coimbra. A expedição recolheu amostras e material de pesquisa de várias regiões da Amazônia e da bacia do Paraguai, tendo estado

em Mato Grosso entre 1789 e 1791, quando terminava a administração de Luís de Albuquerque. (fonte: Reis, 2000)

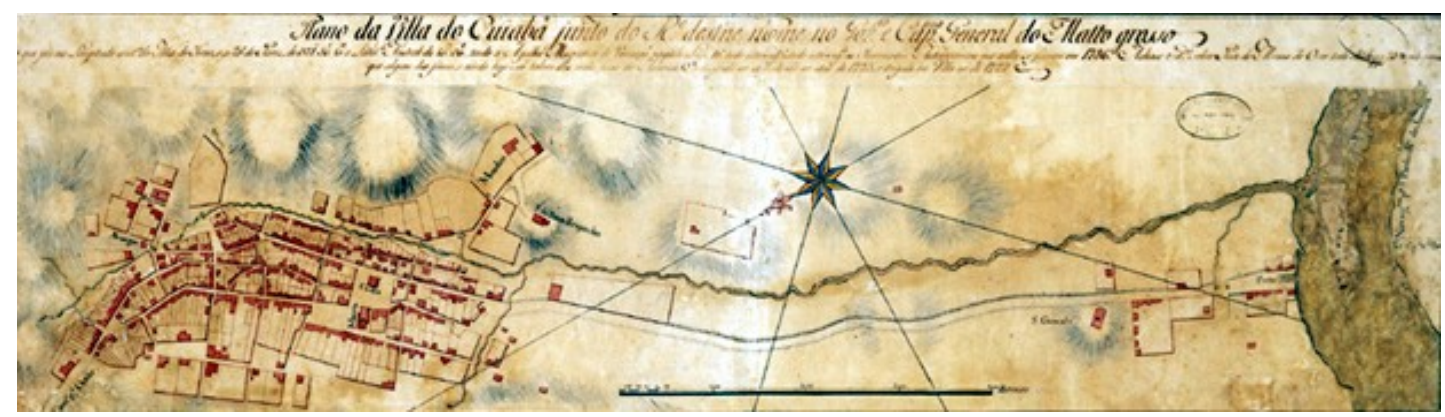

Figura 6.4 - Plano da Villa do Cuiabá, de autor não identificado. A imagem traz a data de 1786, e mostra o núcleo urbano e a sua ligação com o Porto, às margens do Rio Cuiabá. (fonte: Reis, 2000)

Na obra de AZEVEDO (1953) há mapas mostrando a ocupação no século XVIII e meados do XIX (fig.6.5), com a ocupação inicial concentrada ao longo do Córrego da Prainha, próximo à Igreja do Rosário, e no Porto, próximo ao Rio Cuiabá

No início da ocupação, a comunicação com os grandes centros era feita basicamente por via fluvial através dos rios Tietê, Paraná, Pardo, Taquari, Paraguai e Cuiabá, chegando a mais de cinco meses o tempo de viagem entre o Rio de Janeiro e Cuiabá, que era o tempo ordinariamente empregado nas navegações de Lisboa à Índia, e muito mais do que o tempo necessário para ir do Rio de Janeiro à boca do Tejo. Mas nas primeiras décadas do século XIX as viagens fluviais para Cuiabá já eram raras; as últimas foram por volta de 1838 (HOLANDA, 1994, p.138, 151).

Outra opção era a rota terrestre que, partindo de São Paulo, atravessava o sul de Minas Gerais e o estado de Goiás. Uma dessas viagens foi empreendida por Luiz D’Alincourt em 1818, e registrada em suas Memórias sobre a viagem do porto de Santos à cidade de Cuiabá (D’ALINCOURT, 1975, p.155-156): “É a Cidade do Cuyabá medíocre, mas abastada de carne, peixe, feijão, milho, laranjas, limas, ananazes e leite; tira o nome do rio Cuyabá, e dista da sua margem esquerda uma 
milha; está fundada em um vale espaçoso e alegre, que se alonga na direção Nornordeste, ao Sul-sudoeste, fechado ao Nascente pelos morros do Bom Despacho, e Rozario, e ao Poente pelo da Boa Morte (...) todo o terreno que a cidade ocupa é geralmente coberto de cascalho e cristal de rocha, que assenta sobre grossos, $e$ unidos bancos de argila. O ouro deu motivo à fundação desta Cidade, e todo o terreno imediato, e circunvizinho o forneceu em grande cópia, e do melhor quilate, principalmente o morro do Rozario de que extrairam em um só mês, quatrocentas arrobas, em o ribeirão da Prainha, que vai correndo para o rio Cuyabá junto a Leste da mesma Cidade. As casas são de taipa e terreas, à exce'xão de seis, ou sete moradas, uma das quais é um magnífico edifício para a terra e de gosto mui moderno; a Igreja Matriz da Invocação do Sr. Bom Jesus é regular; há mais quatro Templos de menores dimensões; o de N.S. do Bom Despacho, do Rozario, da BoaMorte, e do Sr. dos Passos; tem dois hospitais muito bons; o dos Lázaros fora da Cidade, e o da Misericórdia ainda imperfeito.”

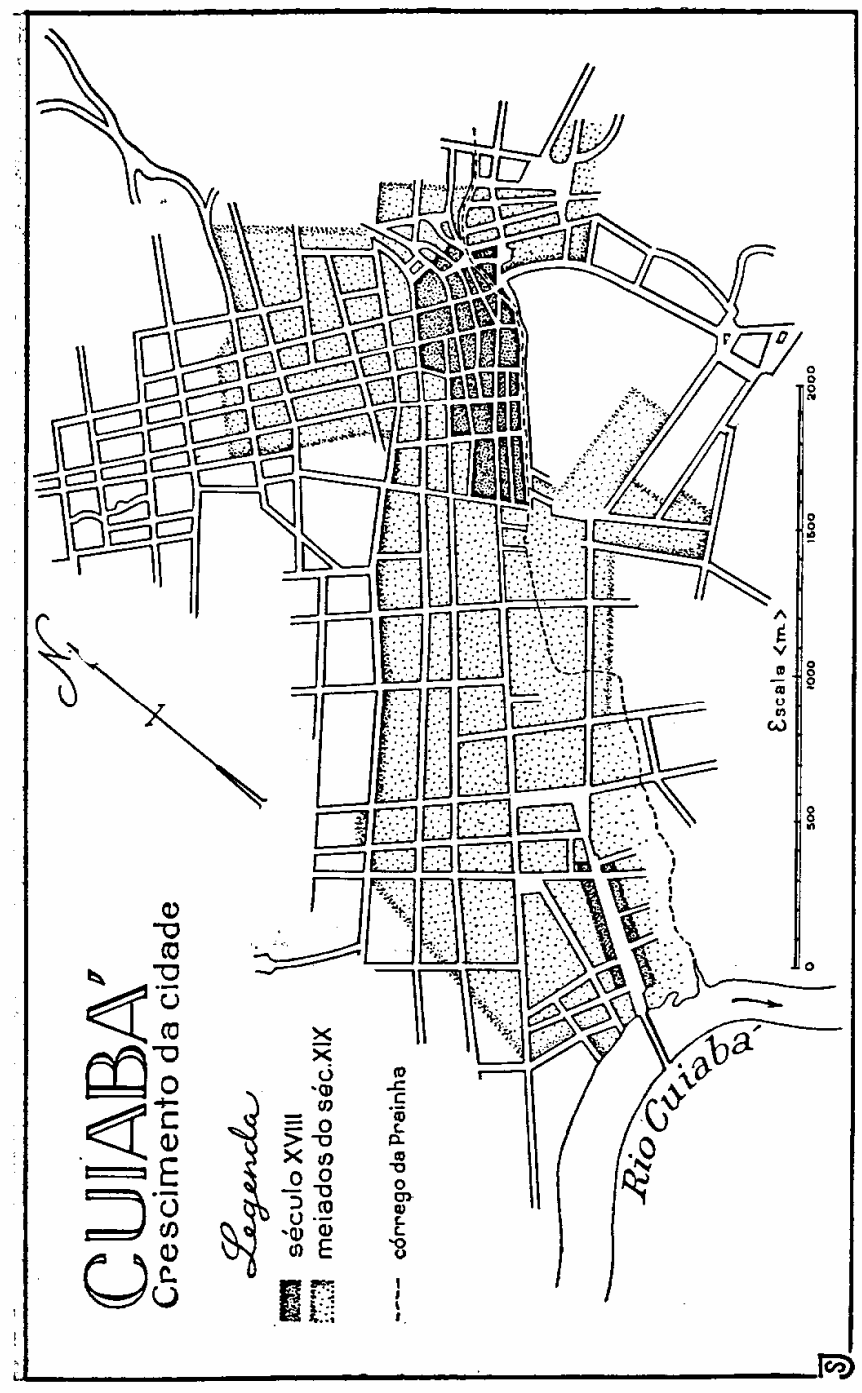

Figura 6.5 - Cuiabá. Crescimento da cidade. (fonte: Azevedo A. Cuiabá. Estudo de Geografia Urbana,1953) 
Uma alternativa era a viagem pela rota do Prata que, saindo de Cuiabá, atravessava Paraguai, Argentina e Uruguai, percorrendo a costa brasileira ao longo do Rio Grande do Sul, Santa Catarina, Paraná e São Paulo, chegando à corte cerca de 45 dias depois. De acordo com CALDEIRA (1995, p.201), em Mauá, Empresário do Império, a idéia de intervir no Prata estava ligada ao desenvolvimento do Brasil. O acesso por terra aos vastos territórios de Mato Grosso era complicado demais para permitir qualquer espécie de colonização; uma viagem de ida do Rio de Janeiro a Cuiabá levava cinco meses. A disseminação dos navios a vapor criou a alternativa do contorno via Buenos Aires e daí pelo Rio Paraná acima, em um percurso no qual se gastaria um terço do tempo, se fosse possível fazer as viagens, mas o governo argentino não permitia que navios estrangeiros navegassem por ali.

Essa rota foi interrompida de 1813 a 1840, pelo fechamento à navegação no Rio Paraguai, e depois, durante os cinco anos da Guerra do Paraguai, de 1865 a 1870, quando o isolamento da região tornou-se dramático. Segundo PÓVOAS (1987) a segregação era tão grande, que a notícia da Abolição da Escravidão só chegou a Cuiabá em 6 de junho de 1888 e a da Proclamação da República, em 9 de dezembro de 1889. "Apenas dois anos decorridos de sua elevação à categoria de vila, Cuiabá entrou em lastimável decadência. Mais de mil pessoas abandonaram-na, tomando o rumo de Goiás; suas casas de telha não chegavam a 10. (...) Mais gente abandonou a vila que, por essa época, não teria mais do que seis ruas. (...) Assim sendo, é muito provável que a fisionomia urbana de Cuiabá no primeiro quartel do século XIX correspondesse, em linhas gerais, à da vila do século XVIII." Azevedo afirma na década de 1950 que "no que concerne à área urbana, percebe-se que a Cuiabá desse tempo não seria muito diferente da de nossos dias, salvo em seus extremos norte $e$ sul. (...) A capital matogrossense teria, por essa época, uns 10.000 habitantes.” (...) Nesse tempo, o comércio fazia-se pela via fluvial, consistindo a importação em conservas, artigos de ferro, manufaturas em geral; a chegada do vapor mensal constituía, sempre, um acontecimento mais ou menos sensacional para a pacata vida urbana. (...) Os derradeiros anos do século passado e a primeira década do atual correspondem a um período amargo da capital matogrossense. Diminuiu a população urbana, mais precárias se tornaram as condições da navegação fluvial, maior se tornou o isolamento de Cuiabá.” (AZEVEDO, 1953, p.26, 31-34).

\subsubsection{Ciclo da Sedimentação Administrativa}

Até o início do século XX, a expansão descontínua e o despojamento são as principais marcas da identidade urbana e arquitetônica de Cuiabá, frutos da escassez de recursos técnicos e materiais. A rancharia de palha, que conferia o aspecto inicial de acampamento provisório, foi aos poucos sendo substituída pelas primeiras moradias cobertas com telha. De acordo com FREIRE (1988), a arquitetura das primeiras casas segue o padrão paulista do século XVIII, que assume em Cuiabá algumas características particulares (fig.6.6). As casas eram implantadas sobre o alinhamento das ruas e limites laterais do terreno, umas coladas às outras. Inicialmente o pé-direito era baixo, e as fachadas estreitas reproduziam um único padrão, o que conferia uma certa monotonia à paisagem. Os telhados avermelhados eram de duas águas, com caídas para a rua e para o quintal. As aberturas eram estreitas e pequenas. Os alicerces eram de pedra-cristal, os baldrames, largos e altos, eram construídos em pedra canga, e as paredes, de pau-a-pique, taipa socada ou adobe. 


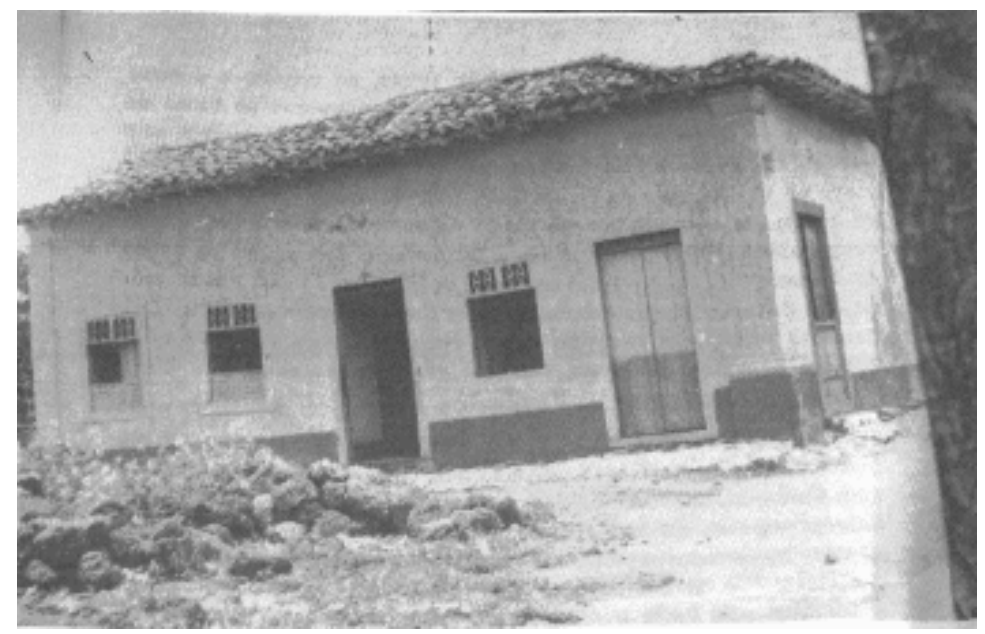

Figura 6.6 - Primeira casa construída em Cuiabá, em 1720. (fonte: Mendonça, R. Roteiro Histórico \& Sentimental da Vila Real do Bom Jesus de Cuiabá, p. 72).

Uma outra descrição da cidade de Cuiabá, feita em janeiro de 1827, foi encontrada no diário de viagem de Hercules Florence, artista francês, relatando a primeira parte da expedição Langsdorff ao interior do Brasil. Florence, logo depois de chegar ao Brasil, em 1824, engajou-se na expedição científica organizada pelo Barão de Langsdorff, então Cônsul Geral da Rússia, no Rio de Janeiro, com o objetivo de estudar certas regiões brasileiras até então pouco conhecidas (fig.6.7). De Cuiabá, foram remetidos para a Rússia cerca de 60 desenhos (fig.6.8 a 6.11), material botânico e zoológico. Há informações de que muitos outros trabalhos se perderam (Expedição Langsdorff ao Brasil, 1988).

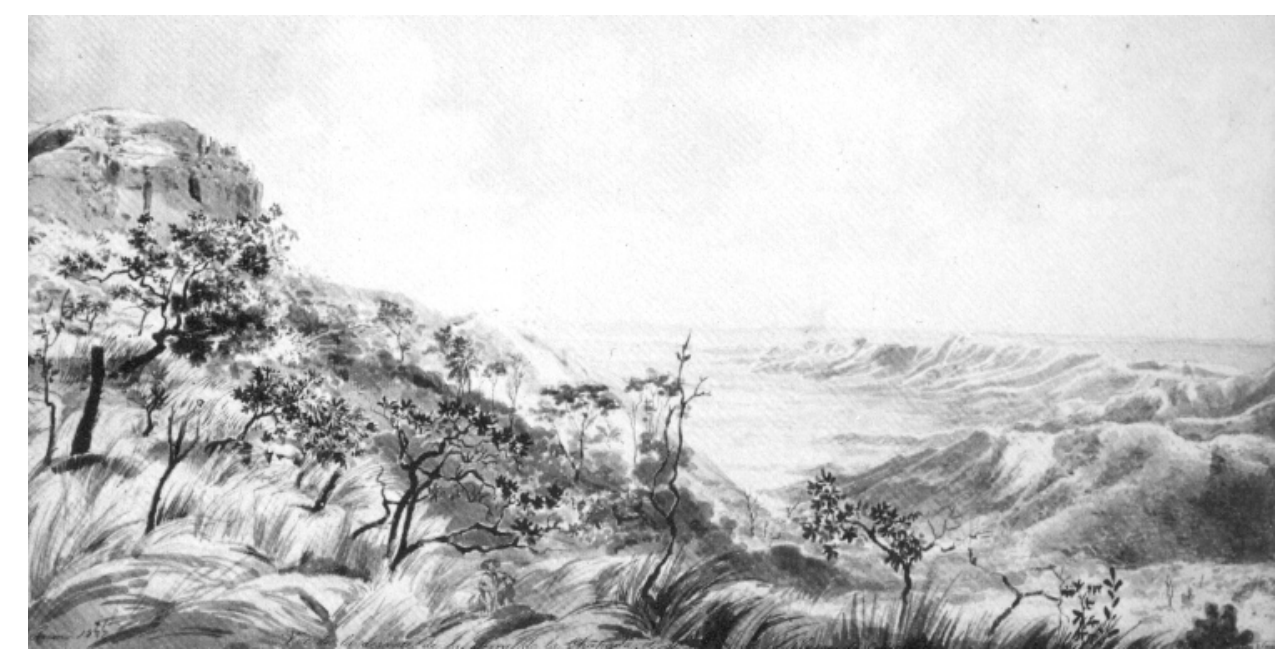

Figura 6.7 - Vista de larga extensão da Chapada e um dos vales que comunicam o Planalto de Guimarães com a Depressão Cuiabana. Aquarela negra de Taunay, um dos três artistas que fizeram parte da expedição, em junho de 1827. (fonte: Expedição Langsdorff ao Brasil, 1988)

De acordo com FLORENCE (1977, p.137-142), “a cidade pode ter meio quarto de légua de poente a nascente e dois terços dessa distância de N. a S. Não há senão 18 a 20 casas de sobrado, esse mesmo pequeno: todas as mais são térreas. Cada casa 
tem nos fundos um jardim plantado de laranjeiras, limoeiros, goiabeiras, cajueiros e tamarindeiros, árvores cuja folhagem densa e escura forma no meio das outras agradável contraste, concorrendo todas elas para darem à povoação aspecto risonho e pitoresco. Rebocam-se por fora as habitações com tabatinga, que lhes dá extrema alvura: entretanto muitas há, principalmente nos arredores, que conservam a cor sombria da taipa de que são feitas, bem como todos os muros e cercados. Não há uma só casa que tenha chaminé: a cozinha faz-se no jardim debaixo de um telheiro. $O$ edifício em que estão o presidente e a intendência chama-se palácio: é térreo; as janelas, únicas na cidade, têm caixilhos com vidros.(...) O clima da cidade é muito quente: sua latitude $15^{\circ} 36^{\prime}$ '."

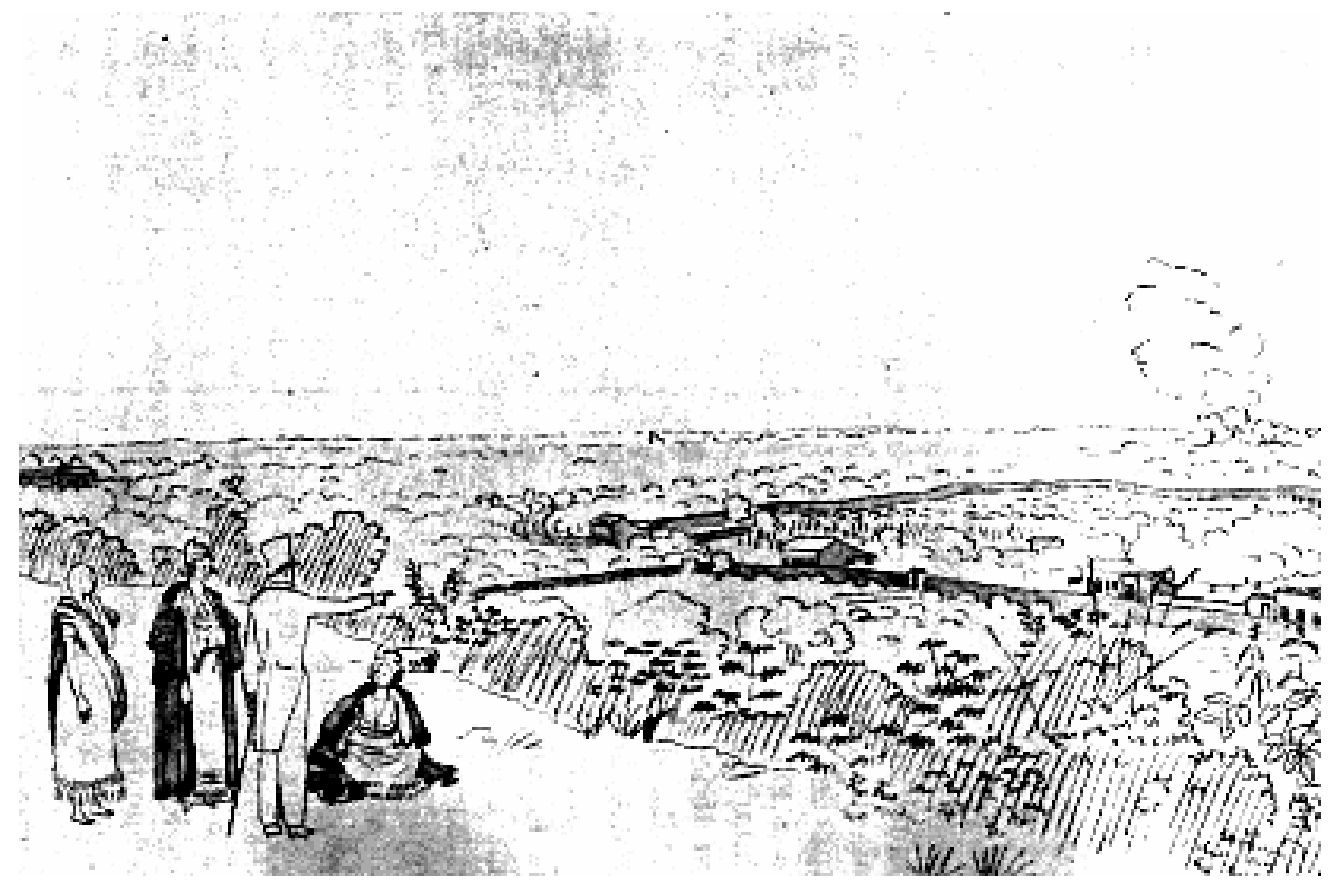

Figura 6.8- Cidade de Cuiabá. (fonte: Florence. Viagem Fluvial do Tietê ao Amazonas. p.138).

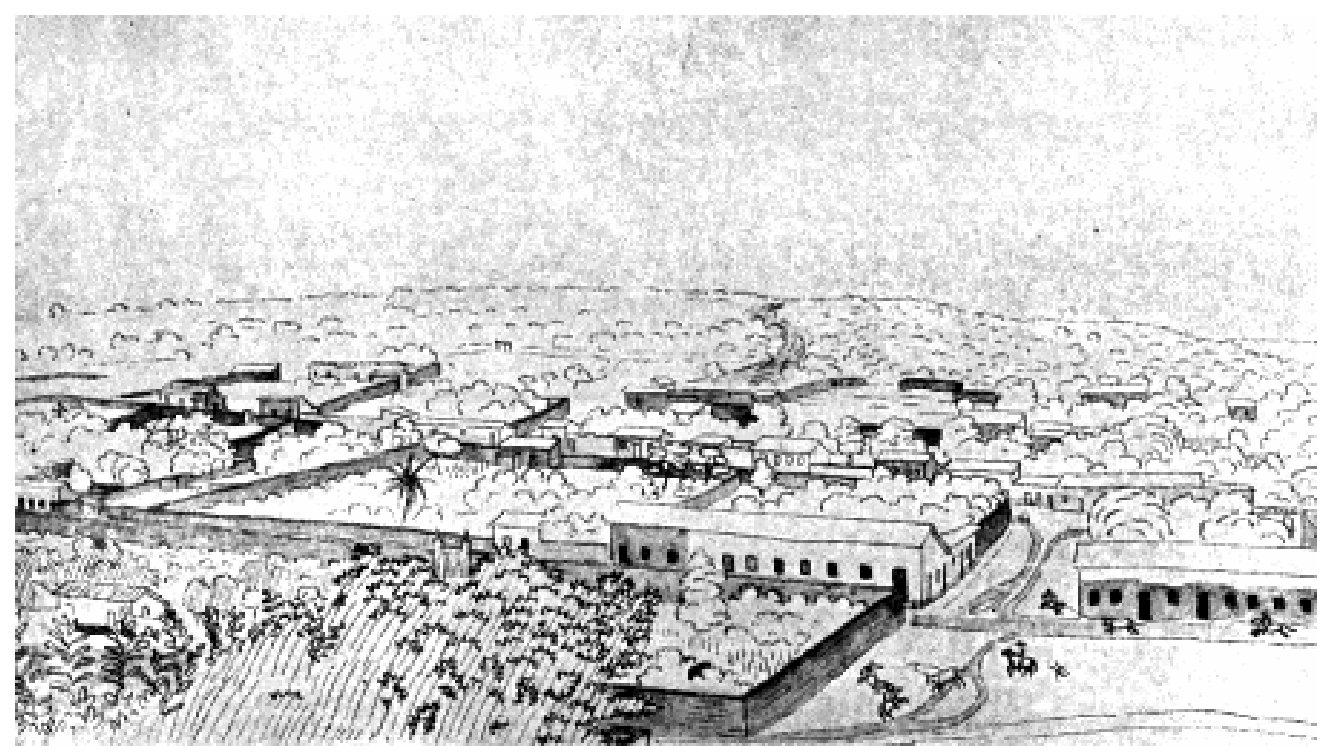

Figura 6.9- Cidade de Cuiabá. (fonte: Florence. Viagem Fluvial do Tietê ao Amazonas. p.139). 


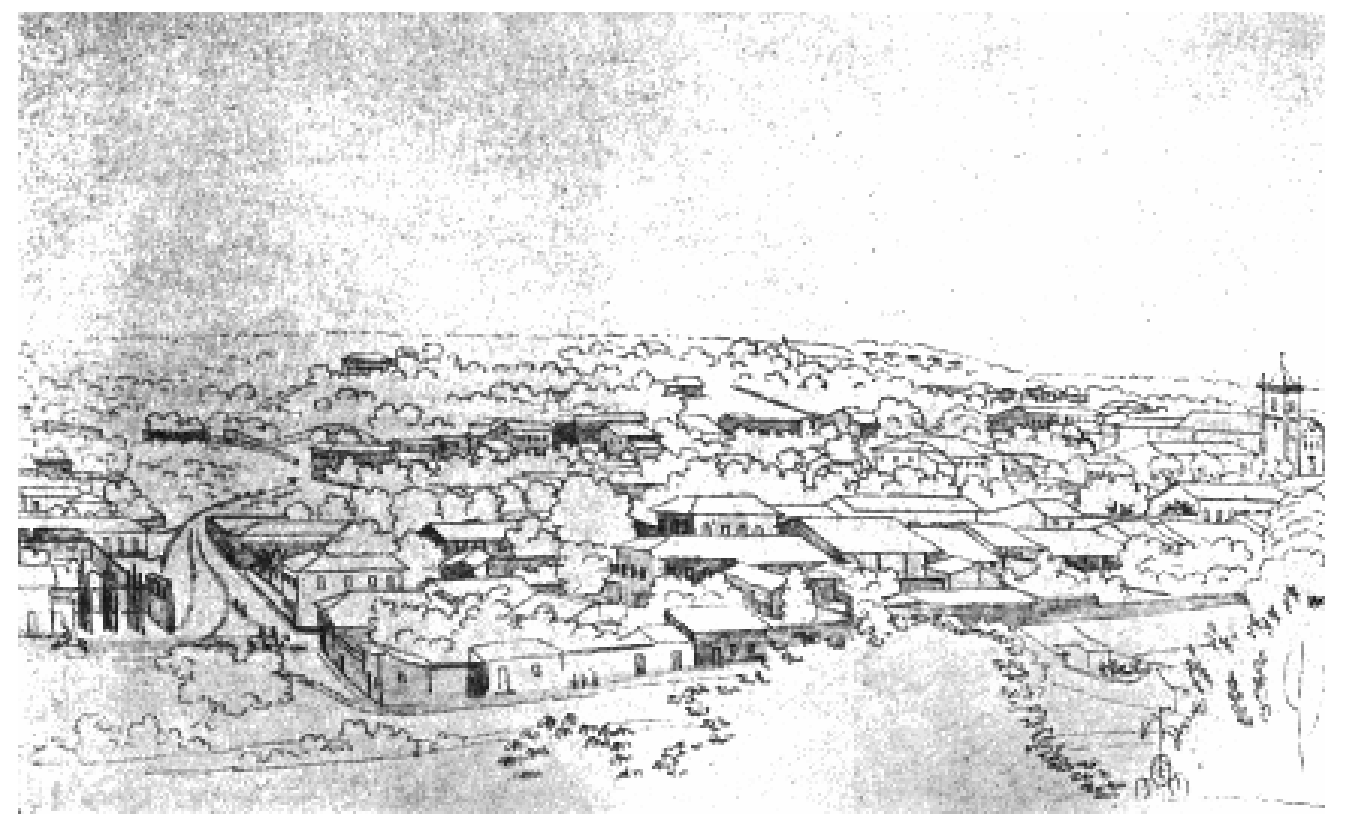

Figura 6.10- Cidade de Cuiabá. (fonte: Florence. Viagem Fluvial do Tietê ao Amazonas. p. 140).

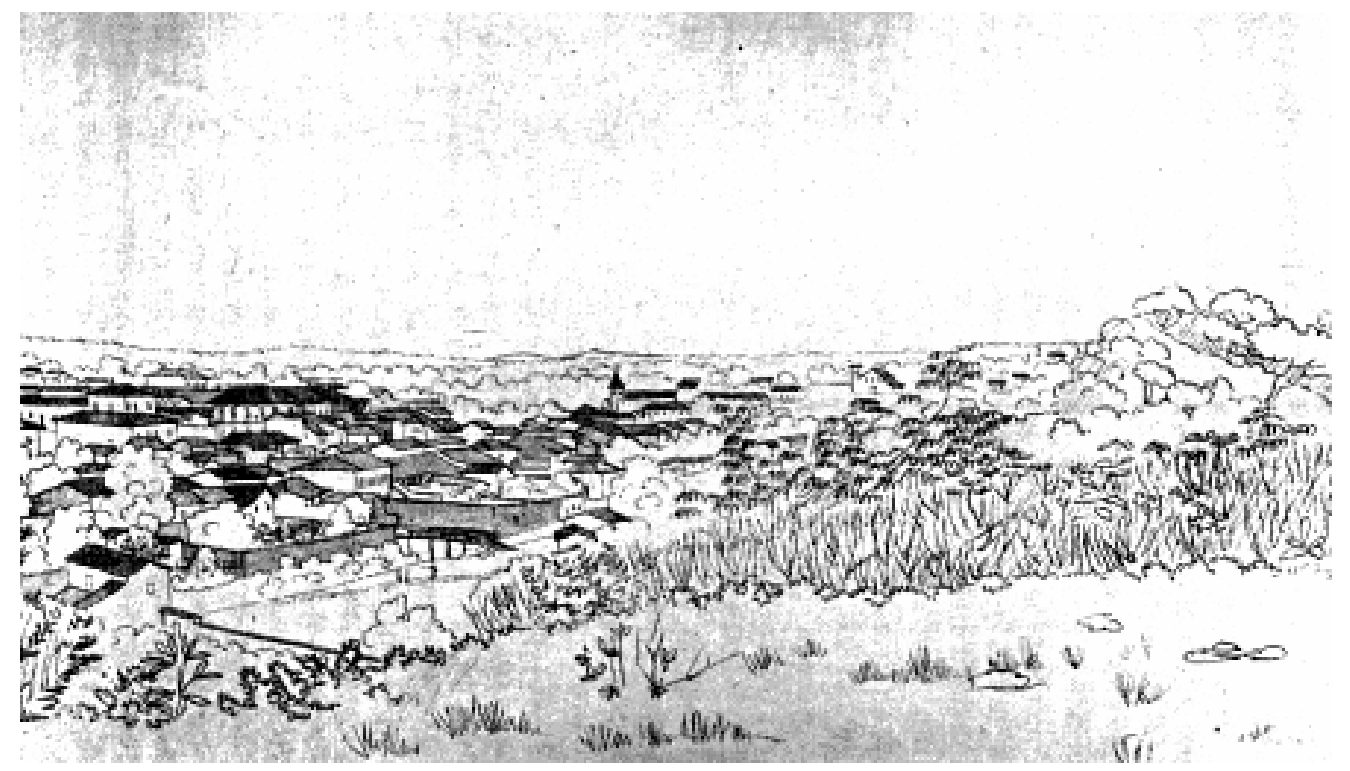

Figura 6.11- Cidade de Cuiabá. (fonte: Florence. Viagem Fluvial do Tietê ao Amazonas. p. 141).

"Outra descripção, datada de 1868, mostra o seu desenvolvimento no espaço de quarenta e um annos: 'Cuiabá tem um aspecto alegre, não obstante reinar no seu interior bastante monotonia. As suas ruas são quasi todas calçadas de pedra cristal que, quando lavadas pelas chuvas, tornam-se bastante aceadas. Tem não pequeno numero de ruas, sendo a principal a rua Bella do Juiz que parte do largo da Matriz e vae desembocar no Arsenal de Guerra, continuando ainda com outro nome. Existem n'ella as melhores casas, cuja maior parte foi construida ha pouco tempo pelo systema moderno. Ha também as ruas - Direita, do Commercio, Augusta, do Campo, da Esperança, da Piçarra, Formosa e a do Mundéo, que ficam no centro da cidade, todas ellas cortadas por beccos na maior parte tortuosos.” (Album Graphico do Estado de Matto-Grosso, 1914, p.318) 
No Album Graphico do Estado de Matto-Grosso, publicado em janeiro de 1914, encontram-se inúmeras descrições e fotografias de diversas regiões do Estado. Na panorâmica da cidade de Cuiabá (fig.6.12), vista do Morro da Luz, pode-se ter uma idéia das construções locais do início do século: telhados cobertos com telhas de barro, em sua maioria de duas águas, cores claras nas paredes, amplos beirais, ocupação total do lote, com as casas umas encostadas às outras, e inúmeros quintais fartamente arborizados com árvores de copas altas e largas.

Disse um engenheiro ao chegar a Cuiabá, em fins de 1938: “No trajeto para o hotel compreendi porque chamavam Cuiabá, Cidade Verde. Embora as ruas não apresentassem arborização, os quintais, os espaços vazios eram cobertos de vegetação". (SÁ, 1980, p.49) No interior do estado de Mato Grosso as cidades apresentavam as mesmas características, seguindo o mesmo padrão construtivo. Observam-se os telhados cobertos com telhas de barro, as casas justapostas, sem recuo frontal, e os quintais arborizados. Só no início do século XX as residências começaram a adotar o afastamento de um ou ambos os limites do lote e da fachada, adotando também os jardins, o alpendre lateral e um maior requinte na decoração das fachadas. "A arquitetura das residências oscila entre o novo e o velho; entre as inovações dos recuos alpendrados e as soluções tradicionais." (FREIRE, 1988, p.44) Nessa época, as residências urbanas das províncias eram cópias imperfeitas das construções dos grandes centros. As pessoas de maiores posses, que frequentavam a corte, levavam, ao regressar à sua terra, as novas idéias, que procuravam reproduzir em suas residências. Porém, os elementos estruturais, sempre grosseiros, construídos de taipa ou adobe, não permitiam o uso de colunatas, escadarias, frontões ou quaisquer tipos de soluções mais complexas, ficando as modificações, na maioria das vezes, bastante superficiais, restritas aos detalhes (REIS FILHO, 1987).

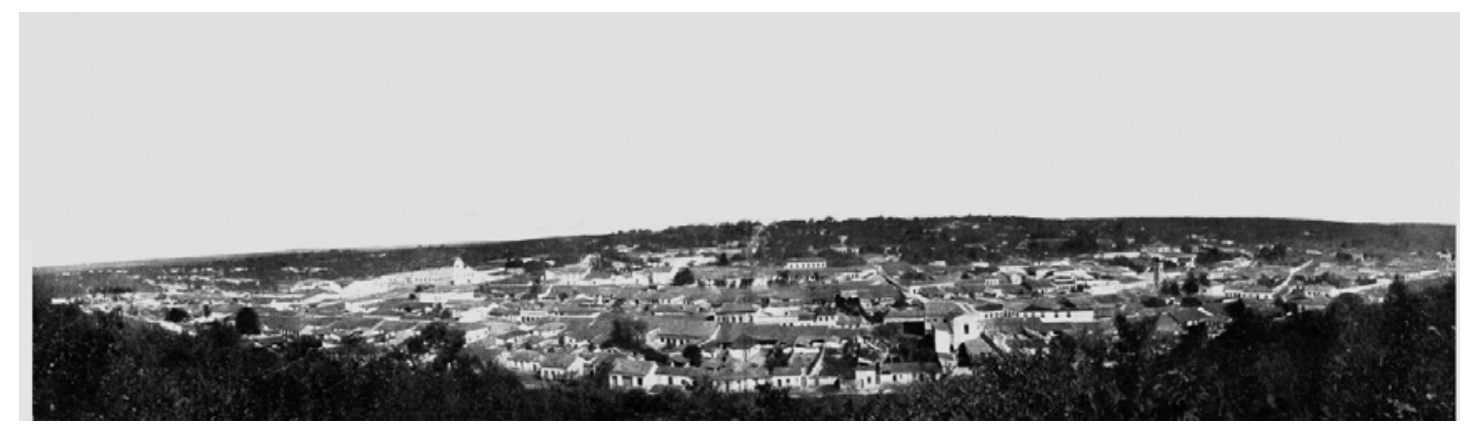

Figura 6.12 - Vista panorâmica de Cuiabá no início do século. (fonte: Album Graphico do Estado de Matto-Grosso, p. 34-35).

De acordo com FREIRE (1988, p.7), o repertório da linguagem arquitetônica cuiabana está impregnado pela paisagem, pelas ruas, as casas, o cotidiano e o modo de vida, historicamente estruturados e organizados através de um lento processo de evolução urbana. Cuiabá é uma cidade do início do século XVIII, com um desenho urbano de ruas tortuosas e estreitas, topografia acidentada, becos, largos e praças. $\mathrm{O}$ espaço produzido reflete, nas curvas da malha urbana, a ondulação do relevo e a sinuosidade dos rios. A luminosidade intensa e o calor escaldante infiltram-se no desenho da cidade, ajudando a compor o equilíbrio telúrico do ambiente cuiabano. 
Cuiabá conservou, até bem pouco tempo, o seu aspecto tipicamente colonial, traduzido na sua arquitetura e nos hábitos de seu povo. Por exemplo, a sesta vespertina, que "é um hábito inteligente de autodefesa do organismo, que se enraizou em todos os povos que habitam regiões de climas causticantes.(...) Mas o descanso do meio do dia, até esperar que o 'sol esfrie', não foi a única precaução que os antigos cuiabanos de maiores recursos tomaram contra a inclemência do seu clima. Em muitas outras cousas essa preocupação sempre se manifestou. As ruas estreitas de Cuiabá colonial confirmam isso. (...) As ruas estreitíssimas são uma defesa contra o calor. (...) As casas típicas da Cuiabá antiga, das quais ainda restam alguns exemplares no centro comercial da cidade, eram construídas umas encostadas às outras. (...) A aeração era compensada pelo pé direito, quase sempre alto, de cerca de quatro metros, e pelos telhados de telhas vãs, sem forros, o que as tornava adequadas ao clima quente da região. Eram também construídas sobre o alinhamento das calçadas, sem nenhum recuo (...) No século $X X$, com a influência de construtores de origem européia, sobretudo italianos, introduziu-se a platibanda, em substituição aos beirais, nas casas dos proprietários de maiores posses. (...) Os pisos, antes de tijolo batido e depois de mosaico (outra reminiscência árabe), muito contribuíam para refrescar o ambiente. As janelas que davam para a rua, de rótulas ou de venezianas, que mesmo fechadas deixavam passar a ventilação, completavam o conjunto de medidas para adequar a habitação ao meio. Essas precauções foram banidas pela arquitetura moderna, importada de outras raízes, quiçá norteamericanas, que substituíram o pé direito alto pelo baixíssimo, o mosaico pelo carpete e as rótulas e venezianas pelos vitrôs fixos, forçando o oneroso recurso aos aparelhos de ar refrigerado.(...) Outra providência tomada pelos antigos cuiabanos para se defenderem dos ardores do verão era a existência, nas casas, de áreas internas ajardinadas e ensombradas e de quintais profusamente arborizados." (PÓVOAS, 1987, p.21-28, 49-52)

Herbert SMITH (1922, p.281-322), em seu livro Do Rio de Janeiro a Cuyabá. Notas de um Naturalista, descreve assim a paisagem ao entrar no vale do Rio Cuiabá: "as margens são geralmente acompanhadas de florestas, como no Bananal, mas de pequena extensão, escondendo por traz grandes várzeas; (...) As poucas casas que vimos eram de taipa, quasi sempre de telha, e pelo tamanho mostravam ter sido outr'ora estabelecimentos importantes; mas quasi todas estavam desprezadas e meio arruinadas. (...) diante de nós appareceu uma praia baixa, aprumadamente cortada, coroada com uma carreira de casaria branca, coberta de telhas vermelhas. Eramos chegados a Cuyabá.(...) Com uma largura que em varios logares excede a um kilometro, a cidade estende-se por outros tres; o chamado Porto, situado junto ao rio, forma freguezia à parte, com o nome de S. Gonçalo de Pedro II. (...) Uma rua espaçosa leva ao largo da Sé; ahi está a igreja matriz, começada em 1722, edificio simples, de uma só torre de um lado, obra essa prejudicada pela conhecida asymetria da falta de dinheiro; o interior foi recentemente restaurado. (...) Nas ruas mal se percebe que se vive nos tropicos. Este solo ondulado, este calçamento exemplar, estas casinhas estreitas, estes candieiros de azeite, desprendendo-se das paredes, esta independência patriarchal do bom gado, tudo nos envolve num bafejo de idyllico repouso, tão indescriptivel que dir-se-ia uma aldeola rural da Thuringia (...) Um acontecimento apenas perturba esta agradavel pasmaceira; só uma vez por mez soa a voz do seculo XIX no rio Cuyabá. Um tiro de canhão, toque de cornetas nos quarteis; o vapor chegou." 
Durante a Guerra o Paraguai o fechamento do acesso pelo rio forçou a utilização do acesso por terra. Época também do surgimento da atividade militar e industrial para fabricação de fardas, responsável também pela fundação de Várzea Grande, que inicialmente era um campo de concentração de prisioneiros paraguaios. Quando terminou a Guerra, muitos não voltaram ao Paraguai. Após a guerra intensificou-se a circulação de mercadorias através da bacia do Prata para o interior de Mato Grosso. Dadas as vantagens oferecidas pela rota fluvial, principalmente o barateamento das mercadorias, a antiga rota terrestre por Goiás, longa e tortuosa, quase foi relegada (IBGE, 1988, p.195).

A cidade de Corumbá, hoje em Mato Grosso do Sul, ocupava, nos séculos XVIII e principalmente XIX, posição destacada na região; era o centro de conexão da navegação fluvial de menor e maior calado para os portos de Cáceres, Cuiabá e Porto Murtinho, e também para os de Assunção, Montevidéu e Buenos Aires. A ausência de estradas razoáveis transformou Corumbá na porta de entrada da região, por sua posição geográfica privilegiada, que permitia o acesso a Mato Grosso através do Paraguai.

Corumbá chegou ao início do século XX como o principal empório de Mato Grosso e um dos portos fluviais importantes do país (fig.6.13). Embarcações de calado médio, provenientes das capitais platinas, não só abasteciam as casas comerciais, mas também transferiam as mercadorias para embarcações menores, que seguiam para outras direções, principalmente para Cuiabá. A centralidade de Corumbá só foi abalada no início do século, com a chegada da Estrada de Ferro Noroeste do Brasil ao sul de Mato Grosso (hoje Mato Grosso do Sul), e da rodovia Cuiabá - Campo Grande (IBGE, 1988, p.195 - 196).

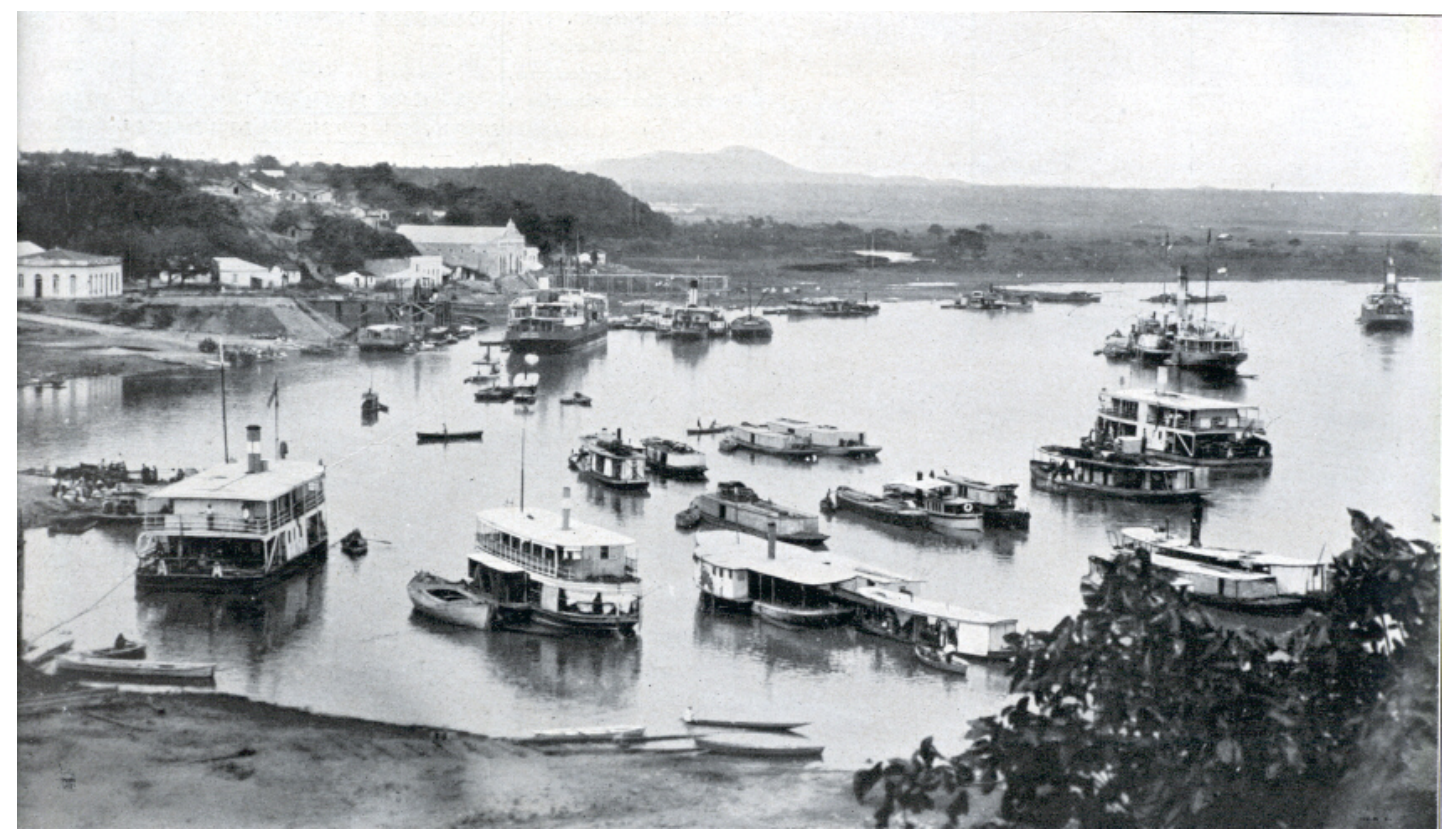

Figura 6.13 - Porto de Corumbá no início do século XX. (fonte: Album Graphico do Estado de MattoGrosso, p.110) 
Em 1872 chegou uma comitiva de imigrantes mineiros à Vila de Santo Antonio de Campo Grande, que construiu as primeiras casas em taipa de mão e madeira. Apesar do acesso bastante difícil, o novo vilarejo tornou-se bastante conhecido, em parte pelo clima, bem mais ameno quando comparado aos demais povoados da região. Em 1902 se deu a implantação definitiva do município. Em 1905 foi aprovado um Código de Posturas que regulamentava condições de higiene, comércio e construções, na verdade uma cópia do código de Corumbá, cidade muito mais antiga. Em 1906 foi instituída uma lei que aprovava a criação e o alinhamento de ruas de Campo Grande, que tinha o propósito de melhorar a única rua existente e também planejar outras que viriam com o crescimento. Em 1909 o traçado urbano foi elaborado a pedido da Intendência Municipal pelo Eng. Nilo Javary Barém, estabelecendo o plano de alinhamento de ruas e praças de Campo Grande, de traçado ortogonal com ruas e avenidas mais largas no sentido Leste/Oeste e quadras retangulares divididas em lotes de $2500 \mathrm{~m}^{2}$ e $50 \mathrm{~m}$ de testada. Era, na verdade, um projeto de expansão urbana, com ruas e calçadas bastante largas e retilíneas, formando um tabuleiro de xadrez. O projeto previa a construção de quatro praças e as principais preocupações eram o trânsito e a higienização, assim em muitas outras cidades no início do século (OLIVEIRA NETO, 1997).

Com a chegada dos trilhos da Estrada de Ferro Noroeste do Brasil, em 1914, Campo Grande começou a sair do isolamento. Em 1918 foi elevada à categoria de cidade. Quando da execução do projeto de expansão urbana algumas casas na única rua da cidade foram demolidas para que o traçado das ruas ficasse retilíneo, largo, com amplas calçadas e de acordo com as novas vias criadas na planta. Nesse momento houve uma forte intervenção do Estado no sentido de planejar a cidade. A preocupação com o novo trouxe, na década de 1940, o primeiro Código de Obras, que estabeleceu um zoneamento no perímetro urbano e proibiu a reforma das antigas construções existentes na zona comercial, forçando os proprietários a substituí-las por outras mais modernas. O decreto determinava que as novas ruas que fossem surgindo seguissem o mesmo padrão de caixa e de calçada, e que $20 \%$ dos novos loteamentos deveriam ser reservados para as ruas e outros $20 \%$ para praças e jardins $\mathrm{O}$ traçado xadrez foi sendo reproduzido em todas as direções; somente em alguns bairros de classe alta surgiram traçados diferenciados, com ruas sinuosas e sem saída. Nos bairros para a população de baixa de baixa renda o traçado é xadrez, mas com significativa diminuição na largura das ruas e calçadas. Só em 1977 foi criado o Estado de Mato Grosso do Sul a partir do desmembramento do Estado de Mato Grosso; Campo Grande tornou-se a capital do novo estado no ano de 1979. Em 1909 eram apenas 1200 habitantes; hoje são mais de 650 mil (OLIVEIRA NETO, 1997).

Ainda na década de 1950, mais de duzentos anos após a fundação de Cuiabá, afirmou AZEVEDO (1953, p.36-39) que "tudo parece indicar que foi somente nos últimos 20 anos que teve início uma fase nova na vida de Cuiabá. (...) Muitas das velhas habitações tiveram suas fachadas reformadas, construções modernas apareceram, aumentou a área urbana, como se um sangue novo tivesse sido injetado na velha cidade setecentista (fig.6.14 a 6.16). O desenvolvimento econômico do Estado, o loteamento de grandes glebas situadas na vizinha chapada e, notadamente, a ligação rodoviária com São Paulo (via Goiás) e com o sul do Estado podem explicar esse surto de progresso e o abandono do marasmo anterior. Cuiabá não é mais a 'decrépita capital de Mato Grosso; é uma cidade cheia de vida. De fato, a Cuiabá 
que conhecemos em julho de 1953, embora guardando profundamente os traços inconfundíveis de seu passado, espraia-se hoje bem além do vale do córrego da Prainha. Ocupou efetivamente toda a margem direita desse modesto curso d'água, em larga faixa que se estende desde o primitivo núcleo até as barrancas do rio Cuiabá; caminha decididamente ara os níveis mais altos, no setor norte, como amplia-se para além da margem escarpada, no rumo do sul. (...) Vista de longe ou de avião, continua a ser a Cidade Verde, que o poeta ilustre da cidade tão bem cantou em versos cheios de ternura --- enfeitada pelas copas altas de suas elegantes palmeiras, ensombrada por uma impressionante massa de copadas árvores, que os viajantes antigos já haviam admirado e que lhe dão, realmente, um encanto todo especial.(...) Cuiabá é uma cidade que possui hoje cerca de 30.000 habitantes, colocando-se em segundo lugar dentro do Estado, apenas superada pela nova e dinâmica Campo Grande, metrópole sulina. Os dados do recenseamento de 1950 acusaram 27.306 habitantes para as zonas urbana e suburbana, num total de 56.204 para o município."

Em julho de 1953, Prof. Aroldo de Azevedo já mencionava dois graves problemas urbanos em Cuiabá: água e energia elétrica, além da insuficiência da rede de esgotos e do transporte urbano, publicados no primeiro estudo de caráter estritamente geográfico da cidade de Cuiabá. Apesar disso, chega a uma conclusão otimista em relação às perspectivas para o futuro: "Não saímos de Cuiabá com nenhum pessimismo quanto ao seu futuro. Muito pelo contrário, sentimos que novas perspectivas abrem-se à sua frente, prognosticando um constante desenvolvimento. Em primeiro lugar porque Cuiabá, cada vez mais, vai se caracterizando por ser um importante nó de comunicações: dispõe da via fluvial, que a técnica moderna poderá melhorar e que a coloca em contacto com o futuroso Pantanal, hoje simples área pastoril, mas amanhã, quem sabe, um dos celeiros agrícolas do Estado, se a cultura do arroz puder ser ali praticada; acha-se em comunicação com a zona da garimpagem, através de boas estradas, que conduzem a Goiás, a São Paulo e ao sul do Estado; liga-se ao norte através do vale do Cuiabá, o que significa que será, um dia, uma das portas de entrada terrestres para a vastidão amazônica. Mormente quando estiver concluída a 'Rodovia General Rondon', ora em construção pelo Exército e que a ligará com Santarém; espera, ansiosa, que até lá cheguem os trilhos da Estrada de Ferro Araraquarense, para colocá-la em comunicação direta com o Estado de São Paulo. São fatos que não podem sofrer contestações. Além disso, encontra-se numa posição excepcional, na zona de contacto entre duas importantes regiões matogrossenses --- o Pantanal e a Chapada; e todos sabem que, quando isso acontece, nenhum aglomerado urbano pode ter dúvidas quanto ao seu destino. Dispondo de um peneplano, através do qual poderá expandir livremente sua área urbana; e podendo contar como certa a abundância de energia hidroelétrica, graças à relativa proximidade da Chapada, Cuiabá pode ficar tranquila e confiante quanto ao seu porvir. Não lhe será reservado o mesmo destino de outras cidades nascidas da mineração do ouro; os exemplos de Ouro Preto e de Goiás não a devem amedrontar, porque outras bem diferentes são as suas condições geográficas. Seus horizontes, em relação ao futuro, são tão vastos como os que caracterizam a peneplanície em que se acha engastada. E isto muito conforta os nossos corações de brasileiros." (AZEVEDO, 1953, p.65-66) 


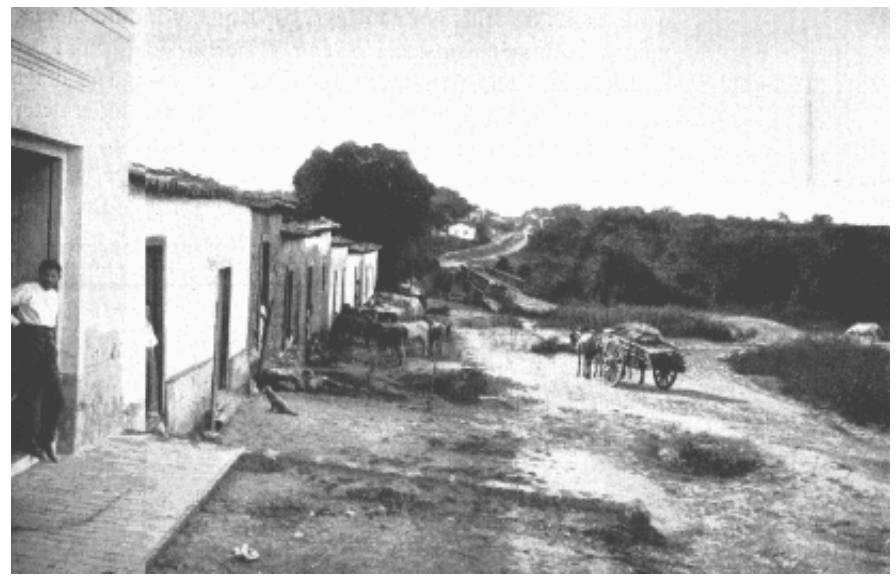

Figura 6.14 - Casas populares, já demolidas, próximas à ponte sobre o Rio Coxipó. (fonte: Album Graphico do Estado de Matto-Grosso, p.238)

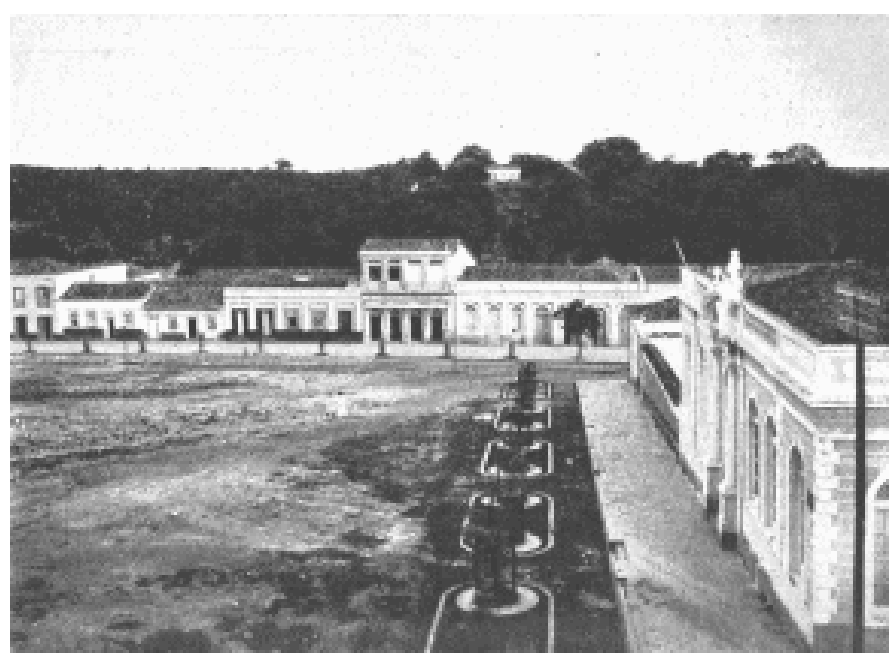

Figura 6.15 - Vista da Praça da República no início do século; hoje uma das principais da cidade. (fonte: Album Graphico do Estado de Matto-Grosso, p. 321 ).

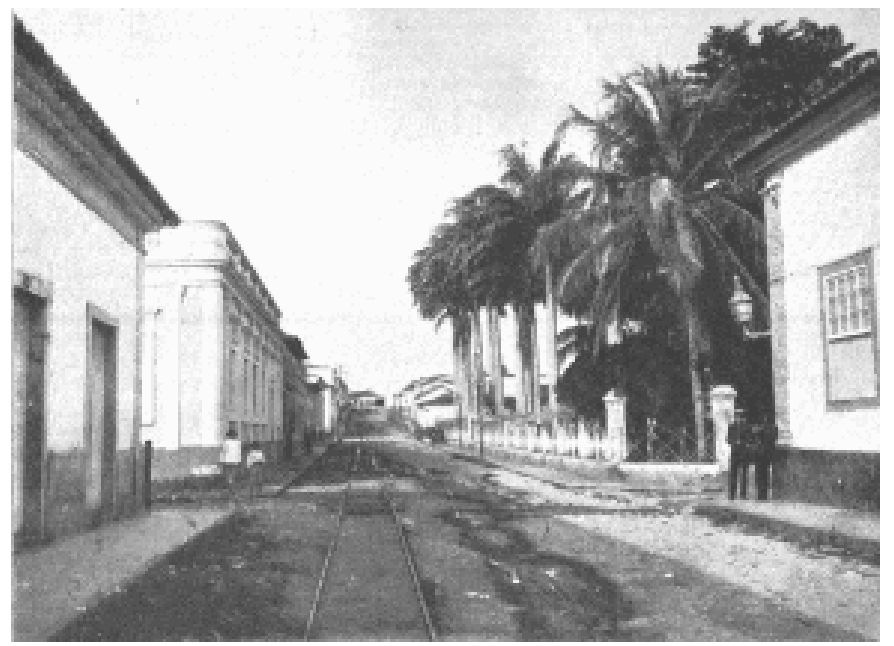

Figura 6.16- Rua 13 de Junho, antiga Rua Bela do Juiz. (fonte: Album Graphico do Estado de MattoGrosso, p. 316 ). 
Este período caracteriza-se pela presença marcante do poder público na região, que tomou a iniciativa de construir edificações de grande porte e incorporar elementos que exprimissem maior requinte às fachadas e aos espaços construídos. A sofisticação das construções públicas começou a influenciar as novas edificações residenciais. A camada dominante passou a construir sobrados e grandes residências térreas que modificaram a fisionomia da cidade, porém, a população de baixa renda continuava vinculada às choupanas, às casas de palha e taipa e, mais tarde, de adobe (FREIRE, 1988, p.27-29). Nesse período, o traçado urbano ganhou contornos mais nítidos e o repertório arquitetônico se enriqueceu e se diversificou com a construção de edifícios públicos. A malha viária central ganhou contornos mais claros e as ruas transversais começaram a se definir.

Duas características se impõem como parâmetros estéticos neste período: o pé-direito mais alto e a presença de elementos singelos de decoração nas fachadas. Nessa época estabeleceram-se certas características que, pela regularidade de sua reprodução, configuraram o estilo tradicional que marcou a casa cuiabana: o despojamento e a simplicidade. "As dimensões do espaço interior marcavam o status do proprietário. Embora conservando em sua fisionomia traços da casa paulista em que se inspirou, a casa cuiabana traz a novidade do pé-direito alto, diferenciando-se das casas do século XVIII do Beco do Candieiro, das ruas de Baixo e do Meio. (...) O único traço externo denotando abastança de seus donos era o uso de janelas de guilhotina com vidros, material de alto custo na época. A fragilidade dos vidros e as distâncias transcontinentais dificultavam e oneravam sua importação. Internamente a dignidade da residência se expressava nos grandes espaços e no mobiliário, esse também importado da Europa. A varanda, inicialmente fechada e mais tarde aberta para o quintal, tornou-se um dos traços marcantes da casa cuiabana.(...) As classes menos favorecidas procuravam reproduzir o modelo de residência da classe dominante nas construções de suas casas. A proporção reduzida da área construída, a inexistência de vidraças, a simplicidade do mobiliário de fabricação local, a altura menor do pé-direito estabeleciam as diferenças de status entre as habitações das diferentes classes. (...) Os que não construíam novas residências procuravam incorporar alguns elementos simbólicos do modelo às suas casas, principalmente vidraças e mobiliário importado.” (FREIRE, 1988, p.39-40)

O historiador Lenine Póvoas afirma que, até o início do século, Cuiabá assemelhavase bastante a algumas aldeias de Portugal $^{2}$, assim como muitas outras cidades brasileiras. "Aproveitando antigas tradições urbanísticas de Portugal, nossas vilas e cidades apresentavam ruas de aspecto uniforme, com residências construídas sobre o alinhamento das vias públicas e paredes laterais sobre os limites dos terrenos. (...) Revelam uma preocupação de caráter formal, cuja finalidade era, em grande parte, garantir para as vilas e cidades brasileiras uma aparência portuguesa.” (REIS FILHO, 1987)

A arquitetura popular portuguesa é fruto de inúmeras raízes; os estilos ganharam expressões locais bastante diferenciadas, fruto de uma adaptação às condições de cada região, inclusive ao clima. Apesar da predominante singeleza de linhas e estilo, não se pode dizer que existe apenas uma arquitetura portuguesa ou uma casa

\footnotetext{
2 informação verbal, 1997.
} 
portuguesa; entre as aldeias, muitas vezes, há diferenças mais profundas do que entre certas construções portuguesas e gregas (Associação dos Arquitetos Portugueses, 1980). Além disso, no Brasil as construções portuguesas adaptaram-se às condições tropicais e mesclaram-se às soluções regionais. Ainda assim é possível identificar os traços mais marcantes; pode-se perceber a semelhança das características encontradas em Cuiabá até o início deste século com algumas regiões lusitanas, como a simplicidade das casas térreas, a sobriedade dos sobrados e o traçado urbano de ruas tortuosas e estreitas. Nas regiões portuguesas de invernos temperados, com dias ensolarados e verões quentes, o clima determinou o caráter do espaço exterior contíguo à habitação que, pela existência de um alpendre ou de uma varanda alpendrada, criou uma zona de transição climática entre o ambiente tórrido e o interior fresco. Este elemento e suas variações foram largamente utilizados no Brasil, principalmente nas regiões mais cálidas.

De acordo com HOLANDA (1995, p.47), os portugueses e seus descendentes procuraram recriar aqui o meio de sua origem e fizeram-no com uma facilidade que ainda não encontrou, talvez, segundo exemplo na história. A casa peninsular, severa e sombria, voltada para dentro, ficou menos circunspecta sob o novo clima, perdeu um pouco de sua aspereza, ganhando a varanda externa: um acesso para o mundo de fora. Com essa nova disposição, importada por sua vez da Ásia oriental e que substituía com vantagem, em nosso meio, o tradicional pátio mourisco, formaram o padrão primitivo e ainda hoje válido para as habitações européias nos trópicos.

Outra semelhança está na construção com taipa, que é um material bastante comum na arquitetura popular de Portugal, principalmente onde o clima é quente e seco, e os cursos d'água são pouco frequentes. A presença de terrenos argilosos e a economia de meios necessária à sua execução também podem justificar a frequência com que ela é utilizada. As casas de taipa encontram-se principalmente em regiões pobres ou serranas, cujo isolamento econômico ou geográfico constitui um poderoso fator arcaizante, propício à conservação do modo de vida e das tradições (OLIVEIRA e GALHANO, 1992, p.23) "As paredes deste material, quando bem realizadas $e$ rebocadas, são muito duradouras e a sua espessura oferece boas condições de isolamento térmico. A taipa necessita, contudo, de certas precauções na sua execução, sendo uma delas o evitar o contacto com a humidade do solo e o seu consequente apodrecimento; para isso, constrói-se uma fundação em alvenaria de pedra, que se eleva sempre acima do terreno." (Associação dos Arquitetos Portugueses, 1980). Em Cuiabá foram muito comuns as construções de taipa assentadas sobre fundações de pedra cristal e pedra canga, largamente encontradas na região.

Segundo OLIVEIRA e GALHANO (1992, p.13), a casa popular é um produto imediato das relações do homem com o meio natural que o rodeia, seja ajustando-se às peculiaridades climáticas ou utilizando os materiais locais. Na arquitetura popular portuguesa, a importância do clima sobre o homem é evidente, se observados o vestuário, o emprego da cal nas paredes externas das construções ou as pequenas e escassas aberturas para o exterior (fig.6.17 a 6.18). Observa-se também que, em algumas regiões, os quintais são verdadeiros jardins, onde não falta a figueira, a laranjeira ou o limoeiro, contrastando com o branco da cal. 


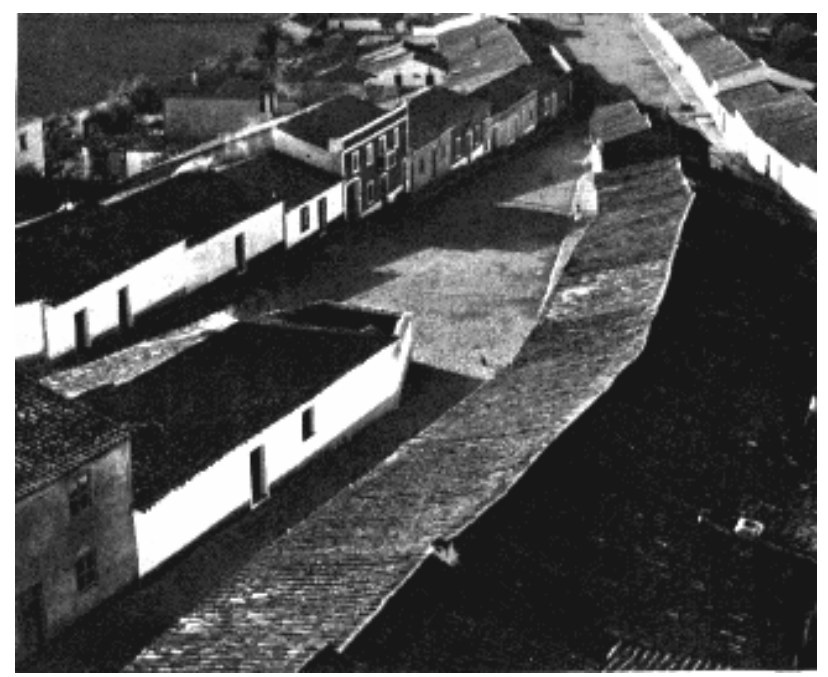

Figura 6.17 - Vista de uma aldeia portuguesa, na região de Castro Verde. (fonte: Associação dos Arquitetos Portugueses. Arquitectura Popular em Portugal, p.604).

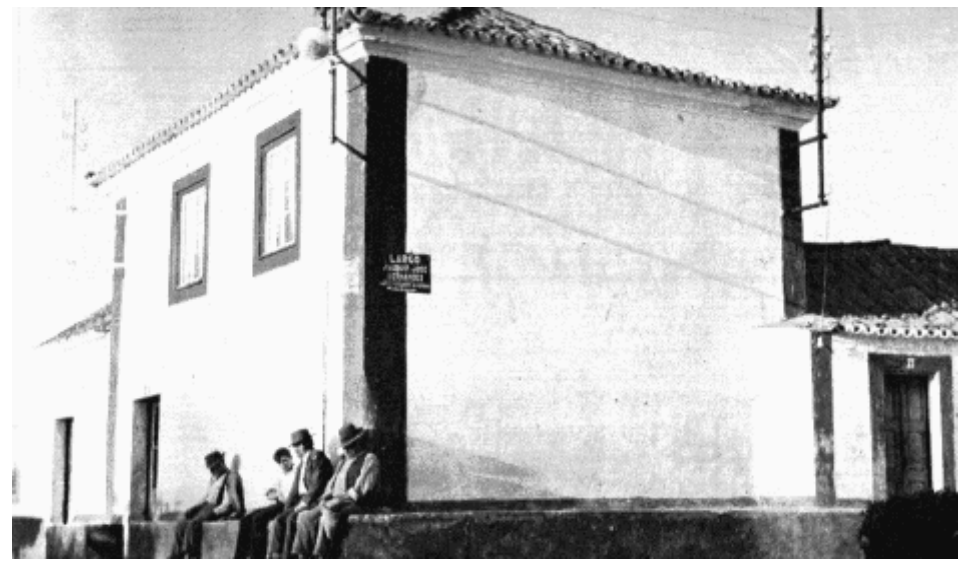

Figura 6.18 - Típico sobrado português. (fonte: Associação dos Arquitetos Portugueses. Arquitectura Popular em Portugal, p.363).

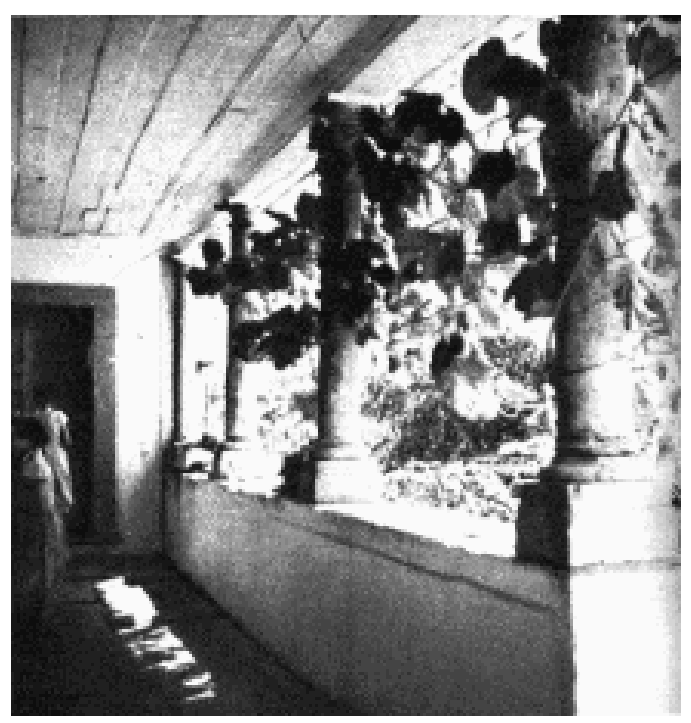

Figura 6.19 - Transição entre o exterior e o interior em uma casa lusitana na região da Estremadura. (fonte: Associação dos Arquitetos Portugueses. Arquitectura Popular em Portugal, p.378). 
Em Portugal é frequente o caráter compacto e estruturado dos núcleos antigos do interior. A casa isola-se da rua e mantém-se sempre fechada. Toda a atividade se passa no interior, no quintal desarrumado, confuso, com escadas e anexos, vasos e gaiolas abrigados por trepadeiras, verdadeiro prolongamento da habitação. A população do sul gosta do ar livre; as pessoas só vivem ou trabalham em casa quando não o podem fazer no quintal. Gostam de espaços que lhes dêem sombra no verão e aconchego nas tardes de inverno, e ao mesmo tempo apreciam a intimidade que a rua lhes nega. As janelas da frente abrem-se somente em dias de festa (Associação dos Arquitetos Portugueses, p.360-362). O pátio reflete um claro desejo de isolamento, quase de defesa. A casa forma um todo vedado ao acesso e até a vista de estranhos (OLIVEIRA e GALHANO, 1992, p.103). Outra razão para esse isolamento é a agressividade do clima quente e seco que predomina em algumas regiões. O microclima interno, criado pelo pátio arborizado, difere enormemente da aspereza das condições exteriores. Este foi outro recurso largamente utilizado nas antigas casas cuiabanas.

"A característica principal da habitação algarvia é a sua simplicidade, que se manifesta no aspecto exterior, duma grande pureza de formas e de superfícies, e na disposição das peças que a compõem interiormente.(...) Os pátios, tão característicos das casas algarvias, aparecem em quase toda a província com aspectos e tamanhos variados, cobertos total ou parcialmente pela parreira. (...) No Verão, é aí que se recebem as visitas, servindo então como prolongamento da sala..." (Associação dos Arquitetos Portugueses, 1980). As casas na região do Algarve são quase sempre cobertas com telhas; os pavimentos são térreos, e a maior parte das portas e janelas tem apenas folhas de madeira sem vidro. A casa popular do sul de Portugal é geralmente de taipa ou adobe, sempre rebocada e caiada, com poucas janelas, como um meio de defesa contra o calor; o chão é de terra batida, tijolo ou ladrilho, e a cobertura, sempre de telhas. Principalmente nessa região são encontradas as influências romanas e árabes. No norte da África e na Ásia é frequente construir-se com terra; o fato do nome adobo ser de origem árabe - attob é um indicativo de que foram os muçulmanos que introduziram essa técnica entre os portugueses (OLIVEIRA \& GALHANO, 1992, p.151-153, 188).

Por esse motivo, as influências árabes também deixaram suas marcas em diversas regiões do Brasil, como o desenho urbano de ruas tortuosas e estreitas e as casas justapostas que proporcionavam sombra, protegendo-se umas às outras, e as casas compactas voltadas para o jardim interno, que surgiram da adição de elementos construtivos ao redor de um espaço aberto e sombreado. A arquitetura vernacular árabe resolveu seus problemas climáticos com beleza e funcionalidade. Para eles, a principal finalidade do edifício é criar um microclima agradável, contrastante com o meio exterior tão agressivo. Através do pátio interno podia-se modificar o microclima, já que nele era possível manter água e plantas e garantir maior privacidade para a realização das tarefas domésticas. É indiscutível o contraste entre o exterior, onde há calor e intensa radiação solar, e o interior, que proporciona intimidade, sombra e frescor. Neste caso, o pátio funciona como um poço de ar fresco (fig.6.19 e 6.20).

MOURA (1976, p.10) afirmou, na década de 70, que ainda era possível ver em Cuiabá, Cáceres e outras cidades mato-grossenses alguns dos elementos mais característicos da arquitetura colonial brasileira: as rótulas e gelosias (fig.6.21 e 
6.22). "De indiscutível origem oriental, introduzido na Península Ibérica pelos árabes, esse tipo de esquadria trazido pelos colonos portugueses adaptava-se admiravelmente ao clima tropical e passou a caracterizar a arquitetura das cidades brasileiras antigas."

No século XIX, as rótulas e gelosias foram proibidas no Rio de Janeiro e em São Paulo, sob o pretexto de 'modernizar as cidades'. A capital da corte de D. João VI queria 'civilizar' a cidade, "expurgando-a das atrasadas construções arabizantes dos estreitos becos, providas de inaceitáveis rótulas, treliças, balcões e muxarabis de velhos tempos do isolamento da colônia às novidades do mundo. (...) Quem acabou lucrando com tudo isso foi evidentemente a mesma indústria inglesa cujos produtos, a começar pelo vidro plano, vieram permitir a reformulação desejada." (LEMOS, 1989, p.46) Em 1759 as rótulas e gelosias já eram proibidas em Lisboa e em outras cidades portuguesas.

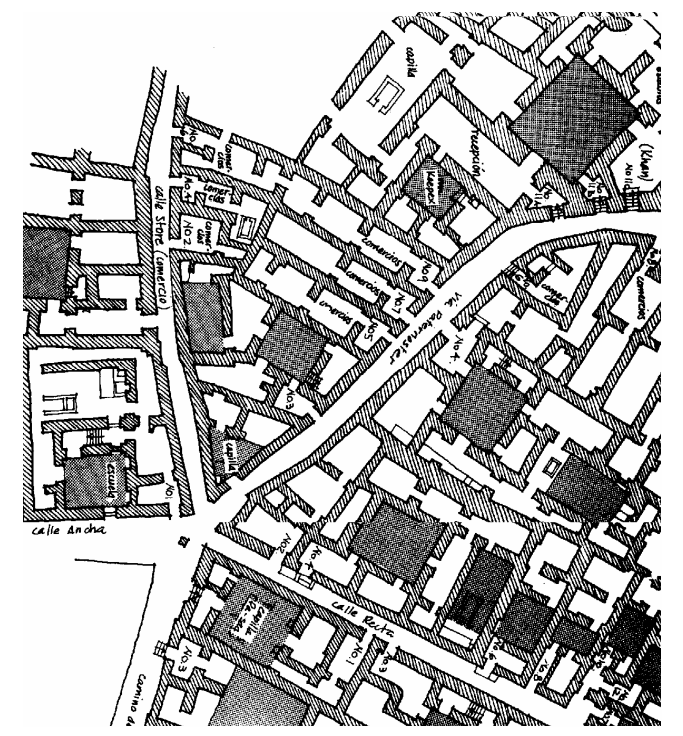

Figura 6.20- Zona Residencial Oriental. Ruas tortuosas e estreitas. (fonte: Schoenauer. 6.000 Años de Hábitat, p. 127)

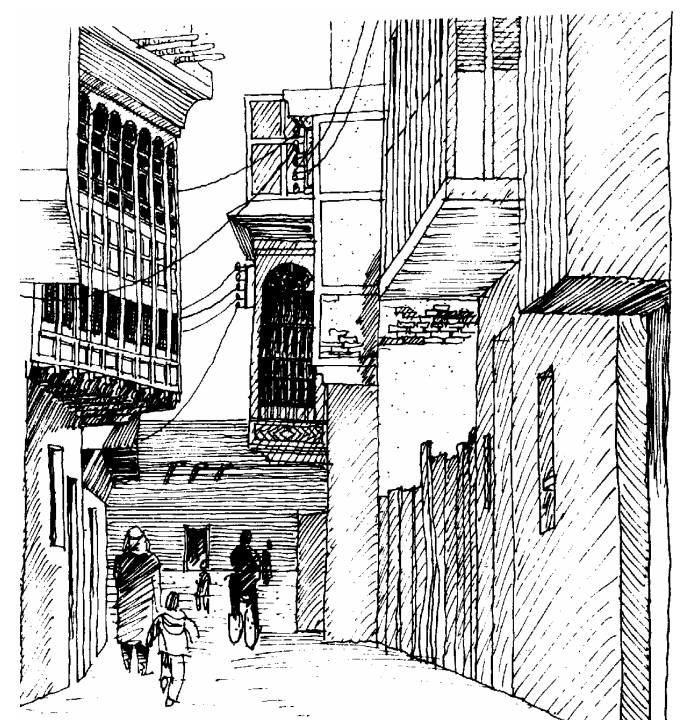

Figura 6.21 - Rua em Al-Kazimiyah. (fonte: Schoenauer. 6.000 Años de Hábitat, p. 146) 


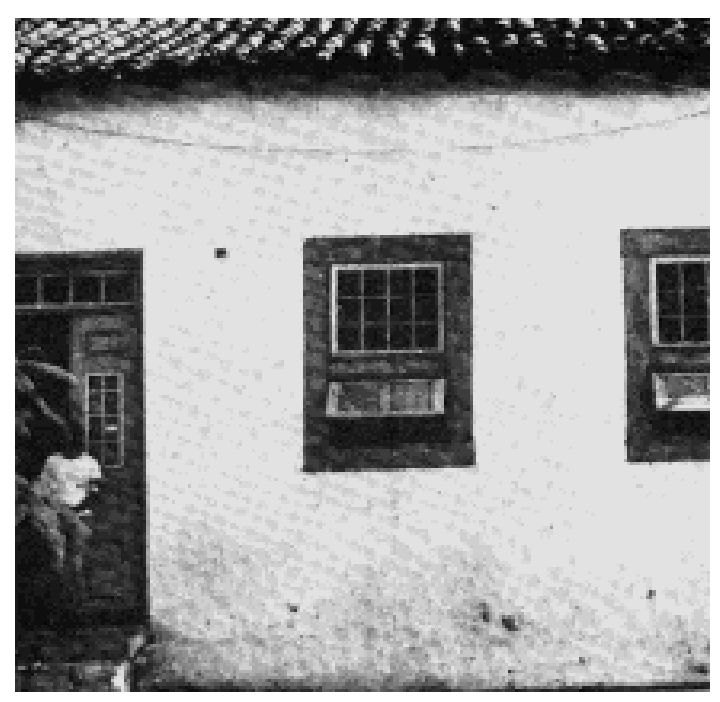

Figura 6.22 - Esquadrias encontradas em Cuiabá. Década de 70. (fonte: Moura. Notas sobre a História da Arquitetura em Mato Grosso. p. 18).

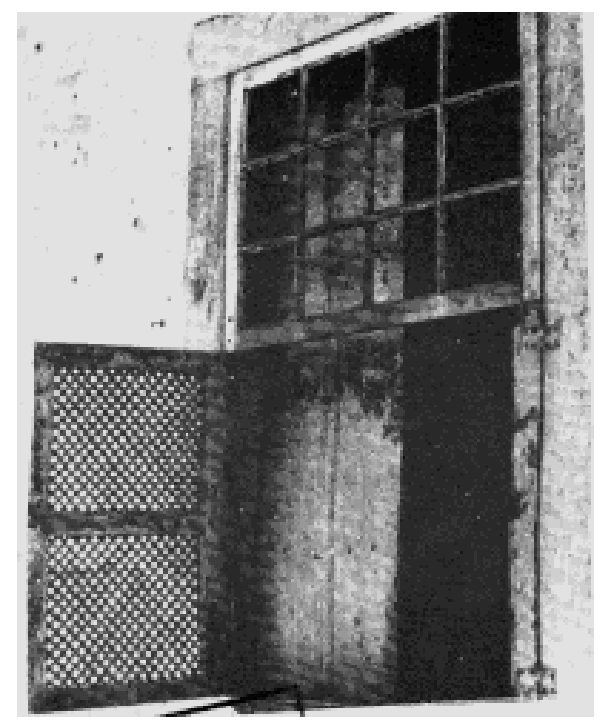

Figura 6.23 - Esquadria encontrada em Cuiabá. Década de 70. (fonte: Moura. Notas sobre a História da Arquitetura em Mato Grosso. p. 17).

“Em Cuiabá, isolada da costa por centenas de léguas de sertão, as rótulas resistiram por muito mais tempo. Para isso contribuíram não só o ambiente social arcaizado desde o século XVIII como as dificuldades de transporte do vidro, material altamente quebradiço, através dos ásperos caminhos da época. (...) Com o declínio da riqueza aurífera o uso do vidro, que era caro, diminuiu em favor das rótulas” (MOURA, 1976, p.17-19). FLORENCE (1977, p.137) afirmou, em 1827, que o edifício em que se encontravam o presidente da província e a intendência possuía janelas únicas na cidade, porque tinham caixilhos com vidros, o que confirma a raridade deste elemento na região, naquela época. Hoje esses elementos trazidos pelos imigrantes já não existem mais. Não resistiram ao tempo e às transformações. 


\subsubsection{Ciclo da Modernização}

O terceiro ciclo começou a se formar com a construção de Brasília, que veio fortalecer o crescimento das cidades em Goiás e Mato Grosso. Os primeiros fluxos migratórios da década de 1960 começaram a exercer pressão sobre a cidade, de estrutura urbana despreparada para absorvê-la. Com o início da construção da rodovia Cuiabá/Porto Velho, Cuiabá deixou de ser uma cidade de fim de linha para assumir a posição de medianeira urbana do projeto de 'integração nacional' da Amazônia; "o povo começa a ser expropriado de seu papel histórico de artífice do urbano e o capital, através da especulação imobiliária, assume as decisões sobre o crescimento da cidade, impondo regras de seu interesse.” (FREIRE, 1988, p.55-57) As frentes pioneiras avançavam sobre o norte mato-grossense e Cuiabá se transformava em uma importante base urbana de apoio ao processo de expansão.

FIGUEIREDO (1979, p.174) explica a sede de progresso e modernidade que invadiu Cuiabá nesse período. "O moderno caracterizou-se pela aversão ao antigo que, imediatamente, passou a significar atraso, anacronismo, incapacidade para o progresso. A rivalidade com Campo Grande acentuava-se na medida que esta se enriquecia e se transformava. Goiânia, de sua parte, contribuía também para que Cuiabá sentisse mais diretamente os 'desconfortos do antigo', pois era exemplo de cidade moderna e progressista.(...) De certa forma, tudo isso gerou uma inibição que levou o cuiabano a esquecer a sua tradição e importância, dando as costas para o passado no intento de receber uma imagem progressista e inovadora." Para FREIRE (1988, p.65-66) "esse processo caracteriza-se pela oscilação entre perda e ganho. Inicialmente, a perda se materializa na destruição da arquitetura tradicional; o ganho se concretiza na modernização de suas funções, no campo econômico e cultural. (...) Essas contradições fazem do centro um espaço de ambiguidades. É, ao mesmo tempo, interiorano e cosmopolita, aconchegante e inóspito."

FREIRE (1992, p.55) afirma que o cuiabano questionava a importância das tradições de sua cidade, da arquitetura de seus casarões e edifícios públicos, baseando-se em novos conceitos e preconceitos sobre o progresso. Para muitos, os modelos para as novas construções e os novos caminhos para o crescimento da cidade deveriam ser buscados lá fora e não no interior das nossas tradições, já que o progresso caminhava de fora para dentro. Ao lado das novas construções, tudo parecia velho e ultrapassado. O que fosse diferente do velho, não importando a sua qualidade, impunha-se como expressão do novo, do moderno. O preço do progresso passou a ser a imposição do novo pela destruição do velho, instalando-se assim um doloroso e agressivo processo de modernização para a cidade. "O antigo começou a ser visto como um entrave ao progresso. A arquitetura cuiabana foi desprezada por endinheirados e poderosos que, por sua vez, ergueram pelos quatro cantos da cidade as residências modernosas, com colunatas do Palácio da Alvorada, cravadas de pedras, colunas em $V$ ou palitos, na famigerada ânsia de parecer opulento $e$ avançado.” (FIGUEIREDO, 1979, p.174-175) Com a demolição dos antigos edifícios, a cidade encontrou um passe livre para a sua descaracterização. Sem as suas referências, a sociedade foi desestimulada a preservar sua cidade, suas casas, suas tradições.

Após um longo período de estagnação, devido principalmente à distância e ao seu isolamento das grandes cidades, Cuiabá vem se transformando rapidamente, muitas 
vezes ignorando as limitações existentes no centro antigo da cidade. "No caso da estrutura espacial da Região Centro-Oeste, na atualidade, identificam-se espaços construídos na fase em que a mineração do ouro foi o fator de um processo de apropriação do solo e construção de espaços. Os núcleos urbanos surgidos naquela época estão na estrutura espacial atual, como marcos daquele processo. Isto é evidenciado na paisagem urbana de Cuiabá, no trecho correspondente ao centro comercial antigo, com o casario, o traçado das ruas e as igrejas construídas no Século XVIII. ”(IBGE, 1988, p.243).

Foi marcante o acelerado processo de urbanização que ocorreu principalmente a partir da segunda metade da década de 1970 na cidade de Cuiabá, contrastando com a situação anterior relativamente estável. PÓVOAS (1980, p.27) comenta o "violento processo de transformação da velha cidade colonial. As antigas casas, no centro urbano, foram cedendo lugar aos edifícios destinados às sedes dos hotéis, dos bancos, das repartições públicas, das lojas e das galerias. As grandes residências foram sendo divididas e transformadas as suas fachadas: por entre elas foram surgindo construções de moderna arquitetura; ruas foram sendo alargadas; avenidas foram sendo rasgadas; novos bairros foram surgindo e por toda a parte o requintado gosto das novas construções foi transformando inteiramente o aspecto da vetusta capital mato-grossense."

Para FREIRE (1992) a área central é a própria história da cidade; o espaço urbano e a arquitetura conferem-lhe personalidade (fig.6.24). Porém, o acelerado desenvolvimento dos últimos anos vem exercendo forte pressão sobre o centro, provocando sua descaracterização e alterando as relações entre seus componentes. A estrutura das ruas, delineada no século XVIII (fig.6.25 a 6.27), não comporta a verticalização maciça que hoje cerca a área central da cidade. O trânsito foi ficando cada vez mais difícil nessas áreas e, hoje, o acesso de veículos já não é permitido em algumas ruas, transformadas em calçadões. Restam pouquíssimos moradores no centro histórico. Os edifícios foram transformados em lojas, galerias comerciais e repartições públicas; uns encontram-se bem conservados, outros descaracterizados e muitos em estado de abandono. Nas ruas do centro, algumas antigas construções ainda resistem, apesar de descaracterizadas ou escondidas sob as falsas marquises e os anúncios do comércio. Em alguns trechos, o trânsito de veículos ainda é permitido, mesmo com ruas e calçadas extremamente estreitas.

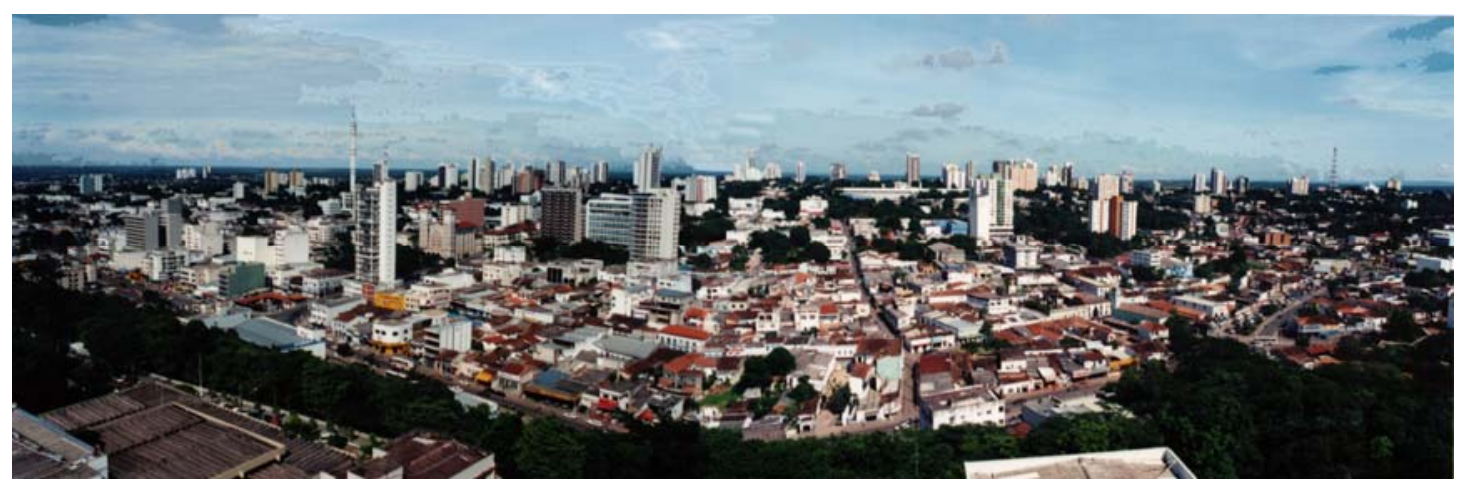

Figura 6.24 - Vista do centro antigo da cidade em janeiro de 1995. Comparar com as figuras 6.3 e 6.12, que mostram o mesmo local em meados do século XVIII e início do século XX, respectivamente. (foto J. Calsinski) 


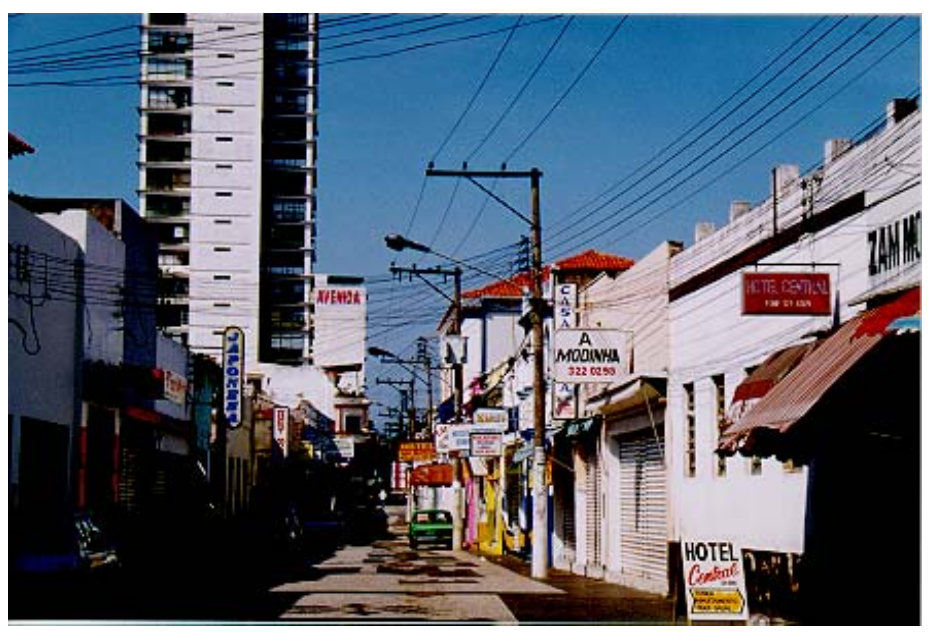

Figura 6.25 - Rua Galdino Pimentel, conhecida como Rua de Baixo, no centro antigo de Cuiabá. (foto D. Duarte)

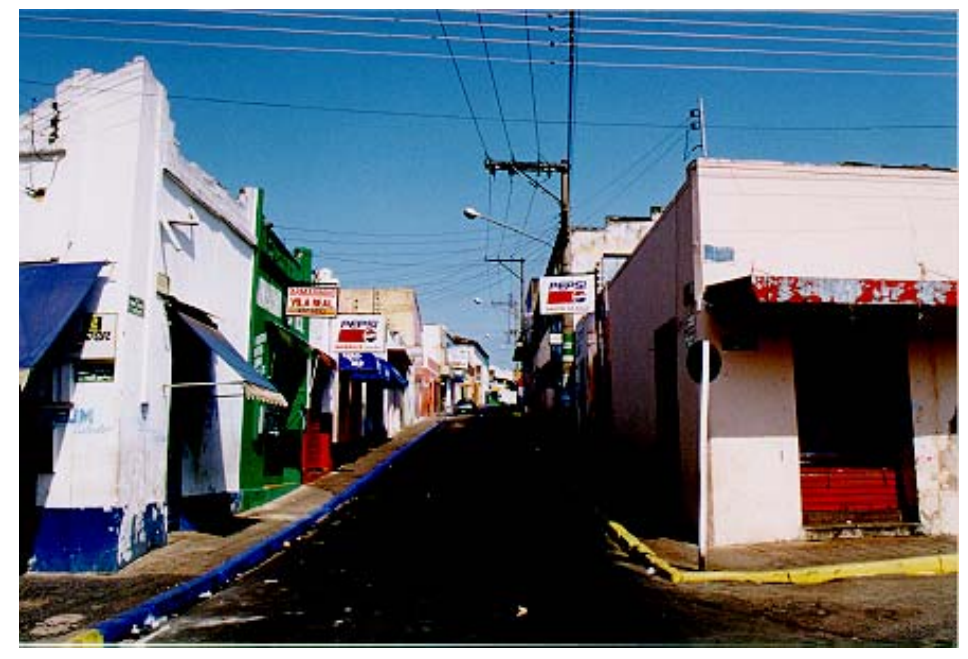

Figura 6.26- Rua Campo Grande, no centro antigo de Cuiabá. (foto D. Duarte)

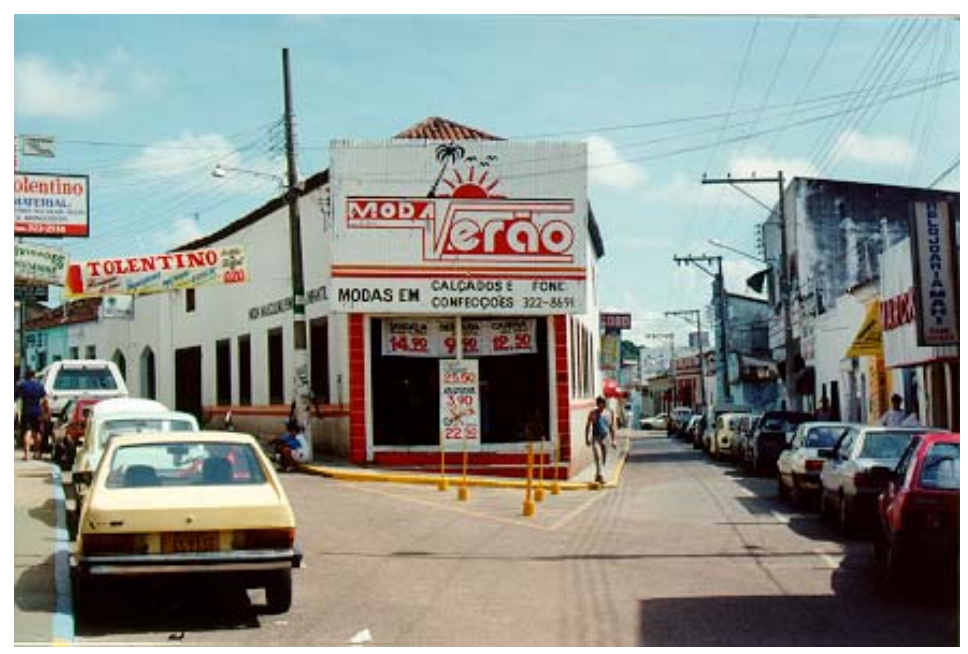

Figura 6.27- Entroncamento da Rua do Meio com a Travessa 21 de Abril, conhecida como Beco Torto, no centro antigo de Cuiabá. (foto J. Calsinski) 
Nos anos 1970 o PDLI - Plano de Desenvolvimento Local Integrado traçou as diretrizes da organização físico-territorial do espaço urbano de Cuiabá, e propostas do projeto CURA - Comunidades Urbanas de Renovação Acelerada, para os bairros Lixeira, Quilombo e Araés (fig.6.28), foram colocadas em prática. As propostas incluíam a criação de praças, considerando os vazios existentes em algumas quadras que eram utilizados como campo de pelada, e onde era perfeitamente viável a implantação de equipamentos de lazer. Foram previstos grandes canteiros entrecortados por caminhos e patamares dotados de bancos e equipamentos de playground, com arborização intensa utilizando-se espécies nativas (Cuiabá. Projeto Cura Cuiabá, [s.d.]). Na época, em muitos bairros antigos predominava a ocupação espontânea, isenta de qualquer diretriz inicial, que acabou resultando num sistema viário bastante desordenado. As vias locais eram pouco definidas, e não se podia identificar sequer um alinhamento para as construções mais antigas. A maioria delas se encontrava junto às vias públicas, sem recuo frontal, com áreas verdes privativas nos centros das quadras.

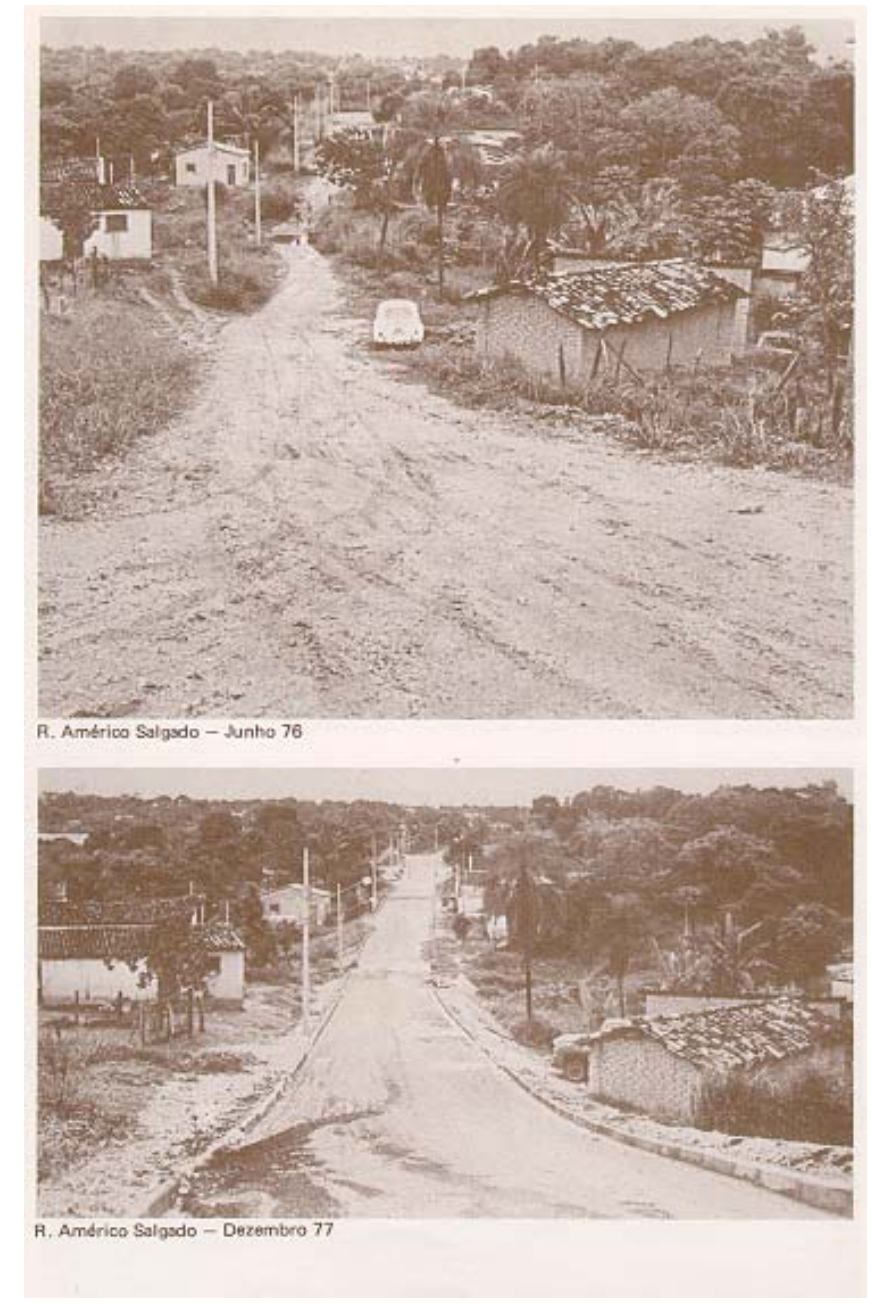

Figura 6.28 - Bairro Araés antes e depois da intervenção do CURA. (fonte: Cuiabá. Prefeitura Municipal de Cuiabá. Projeto Cura Cuiabá) 
A partir dos anos 1970 a ocupação de novas áreas, além dos limites ocupados pela cidade, tornou-se uma necessidade frente ao crescimento que a cidade vivia na época. Uma das áreas mais importantes foi o CPA, que surgiu com a decisão de se direcionar um dos eixos de crescimento da cidade para essa região e transferir os órgãos do Governo do Estado para a nova área (fig.6.29 e 6.30). De acordo com FREIRE (1992, p.10-15), o CPA foi uma proposta dos técnicos ligados à Prefeitura Municipal e ao Governo do Estado, no final dos anos 60, trabalhando sobre a planta de Cuiabá e sobre sua realidade. "Havia urgência de que a cidade se estruturasse para crescer sem maiores sofrimentos. Novas áreas deveriam ser planejadas $e$ dotadas de infra-estrutura básica necessária à sua ocupação racional (...) O centro da cidade, espaço inicial do surgimento de Cuiabá, começava a se congestionar pelo movimento provocado essencialmente pelos órgãos do governo localizados nessa área e pela rede bancária em expansão.”

A área hoje conhecida como CPA "reuniu maior número de vantagens: facilidade para apropriação do terreno pelos vários projetos a serem implantados; maior facilidade para lançamento da infra-estrutura; qualidade do solo; área com mais de 100 metros de altitude, em média, acima do centro da cidade, propiciando melhores condições de clima; terras pertencentes ao Estado, com apenas 12\% de terrenos titulados de propriedade particular; e, fator muito relevante, prolongamento natural do principal eixo urbano, a avenida Tenente Coronel Duarte, a nossa avenida da Prainha. A 5 quilômetros de Cuiabá, a nova sede do Governo seria um polo de atração do crescimento da cidade, formando com o Centro Histórico e a Universidade Federal um triângulo de forças que deveriam provocar o adensamento da cidade em áreas mais favoráveis, possibilitando, ainda, a preservação do nosso patrimônio arquitetônico, encontrado, basicamente, na área setecentista do centro. (...) A avenida do CPA, hoje Rubens de Mendonça, então projetada, não seria apenas uma ligação do Centro Histórico com o Centro Político. Atravessando Zona prioritária para o replanejamento, deveria assumir o papel de eixo ordenador do espaço nas suas vizinhanças (...) uma grande avenida com infra-estrutura que dá suporte à adequada verticalização dos edifícios (...)” Na opinião de FREIRE (1992, p.16) não há dúvida quanto ao acerto da decisão. Hoje, após a implantação dos conjuntos habitacionais CPA I, II, III e IV, próximos aos Centro Político Administrativo, a área tem mais de 150.000 habitantes (fig.6.31).

De acordo com FREIRE (1992, p.32, 51-52), hoje, um dos maiores problemas da cidade está no crescimento urbano sem o aumento significativo da produção agrícola e industrial, sem o suporte do desenvolvimento de uma economia urbana consistente, submetendo a cidade a um verdadeiro 'inchamento' urbano. "Estamos vivendo uma incrível experiência, nestes tempos em que Cuiabá, após duzentos e tantos anos de crescimento vegetativo e lento, viu-se alcançada e invadida por um processo que estrangula e estraçalha, e ao mesmo tempo redescobre seu destino. Ponto de apoio decisivo à conquista e expansão de novas fronteiras, recebe gente de todos os cantos, todas as pronúncias, todos os costumes, todas as diferentes nuances que compõem esse rico tecido das culturas brasileiras. (...) Sob o encanto da promessa de progresso, estamos vivendo um momento de conflito entre preservar $e$ desenvolver, quando a cultura tradicional se antepõe às formas de produção tecnológica. De resto, uma luta assistida por todas as sociedades do mundo moderno.“ 


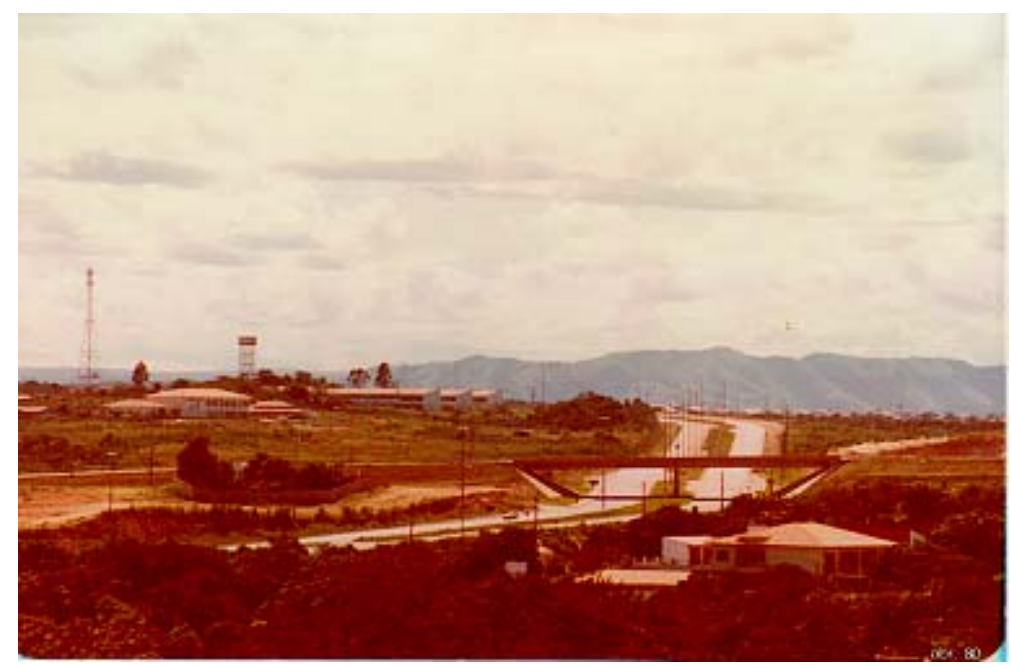

Figura 6.29 - Vista da Av. do CPA em 1980, próximo ao viaduto da Av. Miguel Sutil, no sentido Centro-CPA. (foto: A. Duarte)

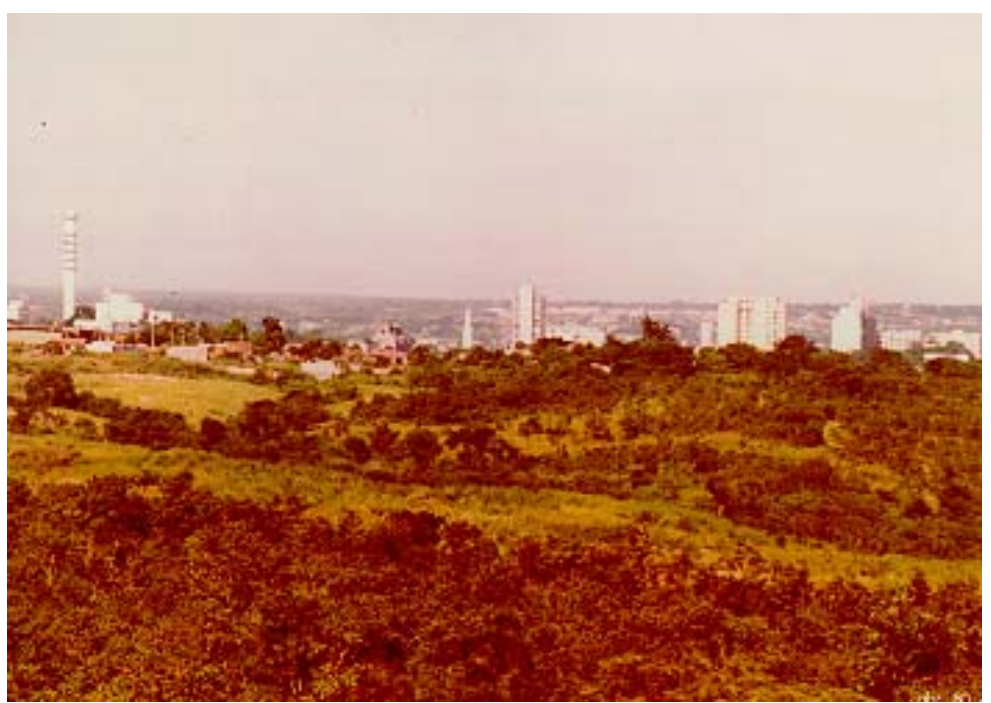

Figura 6.30- Vista do CPA em 1980 no sentido CPA-Centro.(foto: A. Duarte)

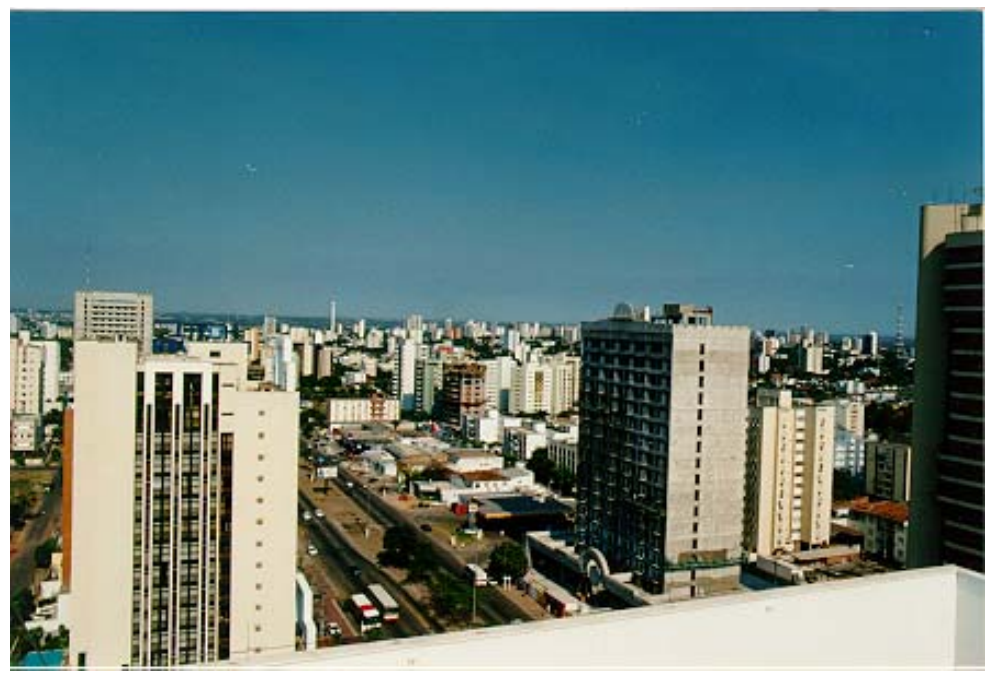

Figura 6.31 - Vista da Av. Rubens de Mendonça em 1997. (foto: A. Duarte) 


\subsection{O quadro atual}

Como principal ponto de apoio dos programas de desenvolvimento da região Cuiabá passou a receber migrantes de outros estados; o crescimento populacional atingiu, nos momentos mais críticos, a taxa de $18 \%$ ao ano. Esses fluxos migratórios, muitas vezes formados por populações carentes, encontraram a administração municipal despreparada para enfrentar a nova realidade urbana, agravando os problemas de infra-estrutura nas áreas da saúde, educação, transporte, segurança e principalmente habitação, resultando em invasões de áreas públicas e privadas. Com as invasões no final da década de 70 novos bairros surgiram nas margens do rio Cuiabá e de seus afluentes, consideradas áreas de risco pela constante ameaça de inundação no período chuvoso. Essas áreas foram sendo ocupadas rapidamente, sem que o poder público tomasse as medidas necessárias.

Na década de 1970 o Plano de Desenvolvimento Local Integrado de Cuiabá - PDLI (NEW'PLAN, [s.d.]) foi elaborado estabelecendo normas e diretrizes para orientar o desenvolvimento da cidade. Já nessa época se alertava para um melhor aproveitamento das áreas verdes nativas, como as margens dos rios, face à carência de áreas públicas de lazer. A médio prazo, dentre os objetivos do plano, estava elevar o índice de área verde por habitante para $16 \mathrm{~m}^{2}$ até 1990 , otimizar a utilização das margens dos rios Cuiabá e Coxipó, preservar a vegetação existente nas áreas privadas e públicas da cidade, efetivar a utilização das áreas verdes previstas nos loteamentos aprovados e preservar áreas íngremes para arborização. Na época os instrumentos eram a Lei de Zoneamento e o programa de reserva, desapropriação e aproveitamento das áreas disponíveis para recreação e paisagismo. A manutenção de uma faixa verde entre o Rio Cuiabá e a Av. Beira Rio já era prevista, porém, só recentemente esse projeto começou a ser concretizado, com a inauguração do Museu do Rio em 1999 e do Aquário Municipal em 2000, desencadeando o processo de revitalização ribeirinha.

Na gestão do prefeito Dante de Oliveira, de 1986 a 1988, surgiram reivindicações exigindo um Plano Diretor para o município por parte da Câmara Municipal, motivadas por pressões populares e por órgãos como IAB, CREA, ADEMI, devido aos problemas decorrentes do crescimento acelerado da cidade, com taxas de $7 \%$ a $10 \%$ ao ano. Essa iniciativa surgiu antes da constituição de 1988, que determinou que cidades com mais de 20.000 habitantes deveriam ter um plano diretor.

Já em 1996, com a publicação do Plano Diretor de Desenvolvimento Urbano de Cuiabá, disse o então prefeito José Meirelles que "No início da década de oitenta, a Câmara Municipal de Cuiabá deflagrou importante processo de discussões em toda a sociedade cuiabana sobre o futuro de nossa capital, antepondo de maneira sábia a premência de instituir o planejamento urbano como instrumento democrático de gestão de nosso desenvolvimento urbano que já se fazia acelerado. Todo esse processo de discussões culminou com a Lei n.2.259 de 26 de abril de 1985, artigo 58, que autorizou a criação do Instituto de Pesquisa e Desenvolvimento Urbano IPDU. Hoje que Cuiabá ultrapassou a casa do meio milhão de habitantes, entendemos o quanto fora acertada aquela decisão, que não podia mais ser retardada.” (Cuiabá. Caderno do IPDU, [s.d.], p.11).

O Plano Diretor, planejado para ser aprovado em etapas, vem sendo elaborado pelo IPDU - Instituto de Pesquisa e Desenvolvimento Urbano, vinculado à Secretaria 
Municipal de Meio Ambiente e Desenvolvimento Urbano da Prefeitura Municipal de Cuiabá, desde o ano de 1992, na época da gestão do prefeito Frederico Carlos Soares Campos. O processo de planejamento foi desencadeado com a aprovação da primeira etapa do Plano Diretor de Desenvolvimento Urbano e o fortalecimento institucional derivado da transformação do Instituto em Fundação de Direito Público (Cuiabá. Caderno do IPDU, [s.d.]).

O IPDU é o Órgão de Planejamento e Apoio Técnico do Sistema Municipal de Desenvolvimento Urbano de Cuiabá, e tem a responsabilidade legal definida pela Lei Orgânica Municipal de propor o Plano Diretor de Desenvolvimento Urbano de Cuiabá. O Instituto originou-se de uma autorização legislativa de 1985, mas só veio a ser implantado em 1990. O IPDU tem como finalidade a elaboração, acompanhamento e monitoramento do Plano Diretor de Desenvolvimento Urbano e seus desdobramentos; o Instituto conta com uma equipe multidisciplinar composta por arquitetos, advogados, assistentes sociais, economistas, engenheiros civis, engenheiros eletricistas, engenheiros sanitaristas, engenheiros de transportes, cartógrafos, geógrafos, geólogos, além de técnicos auxiliares e administrativos.

A elaboração do plano Diretor foi planejada em três etapas pelo IPDU, e só se passa à etapa seguinte depois que a anterior for aprovada. De maneira geral, essas etapas foram definidas da seguinte maneira:

1 a etapa: diretrizes gerais (já aprovada pela Câmara)

2 a etapa: diretrizes setoriais (com algumas leis já aprovadas e projetos de lei em discussão no Conselho e/ou aguardando aprovação da Câmara Municipal)

3 a etapa: planos locais; segundo o superintendente do IPDU, esta é uma "etapa pretensiosa, quando se pretende levar o plano até os bairros". ${ }^{3}$

Esta é uma inovação em relação aos planos anteriores que eram concebidos de uma só vez. A Lei do Plano Diretor criou um sistema no qual o Plano está incluído; esse sistema, formado pelo Conselho, pela Secretaria de Meio Ambiente e Desenvolvimento Urbano, pelo Fundo e pelo IPDU, cerca o Plano e redireciona suas ações quando necessário.

Os anteprojetos de lei são analisados por um Conselho que se reúne quatro vezes por ano, e reúne 36 pessoas: 12 representantes da Prefeitura, 12 representantes de órgãos do Estado e da União (Universidade Federal de Mato Grosso, CEMAT, SANEMAT, etc.) e 12 colaboradores, dos quais 4 são representantes de associações de bairros, e os demais representam entidades como o CREA, IAB, SINDUSCON, ADEMI, etc. Os 4 representantes da comunidade são indicados pelas associações de bairros e posteriormente nomeados pelo Prefeito. Nas reuniões do Conselho são apresentados os anteprojetos de lei; ao final, cada conselheiro leva a discussão para a sua entidade. As diretrizes gerais são apresentadas ao Conselho e distribuídas às Câmaras Setoriais; depois o Conselho reúne-se em plenário para discussão e aprovação. Segundo o superintendente do IPDU, esse processo de elaboração em etapas é mais lento, porém, mais participativo, e mais seguro de ser aplicado.

Fazendo-se uma avaliação crítica do processo de elaboração e dos resultados parciais já alcançados pelo Plano, pode-se dizer que ele apresenta uma série de inovações em

\footnotetext{
3 informação verbal, 1997.
} 
relação aos anteriores e, apesar de estar ainda em fase de elaboração, já prenuncia algumas mudanças bastante positivas em relação ao método de elaboração de planos diretores comumente desenvolvidos no Brasil.

A maior inovação está na elaboração do plano; o planejamento em etapas é um avanço em relação aos anteriores; outro ponto positivo é a criação e o bom funcionamento do Conselho. Também é positivo o fato de que boa parte do plano é voltada para auto-aplicação, com a aprovação das leis. Já a aplicação das leis cabe à Secretaria de Meio Ambiente e Desenvolvimento Urbano, mas a Câmara não fixa prazos; a partir da aprovação, o cumprimento e a aplicação ficam sujeitos a cada administração, a cada prefeito. O IPDU apenas acompanha e monitora essa aplicação.

O Plano já passou por quatro prefeitos; segundo o superintendente do IPDU, as linhas gerais do plano e a equipe do IPDU vêm sendo mantidas, com pequenas alterações; as leis já aprovadas vêm sendo cumpridas, e o sistema tem funcionado porque o Conselho pressiona a agilização dos trabalhos. Como exemplo, a criação das Administrações Regionais no Município de Cuiabá e o abairramento da cidade, que era totalmente informal até então, já foram aprovados pela Câmara Municipal. Em dezembro de 1997, após meses de discussão no Conselho e na Câmara, foi aprovada a nova Lei de Uso e Ocupação do Solo. Estão em implantação a regulamentação da Aquisição Onerosa de Potencial Construtivo, a Hierarquização Viária, o Relatório de Impacto Urbano e o Cadastro de Arborização Urbana.

A Lei de Uso e Ocupação do Solo de 23 de dezembro de 1997 propôs, entre outros, o adensamento populacional como forma de reduzir os custos dos serviços na cidade. A Lei propôs alterações em função da disponibilidade de infra-estrutura urbana com o aumento do limite de adensamento 4 (máximo permitido até então) para 6, em determinados locais. O documento aprovado diz que (grifo da autora):

Art. $5^{\circ}$. Esta Lei tem como objetivo ordenar o pleno desenvolvimento das funções sociais da cidade e garantir o bem-estar de seus habitantes em padrões dignos de conforto ambiental, através de intervenções que:

I - assegurem condições de convivência entre as diversas funções urbanas;

II - assegurem padrões mínimos e máximos de intensidade de Ocupação do Solo.

Pela Lei em vigor, o critério básico para a diferenciação dos parâmetros de ocupação do solo é a disponibilidade de infra-estrutura urbana. Seguindo esse critério as vias e logradouros públicos ficam classificados de acordo com sua disponibilidade de infraestrutura nos seguintes padrões: inabitável, mínimo, médio, alto e máximo. Do padrão médio em diante, além da infra-estrutura mínima o mesmo deve contar com pavimentação e arborização pública consolidada, pela qual se entende a existência de árvores ou palmeiras adaptadas ao ambiente, como no mínimo $2 m$ de altura.

A Lei aprovada considera também como aproveitamento adequado do lote a existência e manutenção de árvore ou palmeira adulta, cadastrada pelo órgão ambiental do Município, na proporção mínima de um indivíduo para cada $180 \mathrm{~m}^{2}$ de área do terreno ou fração. Para cada árvore ou palmeira adulta cadastrada corresponderá o desconto de 1\% do valor do IPTU devido pelo imóvel. Também foi instituída a transferência de potencial construtivo através de aquisição onerosa junto 
à Prefeitura, que pode ser feita por compra, troca ou prestação de serviços. Os recursos provenientes dessa aquisição serão destinados ao Fundo Municipal de Desenvolvimento Urbano.

Após esta retrospectiva, torna-se mais fácil compreender o atual estágio de desenvolvimento da cidade de Cuiabá e os caminhos percorridos pela evolução urbana e pela arquitetura na região. Depois de sofrer um crescimento lento - em razão do seu isolamento dos grandes centros - e instável - em função dos altos e baixos da exploração do ouro e depois, da economia de um modo geral - Cuiabá vem se modificando rapidamente, e entra em uma nova fase de sua história, planejando a ocupação das novas áreas de crescimento.

\section{Referências Bibliográficas}

1. Album Graphico do Estado de Matto-Grosso. Corumbá/Hamburgo, 1914.

2. ASSOCIAÇÃO DOS ARQUITETOS PORTUGUESES. Arquitectura Popular em Portugal. Lisboa: Associação dos Arquitetos Portugueses, 1980.

3. AZEVEDO, Aroldo de. Cuiabá. Estudo de Geografia Urbana. Relatório apresentado por Aroldo de Azevedo, orientador geral das pesquisas de campo. Anais da Associação dos Geógrafos Brasileiros. Julho, 1953.

4. CALDEIRA, Jorge. Mauá: empresário do império. São Paulo: Companhia das Letras, 1995.

5. Cuiabá. Prefeitura Municipal de Cuiabá. Caderno do IPDU. Diretoria de Projetos Especiais/Diretoria de Plano Diretor. [s.l.], [s.d.].

6. Cuiabá. Prefeitura Municipal de Cuiabá. Plano Diretor de Desenvolvimento Urbano de Cuiabá e Lei do Gerenciamento Urbano. Cuiabá: IPDU, 1995.

7. Cuiabá. Prefeitura Municipal de Cuiabá. Projeto Cura Cuiabá. [s.l.], [s.d.].

8. D’ALINCOURT, Luiz. Memória sobre a viagem do porto de Santos à cidade de Cuiabá. Belo Horizonte: Itatiaia/São Paulo: EDUSP, 1975. (Coleção Reconquista do Brasil).

9. Expedição Langsdorff ao Brasil 1821-1829. 3v. Rio de Janeiro: Alumbramento/ Livroarte, 1988.

10. FIGUEIREDO, Aline. Artes Plásticas no Centro-Oeste. Cuiabá: UFMT/MACP, 1979.

11. FLORENCE, Hercules. Viagem Fluvial do Tietê ao Amazonas: 1825 a 1829. São Paulo: Cultrix/EDUSP, 1977. Gravuras do autor e Trad. Visconde de Taunay.

12. FREIRE, Júlio De Lamonica. Cuiabá Nosso Bem Coletivo. Cuiabá: UFMT, 1992.

13. FREIRE, Júlio De Lamonica. Por Uma Poética Popular da Arquitetura. São Paulo: ECAUSP, 1988. Dissertação (Mestrado em Artes). Escola de Comunicação e Artes, Universidade de São Paulo, 1988. 
14. FURTADO, Celso. Formação Econômica do Brasil. 25.ed. São Paulo: Nacional, 1995.

15. HOLANDA, Sérgio Buarque. Caminhos e Fronteiras. 3.ed. São Paulo: Companhia das Letras, 1994.

16. HOLANDA, Sérgio Buarque. Raízes do Brasil. 26.ed. São Paulo: Companhia das Letras, 1995.

17. IBGE. Geografia do Brasil. Rio de Janeiro: IBGE, Fundação Instituto Brasileiro de Geografia e Estatística, Diretoria de Geociências, 1988. 5v. V. 1: Região Centro-Oeste.

18. LEMOS, Carlos. História da Casa Brasileira. São Paulo: Contexto, 1989. (Coleção Repensando a História).

19. MENDONÇA, Rubens de. Roteiro Histórico \& Sentimental da Vila Real do Bom Jesus de Cuiabá. Cuiabá: Igrejinha, 1975.

20. MOURA, Carlos Francisco. Notas sobre a História da Arquitetura em Mato Grosso. Belém: UFMT/SUDAM, 1976.

21. NEW’PLAN. Plano de Desenvolvimento Local Integrado de Cuiabá. [s.l.],[s.d.].

22. OLIVEIRA, Ernesto V., GALHANO, Fernando. Arquitectura Tradicional Portuguesa. Lisboa: Dom Quixote, 1992. (Portugal de Perto, n.24).

23. OLIVEIRA NETO, Antonio Firmino de. Ruas e calçadas de Campo Grande-MS: uma contribuição ao estudo dos espaços públicos urbanos. São Paulo, 1997. Dissertação (Mestrado em Geografia) - Faculdade de Filosofia, Letras e Ciências Humanas, Universidade de São Paulo.

24. PÓVOAS, Lenine C. Cuiabanidade. Cuiabá : [s.n.], 1987.

25. PÓVOAS, Lenine C. Sobrados e Casas Senhoriais de Cuiabá. [Cuiabá] : Fundação Cultural de Mato Grosso, 1980.

26. REIS FILHO, Nestor Goulart. Quadro da Arquitetura no Brasil. 6.ed. São Paulo: Perspectiva, 1987.

27. REIS, Nestor Goulart. Imagens de Vilas e Cidades do Brasil Colonial. São Paulo: EDUSP/Imprensa Oficial do Estado/Fapesp, 2000. (Também em CD-ROM)

28. SÁ, Cássio Veiga de. Memórias de um Cuiabano Honorário. São Paulo: Resenha Tributária, 1980.

29. SERRA, Geraldo. O Espaço Natural e a Forma Urbana. São Paulo: Nobel, 1987.

30. SMITH, Herbert. Do Rio de Janeiro a Cuyabá. Notas de um Naturalista. São Paulo: Melhoramentos, 1922. (Com um capítulo de Carlos von den Steinen sobre a capital de Matto Grosso). 


\section{PARTE 3}

Levantamento de dados primários para descrição qualitativa e quantitativa dos casos estudados 


\section{USO E OCUPAÇÃO DO SOLO NA REGIÃO EM ESTUDO}

Combinando dados do cadastro imobiliário, fotos aéreas, imagens de satélite e pesquisa de rua, são identificados os diferentes padrões de ocupação urbana na cidade de Cuiabá. Também foi feito um levantamento de vegetação e de corpos d’água significativos - bem como de áreas degradadas - antes da escolha dos pontos para as medições de microclimas urbanos e o levantamento das variáveis urbanísticas de interesse para a pesquisa.

\subsection{Análise da evolução da mancha urbana através de imagens de satélite}

Há imagens registradas pelo satélite Landsat desde $1972^{1}$ com o sensor MSS (MultiSpectral Scanner), com resolução de 80m. A partir de 1984 essas imagens foram captadas com o sensor TM (Thematic Mapper) e digitalizadas. As anteriores só são encontradas em papel, na escala 1:250.000. Atualmente as imagens do Landsat podem ser obtidas até a escala 1:50.000. A estação de recepção e gravação de dados fica na zona urbana de Cuiabá, no Morro da Conceição.

O Landsat observa a área a cada 16 dias a uma altitude de $705 \mathrm{Km}$, mas a cobertura de nuvens dificulta a visualização durante parte do ano. Uma imagem inteira do satélite representa uma área de abrangência de 185 x 185Km. Para cada quadrante a abrangência é de 92 x 92Km. O sensor TM do Landsat possui sete bandas, sendo que cada uma representa uma faixa do espectro eletromagnético captada pelo satélite. As imagens aqui apresentadas foram geradas com a combinação das bandas 3, 4 e 5 . A banda $3(0,63$ a $0,69 \mu \mathrm{m})$ é a mais utilizada para delimitar a mancha urbana, incluindo a identificação de novos loteamentos. A vegetação verde, densa e uniforme, apresenta grande absorção, ficando escura, permitindo bom contraste com as áreas de solo exposto, estradas e áreas urbanas. Na banda $4(0,76$ a 0,90 $\mu \mathrm{m})$ os corpos d'água aparecem escuros, permitindo o seu delineamento. A vegetação verde, densa e uniforme, reflete muita energia nesta faixa, aparecendo bem clara nas imagens, e a banda $5(1,55$ a $1,75 \mu \mathrm{m})$ apresenta sensibilidade ao teor de umidade das plantas. A banda $6(10,4-12,5 \mu \mathrm{m})$ apresenta sensibilidade aos fenômenos relativos aos contrastes térmicos, servindo para detectar propriedades termais de rochas, solo, vegetação e água, porém esta faixa encontra-se inoperante já há algum tempo. No Landsat TM a resolução é de 30m (cada pixel representa uma área de 0,09ha), com exceção da banda 6 que é de 120m (cada pixel representa uma área de 1,4ha).

Para aplicação em áreas urbanas é mais importante a resolução espacial do que a espectral. Fazendo-se uma interpretação visual, essas imagens podem ser utilizadas para o acompanhamento da evolução da mancha urbana, e permitem a visualização das alterações na paisagem em função do desmatamento e da desertificação de grandes áreas na periferia onde se localizam os loteamentos recentes. Analisando as imagens de satélite de 18 de setembro de 1984 e de 9 de novembro de 1997 do Landsat $^{2}$ pode-se a visualizar a expansão da zona urbana, a localização de áreas

\footnotetext{
1 http://www.dgi.inpe.br

${ }^{2}$ Imagens da órbita 226.71, quadrante A, do Landsat TM, bandas 3, 4 e 5, correção de cena nível 6. Banda 3 (vermelho), banda 4 (infravermelho próximo) e banda 5 (infravermelho médio).
} 
verdes e corpos d'água (fig.7.1 e 7.2). As imagens foram tratadas no Laboratoire COSTEL - Climat et Occupation du Sol par Teledetection, pelos pesquisadores Pascal Govery e Vincent Dubrueil, do Departamento de Geografia da Université Rennes 2, na França, para melhor visualização.

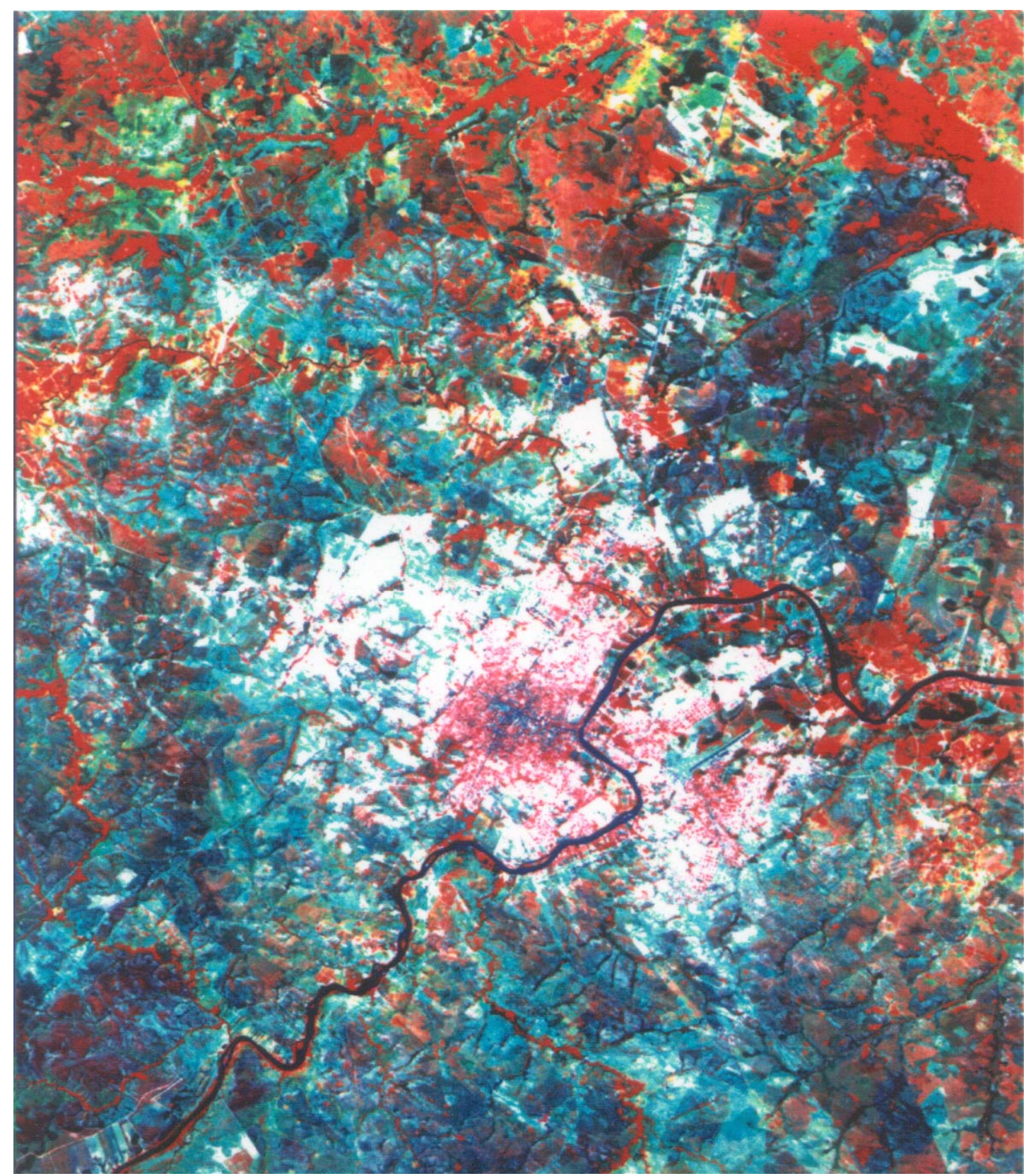

Figura 7.1 - Imagem do Landsat de setembro de 1984, formada pela combinação das bandas 3, 4 e 5. (fonte: INPE)

Nesta imagem de 1984 (fig.7.1) pode-se ver a mancha urbana de Cuiabá ainda bastante contida dentro dos limites da perimetral (com o espaço construído em azul e a vegetação em vermelho), e o solo já devastado (em branco) nas novas áreas destinadas à ocupação, principalmente no CPA e no Tijucal. O distrito industrial é apenas um esboço e, em Várzea Grande a ocupação ainda é rala e localizada próxima ao Aeroporto Marechal Rondon. Os rios e córregos aparecem em preto. 


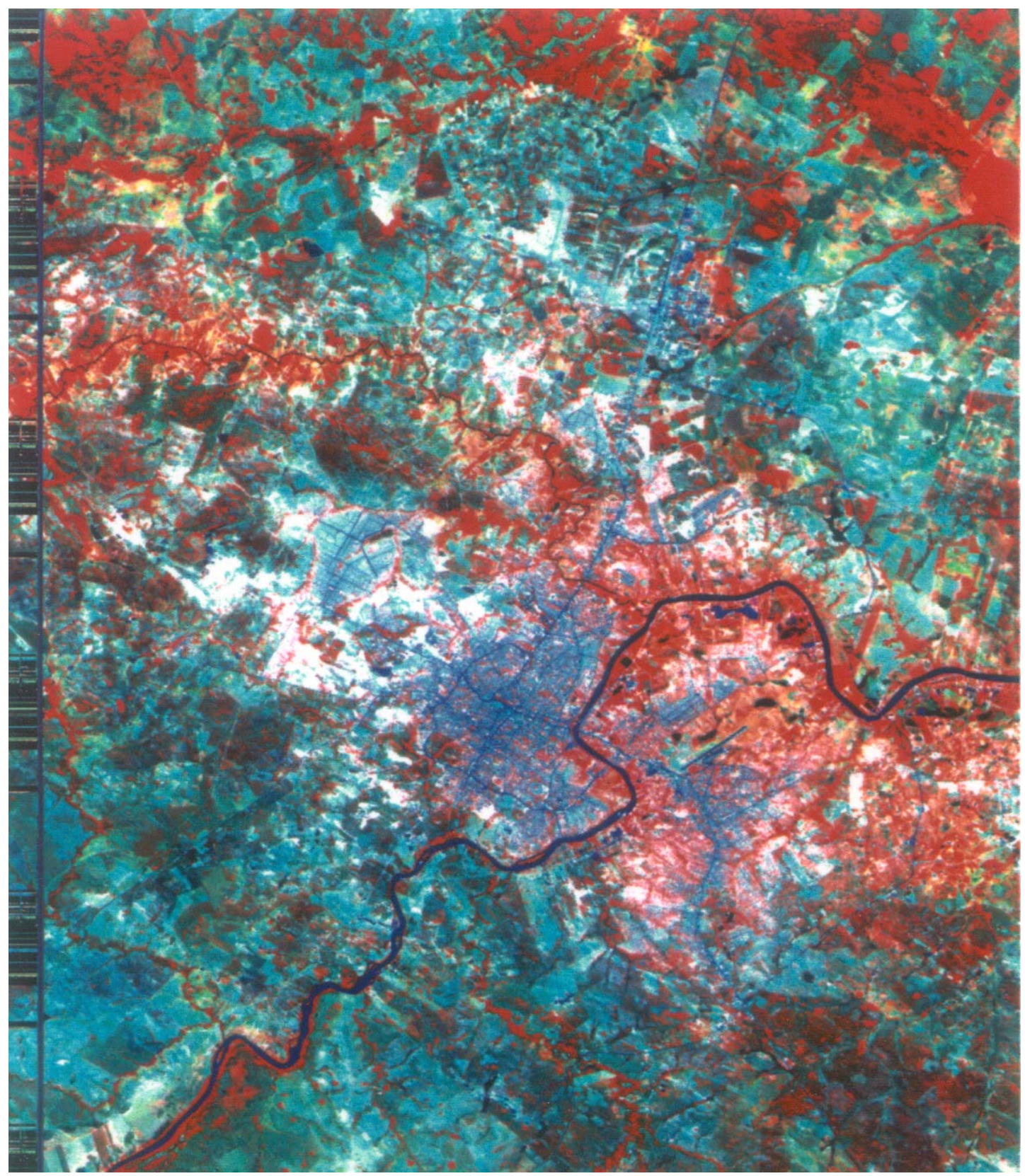

Figura 7.2 - Imagem do Landsat de novembro de 1997, formada pela combinação das bandas 3, 4 e 5. (fonte: INPE)

Nesta imagem de 1997 (fig.7.2) é nítida a consolidação da ocupação (em azul) além dos limites da perimetral e a expansão da mancha urbana em direção aos conjuntos habitacionais CPA I, II, III e IV que, já nessa época, contavam com cerca de 150.000 habitantes. As áreas do Tijucal e do distrito industrial já aparecem bastante ocupadas; o município de Várzea Grande também apresenta uma ocupação mais densa no bairro Cristo-Rei e na área central da cidade, próxima ao Aeroporto Marechal Rondon, e já se vê a ocupação avançando em direção ao Trevo do Lagarto. Em toda a mancha urbana já é nítida a diminuição da vegetação (em vermelho), que fica restrita às margens dos rios e córregos e a alguns pontos isolados na área central, tais como o Morro da Luz, a Mata da Mãe Bonifácia, e os quintais em alguns bairros da cidade. 


\subsection{Levantamento de vegetação e corpos d’água significativos}

Em outubro de 1997 foi feito um levantamento de vegetação e corpos d’água significativos em parte da amostra, com interesse onde se tem um espaço considerável ocupado por água, árvore ou grupo de árvores, bem como o levantamento de áreas degradadas; as dimensões desses espaços não são o único fator que interessa, e sim, os benefícios que eles trazem para amenizar as condições climáticas, tanto do ponto de vista físico como psicológico, pela sensação de conforto e proteção em relação ao meio. Segue um relatório com os resultados desse levantamento acompanhado de documentação fotográfica dos pontos de interesse para a pesquisa. Simultaneamente foi feito um percurso exploratório na amostra para o reconhecimento de pontos para futuras medições de microclimas urbanos.

\subsection{1 Áreas Protegidas pela legislação municipal}

Pelo Plano Diretor de Desenvolvimento Urbano de Cuiabá, são consideradas Unidades de Proteção Integral as matas ciliares do Córrego Quarta-feira, do Ribeirão da Ponte, do Ribeirão do Lipa e do Rio Cuiabá, dentro do território municipal.

Como Unidades de Manejo Sustentável estão o Morro da Luz e o Horto Florestal como Áreas Verdes Essenciais; o Rio Coxipó, como Rio Cênico; a Mata da Mãe Bonifácia, o Cerrado e Cerradão do Centro de Zoonoses de Cuiabá, o Cerrado do Centro Político-Administrativo, a Mata semi-decídua do Córrego Manoel Pinto (Campo do Bode), as matas ciliares dos córregos Moinho, Gumitá e Barbado e a cabeceira do Córrego da Prainha.

Segundo a Lei Complementar de Gerenciamento Urbano de Cuiabá (Cuiabá, [s.d.]):

“Art.584. As unidades de conservação serão de domínio e/ou de interesse público ou de propriedade privada, respeitadas as determinações e restrições constantes nesta Lei.

$\xi 1^{\circ}$. As unidades de conservação de domínio e/ou de interesse público serão definidas, criadas, implantadas, mantidas e administradas pelo Poder Público.

$\xi 2^{\circ}$. As unidades de conservação de propriedade privada deverão integrar o Setor Especial de Áreas Verdes e estarão sujeitas à fiscalização do Poder Público, com a finalidade de garantir a permanência das condições que justificam a sua inclusão no referido setor.

$\xi 3^{\circ}$. Do ato da criação das unidades de conservação constarão seus limites geográficos, o órgão ou entidades responsáveis pela sua administração $e$, disporão de um plano de manejo, no qual se definirá o zoneamento da unidade e sua utilização.

$\xi 4^{\circ}$. São VEDADAS no interior das unidades de conservação quaisquer alterações, atividades ou modalidades de utilização em desacordo com suas finalidades e estranhos ao respectivo plano de manejo.

Art.585. As terras privadas de interesse público para a preservação dos ecossistemas naturais poderão ser desapropriadas, atendendo ao disposto no inciso V do artigo 41 da Lei Orgânica Municipal.” 


\subsubsection{Mata Ciliar do Rio Cuiabá}

A poluição do Rio Cuiabá e de alguns de seus afluentes é alarmante; esgoto e lixo são lançados nos cursos d'água, contribuindo ainda mais para o atual cenário de abandono da Av. Beira Rio (fig.7.3 e 7.4). Essa área já chamava a atenção de alguns profissionais há quase 30 anos; há um projeto para a urbanização das áreas marginais do Rio Cuiabá, no Bairro do Porto, desenvolvido pelo Arq. Paulo Mendes da ROCHA (1979) na década de $70^{3}$. Na verdade, trata-se de um plano piloto para a urbanização das áreas marginais do Rio Cuiabá, quando foi feita a caracterização das áreas marginais e da Avenida Beira-Rio. Há um projeto básico para a determinação de critérios de uso do solo, recuperação de antigos arruamentos junto ao bairro do Porto com valor histórico, bem como o estabelecimento de áreas de parques e jardins e reorganização do sistema viário, indicando também o planejamento de obras de infra-estrutura tais como saneamento, retificação de córregos e proteção contra enchentes.

Segundo Paulo Mendes da Rocha, a avenida ao longo do rio seria uma via de tráfego lento, através de um parque densamente arborizado, servindo de acesso às áreas destinadas aos conjuntos habitacionais, escolas, etc., de atendimento local. O projeto aponta a necessidade de se considerar a criação de um microclima adequado nas áreas destinadas aos conjuntos habitacionais, bem como uma legislação que assegure a esses edifícios a ambientação condizente com o clima do lugar.

Na proposta de Paulo Mendes da Rocha o Bairro do Porto seria um local essencialmente para pedestres, com o aproveitamento das áreas interiores às quadras, que são os antigos quintais arborizados, transformadas em jardins. O projeto sugeriu também que as edificações novas deveriam receber legislação especial, com o objetivo de se estabelecerem ligações através desses jardins; propõe também a criação de um projeto específico de arborização, ajardinamento e recomposição paisagística nas margens do Rio Cuiabá na área do Porto. Nenhuma destas propostas foi executada.

Atualmente há um projeto para essa área da equipe do Plano Diretor, que prevê a implantação de calçadas, iluminação, tratamento dos canteiros centrais e adaptação do traçado em função das alterações no sistema viário local, além da construção de ciclovias que vão da Ponte Nova até o Horto Florestal. De acordo com o Arq. José Afonso Portocarrero ${ }^{4}$, um dos autores da proposta, a realização desse projeto tem um forte significado para a população local; se ele for realmente concretizado, a região da Av. Beira Rio será um paradigma da recuperação ambiental para a cidade. Ao longo de sua história Cuiabá sofreu com a derrubada de construções antigas e perdeu espaços de qualidade de maneira irreversível; no caso do Rio Cuiabá e de outros córregos, ainda é possível a recuperação. Para o Arq. Júlio De Lamônica Freire ${ }^{5}$, no tratamento das margens do rio Cuiabá há a necessidade de atuação conjunta com Várzea Grande; a demora na execução desse tratamento já provocou o agravamento da situação da Beira-Rio em toda a sua extensão, e pouco adiantaria o tratamento em apenas uma das margens.

\footnotetext{
3 informação verbal, jan 1997.

${ }^{4}$ informação verbal, out. 1997

${ }^{5}$ informação verbal, out. 1997.
} 


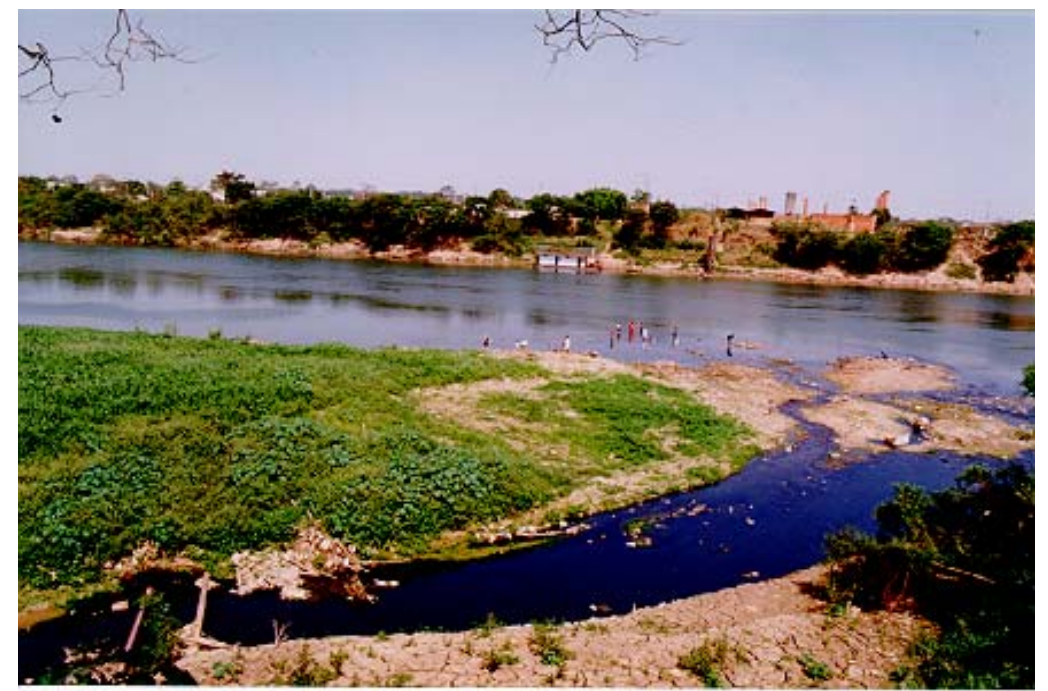

Figura 7.3 - Esgoto sendo lançado no Rio Cuiabá, próximo à Ponte Júlio Müller. (foto: A.Duarte)

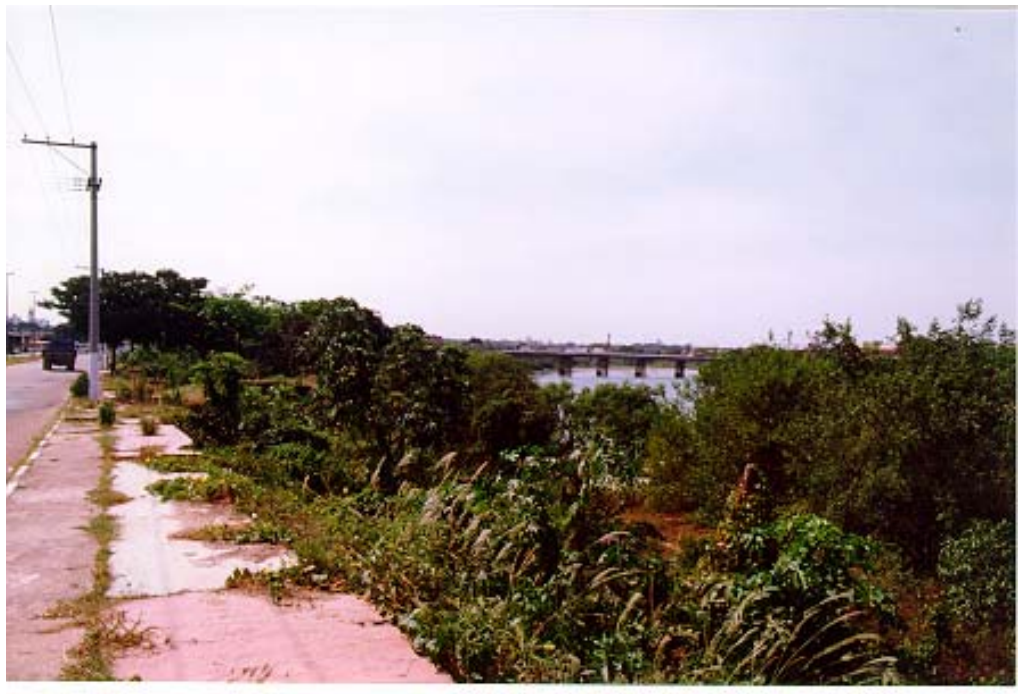

Figura 7.4- Av. Beira-Rio, às margens do Rio Cuiabá. (foto: A. Duarte)

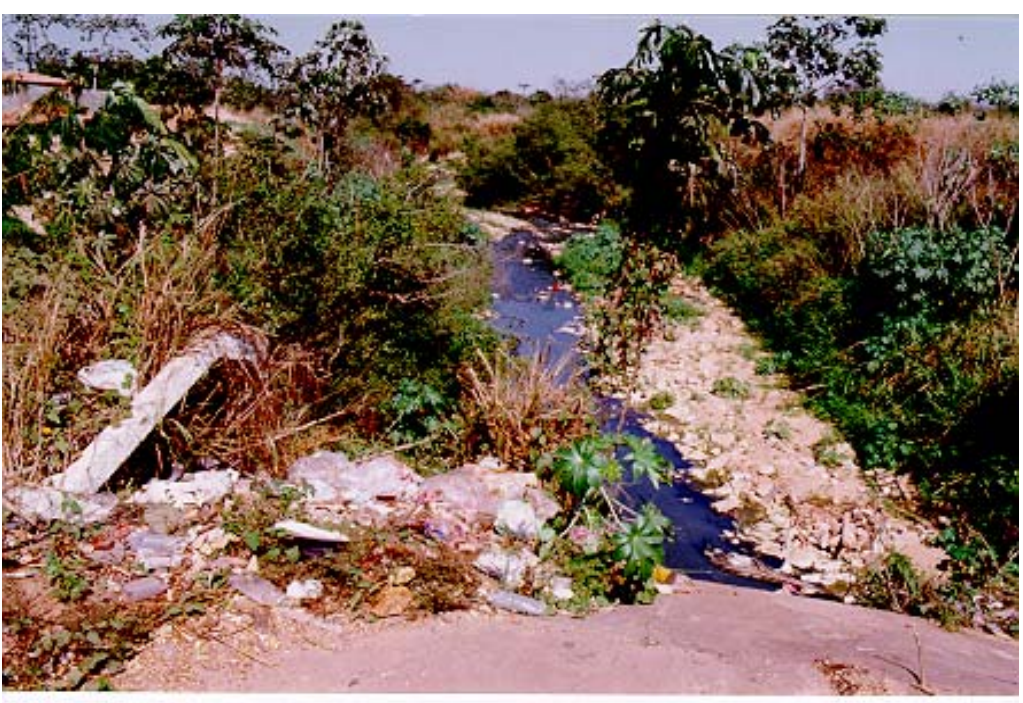

Figura 7.5 - Córrego do Barbado no cruzamento com a Av. Beira-Rio, a poucos metros do Rio Cuiabá. (foto: A. Duarte) 


\subsubsection{Mata Ciliar do Córrego do Barbado}

Em alguns trechos o córrego encontra-se bastante poluído (fig.7.5). Há um projeto da equipe do Plano Diretor para preservar a nascente do Córrego do Barbado, localizada na Reserva Massairo Okamura, na Morada do Ouro. O córrego é um dos afluentes do Rio Cuiabá; ele corta o bairro da Canjica e passa próximo à UFMT. Na proposta do Plano Diretor (CUIABÁ, [s.d.]), a avenida-parque do Barbado ligará a Av. Fernando Corrêa da Costa ao CPA, com uma extensão de 5,6Km e cerca de 34ha de área verde. Segundo o projeto a concepção de córrego-parque baseia-se na necessidade de incorporação útil dos diversos córregos urbanos à vida da cidade como elementos de composição climática e paisagística. Há propostas semelhantes de avenidas-parque para os córregos do Moinho e Ribeirão do Lipa.

\subsubsection{Parque Antônio Pires de Campos (Morro da Luz)}

O Parque Antônio Pires de Campos, conhecido popularmente por Morro da Luz (fig.7.6), localizado na área central de Cuiabá, foi considerado pelo Código de Defesa do Meio Ambiente e Recursos Naturais como Área Verde Essencial; a área comporta espécies remanescentes da mata de galeria do córrego da Prainha. Além da riqueza de espécies regionais, a presença da vegetação é importante para a contenção da encosta, pela sua localização central e pela beleza da paisagem. A ausência total de segurança e falhas na manutenção, denunciadas pela utilização desse espaço como depósito de lixo e entulho de obras próximas, inviabilizam um melhor aproveitamento do parque pela população.

\subsubsection{Horto Florestal e Rio Coxipó}

Também considerado como Área Verde Essencial, o Horto Florestal existe há mais de trinta anos; localiza-se no Balneário São João, às margens do Rio Coxipó (fig.7.7), categorizado pelo Plano Diretor como Rio Cênico. O Horto tem aproximadamente 14ha, com grande variedade de espécies, e hoje é um refúgio para pequenos animais. De acordo com o Eng. Archimedes Pereira Lima Neto, a Prefeitura pretende transformar o local em Centro de Referência de Educação Ambiental, com atividades direcionadas principalmente para professores e alunos de $1^{\circ}$ e $2^{\circ}$ graus. A proposta é válida, e não se pode perder de vista a garantia da produtividade e da eficiência na produção de mudas no Horto, que é fundamental para a sustentação de um programa de arborização urbana. Até o momento, a falta de infra-estrutura para visitação dificulta uma melhor utilização do Horto pela população.

\subsubsection{Mata da Mãe Bonifácia}

No Bairro Duque de Caxias está o local conhecido por Mãe Bonifácia (fig.7.8), antiga área de treinamento do exército, com vegetação nativa formada por cerrado e mata de galeria, e de onde fazem parte a cabeceira e parte do curso do córrego Mãe Bonifácia, integrante do Ribeirão da Ponte, e afluente do Rio Cuiabá. A área é um refúgio para pequenas aves e animais silvestres. Atualmente a Prefeitura tenta permutar a área com o exército para a implantação do Parque Mãe Bonifácia. No projeto da equipe do Plano Diretor, a barragem do córrego Mãe Bonifácia possibilitará a formação de um lago e duas ilhas artificiais, criando um ambiente propício ao crescimento de animais silvestres e à atração de aves. 


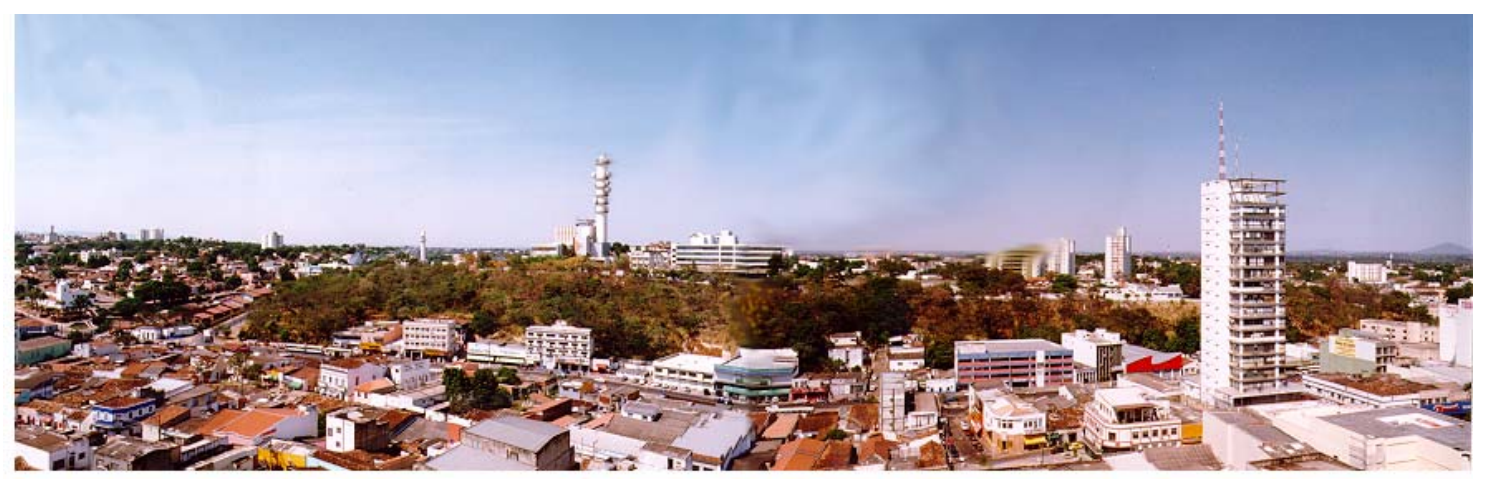

Figura 7.6 - Morro da Luz visto a partir do centro da cidade. (foto: A. Duarte)

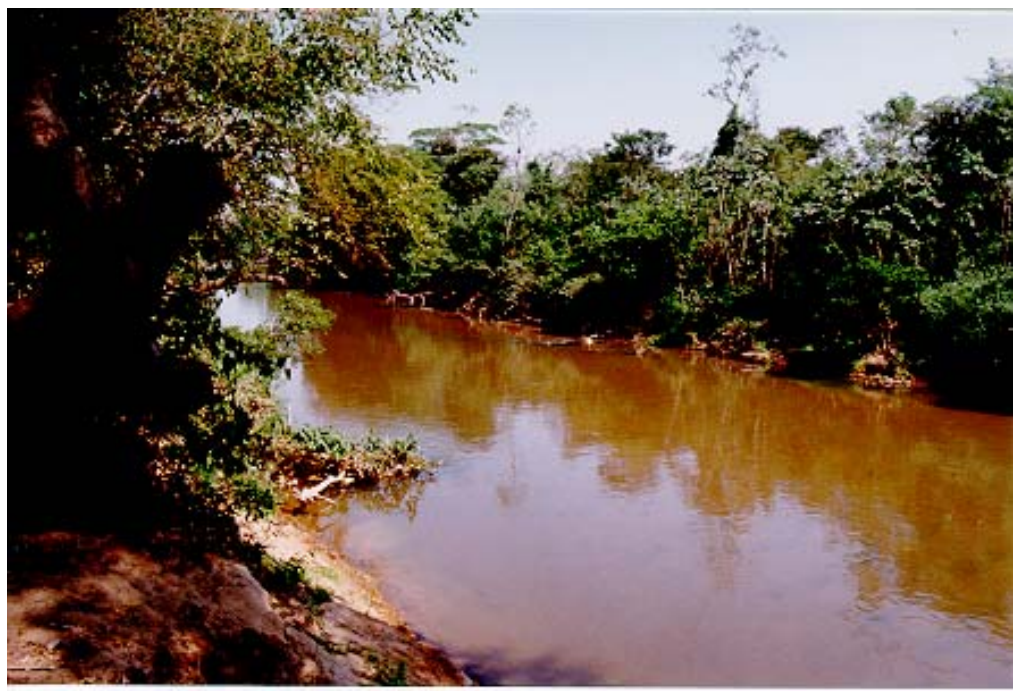

Figura 7.7 - Rio Coxipó ao longo do Horto Florestal.(foto: A. Duarte)

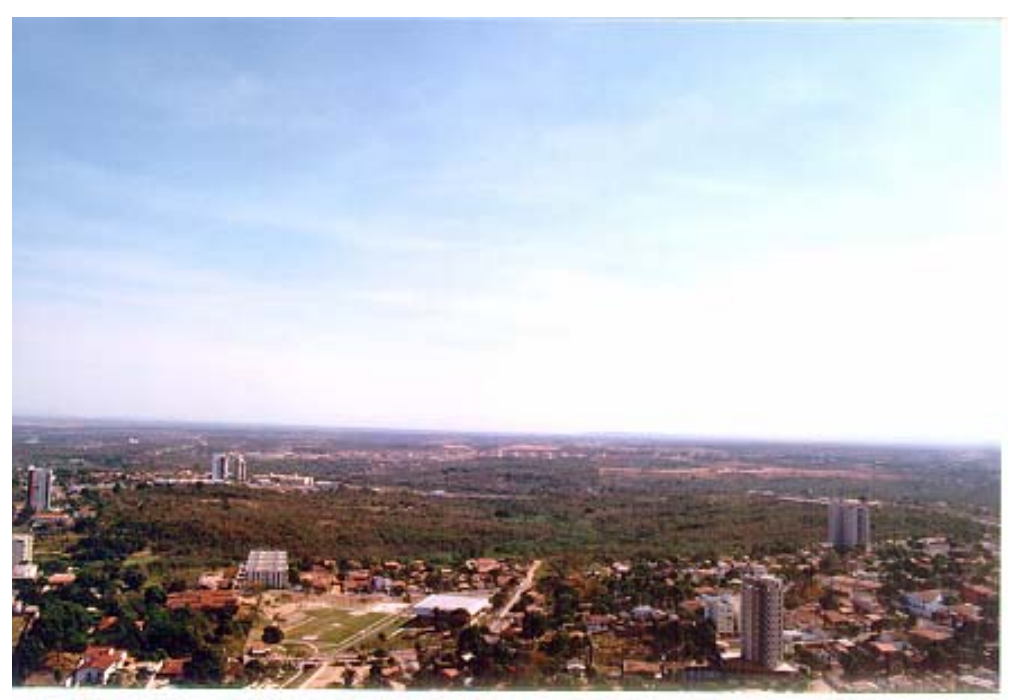

Figura 7.8 - Mata da Mãe Bonifácia. (foto: A. Duarte)

\subsubsection{Cabeceira do Córrego da Prainha}

Para a área da cabeceira do Córrego da Prainha (fig.7.9), próximo à Av. Miguel Sutil, entre os bairros Consil e Quarta-Feira, a proposta da Prefeitura prevê a urbanização 
do canal principal e a desapropriação de 3 quadras para a criação de um pequeno parque urbano; o projeto está sendo viabilizado em parceria com um grande supermercado próximo ao local. O córrego é canalizado e, com exceção do trecho inicial, já foi totalmente coberto pelas avenidas e conduz esgoto para o Rio Cuiabá. Na opinião de Portocarrero ${ }^{6}$, uma recuperação desse curso d’água já é inviável.

\subsubsection{Outros espaços significativos}

Além das grandes áreas protegidas pela legislação, é preciso pensar em soluções para um melhor aproveitamento de outros espaços, espalhados por toda a cidade. Alguns são importantes pelas suas dimensões, pela sua localização, pelas melhorias que podem proporcionar aos pedestres, pela existência de corpos d'água ou de áreas verdes significativas.

\subsubsection{Campus da Universidade Federal de Mato Grosso}

O campus da Universidade Federal de Mato Grosso (fig.7.10) caracteriza-se como uma área verde significativa; tem 67\% de área verde, com espécies nativas e exóticas (Diagnóstico Florístico e Faunístico da Cidade de Cuiabá, 1990). Pela existência de grandes áreas verdes e pela presença do zoológico, esse espaço é bastante utilizado nos finais de semana, e vem funcionando como uma opção de lazer para a população.

\subsubsection{Morro do Seminário}

O Morro do Seminário (fig.7.11), na região central da cidade, poderia ser muito melhor aproveitado; falta manutenção e segurança, o que vem permitindo inclusive o ataque de vândalos ao patrimônio histórico. Segundo o Eng. Archimedes Pereira Lima Neto ${ }^{7}$, a Prefeitura estuda a restauração da Igreja de Nossa Senhora do Bom Despacho e do entorno, mas até o momento não há nenhum projeto específico.

\subsubsection{Arborização de rua}

A adoção de trechos de rua por moradores e comerciantes locais pode ser uma solução bastante interessante a curto prazo. Em trechos de algumas ruas da cidade que são densamente arborizados (fig.7.12 a 7.14)), a sensação de alívio frente à aspereza das condições climáticas locais é evidente para o pedestre. Em outras, a falta de um tratamento adequado acaba criando um ambiente inóspito para o pedestre - como na Av. da Prainha (fig.7.15), por exemplo, importante corredor de tráfego, comércio e serviços.

Há propostas da equipe do Plano Diretor no sentido de se criar parcerias com empresas privadas para a manutenção de áreas verdes próximas aos seus estabelecimentos comerciais. Em Cuiabá já vêm acontecendo parcerias entre a Prefeitura e comerciantes próximos às praças da área central e também ao longo da Av. Rubens de Mendonça, para padronização das calçadas com 9m de largura, incluindo áreas de estacionamento e possibilitando a inclusão da arborização. Plantio e manutenção podem ser custeados pela publicidade; a iniciativa privada pode ser estimulada a participar de um programa mediante concessão na exploração do espaço para veiculação publicitária, assumindo custos para a sustentação do programa.

\footnotetext{
${ }^{6}$ informação verbal, out. 1997

${ }^{7}$ informação verbal, out. 1997.
} 


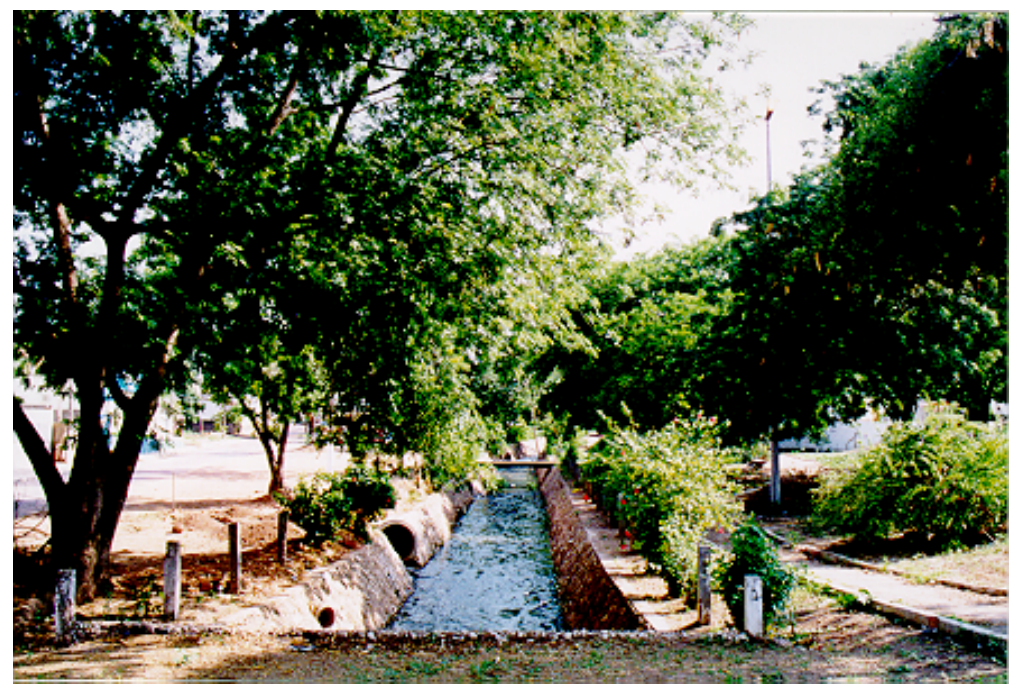

Figura 7.9 - Vista do trecho inicial do Córrego da Prainha. (foto: D.Duarte)

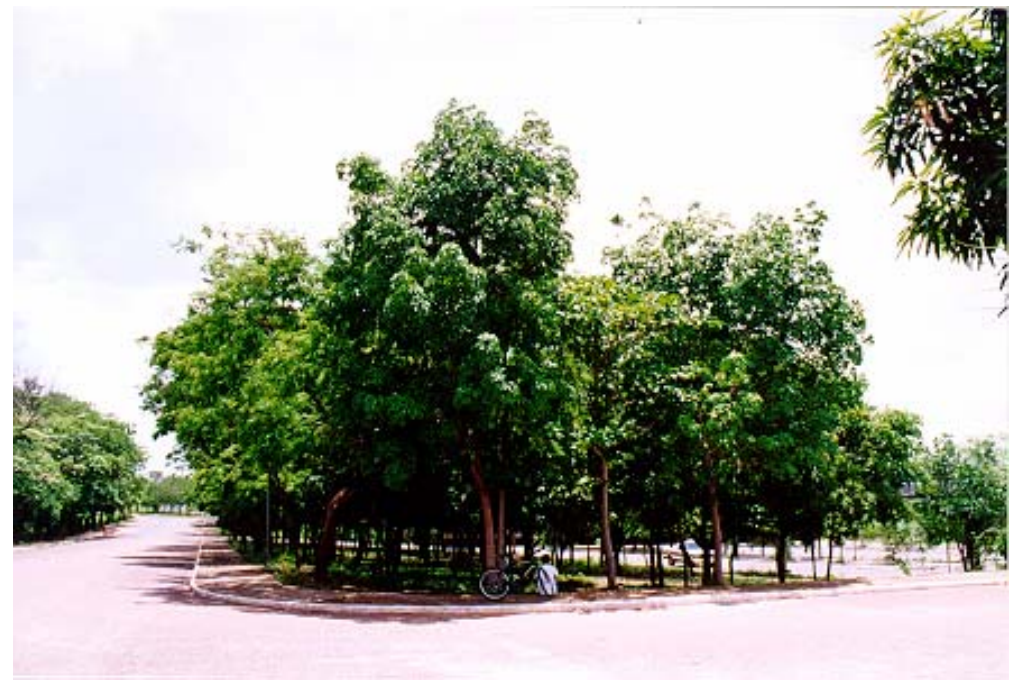

Figura 7.10 - Vista de um dos estacionamentos no campus universitário. (foto: D. Duarte)

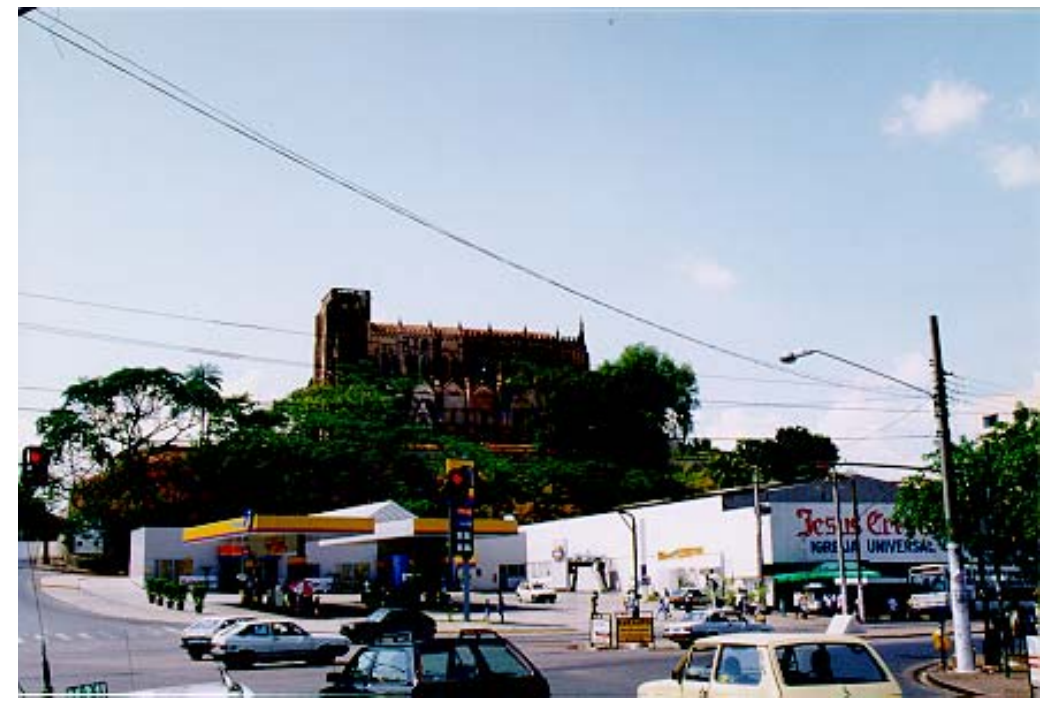

Figura 7.11 - Morro do Seminário, na área central da cidade. (foto: J. Calsinski) 


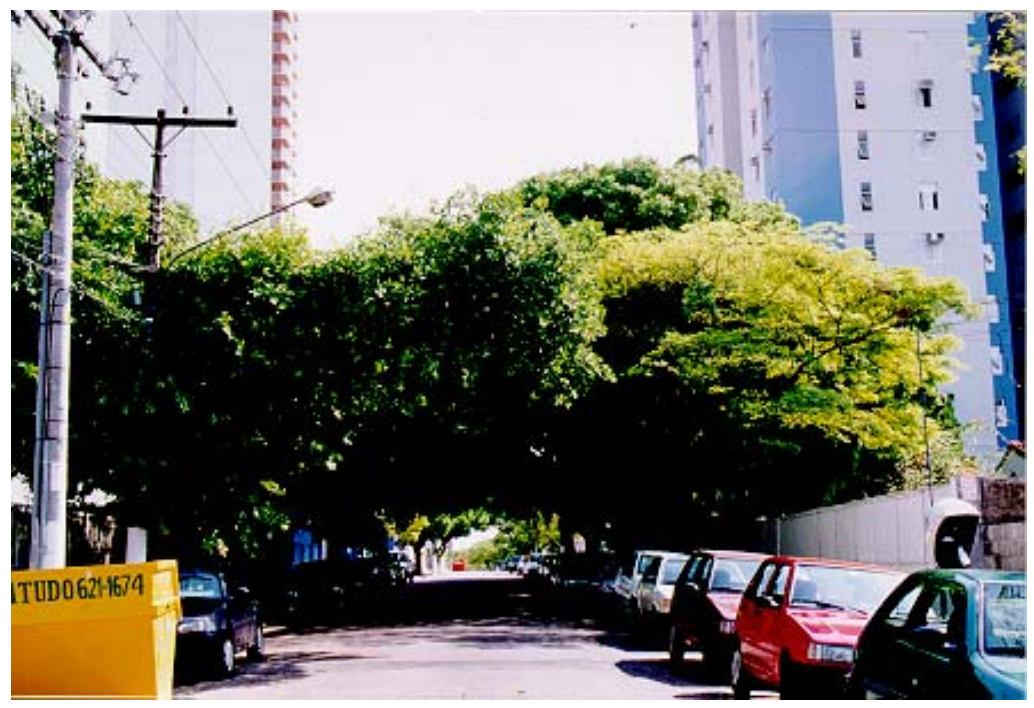

Figura 7.12 - Trecho arborizado da Av. Presidente Marques. (foto: D. Duarte)

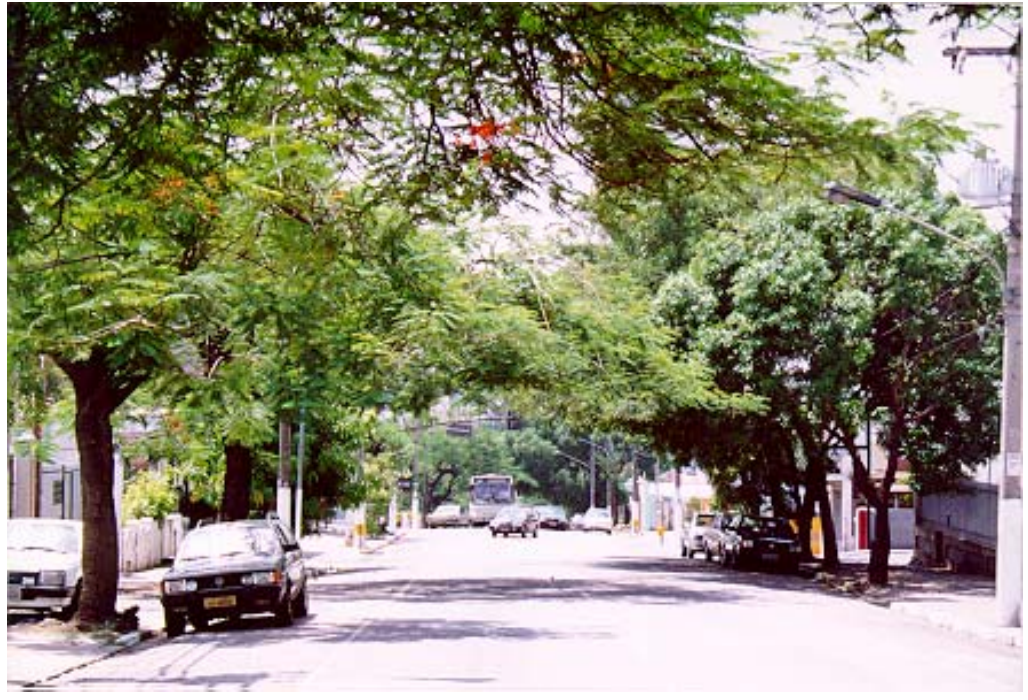

Figura 7.13 - Trecho arborizado da Av. Getúlio Vargas. (foto: D. Duarte)

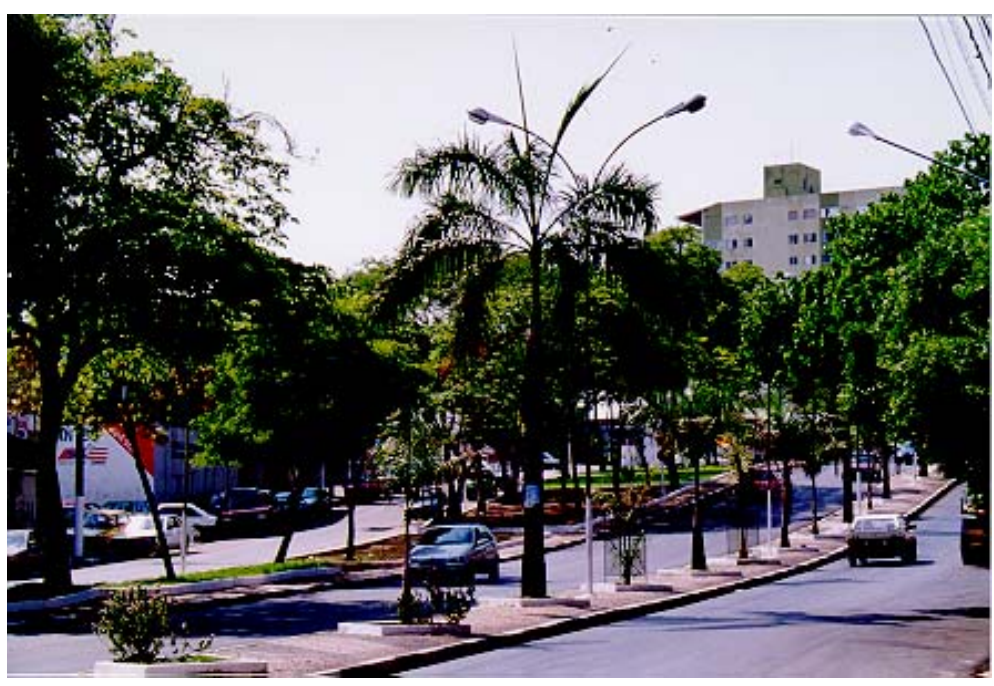

Figura 7.14 - Trecho arborizado da Av. Coronel Escolástico. (foto: D. Duarte) 


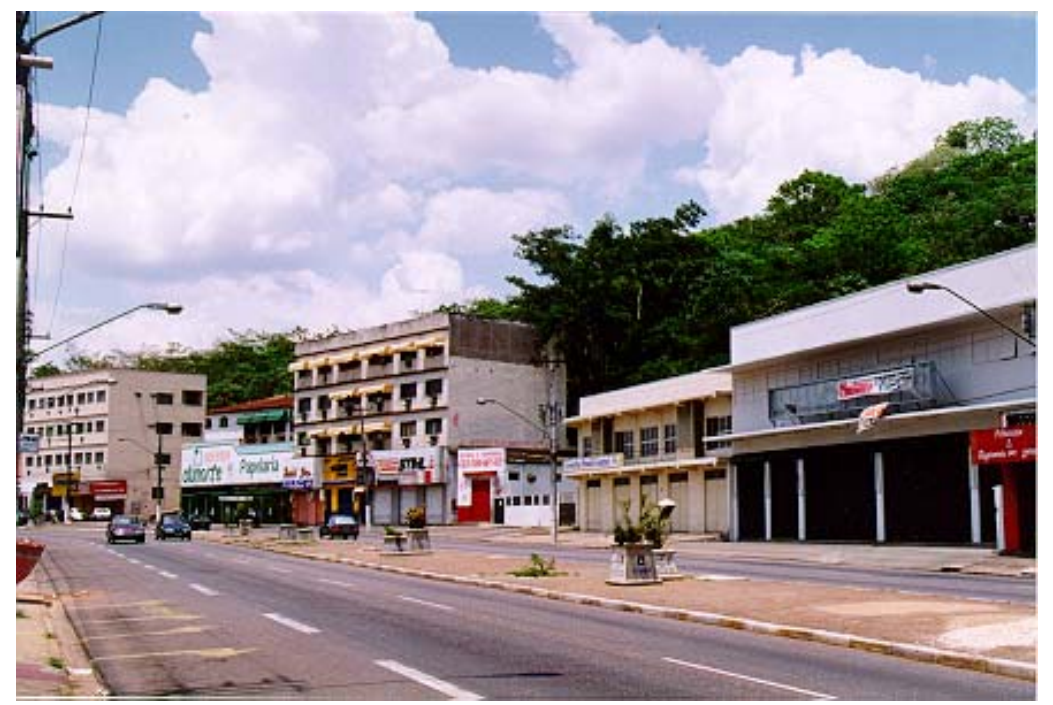

Figura 7.15 - Ambiente inóspito para o pedestre na Av. da Prainha. (foto: D. Duarte)

\subsubsection{Praças urbanas}

Muitas praças na área central da cidade (fig.7.16 a 7.22) já foram recuperadas e estão sendo mantidas pela iniciativa privada, geralmente por comerciantes próximos a esses locais, em troca de uso do espaço para publicidade. As parcerias têm aproximado a cidade de Prefeitura; as empresas financiam projetos e assumem a manutenção de alguns espaços em troca de publicidade.

O projeto é feito pelos órgãos competentes da Prefeitura, que indica as espécies a serem plantadas; a iniciativa privada faz o levantamento de preços, financia as obras e se responsabiliza pela manutenção em troca da publicidade; nesses projetos cerca de $90 \%$ das mudas são provenientes de viveiros privados, e os $10 \%$ restantes, do Horto Municipal, já que a capacidade da produção do Horto não atende a demanda ${ }^{8}$.

As parcerias com a iniciativa privada vêm acontecendo principalmente na área central e nas proximidades do comércio de alto padrão, que atrai o interesse dos comerciantes para a veiculação publicitária. Nessas áreas as praças estão arborizadas e bem cuidadas mas, à medida que o observador se afasta do centro, é notória a precariedade desses espaços; muitas vezes são lugares abandonados, sem condições mínimas de uso. É preciso continuar estimulando a participação da iniciativa privada mas, em locais estritamente residenciais e mais afastados do centro, as associações de bairros também podem atuar como agentes de um programa, através da organização de mutirões de plantio e manutenção nos finais de semana. O plantio pode ser feito pelos próprios moradores, em conjunto com funcionários capacitados da Prefeitura. Segundo a Secretaria do Verde e do Meio Ambiente da cidade de São Paulo (SÃO PAULO, 1993), apesar da enorme perda de mudas plantadas, as experiências de arborização com ativa participação da comunidade têm atingido maior sucesso.

\footnotetext{
${ }^{8}$ informação verbal, out.1997.
} 


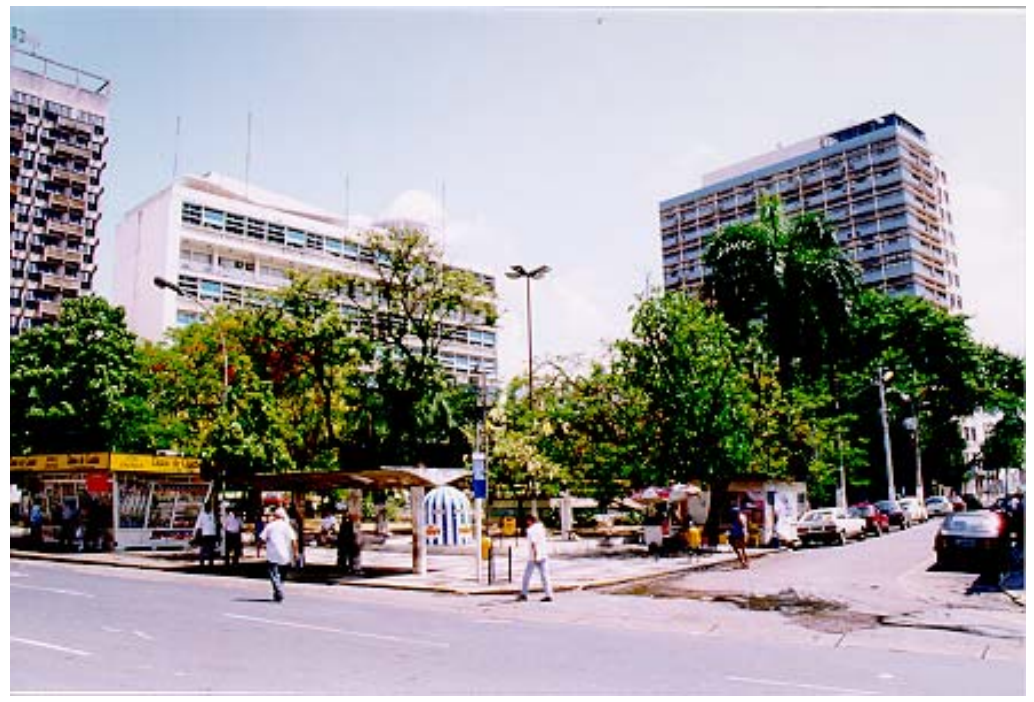

Figura 7.16 - Praça Alencastro, em frente à Prefeitura Municipal de Cuiabá, ainda não recuperada. (foto: J.Calsinski)

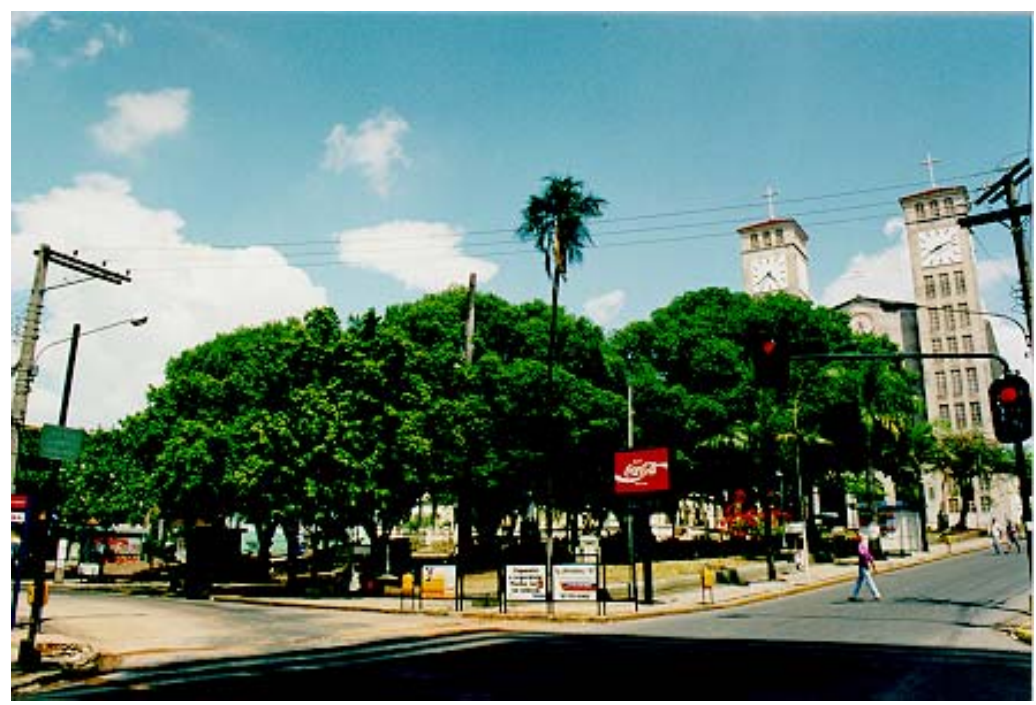

Figura 7.17 - Praça da República, mantida por uma loja de departamentos. (foto: J. Calsinski)

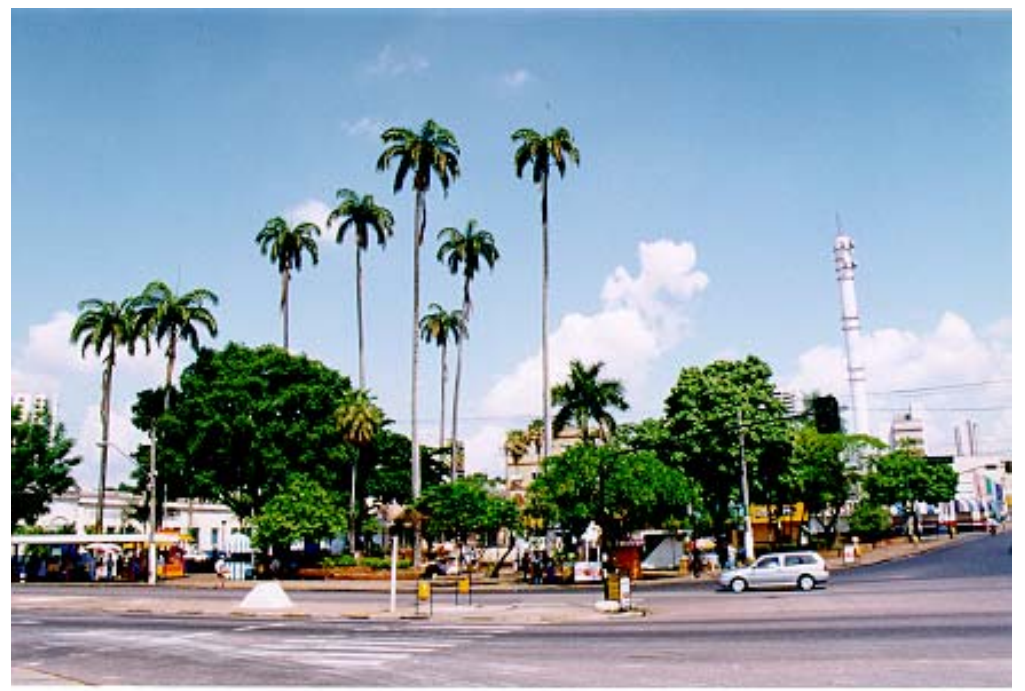

Figura 7.18 - Praça Ipiranga. (foto: J.Calsinski) 


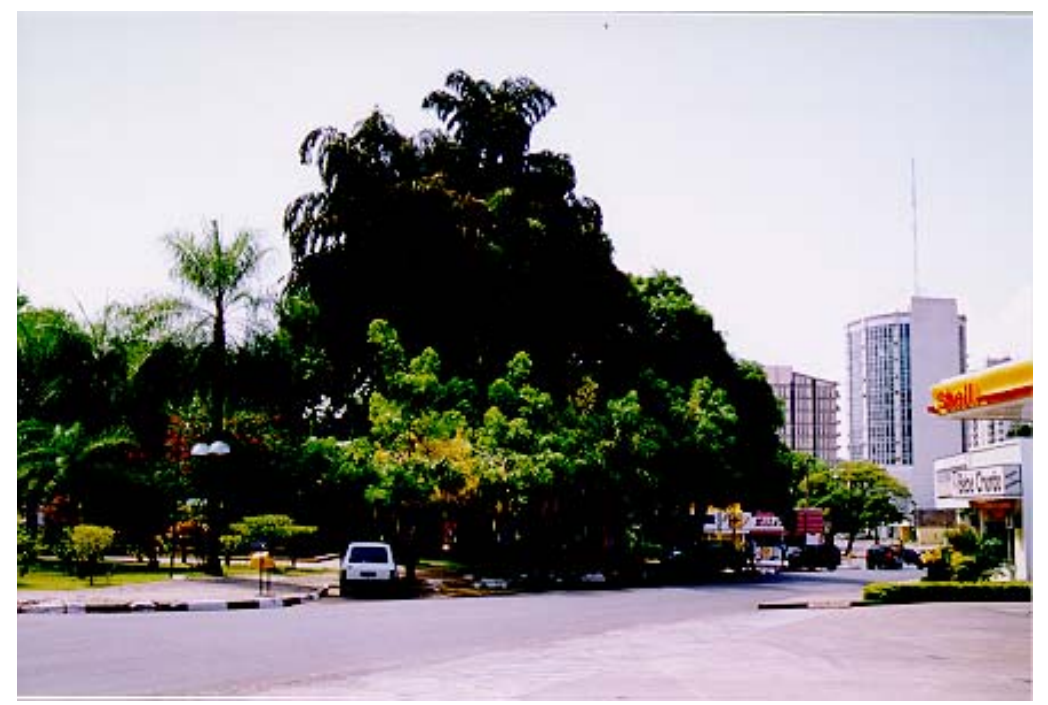

Figura 7.19 - Praça 8 de Abril (Praça do Chopão), antigo ponto de prostituição. Atualmente é mantida pelos comerciantes das proximidades. (foto: J. Calsinski)

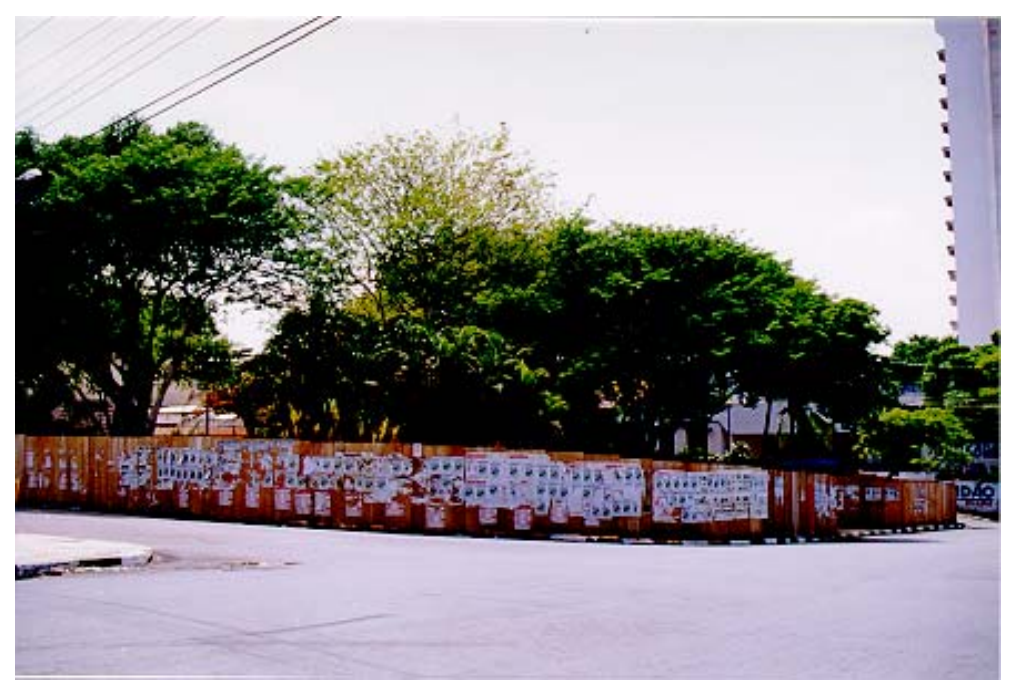

Figura 7.20 - Praça Clóvis Cardoso, na época em reforma, na Av. Isaac Povoas. (foto: J. Calsinski)

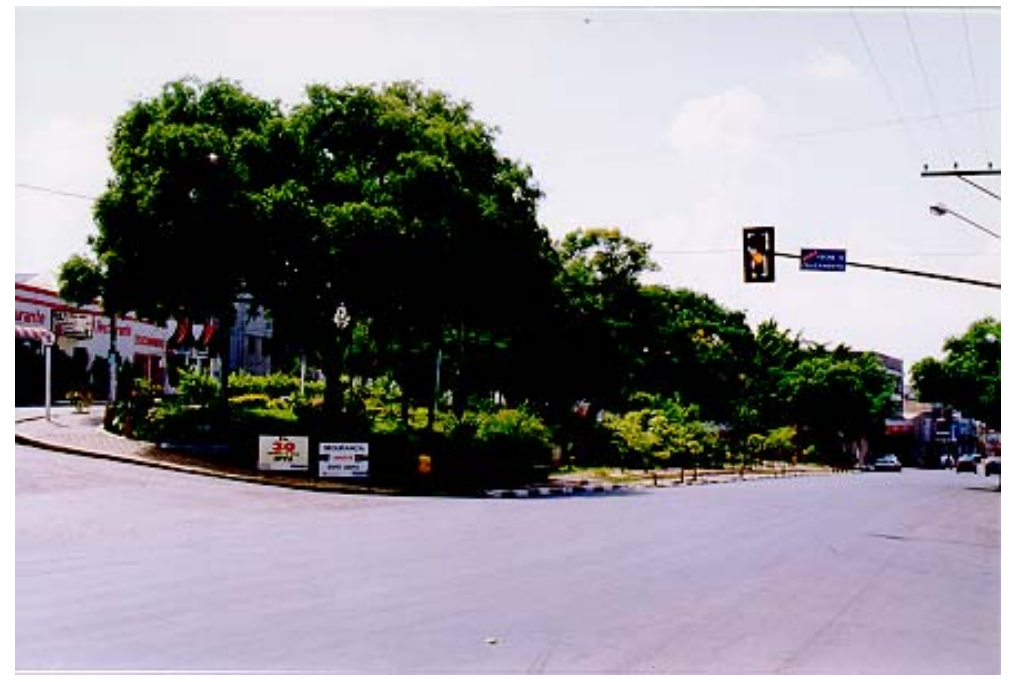

Figura 7.21 - Praça Rachid Jaudy, na Av. Generoso Ponce, mantida por uma floricultura próxima. (foto: J.Calsinski) 


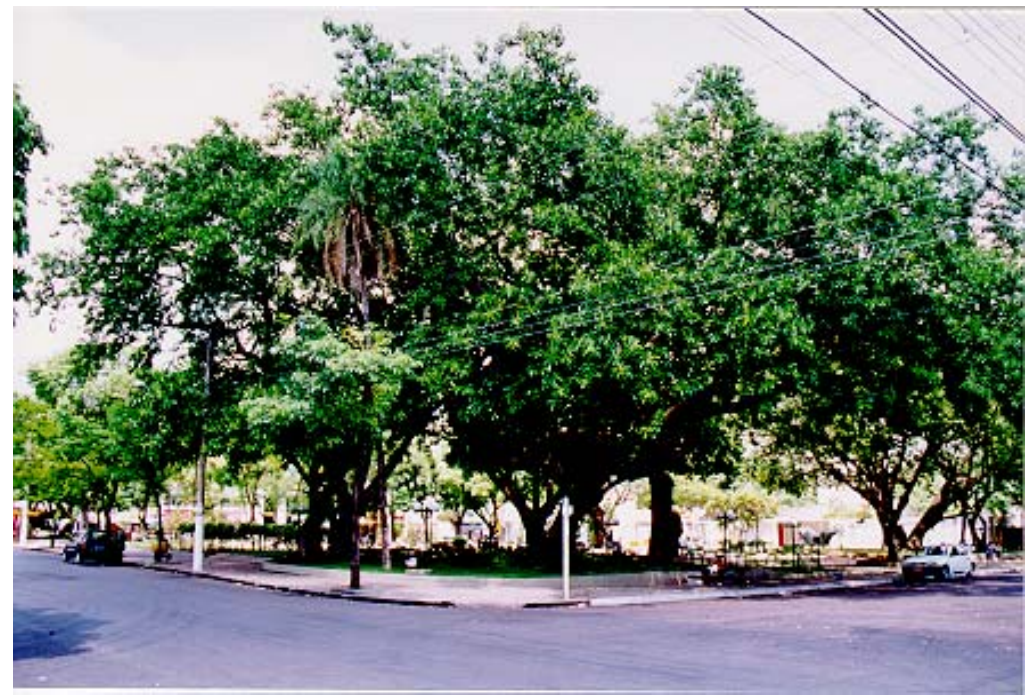

Figura 7.22 - Praça Santos Dumont, na Av. Getúlio Vargas. (foto: J. Calsinski)

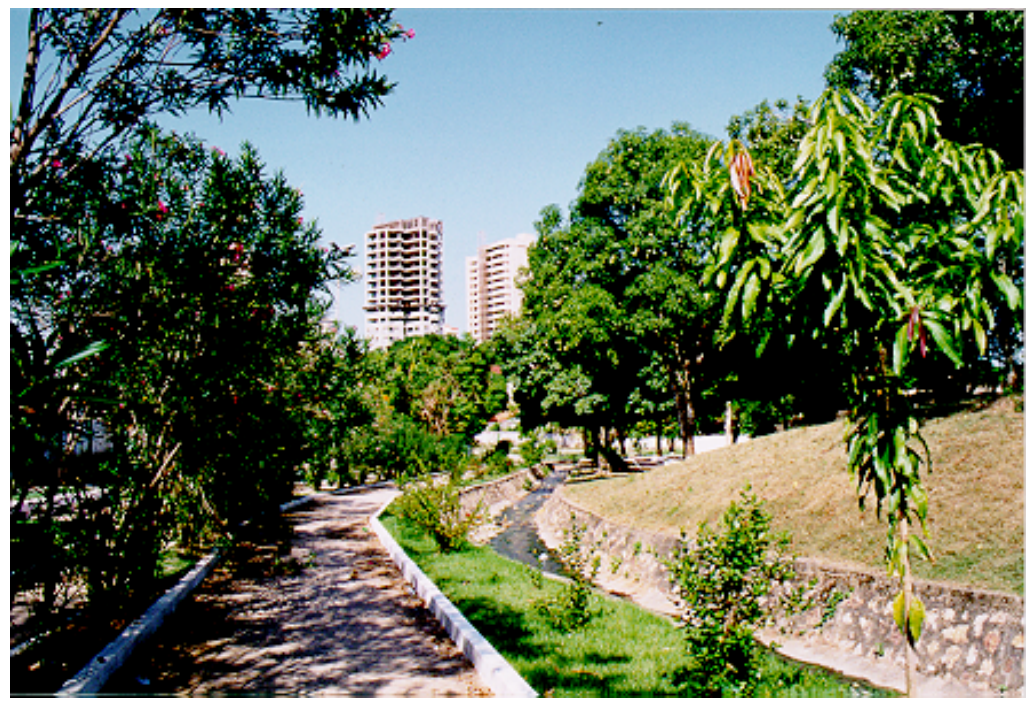

Figura 7.23 - Área verde ao longo do Córrego do Caixão, no Quilombo. (foto: D. Duarte)

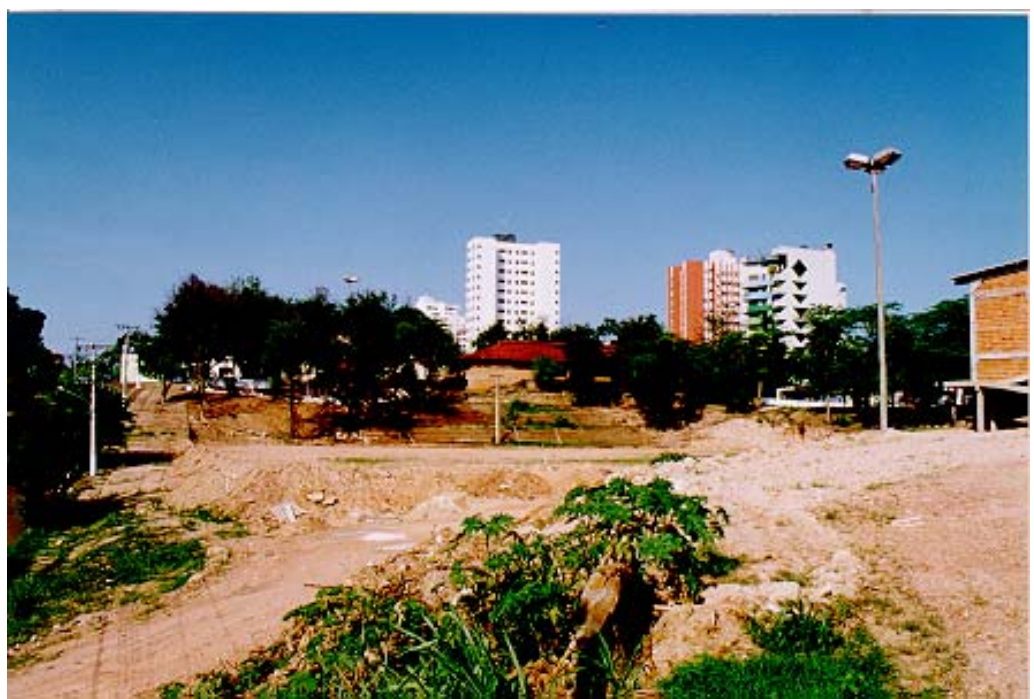

Figura 7.24 - Área de lazer abandonada no Centro Esportivo do Araés, área do Projeto CURA. (foto: D.Duarte) 


\subsubsection{5 Áreas do Projeto CURA nos bairros Araés, Lixeira e Quilombo}

Existem propostas do projeto CURA - Comunidades Urbanas de Renovação Acelerada, para os bairros Lixeira, Quilombo (fig.7.23) e Araés, colocadas em prática na cidade de Cuiabá na década de 70 (CUIABÁ. Projeto CURA, [s.d.]). Nas pesquisas realizadas na época ${ }^{9}$, áreas verdes e de lazer eram carências quase absolutas da população. As únicas opções eram os campos de pelada, improvisados pelos próprios moradores. As propostas do CURA incluíam a criação de praças, considerando os vazios existentes em algumas quadras que eram utilizados como campo de pelada, e onde era perfeitamente viável a implantação de equipamentos de lazer. Foram previstos grandes canteiros entrecortados por caminhos e patamares dotados de bancos e equipamentos de play-ground, com arborização intensa utilizando-se espécies nativas.

Outra proposta era o tratamento paisagístico nas margens dos córregos, com a finalidade de se ampliar as áreas verdes dos bairros, aproveitando-se as margens dos córregos canalizados a céu aberto. Um exemplo que deu certo foi o tratamento ao longo do Córrego do Caixão, no Quilombo. O espaço de $15.000 \mathrm{~m}^{2}$ é significativo, protege as margens de córregos que correm para a Mata da Mãe Bonifácia e oferece opções de descanso e lazer para a população. Esse projeto tira partido da topografia acidentada, que encareceria as obras do sistema viário. O trecho inicial do Córrego da Prainha, que é canalizado a céu aberto, também foi tratado pelo CURA. Infelizmente, outras áreas do projeto - como a quadra de lazer do Araés (fig.7.24) que já foram intensamente utilizadas pela população, encontram-se em estado de abandono.

\subsubsection{Quintais remanescentes no centro da cidade e nos bairros mais antigos}

Em Cuiabá, a vegetação domiciliar presente nos quintais era a mais representativa (fig.7.25 e 7.26). Embora as ruas não apresentassem arborização, os quintais eram cobertos de vegetação. Os poucos remanescentes na área central da cidade contam um pouco da história e dos costumes locais; uma característica marcante das antigas casas cuiabanas é o jardim interno, recurso que proporciona intimidade, sombra e frescor, contribuindo para se criar um microclima que difere enormemente da aspereza das condições exteriores. O jardim interno era característico de todas as residências, a despeito de qualquer categoria social. Além do jardim eram comuns a horta e o pomar. Hoje as áreas verdes dos quintais remanescentes no centro e nos bairros encontram-se ameaçadas pela verticalização das construções. Essas áreas verdes, sendo domiciliares, ficam muito vulneráveis do ponto de vista da preservação.

Além dos pontos localizados na área central, os bairros mais antigos, tais como o Quilombo, Araés e Lixeira ainda conservam parte de sua vegetação domiciliar. Há quintais remanescentes ricamente arborizados com árvores frutíferas e ornamentais. O Bairro Poção, por exemplo, é visto do alto como uma massa verde compacta, definida pela vegetação dos quintais aí existentes. Os quintais remanescentes poderiam ser aproveitados para a criação de jardins internos às quadras, que poderiam funcionar como praças em centro de quarteirão mantidas pelos moradores.

\footnotetext{
${ }^{9}$ Na época a equipe técnica de projeto e planejamento do CURA foi coordenada pelo Prof.Dr.Geraldo Gomes Serra.
} 


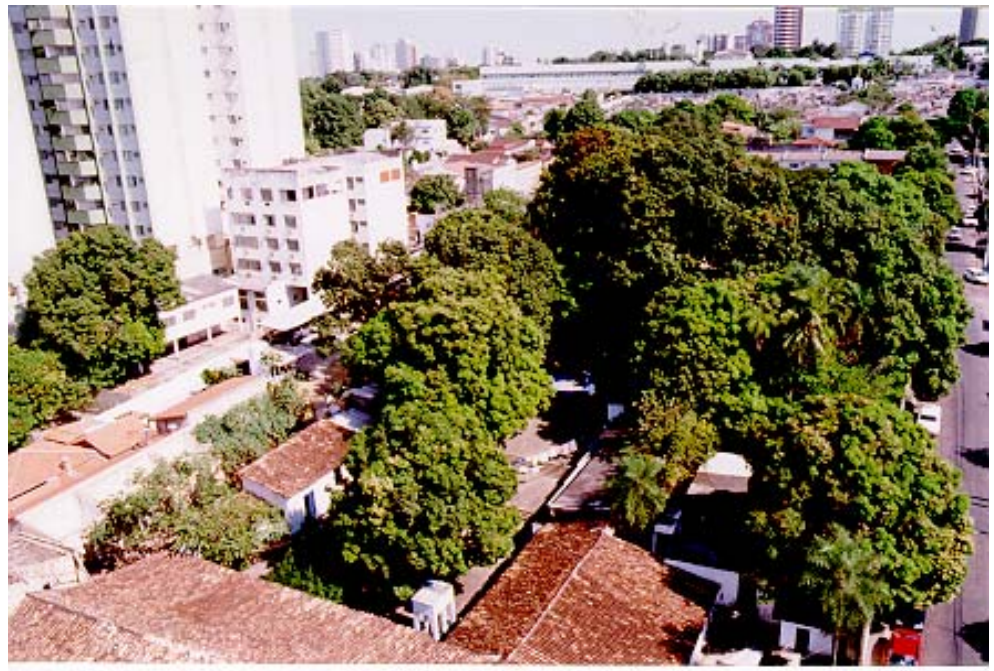

Figura 7.25 - Quintal remanescente na área central da cidade.(foto: A. Duarte)

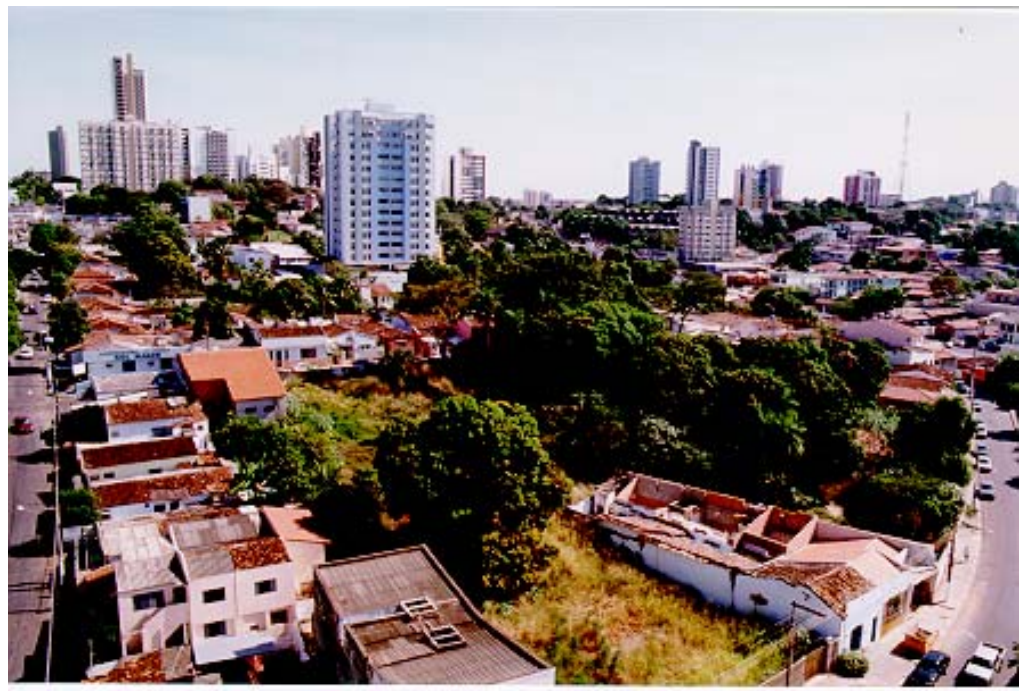

Figura 7.26 - Quintal remanescente na área central da cidade.(foto: A. Duarte)

\subsubsection{Conclusões do levantamento}

Nas áreas de ocupação recente, a verticalização não é acompanhada na mesma intensidade pela arborização urbana e áreas verdes; nessas áreas resta alguma vegetação nos quintais e são poucas as ruas arborizadas; há alguns espaços destinados a praças, porém, ainda não arborizados; alguns estão abandonados e, nos bairros, são usados como campo de futebol.

O levantamento imediato das áreas públicas ainda desocupadas, e com viabilidade para a criação de áreas verdes, pode abrir novas possibilidades para a criação de espaços importantes para a melhoria das condições de conforto na cidade, não só do ponto de vista físico mas também psicológico, além desse tratamento diminuir o risco de invasões. Com o ritmo acelerado de crescimento que a cidade vem experimentando nas últimas décadas, o planejamento de futuras intervenções nesse sentido torna-se urgente, evitando, num futuro próximo, a necessidade de intervenções mais drásticas à custa de desapropriações e conflitos. 
Devido à conjugação de dois fatores, a ocupação inadequada e o clima rigoroso, um novo padrão de urbanização, com a criação de microclimas mais amenos nos espaços públicos, torna-se imperativo para a melhoria das condições de conforto na cidade. Como providências imediatas deve-se promover o aumento de áreas verdes públicas bem como a recuperação e manutenção das já existentes; áreas verdes de dimensões significativas remanescentes em quintais podem ser tombadas como patrimônio ambiental da cidade; para tanto é necessário levantar a situação legal desses lotes para uma possível utilização da área como parque ou unidade de conservação.

A concretização das propostas existentes para os parques urbanos e as parcerias para a manutenção de praças e trechos de rua trará enormes benefícios para a população, possibilitando o uso e incentivando o convívio em espaços públicos sob condições mínimas de conforto.

\subsection{Descrição qualitativa dos sete casos estudados}

Este item descreve os locais utilizados para medição de parâmetros microclimáticos e o levantamento de suas condições de ocupação. Após o reconhecimento da cidade foram escolhidos sete casos na zona urbana. De acordo com MILLER-CHAGAS (1980), que fez um estudo para Strasbourg, além da simultaneidade das medidas em diferentes pontos de referência, na escolha dos casos a serem estudados deve-se responder a dois interesses:

- a diversidade das morfologias, para colocar em evidência as relações entre as diferentes configurações urbanas e a distribuição dos parâmetros microclimáticos e energéticos dos espaços externos;

- a uniformidade dos elementos morfológicos numa determinada fração urbana

Sendo assim, procurou-se escolher criteriosamente casos com diferentes padrões de ocupação urbana e, ao mesmo tempo, estabelecer critérios de uniformidade para a delimitação de cada área estudada. Além do entorno das duas estações meteorológicas de apoio foram escolhidos outros 5 pontos-chave da amostra, como o centro antigo e a área de verticalização recente, no CPA. De acordo com MONTEIRO (1990) e SAMPAIO (1981), essa forma intencional de seleção dos pontos é mais adequada do que procedimentos estatísticos de tipo aleatório; além disso foram consideradas as condições do local e a segurança para instalação dos equipamentos. No centro da cidade foram escolhidos três pontos:

\subsubsection{Morro da Luz}

Maior área verde na parte central da cidade, o Morro da Luz fica junto ao núcleo de ocupação do período colonial, no centro antigo, que por sua vez é densamente ocupado em suas ruas estreitas e tortuosas (fig.7.27). O acelerado desenvolvimento dos últimos anos vem exercendo forte pressão sobre o centro, provocando sua descaracterização e alterando as relações entre seus componentes. O trânsito foi ficando cada vez mais difícil nessas áreas e hoje o acesso de veículos já não é permitido em algumas ruas, transformadas em calçadões. As ruas são todas pavimentadas. Com exceção do Morro, há vegetação arbórea em algumas praças e em alguns poucos quintais remanescentes. A altitude do posto de medição é de aproximadamente $180 \mathrm{~m}$. 


\subsubsection{Araés}

Araés, bairro antigo já consolidado e que foi remodelado pelo projeto CURA Comunidades Urbanas de Renovação Acelerada - na década de 70 (Cuiabá. Projeto Cura, [s.d.]). Na época predominava a ocupação espontânea, isenta de qualquer diretriz inicial, que acabou resultando num sistema viário bastante desordenado. As vias locais eram pouco definidas, e não se podia identificar sequer um alinhamento para as construções mais antigas. A maioria delas se encontrava junto às vias públicas, sem recuo frontal, com áreas verdes privativas nos centros das quadras. A proposta do CURA acabou por considerar o emaranhado das vias internas como vias locais, desestimuladoras do tráfego pela sua descontinuidade, deixando mais sujeitas ao movimento as vias limítrofes. Do alto, o bairro ainda hoje é visto como uma densa massa verde (fig.7.28) devido à farta vegetação existente nos quintais remanescentes e algumas árvores nas calçadas; a altitude do posto de medição é de aproximadamente $180 \mathrm{~m}$.

\subsubsection{Av. CPA}

O CPA - Centro Político Administrativo é uma das principais áreas de crescimento da cidade. Apesar da proximidade do centro antigo, o padrão urbanístico é completamente diferente da ocupação tradicional da cidade, com edifícios altos ao longo de largas avenidas (fig.7.29). O principal eixo dessa área de expansão é a Av.Historiador Rubens de Mendonça, conhecida como Av. do CPA, que é ocupada principalmente por edifícios comerciais de alto padrão, hotéis, bares, restaurantes, lanchonetes, lojas de conveniência, etc.; ao longo desse eixo a Avenida é circundada por edifícios residenciais. Com poucas exceções a vegetação se resume a árvores jovens plantadas recentemente ao longo das avenidas e alguma vegetação nativa em terrenos ainda desocupados. A altitude do posto de medição é de aproximadamente $180 \mathrm{~m}$.

No trecho próximo ao viaduto da Av. Miguel Sutil boa parte dos terrenos ao longo da Avenida e suas imediações estão sendo ocupados por edifícios altos. São imóveis residenciais e comerciais de médio e alto padrão. Nesse trecho a Prefeitura tenta já há alguns anos a negociação com os proprietários dos imóveis para a padronização das calçadas de $9 \mathrm{~m}$ de largura com a incorporação da arborização junto às vagas para estacionamento. Com poucas exceções a administração municipal tem conseguido a adesão dos proprietários. As avenidas são largas, bastante diferentes da ocupação tradicional nas áreas mais antigas da cidade, onde a sombra e o confinamento surgem como resultado dos próprios edifícios, com as construções alinhadas em ruas estreitas e tortuosas.

Mais afastados do centro estão os pontos:

\subsubsection{UFMT}

A Estação Climatológica Mestre Bombled localiza-se no campus da UFMT Universidade Federal de Mato Grosso (fig.7.30), que possui 67\% de área verde, com espécies nativas e exóticas. Pela existência de grandes áreas verdes e pela presença do zoológico esse espaço é bastante utilizado nos finais de semana, e vem funcionando como uma opção de lazer para a população. A altitude do posto é de 170m acima do nível do mar. 


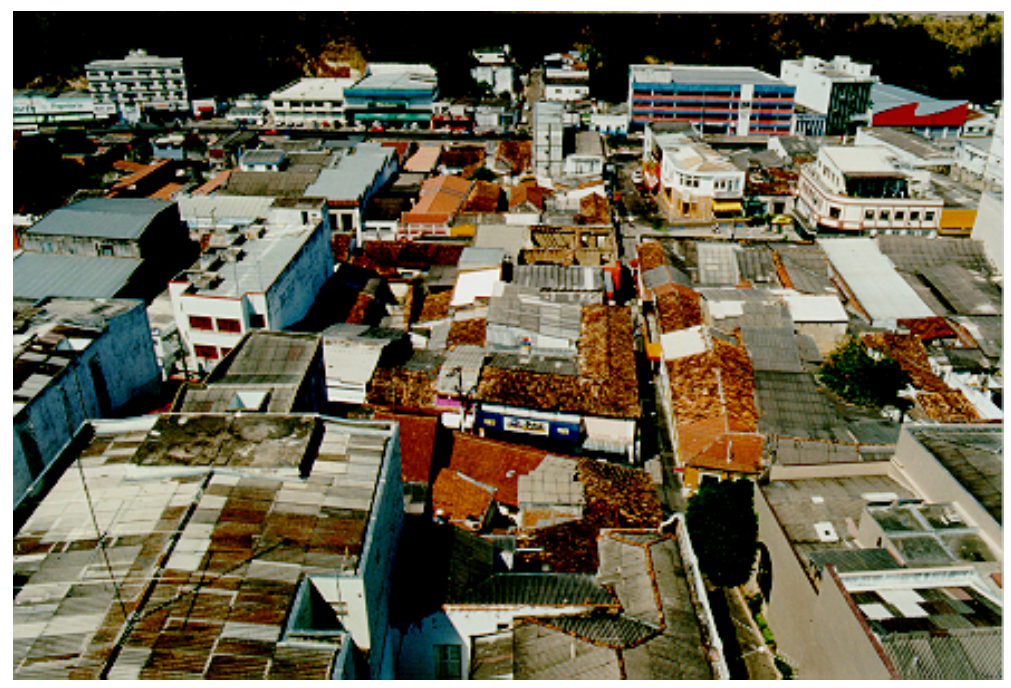

Figura 7.27 - Alta densidade de ocupação no centro antigo (foto: A. Duarte)

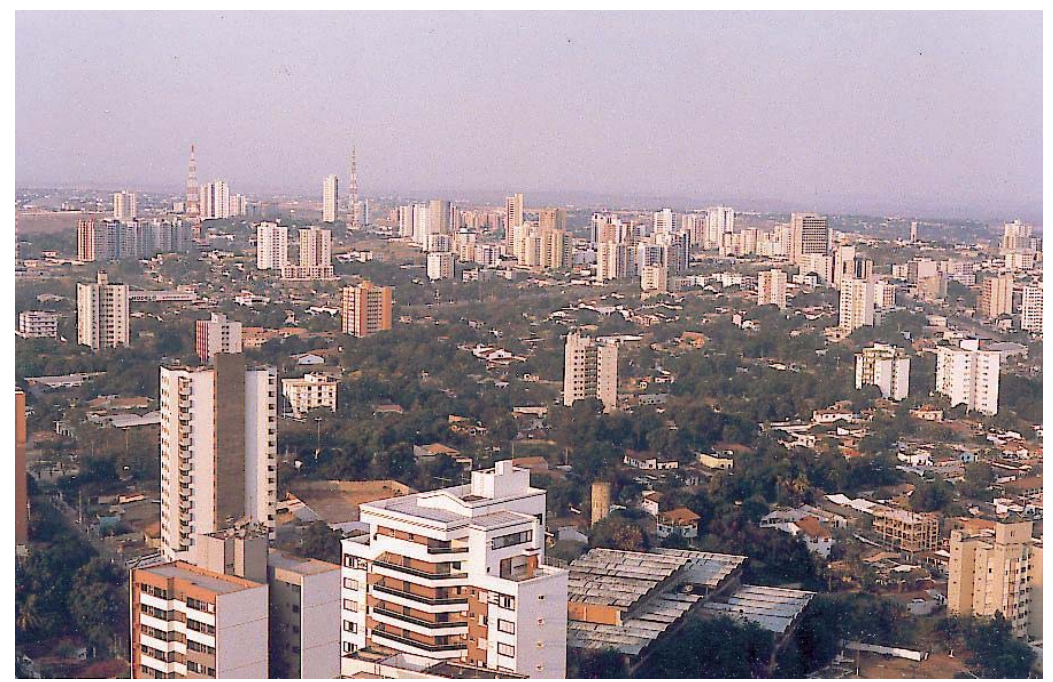

Figura 7.28 - Araés visto do alto em 1997. Ao fundo a ocupação vertical al longo da Av. CPA. (foto: A.Duarte)

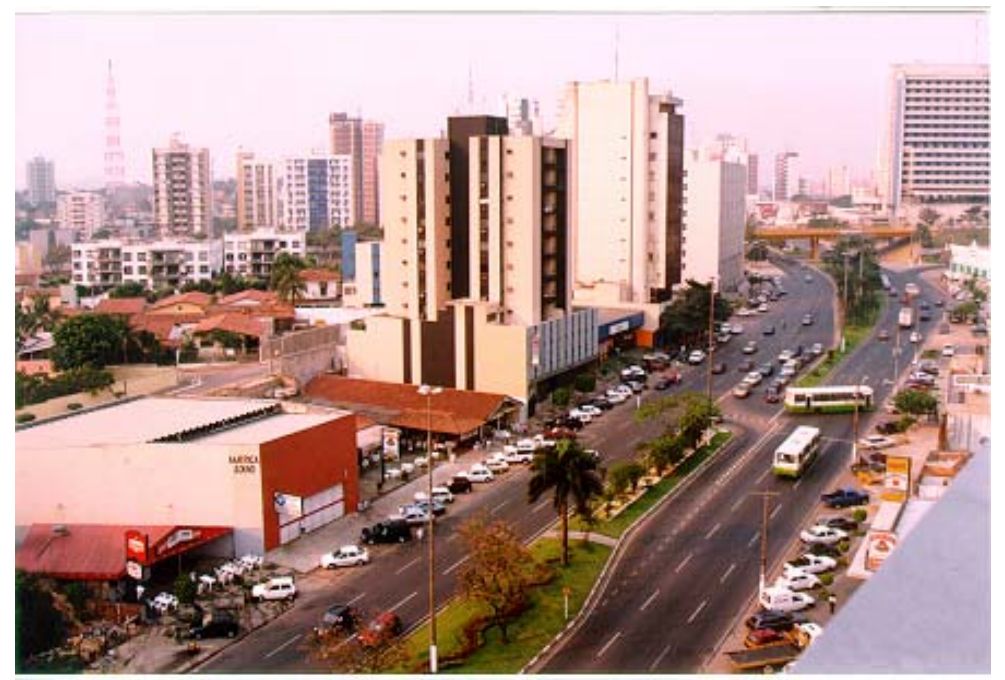

Figura 7.29 - Vista da Avenida no sentido Centro-CPA, próximo ao viaduto da Av. Miguel Sutil, em agosto de 1998. (foto: D. Duarte) 


\subsubsection{Horto Florestal}

O Horto Florestal (fig.7.31) tem 19,75ha de área verde, com grande variedade de espécies. Além do perímetro do Horto, a área é cercada pela mata ciliar do Rio Coxipó e é cortada por dois córregos. No Horto foram encontrados bosques homogêneos bastante sombreados às margens do rio; a área é coberta por mata ciliar e cerradão, e em poucos pontos das suas margens existe uma vegetação ciliar ainda íntegra, com áreas alagáveis e de várzea. O cerradão é nitidamente florestal, com alta densidade, e dossel atingindo cerca de $14 \mathrm{~m}$ de altura. A altitude do posto de medição é de aproximadamente $150 \mathrm{~m}$.

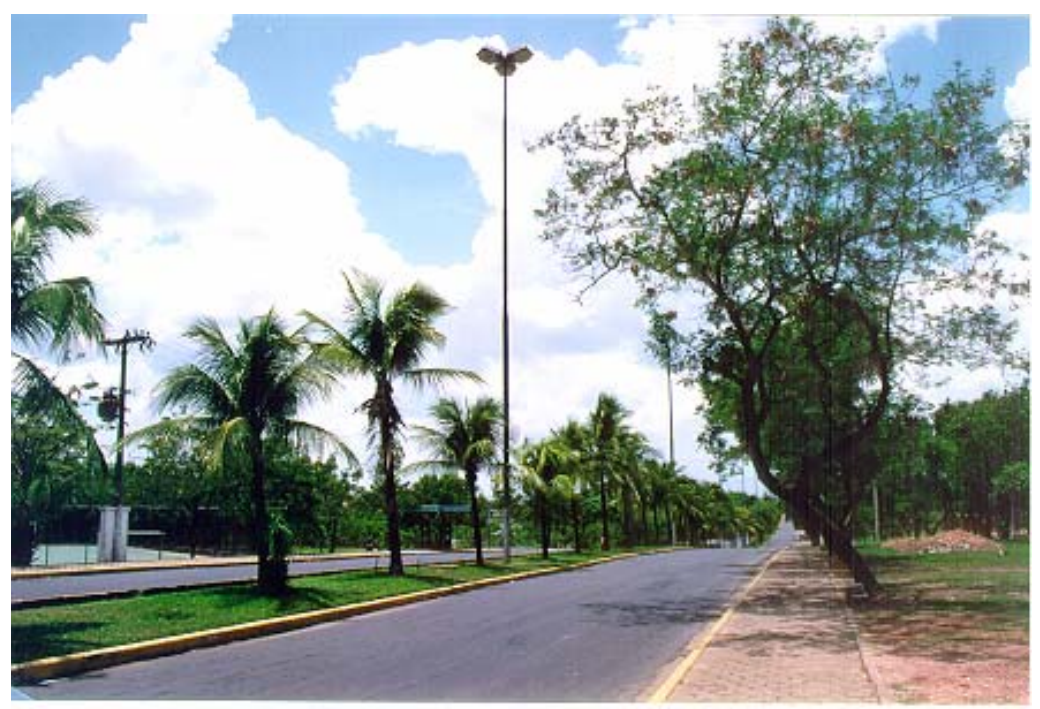

Figura 7.30 - Campus da UFMT, a aproximadamente 3Km da área central. (foto: D. Duarte)

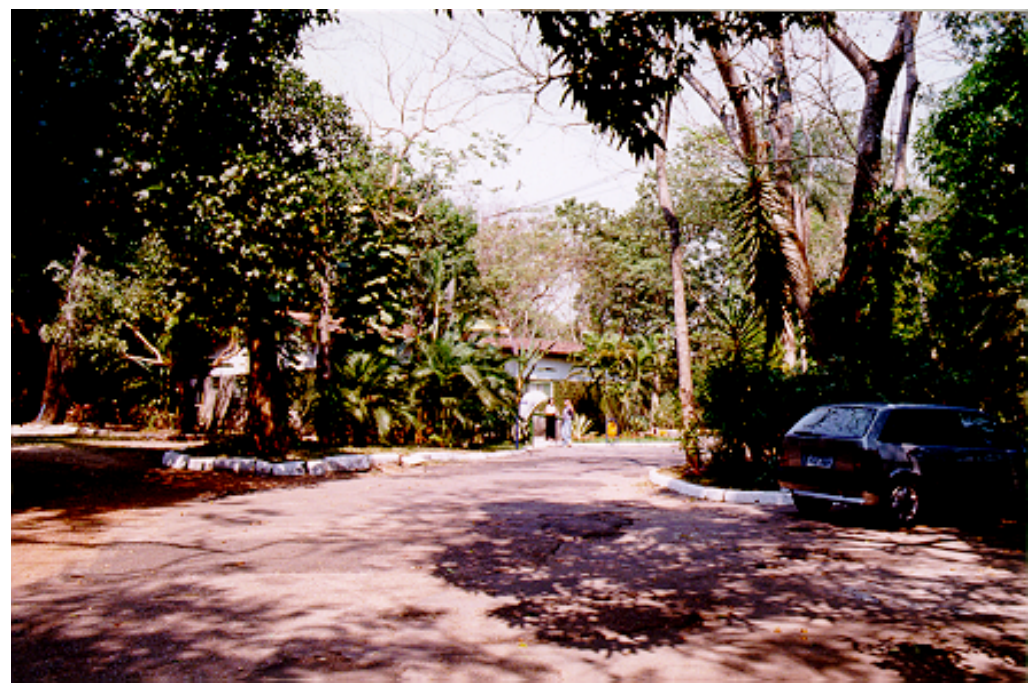

Figura 7.31 - Acesso ao Horto Florestal, a aproximadamente 5Km da área central (foto: A. Duarte)

\subsubsection{Pascoal Ramos}

O Pascoal Ramos (fig.7.32), uma ex-colônia agrícola que até 1994 ficava fora do perímetro urbano, é hoje um bairro próximo ao Distrito Industrial de Cuiabá, de acordo com a lei de abairramento de dezembro de 1997. Ainda são poucas as ruas pavimentadas. Encontram-se quintais bastante arborizados e alguma vegetação nas ruas. A altitude do posto de medição é de aproximadamente $180 \mathrm{~m}$. 


\subsubsection{INMET}

O $9^{\circ}$ Distrito de Meteorologia do INMET (fig.7.33) localiza-se no município vizinho de Várzea Grande, aproximadamente a 1Km após a travessia da Ponte Júlio Müller sobre o Rio Cuiabá. A altitude do posto é de 151,34m e o entorno é coberto por vegetação das margens do Rio Cuiabá. O posto fica próximo à Av. da FEB, principal acesso à cidade; a ocupação é rala e não há edifícios altos nessa região da cidade.

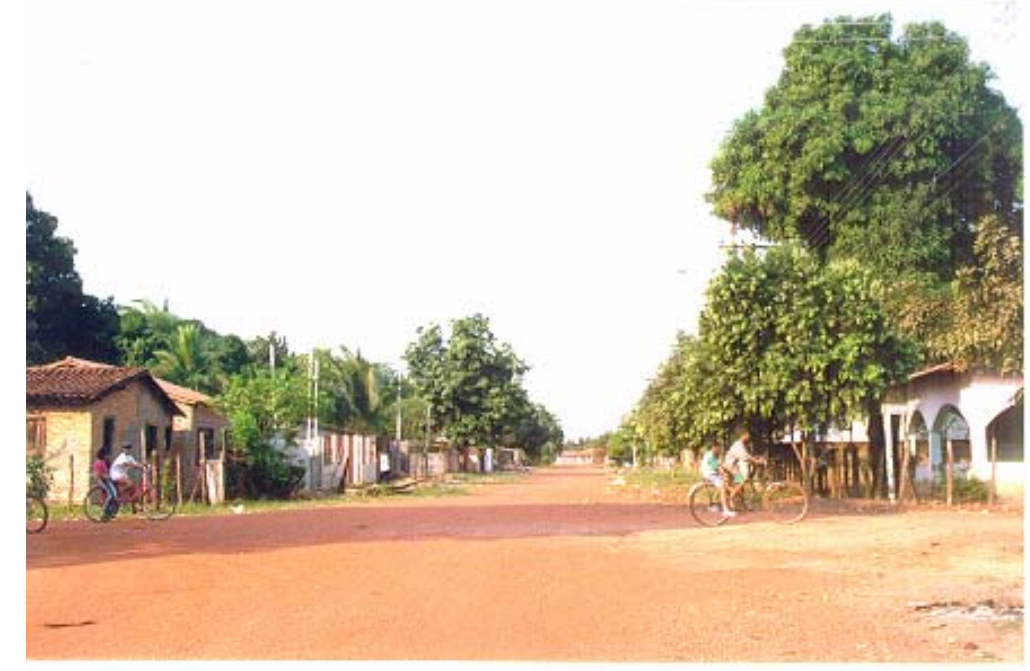

Figura 7.32 - Bairro Pascoal Ramos, a mais de 15 Km do centro de Cuiabá. (foto: D. Duarte)

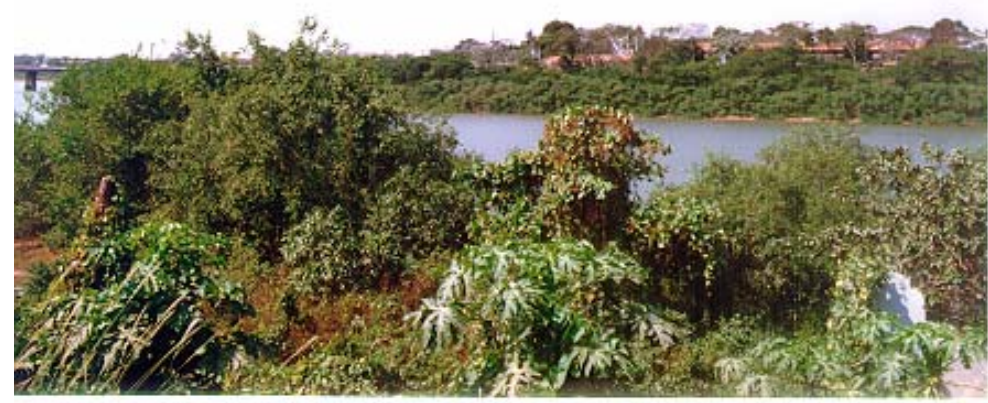

Figura 7.33 - Entorno do INMET, no município vizinho de Várzea Grande, às margens do Rio Cuiabá, a 3,5Km da área central de Cuiabá. (foto: D. Duarte)

\subsection{Quantificação de variáveis urbanísticas nos sete casos estudados}

Foi estabelecida uma área de 25 ha no entorno de cada ponto escolhido ${ }^{10}$ para as medições de microclimas urbanos; as áreas são irregulares e o fator determinante para a delimitação do entorno foi a homogeneidade do padrão de ocupação. A inexistência de mapas temáticos e de cadastros atualizados referentes ao meio ambiente urbano dificultou o levantamento de dados obrigando-nos a buscar

\footnotetext{
${ }^{10}$ ver fotos aéreas no anexo 2.
} 
alternativas. A desatualização dos bancos de dados da Prefeitura Municipal de Cuiabá inviabilizou a utilização do Cadastro Imobiliário como pensado inicialmente para o levantamento das taxas de ocupação e índices de aproveitamento em alguns dos pontos de interesse para a pesquisa. Essas lacunas foram preenchidas com a combinação de todas as fontes disponíveis, incluindo interpretação de fotos aéreas, o uso do cadastro imobiliário onde foi possível e pesquisa de rua com documentação fotográfica, anotações em mapas, tabelas, gráficos, etc. Dessa forma foram obtidos:

- taxas de arborização (área da projeção horizontal das copas das árvores) e de superfícies d’água, área ocupada por ruas, área da projeção construída e área total construída dentro dos limites de 25ha estabelecidos;

- taxas de ocupação e coeficientes de aproveitamento líquidos e brutos em 25ha no entorno de cada ponto de medição.

Cabe lembrar que os índices foram levantados não no bairro como um todo, mas dentro do perímetro estabelecido, totalizando 25ha no entorno de cada ponto de medição, e que em alguns casos não correspondem à totalidade do bairro, parque ou instituição que deu o nome ao posto (tab.7.1 a 7.3, fig.7.34).

Tabela 7.1 - Índices levantados em área de área $\left(\mathrm{m}^{2}\right)$ no entorno de cada ponto de medição.

\begin{tabular}{|l|c|r|r|r|r|r|r|}
\hline & $\begin{array}{l}\text { área } \\
\text { total }\end{array}$ & \multicolumn{1}{c|}{ água } & verde & vazios & ruas & \multicolumn{1}{c|}{$\begin{array}{c}\text { projeção } \\
\text { construída }\end{array}$} & $\begin{array}{l}\text { área total } \\
\text { construída }\end{array}$ \\
\hline Horto Florestal & 250000 & 24460 & 216722 & 8521 & 0 & 298 & 298 \\
Pascoal Ramos & 250000 & 0 & 61680 & 77564 & 52628 & 58128 & 58128 \\
Araés & 250000 & 607 & 78035 & 7475 & 45857 & 118025 & 189475 \\
Morro da Luz & 250000 & 0 & 53603 & 0 & 33937 & 162461 & 310319 \\
Av. do CPA & 250000 & 0 & 12755 & 62258 & 88775 & 86212 & 217192 \\
UFMT & 250000 & 4139 & 74383 & 144682 & 1080 & 25715 & 42883 \\
INMET & 250000 & 82264 & 67713 & 85498 & 1142 & 13382 & 13382 \\
\hline
\end{tabular}

Tabela 7.2 - Índices levantados em \% no entorno de cada ponto de medição.

\begin{tabular}{|l|r|r|r|r|r|r|r|}
\hline & \multicolumn{1}{|c|}{$\begin{array}{l}\text { área } \\
\text { total }\end{array}$} & \multicolumn{1}{c|}{ água } & \multicolumn{1}{c|}{ verde } & vazios & \multicolumn{1}{c|}{ ruas } & $\begin{array}{l}\text { taxa de } \\
\text { ocup.bruta }\end{array}$ & $\begin{array}{l}\text { área total } \\
\text { construída }\end{array}$ \\
\hline Horto Florestal & 100 & 9,8 & 86,7 & 3,4 & 0,0 & 0,1 & 0,1 \\
Pascoal Ramos & 100 & 0,0 & 24,7 & 31,0 & 21,1 & 23,3 & 23,3 \\
Araés & 100 & 0,2 & 31,2 & 3,0 & 18,3 & 47,2 & 75,8 \\
Morro da Luz & 100 & 0,0 & 21,4 & 0,0 & 13,6 & 65,0 & 124,1 \\
Av. do CPA & 100 & 0,0 & 5,1 & 24,9 & 35,5 & 34,5 & 86,9 \\
UFMT & 100 & 1,7 & 29,8 & 57,9 & 0,4 & 10,3 & 17,2 \\
INMET & 100 & 32,9 & 27,1 & 34,2 & 0,5 & 5,4 & 5,4 \\
\hline
\end{tabular}

Tabela 7.3 - Taxas de ocupação e coeficientes de aproveitamento líquidos e brutos no entorno de cada ponto de medição.

\begin{tabular}{|l|r|r|r|r|}
\hline & taxa ocup líquida & coef. aprov. líquido & taxa ocup. bruta & coef. aprov. bruto \\
\hline Horto Florestal & 0,00 & 0,00 & 0,00 & 0,0 \\
\hline Pascoal Ramos & 0,31 & 0,31 & 0,23 & 0,2 \\
\hline Araés & 0,60 & 0,94 & 0,47 & 0,8 \\
\hline Morro da Luz & 0,92 & 1,98 & 0,65 & 1,2 \\
\hline Av. do CPA & 0,54 & 2,50 & 0,34 & 0,9 \\
\hline UFMT & 0,12 & 0,20 & 0,10 & 0,2 \\
\hline INMET & 0,12 & 0,12 & 0,05 & 0,1 \\
\hline
\end{tabular}




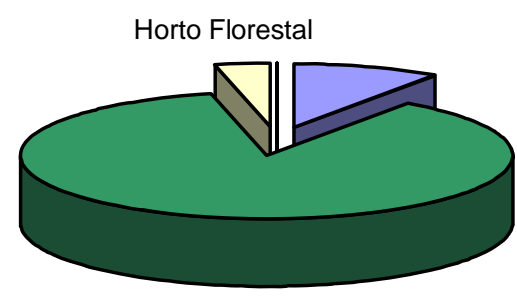

INMET

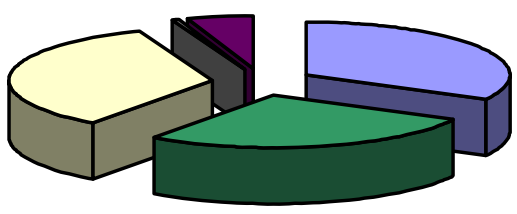

Pascoal Ramos

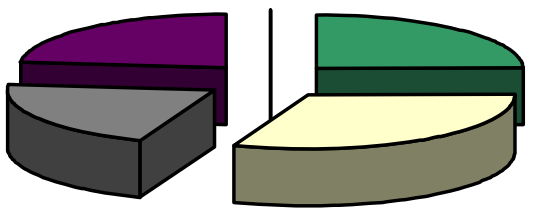

UFMT

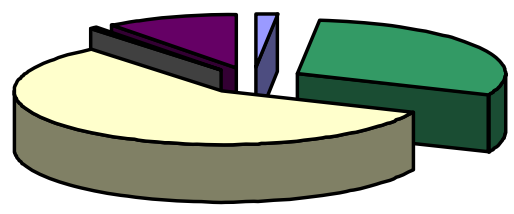

Araés

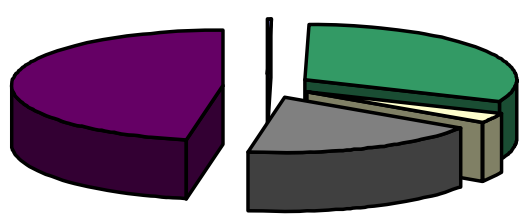

Av. do CPA
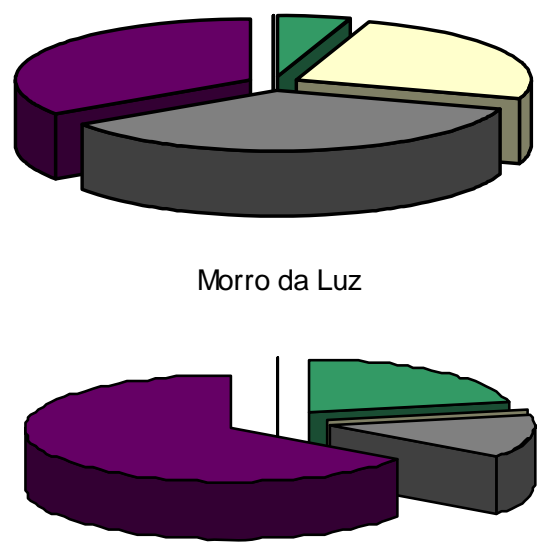

\begin{tabular}{|l|}
\hline$\square$ água \\
$\square$ árvores \\
$\square$ vazios \\
$\square$ ruas \\
$\square$ proj.constr. \\
\hline
\end{tabular}

Figura 7.34 - Proporções entre superfícies d’água, verde, vazios, ruas e projeção construída em cada um dos pontos escolhidos. 


\section{Referências Bibliográficas}

1. CUIABÁ. Prefeitura Municipal de Cuiabá. Cadastro Imobiliário. Cuiabá: Secretaria de Finanças.

2. CUIABÁ. Prefeitura Municipal de Cuiabá. Caderno do IPDU. [Cuiabá], [s.d.].

3. CUIABÁ. Prefeitura Municipal de Cuiabá. Plano Diretor de Desenvolvimento Urbano de Cuiabá. Cuiabá: IPDU, 1995.

4. CUIABÁ. Prefeitura Municipal de Cuiabá. Projeto Cura Cuiabá. [Cuiabá]: [s.n.],[s.d.].

5. Diagnóstico Florístico e Faunístico da Cidade de Cuiabá. Convênio UFMT/Prefeitura Municipal de Cuiabá. Set. 1990.

6. MILLER-CHAGAS, Philomena. Apports énergétiques solaires, microclimats et configuration urbaine dans trois cités à Strasbourg. Recherche Géographiques à Strasbourg, n.13-14, 1980. (Extrait des Actes des Journées de Climatologie 1980. Strasbourg, 13-15 novembre 1980).

7. MONTEIRO, Carlos A. F. Adentrar a cidade para tomar-lhe a temperatura. Geosul, Florianópolis, n.9, p.61-79, 1990.

8. ROCHA, Paulo Mendes da. Av. Beira Rio/Bairro do Porto. Plano Piloto para a urbanização das áreas marginais do Rio Cuiabá. Out. 1979.

9. SAMPAIO, Antonio Heliodorio Lima. Correlações entre o uso do solo e ilhas de calor no ambiente urbano: o caso de Salvador. São Paulo, 1981. Dissertação (Mestrado em Geografia), Faculdade de Filosofia, Letras e Ciências Humanas, Universidade de São Paulo. 


\section{MEDIÇÕES DE PARÂMETROS MICROCLIMÁTICOS NA REGIÃO EM ESTUDO}

Este capítulo apresenta o planejamento, a descrição, a documentação fotográfica e os resultados das medições de microclimas urbanos. Cabe lembrar que não estamos medindo a intensidade da ilha de calor na cidade, e sim, estudando a correlação entre microclimas urbanos e condições de ocupação em sete casos previamente determinados.

O planejamento das medições foi embasado nas experiências anteriores de Monteiro, Sezerino e Maitelli ${ }^{1}$, e foram realizadas com a colaboração do Laboratório de Climatologia da Universidade Federal de Mato Grosso.

Optou-se por realizar essas medições em dois períodos representativos para o clima regional, na estação seca e na estação chuvosa, em agosto de 1998 e janeiro/fevereiro de 1999, respectivamente. Foram seis dias consecutivos de medições em cada estação, sendo um dia com leituras de hora em hora, das 8 h às 20h e, nos outros cinco, leituras em três horários que coincidem com os utilizados pelas estações meteorológicas de apoio: 8h, 14h e 20h, sendo estas o $9^{\circ}$ Distrito de Meteorologia do INMET- Instituto Nacional de Meteorologia, e a Estação Climatológica Mestre Bombled, no campus da Universidade Federal de Mato Grosso (fig.8.1). Nos outros cinco casos foi utilizado um abrigo meteorológico simplificado com um psicrômetro estático para registrar temperatura de bulbo seco e de bulbo úmido, podendo-se assim extrair os valores de umidade do ar.

O Horto Florestal foi considerado como representativo das condições climáticas regionais, com pouquíssima intervenção urbana; nos mesmos horários foram feitas medições nos outros pontos da cidade, com condições de ocupação bastante diversas, já descritas qualitativa e quantitivamente ${ }^{2}$.

Para garantir uma certa uniformidade nas condições de medição em relação às estações de apoio e ao Horto Florestal, todos os abrigos foram locados sobre solo natural, em quintais de residências ou em estacionamento não pavimentado (fig.8.2). Os abrigos foram confeccionados em madeira, pintados de branco por dentro e por fora, com paredes duplas ventiladas, com a base a aproximadamente $1,5 \mathrm{~m}$ do chão e com os instrumentos sempre protegidos da radiação solar direta.

Foram utilizados termômetros meteorológicos de mercúrio para psicrômetro idênticos, da marca Incotherm, com precisão de $0,2^{\circ} \mathrm{C}$. De acordo com OKE (1987, p.362), existem pelos menos trinta instrumentos diferentes para medição de umidade, mas "the simple but well-tested approach of wet and dry-bulb psychrometry remains the most popular. The method consists of exposing two identical thermometers, one to measure the actual air temperature $\left(T_{a}\right)$ and the other (covered with a wetted wick) to measure the wet-bulb temperature which is lower than $T_{a}$ due to evaporative cooling."

\footnotetext{
${ }^{1}$ já descritas nos capítulos 2 e 5 .

2 ver capítulo 7 .
} 
As variáveis direção e velocidade de vento foram registradas na estação do INMET; as medições da UFMT não foram consideradas confiáveis por causa de problemas com o equipamento. Conforme justificado anteriormente ${ }^{3}$, não se mediu direção e velocidade de vento em todos os pontos em função da baixa velocidade na zona urbana; as medições não seriam muito precisas e nem significativas.

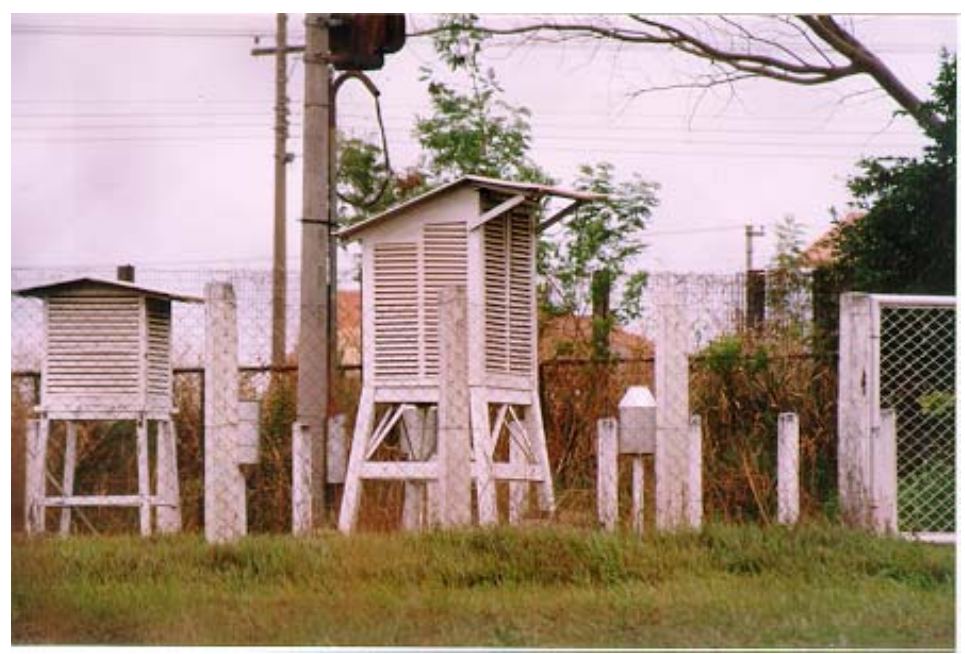

Figura 8.1 - Abrigo meteorológico padrão na Estação Climatológica Mestre Bombled, no campus da UFMT. (foto: D. Duarte)

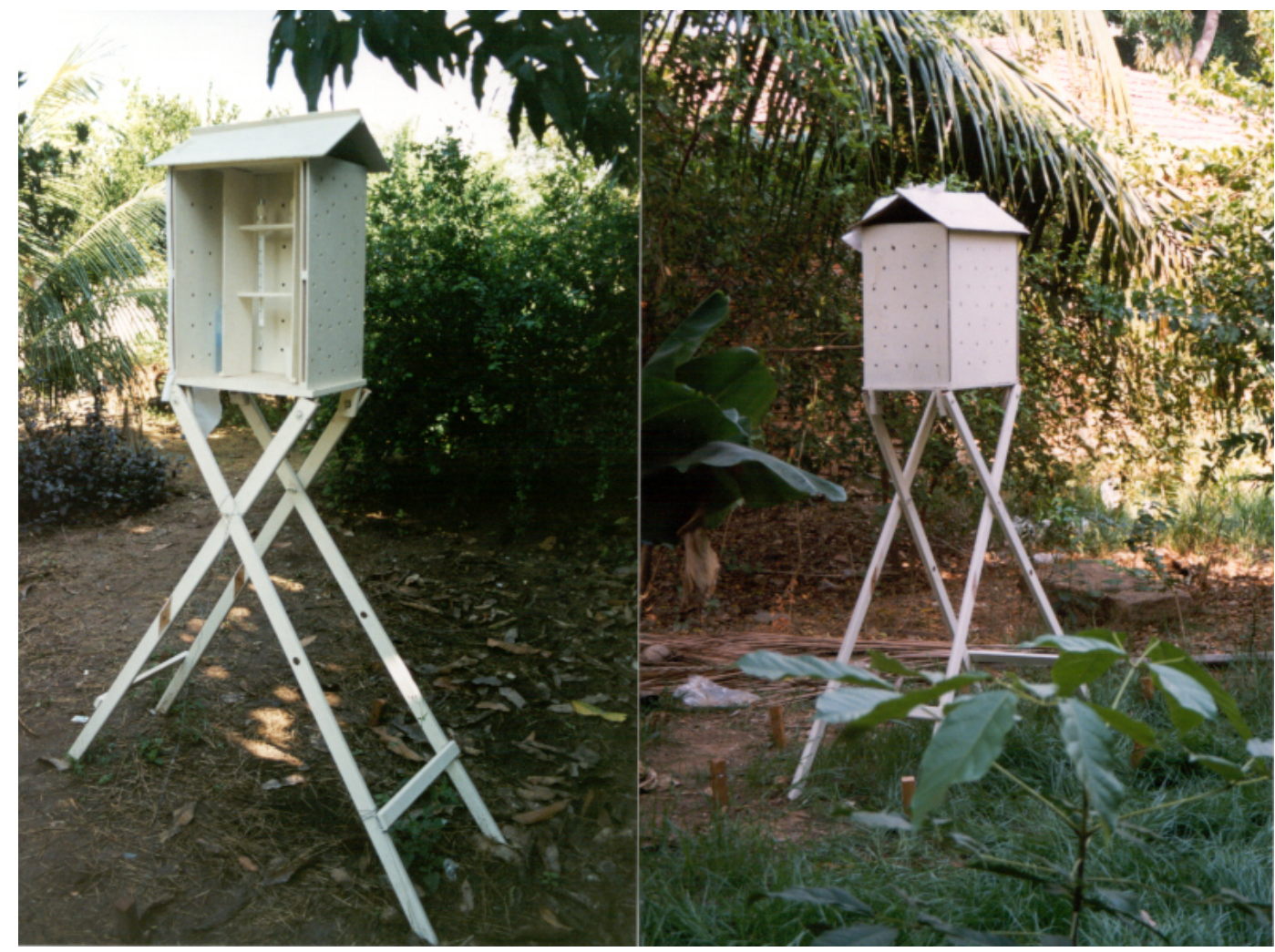

Figura 8.2 - Abrigo meteorológico simplificado utilizado para as medições. (foto: D. Duarte)

\footnotetext{
${ }^{3}$ ver capítulo 1.
} 
Também não se julgou significativa a correção das leituras em função da altitude devido à pequena diferença entre os postos de medição; de acordo com Prof. Pedro Dias, ${ }^{4}$ do Departamento de Ciências Atmosféricas do Instituto Astronômico e Geofísico da USP - IAG/USP, a correção em função da altitude faz sentido quando a topografia varia muito, e segundo a Prof. Gilda Maitelli, ${ }^{5}$ coordenadora do Laboratório de Climatologia da Universidade Federal de Mato Grosso - UFMT, essa correção seria mais adequada se as medidas fossem feitas bem acima da superfície; as diferenças de altitude não são significativas entre os pontos amostrados e a influência espaço construído supera possíveis variações. Teoricamente ocorre uma variação de $0,65^{\circ} \mathrm{C}$ para cada $100 \mathrm{~m}$ quando não há influência da superfície construída, o que não é o caso em medições de clima urbano. Em Cuiabá o relevo é suave e não há grandes diferenças de pressão atmosférica; considerando toda a zona urbana do município as altitudes variam de $150 \mathrm{~m}$ a 200m. Além disso não é eficaz isolar o efeito da altitude nesse tipo de medição porque, além desse, há outros fatores contribuindo para as condições microclimáticas, como a intensidade de tráfego e a poluição atmosférica. O efeito da altitude também não é isolado nas leituras termais das imagens de satélite.

\subsection{Variáveis microclimáticas medidas e calculadas}

O psicrômetro registra temperatura de bulbo seco (tbs) e temperatura de bulbo úmido (tbu). Para o cálculo da umidade absoluta foram utilizadas as seguintes equações (WMO, [s.d], OKE, 1987 e MONTEITH, 1990):

$\mathrm{U}_{\mathrm{abs}}=217 . \mathrm{e}_{\mathrm{ar}} / \mathrm{tbs} \quad \ldots \ldots \ldots \ldots . . . \mathrm{g} / \mathrm{m}^{3}$, onde:

obs: na eq. (1) a tbs é dada em graus Kelvin tbs $_{K}=$ tbs ${ }^{\circ} \mathrm{C}+273$

sendo $e_{a r}$ a pressão de vapor no ar dada pela equação

$\mathrm{e}_{\mathrm{ar}}=\mathrm{es}_{\mathrm{tbu}}-0,66(\mathrm{tbs}-\mathrm{tbu})$

sendo es a pressão saturante de vapor dado pela equação de Tetens

$\mathrm{es}_{\mathrm{tbu}}=6,1078 \times 10^{[7,5 \mathrm{xt} / 237,3+\mathrm{t}]}$

neste caso sendo t a temperatura de bulbo úmido

0,66 é a constante psicrométrica para pressão atmosférica de aproximadamente 1000 mbar e temperatura entre $20^{\circ} \mathrm{C}$ e $30^{\circ} \mathrm{C}$, bastante próximas às condições registradas em Cuiabá. Na estação do INMET a pressão média registrada no período de medições da estação seca foi de 995,48mbar, e na estação chuvosa de 991,38mbar.

Os valores de umidade absoluta calculados foram um pouco mais elevados do que o esperado devido à utilização do psicrômetro estático ao invés do psicrômetro de ventoinha, ou seja, a temperatura de bulbo úmido é influenciada apenas pela ventilação natural do lugar, que na maior parte do tempo é bastante baixa.

\footnotetext{
${ }^{4}$ informação verbal.

5 informação verbal.
} 
Para o cálculo da umidade relativa do ar:

$\mathrm{UR}=\mathrm{e}_{\mathrm{ar}} / \mathrm{es}_{\mathrm{tbs}} \mathrm{X} 100$

sendo $\mathrm{e}_{\mathrm{ar}}=\mathrm{es}_{\mathrm{tbu}}-0,66(\mathrm{tbs}-\mathrm{tbu})$

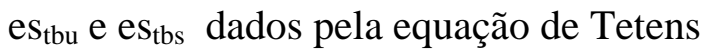

es $=6,1078 \times 10^{[7,5 \times \mathrm{t} / 237,3+\mathrm{t}]}$

sendo $\mathrm{t}$ a temperatura de bulbo úmido e bulbo seco, respectivamente.

\subsection{Estação seca}

Conforme descrito anteriormente, ${ }^{6}$ nos meses de inverno a região passa por uma estação quente e seca bem definida, com amplitude térmica diária por volta de $15^{\circ} \mathrm{C}$. Apesar das temperaturas mais baixas durante a noite e primeiras horas da manhã, altas temperaturas por volta dos $37^{\circ} \mathrm{C}$ são facilmente alcançadas à tarde, principalmente nas áreas centrais, densamente ocupadas e pavimentadas, com tráfego intenso, com pouca vegetação ou outro tipo de sombreamento significativo. As temperaturas máximas e mínimas absolutas registradas no posto do INMET durante o período de medições foram (tab.8.1):

Tabela 8.1 - Temperaturas mínimas e máximas absolutas registradas na estação do INMET.

\begin{tabular}{|c|l|l|}
\hline data da medição & $\mathbf{t ~ m i ́ n ~}{ }^{\mathbf{C}} \mathbf{C}$ & $\mathbf{t ~ m a ́ x ~}{ }^{\mathbf{}} \mathbf{C}$ \\
\hline $23 / 08$ & 19.3 & 31.6 \\
\hline $24 / 08$ & 18.4 & 35.4 \\
\hline $25 / 08$ & 18.4 & 37.2 \\
\hline $26 / 08$ & 17 & 27.3 \\
\hline $27 / 08$ & 14.8 & 26 \\
\hline $28 / 08$ & 14 & 31 \\
\hline
\end{tabular}

Tabela 8.2 - Direção e velocidade do vento registrados na estação do INMET durante a estação seca.

\begin{tabular}{|l|l|l|l|}
\hline dia & horário & direção & $\mathbf{v}(\mathbf{m} / \mathbf{s})$ \\
\hline $23 / 08$ & 8 & S & 1.6 \\
\hline & 14 & S & 1.6 \\
\hline & 20 & - & 0 \\
\hline $24 / 08$ & 8 & NW & 1.6 \\
\hline & 14 & SE & 2 \\
\hline & 20 & S & 0.8 \\
\hline $25 / 08$ & 8 & NW & 1.3 \\
\hline & 14 & SW & 1.6 \\
\hline & 20 & SE & 0.5 \\
\hline $26 / 08$ & 8 & N & 2.1 \\
\hline & 14 & W & 2 \\
\hline & 20 & W & 1.8 \\
\hline $27 / 08$ & 8 & S & 3.3 \\
\hline & 14 & SW & 2 \\
\hline & 20 & SW & 0.8 \\
\hline $28 / 08$ & 8 & NW & 1.6 \\
\hline & 14 & SE & 1.6 \\
\hline & 20 & SE & 1 \\
\hline
\end{tabular}

\footnotetext{
${ }^{6}$ ver capítulo 5 e anexo 1.
} 
Durante o período de medições na estação seca houve uma invasão de massa polar (fig. 8.3 e 8.4) que durou dois dias, provocando queda de temperatura e aumento da umidade do ar. Esse fenômeno conhecido regionalmente como friagem é comum nessa época do ano, apesar de que em alguns anos não ocorre sequer uma invasão. Apesar da frente fria, considerando os seis dias, a temperatura média às $14 \mathrm{~h}$ ficou por volta dos $30^{\circ} \mathrm{C}$ em todos os postos. A tabela 8.2 mostra os valores de direção e velocidade de vento registradas no INMET. As direções S, SE e SW anunciam a chegada da frente fria; em condições normais a direção predominante é N e NW.

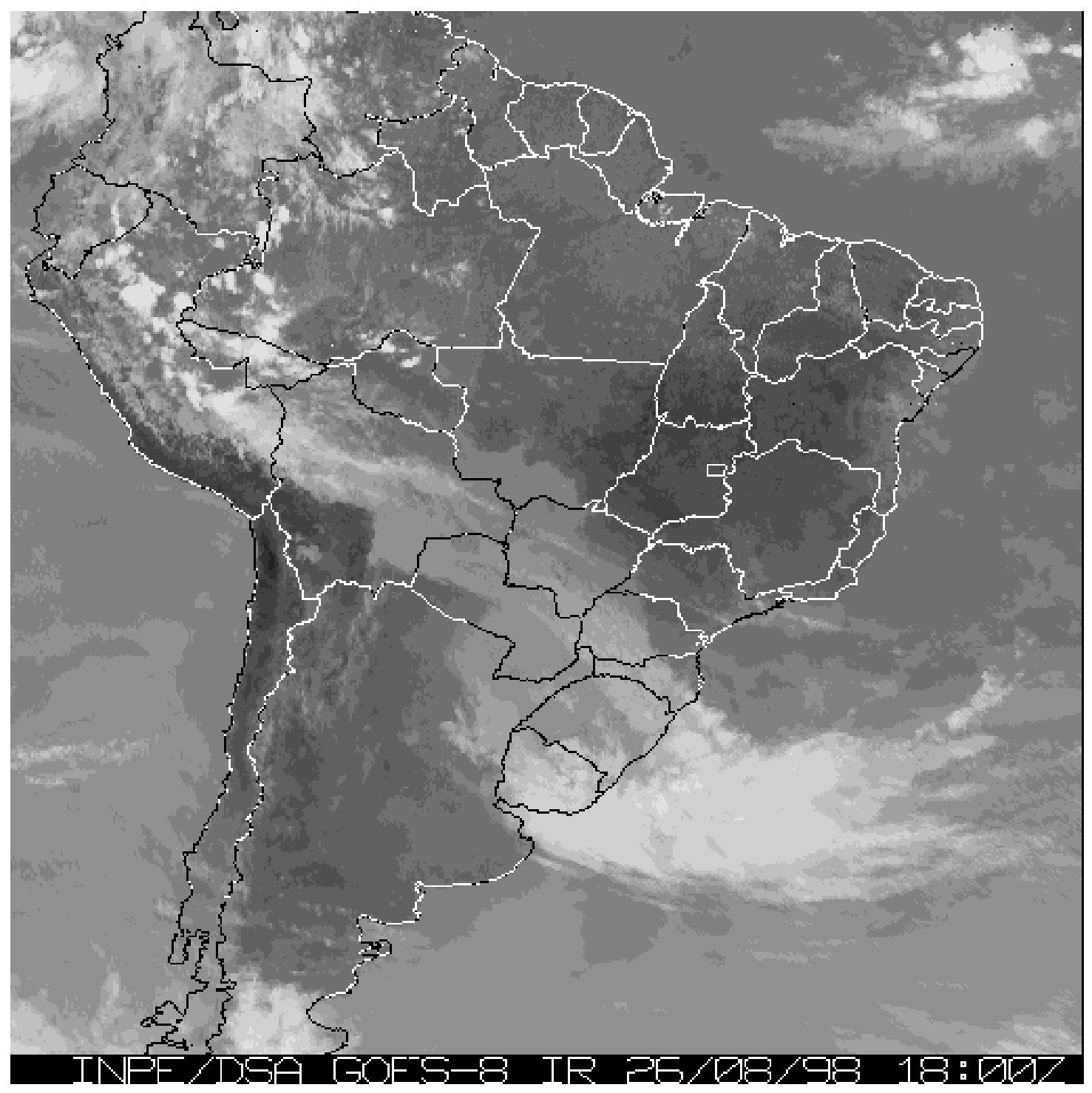

Figura 8.3 - Imagem do satélite GOES-8 às 15h (horário de Brasília) do dia 26/08/1998, mostrando a chegada da frente fria. (fonte: imagem cedida pelo Laboratório de Meteorologia Aplicada a Sistemas Regionais - MASTER, do IAG/USP) 


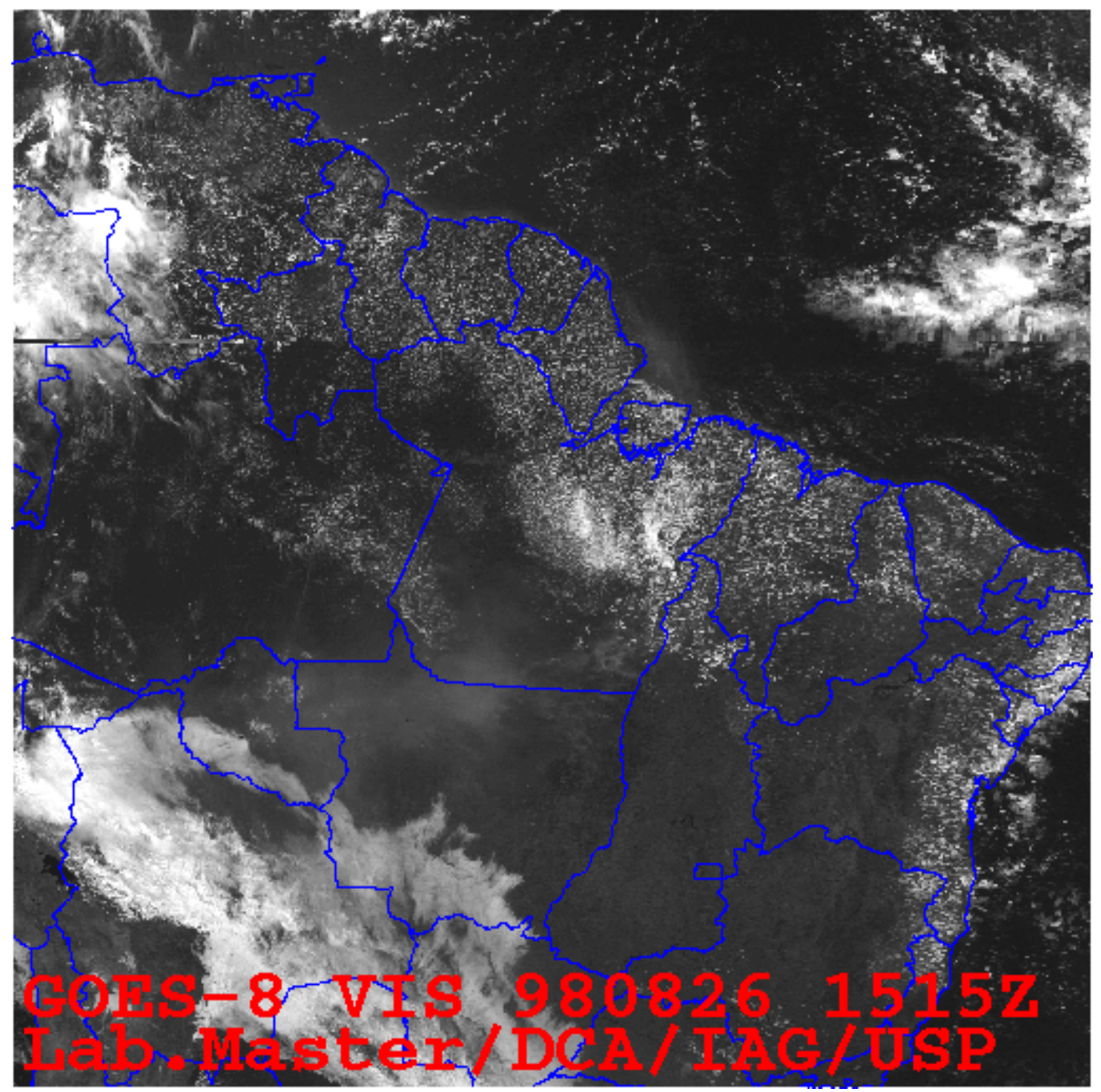

Figura 8.4 - Imagem do satélite GOES-8 às 12 h15 (horário de Brasília) do dia 26/08/1998 mostrando a frente fria sobre a região de Cuiabá. (fonte: imagem cedida pelo Laboratório de Meteorologia Aplicada a Sistemas Regionais - MASTER, do IAG/USP)

Seguem os resultados e a descrição das condições sinóticas em cada dia de medição. No primeiro dia, em 23/08/1998, foram feitas as leituras de hora em hora, dos 8 h às 20h; dos sete postos apenas o INMET registra somente em três horários. Nos cinco dias subsequentes foram feitas leituras às $8 \mathrm{~h}, 14 \mathrm{~h}$ e $20 \mathrm{~h}$ em todos os postos. São apresentados gráficos da temperatura de bulbo seco - tbs, umidade relativa do ar UR e umidade absoluta - $\mathrm{U}_{\text {abs. }}$ Em conjunto com a temperatura de bulbo seco, os valores de umidade relativa do ar são mais adequados para uma análise das condições de conforto higrotérmico humano e, para os processos físicos, torna-se mais adequada uma análise com os valores de umidade absoluta do ar. 
23/08/1998 - garoa durante a madrugada e início da manhã, antes das medições; pouco depois, céu claro com sol o dia todo.

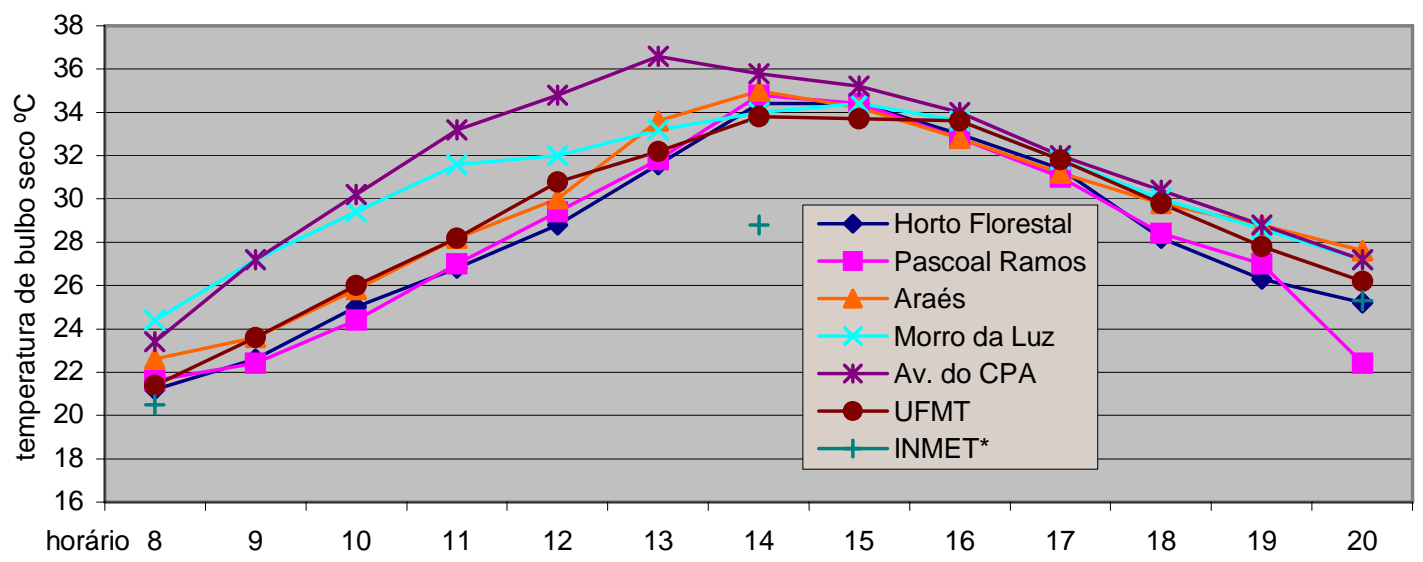

Figura 8.5 - Temperatura de bulbo seco em 23/08/98, com medições horárias das 8h às 20h.

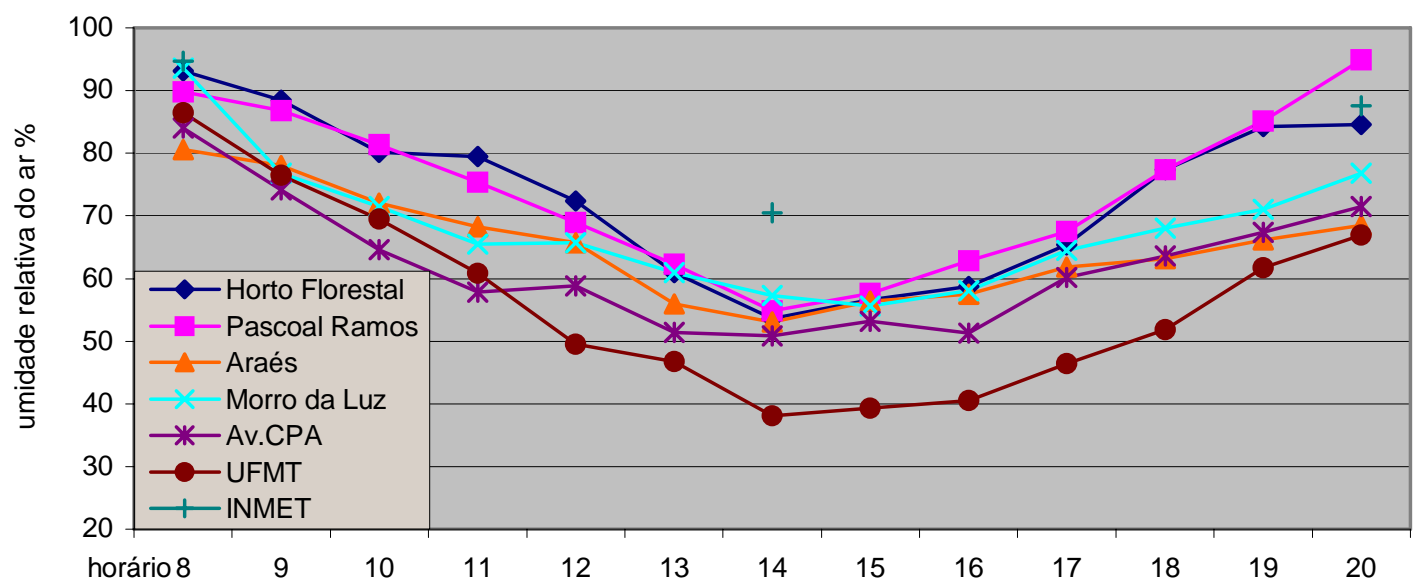

Figura 8.6 - Umidade relativa do ar em 23/08/98, com medições horárias das 8h às 20h.

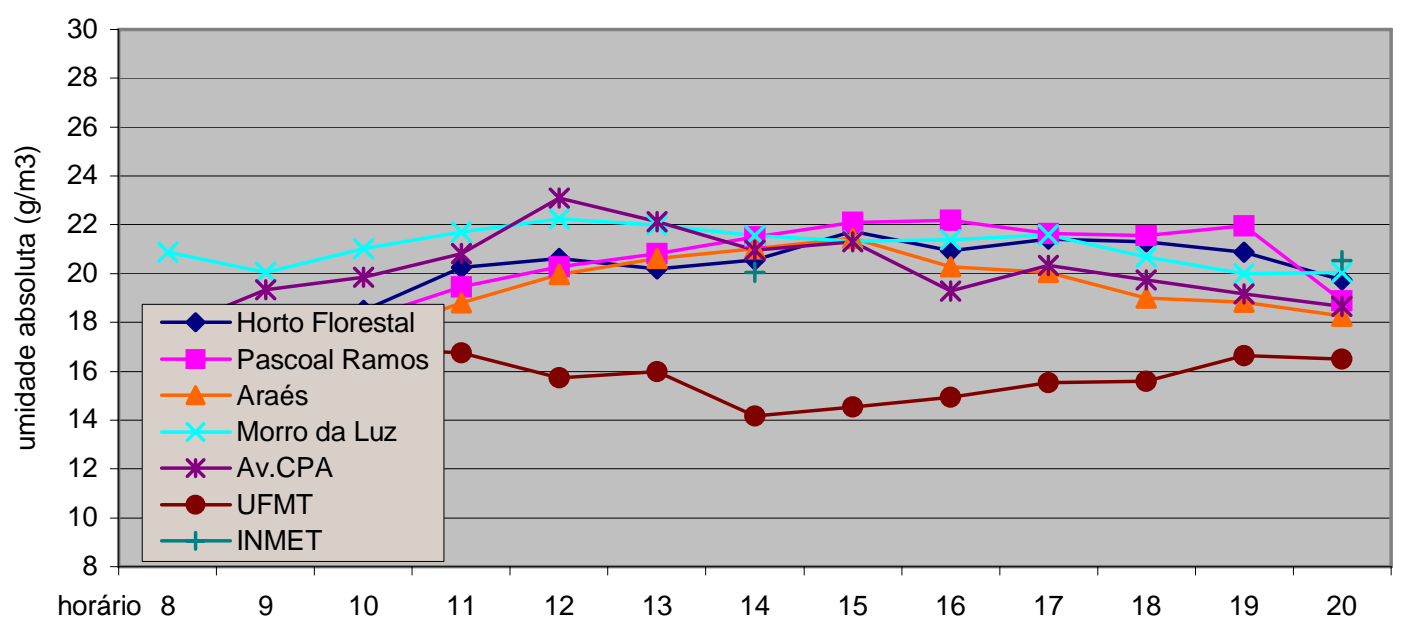

Figura 8.7 - Umidade absoluta do ar em 23/08/98, com medições horárias das 8h às 20h. 
24/08/1998 - temperatura bem mais amena durante a madrugada; depois tempo bom, com céu parcialmente nublado o dia todo; muita poeira no ar durante à tarde.

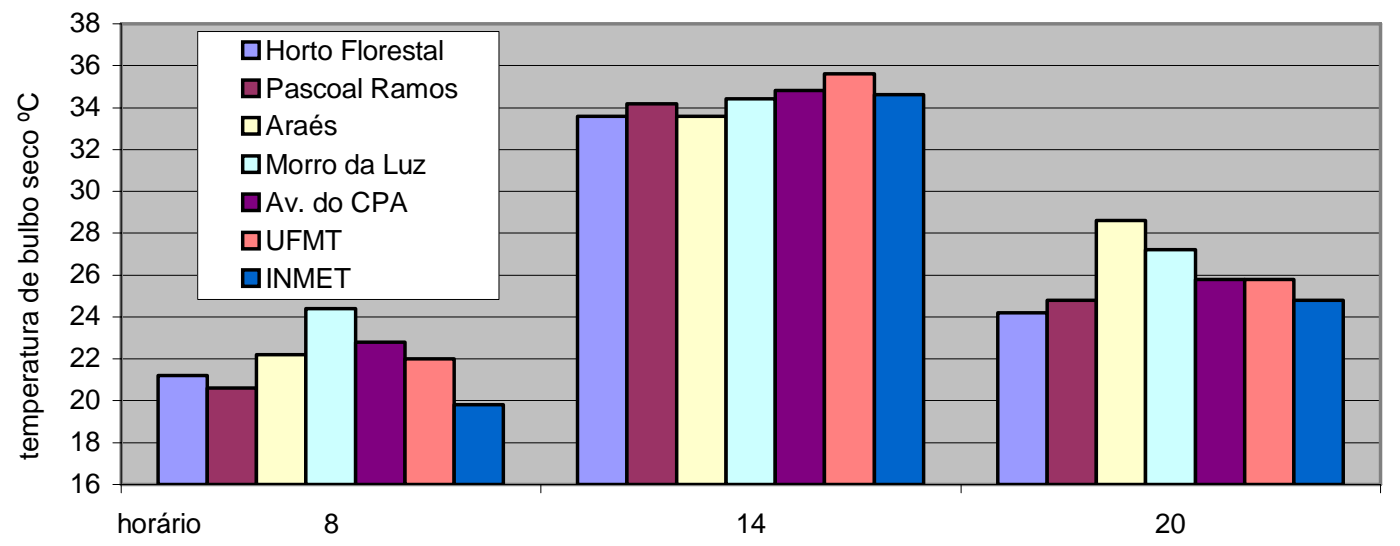

Figura 8.8 - Temperatura de bulbo seco em 24/08/98, com leituras às 8h, 14h e 20h.

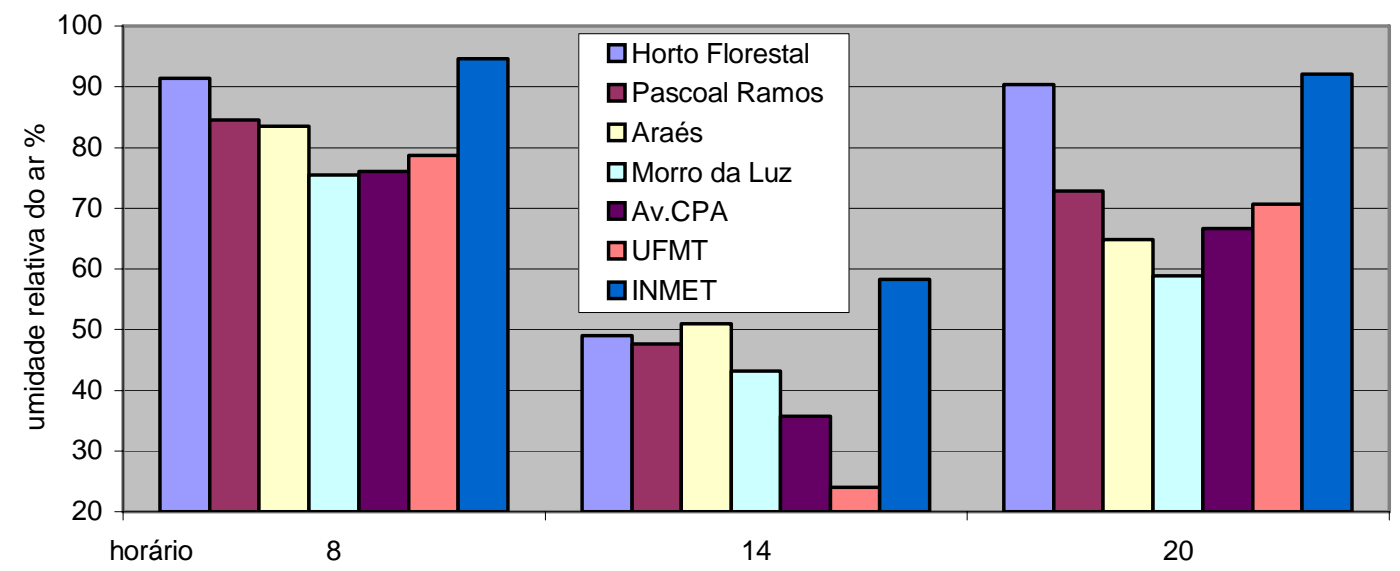

Figura 8.9 - Umidade relativa do ar em 24/08/98, com medições às 8h, 14h e 20h.

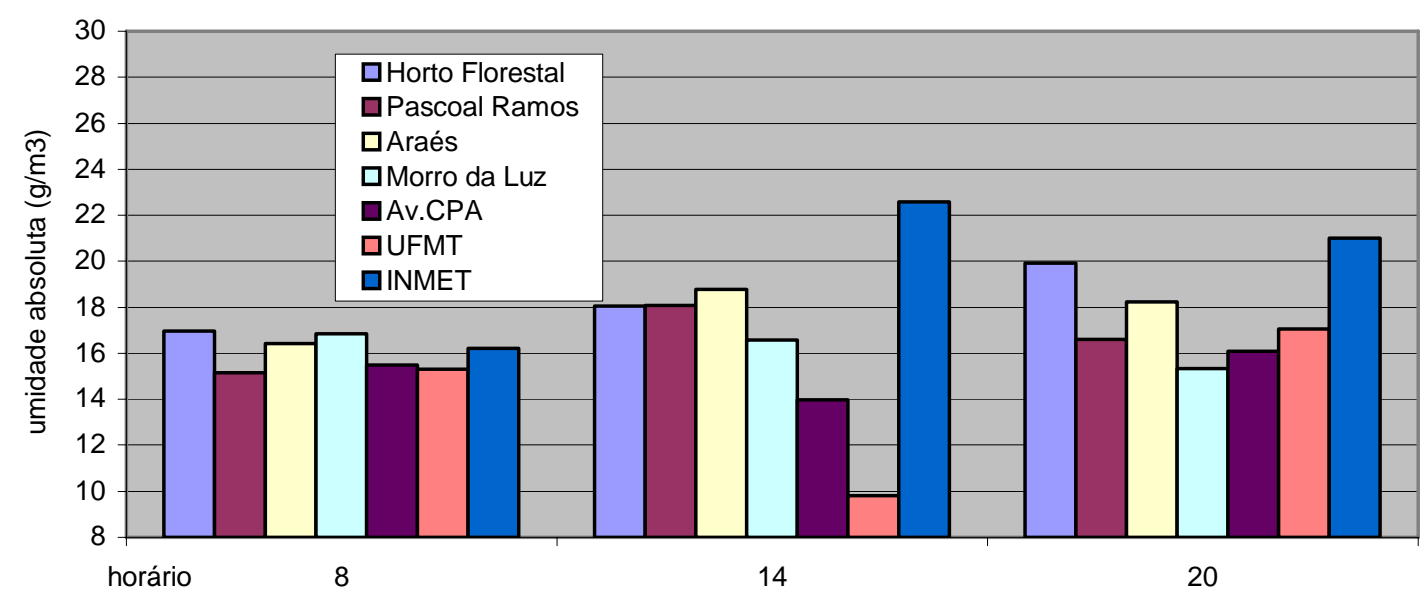

Figura 8.10 - Umidade absoluta do ar em 24/08/98, com medições às 8h, 14h e 20h. 
25/08/1998 - tempo bom, parcialmente nublado; dia mais quente deste período de medições, típico da estação quente e seca, com altas temperaturas no período da tarde.

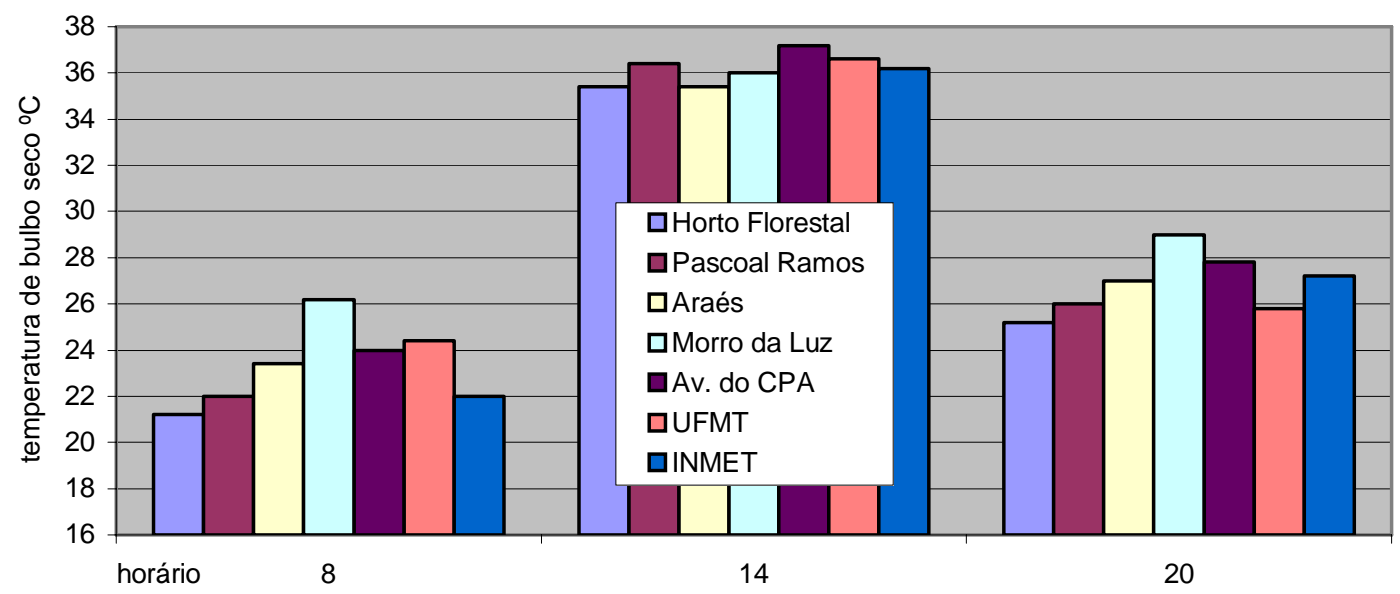

Figura 8.11 - Temperatura de bulbo seco em 25/08/98, um dia típico da estação quente e seca dentro do período de medições, com leituras às $8 \mathrm{~h}, 14 \mathrm{~h}$ e $20 \mathrm{~h}$.

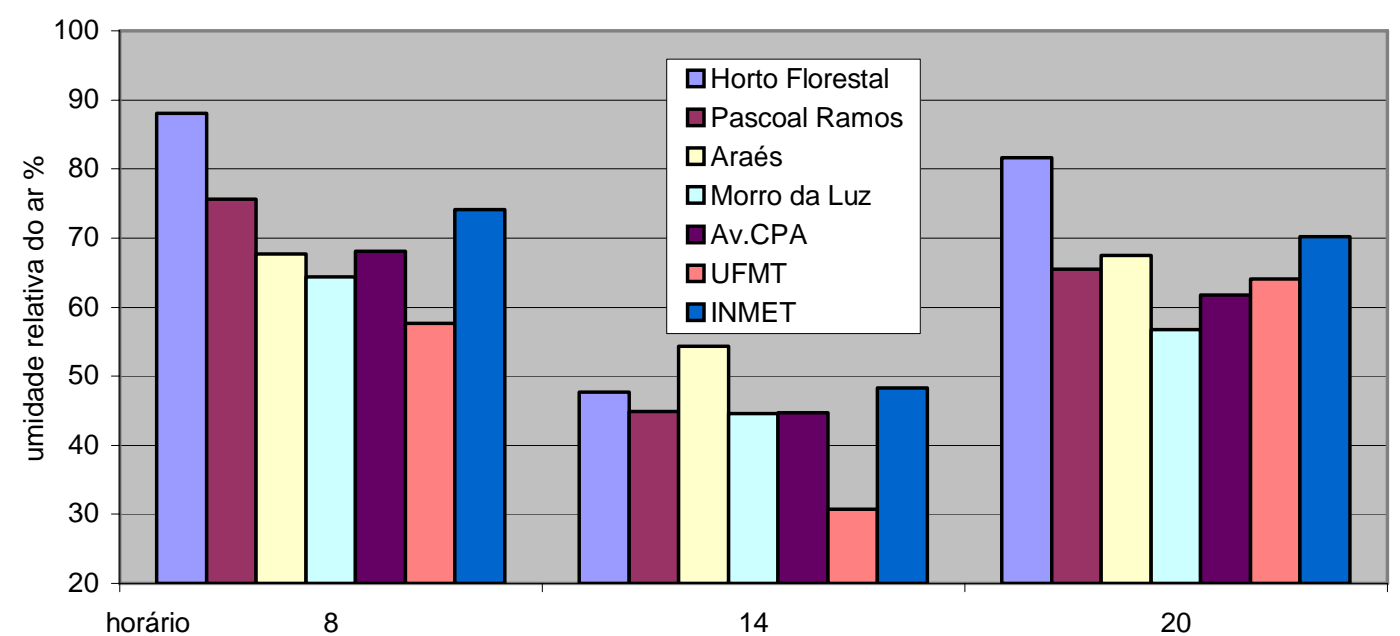

Figura 8.12 - Umidade relativa do ar em 25/08/98, com medições às 8h, 14h e 20h.

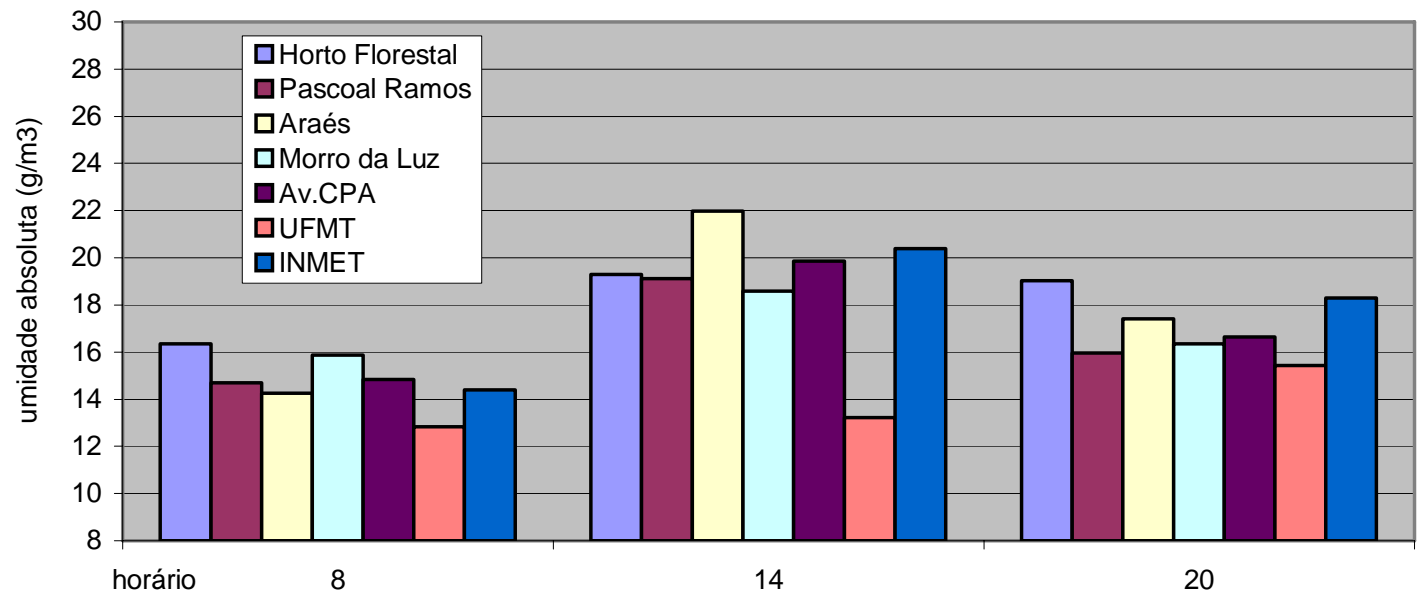

Figura 8.13 - Umidade absoluta do ar em 25/08/98, com medições às 8h, 14h e 20h. 
26/08/1998 - chegada de frente fria com garoa durante a madrugada; pela manhã a temperatura continua caindo; o ar fica muito mais úmido, com vento e neblina.

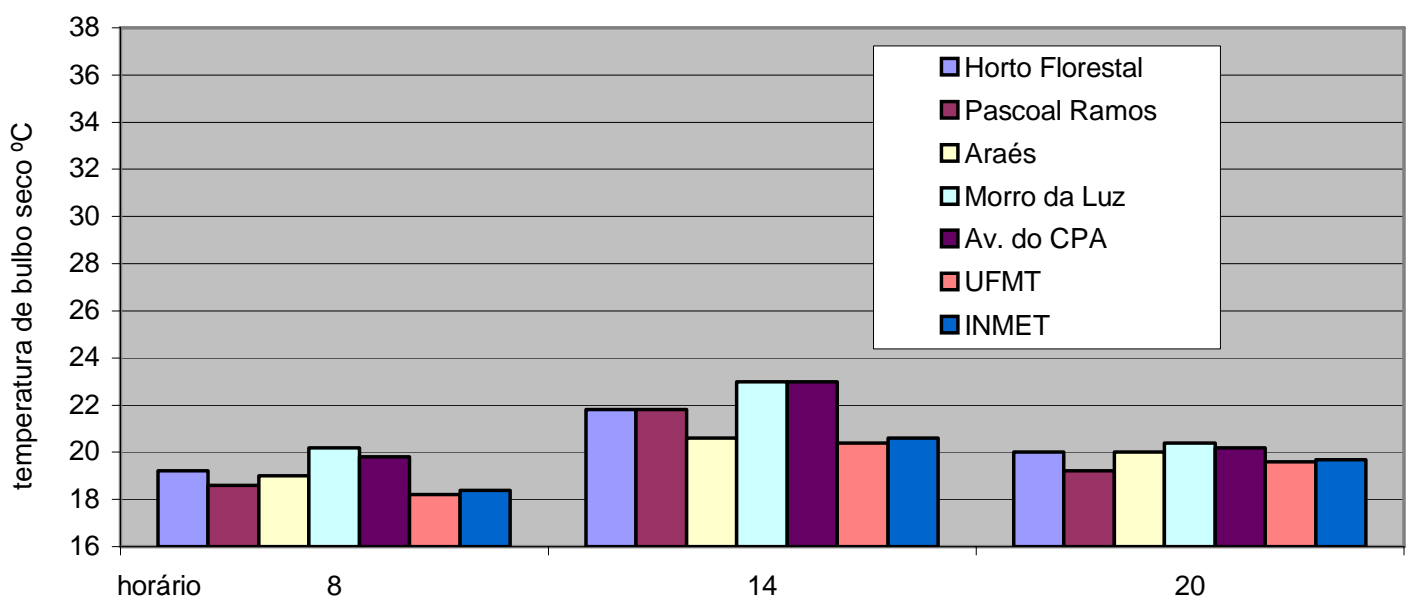

Figura 8.14 - Temperatura de bulbo seco em 26/08/98, no primeiro dia da frente fria, com leituras às $8 \mathrm{~h}, 14 \mathrm{~h}$ e $20 \mathrm{~h}$.

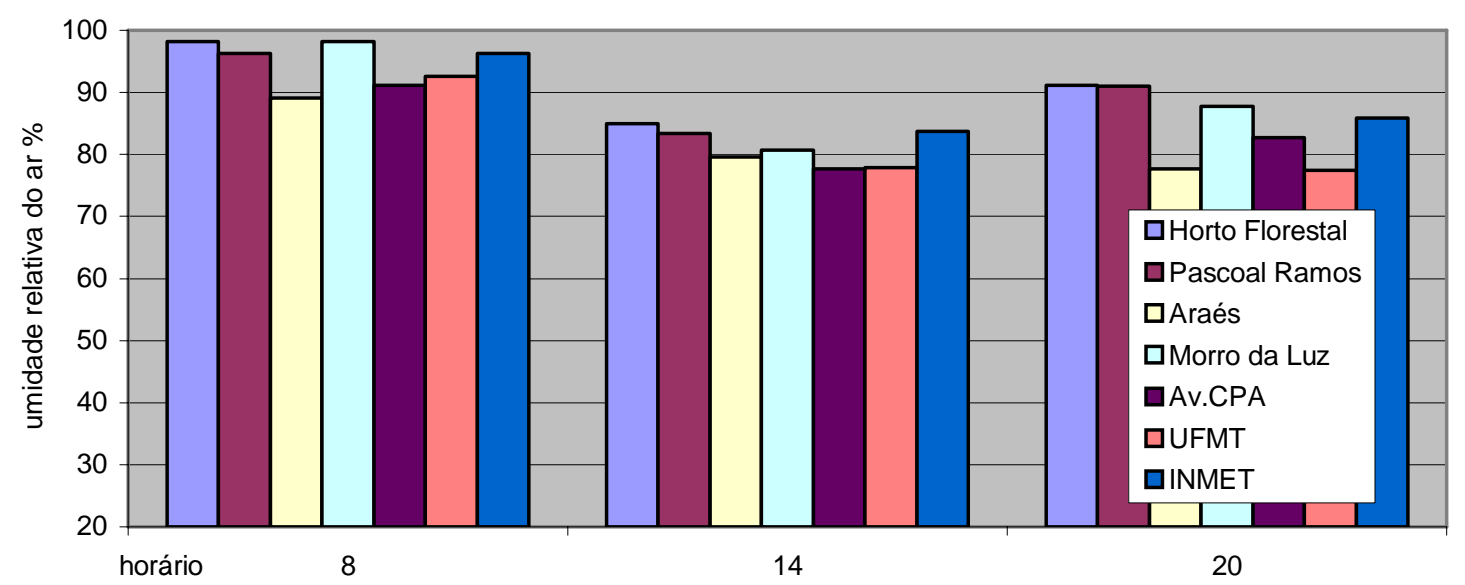

Figura 8.15 - Umidade relativa do ar em 26/08/98, com medições às 8h, 14h e 20h.

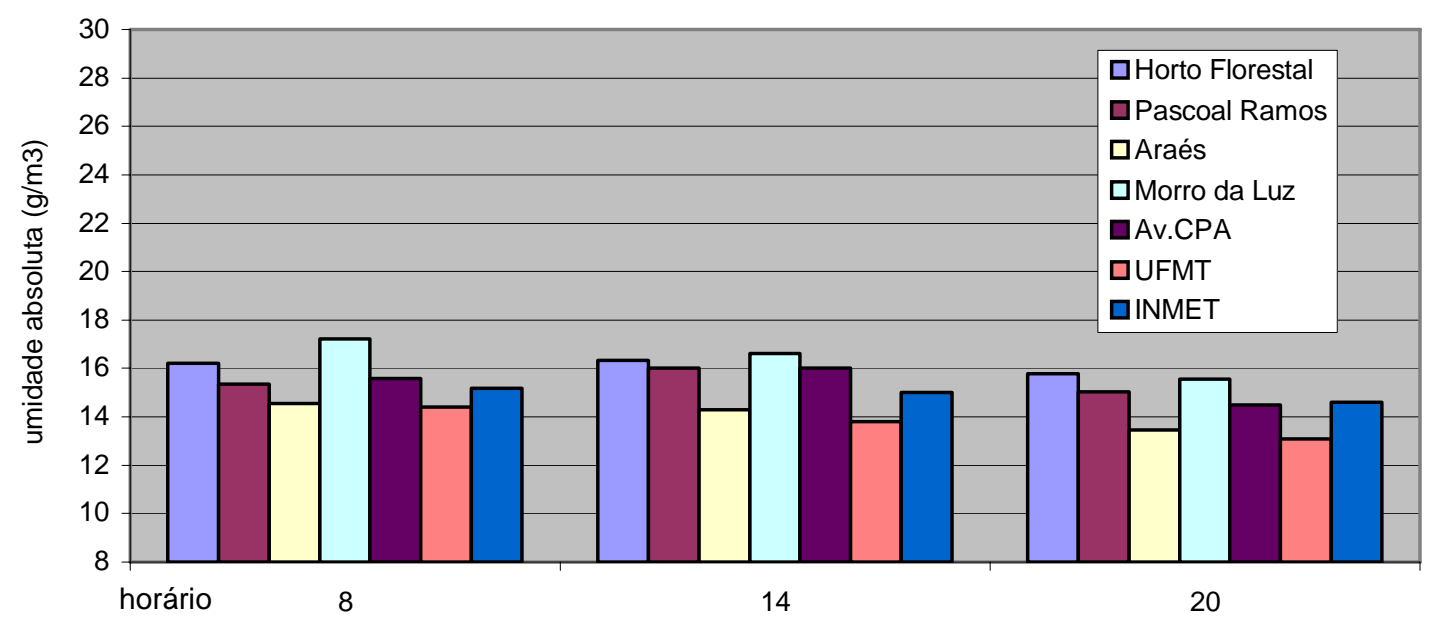

Figura 8.16 - Umidade absoluta do ar em 26/08/98, com medições às 8h, 14h e 20h. 
27/08/1998 - pela manhã foram registradas as temperaturas mais baixas neste período de medições; o dia amanhece com céu nublado e vento; por volta das $11 \mathrm{~h}$ céu claro com sol e calor no período da tarde; à noite, a temperatura voltou a cair.

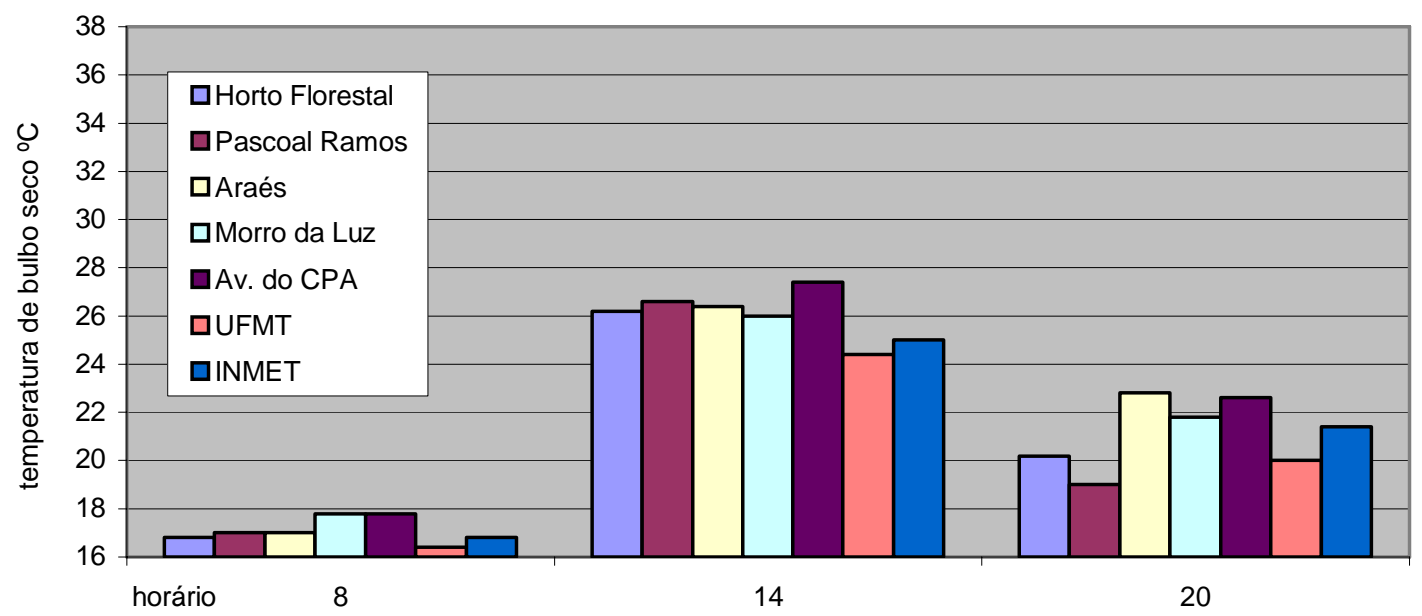

Figura 8.17 - Temperatura de bulbo seco em 27/08/98, no segundo dia da frente fria, com leituras às $8 \mathrm{~h}, 14 \mathrm{~h}$ e $20 \mathrm{~h}$.

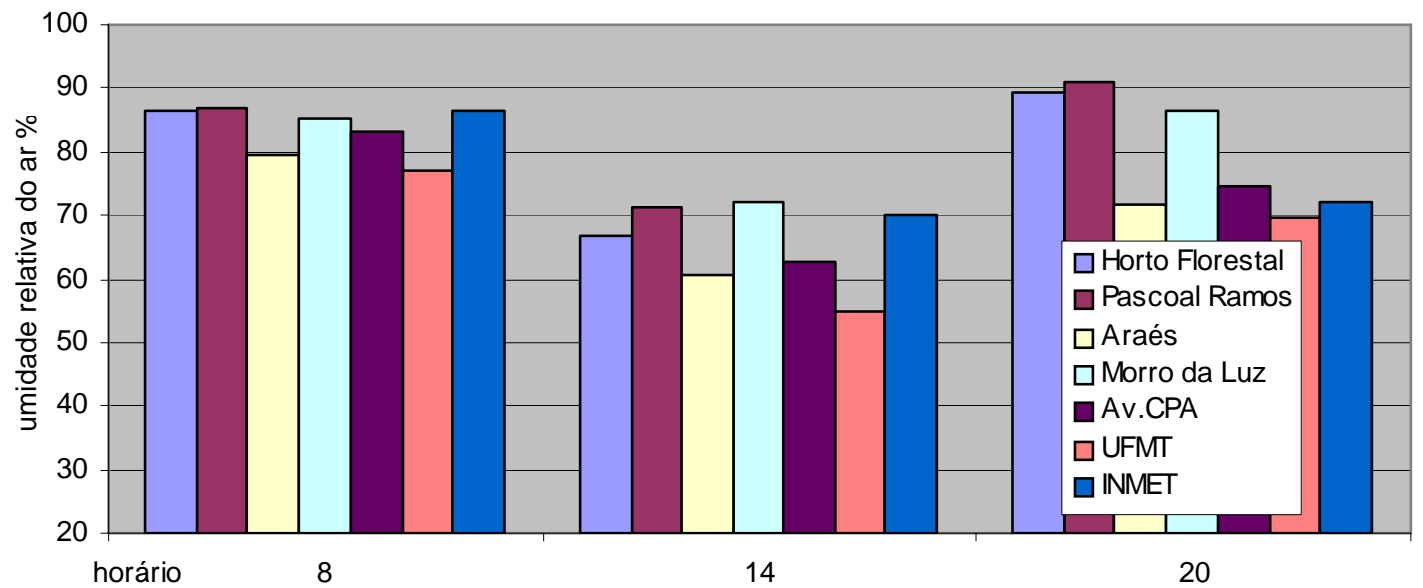

Figura 8.18 - Umidade relativa do ar em 27/08/98, com medições às 8h, 14h e 20h.

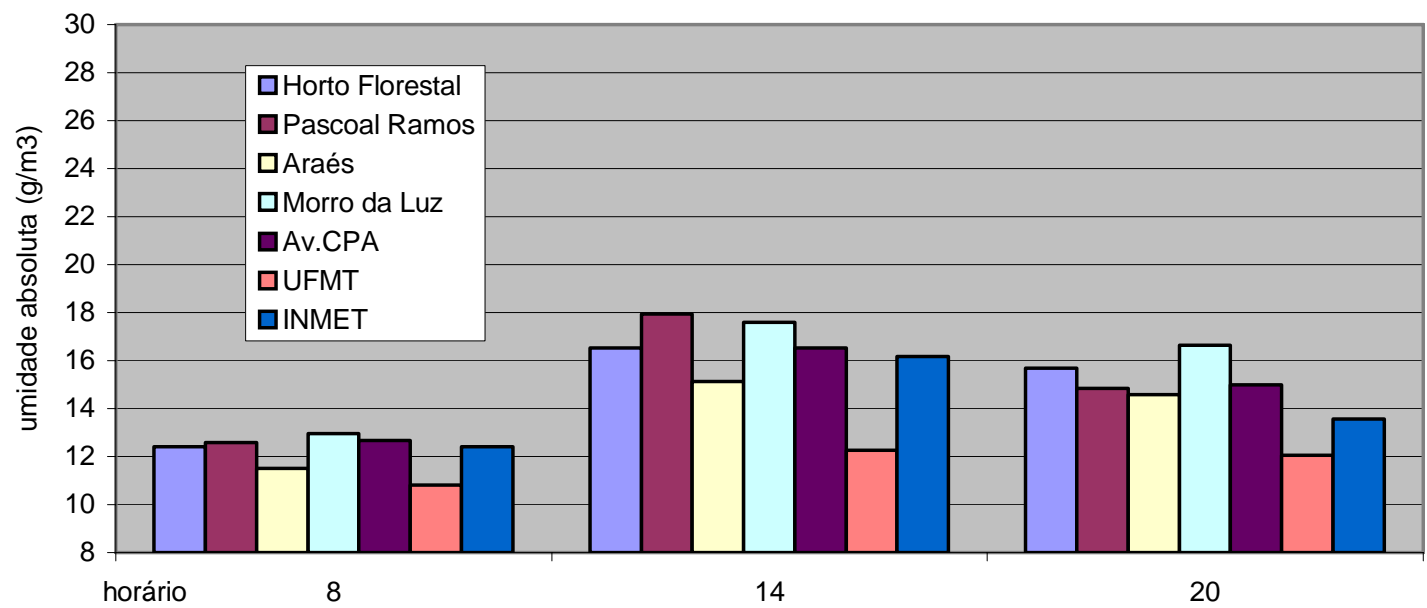

Figura 8.19 - Umidade absoluta do ar em 27/08/98, com medições às 8h, 14h e 20 h. 
28/08/1998 - diminui a intensidade da frente fria; às 8h da manhã já com céu aberto; tempo bom o dia todo; a temperatura volta a subir.

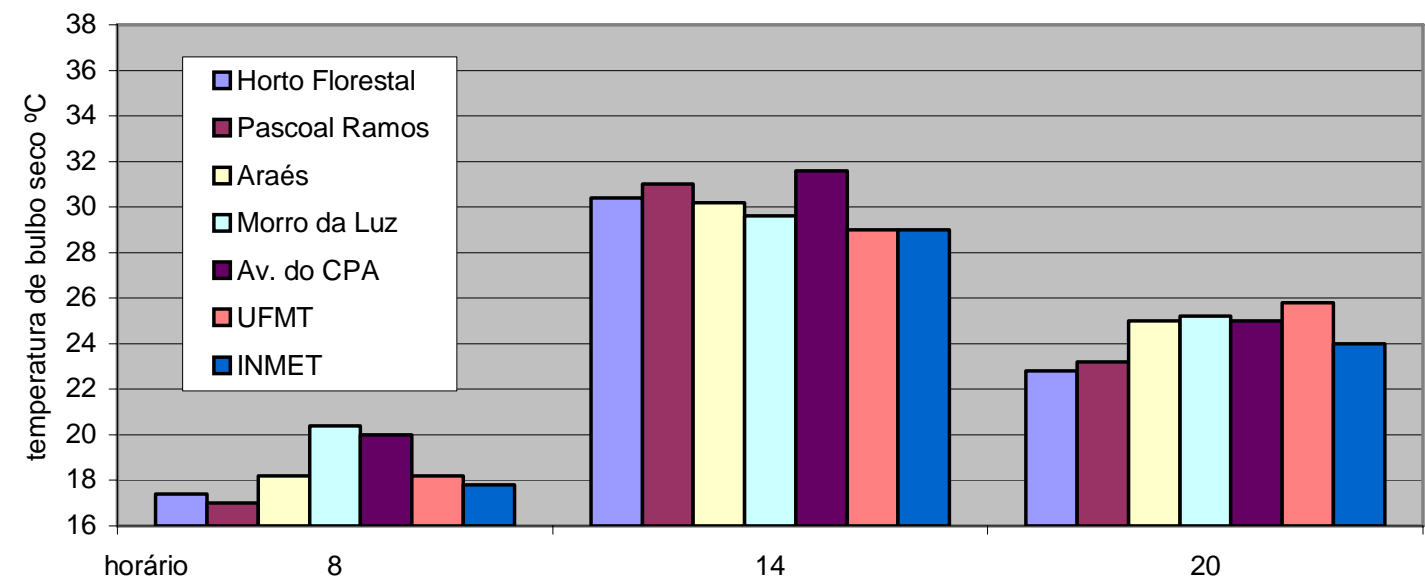

Figura 8.20 - Temperatura de bulbo seco em 28/08/98, saindo da frente fria, com leituras às $8 \mathrm{~h}, 14 \mathrm{~h}$ e 20h.

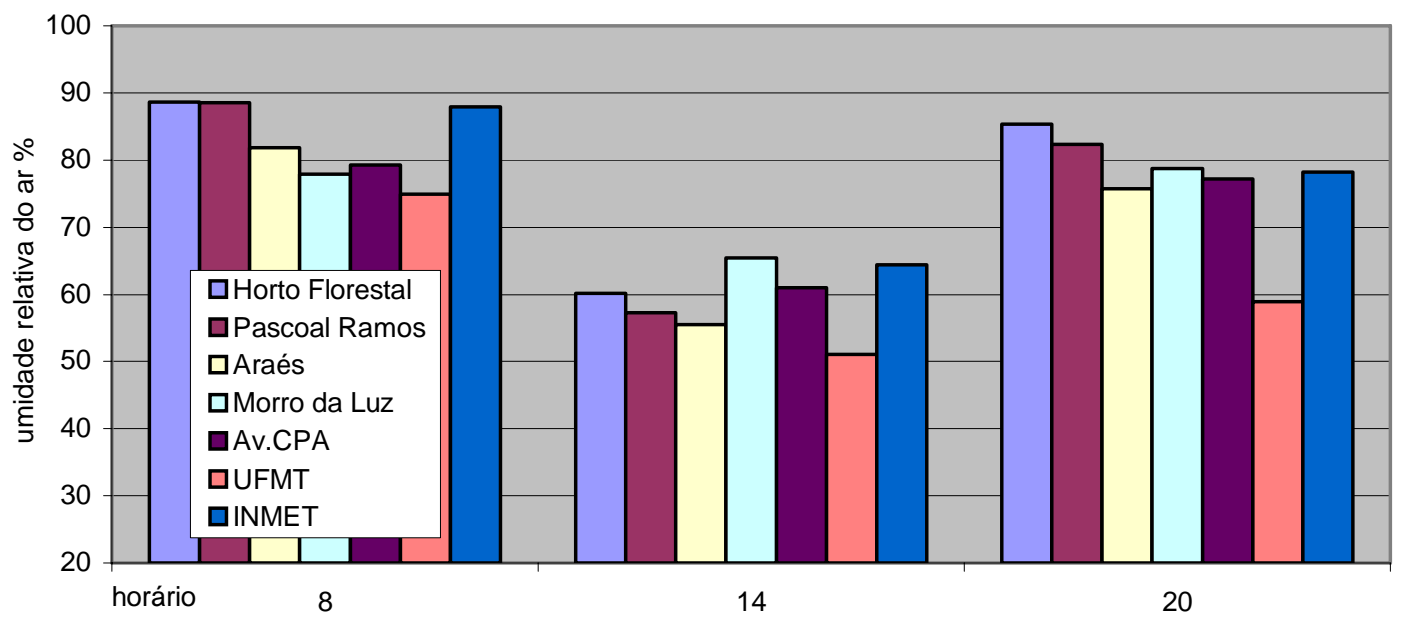

Figura 8.21 - Umidade relativa do ar em 28/08/98, com medições às 8h, 14h e 20h.

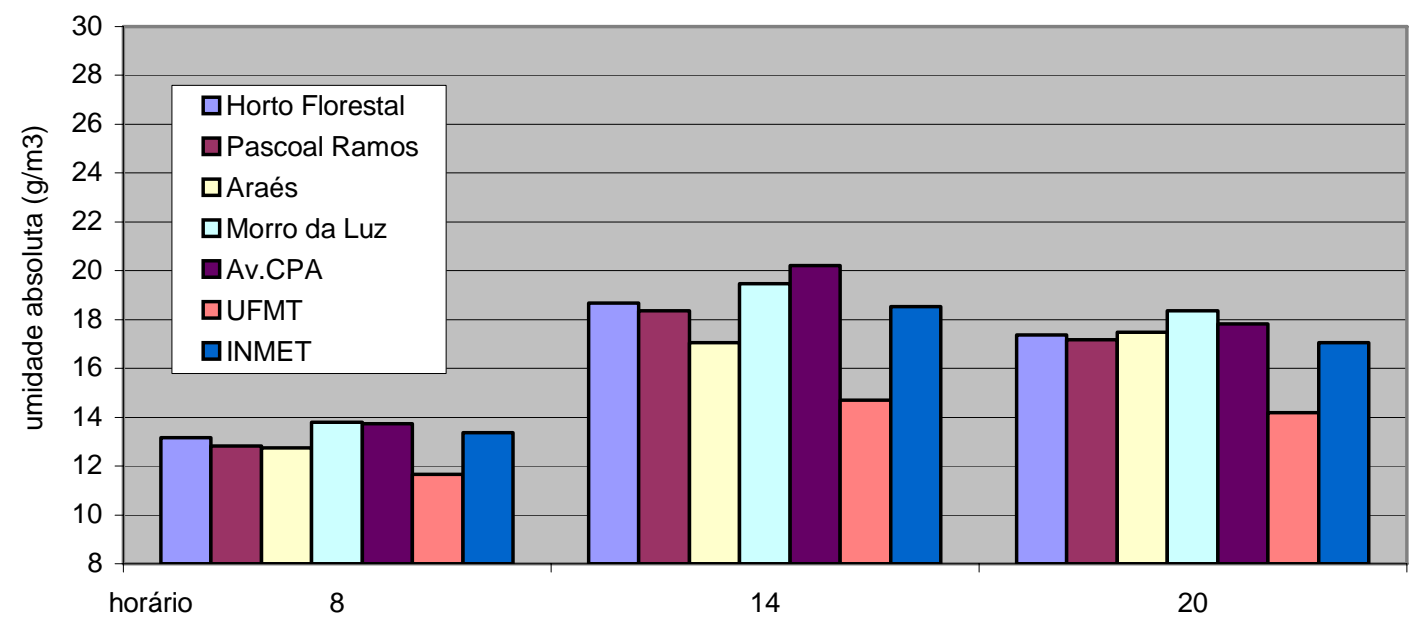

Figura 8.22 - Umidade absoluta do ar em 28/08/98, com medições às 8h, 14h e 20h. 


\subsubsection{Análise dos dados e observações pertinentes}

Analisando o conjunto de resultados verifica-se que, nas condições microclimáticas medidas, a variável temperatura do ar é dominante, e não a umidade; esta se mantém mais ou menos constante em termos absolutos, caindo apenas no caso do campus da UFMT por fatores que são explicados a seguir.

Apesar da frente fria foram registradas altas temperaturas no período da tarde. Como se pode observar nas figuras anteriores foram encontradas diferenças absolutas de temperatura de mais de $6^{\circ} \mathrm{C}$ entre os postos, em determinados horários. Nas leituras das 14h, de uma maneira geral e principalmente na situação pós-frontal, os contrastes de temperatura entre os postos diminuem, pois à tarde há mais vento e turbulência na atmosfera. A figura 8.23 mostra as temperaturas médias dos seis dias de medição por faixa de horário.

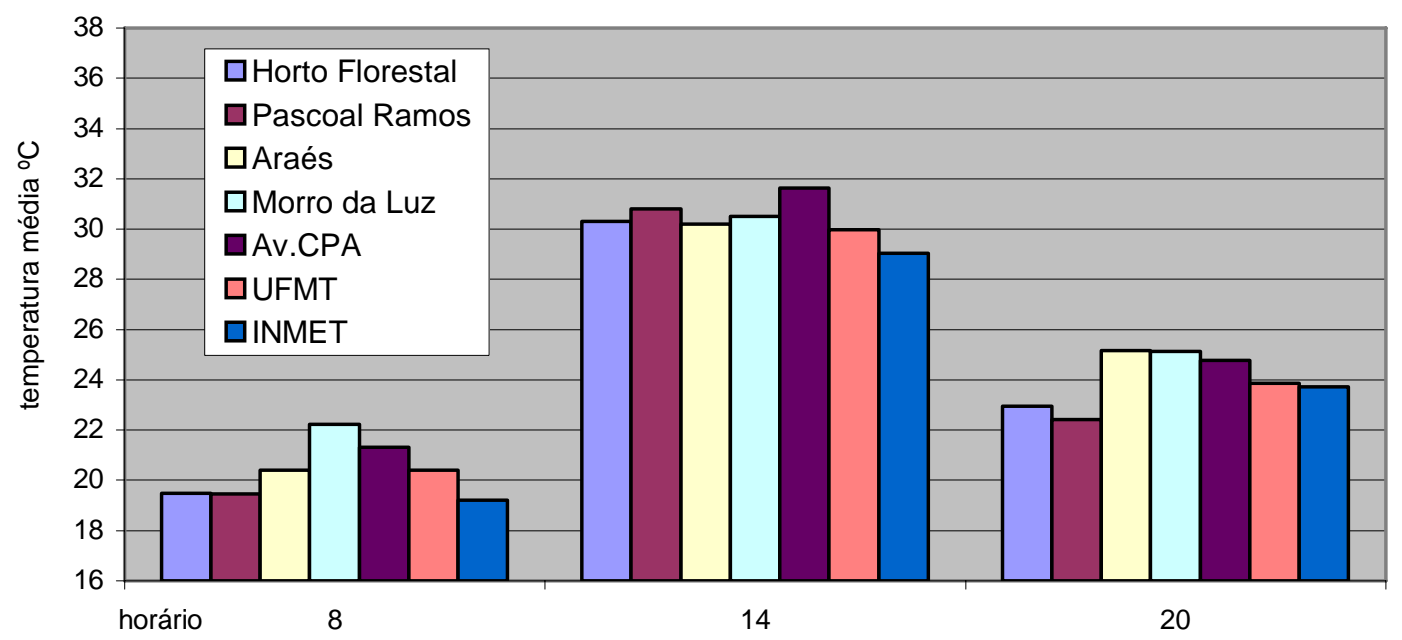

Figura 8.23 - Temperatura média dos seis dias, por faixa de horário, na estação seca.

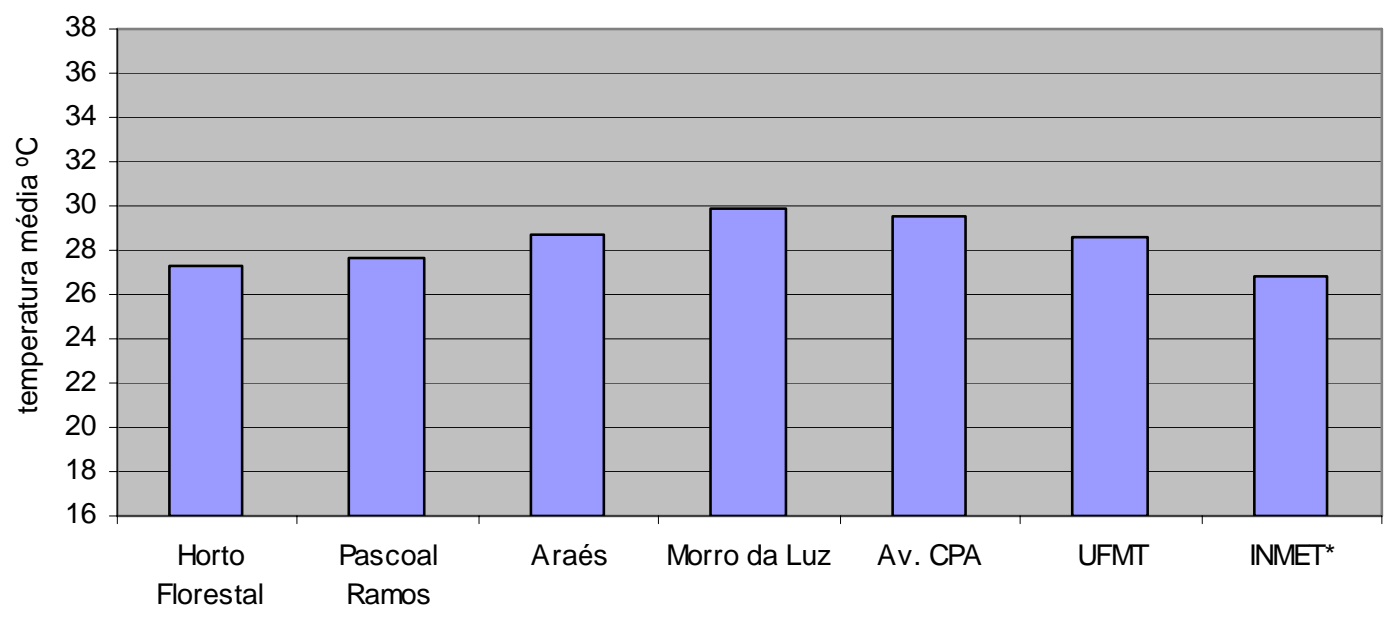

Figura 8.24 - Média das temperaturas registradas por posto nos seis dias de medição.

A figura 8.24 mostra a média aritmética das temperaturas registradas por posto durante os seis dias de medições. Assim pode-se classificar as áreas da mais quente 
para a mais amena: Morro da Luz, Av. CPA, Araés, UFMT, Pascoal Ramos, Horto Florestal e INMET. A tabela 8.3 mostra a temperatura média, a classificação dos postos e a variação percentual da temperatura média de cada posto na escala Celsius em relação ao posto de maior temperatura média, que neste caso foi o Morro da Luz.

Tabela 8.3 - Temperatura média do dia, classificação dos postos e variação percentual da temperatura na escala Celsius em relação ao posto de maior temperatura média.

\begin{tabular}{|c|c|c|c|c|c|c|c|c|c|}
\hline \multirow[b]{2}{*}{ POSTOS } & \multicolumn{6}{|c|}{$t_{\text {média }}$ do dia } & \multirow{2}{*}{$\begin{array}{l}t_{\text {média }} \\
6 \text { dias }\end{array}$} & \multirow{2}{*}{$\begin{array}{l}\text { classif. } \\
\text { postos }\end{array}$} & \multirow{2}{*}{$\begin{array}{l}\text { var.\% em } \\
\text { relação ao } \\
\text { Morro da } \\
\text { Luz }\end{array}$} \\
\hline & 23/ago & 24/ago & 25/ago & 26/ago & 27/ago & 28/ago & & & \\
\hline Horto Florestal & 28,4 & 26,3 & 27,3 & 27,3 & 27,0 & 27,2 & 27,2 & 6 & 9,59 \\
\hline Pascoal Ramos & 28,3 & 26,5 & 28,1 & 27,6 & 27,4 & 27,7 & 27,6 & 5 & 8,08 \\
\hline Araés & 29,5 & 28,1 & 28,6 & 28,7 & 28,5 & 28,6 & 28,7 & 3 & 4,12 \\
\hline Morro da Luz & 30,6 & 28,7 & 30,4 & 29,9 & 29,6 & 30,0 & 29,9 & 1 & 0 \\
\hline Av. CPA & 31,4 & 27,8 & 29,7 & 29,6 & 29,0 & 29,4 & 29,5 & 2 & 1,19 \\
\hline UFMT & 29,1 & 27,8 & 28,9 & 28,6 & 28,5 & 28,7 & 28,6 & 4 & 4,37 \\
\hline INMET & 24,9 & 26,4 & 28,5 & 26,6 & 27,1 & 27,4 & 26,8 & 7 & 11,37 \\
\hline
\end{tabular}

Conforme esperado, nas três áreas próximas ao centro (Morro da Luz, Av. CPA e Araés) foram encontradas as temperaturas mais altas, o que concorda com as medições feitas por MAITELLI (1994) ${ }^{7}$. Dentre estas três áreas as condições mais amenas foram encontradas no Araés. Apesar da proximidade com o centro antigo e com a Av. do CPA o bairro tem uma ocupação peculiar, com uma densa e exuberante vegetação nos quintais que proporciona umidificação e sombreamento e contribui para a criação de um microclima diferenciado, além de receber bem menos tráfego do que o centro antigo e o CPA. No Araés, como boa parte do solo está sombreado pela vegetação, era de se esperar que as temperaturas fossem menores. O ar é transparente à radiação solar, e ele se aquece porque o solo se aquece. Os contrastes foram mais acentuados no período da manhã, como fica claro pelos resultados medidos hora a hora no dia 23/08/98 (fig.8.25).

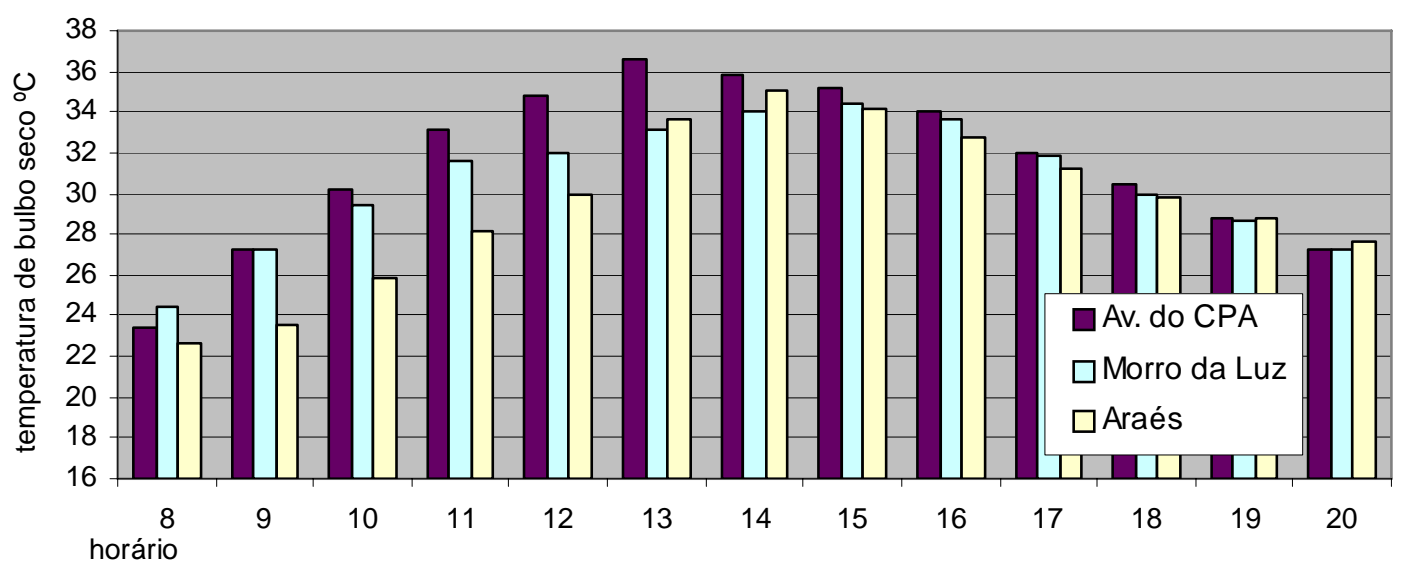

Figura 8.25 - Temperatura de bulbo seco em 23/08/98 nas três estações próximas ao centro.

\footnotetext{
${ }^{7}$ ver configuração da ilha de calor registrada por Maitelli (1994) na figura 5.11.
} 
As três áreas mais amenas (Pascoal Ramos, Horto Florestal e INMET) são mais afastadas do centro da cidade, têm grande quantidade de vegetação, e ausência quase total de áreas pavimentadas, sendo o Horto e o INMET próximos aos rios Coxipó e Cuiabá, respectivamente, e cercados por mata de galeria.

Em relação à umidade do ar foram encontradas diferenças absolutas de até $12 \mathrm{~g} / \mathrm{m}^{3}$ em determinados horários entre os postos. O campus da UFMT se apresentou bastante árido se comparado aos demais, mas com um desvio consistente em relação aos outros postos. No campus são muitas as áreas pavimentadas e, apesar da grande quantidade de vegetação, boa parte dela é formada por palmeiras dispersas, que não têm as características de bosque ou de mata ciliar como o Horto Florestal às margens do Rio Coxipó, ou o entorno do INMET, às margens do Rio Cuiabá. O posto meteorológico está instalado sobre solo duro e seco, que perde a vegetação rasteira no período da seca.

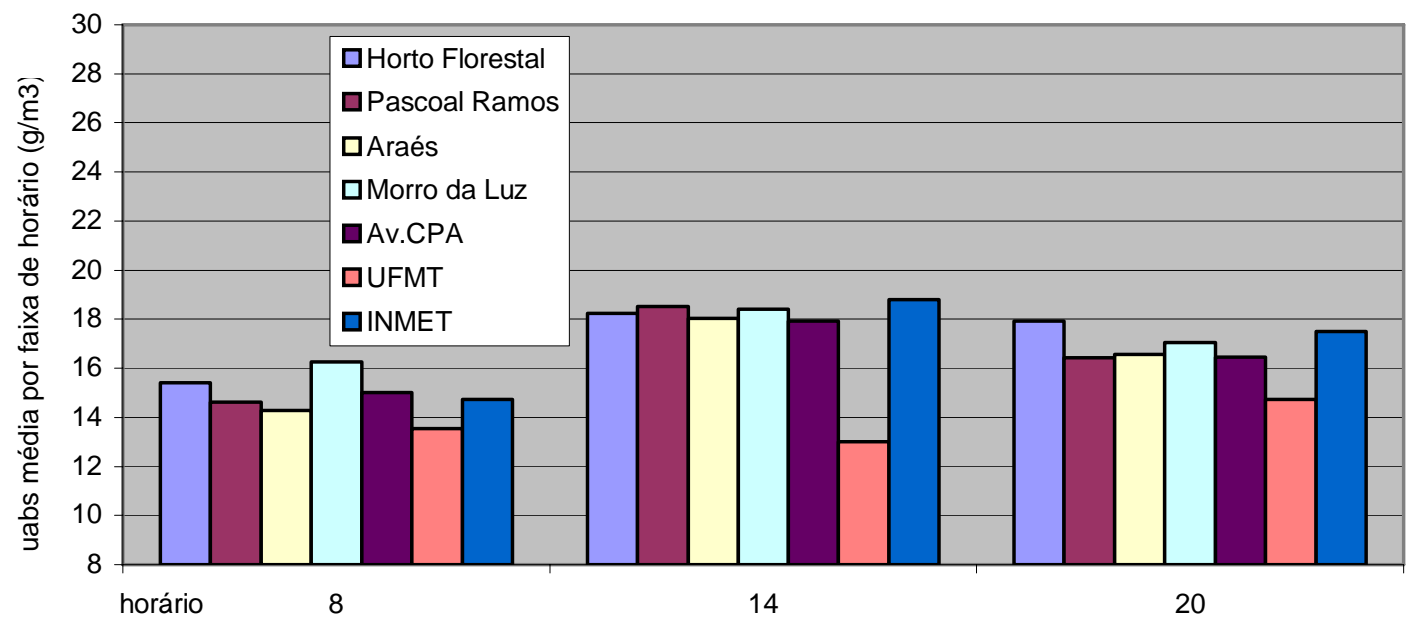

Figura 8.26 - Umidade absoluta média dos seis dias, por faixa de horário, na estação seca.

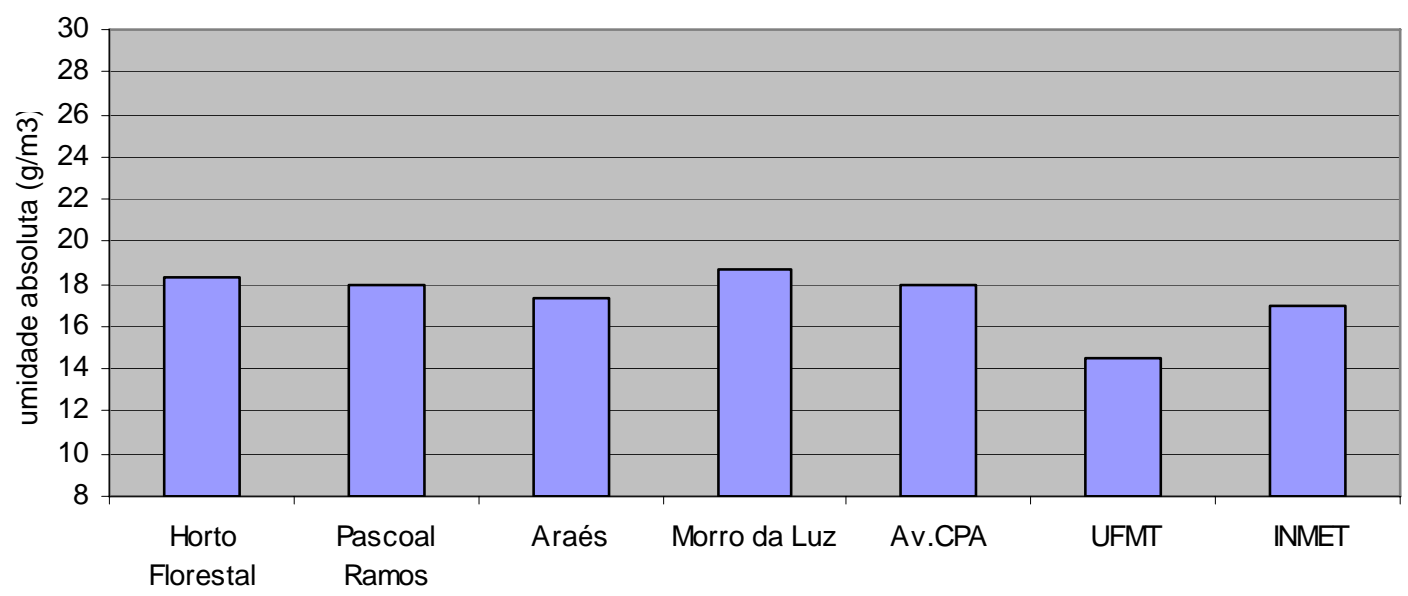

Figura 8.27 - Média das umidades absolutas registradas por posto nos seis dias de medição.

A retração da vegetação é bastante acentuada nesse período em toda a cidade. Porém, na estação seca as praças e canteiros das avenidas na área central são irrigados por caminhões-pipa no período da noite, aumentando a taxa de evaporação, o que minimiza a aridez das condições naturais, agravadas pela ocorrência de queimadas nos arredores da cidade. Os valores muito baixos de umidade do ar registrados no 
campus da UFMT são devidos à aridez do local onde está instalado o abrigo meteorológico e à ausência de irrigação. Se compararmos a umidade absoluta nos sete postos, as diferenças aparecem justamente pelo fato de alguns locais serem irrigados diariamente e outros não.

Classificando os sete pontos do mais úmido para o mais seco, considerando os seis dias medidos, encontramos: Morro da Luz, Horto Florestal, Pascoal Ramos, Av. CPA, Araés, INMET e UFMT (fig.8.26 e 8.27).

\subsection{Estação chuvosa}

No verão o clima é quente e úmido, com baixa amplitude térmica de novembro a março, quando ocorrem fortes chuvas, alternadas por períodos de transição sob o calor do sol intenso, com um aumento rápido da temperatura do ar. As medições foram feitas de 29/01 a 03/02 de 1999, sendo que as leituras de hora em hora, das 8h às 20h, foram feitas no dia 31/01/1999. Nos demais, três leituras diárias às 8h, 14h e 20h em todos os postos. As temperaturas máximas e mínimas absolutas e as direções e velocidades de vento registradas no posto do INMET durante o período de medições foram (tab.8.4 e 8.5):

Tabela 8.4 - Temperaturas mínimas e máximas absolutas registradas na estação do INMET.

\begin{tabular}{|c|l|l|}
\hline data da medição & $\mathbf{t}_{\text { mín }}{ }^{\mathbf{}} \mathbf{C}$ & $\mathbf{t ~ m a ́ x ~}^{\mathbf{}} \mathbf{C}$ \\
\hline $29 / 01$ & 24.1 & 34 \\
\hline $30 / 01$ & 23.5 & 31.7 \\
\hline $31 / 01$ & 23.8 & 31 \\
\hline $01 / 02$ & 23.8 & 33 \\
\hline $02 / 02$ & 23.6 & 33.2 \\
\hline $03 / 02$ & 23.4 & 34.2 \\
\hline
\end{tabular}

Tabela 8.5 - Direção e velocidade do vento registrados na estação do INMET.

\begin{tabular}{|l|l|l|l|}
\hline dia & horário & direção & $\mathbf{v}(\mathbf{m} / \mathbf{s})$ \\
\hline $29 / 01$ & 8 & $\mathrm{~N}$ & 1.6 \\
\hline & 14 & $\mathrm{~N}$ & 1.4 \\
\hline & 20 & $\mathrm{~W}$ & 1.6 \\
\hline $30 / 01$ & 8 & $\mathrm{~N}$ & 4.3 \\
\hline & 14 & $\mathrm{NW}$ & 1.5 \\
\hline & 20 & $\mathrm{SE}$ & 1.3 \\
\hline $31 / 01$ & 8 & $\mathrm{~N}$ & 1 \\
\hline & 14 & $\mathrm{~S}$ & 3.3 \\
\hline & 20 & $\mathrm{~S}$ & 0.8 \\
\hline $01 / 02$ & 8 & $\mathrm{~N}$ & 1.4 \\
\hline & 14 & $\mathrm{~N}$ & 1 \\
\hline & 20 & $\mathrm{~W}$ & 0.7 \\
\hline $02 / 02$ & 8 & $\mathrm{~N}$ & 1.5 \\
\hline & 14 & $\mathrm{~N}$ & 1.3 \\
\hline & 20 & $\mathrm{~N}$ & 0.5 \\
\hline $03 / 02$ & 8 & $\mathrm{~N}$ & 1.4 \\
\hline & 14 & $\mathrm{NW}$ & 0.8 \\
\hline & 20 & $\mathrm{E}$ & 1.3 \\
\hline
\end{tabular}

Segue a descrição das condições sinóticas em cada dia de medição: 
29/01/99 - tempo bom, sem vento, com altas temperaturas que chegaram aos $36^{\circ} \mathrm{C}$; dia sem chuvas, mas bastante úmido nos pontos periféricos.

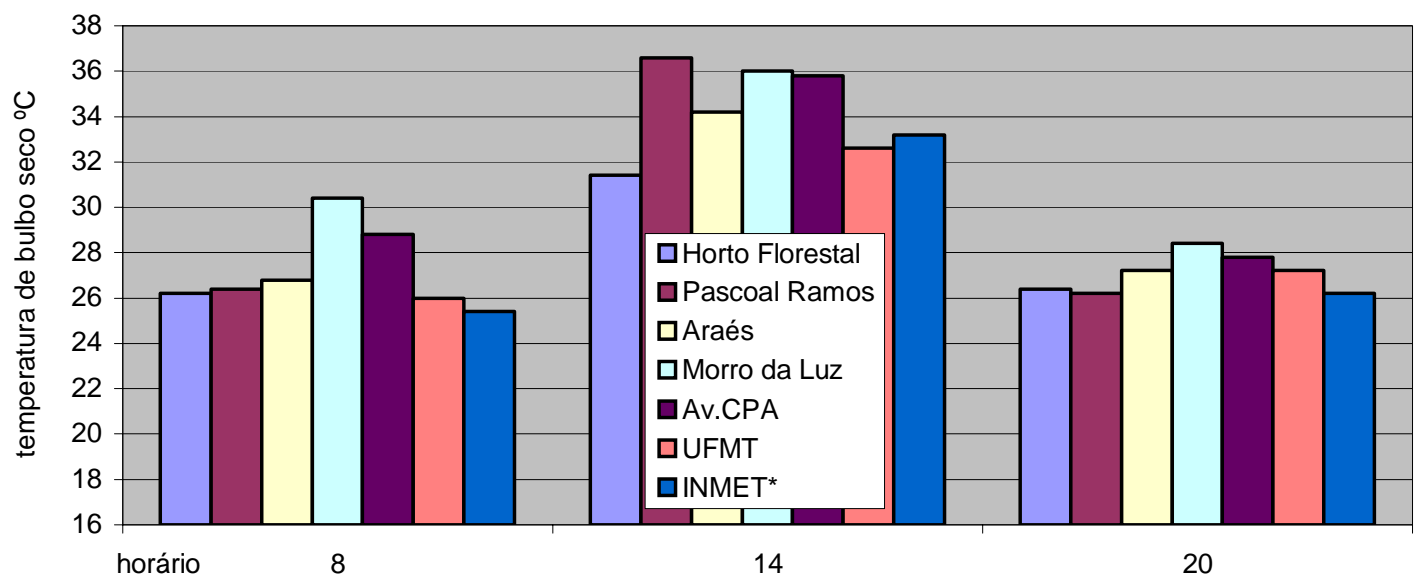

Figura 8.28 - Temperatura de bulbo seco em 29/01/99, com leituras às 8h,14h e 20h.

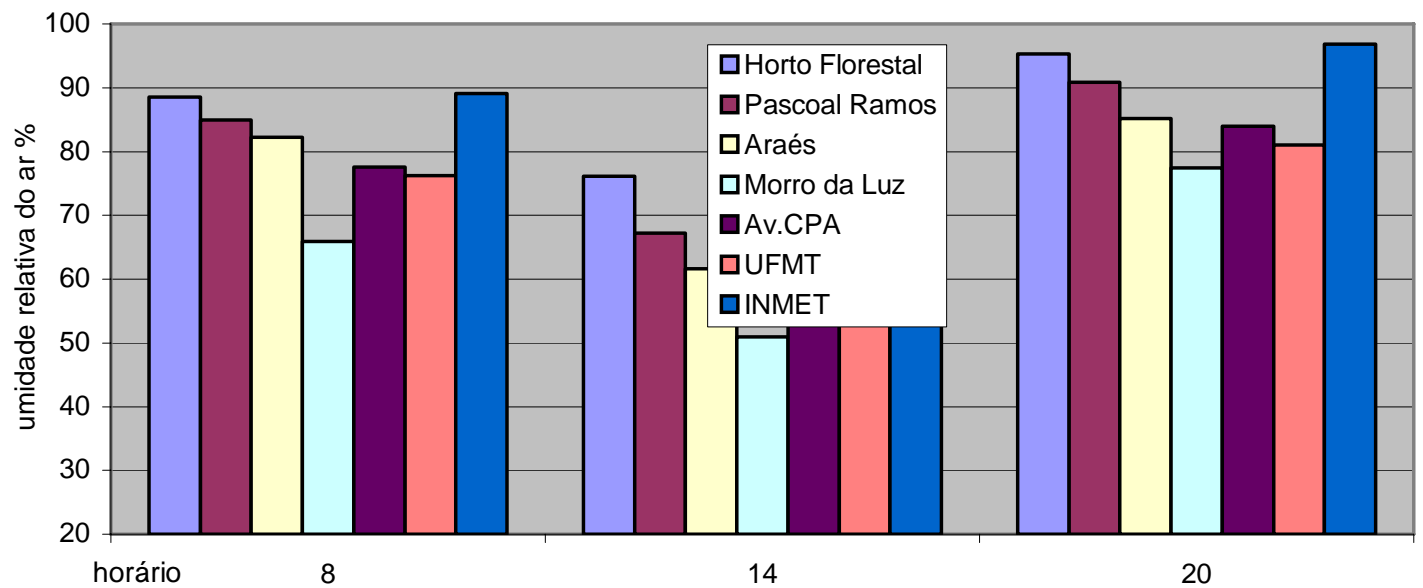

Figura 8.29 - Umidade relativa do ar em 29/01/99, com medições às 8h,14h e 20h.

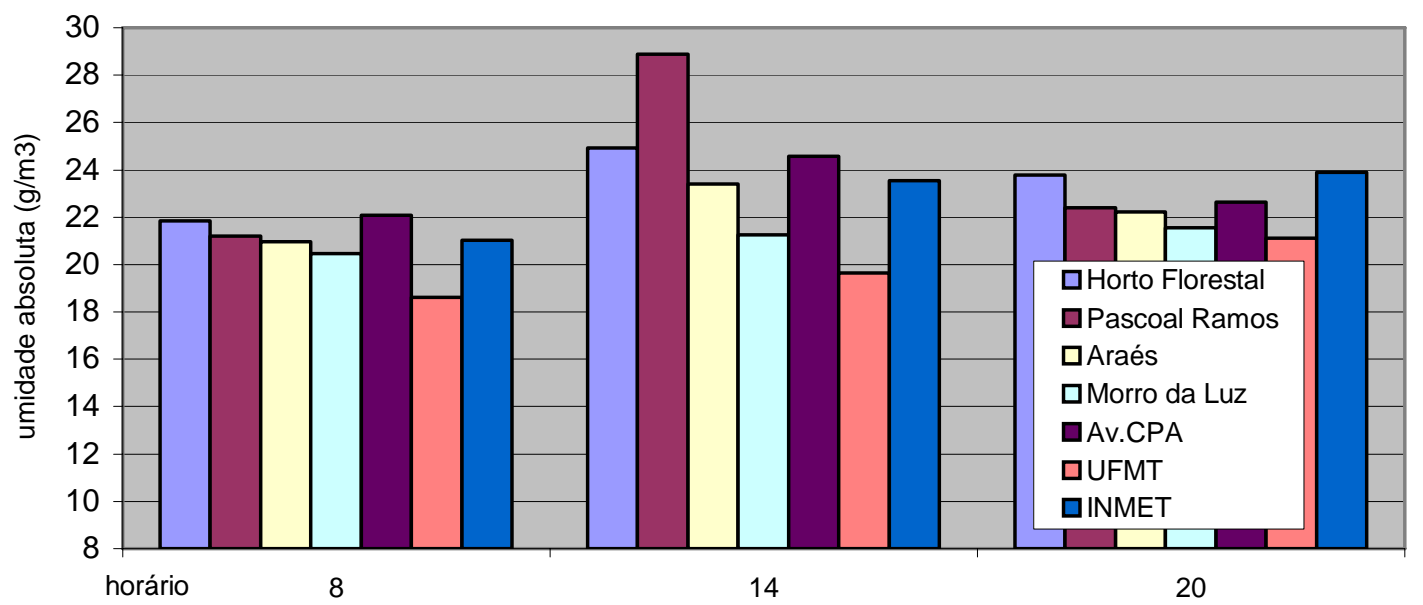

Figura 8.30 - Umidade absoluta do ar em 29/01/99, com leituras às 8h, 14h e 20h. 
30/01/99 - tempo encoberto com chuvas e trovoadas no início da manhã; às 9h sol forte, sem chuvas; à tarde, céu parcialmente nublado; à noite, tempo bom, sem vento.

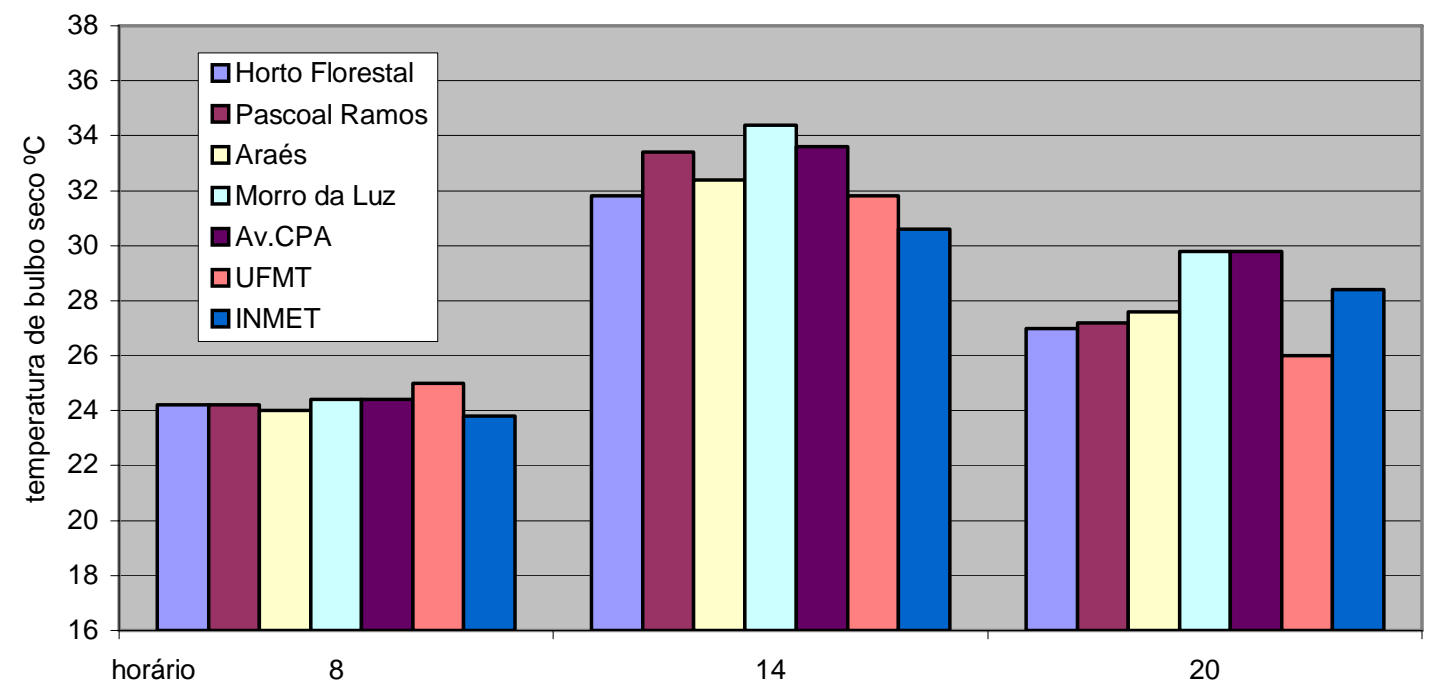

Figura 8.31 - Temperatura de bulbo seco em 30/01/99, com leituras às 8h,14h e 20h.

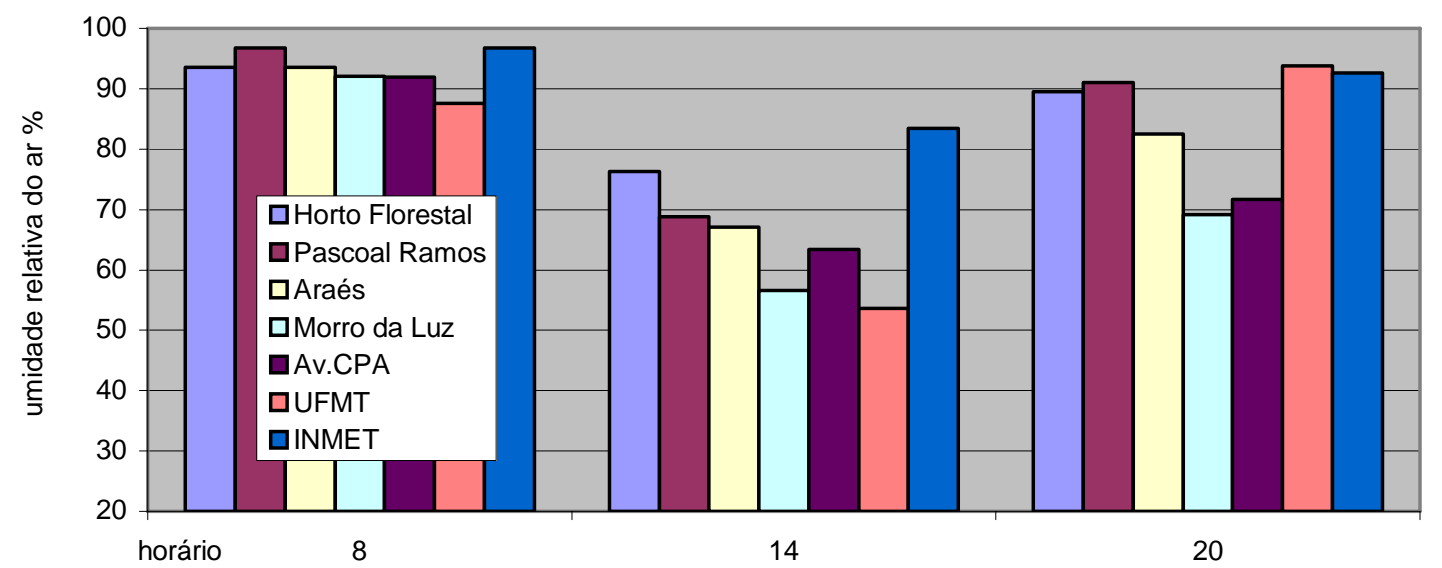

Figura 8.32 - Umidade relativa do ar em 30/01/99, com medições às 8h,14h e 20h.

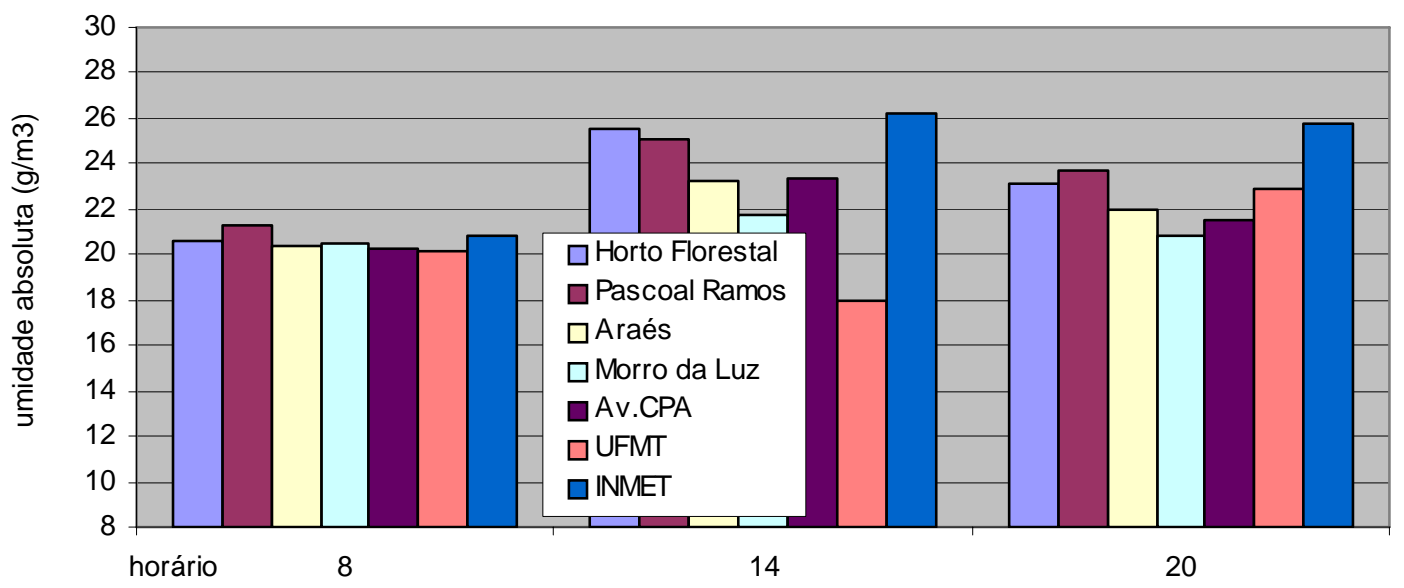

Figura 8.33 - Umidade absoluta do ar em 30/01/99, com leituras às 8h, 14h e 20h. 
31/01/99 - o dia começou nublado, abafado, sem vento, mas já com sol forte no final da manhã; houve uma queda acentuada das temperaturas em todos os pontos no período da tarde devido às fortes pancadas de chuva que atingiram a cidade pelo resto do dia. Como normalmente acontece nesse período de instabilidade, o dia seguinte foi de sol forte e sem chuvas, e a temperatura voltou a subir.

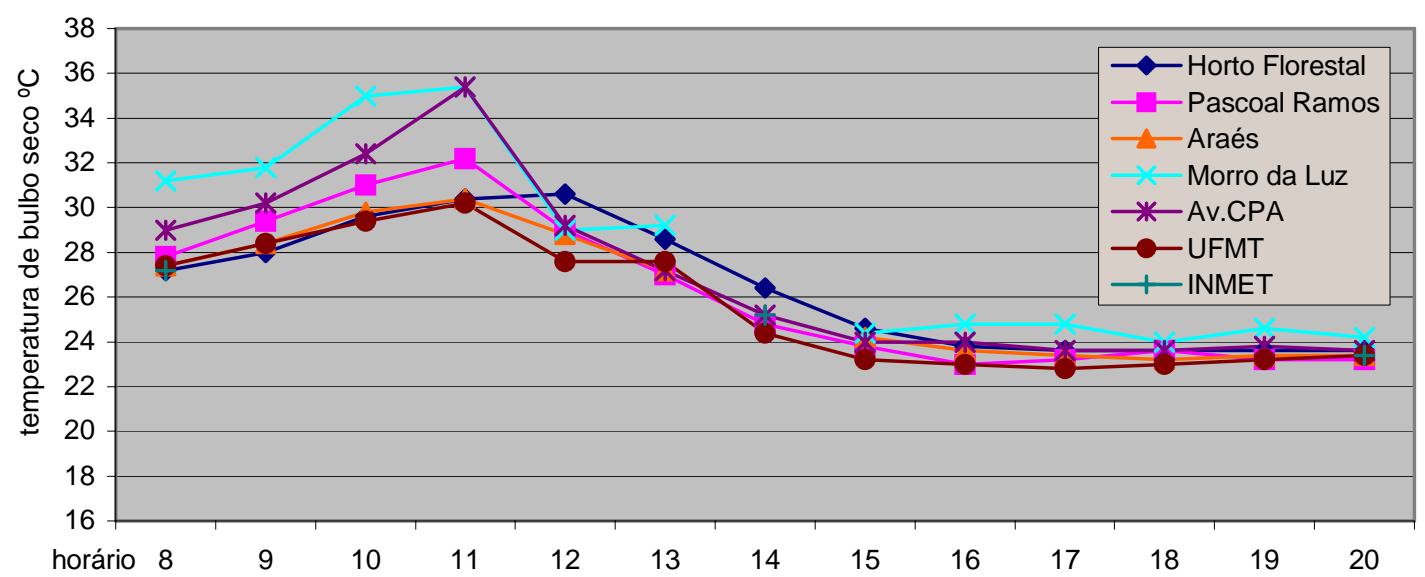

Figura 8.34 - Temperatura de bulbo seco em 31/01/99, com leituras horárias das 8h às 20h.

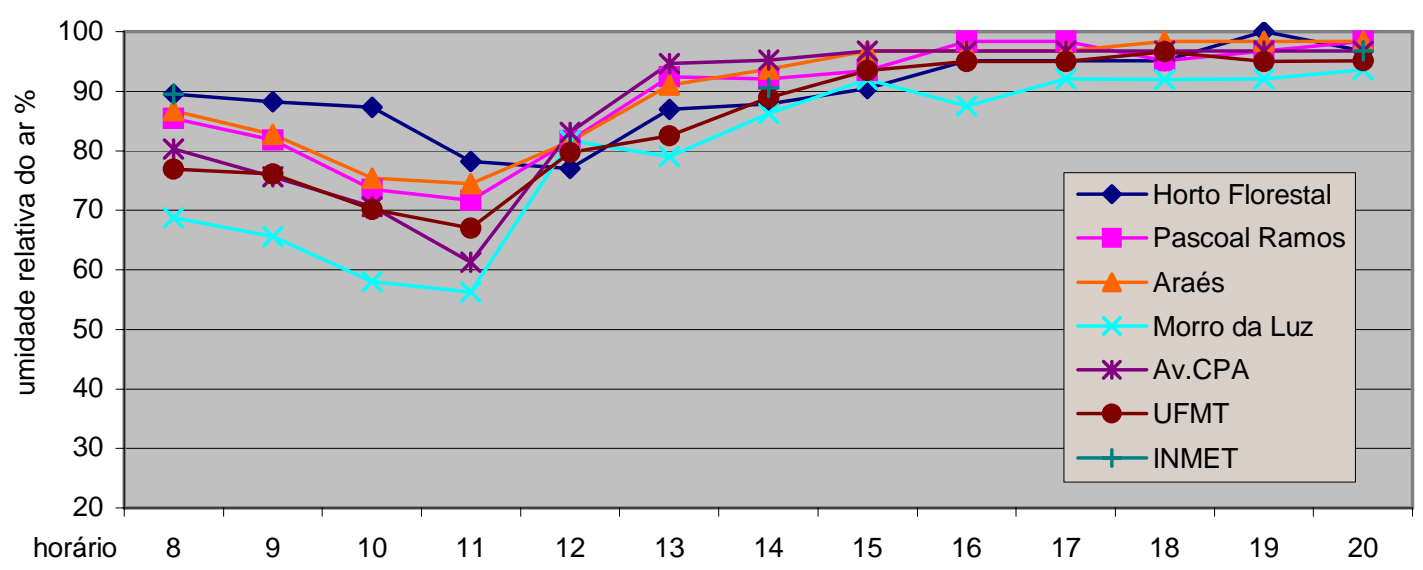

Figura 8.35 - Umidade relativa do ar em 31/01/99, com medições horárias das 8h às 20h.

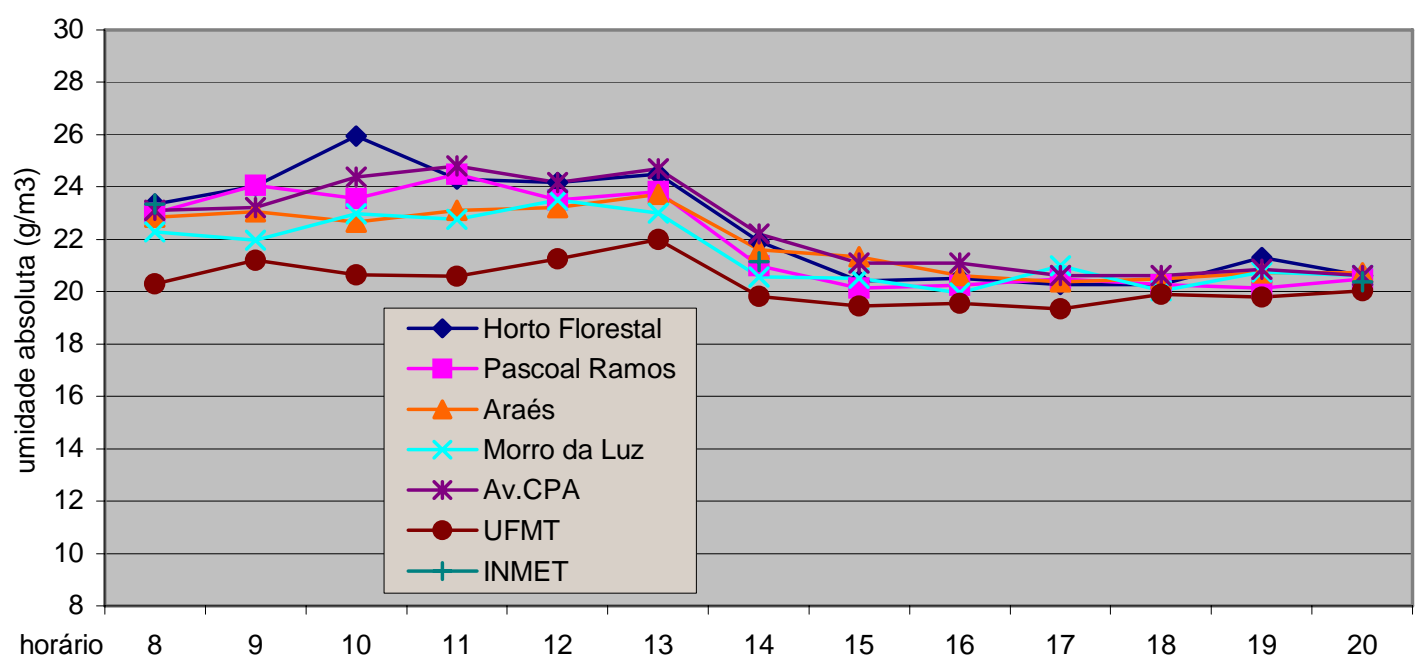

Figura 8.36 - Umidade absoluta do ar em 31/01/99, com medições horárias das 8h às 20h. 
01/02/99 - dia sem chuva, com sol e céu claro todo o tempo.

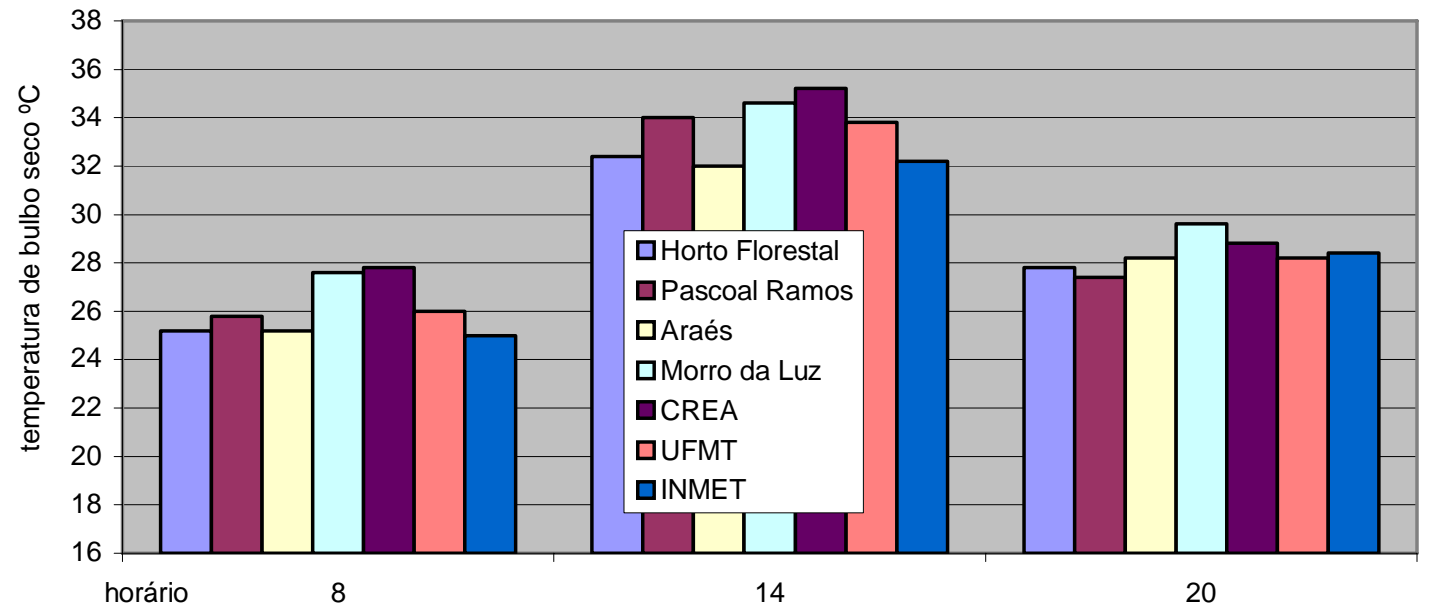

Figura 8.37 - Temperatura de bulbo seco em 01/02/99, com leituras às 8h,14h e 20h.

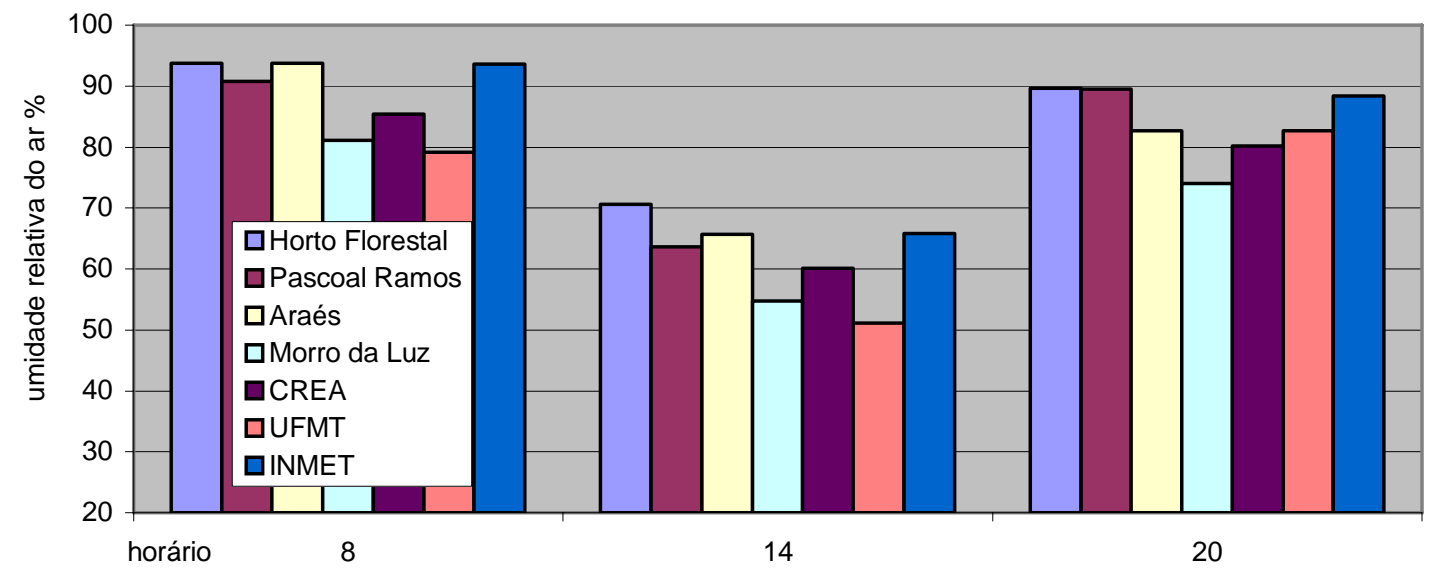

Figura 8.38 - Umidade relativa do ar em 01/02/99, com medições às 8h,14h e 20h.

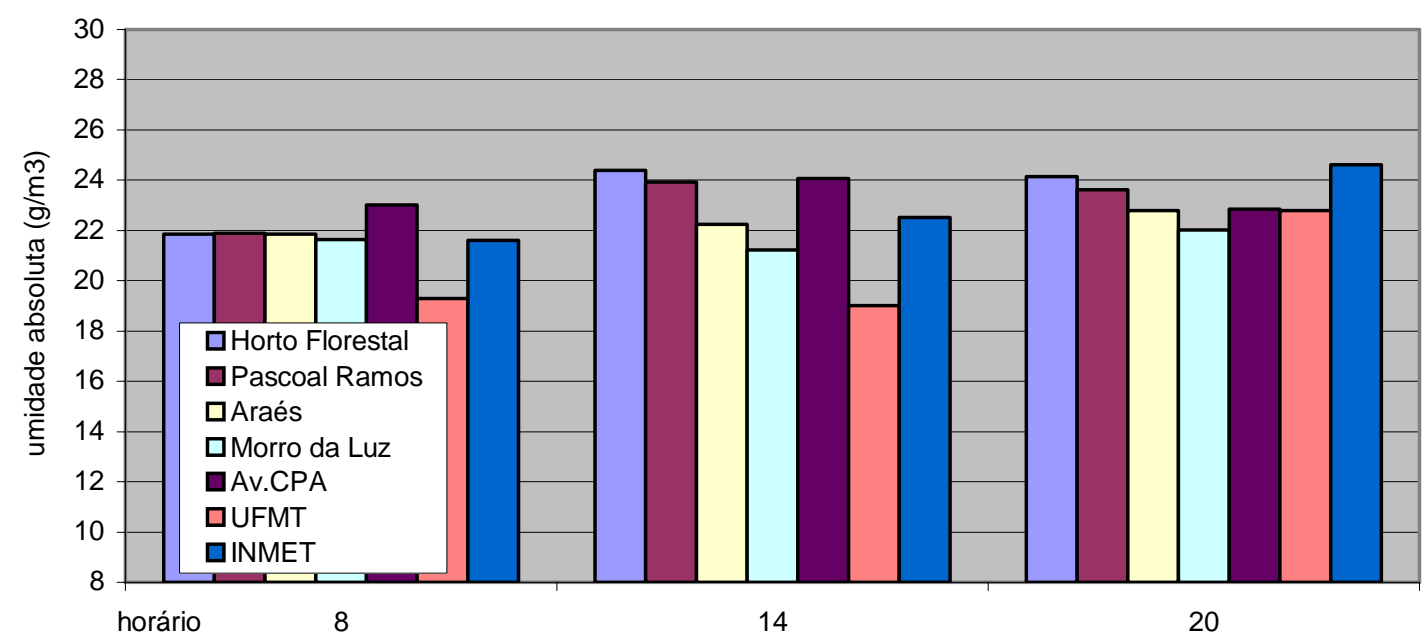

Figura 8.39 - Umidade absoluta do ar em 01/02/99, com leituras às 8h, 14h e 20h. 
02/02/99 - céu claro e sol o dia todo, sem vento.

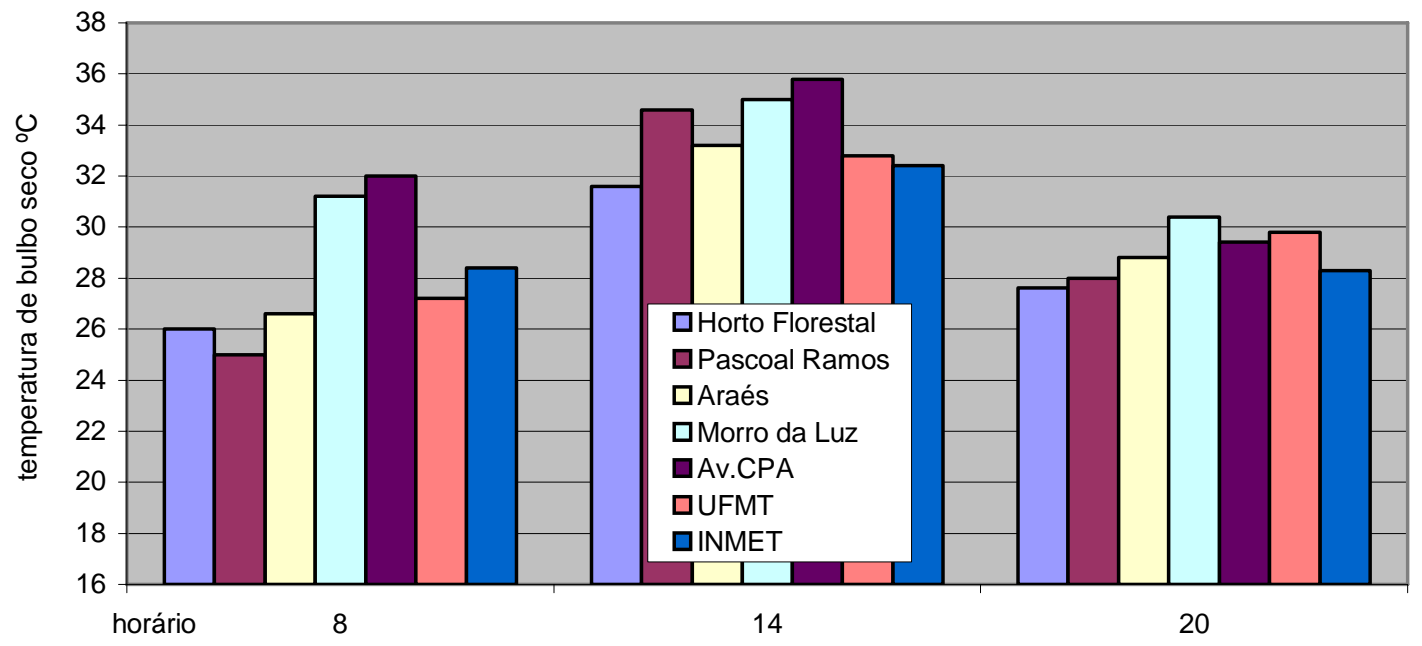

Figura 8.40 - Temperatura de bulbo seco em 02/02/99, com leituras às 8h,14h e 20h.

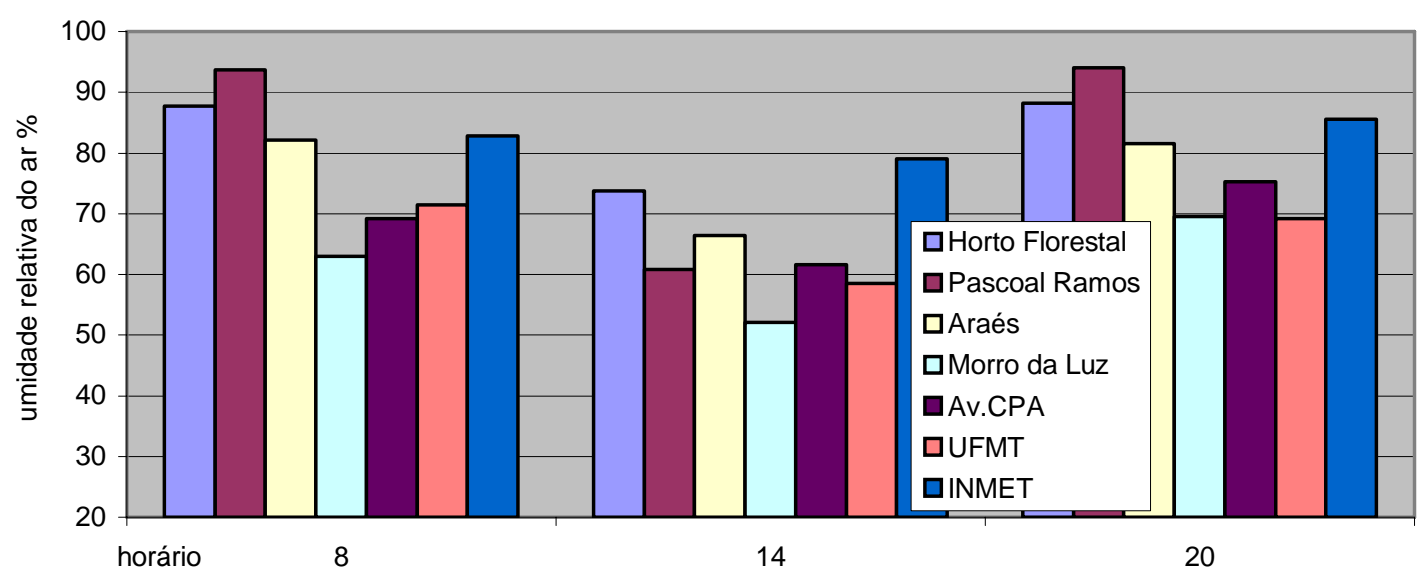

Figura 8.41 - Umidade relativa do ar em 02/02/99, com medições às 8h,14h e 20h.

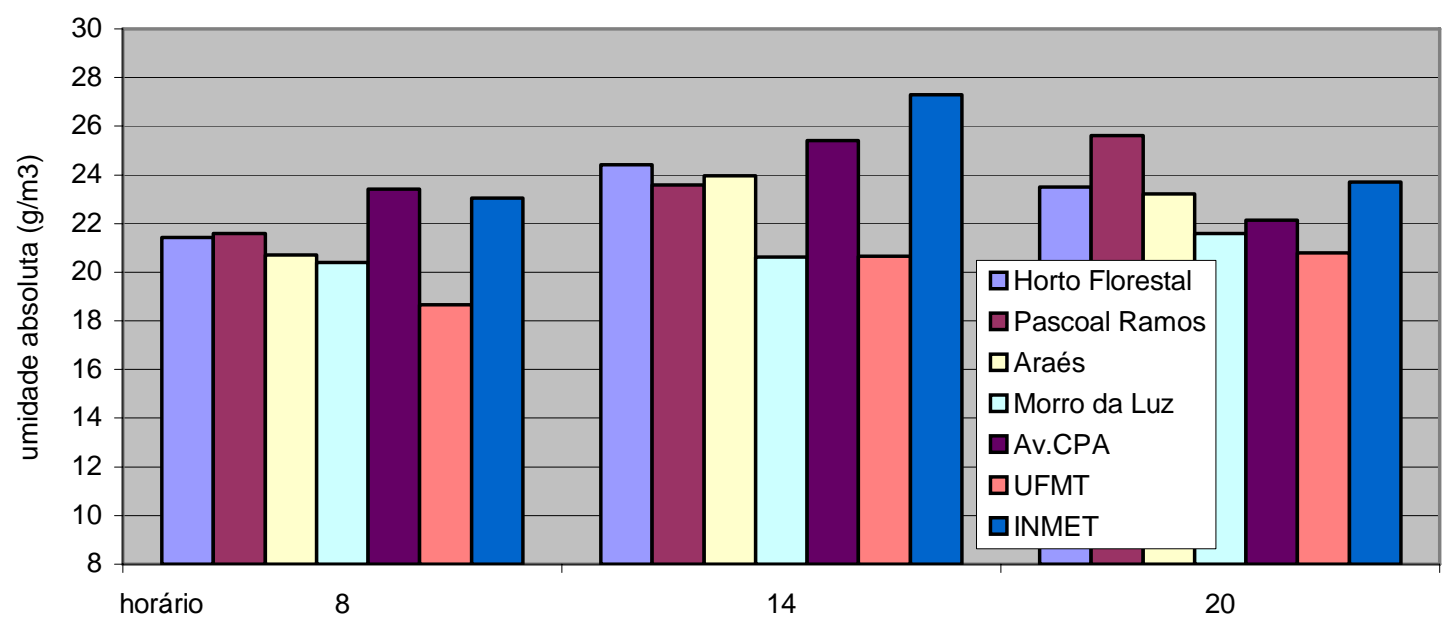

Figura 8.42 - Umidade absoluta do ar em 02/02/99, com medições às 8h,14h e 20h. 
03/02/99 - sol com céu parcialmente nublado pela manhã e à tarde, sem vento; chuva pesada no final da tarde.

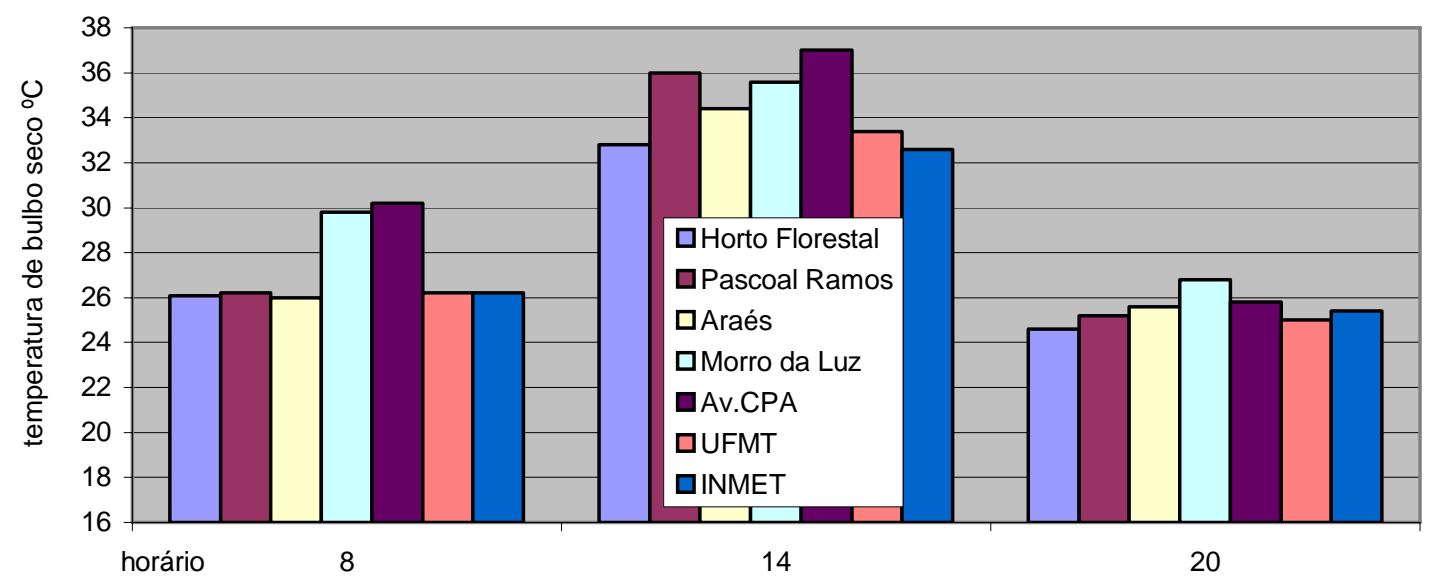

Figura 8.43 - Temperatura de bulbo seco em 03/02/99, com leituras às 8h,14h e 20h.

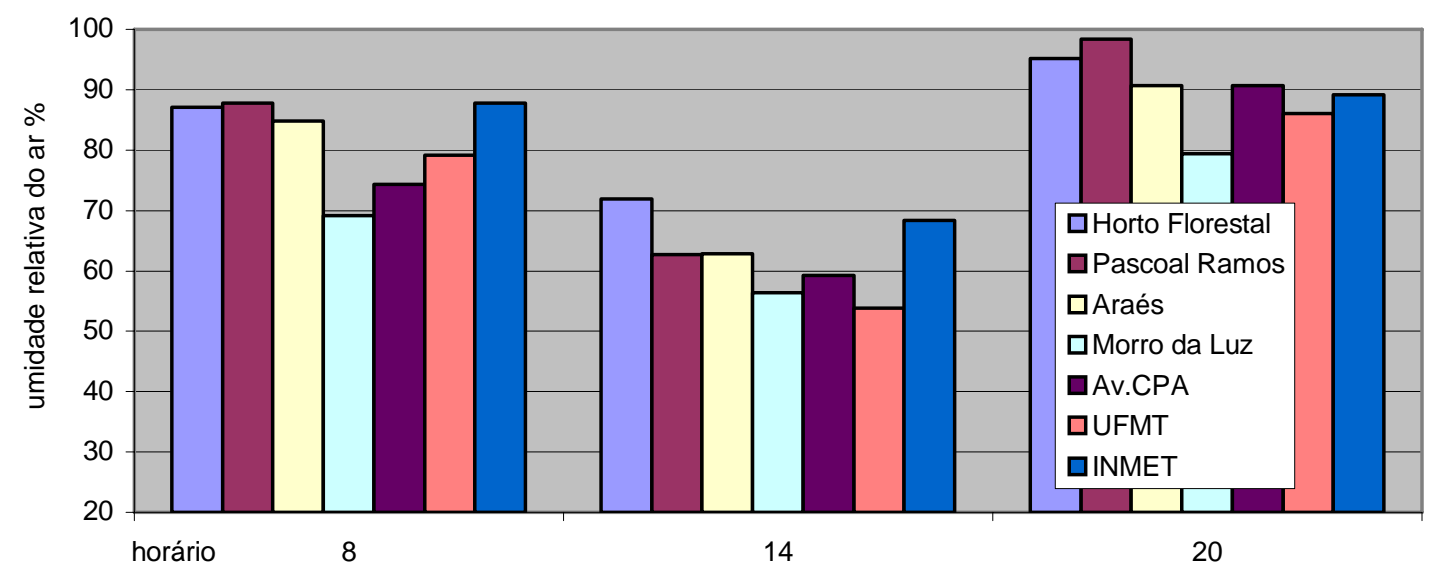

Figura 8.44 - Umidade relativa do ar em 03/02/99, com medições às 8h,14h e 20h.

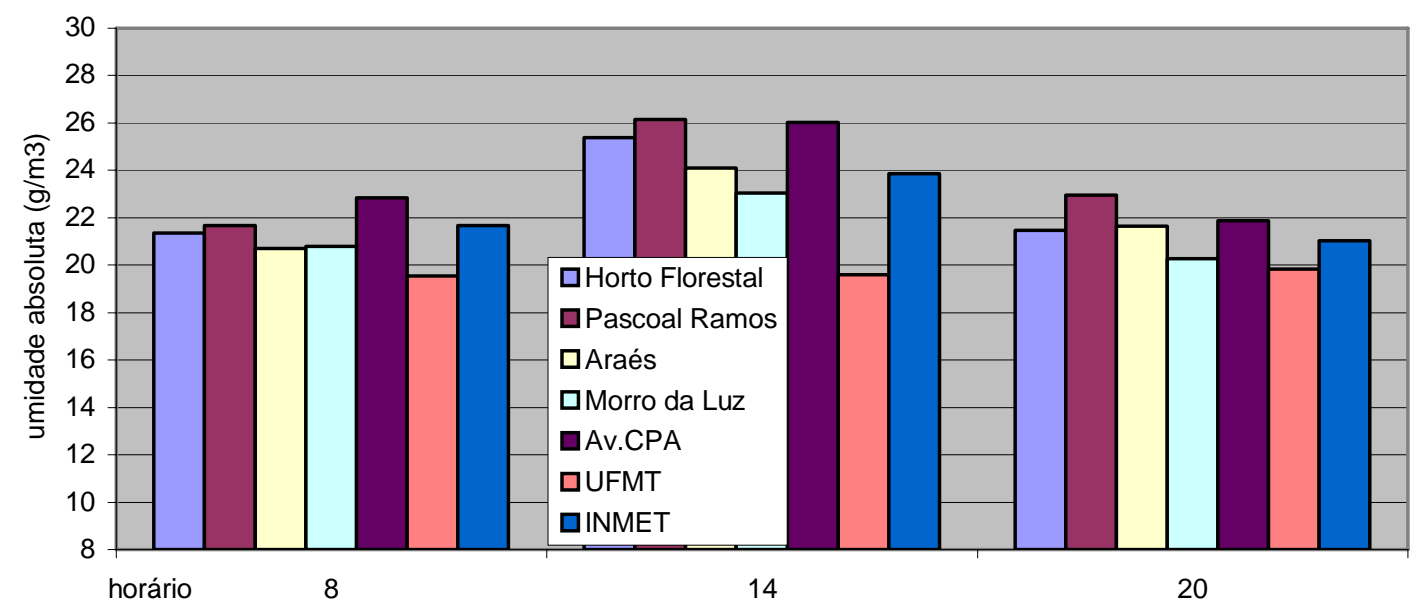

Figura 8.45 - Umidade absoluta do ar em 03/02/99, com medições às 8h,14h e 20h. 


\subsubsection{Análise dos dados e observações pertinentes}

Como se pode observar nas figuras anteriores foram encontradas diferenças absolutas de temperatura de até $7^{\circ} \mathrm{C}$ entre o posto do Pascoal Ramos e o da Av. do CPA, em determinados horários. Às $14 \mathrm{~h}$ as temperaturas máximas não diferem muito da estação seca, mas às $8 \mathrm{~h}$ sim, refletindo a menor amplitude térmica do período chuvoso. A figura 8.46 mostra as temperaturas médias dos seis dias de medição por faixa de horário.

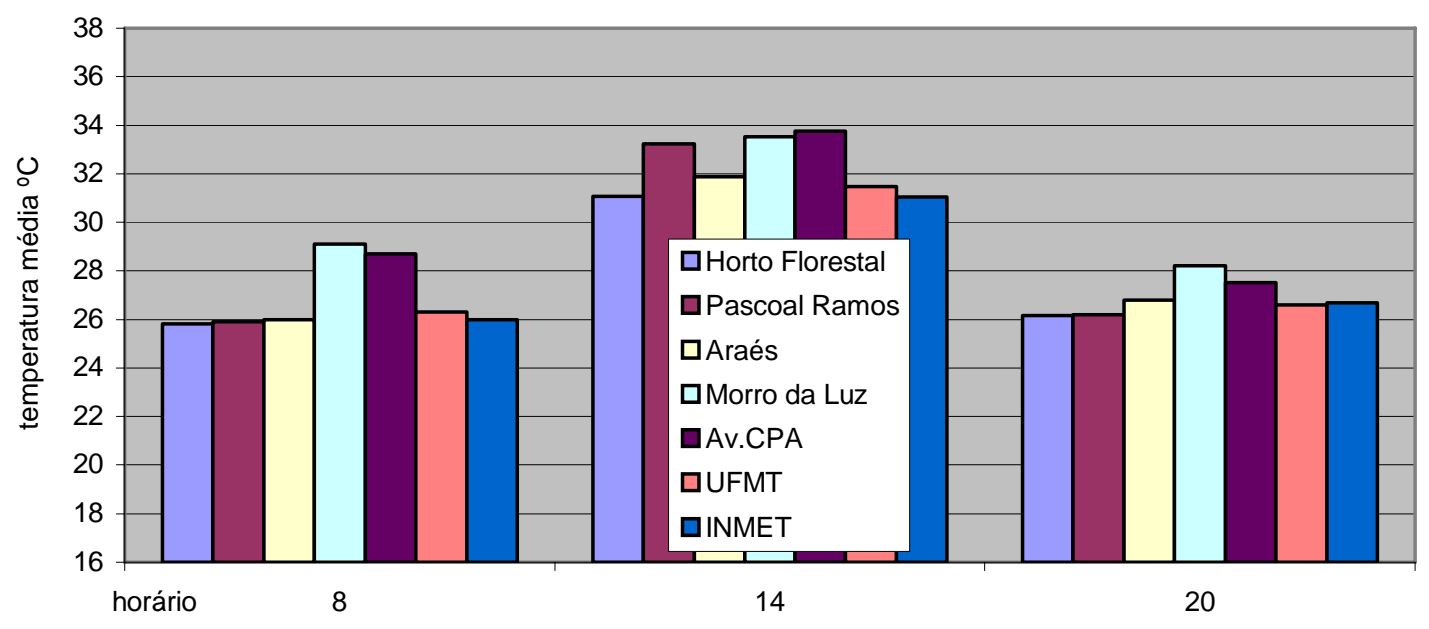

Figura 8.46 - Temperatura média por faixa de horário na estação chuvosa.

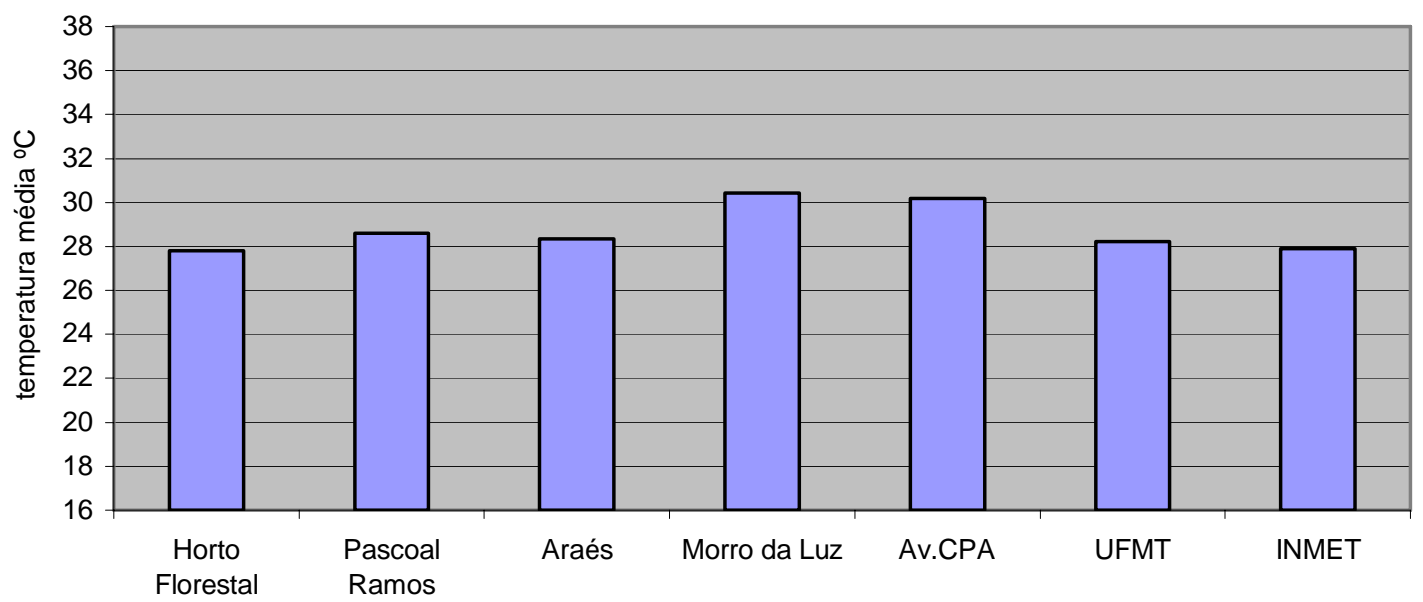

Figura 8.47 - Média das temperaturas registradas por posto nos seis dias de medição.

A figura 8.47 mostra a média aritmética das temperaturas registradas por posto durante os seis dias de medições. Considerando os resultados desses seis dias de medições durante a estação chuvosa podemos classificar as sete áreas, da mais aquecida para a mais amena, na seguinte ordem: Morro da Luz, Av. do CPA, Pascoal Ramos, Araés, UFMT, INMET e Horto Florestal. A tabela 8.6 mostra a temperatura média, a classificação dos postos e a variação percentual da temperatura média de cada posto na escala Celsius em relação ao posto de maior temperatura média, que neste caso foi o Morro da Luz. 
Tabela 8.6 - Temperatura média do dia, classificação dos postos e variação percentual da temperatura na escala Celsius em relação ao posto de maior temperatura média.

\begin{tabular}{|c|c|c|c|c|c|c|c|c|c|}
\hline \multirow[b]{2}{*}{ POSTOS } & \multicolumn{6}{|c|}{$t_{\text {média }}$ do dia } & \multirow{2}{*}{$\begin{array}{l}t_{\text {média }} \\
6 \text { dias }\end{array}$} & \multirow{2}{*}{$\begin{array}{l}\text { classif. } \\
\text { postos }\end{array}$} & \multirow{2}{*}{$\begin{array}{l}\text { var.\% em } \\
\text { relação ao } \\
\text { Morro da } \\
\text { Luz }\end{array}$} \\
\hline & 29/jan & 30/jan & 31/jan & $01 /$ fev & $02 / \mathrm{fev}$ & 03/fev & & & \\
\hline Horto Florestal & 28,0 & 27,7 & 26,4 & 28,5 & 28,4 & 27,8 & 27,8 & 7 & 9,5 \\
\hline Pascoal Ramos & 29,7 & 28,3 & 26,2 & 29,1 & 29,2 & 29,1 & 28,6 & 3 & 6,4 \\
\hline Araés & 29,4 & 28,0 & 26,0 & 28,5 & 29,5 & 28,7 & 28,3 & 4 & 7,37 \\
\hline Morro da Luz & 31,6 & 29,5 & 28,0 & 30,6 & 32,2 & 30,7 & 30,4 & 1 & 0 \\
\hline Av. CPA & 30,8 & 29,3 & 27,0 & 30,6 & 32,4 & 31,0 & 30,2 & 2 & 0,86 \\
\hline UFMT & 28,6 & 27,6 & 25,7 & 29,3 & 29,9 & 28,2 & 28,2 & 5 & 7,87 \\
\hline INMET & 28,3 & 27,6 & 25,3 & 28,5 & 29,7 & 28,1 & 27,9 & 6 & 9,06 \\
\hline
\end{tabular}

Na estação chuvosa as três áreas mais aquecidas foram o Morro da Luz, a Av. CPA (ambas na área central) e o Pascoal Ramos, com pouca diferença em relação ao Araés. Em relação à umidade do ar foram encontradas diferenças absolutas de até $9 \mathrm{~g} / \mathrm{m}^{3}$ em determinados horários entre os postos, com contrastes menos acentuados se comparados aos da estação seca (fig. 8.48 e 8.49).

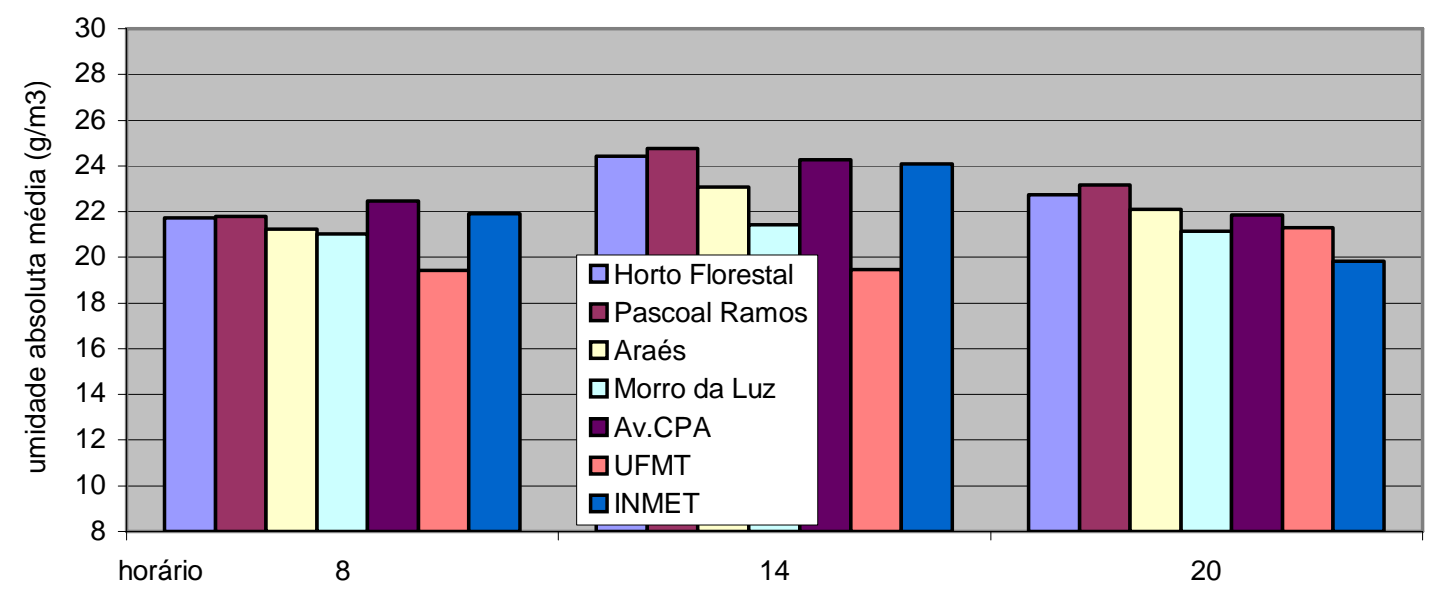

Figura 8.48 - Umidade absoluta média por faixa de horário na estação chuvosa.

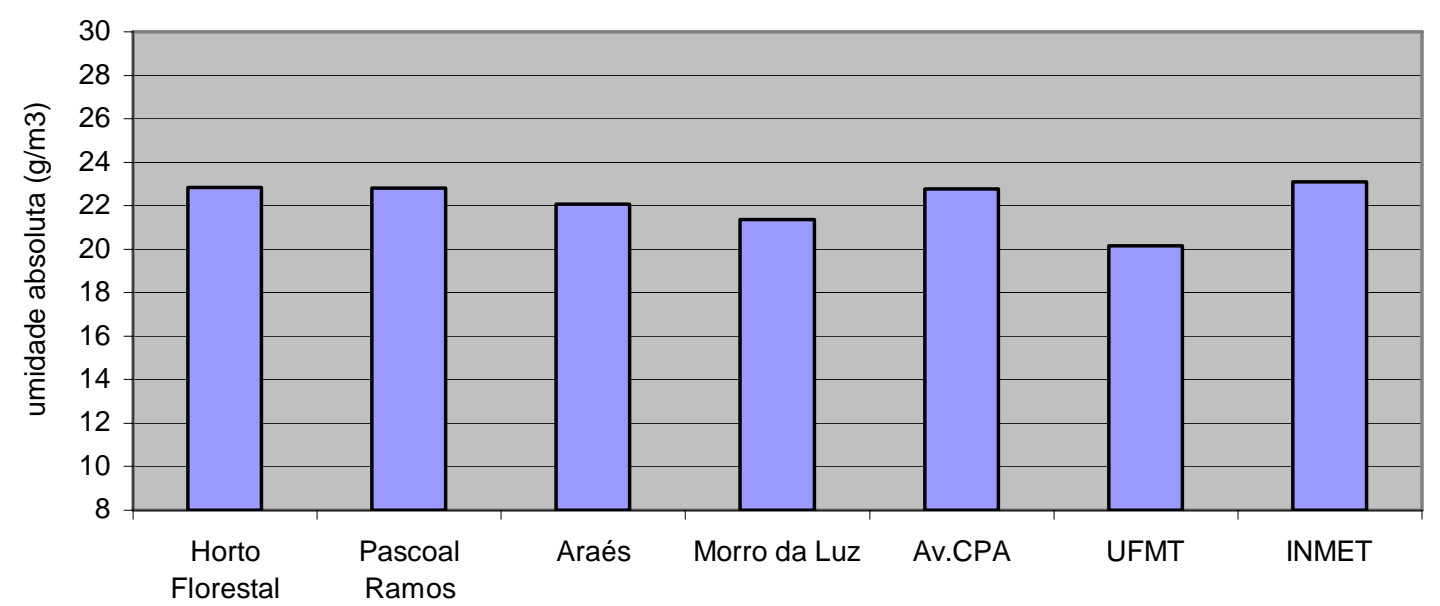

Figura 8.49 - Média das umidades absolutas registradas por posto nos seis dias de medição. 
Também foi feita uma outra série de medições de temperatura superficial sobre diferentes tipos de pavimentos: asfalto, concreto, terra, grama seca, grama úmida e bloco de concreto entremeado por vegetação. O equipamento utilizado foi um piranômetro modelo Ranger II Plus (fig.8.50), que registra a temperatura superficial; as leituras foram feitas no campus da UFMT em 15 de março de 2000, um dia quente de céu claro, nos horários 9h, 12h, 15h e 18h, e as temperaturas superficiais foram registradas ao sol e à sombra para cada caso.

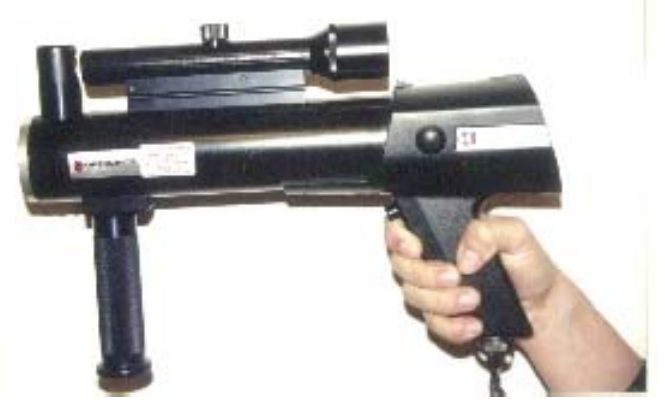

Figura 8.50 - Piranômetro modelo Ranger II Plus utilizado para as medições de temperatura superficial sobre pavimentos. (foto: R. Andrade)

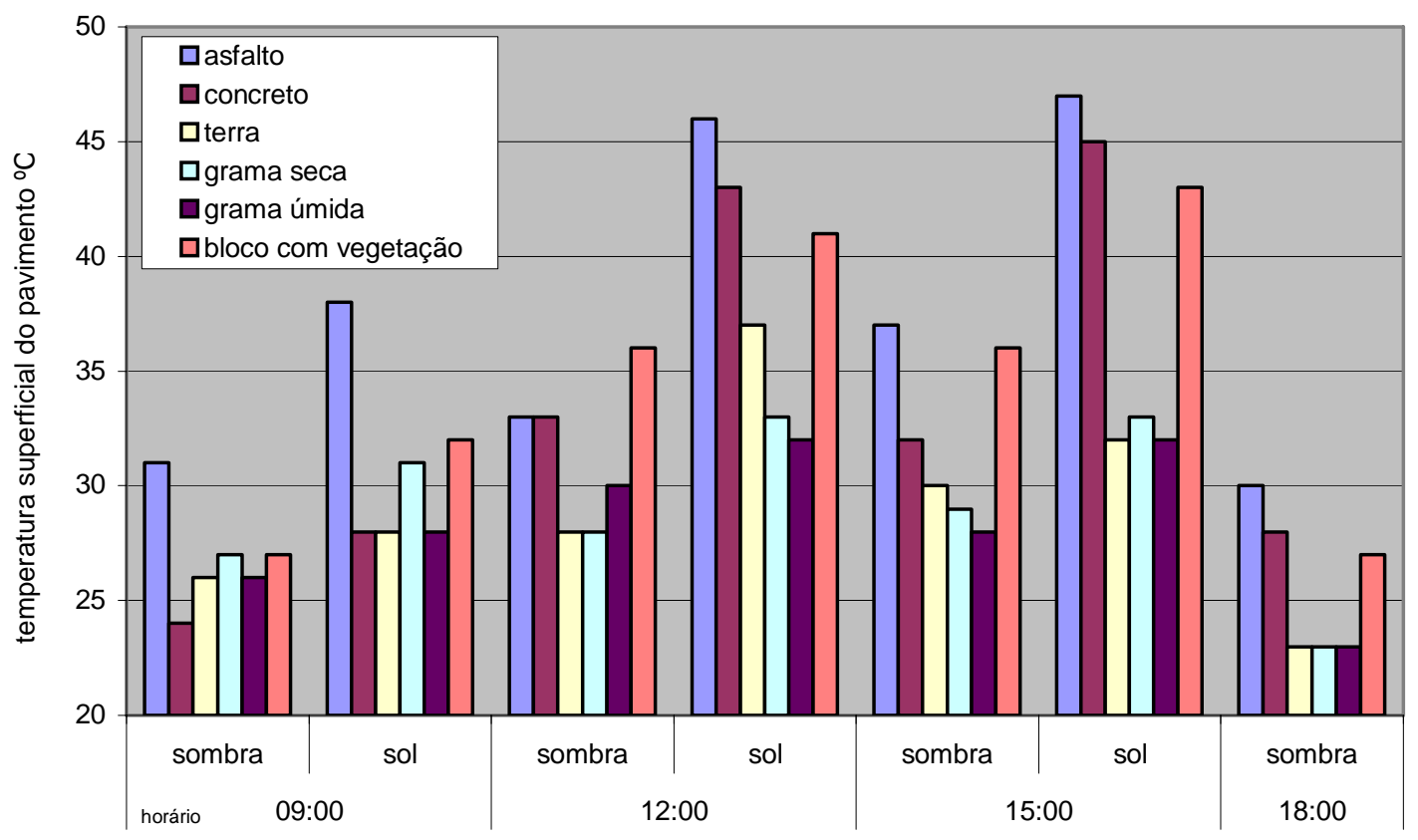

Figura 8.51 - Temperatura superficial dos pavimentos ao sol e à sombra.

Pelos resultados (fig. 8.51) percebe-se a grande diferença de temperatura superficial entre os pavimentos sob as mesmas condições de exposição; diferença essa que se reflete sobre o conforto do pedestre ao transitar sobre eles. Sob a incidência de radiação solar, as diferenças são ainda mais evidentes; o asfalto chega a superar os $45^{\circ} \mathrm{C}$ ao sol nos horários mais críticos, e o pavimento de concreto, um pouco mais 
claro, chega aos $45^{\circ} \mathrm{C}$ às $15 \mathrm{~h}$. Os resultados apontam a necessidade de critérios para a especificação desses materiais para uso em espaços públicos. ${ }^{8}$ Não se pode pensar em um espaço de convívio, como uma praça ou área de lazer, por exemplo, submetendo os usuários a tais temperaturas.

\section{Referências Bibliográficas}

1.OKE, T. R. Boundary Layer Climates. 2.ed. London/New York: Methuen, 1987.

2.MAITELLI, Gilda T. Uma Abordagem Tridimensional de Clima Urbano em Área Tropical Continental: o exemplo de Cuiabá - MT. São Paulo, FFLCH - USP, 1994. Tese (Doutorado em Geografia). Faculdade de Filosofia, Letras e Ciências Humanas, Universidade de São Paulo, 1994.

3.MONTEITH, John Lennox. Principles of Environmental Physics. 2.ed. London/New York : E. Arnold / Routledge, Chapman and Hall, 1990.

4.World Meteorological Organization. Guide to Meteorological Instruments and Methods of Observations. 6.ed. [s.l.]: WMO n.8, [s.d.].

\footnotetext{
${ }^{8}$ ver estudos do Heat Island Group comentados nos capítulos 1 e 4, que tratam da substituição dos materiais nas cidades americanas por causa do sobreaquecimento provocado pelas superfícies, o que também contribui para a elevação da temperatura do ar nas áreas urbanas e http://eetd.lbl.gov/HeatIsland/PUBS/APS-PressRelease/.
} 
PARTE 4

Análise dos resultados e conclusões 


\section{COMPROVAÇÃO DA TESE E ANÁLISE DOS RESULTADOS}

\subsection{Correlação entre os postos de medição}

Admite-se que os locais dos sete casos estudados, hoje dentro zona urbana do aglomerado Cuiabá/Várzea Grande, apresentavam aproximadamente as mesmas condições climáticas antes da urbanização. Todos os postos situam-se na depressão cuiabana, aproximadamente à mesma altitude, e nenhum dos sete casos sofre efeitos particulares da topografia, como acontece em espigões ou fundos de vale, por exemplo. Sendo assim, admite-se que as diferenças hoje encontradas são principalmente devidas à urbanização.

Tomando o Horto Florestal como referência, por este apresentar as condições mais próximas do ambiente natural, foi feito um teste de correlação entre as temperaturas médias dos seis dias medidos entre o Horto e cada um dos outros seis casos, na estação seca e chuvosa, resultando em coeficientes de correlação bastante elevados (tab.9.1). A correlação negativa em relação ao posto do INMET durante a estação seca deve-se, provavelmente, à maior exposição do lugar em relação aos ventos durante a passagem da frente fria. Nos outros locais, inclusive no Horto Florestal, os abrigos meteorológicos com os instrumentos ficaram mais protegidos pelo entorno construído ou arborizado.

Tabela 9.1 - Coeficientes de correlação (r) entre as temperaturas médias, em relação ao caso de referência, no Horto Florestal.

\begin{tabular}{|l|r|r|}
\hline & r (est. seca) & r (est. chuvosa) \\
\hline Pascoal Ramos & 0,87 & 0,91 \\
\hline Araés & 0,99 & 0,90 \\
\hline Morro da Luz & 0,87 & 0,87 \\
\hline Av.CPA & 1,00 & 0,91 \\
\hline UFMT & 0,91 & 0,98 \\
\hline INMET & $-0,49$ & 0,96 \\
\hline
\end{tabular}

\subsection{Classificação das condições de conforto nos casos estudados}

Ainda não foi desenvolvido um índice de conforto adequado para qualificar o desempenho higrotérmico de áreas urbanas em regiões tropicais. ASSIS (2000, p.216) aponta também a necessidade de se desenvolver um índice adequado às variáveis que vêm sendo utilizadas, tais como a capacidade de adensamento e de verticalização das áreas urbanizadas.

Ao se tentar aplicar zonas ou índices de conforto desenvolvidos para outros países, sob condições climáticas e culturais diferentes das nossas, os resultados não fazem o menor sentido. GIVONI (1992a), aplicando a zona de conforto normalizada da ASHRAE para edifícios em uma cidade mexicana de clima quente-úmido, conclui que ela é totalmente inadequada para as condições do clima e de aclimatação ${ }^{1}$ dos

\footnotetext{
${ }^{1}$ CARMONA (1986, p.361) define aclimação como sendo "the set of long-term adaptations affecting all organisms which inhabit a basically stable climate. Biothermal processes vary from one organismo to another."
} 
habitantes. Em GIVONI (1992b) o autor propõe uma nova carta bioclimática para edifícios, com limites mais altos para temperatura e umidade, proposta para climas quentes em países em desenvolvimento, para população aclimatada às condições quente-úmidas. Levando em consideração a aclimatação da população, o autor sugere um aumento de $2^{\circ} \mathrm{C}$ para temperatura de bulbo seco e de $2 \mathrm{~g} / \mathrm{Kg}$ para umidade absoluta. "It is reasonable to assume that people in developing hot countries, living mostly in unconditioned buildings, are acclimatized to, and would tolerate, higher temperature and/or humidity." Além de uma certa rusticidade de costumes, resultando em uma maior aceitação do desconforto como algo normal, a aclimatação da população na região de clima tropical continental faz com que a zona de conforto seja bastante alta.

Em Cuiabá, na estação quente e úmida, a cidade toda é desconfortável; as calmarias são freqüentes durante o dia intensificando o stress térmico causado pela combinação de altas temperaturas e umidade elevada. Nesse período o único recurso, além do sombreamento, é favorecer a ventilação a todo custo. $\mathrm{Na}$ estação seca as temperaturas mínimas chegam a patamares mais confortáveis, mas as máximas não caem muito em relação à temperatura média das máximas anuais.

Neste estudo o parâmetro utilizado para comparação das condições de conforto térmico entre os diferentes casos na cidade é a temperatura do ar. Tendo em vista as condições climáticas encontradas, com a temperatura média dos postos sempre elevada, a preocupação com stress térmico pelo frio é desprezível em relação ao stress pelo calor; sendo assim considera-se o local mais confortável quanto menor for a temperatura do ar. Considerando as duas estações do ano, a figura 9.1 mostra temperaturas médias e diferenças médias em relação ao caso mais crítico (posto Morro da Luz), mas cabe lembrar que, dentre as 392 observações de temperatura do ar, ocorreram diferenças pontuais de até $7^{\circ} \mathrm{C}$ em alguns horários.

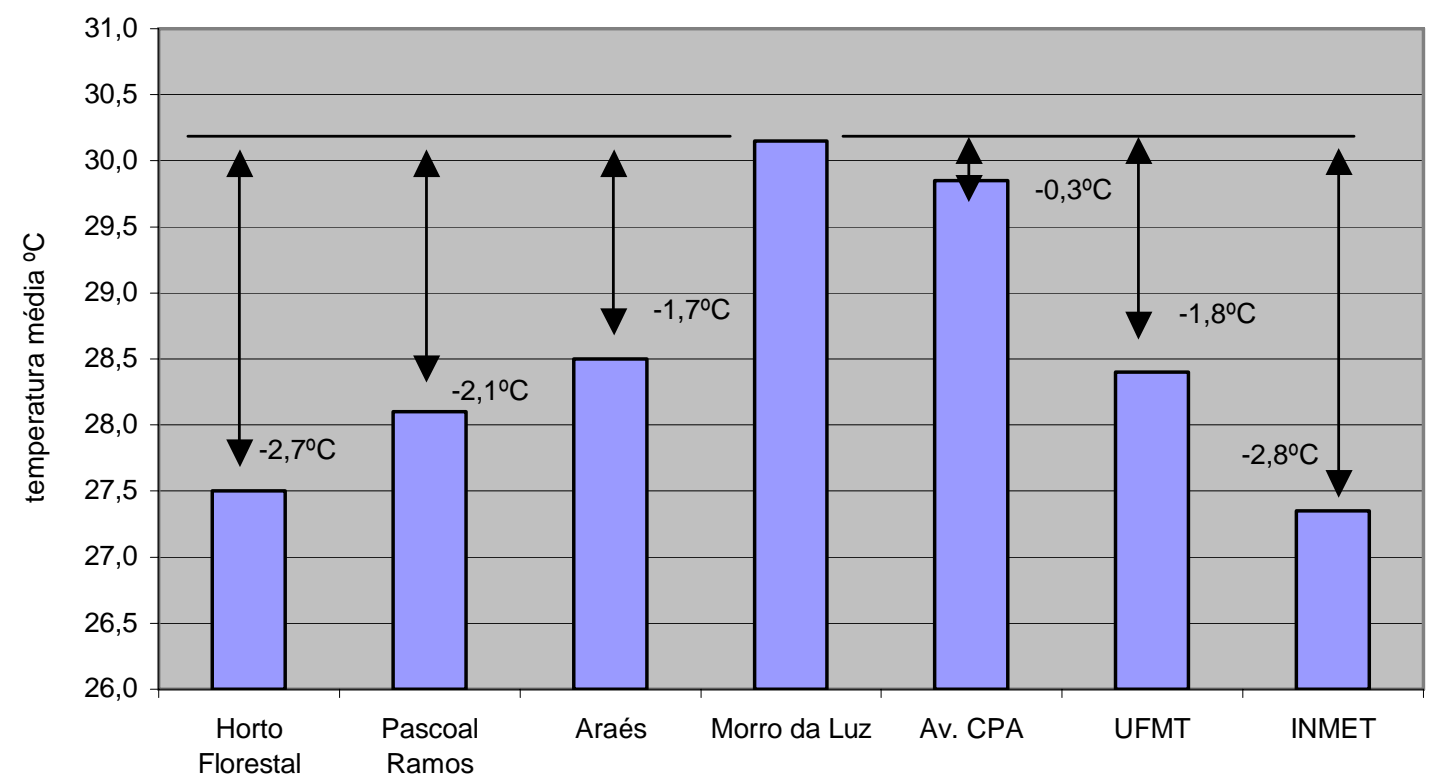

Figura 9.1 - Temperatura média e diferenças médias de temperatura (considerando as estações seca e chuvosa) em relação ao caso mais crítico (Morro da Luz). 


\subsection{Comprovação da tese}

Há uma correlação entre microclimas urbanos e as condições de uso e ocupação do solo. O que a tese está fazendo pela primeira vez é estabelecer uma correlação numérica entre a temperatura do ar e alguns parâmetros de uso e ocupação do solo, não para a cidade como um todo, mas para sete pontos no espaço construído, representativos do seu entorno, usando variáveis de planejamento que podem ser regulamentadas pela legislação municipal.

Para se detectar ou não a correlação entre a variação horizontal da temperatura do ar medida (variável resposta ou variável dependente) e cada uma das variáveis referentes à ocupação (variáveis explicativas ou independentes) - sendo estas a taxa de ocupação e coeficiente de aproveitamento líquidos e brutos, arborização e superfícies d'água, para cada horário de leitura, às $8 \mathrm{~h}, 14 \mathrm{~h}$ e $20 \mathrm{~h}$ - foram construídos gráficos de dispersão, foram calculados os coeficientes de correlação (r) entre as variáveis dependentes e independentes (tab.9.2 e 9.3), duas a duas, e foram feitos testes de regressão linear simples para avaliação da função linear que relaciona estas variáveis para cada leitura (tab.9.4 e 9.5), resultando em 216 testes no total. O número de leituras de temperatura e umidade do ar corresponde ao número de observações (392 pares de dados no total) em diferentes horários e estações do ano, para que se pudesse trabalhar com medidas representativas de cada período em pelo menos três faixas de horário: $8 \mathrm{~h}, 14 \mathrm{~h}$ e $20 \mathrm{~h}$.

Com o estabelecimento do grau de correlação entre a temperatura do ar e cada variável explicativa pode-se saber qual a associação entre elas e quais os períodos de influência de cada uma, pois os fenômenos climáticos urbanos são diferentes para o período diurno e noturno. A ocorrência da ilha de calor, por exemplo, é um fenômeno tipicamente noturno, mas o stress térmico durante o dia é significativo para muitas regiões.

A informação gerada pelo trabalho de campo é considerada apenas uma tendência, já que o pequeno número de casos (sete unidades observacionais) não é suficiente para um tratamento estatístico mais elaborado. Sendo assim, analisam-se os dados sob um contexto mais descritivo do que inferencial. De acordo com a consulta feita ao Centro de Estatística Aplicada - CEA do IME-USP, seriam necessários pelo menos 30 unidades observacionais, ou seja, 30 locais de medição, para se tentar chegar a uma equação na qual a temperatura do ar seria representada como função de diferentes variáveis ligadas ao planejamento, com os respectivos pesos. Com o instrumental de medições utilizado isso significaria 30 abrigos meteorológicos, sessenta termômetros meteorológicos e uma quantidade de pessoas treinadas muito maior para as leituras. Para um número elevado de unidades amostrais seria mais adequado usar instrumentos digitais, de resposta rápida, fazendo-se o percurso dos pontos amostrados em um veículo, em cada horário de leitura.

Ainda de acordo com a consulta ao CEA, cabe ao pesquisador, com seus conhecimentos, decidir até que ponto outras regiões podem ser consideradas similares à região estudada, com diferenças desprezíveis em relação aos fatores em questão, para que se possa estender a validade dos resultados obtidos.

As variáveis taxa de ocupação e coeficiente de aproveitamento foram discriminadas em: líquidas, referentes à ocupação somente das quadras, e brutas, referentes à 
ocupação total do entorno de 25ha, computando-se área das vias, praças, parques, etc. Arborização e superfícies d'água foram quantificadas em dados brutos. A correlação já fica visível quando se sobrepõem as variáveis que caracterizam a ocupação com a temperatura do ar média na estação seca e na estação chuvosa para cada caso estudado (fig.9.2 e 9.3).

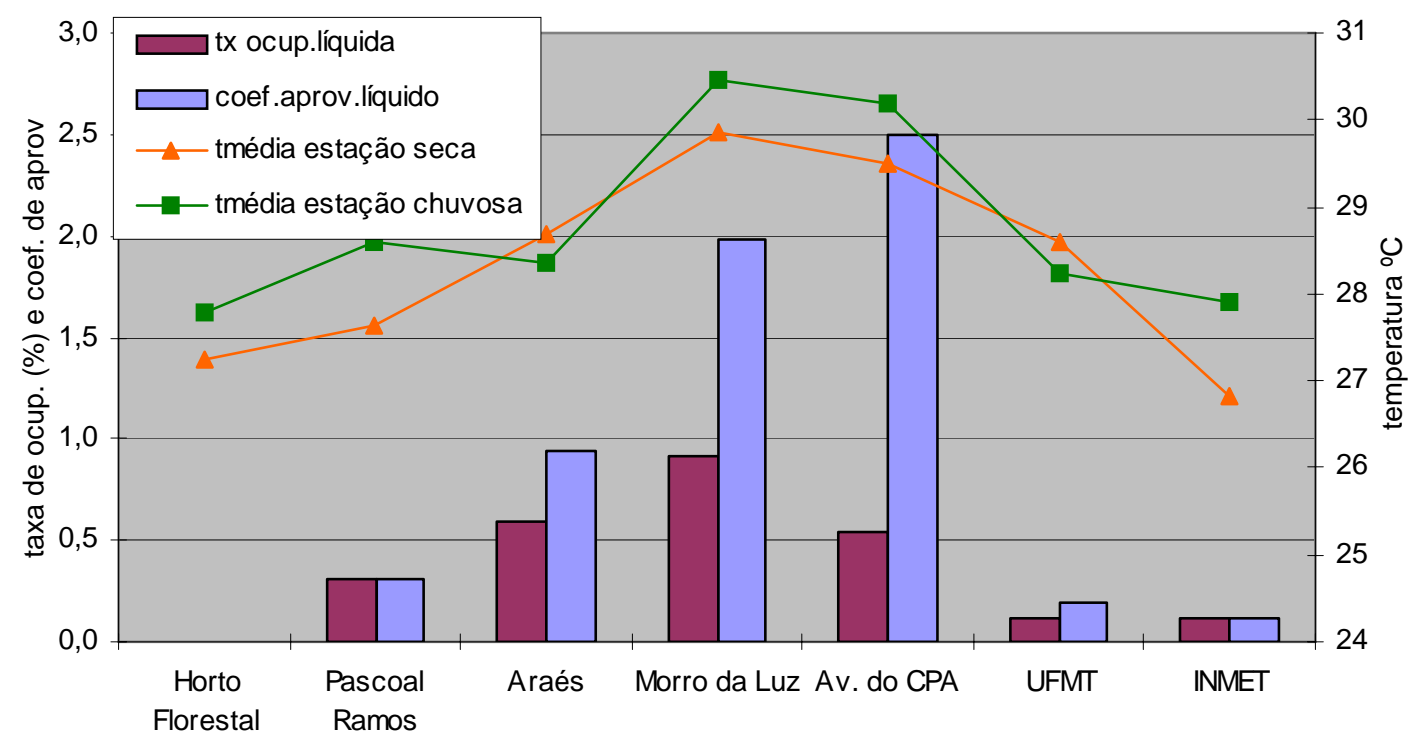

Figura 9.2 - Taxa de ocupação e coeficiente de aproveitamento líquidos versus temperatura média durante as estações seca e chuvosa.

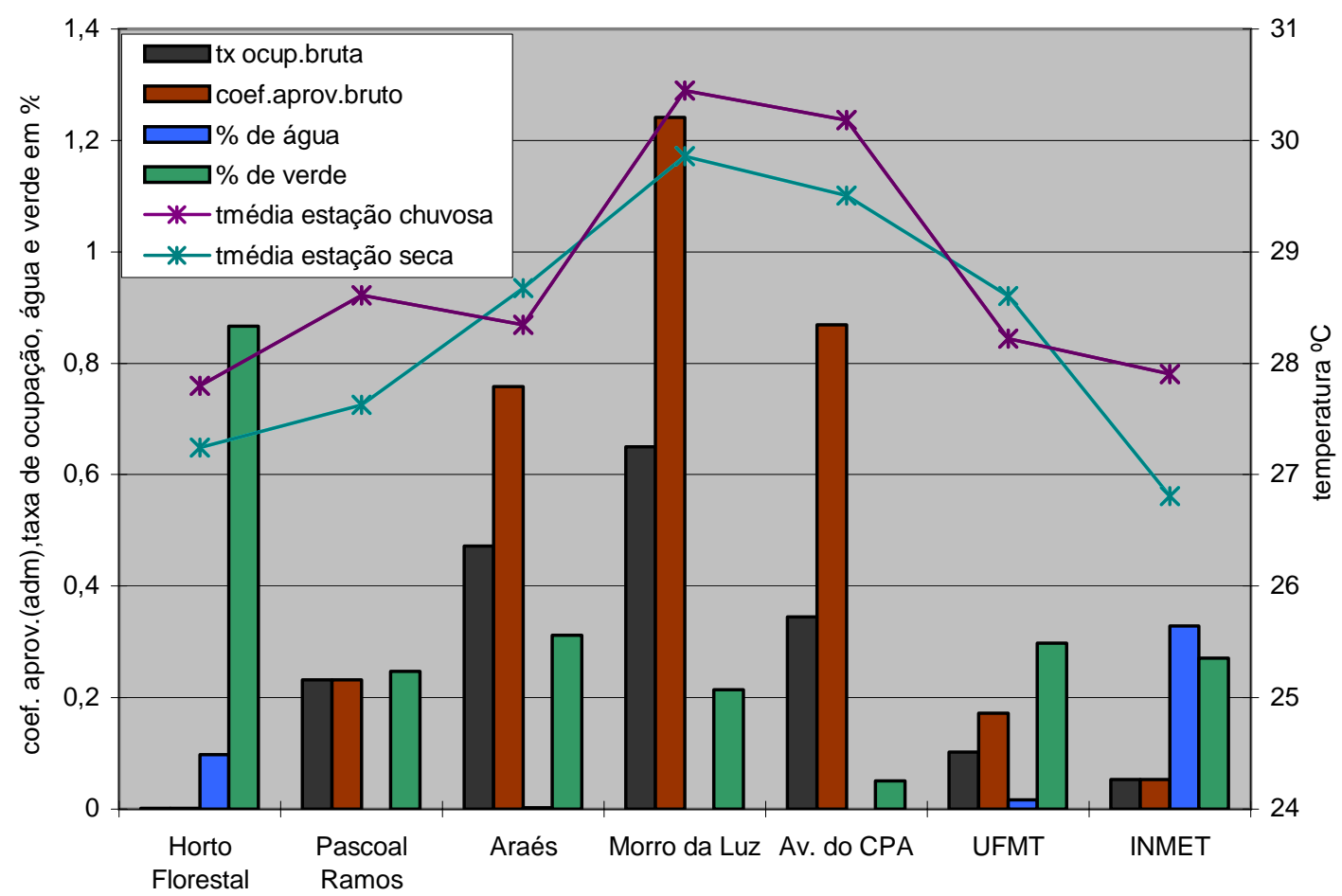

Figura 9.3 - Taxa de ocupação, coeficiente de aproveitamento, percentagem de superfícies d'água e de arborização brutos versus temperatura média durante as estações seca e chuvosa. 
Foram traçadas as linhas de regressão e calculados os coeficientes de correlação (r) entre a temperatura do ar e as variáveis explicativas para cada leitura, às $8 \mathrm{~h}, 14 \mathrm{~h}$ e 20h, separadamente; como exemplo a figura 9.4 mostra a correlação entre temperatura do ar às 8h do dia 23/08/98, na estação seca, e o coeficiente de aproveitamento bruto nas sete unidades observacionais. $\mathrm{O}$ mesmo procedimento foi repetido para cada dia e horário de medição, e para cada variável explicativa envolvida.

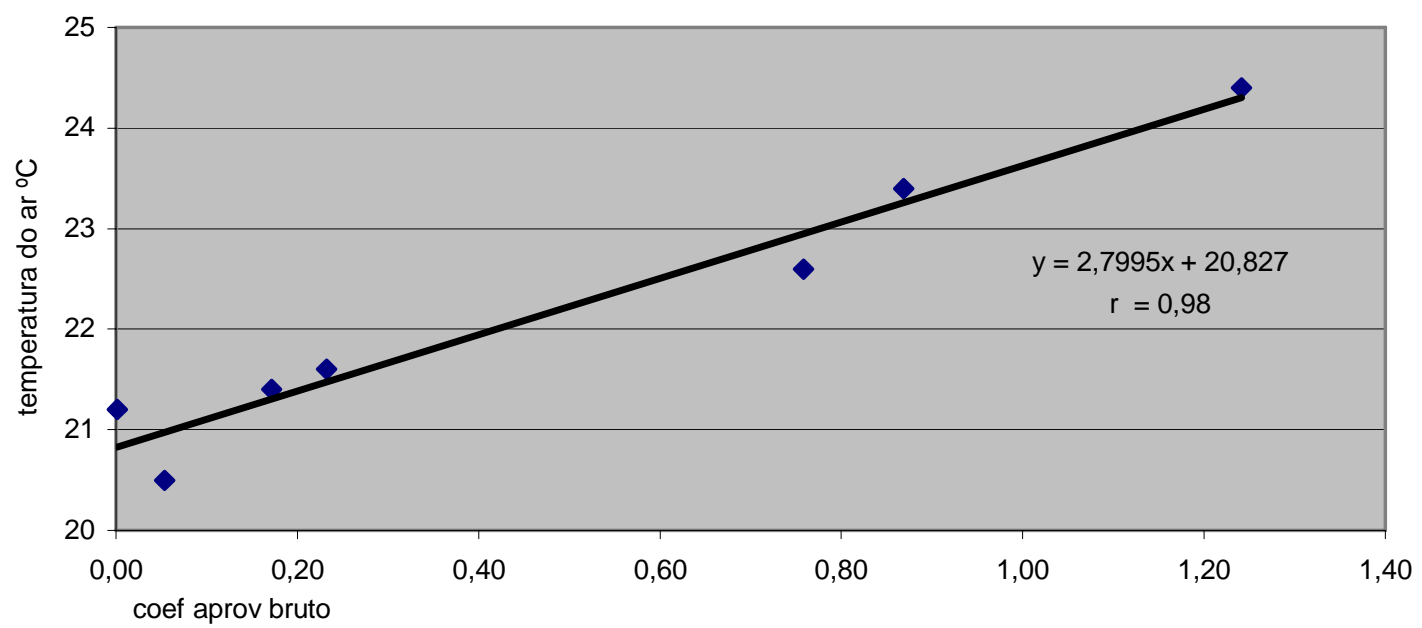

Figura 9.4 - Gráfico de dispersão com a função linear que relaciona as variáveis envolvidas e o coeficiente de correlação $(r=0,98)$ entre temperatura do ar e coeficiente de aproveitamento bruto às 8h, em 23/08/98, durante a estação seca.

Em horários distintos, em função dos diferentes fenômenos relacionados ao clima urbano, os resultados mostraram associação entre as variáveis e o alto grau de correlação entre elas, comprovando a tese. As tabelas 9.2 e 9.3 apresentam os coeficientes de correlação (r) calculados para cada leitura e um coeficiente de correlação médio dos seis dias ( $\mathrm{r}_{\text {médio}}$ ) para cada variável e faixa de horário, para as estações seca e chuvosa.

Os resultados mostram que em ambas as estações, com as variáveis referentes ao espaço construído - taxa de ocupação e coeficiente de aproveitamento líquidos e brutos - o coeficiente de correlação médio foi sempre positivo em relação à temperatura do ar, sendo mais alto às $8 \mathrm{~h}$ e às $20 \mathrm{~h}$ (com $\mathrm{r}_{\text {médio }}$ para taxa de ocupação variando de 0,57 a 0,81 e $r_{\text {médio }}$ para coeficiente de aproveitamento variando de 0,63 a 0,87), refletindo a maior influência do espaço construído no período noturno, o que concorda com a teoria existente.

Às $14 \mathrm{~h}$ as maiores trocas por convecção explicam a menor correlação entre o espaço construído e a temperatura do ar ( $r_{\text {médio }}$ para taxa de ocupação variando de 0,22 a 0,53

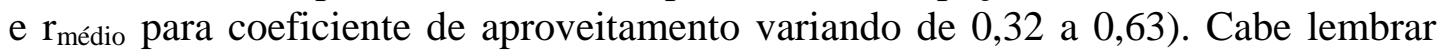
que, durante a estação seca, houve uma invasão de massa polar resultando em instabilidade das condições atmosféricas, principalmente com maiores velocidades de vento do que as habituais, aumentando as trocas por convecção e minimizando a interferência do espaço construído sobre a distribuição horizontal das temperaturas.

Já com as variáveis referentes ao espaço natural, arborização e superfícies d'água, o coeficiente de correlação médio foi sempre negativo em relação à temperatura do ar e parece se comportar de maneira mais ou menos uniforme nos três horários, com 
$\mathrm{r}_{\text {médio }}=-0,4$ para arborização e $\mathrm{r}_{\text {médio }}=-0,37$ para superfícies d'água. Porém, áreas verdes e corpos d'água devem ser considerados principalmente nas trocas de calor latente e na transformação da energia absorvida; em áreas urbanas este fator pode sofrer uma grande diminuição em relação às trocas de calor sensível devido à impermeabilização do solo, canalização de águas superficiais e diminuição da cobertura vegetal.

Tabela 9.2 - Coeficientes de correlação (r) na estação seca.

\begin{tabular}{|c|c|c|c|c|c|c|c|c|c|c|c|}
\hline \multicolumn{4}{|c|}{ coef aprov. líquido } & \multicolumn{4}{|c|}{ taxa ocup. líquida } & \multicolumn{4}{|c|}{ arborização } \\
\hline & $8 \mathrm{~h}$ & $14 \mathrm{~h}$ & $20 \mathrm{~h}$ & & $8 \mathrm{~h}$ & $14 \mathrm{~h}$ & $20 \mathrm{~h}$ & & $8 \mathrm{~h}$ & $14 \mathrm{~h}$ & $20 \mathrm{~h}$ \\
\hline $\mathrm{r}$ & 0,9 & 0,45 & 0,6 & $\mathrm{r}$ & 0,94 & 0,38 & 0,52 & $\mathrm{r}$ & $-0,46$ & $-0,02$ & $-0,22$ \\
\hline $\mathrm{r}$ & 0,78 & 0,11 & 0,48 & $\mathrm{r}$ & 0,82 & $-0,11$ & 0,76 & $\mathrm{r}$ & $-0,3$ & $-0,52$ & $-0,39$ \\
\hline$r$ & 0,69 & 0,43 & 0,81 & $\mathrm{r}$ & 0,77 & 0,05 & 0,86 & $\mathrm{r}$ & $-0,57$ & $-0,71$ & $-0,66$ \\
\hline $\mathrm{r}$ & 0,83 & 0,76 & 0,71 & r & 0,75 & 0,57 & 0,6 & r & $-0,14$ & $-0,2$ & $-0,02$ \\
\hline $\mathrm{r}$ & 0,93 & 0,6 & 0,68 & $\mathrm{r}$ & 0,82 & 0,44 & 0,6 & r & $-0,48$ & $-0,15$ & $-0,38$ \\
\hline $\mathrm{r}$ & 0,91 & 0,46 & 0,5 & $\mathrm{r}$ & 0,78 & 0,2 & 0,49 & $\mathrm{r}$ & $-0,53$ & $-0,12$ & $-0,61$ \\
\hline $\mathrm{r}_{\text {médio }}$ & 0,84 & 0,47 & 0,63 & $\mathrm{r}_{\text {médio }}$ & 0,81 & 0,26 & 0,64 & $\mathrm{r}_{\text {médio }}$ & $-0,41$ & $-0,29$ & $-0,38$ \\
\hline \multicolumn{4}{|c|}{ coef aprov.bruto } & \multicolumn{4}{|c|}{ taxa ocup.bruta } & \multicolumn{4}{|c|}{$\begin{array}{l}\text { superfícies d’água } \\
\end{array}$} \\
\hline & $8 \mathrm{~h}$ & $14 \mathrm{~h}$ & $20 \mathrm{~h}$ & & $8 \mathrm{~h}$ & $14 \mathrm{~h}$ & $20 \mathrm{~h}$ & & $8 \mathrm{~h}$ & $14 \mathrm{~h}$ & $20 \mathrm{~h}$ \\
\hline $\mathrm{r}$ & 0,98 & 0,43 & 0,64 & $\mathrm{r}$ & 0,92 & 0,41 & 0,52 & $\mathrm{r}$ & $-0,65$ & $-0,94$ & $-0,18$ \\
\hline $\mathrm{r}$ & 0,89 & 0,04 & 0,74 & $\mathrm{r}$ & 0,81 & $-0,15$ & 0,81 & $\mathrm{r}$ & $-0,66$ & 0,01 & $-0,46$ \\
\hline $\mathrm{r}$ & 0,82 & 0,12 & 0,86 & $\mathrm{r}$ & 0,77 & $-0,02$ & 0,8 & $\mathrm{r}$ & $-0,49$ & $-0,13$ & $-0,07$ \\
\hline $\mathrm{r}$ & 0,82 & 0,62 & 0,71 & $\mathrm{r}$ & 0,71 & 0,5 & 0,56 & $\mathrm{r}$ & $-0,4$ & $-0,41$ & $-0,16$ \\
\hline $\mathrm{r}$ & 0,85 & 0,46 & 0,67 & $\mathrm{r}$ & 0,75 & 0,41 & 0,57 & $\mathrm{r}$ & $-0,35$ & $-0,45$ & $-0,01$ \\
\hline $\mathrm{r}$ & 0,87 & 0,24 & 0,57 & $\mathrm{r}$ & 0,72 & 0,18 & 0,5 & $\mathrm{r}$ & $-0,33$ & $-0,49$ & $-0,34$ \\
\hline $\mathrm{r}_{\text {médio }}$ & 0,87 & 0,32 & 0,70 & $\mathrm{r}_{\text {médio }}$ & 0,78 & \begin{tabular}{l|}
0,22 \\
\end{tabular} & 0,63 & $\mathrm{r}_{\text {médio }}$ & $-0,48$ & $-0,40$ & $-0,20$ \\
\hline
\end{tabular}

Tabela 9.3 - Coeficientes de correlação (r) na estação chuvosa.

\begin{tabular}{|c|c|c|c|c|c|c|c|c|c|c|c|}
\hline \multicolumn{4}{|c|}{ coef aprov. líquido } & \multicolumn{4}{|c|}{ taxa ocup. líquida } & \multicolumn{4}{|c|}{ arborização } \\
\hline & $8 \mathrm{~h}$ & $14 \mathrm{~h}$ & $20 \mathrm{~h}$ & & $8 \mathrm{~h}$ & $14 \mathrm{~h}$ & $20 \mathrm{~h}$ & & $8 \mathrm{~h}$ & $14 \mathrm{~h}$ & $20 \mathrm{~h}$ \\
\hline $\mathrm{r}$ & 0,9 & 0,64 & 0,85 & $\mathrm{r}$ & 0,8 & 0,73 & 0,82 & $\mathrm{r}$ & $-0,41$ & $-0,75$ & $-0,46$ \\
\hline $\mathrm{r}$ & 0,13 & 0,76 & 0,84 & $\mathrm{r}$ & $-0,003$ & 0,81 & 0,71 & $r$ & $-0,13$ & $-0,42$ & $-0,51$ \\
\hline $\mathrm{r}$ & 0,79 & 0,04 & 0,6 & $\mathrm{r}$ & 0,84 & $-0,04$ & 0,65 & $\mathrm{r}$ & $-0,43$ & 0,68 & $-0,03$ \\
\hline $\mathrm{r}$ & 0,9 & 0,71 & 0,75 & $\mathrm{r}$ & 0,68 & 0,48 & 0,72 & $r$ & $-0,58$ & $-0,59$ & $-0,44$ \\
\hline$r$ & 0,86 & 0,84 & 0,65 & $\mathrm{r}$ & 0,6 & 0,74 & 0,67 & $\mathrm{r}$ & $-0,56$ & $-0,78$ & $-0,6$ \\
\hline $\mathrm{r}$ & 0,94 & 0,79 & 0,79 & $\mathrm{r}$ & 0,71 & 0,69 & 0,93 & $\mathrm{r}$ & $-0,53$ & $-0,66$ & $-0,63$ \\
\hline $\mathrm{r}_{\text {médio }}$ & 0,75 & 0,63 & 0,75 & $\mathrm{r}_{\text {médio }}$ & 0,60 & 0,25 & 0,75 & $\mathrm{r}_{\text {médio }}$ & $-0,44$ & $-0,42$ & $-0,45$ \\
\hline \multicolumn{4}{|c|}{ coef aprov.bruto } & \multicolumn{4}{|c|}{ taxa ocup.bruta } & \multicolumn{4}{|c|}{ superfícies d’água } \\
\hline & $8 \mathrm{~h}$ & $14 \mathrm{~h}$ & $20 \mathrm{~h}$ & & $8 \mathrm{~h}$ & $14 \mathrm{~h}$ & $20 \mathrm{~h}$ & & $8 \mathrm{~h}$ & $14 \mathrm{~h}$ & $20 \mathrm{~h}$ \\
\hline $\mathrm{r}$ & 0,92 & 0,65 & 0,9 & $\mathrm{r}$ & 0,84 & 0,7 & 0,8 & $\mathrm{r}$ & $-0,52$ & $-0,46$ & $-0,55$ \\
\hline $\mathrm{r}$ & 0,09 & 0,8 & 0,74 & $\mathrm{r}$ & 0,01 & 0,79 & 0,62 & r & $-0,56$ & $-0,77$ & 0,01 \\
\hline $\mathrm{r}$ & 0,85 & 0,01 & 0,7 & $\mathrm{r}$ & 0,79 & $-0,07$ & 0,61 & $\mathrm{r}$ & $-0,4$ & 0,19 & $-0,19$ \\
\hline $\mathrm{r}$ & 0,77 & 0,53 & 0,79 & $\mathrm{r}$ & 0,62 & 0,42 & 0,67 & $\mathrm{r}$ & $-0,53$ & $-0,56$ & $-0,07$ \\
\hline $\mathrm{r}$ & 0,71 & 0,75 & 0,73 & $\mathrm{r}$ & 0,51 & 0,69 & 0,66 & $r$ & $-0,05$ & $-0,55$ & $-0,42$ \\
\hline $\mathrm{r}$ & 0,8 & 0,69 & 0,91 & $\mathrm{r}$ & 0,63 & 0,65 & 0,89 & $\mathrm{r}$ & $-0,34$ & $-0,66$ & $-0,24$ \\
\hline $\mathrm{r}_{\text {médio }}$ & 0,69 & 0,57 & 0,80 & $\mathrm{r}_{\text {médio }}$ & 0,57 & 0,53 & 0,71 & $\mathrm{r}_{\text {médio }}$ & $-0,40$ & $-0,47$ & $-0,24$ \\
\hline
\end{tabular}


As tabelas 9.4 e 9.5 apresentam as equações de regressão linear para as estações seca e chuvosa, sendo $y$ a temperatura do ar e $x$ cada uma das variáveis referentes à ocupação.

Tabela 9.4 - Equações de regressão linear para a estação seca.

\begin{tabular}{|c|c|c|}
\hline $8 \mathrm{~h}$ & $14 \mathrm{~h}$ & $20 \mathrm{~h}$ \\
\hline \multicolumn{3}{|c|}{ Coeficiente de aproveitamento líquido } \\
\hline$y=1,245 x+21,083$ & $y=1,0443 x+32,899$ & $y=1,0854 x+24,935$ \\
\hline$y=1,189 x+20,831$ & $y=0,0752 x+34,335$ & $y=0,7433 x+25,244$ \\
\hline$y=1,1973 x+22,281$ & $y=0,279 x+35,931$ & $y=1,053 x+25,948$ \\
\hline$y=0,6151 x+18,526$ & $y=0,8435 x+20,872$ & $y=0,2854 x+19,625$ \\
\hline$y=0,4889 x+16,664$ & $y=0,6065 x+25,477$ & $y=0,9708 x+20,276$ \\
\hline $\mathrm{y}=1,1799 \mathrm{x}+17,41$ & $y=0,4515 x+29,725$ & $y=0,5568 x+23,948$ \\
\hline \multicolumn{3}{|c|}{ Taxa de ocupação líquida } \\
\hline$y=0,0393 x+20,697$ & $y=0,0265 x+32,816$ & $y=0,0288 x+24,802$ \\
\hline$y=0,0377 x+20,458$ & $y=-0,0024 x+34,491$ & $y=0,0356 x+24,562$ \\
\hline $\mathrm{y}=0,0408 \mathrm{x}+21,799$ & $y=0,001 x+36,134$ & $y=0,0342 x+25,587$ \\
\hline$y=0,017 x+18,426$ & $y=0,0194 x+20,881$ & $y=0,0074 x+19,596$ \\
\hline$y=0,0132 x+16,597$ & $y=0,0136 x+25,495$ & $y=0,026 x+20,147$ \\
\hline$y=0,0306 x+17,291$ & $y=0,0062 x+29,885$ & $y=0,0168 x+23,804$ \\
\hline \multicolumn{3}{|c|}{ Coeficiente de aproveitamento bruto } \\
\hline $\mathrm{y}=2,7995 \mathrm{x}+20,827$ & $y=2,0802 x+32,811$ & $y=2,4222 x+24,72$ \\
\hline$y=2,8043 x+20,524$ & $y=-0,0652 x+34,431$ & $y=2,3899 x+24,75$ \\
\hline$y=2,9451 x+21,915$ & $y=0,1624 x+36,094$ & $y=2,3435 x+25,743$ \\
\hline$y=1,2596 x+18,459$ & $y=1,4423 x+20,915$ & $y=0,6015 x+19,586$ \\
\hline$y=0,9373 x+16,64$ & $y=0,9679 x+25,54$ & $y=2,0003 x+20,164$ \\
\hline $\mathrm{y}=2,3506 \mathrm{x}+17,311$ & $y=0,4892 x+29,882$ & $y=1,3174 x+23,802$ \\
\hline \multicolumn{3}{|c|}{ Taxa de ocupação bruta } \\
\hline $\mathrm{y}=0,053 \mathrm{x}+20,75$ & $y=0,0399 x+32,742$ & $y=0,0393 x+24,829$ \\
\hline$y=0,0516 x+20,487$ & $y=-0,0045 x+34,52$ & $y=0,0526 x+24,489$ \\
\hline$y=0,0556 x+21,839$ & $y=-0,0007 x+36,189$ & $y=0,0441 x+25,689$ \\
\hline $\mathrm{y}=0,0219 \mathrm{x}+18,476$ & $y=0,0233 x+20,982$ & $y=0,0096 x+19,618$ \\
\hline$y=0,0166 x+16,644$ & $y=0,0175 x+25,536$ & $y=0,0343 x+20,205$ \\
\hline$y=0,0391 x+17,392$ & $y=0,0074 x+29,918$ & $y=0,0236 x+23,804$ \\
\hline \multicolumn{3}{|c|}{ Arborização } \\
\hline$y=-0,0245 x+22,949$ & $y=-0,0017 x+33,856$ & $y=-0,0154 x+26,37$ \\
\hline$y=-0,0178 x+22,43$ & $y=-0,0144 x+34,863$ & $y=-0,0236 x+26,649$ \\
\hline$y=-0,0386 x+24,561$ & $y=-0,018 x+36,751$ & $y=-0,0337 x+27,945$ \\
\hline$y=-0,004 x+19,187$ & $y=-0,0088 x+21,885$ & $y=-0,0003 x+19,881$ \\
\hline$y=-0,0099 x+17,406$ & $y=-0,0059 x+26,189$ & $y=-0,021 x+21,791$ \\
\hline$y=-0,0269 x+19,296$ & $y=-0,0045 x+30,259$ & $y=-0,0269 x+25,296$ \\
\hline \multicolumn{3}{|c|}{ Superfícies d’água } \\
\hline$y=-0,0725 x+22,619$ & $\mathrm{y}=-0,1765 \mathrm{x}+34,924$ & $y=-0,0272 x+26,045$ \\
\hline$y=-0,0822 x+22,381$ & $y=0,0006 x+34,396$ & $y=-0,0576 x+26,253$ \\
\hline$y=-0,0692 x+23,755$ & $y=-0,0068 x+36,215$ & $y=-0,0074 x+26,904$ \\
\hline$y=-0,0241 x+19,211$ & $y=-0,037 x+21,836$ & $y=-0,0054 x+19,906$ \\
\hline$y=-0,0149 x+17,181$ & $y=-0,0373 x+26,238$ & $y=-0,0011 x+21,121$ \\
\hline$y=-0,0347 x+18,65$ & $y=-0,0398 x+30,368$ & $y=-0,0308 x+24,625$ \\
\hline
\end{tabular}


Tabela 9.5 - Equações de regressão linear para a estação chuvosa.

\begin{tabular}{|c|c|c|}
\hline $8 \mathrm{~h}$ & $14 \mathrm{~h}$ & $20 \mathrm{~h}$ \\
\hline \multicolumn{3}{|c|}{ Coeficiente de aproveitamento líquido } \\
\hline$y=1,6068 x+25,754$ & $y=1,2588 x+33,169$ & $y=0,7213 x+26,434$ \\
\hline$y=0,0504 x+24,242$ & $y=0,9868 x+31,719$ & $y=1,2151 x+26,921$ \\
\hline$y=1,1642 x+27,165$ & $y=0,0246 x+25,207$ & $y=0,1937 x+23,375$ \\
\hline$y=1,0401 x+25,187$ & $y=0,893 x+32,685$ & $y=0,5328 x+27,882$ \\
\hline$y=2,2813 x+26,085$ & $y=1,2935 x+32,511$ & $y=0,6619 x+28,328$ \\
\hline$y=1,779 x+25,705$ & $y=1,3541 x+33,372$ & $y=0,5522 x+25,008$ \\
\hline \multicolumn{3}{|c|}{ Taxa de ocupação líquida } \\
\hline$y=0,0482 x+25,353$ & $y=0,0435 x+32,641$ & $y=0,0212 x+26,27$ \\
\hline$y=-3 E-05 x+24,287$ & $y=0,032 x+31,381$ & $y=0,0313 x+26,808$ \\
\hline$y=0,0379 x+26,764$ & $y=-0,0007 x+25,255$ & $y=0,0063 x+23,308$ \\
\hline$y=0,0242 x+25,186$ & $y=0,0184 x+32,774$ & $y=0,0157 x+27,761$ \\
\hline$y=0,0486 x+26,253$ & $\mathrm{y}=0,0347 \mathrm{x}+32,341$ & $y=0,0208 x+28,127$ \\
\hline$y=0,0408 x+25,726$ & $y=0,0357 x+33,216$ & $y=0,0199 x+24,745$ \\
\hline \multicolumn{3}{|c|}{ Coeficiente de aproveitamento bruto } \\
\hline$y=3,4504 x+25,506$ & $\mathrm{y}=2,6519 \mathrm{x}+32,999$ & $y=1,5953 x+26,301$ \\
\hline$y=0,0734 x+24,251$ & $y=2,166 x+31,544$ & $y=2,2325 x+26,913$ \\
\hline$y=2,6233 x+26,927$ & $y=0,0153 x+25,221$ & $y=0,4673 x+23,321$ \\
\hline$y=1,8537 x+25,207$ & $y=1,4085 x+32,789$ & $y=1,165 x+27,79$ \\
\hline$y=3,8995 x+26,208$ & $\mathrm{y}=2,3775 \mathrm{x}+32,501$ & $y=1,5451 x+28,167$ \\
\hline$y=3,1335 x+25,757$ & $y=2,4488 x+33,381$ & $y=1,3298 x+24,855$ \\
\hline \multicolumn{3}{|c|}{ Taxa de ocupação bruta } \\
\hline$y=0,0632 x+25,467$ & $y=0,0576 x+32,73$ & $y=0,0285 x+26,302$ \\
\hline$y=0,0002 x+24,281$ & $y=0,0433 x+31,422$ & $y=0,0378 x+26,968$ \\
\hline$y=0,0493 x+26,864$ & $y=-0,0018 x+25,277$ & $y=0,0082 x+23,326$ \\
\hline$y=0,0302 x+25,286$ & $y=0,0221 x+32,871$ & $y=0,0199 x+27,814$ \\
\hline$y=0,057 x+26,546$ & $y=0,0445 x+32,447$ & $y=0,028 x+28,157$ \\
\hline$y=0,0498 x+25,922$ & $y=0,0467 x+33,305$ & $y=0,0264 x+24,786$ \\
\hline \multicolumn{3}{|c|}{ Arborização } \\
\hline$y=-0,0291 x+28,082$ & $y=-0,0574 x+36,11$ & $y=-0,0154 x+27,553$ \\
\hline$y=-0,0019 x+24,346$ & $y=-0,0214 x+33,262$ & $y=-0,029 x+28,907$ \\
\hline$y=-0,025 x+28,977$ & $\mathrm{y}=0,0169 \mathrm{x}+24,682$ & $y=-0,0004 x+23,557$ \\
\hline$y=-0,0262 x+26,93$ & $y=-0,0292 x+34,4$ & $y=-0,0123 x+28,741$ \\
\hline$y=-0,0583 x+29,94$ & $\mathrm{y}=-0,0467 \mathrm{x}+35,137$ & $y=-0,0237 x+29,666$ \\
\hline $\mathrm{y}=-0,0391 \mathrm{x}+28,506$ & $y=-0,0438 x+35,955$ & $y=-0,0172 x+26,041$ \\
\hline \multicolumn{3}{|c|}{ Superfícies d’água } \\
\hline $\mathrm{y}=-0,0764 \mathrm{x}+27,629$ & $y=-0,073 x+34,722$ & $y=-0,0383 x+27,301$ \\
\hline $\mathrm{y}=-0,0175 \mathrm{x}+24,397$ & $y=-0,0822 x+33,095$ & $y=0,0014 x+27,963$ \\
\hline$y=-0,0478 x+28,476$ & $y=0,0101 x+25,164$ & $y=-0,0049 x+23,574$ \\
\hline$y=-0,0499 x+26,403$ & $y=-0,0574 x+33,823$ & $y=-0,0041 x+28,369$ \\
\hline$y=-0,0118 x+28,133$ & $y=-0,0688 x+34,067$ & $y=-0,0345 x+29,12$ \\
\hline$y=-0,053 x+27,58$ & $y=-0,0924 x+35,131$ & $y=-0,0137 x+25,573$ \\
\hline
\end{tabular}

Para as condições climáticas da região em estudo o padrão de ocupação mais adequado para o conforto térmico noturno é contraditório com as necessidades 
diurnas de conforto humano. Vários estudos já demonstraram que uma maior relação H/W nos canyons urbanos dificulta a irradiação noturna do calor acumulado, mas resulta em menores temperaturas durante o dia por causa do sombreamento provocado pelos edifícios. Já a vegetação tem menor taxa de aquecimento durante o dia e maior taxa de resfriamento à noite, se comparada aos materiais correntes de construção e demais superfícies urbanas.

O experimento de ASSIS (2000) para Belo Horizonte mostrou que grandes áreas livres dentro de regiões verticalizadas parecem contribuir para a redução do efeito de aquecimento urbano. Mostrou também que nos canyons urbanos com uma obstrução de até $15 \%$ da hemisfera celeste local não há um aumento relevante da capacidade do recinto urbano reter calor, enquanto que, quando o fator de visão de céu é da ordem de $60 \%$, ou seja, com $40 \%$ de obstrução, provoca uma certa persistência do efeito de sobreaquecimento nos recintos urbanos mais verticalizados até por volta das 9:00h, refletindo o período de aquecimento noturno. Estimando ângulos de obstrução para torres com distância horizontal frontal da ordem de 30m (padrão comum em alguns recintos urbanos de Belo Horizonte), Assis chegou à altura de 8 ou 9 pavimentos. A autora lembra que o que acontece durante o dia também é crítico; sem o adequado sombreamento dos espaços públicos em cidades de clima tropical, seja por árvores ou elementos construtivos, pode ocorrer stress térmico durante o dia, mesmo no inverno em algumas regiões.

Esse sombreamento tão necessário (e também a refrigeração do ar pela evapotranspiração das folhas) pode ser alcançado com o uso de vegetação em larga escala.

\subsection{Proposta de um parâmetro relacionando densidade construída, arborização e superfícies d’água em áreas urbanizadas}

Tendo em vista a correlação encontrada nesta tese e os inúmeros estudos existentes recomendando a distribuição da área verde em pequenos espaços espalhados por toda a cidade ao invés de um único parque com maiores proporções, propõe-se um parâmetro relacionando densidade construída, arborização e superfícies d’água para ser aplicado em áreas urbanizadas.

Ao invés de se contabilizar a área verde em função do tamanho da população como usualmente se faz, seria mais interessante determinar esse parâmetro em função da densidade construída para cada bairro ou zona da cidade, mantendo como critério de uniformidade a homogeneidade do padrão de ocupação. $\mathrm{O}$ índice área verde por habitante não faz o menor sentido em algumas cidades, como as que ficam no meio da floresta, por exemplo. Do ponto de vista do conforto térmico e da poluição do ar esse índice pode não significar nada. Mesmo que esse índice seja elevado, essa área verde pode estar concentrada em apenas um ou em alguns pontos, oferecendo pouca ou nenhuma vantagem para a população. "The effects of plants on the climate in the built-up areas depend on the fraction of 'green' areas, public as well as private, relative to the whole built-up urban area."(GIVONI, 1998, p.319)

Pelos motivos expostos parece que essa relação entre densidade construída, arborização e superfícies d’água para ser aplicada em áreas urbanizadas é válida, mas ainda precisa ser testada em outros estudos de caso. Um parâmetro desse tipo parece mais adequado ao planejamento e, depois de calibrado, pode indicar um mínimo de 
vegetação e superfícies d'água desejáveis para a melhoria das condições de conforto higrotérmico humano no espaço construído. Dessa forma se pode aferir se o verde está distribuído ou concentrado em alguns pontos na cidade, e qual a sua proporção em relação à densidade construída. Essa proposta concorda com muitos autores que simularam a distribuição de vegetação em espaços urbanos, porque os benefícios microclimáticos e de filtragem da poluição do ar são muito localizados, e se estendem apenas por algumas dezenas de metros, mesmo na periferia de grandes parques urbanos.

GIVONI (1991 e 1998), SPIRN (1995), HONJO e TAKAKURA (1990/91) e ASSIS, (1990), dentre outros, considerando o efeito extremamente localizado das áreas verdes, recomendam a sua distribuição pela área construída. Givoni sugere que, a partir de um certo ponto, o tamanho de um único parque faz pouca diferença nas condições climáticas além dos seus limites. Porém, a divisão da área verde em um maior número de pequenos parques, espalhados por toda a cidade, estende os benefícios a uma área maior, a um maior número de pessoas. Cada bairro deve ter uma parcela de área verde e superfícies d’água para criar no seu entorno condições de conforto higrotérmico e de qualidade do ar mais adequados. Os parques urbanos também podem atuar como elementos de ligação entre bairros, compartilhando equipamentos e serviços. Givoni ainda lembra que, para as condições de conforto higrotérmico do edifício e para a redução do consumo de energia para resfriamento, a vegetação nos lotes no entorno dos edifícios é muito mais significativa. Além disso, com essa distribuição, os edifícios não dominam a paisagem, mas passam a fazer parte dela.

O efeito direto da vegetação na poluição do ar é a filtragem de parte dos poluentes e o efeito indireto é incrementar as condições de ventilação na cidade, que por sua vez afeta a dispersão de poluentes, principalmente os gerados pelo trânsito nas ruas, próximo ao solo. Do ponto de vista da filtragem de poluentes também é mais eficiente espaçar árvores e parques urbanos do que concentrá-los em alguns pontos (GIVONI, 1998, p.320-321). Do ponto de vista do ruído urbano o efeito da vegetação é quase nulo, mas as áreas verdes exercem um efeito psicológico, escondendo a fonte de ruído.

Para o planejamento de um programa de arborização devem ser considerados diversos fatores (GIVONI, 1998, p.304): a área livre total disponível, a divisão dessa área em parcelas menores, a distribuição nas áreas centrais e na periferia, o tamanho de cada parcela e sua localização em relação às áreas residenciais e o desenho de cada parcela, dos equipamentos, dos acessos, etc.

Observando a retração da vegetação na estação seca na região de clima tropical continental, o plantio pontilhado, distribuído em pequenas áreas verdes também facilita a manutenção. É preciso investigar melhor a otimização do tamanho das áreas verdes e do correspondente investimento a ser feito frente aos ganhos no consumo de energia e bem-estar da população.

Segundo o princípio da melhor distribuição das áreas verdes, hoje largamente aceito, o parâmetro área verde/habitante não faz o menor sentido, pois não reflete a distribuição desse verde pela cidade. Tão importantes quanto a disponibilidade das áreas verdes são a sua distribuição e a qualidade dos espaços produzidos, bem como as vantagens sociais que a população usufrui. "Determination of the optimal size of 
open spaces, for a given urban area and population, is a complex problem. (...) Determining the area of parks according to the number of acres required for a specific population size reflects current planning methods, yet is does not deal with the functional needs of the population destined to use the park, and the degree to which the specific planned elements in the park fulfill these needs." (GIVONI, 1998, p.326)

MENNEH e COELHO (2000) mostram a distribuição irregular das áreas verdes na cidade de São Paulo que hoje, em média, é de $3,65 \mathrm{~m}^{2} / \mathrm{hab}$, e demonstram que esse índice variou muito durante o processo de urbanização. As autoras sugerem uma maior participação privada no aumento de áreas verdes, que poderia se dar nos processos de verticalização dos bairros, uma vez que no parcelamento não é levada em consideração a densidade que o bairro virá a tingir. À medida que se altera o zoneamento e/ou o perfil da região pela verticalização, não se questiona a necessidade do aumento das áreas públicas. As autoras sugerem mecanismos de compensação, como a compra de áreas equivalentes ao aumento de potencial construtivo durante a verticalização. Pelo levantamento de LOMBARDO (1995) a cobertura vegetal em São Paulo é de 70\% no Morumbi, e de apenas 3\% na área central.

De acordo com GONÇALVES (1994) se, por um lado, o loteador tem algum interesse no melhor aproveitamento do solo em termos de área construída, a administração pública corrobora esse interesse, à medida que quanto maior a área construída, maior a arrecadação de impostos e menores os custos de manutenção pela redução no número de áreas verdes. Além disso, os bicos de quadra destinados às áreas verdes atendem, na melhor das hipóteses, a uma porcentagem de área verde por habitante, mas não às funções sociais a que se destinam.

Apesar da relevância da arborização urbana para algumas cidades, é preciso desmistificar essa reposição do verde; o elemento natural também pode ser a presença de água na paisagem; em Veneza, por exemplo, o sombreamento para os pedestres é promovido pelo próprio confinamento das ruas estreitas e pelas galerias nos pavimentos térreos dos edifícios, e quase não existem árvores, o que é comum em cidades medievais, e nem por isso a cidade é termicamente desconfortável. Em regiões predominantemente quentes e úmidas o incremento de superfícies d'água não é necessário nem desejável; nesse caso o rigor climático é mais bem resolvido com vegetação que proporcione o maior sombreamento possível sem obstruir a ventilação na altura dos ocupantes. Em outros casos, como em Sevilha, por exemplo, a presença de água ameniza o rigor do clima extremamente seco, e tem tanta importância quanto a presença do verde.

Sendo assim, na tentativa de se propor um parâmetro que representasse a proporção entre a densidade construída e os elementos naturais - água e vegetação arbórea, dividiu-se o produto taxa de ocupação $x$ coeficiente de aproveitamento (variáveis que se referem ao espaço construído, com correlação positiva em relação à temperatura do ar) pela somatória das variáveis superfícies d’água e arborização (variáveis que se referem ao espaço natural, com correlação negativa em relação à temperatura do ar), e que amenizam as condições climáticas desfavoráveis para o clima da região tropical continental. 
Seguindo esse raciocínio podem ser feitas duas abordagens: com as variáveis líquidas, ou seja, representando a ocupação somente das quadras, ou brutas, englobando a área ocupada por ruas, parques, praças, etc. Do ponto de vista climático é mais interessante trabalhar com valores brutos, pois para o clima não interessa se área verde é publica ou privada, mais isso vai fazer diferença na hora da implementação das medidas.

Esse índice deve ser testado para outros casos para que se possa fazer qualquer proposição mais abrangente, talvez incorporando novas variáveis. Nesta proposta a intenção foi trabalhar com variáveis familiares ao planejamento, e que fossem relativamente fáceis de se obter, facilitando a sua aplicação.

$$
I=\frac{\text { taxa ocup. } x \text { coef. aprov. }}{\text { sup.água }+ \text { arborização }}
$$

Se o índice usasse só a taxa de ocupação, não levaria em conta a verticalização dos edifícios. Usando o coeficiente de aproveitamento, computo a área total construída; mas, se usasse só o coeficiente de aproveitamento isso poderia significar ocupar todo o solo e manter uma alta densidade horizontal, com edifícios baixos, e já foi demonstrado por ASSIS (1990), usando o exemplo de Belo Horizonte, que em áreas verticalizadas, mas com maior área livre, as condições de conforto térmico são melhores do que em áreas horizontais com maior taxa de ocupação. Essa recomendação também concorda com o trabalho de BITTENCOURT et al. (1997 e 2000) e GIVONI (1998). Sob a pressão do aumento da densidade habitacional pretendida pelos planos diretores mais recentes nas cidades brasileiras, se a legislação incentivar a construção em altura em determinados locais, mas com taxas de ocupação mais baixas e recuos mínimos obrigatórios, isso aumenta a porosidade do espaço construído e sobram mais áreas livres no nível da rua, disponíveis para arborização e para lazer dos moradores. E o microclima urbano é apenas um dos fatores que vai determinar se é conveniente verticalizar ou não; isso também depende de outros fatores, tais como a disponibilidade de infra-estrutura urbana.

Neste estudo as variáveis foram quantificadas em áreas de ocupação mais ou menos homogêneas de 25ha mas, como os valores são percentuais, posso usar outras dimensões; o que importa é a homogeneidade do padrão de ocupação.

Segundo Bittencourt, ${ }^{2}$ em teoria, alta densidade de edifícios baixos com gabarito uniforme podem provocar uma redução drástica (quase estagnação) na velocidade do vento na altura dos pedestres, dependendo do grau de adensamento. VILLAS BOAS (1998) sugere ainda a distribuição dos parques dentro da malha urbana, para permitir a recuperação de parte do padrão do vento existente antes de atingir os obstáculos na cidade. A escola alemã de climatologia urbana tem a tradição de mapear as chamadas vias aéreas (fluxos predominantes de vento) para antecipar futuras conseqüências da ocupação da cidade, e assim determinar verdadeiros corredores de vento que devem permanecer desobstruídos para a melhoria das condições de conforto ou para a dispersão de poluentes. Nessas áreas a arborização é mantida para produção de ar limpo e fresco. Os resultados são usados pela administração municipal e são levados em consideração nas decisões políticas (KATZSCHNER, 1997).

\footnotetext{
2 informação verbal.
} 
Porém, de acordo SILVA (1999) ${ }^{3}$ não se pode estender os resultados de estudos de ventilação para outros locais; os escoamentos, a orografia e a rugosidade podem ser diferentes, e os resultados dependem das condições locais de ventilação, da configuração de ocupação do solo, etc.

Mesmo não podendo aplicar diretamente os resultados de estudos de ventilação existentes para as cidades da região tropical continental, tudo indica que a solução de aumentar o afastamento entre os edifícios para a criação de amplas áreas verdes distribuídas no espaço construído seria mais indicada do que adensá-los. Seria interessante ainda que esses edifícios tivessem altura variável, o que também é recomendado por GIVONI (1998). Isso facilita o desvio de parte do fluxo do vento que atinge os edifícios para baixo, favorecendo a circulação do ar no nível da rua, na altura dos pedestres. A adoção de pilotis vazados também ajuda o escoamento do vento por entre os edifícios no nível da rua. Em áreas de ocupação densa, se todos os edifícios tiverem aproximadamente a mesma altura, o nível das coberturas passa a funcionar como se fosse o nível do solo, e o escoamento do vento acontece principalmente nessa nova superfície. BITTENCOURT (1997) lembra que os recuos maiores, além de facilitar a circulação do vento na malha urbana, aumentam o potencial de uso da iluminação natural, reduzindo a carga térmica da iluminação artificial.

Pelo índice sugerido, se a taxa de ocupação for igual a 1 (100\%), na verdade estou dividindo área total construída por área ocupada por água e sombreada pela arborização; se a taxa de ocupação for menor que 1, mais áreas livres estão disponíveis para arborização no terreno, e menor vai ser o índice. Teoricamente o limite superior do índice proposto é infinito, já que mesmo ocupando 100\% dos terrenos posso construir em altura até onde a técnica e a legislação municipal permitirem.

Esse é um índice de valoração, inverso às condições de conforto higrotérmico pretendidas para o clima da região, e que permite uma comparação entre os diversos padrões de ocupação. As medições de temperatura do ar foram consideradas na elaboração do índice porque determinaram o sinal da correlação com cada variável envolvida, e porque permitem comparar o índice de cada bairro com os microclimas encontrados, como sugerido na figura 9.5.

\subsubsection{Exemplo de aplicação do índice para os sete casos estudados em Cuiabá}

Em Cuiabá, dentre os locais estudados, o ambiente mais próximo das condições naturais é o Horto Florestal, que apresenta um índice próximo de zero, e, portanto não é considerado como padrão de ocupação possível porque não é urbano; no entorno do INMET a ocupação também é bastante rala, às margens do Rio Cuiabá; os demais locais são bastante urbanizados. Cabe lembrar que a aplicação deste índice só é válida para áreas urbanas. Para os sete casos estudados em Cuiabá os resultados encontrados são apresentados na figura 9.5, sempre trabalhando com valores brutos para todas as variáveis envolvidas.

Ainda não se pode afirmar qual o índice ideal antes da aplicação para outras áreas urbanas, em outras cidades com o mesmo tipo de clima, a fim de calibrar esse

\footnotetext{
${ }^{3}$ informação verbal
} 
parâmetro. Mas, comparando o índice com as condições climáticas encontradas em Cuiabá, e analisando os três locais mais urbanizados, próximos ao centro da cidade, pode-se apenas sugerir o padrão de ocupação do Araés como um dos padrões adequados de ocupação que, neste caso em particular, é um padrão predominantemente horizontal, com edifícios de um ou dois pavimentos e com alguns edifícios altos isolados, mas com elementos naturais em abundância, apesar do bairro estar quase totalmente ocupado. Pela foto aérea ${ }^{4}$ da área estudada, verificase que praticamente não há lotes vagos.

Acredita-se que, da mesma forma, é possível encontrar outros padrões de ocupação considerados termicamente confortáveis para as condições ambientais da região, mas com ocupação predominantemente vertical, desde que com menor taxa de ocupação e com elementos naturais em determinada proporção, ainda desconhecida.

A área do CPA apresenta um índice mais elevado porque tem muitos edifícios altos, mas praticamente sem arborização. No entanto ainda são muitos os lotes vagos, e medidas específicas para esta área (e para as novas que devem surgir seguindo este mesmo padrão) poderiam ser adotadas visando ajustar a densidade construída à existência de água e/ou arborização necessárias à amenização do rigor climático.

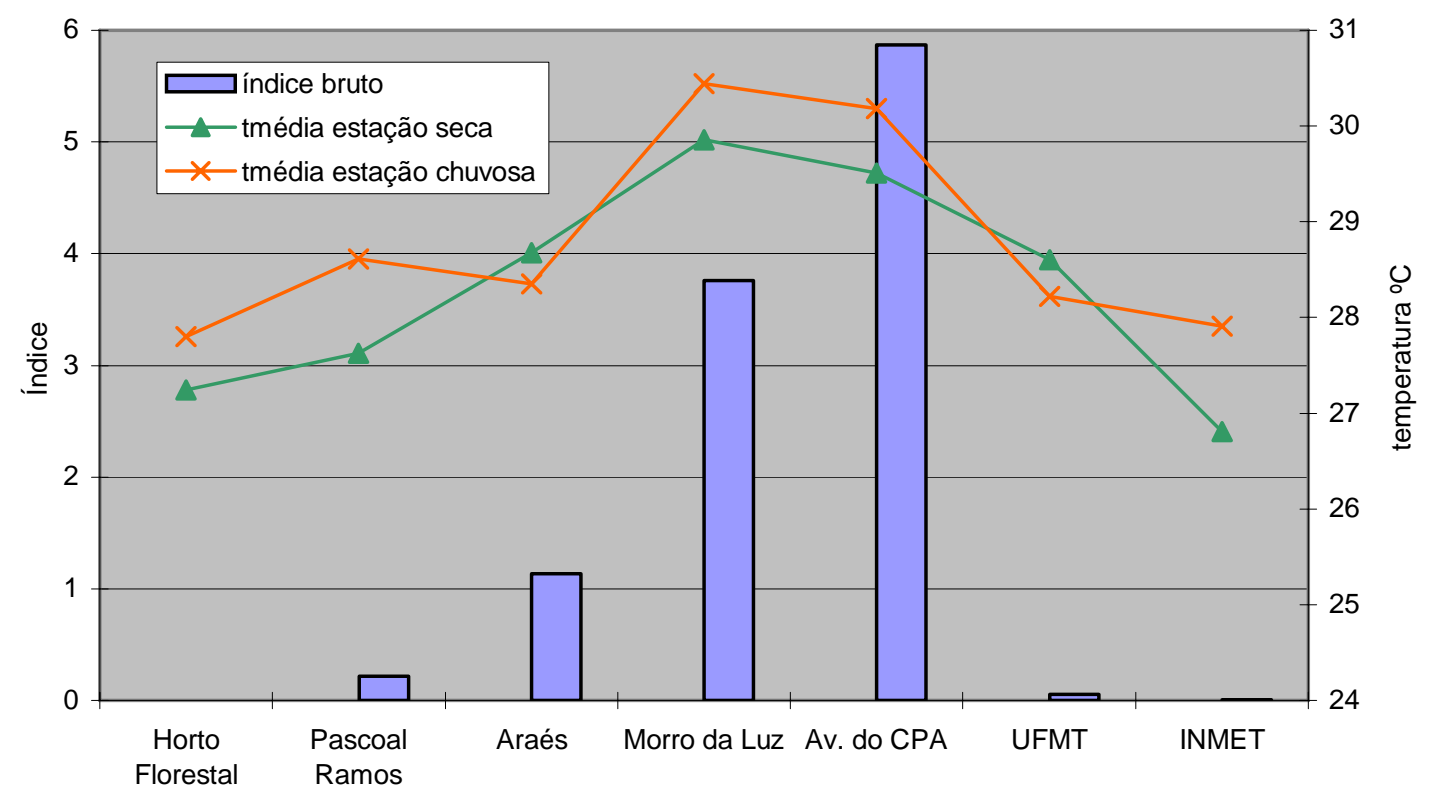

Figura 9.5 - Índice calculado para as sete unidades amostrais em Cuiabá.

Em Cuiabá a região do CPA ainda tem grande potencial para criação do que GIVONI (1992a, p.403, 399) chama de urban cool island; o local é um pouco mais alto do que o centro antigo, melhor servido por ventos, é uma das principais zonas de crescimento da cidade e ainda está em fase de expansão. A vegetação nativa não foi preservada, mas como ainda são muitos os lotes desocupados a área deve ser arborizada enquanto é tempo, podendo chegar a um índice mais favorável mesmo com um padrão de ocupação vertical. Mesmo para a estação úmida, com os espaços entre os edifícios ocupados por áreas verdes ou corpos d’água, esse padrão não traria

\footnotetext{
${ }^{4}$ ver anexo 3.
} 
inconvenientes. "At a given density level, the best urban climate conditions exists in a hot-humid climate when that density is obtained with high narrow buildings ('towers'), placed as far apart from each other as is consistent with the given density. Such a configuration provides the best ventilation conditions for the given urban section as a whole, and especially for the occupants of the buildings."

Em Cuiabá o padrão de ocupação do CPA é uma das tendências de ocupação para as novas áreas; acredita-se que a verticalização não seja um mal em si, o problema é o desequilíbrio da densidade construída com a vegetação e corpos d'água. A legislação municipal exige os recuos, evitando a formação de um paredão que obstruiria a já escassa ventilação, mas falta a inclusão de espaços verdes de amenidade climática para contrabalançar o alto coeficiente de aproveitamento. "In situ measurements of the air temperature in existing neighborhoods with 'promising' urban profiles can provide useful information on urban designs which can minimize the urban temperatures in arid regions. ” (GIVONI, 1992a, p.403)

Já o centro antigo tem um índice mais baixo por causa da vegetação do Morro da Luz, que deve ser preservada, não só para melhoria das condições de conforto higrotérmico, mas para manter a identidade visual do lugar e a contenção da encosta. No centro velho restam pouquíssimos quintais arborizados, mas podem ser inseridos mais espaços verdes em lotes com antigas construções sem valor histórico que, pouco a pouco, vão sendo demolidas.

Por indução o índice foi aplicado para outros bairros próximos à área central da cidade de Cuiabá, ${ }^{5}$ fazendo medidas da ocupação em outros locais delimitados em 25ha, mesmo onde não foram medidos os microclimas. Bairros semelhantes ao Araés, de ocupação espontânea, e também próximos ao centro da cidade, tais como Lixeira e Poção, apresentam um índice I = 0,8 e 2,1 respectivamente, mesmo sendo bastante ocupados; o bairro Bandeirantes, que é mais recente e tem arruamento anterior às construções, segue outro padrão de ocupação, com alguns edifícios altos, resultando em um índice I = 4,1 (fig.9.6).

Investigando a ocupação em bairros como Lixeira e Poção, identificam-se construções térreas muito antigas, com pouca arborização de rua, mas com muita área verde já consolidada em centro de quarteirão (fig.9.7). Bairros antigos como esses têm grande potencial de renovação; quando isso acontecer, mais cedo ou mais tarde, essas áreas verdes domiciliares têm que ser protegidas e adaptadas às suas novas funções, e a mata de galeria remanescente nas margens dos córregos deve receber melhor tratamento. Nesses bairros a arborização de grande porte e já consolidada ainda está presente, mas precisa de adaptação para enfrentar as mudanças que certamente vão acontecer, como já acontece no Araés, que vem sendo verticalizado aos poucos com edifícios de bom padrão.

Observando a cidade do alto, uma área ainda não ocupada para o especulador imobiliário é apenas um espaço vazio para ser ocupado; para o climatologista e o planejador urbano são áreas que ainda podem ser desapropriadas, para viabilizar as intervenções necessárias. Seria interessante desenvolver novos estudos que permitam a avaliação da necessidade de áreas livres, visando preencher funções específicas das áreas urbanas.

${ }^{5}$ ver fotos aéreas no anexo 2. 


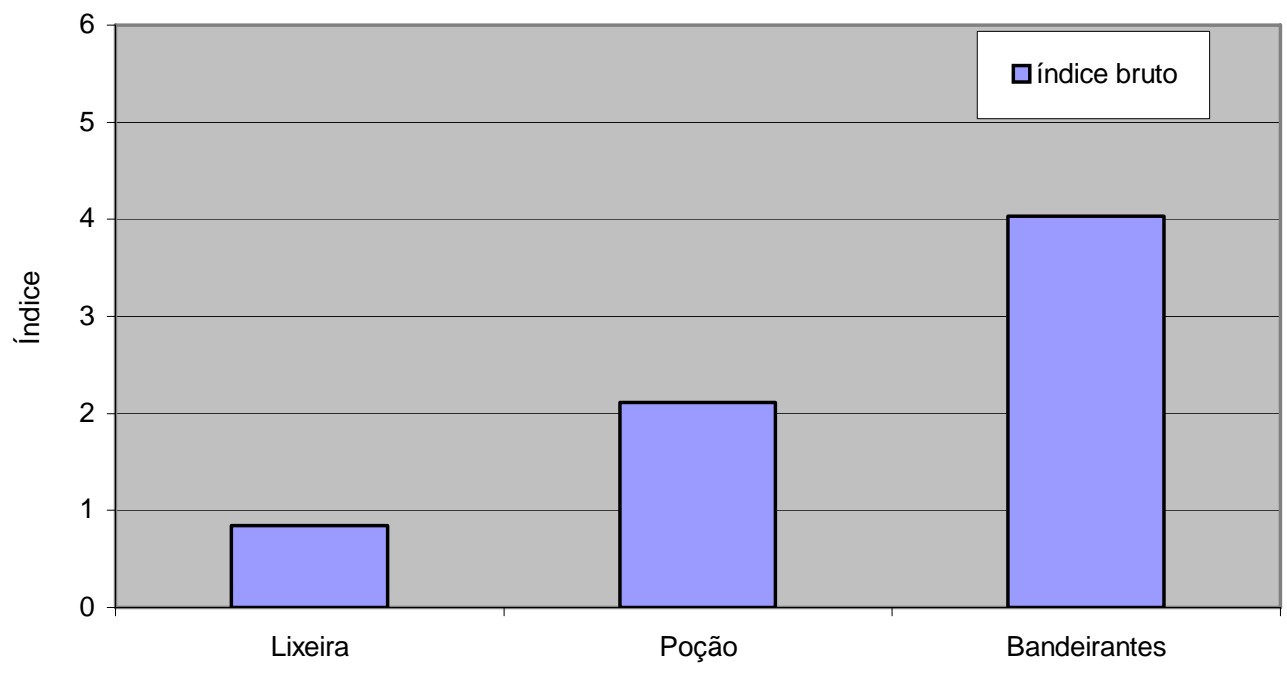

Figura 9.6 - Índice calculado para os bairros Lixeira, Poção e Bandeirantes.

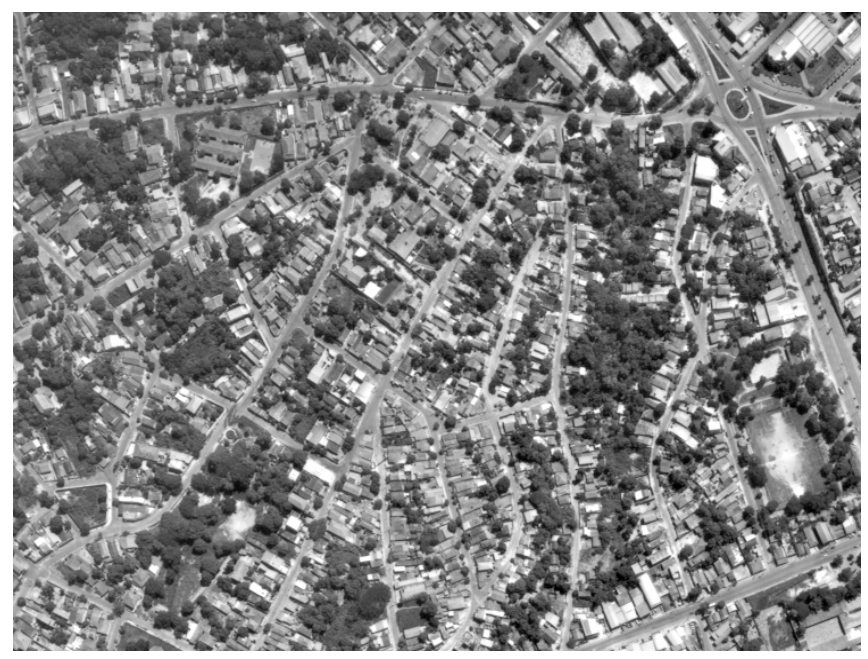

Figura 9.7 - Áreas verdes em centro de quarteirão no bairro da Lixeira. (foto: Esteio Engenharia e Aerolevantamentos)

\subsubsection{Utilidade, implementação e determinação do índice ideal}

A utilidade do índice para o planejamento é comparar o adensamento existente ou pretendido com relação à existência de arborização e espelhos d'água em uma determinada proporção. Resta saber qual a proporção ideal, mas para isso são necessários novos estudos. A partir da taxa de ocupação e do coeficiente de aproveitamento máximo permitido, posso estabelecer uma proporção para áreas verdes e superfícies d’água ideais para amenização das condições climáticas locais, computando benefícios e custos.

Em função dos padrões esperados de microclima, pode-se estabelecer padrões ideais de ocupação, tendo sempre em mente as tradições culturais locais. Em bairros antigos com potencial de renovação o índice pode ser usado para acompanhar o adensamento, que certamente vai acontecer mais cedo ou mais tarde, com relação à manutenção da vegetação ainda existente em centro de quarteirão. 
Se no momento da renovação desses bairros a legislação municipal permitir a derrubada do verde existente no centro das quadras, formado por árvores de grande porte e já aclimatadas, o mínimo que ela pode exigir é a arborização em larga escala nas áreas públicas, o que com certeza seria muito mais dispendioso e demandaria tempo para que árvores jovens atingissem a maturidade da vegetação já existente.

Para o meio ambiente urbano não interessa se área verde é publica ou privada, mas para a implementação das medidas necessárias é preciso estabelecer quem vai criar e manter essas áreas, talvez em parceria entre lotes privados e espaços públicos. Se a opção for arborizar os lotes privados, isso tem que ser exigido pela legislação (podese dar alguma forma de incentivo como já vem sendo feito em Curitiba e em Cuiabá) e novas construções têm que ser obrigadas a plantar e manter um determinado número de árvores nas calçadas ou nos lotes. Um exemplo de sucesso com participação da comunidade é a campanha Sacramento Shade, na Califórnia. ${ }^{6} \mathrm{O}$ cidadão faz uma ligação gratuita e solicita a visita de um técnico que vai indicar como, onde e quantas árvores são necessárias para diminuir o consumo de energia no seu edifício. Como muitas dessas árvores são plantadas nas calçadas, acabam também beneficiando os pedestres, o microclima e qualidade do ar na cidade como um todo.

Outra possibilidade de aplicação é estabelecer um índice máximo para cada lote, para que a responsabilidade do plantio e manutenção seja dividida por todos, além de um índice máximo para áreas públicas do bairro, em princípio, de responsabilidade da administração municipal, mas que também podem ser mantidas em parceria com a iniciativa privada, como já acontece há alguns anos nas praças e canteiros centrais da cidade de Cuiabá.

Para facilitar a aplicação do índice pela administração municipal talvez seja preciso também converter o parâmetro arborização, aqui representado pela área de projeção horizontal das copas das árvores em número de árvores adultas, com um mínimo de altura ou de diâmetro do caule, além de especificar as espécies mais adequadas, de copas altas e largas, que propiciam maior sombreamento e não obstruem a ventilação na altura dos ocupantes, assim como especificado pela Prefeitura de Curitiba, por exemplo. O monitoramento poderia ser feito por fotos aéreas ou de satélite com alta resolução.

Para se chegar ao valor do índice ideal são necessárias medições de microclimas em outras localidades para se formular proposições mais amplas. Quando calibrado esse índice pode representar o ponto de equilíbrio entre densidade construída e elementos naturais; quanto maior o índice, maior a desproporção entre os dois.

OKE (1973) analisa o caso de Montreal como uma série de células frias e quentes; as células frias são evidentes se a velocidade do vento é inferior a $5 \mathrm{~m} / \mathrm{s}$ e estão associadas a grandes parques urbanos; outro oásis urbano foi observado em uma grande árvore isolada em um ambiente hostil em uma rua na área central da cidade. Oke chegou à conclusão que, quando se tem uma área com $20 \%$ da superfície verde, a energia radiante é utilizada predominantemente nos processos de evapotranspiração, e não para aquecer o ar.

\footnotetext{
${ }^{6}$ ver capítulo 4 .
} 
Do ponto de vista climático, o uso de vegetação tem duas vantagens: primeiro, o sombreamento, segundo, o resfriamento indireto do ar por evapotranspiração das folhas. Segundo estudos do Heat Island Group, ${ }^{7}$ uma única árvore de grande porte em terreno irrigado pode evapotranspirar até 40 galões de água em um dia $(151,421)$, o que compensaria o calor produzido por 100 lâmpadas de 100W, acesas durante 8h/dia (ROSENFELD et al. [s.d.]).

O Heat Island Group ainda apresenta vantagens adicionais do plantio de árvores para melhorar a qualidade do ar: "one of our remedies for urban heat islands has an even greater benefit. Most policymakers and environmental activists concerned with the threat of global warming urge two strategies to combat it: cutting the use of fossil fuels; and planting trees, which sequester carbon dioxide in their wood. The planting of trees in cities does both of these, and is far more effective than planting trees in forests. Any tree - whether in the forest or the city - removes $\mathrm{CO}_{2}$ from the air through photosynthesis. Typically, a tree sequesters a few kilograms of carbon per year in its wood. For a forest tree, that is the total benefit of the tree's existence, from the standpoint of cutting $\mathrm{CO}_{2}$ levels. But a tree planted in a city also lowers fossil fuel usage, by cooling the city and thus reducing the amount of electricity consumed in air conditioning. A tree in Los Angeles, for example, will save an additional 3 kilograms of carbon per year by lowering the city's overall need for air conditioning, plus 15 kilograms more if it directly shades a building."

É preciso deixar claro que em momento algum está se propondo a anti-cidade, e sim, modelos de ocupação urbanos, sejam eles horizontais ou verticais, desde que sejam adequados às condições de conforto higrotérmico da região. Como concluiu Clovis Ultramari, ${ }^{8}$ organizador da IV Internacional Ecocity Conference, realizada em Curitiba, em abril de 2000, não se pode mais falar em desencanto com o espaço urbano. O conceito anti-cidade não existe mais; as soluções tem que ser buscadas dentro ambiente urbano, buscando pontos de equilíbrio.

Para médias e grandes cidades a verticalização é irreversível. Porém, apesar dos avanços dos últimos anos muitas questões ainda estão sem resposta. O estabelecimento de parâmetros para adensamento e verticalização, por exemplo, ainda são pontos polêmicos entre os pesquisadores. Em Porto Alegre essa questão ainda não foi resolvida pela proposta do novo Plano Diretor (PORTO ALEGRE, [s.d.]). Em Curitiba, considerada cidade-modelo em todo o mundo, a verticalização é incentivada nos eixos com maior infra-estrutura, mas fica restrita a esses locais. De acordo com o IPPUC $^{9}$ de Curitiba essa verticalização é que permitiu a criação de tantos parques e áreas verdes na cidade. Um dos pontos de revisão da nova lei de zoneamento e uso do solo de Curitiba, que entrou em vigor em abril de 2000, foi garantir maior área de afastamento para as edificações, evitando a formação de áreas de sombra e melhorando as condições de insolação e ventilação em regiões da cidade onde há adensamento excessivo. Em São Francisco, Califórnia, por ocasião de uma das revisões do 1971 Urban Design Plan, ficou estabelecido que novos edifícios de escritórios na área comercial estavam obrigados a prever um espaço aberto proporcional à sua área, assim como contribuir com US\$2.00 por pé quadrado de

\footnotetext{
${ }^{7}$ http://eetd.lbl.gov/HeatIsland/PUBS/PAINTING

8 informação verbal.

${ }^{9}$ http:// www.ippuc.pr.gov.br
} 
área construída para um fundo destinado à manutenção de parques urbanos (MACRIS e WILLIAMS, 1999).

O índice proposto também não é contrário à maior densidade habitacional, pretendida por muitos planos diretores nas cidades brasileiras para reduzir os custos de infra-estrutura e serviços, e pregada por movimentos como Ecocity Builders e o movimento New Urbanism para reduzir deslocamentos e consumo de energia; posso aumentar taxa de ocupação e coeficiente de aproveitamento desde que aumente também a proporção de corpos d'água e vegetação; a idéia é equilibrar a maior densidade construída com os elementos naturais. Isso é viável exigindo uma determinada área verde por lote, e permitindo a construção em altura quando necessário.

\section{Referências Bibliográficas}

1. ASSIS, Eleonora Sad de. Mecanismos de desenho urbano apropriados 'a atenuação da ilha de calor urbana: análise de desempenho de áreas verdes em clima tropical. Rio de Janeiro, 1990. Dissertação (Mestrado em Arquitetura) - Faculdade de Arquitetura e Urbanismo, Universidade Federal do Rio de Janeiro.

2. ASSIS, Eleonora Sad de. Impacto da forma urbana na mudança climática: método para previsão do comportamento térmico e melhoria de desempenho do ambiente urbano. São Paulo, 2000. Tese (Doutorado em Arquitetura) Faculdade de Arquitetura e Urbanismo, Universidade de São Paulo.

3. BITTENCOURT, Leonardo Salazar et al. A influência da relação entre taxa de ocupação $\mathrm{x} \mathrm{n}^{0}$ de pavimentos no potencial de ventilação natural dos ambientes internos e externos. In: IV ENCAC - Encontro Nacional de Conforto no Ambiente Construído, 1997, Salvador. Anais. Salvador: FAUUFBA/LACAM-ANTAC, 1997. p.102-106.

4. BITTENCOURT Leonardo Salazar et al. O efeito da verticalização das edificações na ventilação natural do tecido urbano: o caso da orla marítima de Maceió. In: VIII ENTAC, 2000, Salvador. Anais em CD-ROM. Salvador: ANTAC, 2000.

5. CARMONA, Luiz Sanchez de. Human comfort in the urban tropics. In: URBAN CLIMATOLOGY AND ITS APPLICATIONS WITH SPECIAL REGARD TO TROPICAL AREAS. Mexico D.F., 26-30 November 1984. Proceedings. OKE, T. (ed.) Urban Climatology and its Applications with Special Regard to Tropical Areas. Geneva: WMO n.652, 1986, p.354-404.

6. Centro de Estatística Aplicada do Instituto de Matemática e Estatística da Universidade de São Paulo - CEA/IMEUSP. Relatório de Consulta.

7. COSTA NETO, Pedro L. de O. Estatística. São Paulo: Edgard Blücher, 1977.

8. GIVONI, Baruch. Impact of planted areas on urban environmental quality: a review. Atmospheric Environment, v.25B, n.2, p.289-299, 1991.

9. GIVONI, Baruch. Climatic aspects of urban design in tropical climates. Atmospheric Ennvironment, v.26B, n.3, 1992a, p.397-406. 
10. GIVONI, Baruch. Comfort, climate analysis and building design guidelines. Energy and Buildings, n18, 1992b, p.11-23.

11. GIVONI, Baruch. Climate Considerations in Building and Urban Design. New York: John Wiley \& Sons, 1998.

12. GONÇALVES, Wantuelfer. Padrões de Assentamento de Áreas Verdes Municipais - uma visão crítica. São Paulo, 1994. Tese (Doutoramento). Faculdade de Arquitetura e Urbanismo, Universidade de São Paulo.

13. HONJO, T., TAKAKURA, T. Simulation of thermal effects of urban green reas on their surrounding areas. Energy and Buildings, n.15-16, 1990/91, p.443446.

14. IPUUC. Como Curitiba é planejada. In: www.ippuc.pr.gov.br

15. IV INTERNATIONAL ECOCITY CONFERENCE. Curitiba:Unilivre, abr. 2000.

16. KATZSCHNER, Lutz. Urban climate studies as tools for urban planning and architecture. In: IV ENCAC - Encontro Nacional de Conforto no Ambiente Construído, 1997, Salvador. Anais. Salvador: FAUUFBA/LACAM-ANTAC, 1997. p. 49-58.

17. LOMBARDO, Magda. Qualidade Ambiental e Planejamento Urbano: considerações e métodos. São Paulo, 1995. Tese (Livre-docência). Faculdade de Filosofia, Letras e Ciências Humanas - Departamento de Geografia, Universidade de São Paulo.

18. MACRIS, Dean, WILLIAMS, George. San Francisco's Downtown Plan: Landmark Guidelines Shape City's Growth. August, 1999. In: www.spur.org/downtown.html

19. MENNEH, Márcia H., COELHO, Ana Maria. Características do sistema de parques públicos urbanos da cidade de São Paulo. In: VIII ENTAC, 2000, Salvador. Anais em CD-ROM. Salvador: ANTAC, 2000.

20. OKE, T.R. Evapotranspiration in urban areas and its implications for urban climate planning. In: Conference Teaching the Teachers on Building Climatology. Proceedings. The National Swedish Institute for Building Research, v.2, 1973.

21. Projeto de Lei do $2^{\circ}$ Plano Diretor de Desenvolvimento Urbano e Ambiental de Porto Alegre. Porto Alegre, [s.d.].

22. ROSENFELD, Arthur et al. Painting the Town White and Green. LBL. Heat Island Group. [s.d.] In: http://eetd.lbl.gov/HeatIsland/PUBS/PAINTING

23. SILVA, Francisco A. Gonçalves da. O vento como ferramenta no desenho do ambiente construído. Uma aplicação do nordeste do Brasil. São Paulo, 1999. Tese (Doutorado) - Faculdade de Arquitetura e Urbanismo, Universidade de São Paulo.

24. SPIRN, Anne Whiston. O jardim de granito. São Paulo: EDUSP, 1995.

25. VILLAS BOAS, Márcio. Environmental criteria and design principles for a new community in Brasilia. In: Environmentally Friendly Cities. Proceedings of PLEA’98. Lisbon: James and James, 1998, p.137-140. 


\section{CONSIDERAÇÕES FINAIS E CONCLUSÕES}

\subsection{Resumo das conclusões}

Sem a pretensão de mudar o paradigma, e sim, com a intenção de acrescentar à teoria existente, partiu-se de um princípio largamente aceito pela comunidade científica de que há uma correlação entre microclimas urbanos e condições de uso e ocupação do solo. O que a tese fez pela primeira vez foi comprovar uma correlação numérica entre a temperatura do ar e alguns parâmetros de uso e ocupação do solo para sete pontos do espaço construído, que são representativos do seu entorno, usando variáveis de planejamento que podem ser regulamentadas pela legislação municipal, e em três faixas de horário, mostrando a existência de fenômenos climáticos urbanos diferenciados para o período diurno e noturno, que muitas vezes nos levam a recomendações contraditórias.

Com o estabelecimento do grau de correlação entre a temperatura do ar e cada parâmetro relacionado à ocupação urbana já se sabe qual a associação de cada um deles com a temperatura e quais os seus períodos de maior influência.

Os resultados mostram que, em ambas as estações, com as variáveis referentes ao espaço construído, o coeficiente de correlação médio foi sempre positivo em relação à temperatura do ar, sendo mais alto às $8 \mathrm{~h}$ e às $20 \mathrm{~h}$ (com $\mathrm{r}_{\text {médio }}$ para taxa de ocupação variando de 0,57 a 0,81 e $r_{\text {médio }}$ para coeficiente de aproveitamento variando de 0,63 a 0,87), refletindo a maior influência do espaço construído no período noturno, o que concorda com a teoria existente. Às $14 \mathrm{~h}$ as maiores trocas por convecção explicam a menor correlação entre o espaço construído e a temperatura do ar (com $r_{\text {médio }}$ para taxa de ocupação variando de 0,22 a 0,53 e $\mathrm{r}_{\text {médio }}$ para coeficiente de aproveitamento variando de 0,32 a 0,63 ).

Já com as variáveis referentes à arborização e superfícies d’água o coeficiente de correlação médio foi sempre negativo em relação à temperatura do ar e parece se comportar de maneira mais ou menos uniforme nos três horários, com $r_{\text {médio }}=-0,4$ para arborização e $r_{\text {médio }}=-0,37$ para superfícies d'água. Porém, áreas verdes e corpos d'água devem ser considerados principalmente nas trocas de calor latente e na transformação da energia absorvida; em áreas urbanas este fator pode sofrer uma grande diminuição em relação às trocas de calor sensível devido à impermeabilização do solo, canalização de águas superficiais e diminuição da cobertura vegetal.

\subsection{Inserção da tese no estado da arte}

O estabelecimento dessa correlação já havia sido tentado por SAMPAIO (1981), cujo objetivo era sistematizar metodologicamente um caminho que permitisse aferir e explicitar possíveis correlações entre as variáveis uso do solo e as ilhas de calor para o caso de Salvador, verificando a existência da correlação e determinando o grau de associação entre as variáveis. Nessa mesma linha, TAHA (1988) determinou a correlação temperatura do ar no período noturno e fator de visão de céu para São Francisco, Califórnia. Esta tese acrescenta novas correlações, trabalhando com variáveis familiares ao planejamento urbano e com três faixas de horário, mostrando a diferença dos fenômenos climáticos diurnos e noturnos. 
Foi dado mais um passo na tentativa de transformar dados de microclimas urbanos em critérios de ocupação aplicáveis ao planejamento. A metodologia proposta se mostrou confiável, mas agora é necessário um amplo trabalho de repetição do modelo em outras regiões, revendo o método utilizado para as medições, utilizando instrumentos mais adequados a um maior número de unidades observacionais, a fim de uniformizar medidas nos futuros trabalhos para possibilitar comparações. Tendo em vista os sete casos estudados, parece viável a repetição do modelo para outras cidades em regiões tropicais continentais. Embora as soluções específicas não possam ser transferidas de imediato para outros locais, o conceito é sempre aplicável; a chave é a compreensão do processo.

\subsection{Aplicação dos resultados}

Os resultados podem ser utilizados no planejamento de novas áreas de ocupação para que elas respondam melhor às condições do clima. As conclusões podem subsidiar códigos de obras, leis de uso do solo, o planejamento de cidades novas ou de novos bairros.

De maneira geral o meio ambiente urbano vem sendo gerenciado sobre uma base pouco sistemática, e vem se tratando a economia sem reparar os problemas sociais ou do meio ambiente; como conseqüência as soluções têm sido simplistas e fragmentadas. Nos anos 90 a sociedade começou a reconhecer que a sustentabilidade ambiental global ou local será determinada em grande parte pelas nossas cidades, e só há bem pouco tempo redescobrimos o valor da vegetação, da topografia, da água na criação de ambientes benéficos para o homem; então começamos a medir algo que já se sabia por tentativa e erro (HOUGH, 1998).

O pesquisador deve cumprir seu papel na gestão espacial urbana e, para que seja possível intervir na legislação, é preciso produzir conhecimento imediatamente utilizável, produzindo diretrizes práticas para a atividade profissional. Sob a pressão da ocupação, é preciso encontrar a melhor relação entre condições ambientais e o adensamento para pagar a infra-estrutura instalada. Os critérios são locais, e a diversidade de situações é muito grande. Os resultados são localizados, quando quantificados só valem para a cidade estudada, mas o procedimento é aplicável a outros lugares.

\subsection{Prosseguimento dos trabalhos}

Para dar continuidade ao estudo a correlação entre as variáveis envolvidas deve ser testada em outras áreas urbanas e com maior número de unidades observacionais, com representatividade estatística para que se possa chegar à equação pretendida.

O uso do parâmetro densidade construída, representado neste estudo pelas variáveis taxa de ocupação e coeficiente de aproveitamento, pareceu conveniente pela coerência dos resultados encontrados com os fenômenos de aquecimento urbano. Estudos complementares, tais como os feitos por sobrevôos com câmeras infravermelhas a fim de se determinar a influência dos materiais no aquecimento urbano seriam de grande utilidade, detectando pontos de maior aquecimento na cidade e ajudando a explicar fenômenos ainda não totalmente compreendidos pela ciência. São necessários novos estudos simulando a substituição dos pavimentos e 
das coberturas por materiais mais claros a exemplo do que vem sendo feito nas cidades americanas.

As últimas medições do balanço de energia em áreas densamente ocupadas (OKE, 1999) demonstraram que não se pode aplicar as mesmas relações já encontradas em áreas menos urbanizadas, pois as variáveis parecem interagir de maneira bem mais complexa. Nos estudos aplicados ao planejamento urbano talvez se devesse considerar a variável umidade, o que torna o problema muito mais complexo.

As questões relacionadas à ventilação urbana ainda são controversas; por causa da complexidade dos fenômenos de escoamento não se pode generalizar resultados, e os últimos estudos nos trazem ainda mais dúvidas.

A hipótese de haver compatibilidade entre verticalização, alta densidade ocupacional e manutenção da ventilação em áreas urbanas continua em questão, e necessita de novos estudos para ser comprovada. A possibilidade de se criar oásis urbanos, com microclimas melhores do que nas condições naturais também. Na prática estas duas possibilidades já vêm sendo relatadas por diversos autores.

Em pesquisas futuras seria interessante aplicar os instrumentos desenvolvidos para se chegar às diretrizes de caráter urbanístico em valores mais ou menos absolutos, para cada região climática, e talvez responder às perguntas mais freqüentes dos planejadores e urbanistas, tais como: qual a proporção ideal e melhor distribuição de áreas verdes e superfícies d'água no espaço construído? É melhor ou pior para a cidade se houver uma elevação na altura dos prédios? É melhor construir em altura com maiores recuos ou horizontalmente com maior taxa de ocupação? As simulações de BITTECOURT et al. (1997 e 2000) já apontaram um caminho para Maceió, que agora deve ser testado em outras cidades litorâneas. Com o modelo de ASSIS (2000) já se torna viável a simulação em modelos reduzidos de diferentes configurações para adensamento e altura em cidades tropicais continentais, respeitando as restrições do modelo.

Neste estudo foi dado um novo passo, mas abriram-se outras questões, em maior número do que as que foram resolvidas. A validação do índice proposto neste estudo, por exemplo, é uma porta que se abre à investigação; o índice precisa ser validado para se chegar a valores recomendados para cada tipo de clima.

Para possibilitar o prosseguimento dos estudos é de fundamental importância a colaboração entre equipes de climatologia urbana e planejamento; sem perspectiva interdisciplinar, nada feito; arquitetos e planejadores têm que se preparar para um diálogo permanente com climatologias e vice-versa.

As secretarias de planejamento das administrações municipais devem disponibilizar informações urbanísticas digitalizadas da cidade, de forma a facilitar a atualização cartográfica e de ser compatível com softwares de uso corrente, fornecendo informações sobre a ocupação urbana. A obtenção desses dados in loco é estressante e demorada, e nem sempre eficiente.

Outra necessidade é a disponibilidade de instrumentos automáticos para a obtenção de leituras ao longo de 24h, reduzindo a necessidade de pessoal capacitado para leitura, a construção de abrigos tradicionais, etc., e instrumentos portáteis digitais de resposta rápida para possibilitar a medição fazendo o percurso a pé ou em veículos. Para multiplicar o número de unidades observacionais (e assim talvez chegar a uma 
modelagem matemática de fácil aplicação ao planejamento) o aparato analógico, que depende de um leitor treinado em cada ponto simultaneamente, e o levantamento de rua das variáveis urbanísticas fica praticamente inviável.

\subsection{Necessidade de revisão das leis de uso do solo e dos códigos de obras para incorporar o conhecimento já existente sobre clima urbano}

Para ATAIDE [s.d] os anos 90 assinalaram o limiar de um novo tempo para o planejamento urbano. Algumas idéias foram incorporadas às novas bases constitucionais do país e implementadas nos municípios. Entre os novos parâmetros incorporados evidencia-se a inclusão da variável ambiental como um dos eixos principais de orientação das novas leis urbanísticas de uso e ocupação do solo. O estado de agravamento dos níveis de degradação ambiental das cidades, decorrente de um processo de urbanização acelerado, propiciou as condições para um longo e intenso debate sobre esse problema durante toda a década de 80. A crise urbana revelou-se insustentável e aparentemente irreversível; muitas experiências anteriores de planejamento revelaram-se ineficazes no enfrentamento do problema.

O conhecimento que vem sendo acumulado sobre o meio ambiente urbano lentamente vem sendo incorporado às legislações municipais (DUARTE, 2000). Uma das principais referências nesse sentido foi o 1971 Urban Design Plan de San Francisco, Califórnia (MACRIS e WILLIAMS, 1999). Uma das revisões do plano, feita em 1983, alterou a altura e a localização onde edifícios altos de escritórios poderiam ser construídos, com o objetivo de manter a área de edifícios de escritórios compacta, podendo ser percorrida a pé; essas leis foram revistas para evitar que uma ocupação de alta densidade adentrasse áreas vizinhas. Na época as alternativas para altura dos edifícios foram simuladas na UC Berkeley's Environmental Simulation Lab. Para proteger a ambiência ao nível do solo e a escala existente, as alturas foram reduzidas em algumas quadras. Para evitar uma aparência flat-topped o plano exigiu que os andares superiores fossem menores. Outro objetivo do plano era preservar a ambiência do centro; o plano identificou calçadas e espaços públicos abertos que deveriam ser protegidos da sombra, e determinou alturas dos edifícios para evitar a formação de sombra em certas horas do dia e épocas do ano; isso foi estendido à garantia de acesso solar para parques urbanos ao longo de todo o ano. Novos edifícios foram obrigados a prever um espaço aberto proporcional à sua área assim como contribuir com US\$2.00 por pé quadrado de área para um fundo destinado à manutenção de parques urbanos, "and for the first time in an American zoning ordinance, standards were set to affect the shape of a building to prevent the creation of unpleasant wind currents at ground level in both pedestrian and sitting areas.” Na época Robert Campbell, crítico de arquitetura do jornal Boston Globe, disse que: "The purpose of plans is not to insure beauty or excellence. The purpose of guidelines is to prevent disaster, not to insure great design. Only talent will do that. Guidelines stimulate creativity and talent."

KEEBLE et al.(1990) fizeram uma revisão do potencial de aproveitamento das leis de uso do solo na Europa para a criação de microclimas favoráveis ao redor dos edifícios. Afirmaram que já é largamente aceito que o espaço construído exerce influência no clima local e que observações em todo o mundo já demonstraram como o clima pode ser degradado pela ocupação inadequada. No entanto, o uso prático 
desse conhecimento estava apenas começando. Estudando a legislação de diversos países europeus encontraram muitos instrumentos comuns e detectaram que "increasingly land-use planning is no longer viewed as an apolitical exercise of technical judgement. For example, increased political importance is now attached to the quality of life, ecology, wildlife preservation, landscape protection and enhancement, pollution control and energy efficiency." Nos climas severos do norte da Europa, como na Suécia, Finlândia e Dinamarca, algumas medidas já foram adotadas. Na Alemanha são muitos os casos envolvendo conservação de energia e impacto ambiental.

Detalhes incorporados aos edifícios também podem afetar positivamente as condições ambientais dos espaços externos, tais como a inclusão de arcadas e galerias, com recuo do andar térreo, que proporcionam calçadas sombreadas para os pedestres. Curitiba instituiu o Plano Massa nas estruturais para favorecer o comércio, mas indiretamente fornecem proteção contra sol e chuva para o pedestre. EVANS e SCHILLER (1991) comentam que "municipal regulations encourage clear limits between public and private space to avoid gradual invasion of public space for private activities, thus eliminating the desirable transitional zones."

Para melhor ventilação cruzada e maior permeabilidade aos ventos BITTENCOURT (1999) comenta o erro dos códigos de obras em só regulamentar a entrada de ar, e não as saídas, para ventilação dos edifícios, porque é fundamental a diferença de pressão entre aberturas de entrada e de saída.

GIVONI (1989 p.6-11,17), recomenda a adoção de recuos em função da orientação e não da frente/fundos como normalmente acontece. Também recomenda combinar melhor orientação da rua para ventilação e disposição dos lotes para forçar uma melhor orientação para os edifícios.

Algumas cidades brasileiras já têm implementados, em implantação, ou ainda sob a forma de projetos de lei, alguns instrumentos de intervenção que vão resultar em melhoria das condições de conforto térmico urbano. Esses instrumentos são:

- incentivos fiscais (desconto ou isenção do IPTU em alguns casos) para preservação e aumento de áreas verdes nos lotes urbanos e até a não taxação das áreas verdes dentro e ao redor da cidade;

- uso de instrumentos de política urbana tais como concessão onerosa do direito de construir e transferência de potencial construtivo para incentivo à proteção de patrimônio natural e ambiental;

- criação de um anel de conservação sanitário-ambiental;

- exigência de taxa mínima de permeabilidade do terreno;

- parcerias entre prefeitura e iniciativa privada para plantio e manutenção de áreas verdes, em troca da cessão do espaço para veiculação publicitária;

- estabelecimento de critérios e multas para corte de árvores;

- afastamentos mínimos entre edifícios para garantir melhores condições de insolação e ventilação; 
- incentivos para a adoção de galerias comerciais nos pavimentos térreos dos edifícios proporcionando, dentre outros fatores, proteção contra sol e chuva para o pedestre, incentivando assim o percurso a pé também nas áreas de comércio e serviços.

ATAIDE [s.d.] lembra que a aplicação destes instrumentos depende da existência de algumas condições: espírito de negociação, interesse coletivo e relação de cumplicidade entre as partes envolvidas. A implementação dessas medidas envolve a descentralização das decisões, o controle e a participação da sociedade nas decisões do poder público municipal através dos conselhos populares, e ainda a articulação com outras instâncias de governo.

Dentre as cidades brasileiras, Curitiba já tem um longo histórico em planejamento e as questões de clima urbano acabam inseridas na preocupação com as áreas verdes, presentes em toda a cidade. O sucesso de Curitiba está ligado à continuidade, à legitimação do Plano Diretor e da agência encarregada de implementar o Plano IPPUC - que sobrevive às administrações, o que não vem acontecendo no Rio e São Paulo, por exemplo. Em Curitiba outro ponto importante é o papel da participação popular; segundo o Governador do Estado do Paraná, Jaime Lerner, ${ }^{1}$ em palestra proferida no IV International Ecocity Conference, se o governo coloca o problema ambiental como algo de grande complexidade as pessoas se sentem incapazes de interferir; só através da atuação local é que as pessoas sabem que podem mudar os rumos da cidade e o povo assume essa co-responsabilidade. A educação ambiental, que começa desde cedo nas escolas, é outro diferencial; as crianças têm atividades escolares nos parques das cidades, e crescem conscientes do seu papel na sociedade.

Nas cidades litorâneas, principalmente nas capitais nordestinas, as pesquisas em clima urbano se intensificaram nos últimos anos, e os pesquisadores tentam estabelecer um programa único de monitoramento das condições microclimáticas, que permita a comparação de resultados. Estudos como o de Maceió devem ser analisados e incorporados pela legislação de modo a não permitir a construção de paredões na avenida à beira-mar.

Em São Paulo, com o problema da escala e da falta de continuidade dos programas, nada parece funcionar. Com poucas exceções, grandes programas, que tentam abranger toda cidade, não obtém resultados. As experiências de sucesso são cada vez mais trabalhadas pontualmente, com volumes pequenos de população, em média, de 100mil habitantes. Segundo Clóvis Ultramari, ${ }^{2}$ coordenador da IV International Ecocity Conference, elas dão certo quando se deixa de brincar de Deus e se trabalha numa escala na qual é possível interferir. Outro ponto comum entre as experiências que deram certo é o uso de recursos locais, que acabam levando a um maior comprometimento da população e dos administradores municipais.

Em Belo Horizonte vem sendo feito um trabalho visando o desenvolvimento de uma metodologia integrada de diagnóstico e intervenção urbana, visando a elaboração de parâmetros de planejamento. Estão sendo abordados: ventilação e conforto térmico urbano, poluição sonora, infra-estrutura e dinâmica urbana, avaliando a influência da

\footnotetext{
1 informação verbal.

2 informação verbal.
} 
legislação e da população na configuração de uma área da cidade. O objetivo é a elaboração de um conjunto de recomendações que possa ser levado como proposta de revisão da legislação (BRANDÃO et. al., 2000)

Em Cuiabá, tendo em vista o rigor climático regional e os resultados das medições de clima urbano, medidas ligadas à melhoria das condições de conforto térmico devem ser incorporadas ao planejamento de imediato. Os recursos advindos da aquisição onerosa de potencial construtivo poderiam ser direcionados, por exemplo, para a arborização urbana nos espaços destinados aos pedestres, um dos recursos mais eficientes para a melhoria das condições de conforto higrotérmico para o clima da região. Seria possível também aproveitar o pagamento por prestação de serviços para o plantio de árvores adequadas ou para a construção de dispositivos de sombreamento sobre as calçadas e demais espaços públicos de convívio. Cuiabá já tem parcerias de sucesso com a iniciativa privada e faz as primeiras tentativas de inclusão de incentivos na legislação municipal favoráveis à melhoria das condições ambientais. Há pontos positivos na legislação, tais como o incentivo fiscal à manutenção de árvores adultas nos lotes e a exigência de arborização pública consolidada para o padrão de ocupação médio ou superior.

Em Cuiabá a maior densidade ocupacional pretendida pelo Plano Diretor para a redução de custos da infra-estrutura urbana deve ser conduzida com cautela, entremeando áreas verdes entre os edifícios, para que o novo padrão de ocupação não agrave as condições de conforto higrotérmico urbano, já tão rigorosas. Nas áreas em expansão a maior largura das vias, hoje inevitável para o escoamento do tráfego, deve ser contrabalançada com dispositivos de umidificação e sombreamento, já que nesses moldes não se pode contar com o confinamento encontrado nas ruas do centro antigo da cidade. Cabe aos planejadores urbanos buscar uma forma de convivência mais humana com os diferentes padrões de ocupação, estabelecendo critérios que melhorem a qualidade do espaço construído.

\subsection{Questões para discussão}

Muitas questões continuam sem resposta, ou estão parcialmente resolvidas. Uma delas refere-se às contradições entre densidade de ocupação, consumo de energia em edifícios para condicionamento e iluminação artificiais, condições de ventilação urbana e custos de infra-estrutura urbana.

Os efeitos da densidade de ocupação no consumo total de energia são complexos e contraditórios. Por um lado, alta densidade reduz a necessidade e as distâncias de transporte público e privado, reduzindo então as emissões que contribuem para a poluição do ar. Isso também reduz o comprimento das ruas necessário para acomodar uma determinada densidade habitacional, o que por sua vez, diminui os custos com infra-estrutura e transportes (GIVONI, 1998, p.291). Em Cuiabá já era objetivo do Projeto CURA na década de 1970 incentivar a ocupação do solo e consolidar as áreas loteadas, arruadas ou parcialmente ocupadas, ao invés da abertura de novos loteamentos. Na época a prioridade era para as áreas internas à avenida perimetral (CUIABÁ. Projeto Cura, [s.d.]).

A verticalização em si também apresenta vantagens e desvantagens do ponto de vista climático. Segundo GONÇALVES (1999), em climas quentes e úmidos pode-se tirar proveito das sombras longas e da turbulência de ventos nos arredores. Os andares 
mais altos ficam expostos a maiores velocidades de vento e a temperaturas mais baixas do que no nível da rua, assim como ficam menos sujeitos à poluição sonora e atmosférica. Dependendo da orientação, podem canalizar as correntes de vento, fazendo com que estes cheguem às áreas menos ventiladas da cidade; também ajudam a dispersar a poluição nas ruas em razão da turbulência criada nos níveis inferiores. Permitem a coleta de água da chuva mais limpa, acima da camada de poluição e facilitam o aproveitamento de energia solar e a geração de energia eólica, com a captação dos ventos nos níveis mais altos. Como desvantagem principal do ponto de vista climático está a maior dificuldade de resfriamento noturno no nível da rua (ligado ao fator de visão de céu). Dependendo do tipo de clima as longas sombras (que impedem o acesso de sol e reduzem o aproveitamento da iluminação natural) e a turbulência podem ser prejudiciais.

De acordo com GIVONI (1998, p.247), quando a relação H/W é próxima de 1, a maior parte da radiação refletida atinge outros edifícios ou o chão e é absorvida pelo solo ou próxima ao solo. Já quando a relação H/W é superior a 4, a maior parte da energia solar absorvida acontece muito acima do nível da rua, conseqüentemente a quantidade de radiação que atinge o solo e aquece o ar próximo ao nível da rua é menor.

A alta densidade pode prejudicar a ventilação natural (dependendo dos padrões adotados) e reduzir o potencial para iluminação natural. Edifícios altos também envolvem dispêndio de energia para transporte vertical. Maior densidade construída também se reflete em mais calor gerado pela iluminação artificial e para condicionamento ativo, seja por aquecimento ou refrigeração. Para se chegar a uma solução uma das alternativas possíveis é dar ganho em altura em troca de maior área verde não impermeabilizada no nível da rua.

Para GIVONI (1998, p.284-285, 294, 371) é possível uma área urbana de alta densidade, formada pela mistura de edifícios altos e baixos, com melhores condições de ventilação do que uma área com menor densidade mas com edifícios da mesma altura. Do ponto de vista da ventilação o fator mais importante é a diferença de altura dos edifícios em relação ao seu entorno. "Under a given density condition, high buildings with large open spaces between them will have better ventilation conditions than closely spaced low buildings - approaching in the extreme a pattern similar to a lone building with open space on all sides. However, more than the average building height, it is the difference between building heights which affects the ventilation conditions. (...) The wind can then 'negotiate' between the buildings so that the potential for natural ventilation exists."

Do ponto de vista climático, o mais importante é evitar a formação de um paredão de edifícios, como na Av. Atlântica no Rio de Janeiro, prejudicando as condições de ventilação a partir da Av. Nossa Senhora de Copacabana. Estudos de CORBELLA e YANNAS (1997) demonstraram que o paredão formado pela barreira contínua de edifícios de 12 andares intercepta o vento, que mal chega aos quarteirões subseqüentes. Também foram registradas diferenças de temperatura de até $6^{\circ} \mathrm{C}$ entre a avenida Atlântica e a Praça Arcoverde.

Os recuos poderiam ser estabelecidos em função da orientação, com uma divisão de lotes que permita uma orientação dos edifícios mais flexível. Em climas tropicais, dependendo da latitude, e desde que não seja obstáculo à direção predominante de 
ventos, na direção leste/oeste os recuos podem ser menores para favorecer o sombreamento de um edifício sobre o outro. Já na direção norte/sul a menor distância não seria tão vantajosa e maiores recuos vão ajudar na ventilação.

Outra questão diz respeito às diferenças de desempenho higrotérmico entre área verde e área pavimentada, ou entre superfícies naturais e construídas. Qualquer superfície ganha calor por radiação solar (ondas curtas) e emite calor por radiação de ondas longas. A radiação solar incidente, quando absorvida por um material seco durante o dia, é convertida em calor e eleva a temperatura da superfície. Já a energia absorvida pelas folhas das plantas ou por superfícies úmidas é parcialmente convertida em calor latente pelo processo de evaporação e resulta em menor elevação de temperatura; só a energia remanescente é convertida em calor sensível e resulta em aquecimento da superfície. Ao invés do aumento da temperatura da folha a energia é gasta no processo de evapotranspiração da água das folhas. A evaporação da água das folhas expostas ao sol consome a maior parte da energia solar absorvida. A evaporação diminui significativamente a temperatura das folhas e o ar em contato com elas, e ao mesmo tempo aumenta a umidade do ar. Como resultado o ar próximo ao solo nas áreas verdes é mais fresco do que nas áreas construídas cobertas por edifícios ou qualquer outro tipo de pavimentação. Como resultado da temperatura mais baixa a radiação emitida pelas folhas é menor do que a emitida pelas superfícies construídas, portanto, pessoas em áreas verdes são submetidas à menor carga térmica radiante (GIVONI, 1998, p.307). Em relação à opção entre sombreamento por árvores ou por elementos construídos, ASSIS (2000, p.217) chama a atenção para a diferença na sensação térmica dos indivíduos em ambientes urbanos sombreados por construções ou por vegetação, sendo que no segundo caso, sob condições de stress térmico pelo calor, a sensação de desconforto é menor.

Segundo ROSENFELD et al. [s.d.], no verão, o calor antropogênico liberado por carros, fábricas e pelo condicionamento artificial dos edifícios contribui apenas com $1 \%$ do excesso de temperatura da ilha de calor. No inverno essa proporção chega a $10 \%$, quando o ar aquecido escapa dos edifícios. Para o Heat Island Group, as superfícies horizontais escuras das coberturas e da pavimentação é que causam maiores problemas; "we propose that wiser choices can reverse it. (...) One solution is to use lighter colors for roofs and pavement. The other is to plant lots of trees, which have a two-fold benefit. First, they provide cooling shade. Second, trees, like most plants, soak up groundwater. The water then 'evapotranspires' from the leaves, thus cooling the leaves and, indirectly, the surrounding air." Segundo estudos do Heat Island Group, ${ }^{3}$ uma única árvore de grande porte em terreno irrigado pode evapotranspirar até 40 galões de água em um dia $(151,421)$, o que compensaria o calor produzido por 100 lâmpadas de 100W, acesas durante 8h/dia (ROSENFELD et al. [s.d.]).

Estudos de ROSENFELD et al. (1996) ${ }^{4}$ sobre a relação custo/benefício de um programa de incentivo ao uso de tetos e pavimentos mais claros e arborização para Los Angeles demonstrou que isso reduziria a intensidade da ilha de calor na cidade em $3^{\circ} \mathrm{C}$, reduziria a poluição em $12 \%$ e proporcionaria uma economia de US\$0,5bilhão/ano, incluindo ganhos diretos e indiretos. Nas últimas décadas Los

\footnotetext{
${ }^{3}$ http://eetd.lbl.gov/HeatIsland/PUBS/PAINTING

${ }^{4}$ http://eetd.lbl.gov/HeatIsland/PUBS
} 
Angeles vem sofrendo um aumento de temperatura de $1^{\circ} \mathrm{C}$ a cada 15 anos; "for $L A$, trees are very cost-effective, even if just planted along streets, or in parks, where they do not shade air conditioned buildings. These calculations also clearly show the advantage of urban trees versus forest trees to sequester $\mathrm{CO}_{2}$ and delay global warming.(...) The benefits of light surfaces and shade trees extend beyond Los Angeles. The 18 percent direct savings of air conditioning attained by shading and lightening individual buildings do not depend on the size of the city, only on its climate; Atlanta, for example, would enjoy the same percentage reduction as Los Angeles. The indirect savings, on the other hand, will be significant only in large cities with significant heat islands. Since about half the U.S. population lives in heat islands, we estimate that the annual direct plus indirect U.S. air-conditioning energy savings, after 20 years, might be 10 percent. Peak air-conditioning demand would probably drop by 5 percent."

Para se fazer arborização é preciso haver um horto que produza e bem; produzir mudas, plantar e manter árvores custa dinheiro, e não se pode jogar a responsabilidade só para o governo; pode-se pensar em alternativas privadas: os viveiros, por exemplo, não precisam ser necessariamente públicos; podem ser privados. De acordo com ROSENFELD et al. (1996) o custo de um programa de arborização depende muito do tipo de programa e do porte das árvores plantadas, podendo variar US\$1 a US\$200 por árvore. O programa Sacramento Shade chegou a um custo de US\$45 por árvore de grande porte; para Los Angeles o custo estimado é de US\$35 por árvore, já considerada a taxa de mortalidade esperada, para atingir os benefícios previstos. Programas de plantação de árvores têm aproveitamento muito baixo. ROSENFELD et al. (1996) estimam uma taxa de mortalidade a longo prazo de $30 \%$ a $40 \%$ em áreas urbanas. Quanto aos incentivos os autores recomendam que eles sejam negociados com os fabricantes de materiais para coberturas e pavimentação, para eles se encarreguem de divulgar as vantagens do uso de materiais mais claros, e o mesmo se aplica às arvores, através de hortos e viveiros privados.

A Holanda é um belo exemplo de país densamente ocupado que sobrevive graças a um intenso manejo da paisagem. Dentre muitas inovações Delft criou um parque experimental no interior de um complexo residencial e, ao invés de nivelar a área e plantar novas árvores e arbustos, a administração municipal manteve a vegetação que cresceu durante a construção, com um mínimo de intervenção. Os moradores foram incentivados a usar o espaço e estabelecer seus próprios caminhos. Os holandeses descobriram que uma comunidade de plantas mais diversificada desenvolve-se mais rapidamente, e que a longo prazo sua manutenção será menos dispendiosa do que a manutenção de um parque convencional. Muitos moradores encontraram prazer em moldar a paisagem urbana à sua volta. Os holandeses também converteram muitas ilhas e faixas laterais de rodovias em prados de flores silvestres (SPIRN, 1995).

Em cidades que têm a sua área verde predominantemente domiciliar, o aproveitamento dos quintais remanescentes para criação de jardins internos às quadras, que funcionariam como praças em centro de quarteirão mantidas pelos moradores e a arborização ligada ao sistema viário, com avenidas densamente arborizadas, inclusive nos canteiros centrais, também são viáveis. Árvores de copas altas e largas são as mais indicadas, por proporcionar sombra e permitir a ventilação no nível do corpo, com o cuidado de se evitar espécies inadequadas, e de que a vegetação seja diversificada para que se tenha sombra durante todo o ano, uma vez 
que a queda das folhas acontece em períodos diferentes em função da espécie; fatores tais como conformação das raízes, tolerância à poda e ao transplante e altura máxima alcançada na idade adulta também devem ser considerados. O levantamento imediato das áreas públicas ainda desocupadas, e com viabilidade para a criação de áreas verdes, pode abrir novas possibilidades para a criação de espaços importantes para a melhoria das condições de conforto nas cidades, não só do ponto de vista físico mas também psicológico, além desse tratamento diminuir o risco de invasões. Com o ritmo acelerado de crescimento que a cidade vem experimentando nas últimas décadas, o planejamento de futuras intervenções nesse sentido torna-se urgente, evitando, num futuro próximo, a necessidade de intervenções mais drásticas à custa de desapropriações e conflitos.

Outro ponto importante é a necessidade de proteção ao sol e à chuva nas calçadas: em áreas comerciais, de lazer ou onde mais se quiser incentivar o uso de espaços públicos, com grande quantidade de pessoas ao ar livre, a proteção ao sol e à chuva para os pedestres é um dos requisitos mais importantes de desenho urbano, principalmente em cidades de clima rigoroso. GIVONI (1998, p.298) comenta algumas alternativas ligadas ao desenho dos edifícios e conclui que o recuo do andar térreo com a permissão de se avançar a projeção de um ou dois andares sobre a calçada compensa economicamente o proprietário e incentiva o uso desse elemento de projeto. Os demais pavimentos voltam a seguir o recuo original ou um recuo progressivo com a altura para não prejudicar a ventilação no nível da rua.

Abrigos sombreados devem ser espalhados pela cidade, onde se quer incentivar o percurso a pé, como no centro antigo, proporcionando o mesmo efeito do Paley Park, em Manhattan, mencionado por tantos paisagistas como um belo exemplo, e que pode ser obtido em um lote vazio, desapropriado pela Prefeitura ou permutado com o proprietário (SPIRN, 1995, p.91-92).

A ênfase deve ser dada na seqüência de espaços públicos como um todo, ao invés do espaço individual, isolado. Deve ser dada atenção espacial ao espaço residual entre bairros e na periferia dos bairros, não se esquecendo da retração significativa da área de vegetação durante a estação seca nessas regiões. Do ponto de vista da manutenção, também é mais fácil manter grandes árvores em menor número do que vice-versa; do ponto de vista do conforto também, pois o sombreamento é muito mais eficiente. SPIRN (1995) diz que o efeito das árvores é muito mais sentido na sua ausência: se há árvores as pessoas não se dão conta, mas se faltam árvores, sim. Quando se fala em áreas verdes para o clima da região o uso de vegetação rasteira e de arbustos não basta, porque estes têm pouca biomassa e não produzem sombra (LOMBARDO, 1999). Para amenizar o rigor climático é necessária vegetação arbórea, de preferência de grande porte. Estudos de MIZUNO et al. (1990/91) também já demonstraram que a grama contribui pouco para a diminuição da temperatura do ar.

O uso de vegetação rasteira pode ser muito melhor aproveitado em tetos verdes. Em áreas densamente ocupadas a maior parte das trocas por radiação se dá nas superfícies das coberturas e não ao nível do solo ou nos fechamentos verticais. Estudos de HARAZONO et al. (1990/91) demonstraram que, durante o verão em Osaka, Japão, a temperatura superficial de um teto plano passou dos $50^{\circ} \mathrm{C}$ em dias de céu claro, enquanto que no teto verde dificilmente atingiu os $35^{\circ} \mathrm{C}$. A temperatura do 
cômodo situado abaixo do teto verde se manteve cerca de $2^{\circ} \mathrm{C}$ menor do que sob o teto sem tratamento. O fluxo de calor através do teto sem tratamento era de $200 \mathrm{~W} / \mathrm{m}^{2}$, já através do teto verde era de $10 \mathrm{~W} / \mathrm{m}^{2}$.

A vegetação rasteira é uma boa opção também para calçadas gramadas, com faixa pavimentada somente na largura necessária ao trânsito de pedestres, como em Curitiba; esse recurso já era recomendado pelo projeto CURA para Cuiabá na década de 1970.

O uso de vegetação arbórea ou trepadeira junto à fachada também é eficiente para minimizar o ofuscamento. A recomendação para o uso de cores claras nos fechamentos dos edifícios visa diminuir os ganhos térmicos mas é conflitante com o ofuscamento para as pessoas do lado de fora. Edifícios pintados com cores claras para absorver menos radiação devem ter marquises para evitar ofuscamento para pedestres, ou vegetação nos fechamentos verticais. Isso pode resolvido também com o uso de projeções horizontais na fachada ou de faixas verticais ou ainda do tipo caixa de ovo. O acabamento rugoso também cria pequenas sombras e reduz o ofuscamento na rua.

Em Cuiabá a Prefeitura tem uma série de parcerias estabelecidas com comerciantes para plantio e manutenção de praças e jardins próximos aos seus estabelecimentos, alternativa que vem dando certo na região central da cidade. A iniciativa privada é estimulada a participar do programa mediante concessão na exploração do espaço para veiculação publicitária, custeando assim plantio e manutenção.

Em Belo Horizonte um programa chamado Adote o Verde conta com 296 adesões mantidas em parceria com a iniciativa privada. A Secretaria de Meio Ambiente implanta o projeto, constrói benfeitorias, fornece mudas, paga água e luz, entrega ao parceiro e fiscaliza a manutenção (HOJE EM DIA, 2000). Mediante licitação, uma empresa privada recebeu o direito de explorar comercialmente um espaço de propaganda em cada muda plantada nas vias públicas da cidade. A empresa, além de se responsabilizar pelo plantio e manutenção da árvore - com espécie previamente definida pela Prefeitura - paga ao poder municipal $\mathrm{R} \$ 1,20$ ao ano por unidade e comercializa o espaço de propaganda com outras empresas por aproximadamente $\mathrm{R} \$ 30,00$. Com a concessão e empresa deveria plantar 100 mil árvores. ${ }^{5}$ A Prefeitura pensa em usar o mesmo modelo para instalação e manutenção de cestas de lixo em vias públicas. Essa medida vem sendo vista como um marketing bastante positivo para as empresas privadas; além destas, pequenos comerciantes, condomínios e associações de moradores também participam do programa. O problema é que vêm acontecendo alguns abusos nessa publicidade, acumulando placas e mais placas ao longo dos canteiros centrais das avenidas, aumentando a poluição visual na cidade.

Há alguns anos o programa Um Milhão de Árvores foi uma iniciativa da Prefeitura Municipal de São Paulo para a arborização das vias públicas e ampliação da área verde na cidade. Na proposta a Prefeitura executaria o plantio, a conservação e a manutenção das mudas, forneceria apoio técnico e suporte educacional. As escolas envolveriam a comunidade local, visando a fiscalização e a conservação das árvores através de professores e alunos vigilantes do verde. Segundo a Secretaria Municipal

\footnotetext{
${ }^{5}$ Centro de Referência em Gestão Ambiental para Assentamentos Humanos. Banco de textos em http://www.unilivre.org.br
} 
do Verde e do Meio Ambiente o programa não teve continuidade por falta de verbas. Atualmente está em implantação um outro programa, chamado São Paulo Verde; mediante licitação empresas privadas recebem a permissão de uso dos protetores das árvores para publicidade, em troca da manutenção das mesmas. São Paulo também tem alguns projetos de lei para a criação de calçadas verdes, visando aumentar a permeabilidade do solo e a área verde na cidade, e outros para descontos e até isenção no IPTU para proprietários que mantiverem árvores adultas nos seus lotes, todos aguardando definição na Câmara Municipal. Em vigor estão a lei que disciplina o corte e a poda de árvores e a que decreta imunes ao corte algumas árvores no município e, pela legislação do IPTU, os imóveis revestidos de vegetação arbórea, declarada de preservação permanente, terão desconto de até $50 \%$ no imposto, aplicado proporcionalmente à área protegida. Também é concedido desconto de $50 \%$ para os terrenos considerados não construídos situados em área de proteção aos mananciais.

Curitiba vem aproveitando a transferência de potencial construtivo para, dentre outros, aumentar a área verde na cidade desde o início dos anos 1990. Esse instrumento é usado inclusive entre Curitiba e os demais municípios da Região Metropolitana para assegurar proteção aos mananciais; a aplicação é monitorada pelo IPPUC, que tem poderes para rever a regulamentação dos parâmetros de uso e ocupação do solo, suprimir ou acrescentar zonas e setores. A transferência de potencial construtivo é admitida para imóveis situados nas zonas e setores especiais e também pode ser usada sob a forma de indenização.

Nas áreas com bosques cadastrados é estimulada a preservação através de incentivos fiscais e construtivos, admitindo-se a edificação com parâmetros superiores em altura. Foram instituídos alguns benefícios como a isenção ou redução do imposto imobiliário proporcionalmente à faixa de cobertura florestal, e o estabelecimento de condições especiais de aproveitamento para os terrenos integrantes do Setor Especial de Áreas Verdes. As condições são regulamentadas por decreto que estabelece que as edificações podem ter altura superior à da zona do entorno com redução da taxa de utilização do terreno, visando a adequada preservação das áreas verdes. Em áreas maiores e com cobertura vegetal relevante, essa ocupação pode ser ainda mais incentivada em altura, neste caso condicionada ao recolhimento de recursos aos Fundos Municipais de Meio Ambiente e da Ação Social ou à doação de parte da área verde ao município, necessária para a criação de novos parques ou incorporação aos já existentes. Hoje, mesmo com a lei já em vigor, os parâmetros de uso e ocupação do solo para os setores especiais, que inclui o Setor Especial de Áreas Verdes, podem ser ajustados por ato do Poder Executivo Municipal. Também vem sendo utilizada a Adoção Verde nos bairros pela população, que já é responsável pelo plantio de 15\% das 107mil árvores e arbustos plantados em áreas públicas de Curitiba a cada ano. Dessa forma o morador planta e se sente responsável pela árvore. ${ }^{6}$

Em Cuiabá, pela Lei de Uso e Ocupação do Solo de dezembro de 1997, o critério básico para a diferenciação dos parâmetros de ocupação do solo é a disponibilidade de infra-estrutura urbana. Seguindo esse critério as vias e logradouros públicos ficam classificados de acordo com sua disponibilidade de infra-estrutura nos seguintes

${ }^{6}$ Dados do IPPUC, em http://www.curitiba.pr.gov.br 
padrões: inabitável, mínimo, médio, alto e máximo. Do padrão médio em diante, além da infra-estrutura mínima o mesmo deve contar com pavimentação e arborização pública consolidada, pela qual se entende a existência de árvores ou palmeiras adaptadas ao ambiente, como no mínimo $2 m$ de altura.

A lei considera também como aproveitamento adequado do lote a existência e a manutenção de árvore acima de $3 \mathrm{~m}$ de altura, cadastrada pelo órgão ambiental do município, na proporção mínima de um indivíduo para cada $180 \mathrm{~m}^{2}$ de área do terreno ou fração. Para cada árvore cadastrada corresponderá o desconto de $1 \%$ do valor do IPTU devido pelo imóvel, e o desconto máximo pode chegar a 50\%. A campanha Quem Planta Colhe Descontos lançou o cadastro de arborização urbana na Semana do Meio Ambiente, em junho de 2000.

Uma outra questão controversa diz respeito à largura das ruas. O efeito relacionado à relação H/W é diferente para condições diurnas e noturnas; estudos de GIVONI (1998, p.287) para Sevilha mostraram que nas primeiras horas da manhã a temperatura na avenida larga era mais baixa, de acordo com os modelos de ilha de calor, mas durante o restante do dia, especialmente ao meio dia e à tarde, os padrões de temperatura se inverteram. Cabe lembrar que a largura das vias também é determinada por outros fatores: não se pode resolver o escoamento do tráfego em ruas estreitas. Elas proporcionam melhor sombreamento pelos edifícios nas calçadas para pedestres, mas esse sombreamento também pode ser alcançado mesmo em ruas largas por detalhes nos edifícios ou por árvores.

Outro ponto é o melhor aproveitamento dos cursos d’água nas áreas urbanas. Excetuando-se os maiores, todos os córregos e cursos d'água da paisagem natural desapareceram das cidades modernas; foram canalizados e cobertos por superfícies impermeabilizadas que agem como um escudo à prova d'água (SPIRN, 1995, p.146147). Recursos aplicados para canalização de córregos poderiam ser melhor aproveitados fazendo-se pequenas barragens, de $1 \mathrm{~m}$ ou $2 \mathrm{~m}$ no máximo, para inundar grandes áreas de forma mais ou menos permanente. Como em Curitiba, o armazenamento de água das cheias e o lazer são compatíveis nos grandes parques urbanos situados nos fundos de vale.

Além da impermeabilização, estudos da NASA já mostraram claras diferenças de desempenho térmico entre superfícies naturais e construídas, que afetam as temperaturas na cidade. Nas cidades estudadas (Atlanta, Boston, Sacramento, etc.) os incentivos para a substituição de materiais em pavimentos e coberturas já estão dando resultados. Em vez da pavimentação tradicional, a adoção de blocos vazados, que permitem o crescimento de grama entre eles, seria uma boa opção nas áreas de estacionamento; uso de pavimentação permeável, uma espessa camada de cascalho sob a camada superficial do solo serve tanto de elemento de drenagem como de reservatório, armazenando a água que as raízes conseguem absorver e evitando que fiquem encharcadas (SPIRN, 1995, p.167, 171)

\subsection{Considerações finais}

As conquistas do século XIX nas reformas sanitárias foram importantes e inspiradoras, mas não conseguiram resolver os problemas urbanos do final do século XX (ATAIDE, [s.d.]). Os problemas de hoje requerem novas soluções, muito mais abrangentes. 
A maior densidade de ocupação é um fato, temos que aprender a conviver bem com ela, e testar novas soluções, por exemplo, para sombrear ruas largas, inevitáveis nos eixos de escoamento de tráfego na cidade. "The natural arrangement of buildings in the wet tropics would seem to tend towards a certain amount of scattering, so as not to obstruct incident prevailing winds. However, economic and social imperatives dictate that cities must become more concentrated, making it necessary to increase the density to reduce the cost of public services and achieve required social cohesiveness" (CARMONA, 1986, p.389) A cidade compacta também vem sendo pregada pelos ecourbanistas, por entidades como a Ecocity Builders, por Richard Register e seus seguidores, por Richard Rogers, em seu livro Cities for a small planet, etc. Segundo ROGERS (1997, p.32) "Dense cities can through integrated planning be designed to increase energy efficiency, consume fewer resources, produce less pollution and avoid sprawling over the contryside. It is for these reasons that I believe we should be investing in the idea of a 'Compact City'- a dense and socially diverse city where economic and social activities overlap and where communities are focused around neighbourhoods."

Precisamos testar diferentes padrões possíveis de ocupação urbana e admitir que, se por um determinado conjunto de fatores o padrão deve ser vertical, qual a melhor maneira de se conviver bem com ele? Se o padrão deve ser horizontal, idem. Se a rua deve ser larga para o escoamento do tráfego, qual a melhor forma de tratá-la? Se o volume de tráfego é pequeno, as ruas podem ser estreitas; como tirar proveito disso? Quando fala de seu projeto de cidade compacta para Shangai, ROGERS (1997, p.46) diz que "by varying the heights of buildings, sunlight and daylight could be focused on enlivening the streets, squares and avenues, even through density of construction was high. The variety of roofline also optimised views and the penetration of daylight into the buildings themselves, reducing the need for energy for artificial lighting. The overall composition produced a dense city profile crowned by a series of towers - $a$ striking skyline across the river from old Shangai." Rogers diz ainda que o perfil da cidade segue algumas diretrizes que maximizam o acesso da luz natural nas ruas e nos edifícios, e tiram proveito dos ventos para manter a cidade mais fresca e com ar mais limpo. Edifícios de diferentes alturas são agrupados, minimizando seu impacto sobre os espaços públicos.

ROGERS (1997, p.67) critica a inexistência de políticas públicas que ofereçam incentivos para se investir em tecnologias ambientalmente corretas, que se pagam a médio e longo prazo. "This strategy, which can lonly leave tomorrow worse off, is the anthitesis of sustainable thinking and completely overrules the aesthetic considerations essential to good architecture: it provides no incentive for such public gestures as na árcade, no reason to use good materials, to landscape a building or even plant a tree." Os descontos no IPTU para boas práticas relacionadas ao tema são um ótimo instrumento porque atingem a todos, mas esses descontos têm que ser significativos e deve haver um amplo programa de divulgação, mostrando as vantagens ambientais e financeiras ao cidadão comum. Para um bom funcionamento do programa a monitoração deve ser constante, com o uso de imagens aéreas ou fotos de satélite que permitam a visualização das áreas verdes, e o cadastro precisa ser constantemente atualizado.

Há que se aprender com bons e maus exemplos: as motivações que estavam por trás, a estrutura institucional dentro da qual evoluíram e as estratégias de implementação 
empregadas. As administrações municipais têm obtido sucesso nos projetos envolvendo parcerias; o marketing ambiental que já alterou profundamente o estilo de administrar de grandes empresas (LOVINS, 2000 e Empresa \& Ambiente, 2000) também pode ser explorado por pequenos estabelecimentos comerciais, que poderiam receber algum tipo de selo verde na cidade, por contribuir para a melhoria ambiental da sua rua, do seu bairro, da sua vizinhança.

Boas idéias foram arquivadas por falta de operacionalidade; isso mostra aos planejadores a necessidade de entendimento e principalmente de troca de idéias com o sistema político-institucional, para que bons projetos não tenham o mesmo fim.

\section{Referências bibliográficas}

1. ASSIS, Eleonora Sad de. Impacto da forma urbana na mudança climática: método para previsão do comportamento térmico e melhoria de desempenho do ambiente urbano. São Paulo, 2000. Tese (Doutorado em Arquitetura) Faculdade de Arquitetura e Urbanismo, Universidade de São Paulo.

2. ATAIDE, Ruth. Na trilha da recuperação e preservação ambiental de Natal: limites e possibilidades do plano diretor. Natal, 2000.

3. BITTENCOURT, Leonardo Salazar et al. A influência da relação entre taxa de ocupação $\times \mathrm{n}^{\circ}$ de pavimentos no potencial de ventilação natural dos ambientes internos e externos. In: IV ENCAC - Encontro Nacional de Conforto no Ambiente Construído, 1997, Salvador. Anais. Salvador: FAUUFBA/LACAM-ANTAC, 1997. p.102-106.

4. BITTENCOURT Leonardo Salazar et al. O efeito da verticalização das edificações na ventilação natural do tecido urbano: o caso da orla marítima de Maceió. In: VIII ENTAC, 2000, Salvador. Anais em CD-ROM. Salvador: ANTAC, 2000.

5. BRANDÃO et.al.. A construção do ambiente urbano através da interação das escalas: estudo de caso do Bairro Floresta, Belo Horizonte. In: VIII ENTAC, 2000, Salvador. Anais em CD-ROM. Salvador: ANTAC, 2000.

6. CARMONA, Luis Sanchez de. Human comfort in the tropics. In: URBAN CLIMATOLOGY AND ITS APPLICATIONS WITH SPECIAL REGARD TO TROPICAL AREAS. Mexico D.F., 26-30 November 1984. Proceedings. OKE, T. (ed.) Urban Climatology and its Applications with Special Regard to Tropical Areas. Geneva: WMO n.652, 1986, p.354-404.

7. CENTRO DE REFERÊNCIA EM GESTÃO AMBIENTAL PARA ASSENTAMENTOS HUMANOS. Unilivre: www.unilivre.org.br.

8. CORBELLA, O. YANNAS, S. Posto 3 Copacabana Rio de Janeiro. In: IV ENCAC, 1997, Salvador. Anais. Salvador: FAUUFBA/LACAM-ANTAC, 1997. p.118-123.

9. CUIABÁ. Prefeitura Municipal de Cuiabá. Projeto Cura Cuiabá. [s.l.], [s.d.].

10. DUARTE, Denise. A inclusão de questões de conforto térmico urbano nas regulamentações municipais no Brasil. In: NUTAU'2000. Anais em CDROM. São Paulo: NUTAU, 2000. 
11. Empresa \& Ambiente. Encarte especial da revista Exame, São Paulo, 2000.

12. EVANS, M., SCHILLER, S. Application of microclimate studies in town planning: a new capital city, an existing urban district and urban river front development. In: Atmospheric Environment, Oxford, v.30, n.3, p. 361-364, 1996.

13. GIVONI, Baruch. Urban Design in Different Climates. Geneve: WCAP-10, WMO/TD n.346, 1989.

14. GIVONI, Baruch. Climate Considerations in Building and Urban Design. New York: John Wiley \& Sons, 1998.

15. GONÇALVES, Joana. Limites para a verticalidade. Qualidade na Construção. São Paulo, n.21, 1999, p.16-26.

16. HARAZONO et al. Effects of rooftop vegetation using artificial substrates on the urban climate and the thermal load of buildings. Energy and Buildings, n.1516, 1990/91, p.435-442.

17. HOJE EM DIA. Belo Horizonte. Cidade Jardim. Belo Horizonte: Hoje em Dia/Rede Marketing e Comunicação, 26 mar. 2000.

18. HOUGH, Michael. Naturaleza y ciudad. Barcelona: Gustavo Gili, 1998.

19. IV INTERNATIONAL ECOCITY CONFERENCE. Curitiba: Unilivre, abr. 2000.

20. KEEBLE, E.J., COLLINS, M., RYSER, J. The potential of land-se planning and development control to help achieve favorable microclimates around buildings: a European review. Energy and Buildings, n.15-16, 1990/91, p.823-836.

21. LOMBARDO, Magda. Clima urbano. Notas de aula. Curso ministrado durante o V ENCAC - Encontro Nacional de Conforto no Ambiente Construído, 1999, Fortaleza.

22. LOVINS, Amory, LOVINS, L. Hunter. O capitalismo natural. Exame, São Paulo, ed.715, 31 de maio de 2000, p.160-166.

23. MACRIS, Dean, WILLIAMS, George. San Francisco's Downtown Plan: Landmark Guidelines Shape City's Growth. August 1999. In: www.spur.org/downtown.html

24. MIZUNO M. et al. Effects of land use on urban horizontal atmospheric temperature distributions. Energy and Buildings, n.15-16, 1990/91, p.165176.

25. OKE, T. R. et al. The energy balance of central Mexico City during the dry season. Atmospheric Environment, v.33, 1999, p.3919-3930.

26. PRESSMAN, N. Quality for public urban space and pedestrian movement. In: Architecture and Urban Space. Proceedings of the Ninth International PLEA Conference, Seville: Kluwer, September 1991, p.99-107.

27. ROGERS, Richard. Cities for a small planet. London: Faber and Faber, 1997. 
28. ROSENFELD et al. Painting the town white- and green. In: http://eetd.lbl.gov/HeatIsland/PUBS/PAINTING

29. ROSENFELD et at. Policies to reduce heat islands: magnitudes of benefits and incentives to achieve them. In: ACEEE Summer Study on Energy Efficiency in Buildings. Proceedings. Pacific Grove, CA, v.9, 1996, p.177 (disponível também em http://eetd.lbl.gov/HeatIsland/PUBS).

30. SAMPAIO, Antonio Heliodorio Lima. Correlações entre o uso do solo e ilhas de calor no ambiente urbano: o caso de Salvador. São Paulo, 1981. Dissertação (Mestrado em Geografia), Faculdade de Filosofia, Letras e Ciências Humanas, Universidade de São Paulo.

31. SCHILLER S., EVANS, J. M. Design of outdoor spaces: socio-political tendencies and bioclimatic consequences. In: Architecture and Urban Space. Proceedings of the Ninth International PLEA Conference, Seville: Kluwer, September 1991, p.109-114.

32. SERRA, Geraldo Gomes. Obras urbanas. Notas de aula. São Paulo: FAUUSP, 1996.

33. SPIRN, Anne Whiston. O jardim de granito. São Paulo: EDUSP, 1995.

34. TAHA, Haider. Night Time Air Temperature and the Sky-View Factor: A Case Study in San Francisco, California. Lawrence Berkeley Laboratory, Berkeley CA, LBL- 24009, 1988. 


\section{ANEXOS}

Anexo 1 - Dados climáticos do aglomerado Cuiabá/Várzea Grande Anexo 2 - Fotos aéreas dos casos estudados 


\section{ANEXO 1 - DADOS CLIMÁTICOS DO AGLOMERADO CUIABÁ/VÁRZEA GRANDE}

Inicialmente apresentam-se as normais climatológicas do período de 1961-1990 do INMET - Instituto Nacional de Meteorologia, do Ministério da Agricultura e Reforma Agrária. Os dados foram coletados no $9^{\circ}$ Distrito de Meteorologia localizado no município vizinho de Várzea Grande, aproximadamente a 3,5 $\mathrm{Km}$ da área central de Cuiabá (tab.1, fig.1 a 4).

Tabela 1 - Normais climatológicas 1961-1990.

\begin{tabular}{|l|c|c|c|c|c|c|c|c|c|c|c|c|}
\hline & jan & fev & mar & abr & mai & jun & jul & ago & set & out & nov & dez \\
\hline $\begin{array}{l}\text { tmáx } \\
\text { abs }{ }^{\circ} \mathrm{C}\end{array}$ & 38.2 & 37 & 37.5 & 38.1 & 36.4 & 36.2 & 38.3 & 39 & 41.1 & 40.4 & 40 & 39 \\
\hline $\begin{array}{l}\text { tmédia } \\
\text { máx }{ }^{\circ} \mathrm{C}\end{array}$ & 32.6 & 32.6 & 32.9 & 32.7 & 31.6 & 30.7 & 31.8 & 34.1 & 34.1 & 34 & 31.1 & 32.5 \\
\hline $\begin{array}{l}\text { tmédia } \\
\text { méd }{ }^{\circ} \mathrm{C}\end{array}$ & 26.7 & 25.3 & 26.5 & 26.1 & 24.6 & 23.5 & 22 & 24.7 & 26.6 & 27.4 & 27.2 & 26.6 \\
\hline $\begin{array}{l}\text { tmédia } \\
\text { mín }{ }^{\circ} \mathrm{C}\end{array}$ & 23.2 & 22.9 & 22.9 & 22 & 19.7 & 17.5 & 16.6 & 18.3 & 22.1 & 17.1 & 22.9 & 23 \\
\hline $\begin{array}{l}\text { tmín } \\
\text { abs }{ }^{\circ} \mathrm{C}\end{array}$ & 19.2 & 19.2 & 15.4 & 10.8 & 7 & 6.8 & 3.3 & 6 & 10.2 & 13.1 & 15.8 & 18.3 \\
\hline $\begin{array}{l}\text { amplit. } \\
\text { térm. }\end{array}$ & 9.4 & 9.7 & 10 & 10.7 & 11.9 & 13.2 & 15.2 & 15.8 & 12 & 16.9 & 8.2 & 9.5 \\
\hline \begin{tabular}{l} 
umid.rel $_{\text {ar } \%}$ \\
\hline $\begin{array}{l}\text { precipit } \\
\text { tot mm }\end{array}$
\end{tabular} & 80.7 & 81.6 & 81 & 79.5 & 74.2 & 73.7 & 65.4 & 57.3 & 61.8 & 69.6 & 74.2 & 78.5 \\
\hline
\end{tabular}

(fonte: Ministério da Agricultura e Reforma Agrária. INMET. Normais Climatológicas 1961-1990.).

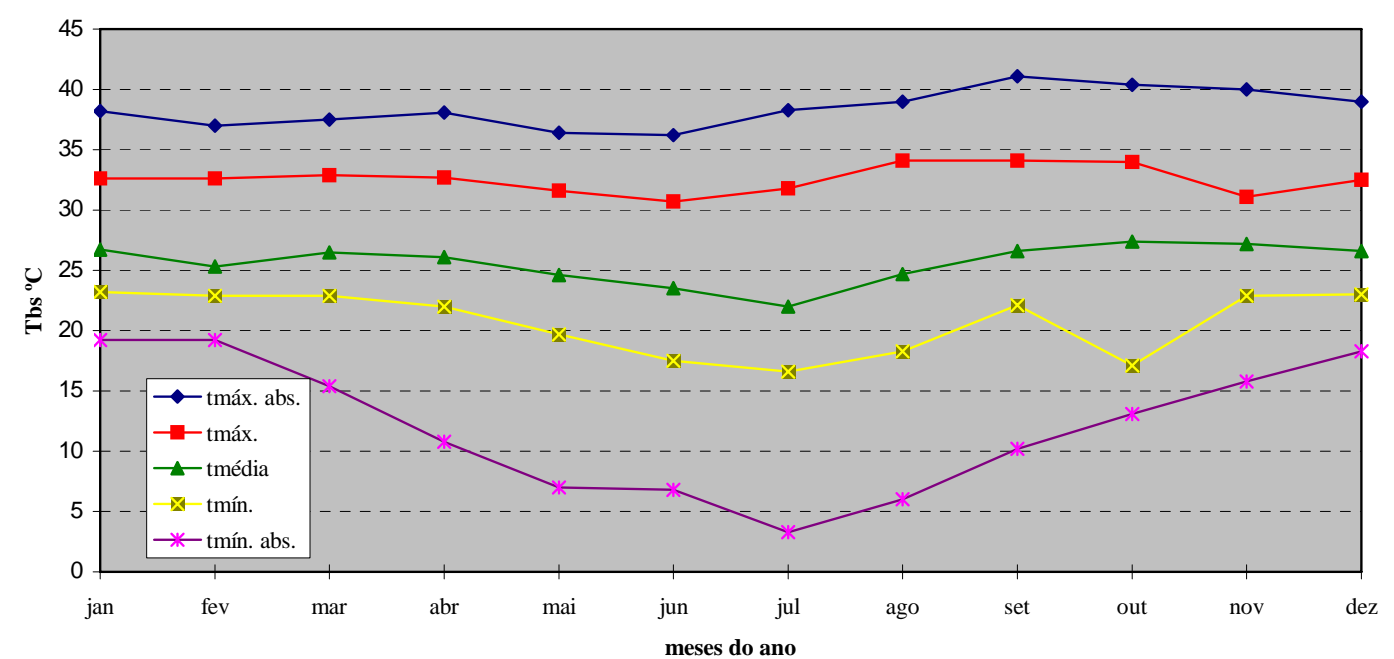

Figura 1 - Temperatura de bulbo seco. (fonte: Normais Climatológicas 1961-1990).

Analisando-se o gráfico referente à temperatura de bulbo seco, suspeita-se que o valor apresentado pelo INMET para a temperatura médias das mínimas do mês de outubro esteja incorreto. Esperava-se um valor em torno de $23^{\circ} \mathrm{C}$, ao invés de $17,1^{\circ} \mathrm{C}$, para esse período. 


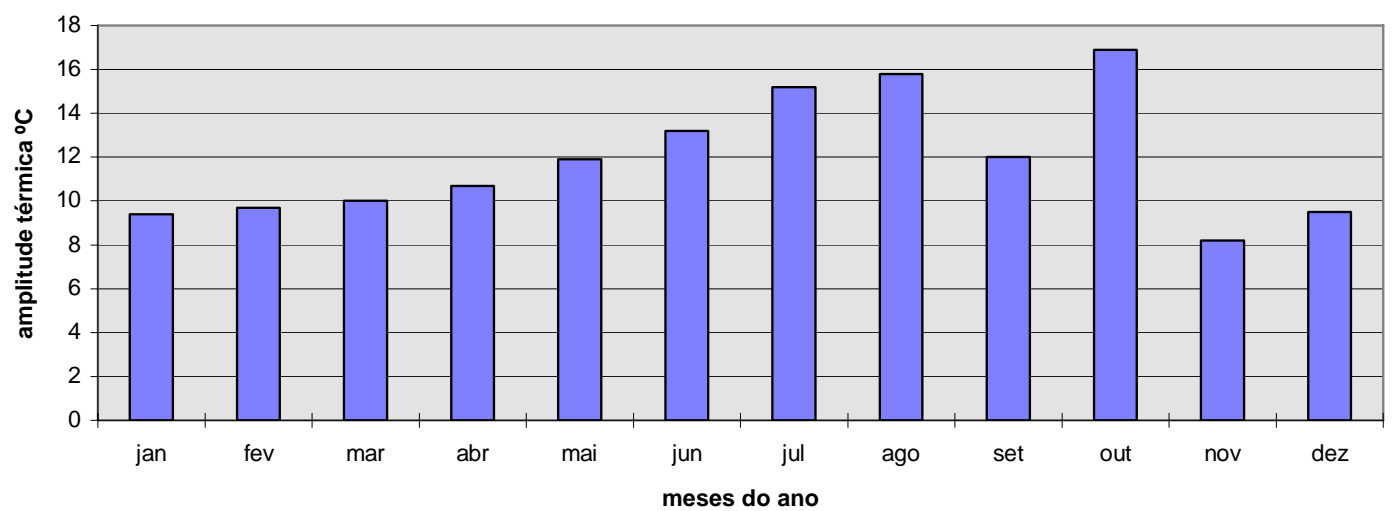

Figura 2 - Amplitude térmica média mensal. (fonte: Normais Climatológicas 1961-1990).

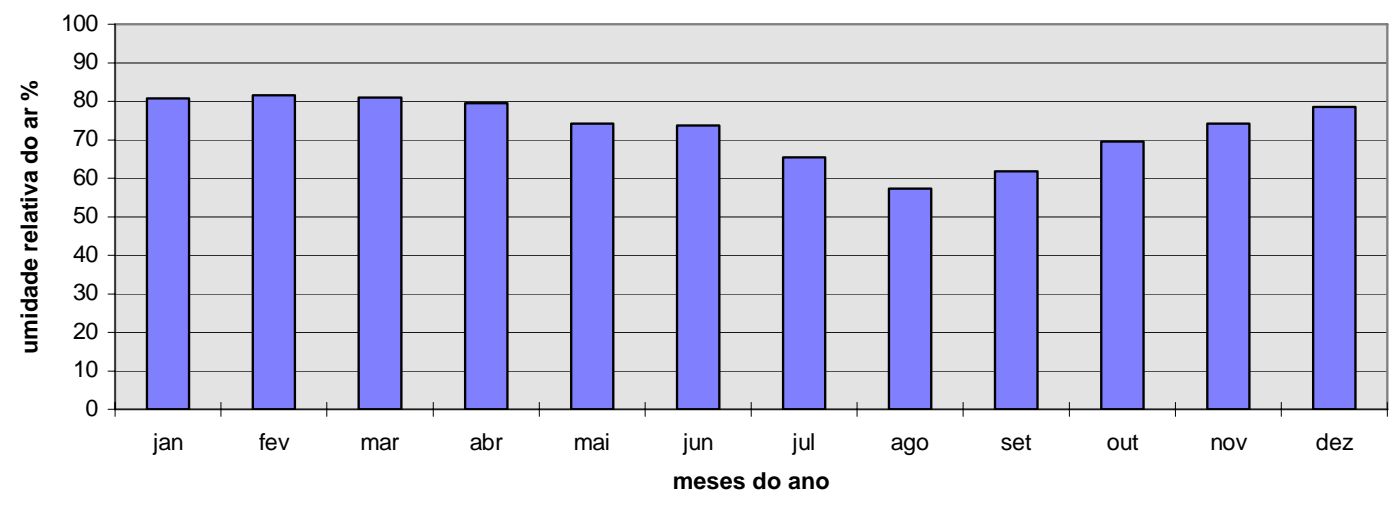

Figura 3 - Umidade relativa do ar. (fonte: Normais Climatológicas 1961-1990).

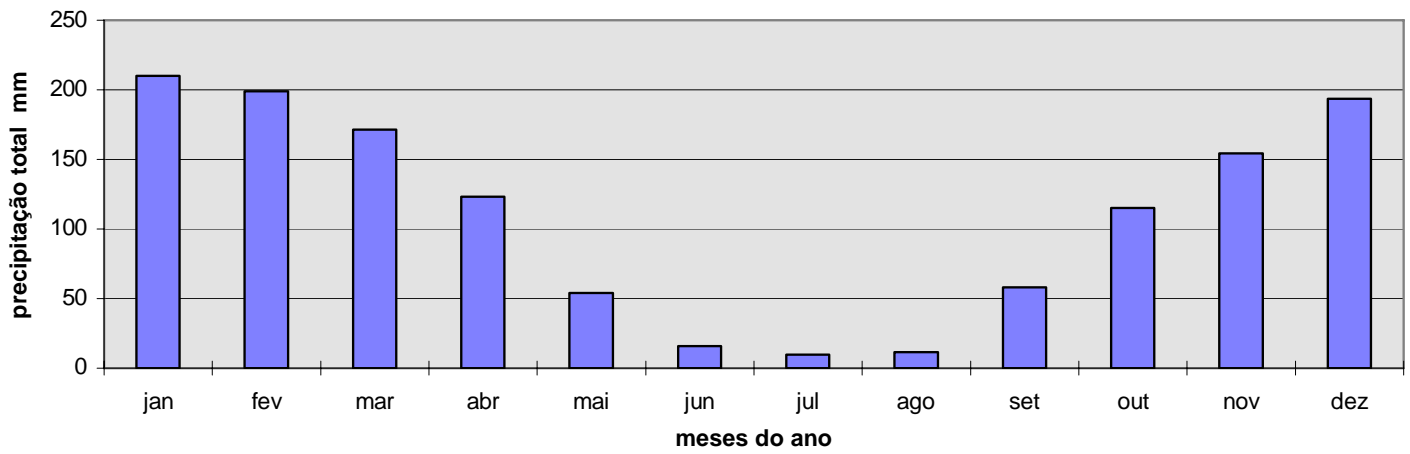

Figura 4 - Precipitação total. (fonte: Normais Climatológicas 1961-1990).

Dispõe-se também de dez anos de dados um pouco mais recentes, do período que vai de 1985 a 1994, extraídos dos Sumários Meteorológicos Mensais, do Ministério da Aeronáutica. Os dados foram coletados na estação meteorológica localizada no Aeroporto Marechal Rondon, em Várzea Grande (tab.2, fig.5 a 8). 
Tabela 2 - Médias mensais 1985-1994.

\begin{tabular}{|l|c|c|c|c|c|c|c|c|c|c|c|c|}
\hline & jan & fev & mar & abr & mai & jun & jul & ago & set & out & nov & dez \\
\hline $\begin{array}{l}\text { tmédia } \\
\text { máx }{ }^{\circ} \mathrm{C}\end{array}$ & 32.69 & 32.2 & 32.54 & 32.96 & 31.52 & 30.77 & 30.34 & 32.85 & 33.21 & 34.02 & 33.41 & 32.88 \\
\hline $\begin{array}{l}\text { tmédia } \\
\text { méd }{ }^{\circ} \mathrm{C}\end{array}$ & 27.37 & 26.78 & 27.07 & 27.35 & 25.58 & 24.58 & 23.48 & 25.96 & 26.95 & 28.32 & 28.3 & 27.87 \\
\hline $\begin{array}{l}\text { tmédia } \\
\text { mín }{ }^{\circ} \mathrm{C}\end{array}$ & 23.96 & 23.41 & 23.53 & 23.11 & 21.27 & 19.31 & 17.56 & 20.04 & 21.81 & 23.33 & 23.88 & 24.09 \\
\hline $\begin{array}{l}\text { amplit. } \\
\text { térm. }{ }^{\circ} \mathrm{C}\end{array}$ & 8.73 & 8.79 & 9.01 & 9.85 & 10.25 & 11.46 & 12.78 & 12.81 & 11.4 & 10.69 & 9.53 & 8.79 \\
\hline $\begin{array}{l}\text { umid.rel. } \\
\text { do ar \% }\end{array}$ & 77.2 & 77.6 & 77.3 & 76.1 & 73.8 & 67.7 & 61.7 & 56.9 & 60.8 & 64.3 & 69.1 & 77.1 \\
\hline $\begin{array}{l}\text { precip.tot } \\
\text { mm }\end{array}$ & 232.19 & 240.35 & 150.56 & 132.65 & 59.91 & 18.81 & 13.01 & 18.95 & 62.78 & 101 & 164.43 & 156.35 \\
\hline
\end{tabular}

(fonte: Ministério da Aeronáutica. Sumários Climatológicos Mensais 1985-1994).

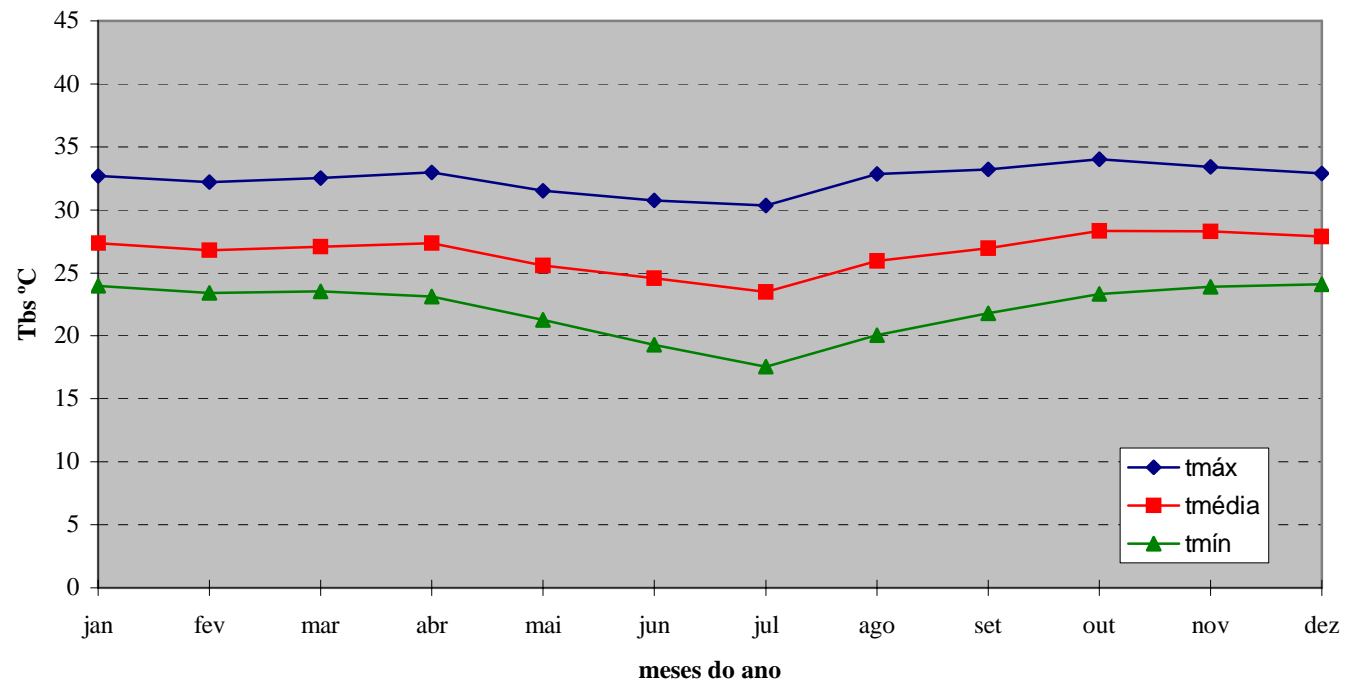

Figura 5 - Temperatura de bulbo seco. (fonte: Sumários Climatológicos Mensais 1985-1994).

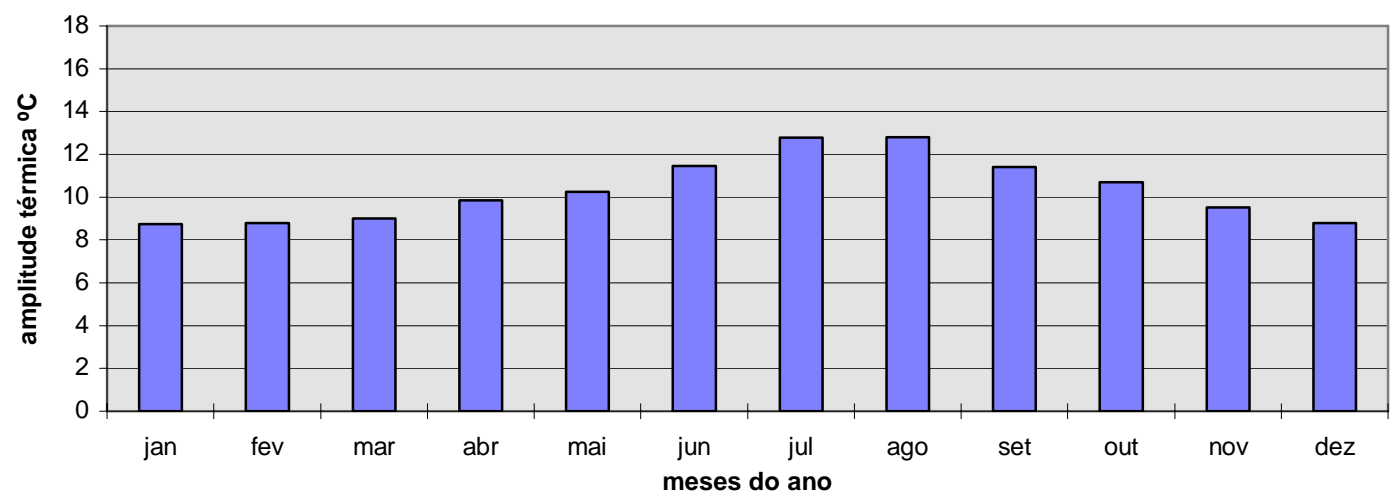

Figura 6 - Amplitude térmica média mensal. (fonte: Sumários Climatológicos Mensais 19851994). 


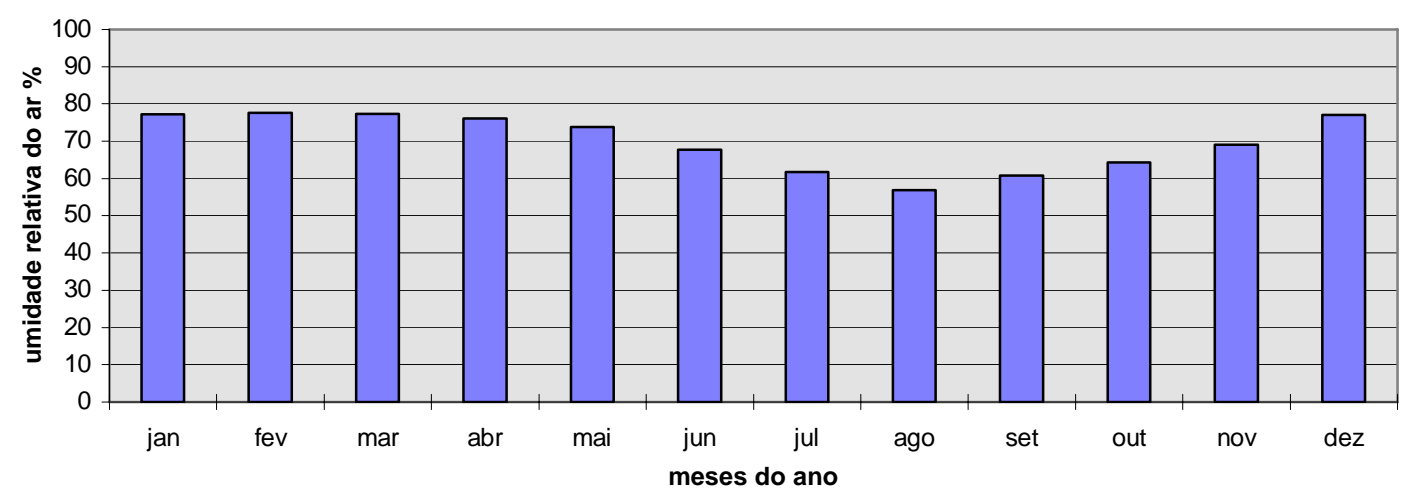

Figura 7 - Umidade relativa do ar. (fonte: Sumários Climatológicos Mensais 1985-1994).

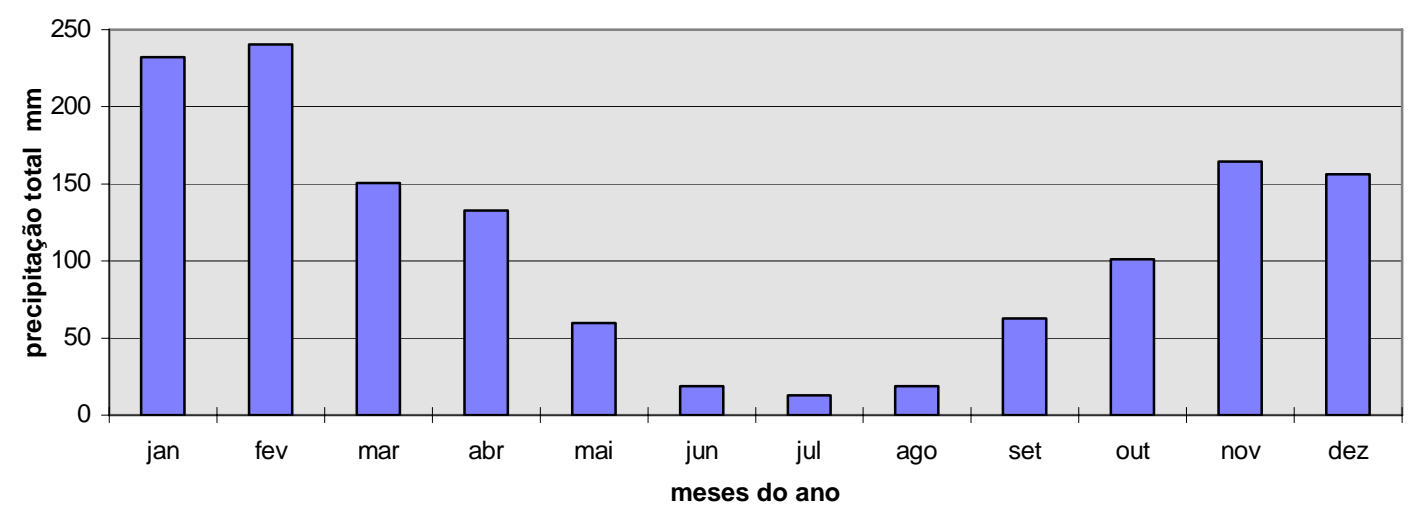

Figura 8 - Precipitação total. (fonte: Sumários Climatológicos Mensais 1985-1994).

Também foram encontrados dados detalhados sobre ventilação, apresentados na tab.3 e na fig.9.

Tabela 3 - Dados de ventilação.

\begin{tabular}{|l|l|l|l|l|l|l|l|l|l|l|l|l|}
\hline Mês & jan & fev & mar & abr & mai & jun & jul & ago & set & out & nov & dez \\
\hline $\begin{array}{l}\text { Vel.Esc. } \\
\text { (m/s) }\end{array}$ & 1,7 & 1,6 & 1,6 & 1,5 & 1,4 & 1,5 & 1,7 & 1,6 & 1,8 & 2,1 & 1,8 & 1,9 \\
\hline $\begin{array}{l}\text { Result. (R) } \\
\text { mód. (m/s) }\end{array}$ & 0,7 & 0,5 & 0,5 & 0,1 & 0,1 & 0,23 & 0,16 & 0,27 & 0,47 & 0,54 & 0,72 & 1,04 \\
\hline $\begin{array}{l}\text { Direção } \\
\text { (graus) }\end{array}$ & 334 & 299 & 317 & 349 & 172 & 317 & 282 & 217 & 241 & 333 & 343 & 337 \\
\hline $\begin{array}{l}\text { Constância } \\
\text { (R/V) x100 }\end{array}$ & 41 & 31 & 31 & 07 & 07 & 15 & 09 & 17 & 26 & 26 & 40 & 55 \\
\hline & \multicolumn{7}{|c|}{ Frequência Relativa (\%) } \\
\hline N & 26 & 22 & 17 & 16 & 17 & 13 & 16 & 13 & 17 & 21 & 33 & 35 \\
\hline NE & 04 & 05 & 06 & 04 & 04 & 04 & 06 & 04 & 03 & 07 & 05 & 05 \\
\hline E & 09 & 11 & 06 & 11 & 07 & 05 & 06 & 08 & 09 & 06 & 07 & 06 \\
\hline SE & 06 & 07 & 06 & 09 & 11 & 07 & 07 & 08 & 08 & 08 & 05 & 03 \\
\hline S & 08 & 10 & 09 & 17 & 21 & 18 & 17 & 20 & 25 & 11 & 12 & 06 \\
\hline SO & 04 & 06 & 09 & 07 & 04 & 10 & 05 & 07 & 08 & 9 & 04 & 04 \\
\hline O & 14 & 13 & 13 & 11 & 08 & 10 & 09 & 15 & 10 & 09 & 09 & 13 \\
\hline NO & 21 & 20 & 16 & 13 & 12 & 09 & 11 & 11 & 10 & 17 & 17 & 20 \\
\hline Calmaria & 08 & 06 & 18 & 12 & 16 & 24 & 23 & 14 & 10 & 12 & 08 & 08 \\
\hline
\end{tabular}

(fonte: Campelo Jr. et al. Caracterização Macroclimática de Cuiabá. Dados de 1970 a 1989) 


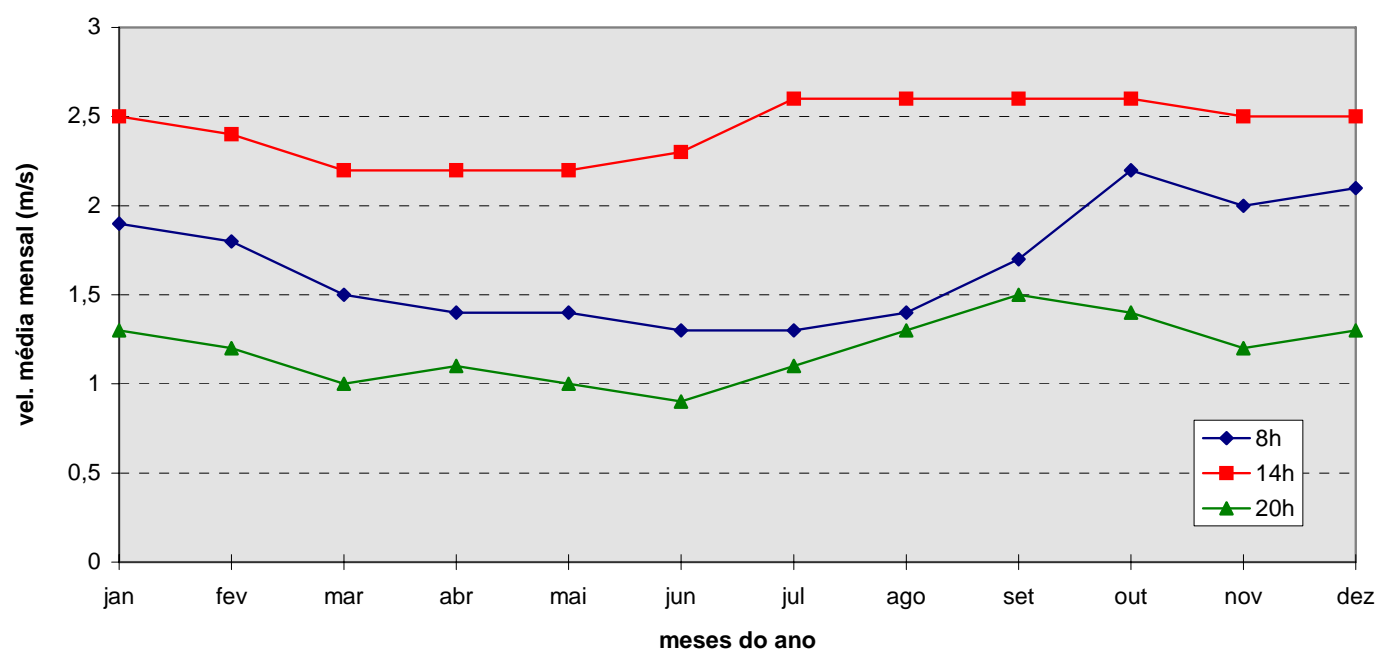

Figura 9 - Médias mensais horárias de velocidade do vento (m/s), do período de 1970-1992. (fonte: dados do INMET apud Maitelli, 1994)

\section{Referências Bibliográficas}

1.BRASIL. Ministério da Agricultura e da Reforma Agrária. Normais Climatológicas 1961-1990. Brasília: INMET, [s.d.].

2.BRASIL. Ministério da Aeronáutica. Sumários Meteorológicos Mensais 1985 a 1994. Várzea Grande: Aeroporto Marechal Rondon.

3.CAMPELO Jr. et al. Caracterização Macroclimática de Cuiabá. In: $3^{\circ}$ Encontro Nacional de Estudos sobre o Meio Ambiente, Londrina 1991. Anais. Londrina, v.1, Comunicações, p.542-552.

4.MAITELLI, Gilda T. Uma Abordagem Tridimensional de Clima Urbano em Área Tropical Continental: o exemplo de Cuiabá - MT. São Paulo, 1994. Tese (Doutorado em Geografia). Faculdade de Filosofia, Letras e Ciências Humanas, Universidade de São Paulo. 


\section{ANEXO 2 - FOTOS AÉREAS DOS CASOS ESTUDADOS}

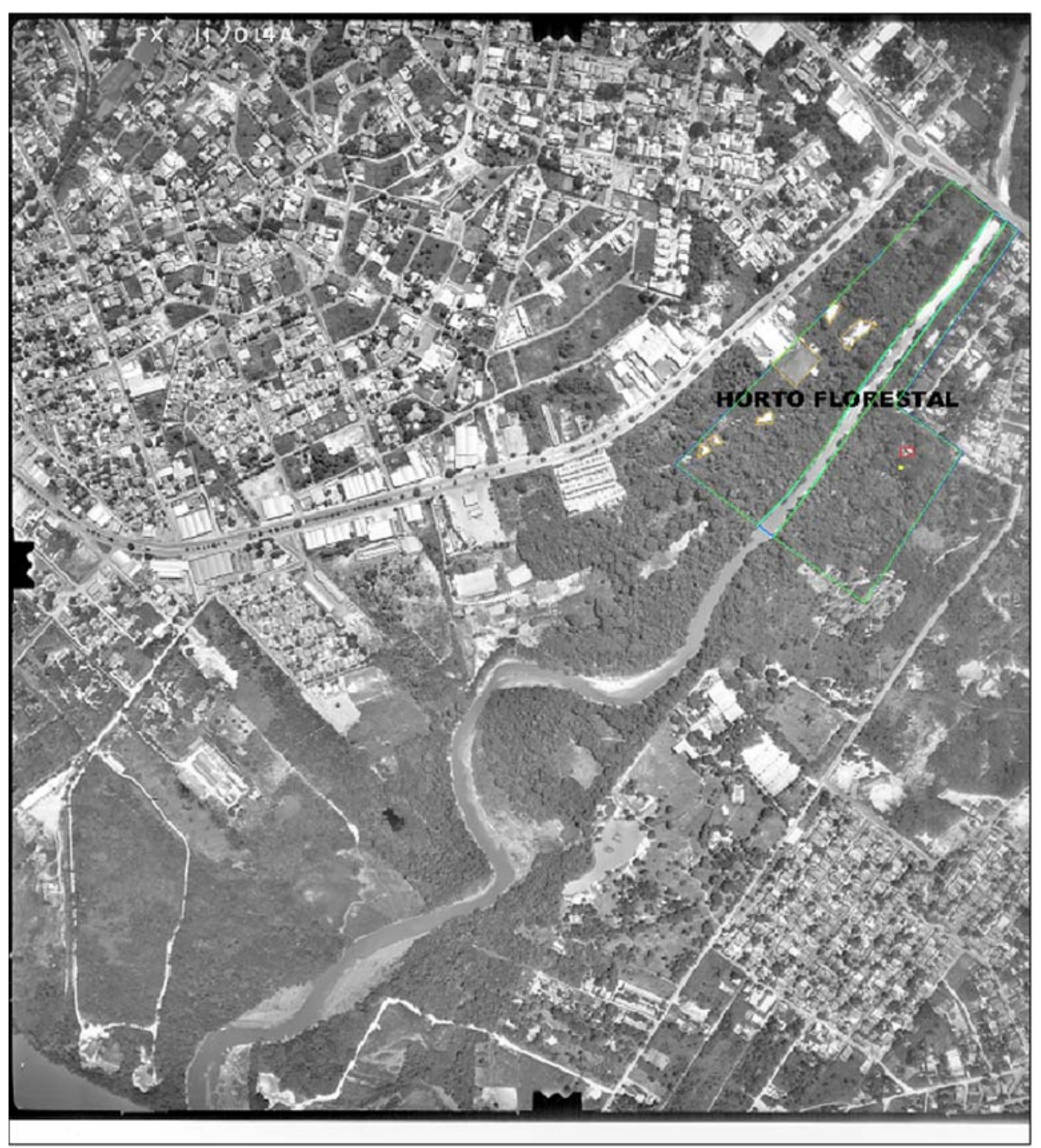

\section{LEGENDA}

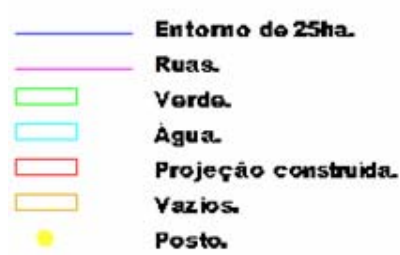

Figura 1 - Foto aérea do Horto Florestal com a demarcação da área quantificada no entorno do posto. (foto: Esteio Engenharia e Aerolevantamentos) 


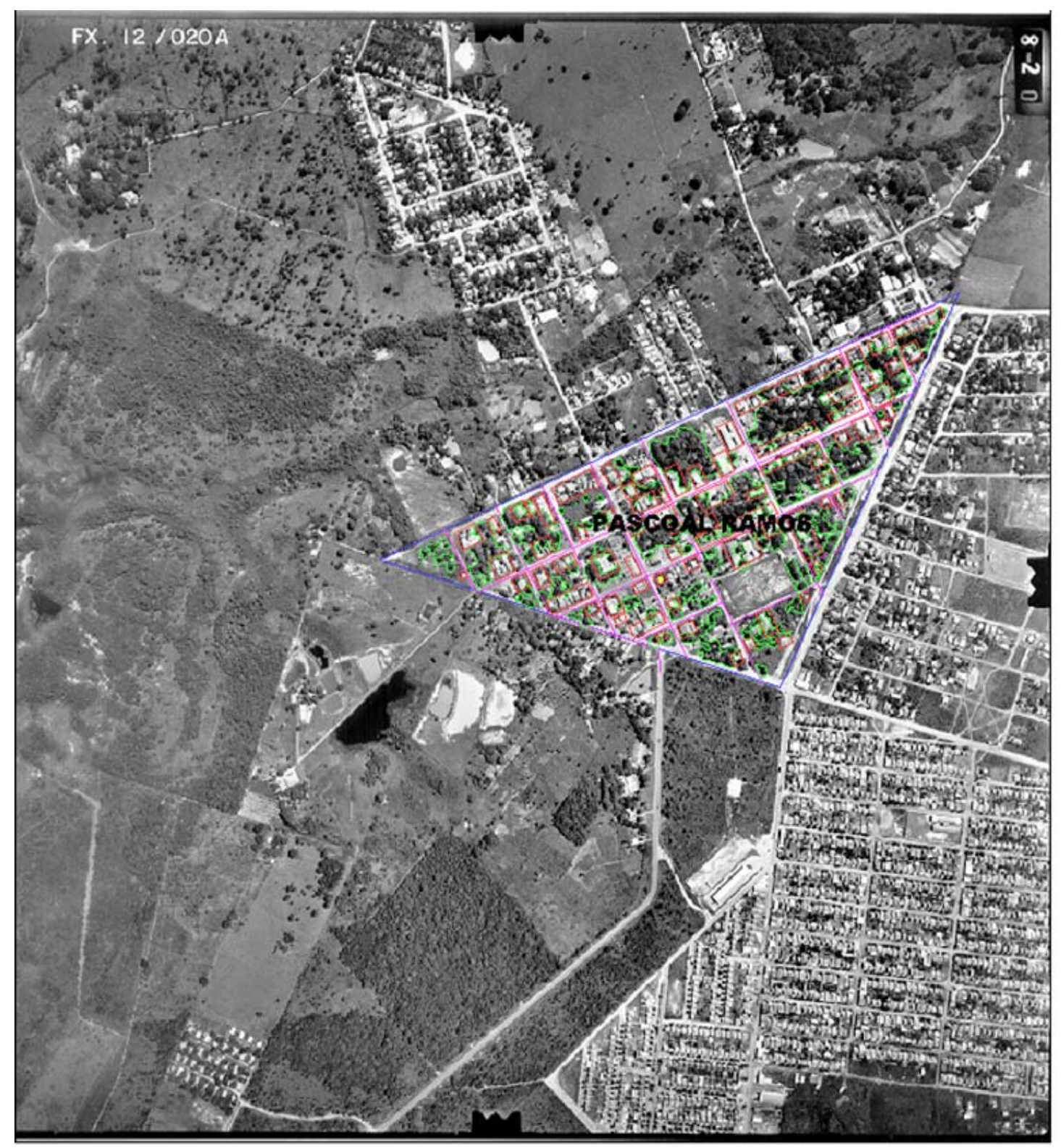

\section{LEGENDA}

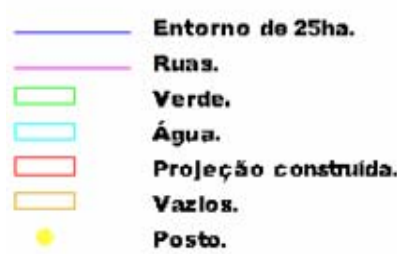

Figura 2 - Foto aérea do Pascoal Ramos com a demarcação da área quantificada no entorno do posto. (foto: Esteio Engenharia e Aerolevantamentos) 


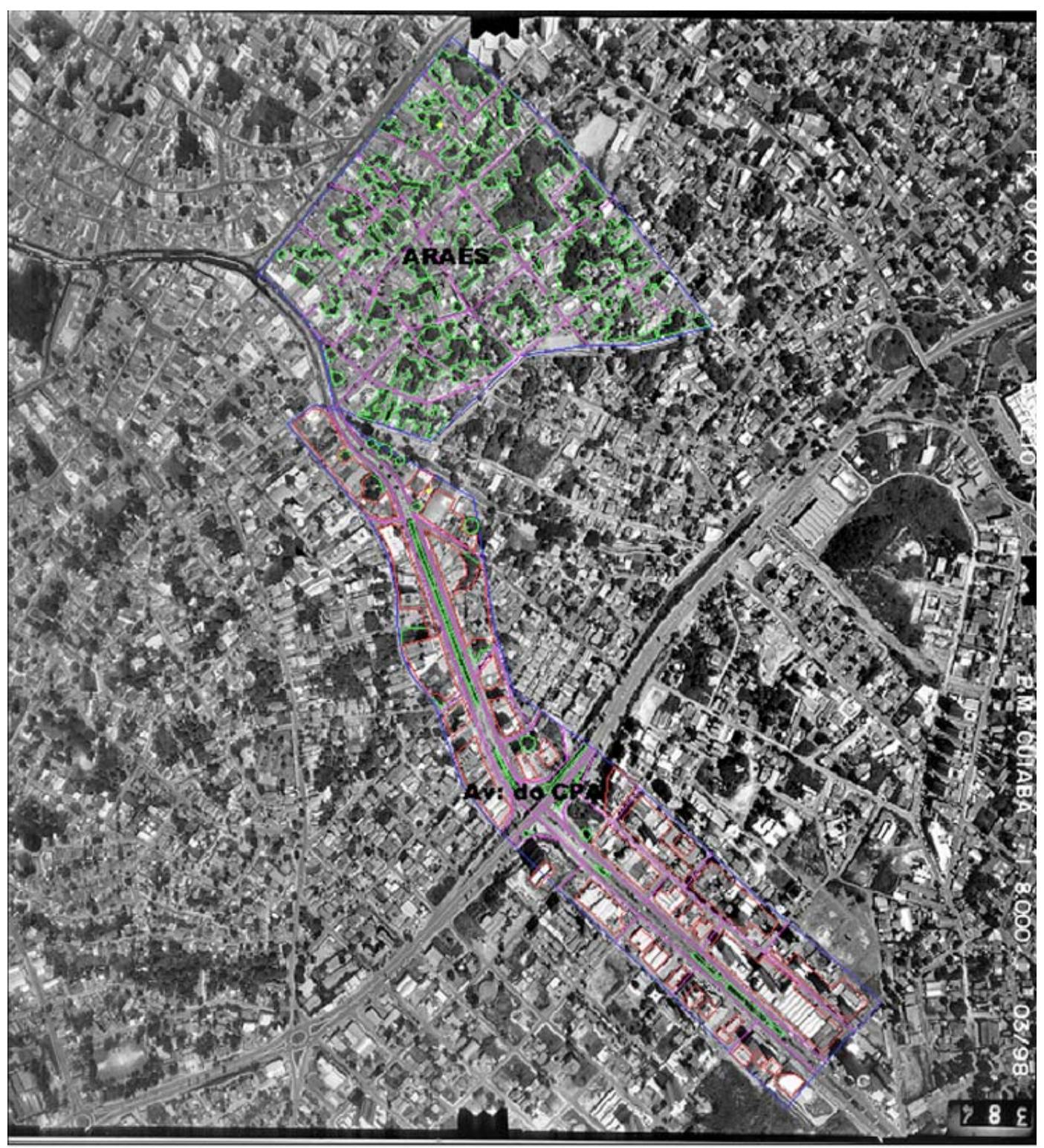

\section{LEGENDA}

$\begin{array}{ll}\square & \text { Entorno de 25ha. } \\ \square & \text { Ruas. } \\ & \text { Varda. } \\ \square & \text { Agua. } \\ \square \quad \text { Projeçăo construida. } \\ \text { Vazlos. } \\ \text { Pasta. }\end{array}$

Figura 3 - Foto aérea do Araés e da Av. do CPA com a demarcação da área quantificada no entorno dos postos. (foto: Esteio Engenharia e Aerolevantamentos) 


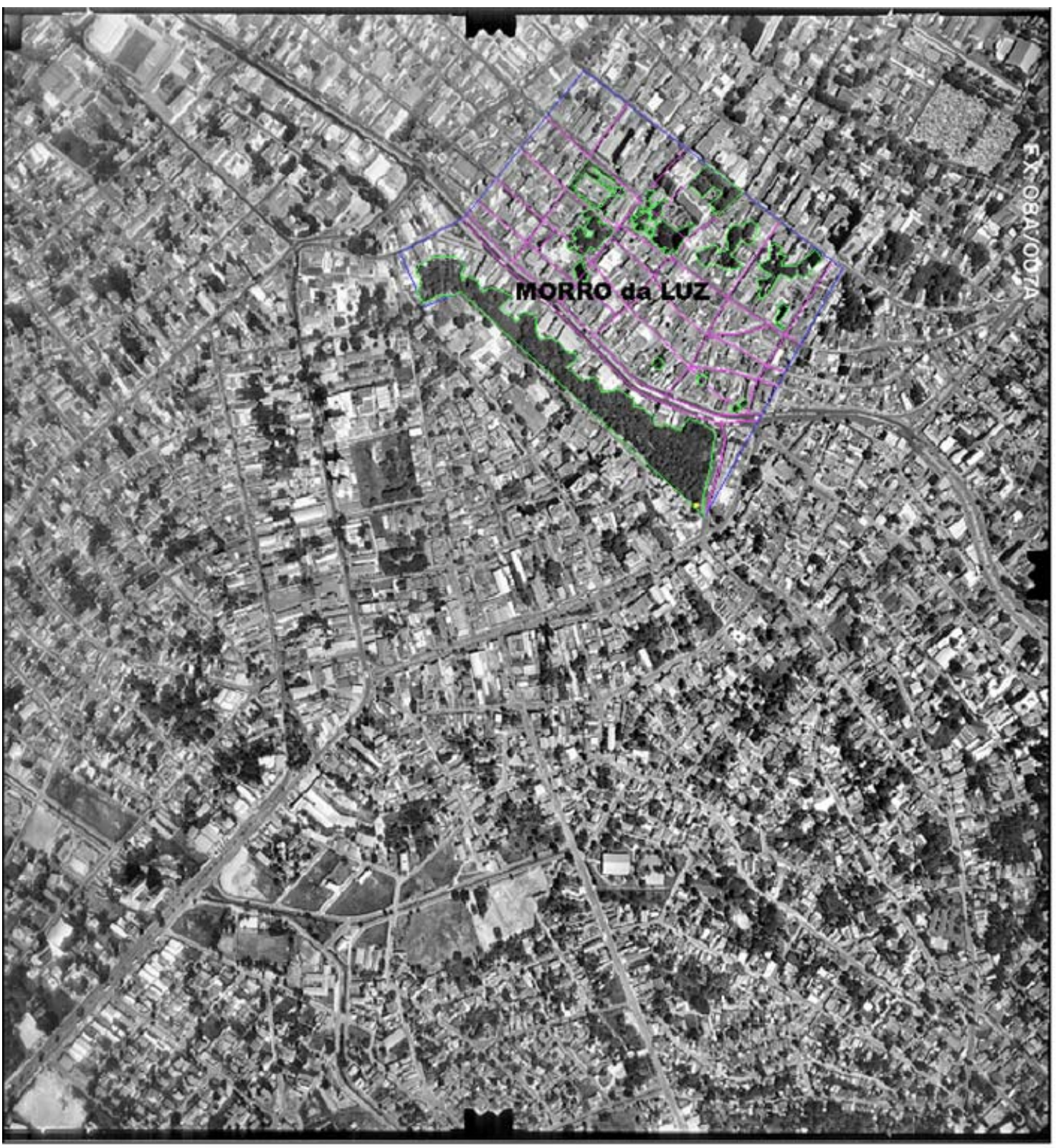

\section{LEGENDA}

$\begin{array}{ll}\square & \text { Entorno de 25ha. } \\ \square & \text { Ruas. } \\ & \text { Verde. } \\ & \text { Agua. } \\ \square \quad \text { Projeçāo construida. } \\ \square \text { Vazios. } \\ \text { Posto. }\end{array}$

Figura 4 - Foto aérea do Morro da Luz com a demarcação da área quantificada no entorno do posto. foto: Esteio Engenharia e Aerolevantamentos) 


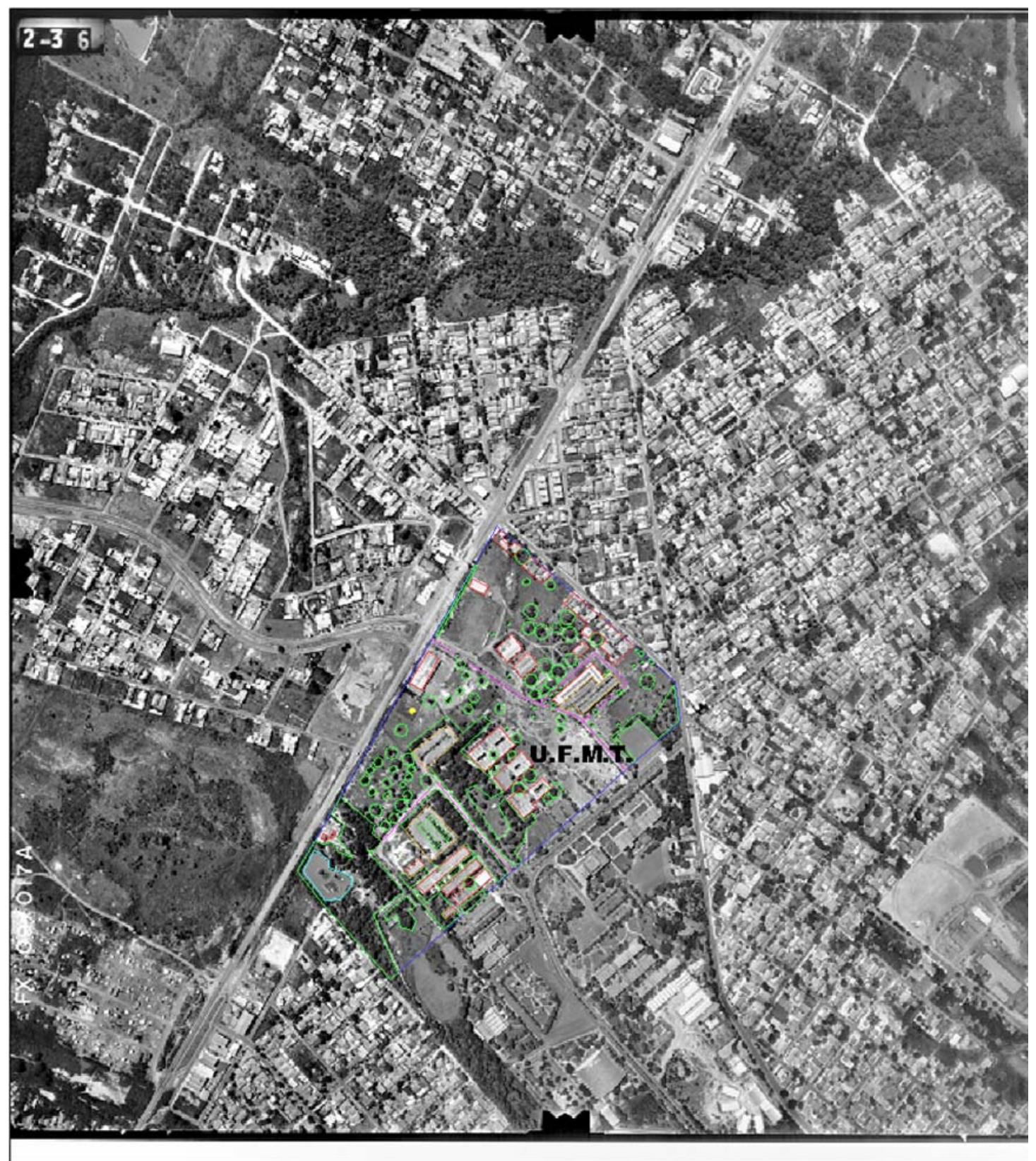

\section{LEGENDA}

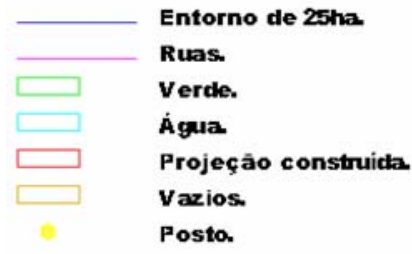

Figura 5 - Foto aérea da UFMT com a demarcação da área quantificada no entorno do posto. (foto: Esteio Engenharia e Aerolevantamentos) 


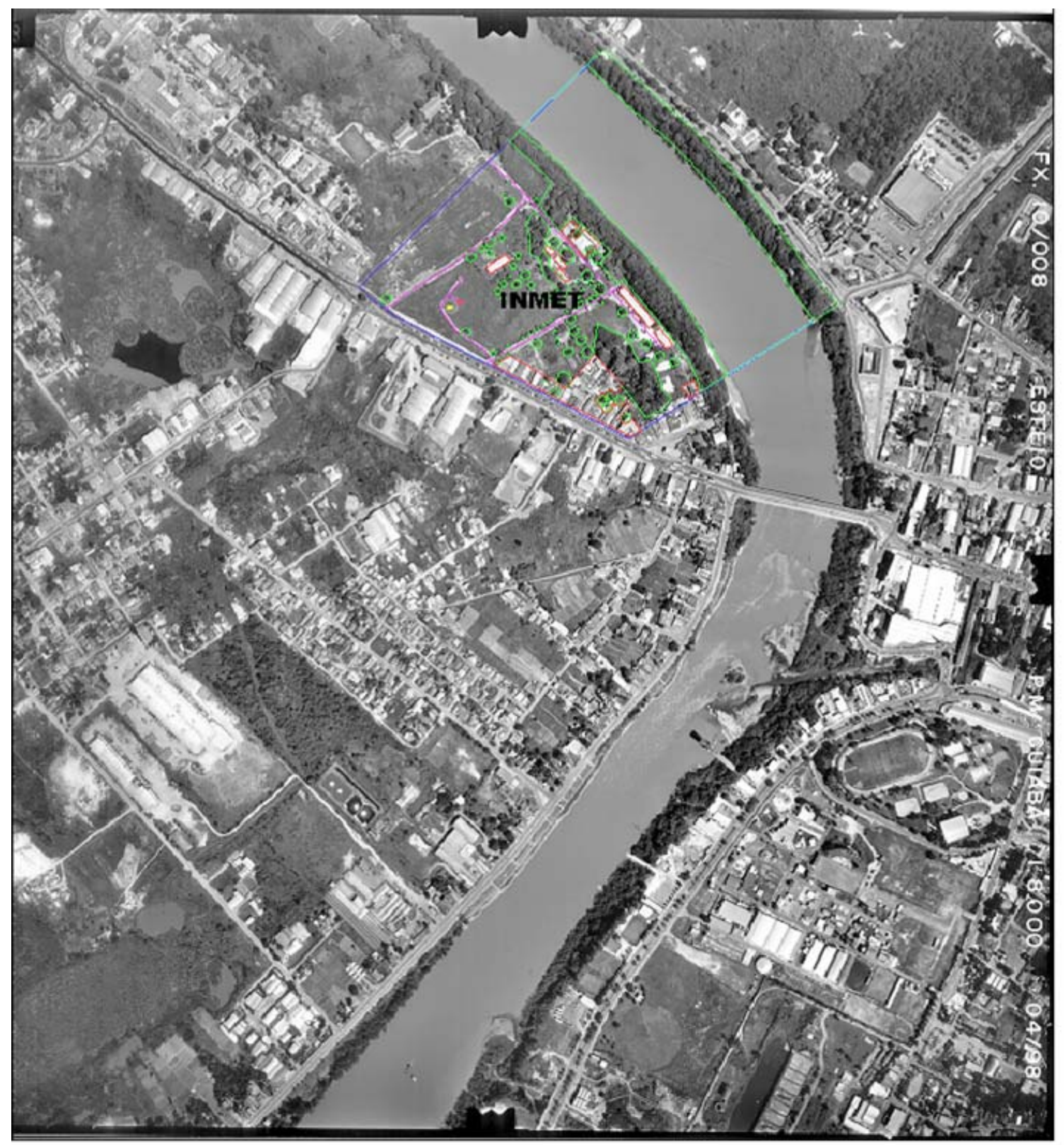

\section{LEGENDA}

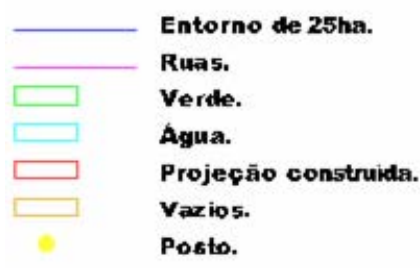

Figura 6 - Foto aérea do INMET com a demarcação da área quantificada no entorno do posto. (foto: Esteio Engenharia e Aerolevantamentos) 


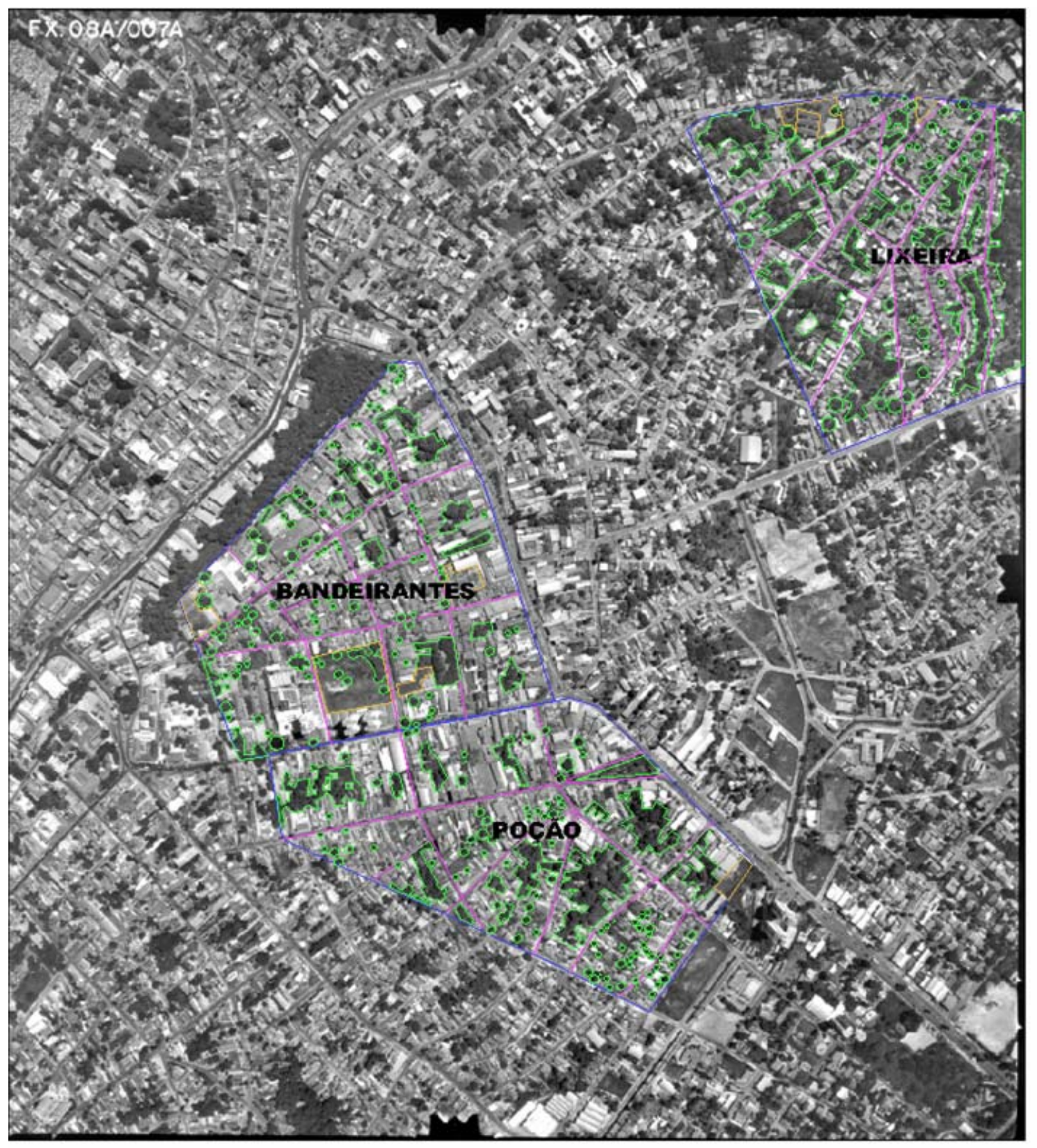

\section{LEGENDA}

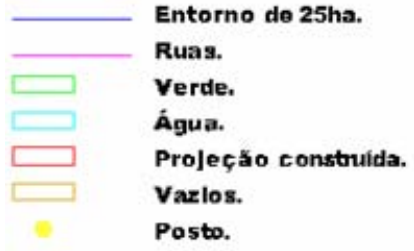

Figura 7 - Foto aérea dos bairros Lixeira, Poção e Bandeirantes, com a demarcação da área quantificada. (foto: Esteio Engenharia e Aerolevantamentos) 


\section{BIBLIOGRAFIA REFERENCIADA E CONSULTADA}

1. ALBERTI, Leon Battista. De Re Aedificatoria. Madri: Akal, 1991.

2. Album Graphico do Estado de Matto-Grosso. Corumbá/Hamburgo, 1914.

3. ALVAREZ DOMINGUEZ, Servando et al. Control Climático en Espacios Abiertos. El Proyecto EXPO’92. Sevilha: CIEMAT, 1992.

4. ALVAREZ, Servando, LOPEZ DE ASIAIN, Jaime, YANNAS, Simos (ed.). Architecture and Urban Space. Proceedings of the Ninth International PLEA Conference, September 24-27, 1991, Seville. Dordrecht: Kluwer, 1991.

5. ASSIS, Eleonora, FROTA, Anésia. Urban bioclimatic design strategies for a tropical city. Atmospheric Environment, Oxford, v.33, n.24-25, p.4135-4142, 1999.

6. ASSIS, Eleonora Sad de. Bases teóricas para a Aplicação da climatologia ao planejamento urbano. In: IV Encontro Nacional de Conforto no Ambiente Construído, 1997, Salvador. Anais. Salvador: FAUUFBA/LACAM-ANTAC, 1997. p.134-139.

7. ASSIS, Eleonora Sad de. Impacto da forma urbana na mudança climática: método para previsão do comportamento térmico e melhoria de desempenho do ambiente urbano. São Paulo, 2000. Tese (Doutorado em Arquitetura) Faculdade de Arquitetura e Urbanismo, Universidade de São Paulo.

8. ASSIS, Eleonora Sad de. Mecanismos de desenho urbano apropriados ‘a atenuação da ilha de calor urbana: análise de desempenho de áreas verdes em clima tropical. Rio de Janeiro, 1990. Dissertação (Mestrado em Arquitetura) - Faculdade de Arquitetura e Urbanismo, Universidade Federal do Rio de Janeiro.

9. ASSOCIAÇÃO DOS ARQUITETOS PORTUGUESES. Arquitectura Popular em Portugal. Lisboa: Associação dos Arquitetos Portugueses, 1980.

10. ATAIDE, Ruth. Na trilha da recuperação e preservação ambiental de Natal: limites e possibilidades do plano diretor. Natal, 2000.

11. AVISSAR, Roni. Potential effects of vegetation on the urban thermal environment. Atmospheric Environment, Oxford, v.30, n.3, p.437-448, 1996.

12. AZEVEDO, Aroldo de. Cuiabá. Estudo de Geografia Urbana. Relatório apresentado por Aroldo de Azevedo, orientador geral das pesquisas de campo. Anais da Associação dos Geógrafos Brasileiros. Julho, 1953.

13. BAHIA, Sérgio Rodrigues (coord.) Modelo para Elaboração de Código de Obras e Edificações. Rio de Janeiro: IBAM/DUMA, 1997. (Núcleo de Meio Ambiente do IBAM - Instituto Brasileiro de Administração Municipal, em convênio com a Eletrobrás através do Programa Nacional de Conservação de Energia - PROCEL).

14. BARBIRATO, Gianna, MATTOS, Arthur. Microclimas Urbanos em Maceió. In: V Encontro Nacional de Conforto no Ambiente Construído e II Encontro 
Latino-Americano de Conforto no Ambiente Construído - ENCAC, 1999, Fortaleza. Caderno de Resumos. Fortaleza: ANTAC, 1999.

15. BARBIRATO, Gianna, MATTOS, Arthur. O uso da modelagem climática no planejamento dos espaços urbanos. In: V Encontro Nacional de Conforto no Ambiente Construído e II Encontro Latino-Americano de Conforto no Ambiente Construído - ENCAC, 1999, Fortaleza. Caderno de Resumos. Fortaleza: ANTAC, 1999.

16. BAUMÜLLER, J. The introduction of climatology into the administration and development of planning in the city of Stuttgart. In: URBAN CLIMATOLOGY AND ITS APPLICATIONS WITH SPECIAL REGARD TO TROPICAL AREAS. Mexico D.F., 26-30 November 1984. Proceedings. OKE, T. (ed.) Urban Climatology and its Applications with Special Regard to Tropical Areas. Geneva: WMO n.652, 1986, p. 455-460.

17. BEHLING, Sophia et al. Sol Power. The evolution of solar architecture. Munich: Prestel, 1996.

18. BERG, Peter et al. A green city program for the San Francisco bay area and beyond. San Francisco: Planet Drum Foundation/Wingbow, 1990.

19. BERG, Peter. A metamorphosis for cities: from gray to green. In: City Lights Review, n.4.

20. BITAN, Arieh, ASSIF, Shamai. Climatic Data Analysis and its use and representation for planners. Energy and Buildings, Netherlands, n.7, p.11-22, 1984.

21. BITAN, Arieh. Bet She'an Master Plan - Climatic Rehabilitation of an Ancient Historic City. Energy and Buildings, Netherlands, n.15-16, p.23-33, 1990/1991.

22. BITAN, Arieh. The high climatic quality city of the future. Atmospheric Environment, Oxford, v.26B, n.3, p.313-329, 1992.

23. BITAN, Arieh. The methodology of applied climatology in planning and building. Energy and Buildings, Netherlands, n.11, p.1-10, 1988.

24. BITTENCOURT Leonardo Salazar et al. O efeito da verticalização das edificações na ventilação natural do tecido urbano: o caso da orla marítima de Maceió. In: VIII ENTAC, 2000, Salvador. Anais em CD-ROM. Salvador: ANTAC, 2000.

25. BITTENCOURT, Leonardo Salazar et al. A influência da relação entre taxa de ocupação $\mathrm{x} \mathrm{n}^{0}$ de pavimentos no potencial de ventilação natural dos ambientes internos e externos. In: IV Encontro Nacional de Conforto no Ambiente Construído, 1997, Salvador. Anais. Salvador: FAUUFBA/LACAM-ANTAC, 1997. p.102-106.

26. BITTENCOURT, Leonardo Salazar et al. Urban design for Natural Ventilation: the influence of pilotis. $X X$ UIA Congress, Barcelona, 1-7 Jul. 96. Barcelona, 1996.

27. BOMBLED, Jorge. Meio Século de Meteorologia. Cuiabá: Centro de Ciências Agrárias/UFMT, [s.d.]. v. II e III. 
28. BORNSTEIN, R. D. Urban climate models: nature, limitations and applications. In: URBAN CLIMATOLOGY AND ITS APPLICATIONS WITH SPECIAL REGARD TO TROPICAL AREAS. Mexico D.F., 26-30 November 1984. Proceedings. OKE, T. (ed.) Urban Climatology and its Applications with Special Regard to Tropical Areas. Geneva: WMO n.652, 1986, p.237-276.

29. BRANDÃO et. al. A construção do ambiente urbano através da interação das escalas: estudo de caso do Bairro Floresta, Belo Horizonte. In: VIII ENTAC, 2000, Salvador. Anais em CD-ROM. Salvador: ANTAC, 2000.

30. BRASIL. Ministério da Aeronáutica. Sumários Meteorológicos Mensais 1985 a 1994. Várzea Grande: Aeroporto Marechal Rondon.

31. BRASIL. Ministério da Agricultura e da Reforma Agrária. Normais Climatológicas 1961-1990. Brasília: INMET, [s.d.].

32. BRUAND, Yves. Arquitetura Contemporânea no Brasil. 2.ed. São Paulo: Perspectiva, 1991.

33. BUCKMINSTER FÜLLER. The Artifacts of R. Buckminster Füller. Vol.4: The Geodesic Revolution, Part 2, 1960-1983. New York, London: Garland, 1985.

34. BUNGE, Mario. Teoria e Realidade. São Paulo: Perspectiva, 1974.

35. CALDEIRA, Jorge. Mauá Empresário do Império. 9.ed. São Paulo: Companhia das Letras, 1995.

36. CALVINO, Italo. As cidades invisíveis. 8.reimp. São Paulo: Companhia das Letras, 1995.

37. CAMPELO Jr. et al. Caracterização Macroclimática de Cuiabá. In: $3^{\circ}$ Encontro Nacional de Estudos sobre o Meio Ambiente, Londrina 1991. Anais. Londrina, v.1, Comunicações, p.542-552.

38. CARMONA, Luis Sanchez de. Human comfort in the tropics. In: URBAN CLIMATOLOGY AND ITS APPLICATIONS WITH SPECIAL REGARD TO TROPICAL AREAS. Mexico D.F., 26-30 November 1984. Proceedings. OKE, T. (ed.) Urban Climatology and its Applications with Special Regard to Tropical Areas. Geneva: WMO n.652, 1986, p.354-404.

39. Cartilha Urbanística do Clima . Título original STÄDTEBAULICHE KLIMAFIBEL. Hinweise für die Bauleitplanung - folge 2. Stuttgart, 1995. Tradução do Arq. Francisco A. Gonçalves da Silva, 1998.

40. CASTElnAU, Francis. Expedição às Regiões Centrais da América do Sul. Tomo II. São Paulo: Companhia Editora Nacional, [s.d.].

41. Centro de Estatística Aplicada do Instituto de Matemática e Estatística da Universidade de São Paulo. Relatório de Consulta. São Paulo: CEA/IMEUSP, 2000.

42. CENTRO DE REFERÊNCIA EM GESTÃO AMBIENTAL PARA ASSENTAMENTOS HUMANOS. Unilivre: www.unilivre.org.br.

43. CENTRO-OESTE EM EXAME. A conquista do oeste. São Paulo: Exame, n.20, ed. 671,23 set. 1998. 
44. CHANDLER, T. J. Urban climatology and its relevance to urban design. Geneva: WMO, Technical Note nº149, WMO nº438, 1976.

45. CIONCO, Ronald M. High resolution urban morphology data for urban wind flow modeling. In: Atmospheric Environment, Oxford, v.32, n.1, p.7-17, 1998.

46. COMISSÃO MUNDIAL SOBRE MEIO AMBIENTE E DESENVOLVIMENTO. Nosso Futuro Comum. 2.ed. Rio de Janeiro: FGV, 1991.

47. COOK, Jeffrey. Searching for the Bioclimatic City. In: Architecture and Urban Space. Proceedings of the Ninth International PLEA Conference, September 24-27, 1991, Seville. Dordrecht: Kluwer, 1991. p.7-16.

48. COOK, Jeffrey. Urban Solar Oasis. Bioclimatic design strategies. ENEA/ ECO, Projects for Sustainable Development. Supplement to l'Arca. Milan and Rome, Italy, the Premier issue of ECO, p.6-9, 1999.

49. CORBELlA, O. YANNAS, S. Posto 3 Copacabana Rio de Janeiro. In: IV ENCAC, 1997, Salvador. Anais. Salvador: FAUUFBA/LACAM-ANTAC, 1997. p.118-123.

50. COSTA NETO, Pedro L. de O. Estatística. São Paulo: Edgard Blücher, 1977.

51. CUIABÁ. Prefeitura Municipal de Cuiabá. Cadastro Imobiliário. Cuiabá: Secretaria de Finanças.

52. CUIABÁ. Prefeitura Municipal de Cuiabá. Caderno do IPDU. [Cuiabá], [s.d.].

53. CUIABÁ. Prefeitura Municipal de Cuiabá. Plano Diretor de Desenvolvimento Urbano de Cuiabá. Cuiabá: IPDU, 1995.

54. CUIABÁ. Prefeitura Municipal de Cuiabá. Projeto Cura Cuiabá. [Cuiabá]: [s.n.],[s.d.].

55. D’ALINCOURT, Luiz. Memória sobre a viagem do porto de Santos à cidade de Cuiabá. Belo Horizonte: Itatiaia/São Paulo: EDUSP, 1975. (Coleção Reconquista do Brasil).

56. DANTAS, Jorge. Modelos Urbanos. Um enfoque científico no planejamento urbano. São Paulo, 1981. Tese (Livre-docência) - Faculdade de Arquitetura e Urbanismo, Universidade de São Paulo.

57. DEL RIO, Vicente. Introdução ao Desenho Urbano no Processo de Planejamento. São Paulo: PINI, 1990.

58. Diagnóstico Florístico e Faunístico da Cidade de Cuiabá. Convênio UFMT/Prefeitura Municipal de Cuiabá. Set. 1990.

59. DUARTE, Denise. Avaliação de Aspectos de Conforto Térmico Pós-Ocupação em Habitações na Região de Cuiabá-MT. In: III Encontro Nacional e I Encontro Latino-Americano de Conforto no Ambiente Construído, 1995, Gramado. Anais. Porto Alegre: ANTAC, 1995, p. 209-214.

60. DUARTE, Denise, BASSO, Admir. Considerações sobre o Estudo de Conforto Térmico para a Implantação de Conjunto Habitacional em Madeira na Cidade 
de Cuiabá - MT. In: V Encontro Brasileiro em Madeiras e em Estruturas de Madeira - EBRAMEM, 1995, Belo Horizonte. Anais. Belo Horizonte: CEFETMG/ EEUFMG / IBRAMEM, 1995, p. 387-394.

61. DUARTE, Denise. O clima como parâmetro de projeto para a região de Cuiabá. São Carlos, 1995. Dissertação (Mestrado em Arquitetura) - Escola de Engenharia de São Carlos, Universidade de São Paulo.

62. DUARTE, Denise. Recomendações de Projeto visando Condicionamento Térmico Natural em Climas Compostos: o caso de Cuiabá. In: VI Encontro Nacional de Tecnologia do Ambiente Construído - ENTAC 95, 1995, Rio de Janeiro. Anais. Rio de Janeiro: ANTAC - Associação Nacional de Tecnologia do Ambiente Construído, 1995, p. 611-616.

63. DUARTE, Denise, BASSO, Admir. Simulações de Desempenho Térmico de Alternativas para Projeto. In: VI Encontro Nacional de Tecnologia do Ambiente Construído - ENTAC 95, 1995, Rio de Janeiro. Anais. Rio de Janeiro: ANTAC - Associação Nacional de Tecnologia do Ambiente Construído, 1995, p. 819.

64. DUARTE, Denise. A Urbanização na Cidade de Cuiabá. Transformações e Perspectivas. In: NUTAU’96. Seminário Internacional: resumos. São Paulo: Universidade de São Paulo, Faculdade de Arquitetura e Urbanismo, Departamento de Tecnologia da Arquitetura, Núcleo de Pesquisa em Tecnologia da Arquitetura e Urbanismo, 1996, p. 64.

65. DUARTE, Denise. A reposição do verde em áreas urbanas: desmistificação e proposição de alternativas para o caso de Cuiabá. In: IV Encontro Nacional de Conforto no Ambiente Construído - IV ENCAC, 1997, Salvador. Anais. Salvador: FAU-UFBA/LACAM -ANTAC, 1997, p. 87-92.

66. DUARTE, Denise. The Urban Occupation in Rigorous Climate Cities. A case study in Cuiabá, Mato Grosso, Brazil. In: Environmentally Friendly Cities: Proceedings of PLEA 1998 - The $15^{\text {th }}$ International Conference on Passive and Low Energy Architecture, 1998, Lisbon, June, 1998, p. 133-136.

67. DUARTE, Denise. Qualidade no Processo Construtivo das Cidades Estudo de Caso: Cuiabá. In: NUTAU’98. Seminário Internacional: CD-ROM e Caderno de Resumos. São Paulo: Universidade de São Paulo, Faculdade de Arquitetura e Urbanismo, Departamento de Tecnologia da Arquitetura, Núcleo de Pesquisa em Tecnologia da Arquitetura e Urbanismo, 1998.

68. DUARTE, Denise, MAITELLI, Gilda. Urban Climate Study in the Mid-West Region of Brazil. Relations between urban land use and microclimatic conditions. In: Sustaining the future: Proceedings of the PLEA'99 Conference. The $16^{\text {th }}$ International Conference on Passive and Low Energy Architecture, v. 2, 1999, Brisbane, September, 1999, p.801-806.

69. DUARTE, Denise, MAITELLI, Gilda. Clima Urbano e Planejamento em Regiões Tropicais Continentais. In: V Encontro Nacional de Conforto no Ambiente Construído - V ENCAC, 1999, Fortaleza. Caderno de Resumos e CD-ROM. Fortaleza, ANTAC, 1999. 
70. DUARTE, Denise. Ocupação e Clima Urbano. In: VIII Encontro Nacional de Tecnologia do Ambiente Construído - ENTAC 2000, Salvador. Anais em CD-ROM. Salvador, ANTAC, 2000.

71. DUARTE, Denise. Occupation and Urban Climate. Comparison among three downtown areas with different urban patterns. Resumo aceito para o PLEA2000 Conference. The $17^{\text {th }}$ International Conference on Passive and Low Energy Architecture. Cambridge, July, 2000.

72. DUARTE, Denise. A inclusão de questões de conforto térmico urbano nas regulamentações municipais no Brasil. In: NUTAU'2000. Anais em CDROM. São Paulo: NUTAU, 2000.

73. DUARTE, Denise. A evolução urbana da cidade de Cuiabá. Do Brasil colônia aos novos caminhos no ano 2000. In: Colóquio Arquitetura Brasileira: Redescobertas, $16^{\circ}$ Congresso Brasileiro de Arquitetos, 2000, Cuiabá. Caderno de resumos. Cuiabá: IAB/MG e IAB/MT, setembro de 2000.

74. ECHENIQUE, Marcial. Modelos: una discusión. In: Martin, L. et al. La Estructura del Espácio Urbano. Barcelona: Gustavo Gili, 1975.

75. ELIASSON, Ingegärd. Urban geometry, surface temperature and air temperature. Energy and Buildings, n.15-16, 1990/91, p.141-145.

76. EMMANUEL, Rohinton. A Hypothetical 'shadow umbrella' for thermal comfort enhancements in the equatorial urban outdoors. Architectural Science Review, n.36, 1993. p.173-184.

77. Empresa \& Ambiente. Encarte especial da revista Exame, São Paulo, 2000.

78. Energy and environment in cities. A global strategy for EXPO'98 Lisbon. Principles and tools. [Lisboa]: [1998].

79. EVANS \& SCHILLER. Training Architects and Planners to Design with Urban Microclimates. In: Atmospheric Environment, Oxford, v.30, n.3, p 449-454, 1996.

80. EVANS, M., SCHILLER, S. Application of microclimate studies in town planning: a new capital city, an existing urban district and urban river front development. In: Atmospheric Environment, Oxford, v.30, n.3, p. 361-364, 1996.

81. Expedição Langsdorff ao Brasil 1821-1829. 3v. Rio de Janeiro: Alumbramento/ Livroarte, 1988.

82. EXPO’98 Lisboa. Guia Oficial. [Lisboa]: [1998].

83. FATHY, Hassan. Natural Energy and Vernacular Architecture. Chicago: The University of Chicago Press, 1986.

84. FIGUEIREDO, Aline. Artes Plásticas no Centro-Oeste. Cuiabá: UFMT/MACP, 1979.

85. FLEURY DE OLIVEIRA, José Luiz Ferreira. Amazônia: Condicionantes da Ocupação e Assentamentos Humanos. São Paulo, 1984. Dissertação (Mestrado) - Faculdade de Arquitetura e Urbanismo, Universidade de São Paulo. 
86. FLEURY DE OLIVEIRA, José Luiz Ferreira. Amazônia: Proposta para uma Ecoarquitetura. São Paulo, 1989. Tese (Doutoramento) - Faculdade de Arquitetura e Urbanismo, Universidade de São Paulo.

87. FLORENCE, Hercules. Viagem Fluvial do Tietê ao Amazonas: 1825 a 1829. São Paulo: Cultrix/EDUSP, 1977. Gravuras do autor e Trad. Visconde de Taunay.

88. FREIRE, Júlio De Lamonica. Cuiabá Nosso Bem Coletivo. Cuiabá: UFMT, 1992.

89. FREIRE, Júlio De Lamonica. Por Uma Poética Popular da Arquitetura. São Paulo: ECAUSP, 1988. Dissertação (Mestrado em Artes). Escola de Comunicação e Artes, Universidade de São Paulo.

90. FREYRE, Gilberto. Sobrados e Mucambos. 8ed. Rio de Janeiro: Record, 1990.

91. FURTADO, Celso. Formação Econômica do Brasil. 25.ed. São Paulo: Nacional, 1995.

92. GIVONI, Baruch. Climate Considerations in Building and Urban Design. New York: John Wiley \& Sons, 1998.

93. GIVONI, Baruch. Climatic aspects of urban design in tropical climates. Atmospheric Ennvironment, v.26B, n.3, 1992a, p.397-406.

94. GIVONI, Baruch. Comfort, climate analysis and building design guidelines. Energy and Buildings, n18, 1992b, p.11-23.

95. GIVONI, Baruch. Design for climate in hot, dry cities. In: URBAN CLIMATOLOGY AND ITS APPLICATIONS WITH SPECIAL REGARD TO TROPICAL AREAS. Mexico D.F., 26-30 November 1984. Proceedings. OKE, T. (ed.) Urban Climatology and its Applications with Special Regard to Tropical Areas. Geneva: WMO n.652, 1986, p.487-513.

96. GIVONI, Baruch. Impact of planted areas on urban environmental quality: a review. Atmospheric Environment, Oxford, v.25B, n.3, p.289-199, 1991.

97. GIVONI, Baruch. Passive and Low Energy Cooling of Buildings. New York: John Wiley \& Sons, 1994.

98. GIVONI, Baruch. Urban Design in Different Climates. Geneva: WMO Technical Document n.346, 1989.

99. GOLDREICH, Yair. Urban climate studies in Johannesburg, a sub-tropical city located on a ridge - a review. Atmospheric Environment, v.26B, n.3, p.407420, 1992.

100. GONÇALVES, Joana. Limites para a verticalidade. Qualidade na Construção. São Paulo, n.21, 1999, p.16-26.

101. GONÇALVES, Wantuelfer. Padrões de Assentamento de Áreas Verdes Municipais - uma visão crítica. São Paulo: FAUUSP, 1994. Tese (Doutoramento). Faculdade de Arquitetura e Urbanismo, Universidade de São Paulo.

102. GOROVITZ, Matheus. Brasília, uma questão de escala. São Paulo: Projeto, 1985. 
103. GOUVEA, Luiz Alberto de Campos. Desenhando a cidade com a natureza. São Paulo, 1995. Tese (Doutorado em Arquitetura), Faculdade de Arquitetura e Urbanismo, Universidade de São Paulo, 1995.

104. GUERRA MACHO, José J. et al. Control Climático em Espacios Abiertos. Evaluación del Proyecto EXPO’92. Sevilha: CIEMAT, 1994.

105. HARAZONO et al. Effects of rooftop vegetation using artificial substrates on the urban climate and the thermal load of buildings. Energy and Buildings, n.15-16, 1990/91, p.435-442.

106. HERZOG, Thomas, KAISER, Norbert, VOLTZ, Michael (ed.). Solar Energy in Architecture and Urban Planning. Munich: Prestel, 1996.

107. HESSEN, Johannes. Teoria do Conhecimento. 8.ed. Coimbra: Armenio Amado, 1987.

108. HILDEBRANDT, Eric W., SARKOVICH, Misha. Assessing the costeffectiveness of SMUD's Shade Tree Program. Atmospheric Environment, Oxford, v.32, n.1, p.85-94, 1998.

109. HOGAN, Daniel Joseph, VIEIRA, Paulo Freire (orgs). Dilemas Socioambientais e Desenvolvimento Sustentável. Campinas: UNICAMP, 1992. p.149-192.

110. HOJE EM DIA. Belo Horizonte. Cidade Jardim. Belo Horizonte: Hoje em Dia/Rede Marketing e Comunicação, 26 mar. 2000.

111. HOLANDA, Sérgio Buarque de. Caminhos e Fronteiras. 3ed. São Paulo: Companhia das Letras, 1994.

112. HOLANDA, Sérgio Buarque de. Raízes do Brasil. 26ed. São Paulo: Companhia das Letras, 1995.

113. HONJO, T., TAKAKURA, T. Simulation of thermal effects of urban green Areas on their surrounding areas. Energy and Buildings, Netherlands, n.1516, 1990/91, p.443-446.

114. HONJO, T., TAKAKURA, T. Simulation of thermal effects of urban green reas on their surrounding areas. Energy and Buildings, n.15-16, 1990/91, p.443446.

115. HOUGH, Michael. Naturaleza y ciudad. Barcelona: Gustavo Gili, 1998.

116. HOWARD, Ebenezer. Cidades-Jardins de Amanhã. Introdução de Dacio A. B. Ottoni. São Paulo: Hucitec, 1996. (Estudos Urbanos. Série Arte e Vida Urbana.)

117. HULL, R. B. Brief encounters with urban forests produce moods that matter. Journal of Arboriculture, v.18, n.6, p.322-324, Nov. 1992.

118. IBGE. Anuário Estatístico do Brasil 1993. Rio de Janeiro, v.52, 1994.

119. IBGE. Geografia do Brasil. Rio de Janeiro: IBGE, Fundação Instituto Brasileiro de Geografia e Estatística, 1988. 5v. V. 1: Região Centro-Oeste.

120. IPUUC. Como Curitiba é planejada. In: www.ippuc.pr.gov.br 
121. IV INTERNATIONAL ECOCITY CONFERENCE. Curitiba: Unilivre, abr. 2000.

122. JAUREGUI, E. The urban climate of Mexico City. In: URBAN CLIMATOLOGY AND ITS APPLICATIONS WITH SPECIAL REGARD TO TROPICAL AREAS. Mexico D.F., 26-30 November 1984. Proceedings. OKE, T. (ed.) Urban Climatology and its Applications with Special Regard to Tropical Areas. Geneva: WMO n.652, 1986, p.63-86.

123. JAUREGUI, E., GODINEZ, L., CRUZ, F. Aspects of heat-island development in Guadalajara, Mexico. Atmospheric Environment, v.26B, n.3, p.391-396, 1992.

124. JAUREGUI, Ernesto. Overview of papers on urban climate in tropical/subtropical areas. In: TECHNICAL CONFERENCE OF TROPICAL URBAN CLIMATES. Dhaka, mar./apr.1993. Report. [Geneva]: WMO/TD n.647, 1994, p.377-390.

125. KATZSCHNER, Lutz. Urban climate studies as tools for urban planning and architecture. In: IV Encontro Nacional de Conforto no Ambiente Construído, 1997, Salvador. Anais. Salvador: FAUUFBA/LACAMANTAC, 1997, p.49-58.

126. KEEBLE, E.J., COLLINS, M., RYSER, J. The potential of land-se planning and development control to help achieve favorable microclimates around buildings: a European review. Energy and Buildings, n.15-16, 1990/91, p.823-836.

127. KLIASS, Rosa G. Parques Urbanos de São Paulo. São Paulo: Pini, 1994.

128. KÖPPEN, Wilheim. Climatologia. México: Fondo de Cultura Económica, 1948.

129. KUHN, Thomas S. A Estrutura das Revoluções Científicas. 3.ed. São Paulo: Perspectiva, 1994.

130. LAMAS, José M. Ressano Garcia. Morfologia Urbana e Desenho da Cidade. [Lisboa]: Fundação Calouste Gulbenkian/Junta Nacional de Investigação Científica e Tecnológia, [s.d.].

131. LANDSBERG, Helmut. The meteorologically utopian city. Bulletin of American Meteorological Society. v.54, n.2, p.86-89, feb. 1973.

132. LE CORBUSIER. A Carta de Atenas. São Paulo: Hucitec/EDUSP, 1993. (Estudos Urbanos. Série Arte e Vida Urbana)

133. LEMOS, Carlos. História da Casa Brasileira. São Paulo: Contexto, 1989. (Coleção Repensando a História).

134. LOMBARDO, Magda. Clima urbano. Notas de aula. Curso ministrado durante o V ENCAC - Encontro Nacional de Conforto no Ambiente Construído, 1999, Fortaleza.

135. LOMBARDO, Magda. Ilha de calor nas metrópoles. São Paulo: Hucitec, 1985. 
136. LOMBARDO, Magda. O clima e a cidade. In: IV Encontro Nacional de Conforto no Ambiente Construído, 1997, Salvador. Anais. Salvador: FAUUFBA/LACAM-ANTAC, 1997. p.59-62.

137. LOMBARDO, Magda. Qualidade Ambiental e Planejamento Urbano: considerações e métodos. São Paulo, 1995. Tese (Livre-docência). Faculdade de Filosofia, Letras e Ciências Humanas - Departamento de Geografia, Universidade de São Paulo.

138. LOVINS, Amory, LOVINS, L. Hunter. O capitalismo natural. Exame, São Paulo, ed.715, 31 de maio de 2000, p.160-166.

139. LYNCH, Kevin. ¿De qué tiempo es este lugar? Para una nueva definición del ambiente. Barcelona: Gustavo Gili, 1975. (Colección Arquitectura y Crítica).

140. MACRIS, Dean, WILLIAMS, George. San Francisco's Downtown Plan: Landmark Guidelines Shape City's Growth. August, 1999. In: www.spur.org/downtown.html

141. MAITELLI, Gilda T. Uma Abordagem Tridimensional de Clima Urbano em Área Tropical Continental: o exemplo de Cuiabá - MT. São Paulo, 1994. Tese (Doutorado em Geografia). Faculdade de Filosofia, Letras e Ciências Humanas, Universidade de São Paulo.

142. MALDONADO, Eduardo, YANNAS, Simos (ed.). Environmentally Friendly Cities. PLEA'98. The $15^{\text {th }}$ Passive and Low Energy Architecture Conference. Lisbon, 1998. Proceedings. London: James \& James, 1998.

143. MARTINS Jr., Osmar Pires. Uma Cidade Ecologicamente Correta. Goiânia: AB, 1996.

144. MENDONÇA, Rubens de. Roteiro Histórico \& Sentimental da Vila Real do Bom Jesus de Cuiabá. Cuiabá: Igrejinha, 1975.

145. MENEZES, Claudino Luiz. Desenvolvimento Urbano e Meio Ambiente. A experiência de Curitiba. Campinas: Papirus, 1996.

146. MENNEH, Márcia H., COELHO, Ana Maria. Características do sistema de parques públicos urbanos da cidade de São Paulo. In: VIII ENTAC, 2000, Salvador. Anais em CD-ROM. Salvador: ANTAC, 2000.

147. MIGLIORINI, Vera L. B. Os padrões de desempenho do uso e ocupação do solo na previsão e controle do adensamento de áreas intra-urbanas. São Paulo, 1997. Tese (Doutorado) Escola Politécnica, Universidade de São Paulo.

148. MILLER-CHAGAS, Philomena. Apports énergétiques solaires, microclimats et configuration urbaine dans trois cités à Strasbourg. Recherche Géographiques à Strasbourg, n.13-14, 1980. (Extrait des Actes des Journées de Climatologie 1980. Strasbourg, 13-15 novembre 1980).

149. MIZUNO M. et al. Effects of land use on urban horizontal atmospheric temperature distributions. Energy and Buildings, n.15-16, 1990/91, p.165176. 
150. MONTEIRO, Carlos A. F. A cidade como processo derivador ambiental e estrutura geradora de um clima urbano’. Geosul, Florianópolis, n.9, p.80114, 1990.

151. MONTEIRO, Carlos A. F. Adentrar a cidade para tomar-lhe a temperatura. Geosul, Florianópolis, n.9, p.61-79, 1990.

152. MONTEIRO, Carlos A. F. Cidade e ambiente atmosférico. Geosul, Florianópolis, n.9, p.115-123, 1990.

153. MONTEIRO, Carlos A. F. Entrevista com o Prof. Carlos Augusto de Figueiredo Monteiro. Geosul, Florianópolis, n.9, p.124-139, 1990.

154. MONTEIRO, Carlos A. F. Por um suporte teórico e prático para estimular estudos geográficos do clima urbano do Brasil. Geosul, Florianópolis, n.9, p.7-19, 1990.

155. MONTEIRO, Carlos A. F. Teoria e Clima Urbano. São Paulo: Universidade de São Paulo, 1976. Série Teses e Monografias, n.25.

156. MONTEITH, John Lennox. Principles of Environmental Physics. 2.ed. London/New York : E. Arnold / Routledge, Chapman and Hall, 1990.

157. MOURA, Carlos Francisco. Notas sobre a História da Arquitetura em Mato Grosso. Belém: UFMT/SUDAM, 1976.

158. MÜLLER, Maria de Arruda, RODRIGUES, Dunga. Cuiabá ao Longo de 100 Anos. [Cuiabá]: [s.n.], 1994.

159. MUMFORD, Lewis. A Cidade na História. 3.ed. São Paulo: Martins Fontes, 1991.

160. NEW'PLAN. Plano de Desenvolvimento Local Integrado de Cuiabá. [s.l.],[s.d.].

161. NIMER, Edmon. Climatologia do Brasil. Rio de Janeiro: IBGE/SUPREN, 1979 (Série Recursos Naturais e Meio Ambiente, n.4).

162. NOVAES, Antonio G. Modelos em Planejamento Urbano, Regional e de Transportes. São Paulo: Edgard Blücher, 1982.

163. Novos Hotéis no Estado do Amazonas. ABA, n.1, p.132-135, 1967/68.

164. OKE, Tim R. Boundary Layer Climates. 2.ed. London/New York: Methuen, 1987.

165. OKE, Tim R. Canyon Geometry and the nocturnal urban heat island: comparison of scale model and field observations. Journal of Climatology, v.1, p.237-254, 1981.

166. OKE, Tim R. City size and the urban heat island. Atmospheric Environment, v.7, 1973a, p.769-779.

167. OKE, Tim R. et al. The energy balance of central Mexico City during the dry season. Atmospheric Environment, v.33, 1999, p.3919-3930.

168. OKE, Tim R. Evapotranspiration in urban areas and its implications for urban climate planning. In: Conference Teaching the Teachers on Building 
Climatology. Proceedings. The National Swedish Institute for Building Research, v.2, 1973.

169. OKE, Tim R. The distinction between canopy and boundary-layer urban heat islands. Atmosphere, v.14, n.4, p.269-277, 1976.

170. OKE, Tim R. The energetic basis of the urban heat island. Quarterly Journal of the Royal Meteorology Society, v.108, n.455, p.1-24, jan.1982.

171. OKE, Tim R. Towards a prescription for the greater use of climatic principles in settlement planning. Energy and Buildings, Netherlands, n.7, p.1-10, 1984.

172. OKE, Tim R., KALANDA, B. D., STEYN, D. G. Parametrization of heat storage in urban areas. Urban Ecology, Netherlands, v.5, 1980/1981, p.4554.

173. OKE, Tim R., TAESLER, Roger, OLSSON, Lars. The Tropical Urban Climate Experiment (TRUCE). Building and Environment, Netherlands, v.15-15, p.67-73, 1990/91.

174. OLIVEIRA NETO, Antonio Firmino de. Ruas e calçadas de Campo GrandeMS: uma contribuição ao estudo dos espaços públicos urbanos. São Paulo, 1997. Dissertação (Mestrado em Geografia) - Faculdade de Filosofia, Letras e Ciências Humanas, Universidade de São Paulo.

175. OLIVEIRA, Ernesto V., GALHANO, Fernando. Arquitectura Tradicional Portuguesa. Lisboa: Dom Quixote, 1992. (Portugal de Perto, n.24).

176. Ordenanzas de descubrimiento, nueva población y pacificación de las Indias, dadas por Felipe II en 1573. Madrid: Instituto de Cultura Hispánica, 1973.

177. ORNSTEIN, Sheila, BRUNA, Gilda, ROMERO, Marcelo. Ambiente Construído \& Comportamento: a avaliação pós-ocupação e a qualidade ambiental. São Paulo: Nobel, FAUUSP, FUPAM, 1995.

178. PAGE, J. K. Climate Considerations and Energy Conservation. In: BACH, W., PANKRATH, J., WILLIAMS J. (ed.). Interactions of climate and energy. Dordrecht: Reidel, 1980. p.73-88.

179. PAULSSON, Bengt. Remote Sensing - an operational tool for urban planning in developing countries. In: Cities of the world as seen from space. Hong Kong: Geocarto International Centre, [s.d.].

180. PEARLMUTTER D., BITAN A. \& BERLINER, P. Microclimatic analyses of compact urban canyons in an arid zone. Atmospheric Environment, Oxford, v.33, n.24-25, p.4143-4150, 1999.

181. POMERANTZ, Melvin et al. Physics and public policy for urban heat island mitigation. In: http://eetd.lbl.gov/HeatIsland/PUBS/APS-PressRelease/

182. PÓVOAS, Lenine C. Cuiabá de Outrora. Cuiabá: Resenha Tributária, 1983.

183. PÓVOAS, Lenine C. Cuiabanidade. Cuiabá : [s.n.], 1987.

184. PÓVOAS, Lenine C. Sobrados e Casas Senhoriais de Cuiabá. [Cuiabá] : Fundação Cultural de Mato Grosso, 1980. 
185. PRESSMAN, N. Quality for public urban space and pedestrian movement. In: Architecture and Urban Space. Proceedings of the Ninth International PLEA Conference, September 24-27, 1991, Seville. Dordrecht: Kluwer, 1991. p.99-107.

186. PRESSMAN, Norman E. P. Sustainable winter cities: future directions for planning, policy and design. Atmospheric Environment, Oxford, v.30, n.3, p.521-529, 1996.

187. Projeto de Lei do $2^{\circ}$ Plano Diretor de Desenvolvimento Urbano e Ambiental de Porto Alegre. Porto Alegre, [s.d.].

188. QUATTROCHI, Dale \& RIDD, Merryll. Analysis of vegetation within a semiarid urban environment using high spatial resolution airborne thermal infrared remote sensing data. Atmospheric Environment, Oxford, v.32, n.1, p.19-33, 1998.

189. RAPOPORT, Amos. House Form and Culture. Englewood Cliffs, NJ: Prentice-Hall, 1969. Foundations of Cultural Geography Series.

190. REGISTER, Richard, PEEKS, Brady (ed.). Village wisdom. Future cities. The Third International Ecocity and Ecovillage Conference, 8-12 jan. 1996. Oakland: Ecocity Builders, 1997.

191. REIS FILHO, Nestor Goulart. Quadro da Arquitetura no Brasil. 6.ed. São Paulo: Perspectiva, 1987.

192. REIS, Nestor Goulart. Imagens de vilas e cidades do Brasil Colonial. São Paulo: FUPAM, 2000.

193. ROCHA, Paulo Mendes da. Av. Beira Rio/Bairro do Porto. Plano Piloto para a urbanização das áreas marginais do Rio Cuiabá. Out. 1979.

194. ROGERS. Richard. Cities for a small planet. London: Faber and Faber, 1997.

195. ROMERO, Marta Adriana Bustos. Viabilidade Ambiental de Urbanização do Distrito Federal. Analise das constantes morfológicas. Brasília: UNB/FAU, Relatório Final de Projeto de Pesquisa CNPq, 1999.

196. ROSENFELD, Arthur et al. Painting the town white- and green. In: http://eetd.lbl.gov/HeatIsland/PUBS/PAINTING

197. ROSENFELD, Arthur et al. Policies to reduce heat islands: magnitudes of benefits and incentives to achieve them. In: ACEEE Summer Study on Energy Efficiency in Buildings. Proceedings. Pacific Grove, CA, v.9, 1996, p.177 (disponível também em http://eetd.lbl.gov/HeatIsland/PUBS).

198. ROSENFELD, Arthur et al. Mitigation of urban heat islands: materials, utility programs, updates. Energy and Buildings, v.22, p.255-265, 1995.

199. RUANO, Miguel. Ecourbanismo. Entornos humanos sostenibles: 60 proyectos. Barcelona: Gustavo Gili, 1999.

200. RUDOFSKY, Bernard. Architecture without architects. New York: The Museum of Modern Art, 1964. 
201. SÁ, Cássio Veiga de. Memórias de um Cuiabano Honorário. São Paulo: Resenha Tributária, 1980.

202. SAILOR, David J. Simulations of annual degree day impacts of urban vegetative augmentation. In: Atmospheric Environment, Oxford, v.32, n.1, p.43-52, 1998.

203. SAILOR, David. Simulated urban climate response to modifications in surface albedo and vegetative cover. Journal of Applied Meteorology, v.34, p.16941701, 1995.

204. SAMPAIO, Antonio Heliodorio Lima. Correlações entre o uso do solo e ilhas de calor no ambiente urbano: o caso de Salvador. São Paulo, 1981. Dissertação (Mestrado em Geografia), Faculdade de Filosofia, Letras e Ciências Humanas, Universidade de São Paulo.

205. SANTAMOURIS, Matheos. Energy and indoor climate in urban environments - recent trends. In: IV Encontro Nacional de Conforto no Ambiente Construído, 1997, Salvador. Anais. Salvador: FAUUFBA/LACAMANTAC, 1997. p.15-24.

206. SANTAMOURIS, Matheos. The Athens urban climate experiment. In: Environmentally Friendly Cities. Proceedings of PLEA'98. Lisbon: James and James, 1998, p.147-152.

207. SANTANA, Andrea. O desenho urbano e a climatologia em Fortaleza. São Paulo, 1997. Dissertação (Mestrado em Geografia) - Faculdade de Filosofia, Letras e Ciências Humanas, Universidade de São Paulo.

208. SÃO PAULO. Prefeitura Municipal de São Paulo. A Questão Ambiental Urbana: Cidade de São Paulo. São Paulo: Prefeitura Municipal de São Paulo/SVMA, 1993.

209. SANTOS, Milton. A urbanização brasileira. São Paulo: Hucitec, 1993.

210. SANTOS, Milton. O espaço do cidadão. São Paulo: Nobel, 1996.

211. SÃO PAULO. Programa um milhão de árvores. Educação Ambiental. Secretaria Municipal do Verde e do Meio Ambiente: DEAPLA, 1997.

212. SCHILLER S., EVANS, J. M. Design of outdoor spaces: socio-political tendencies and bioclimatic consequences. In: Architecture and Urban Space. Proceedings of the Ninth International PLEA Conference, September 24-27, 1991, Seville. Dordrecht: Kluwer, 1991. p.109-114.

213. SCHILLER, S, EVANS, M. Climate responsive urban development in tropical cities: training and practice. In: TECHNICAL CONFERENCE OF TROPICAL URBAN CLIMATES. Dhaka, mar./apr.1993. Report. [Geneve]: WMO/TD n.647, 1994, p.377-390. p.357-364.

214. SCHOENAUER, Norbert. 6.000 Años de Hábitat. De los poblados primitivos a la vivienda urbana en las culturas de oriente y occidente. Barcelona: Gustavo Gili, 1984. Colección Arquitectura / Perpectivas.

215. SERRA, Geraldo Gomes. Modelos. Notas de aula. São Paulo: FAUUSP, 1997. 
216. SERRA, Geraldo Gomes. O espaço natural e a forma urbana. São Paulo: Nobel, 1987.

217. SERRA, Geraldo Gomes. Obras urbanas. Notas de aula. São Paulo: FAUUSP, 1996.

218. SEZERINO, Maria Lurdes e MONTEIRO, Carlos A. F. O campo térmico da cidade de Florianópolis. Geosul, Florianópolis, n.9, p.20-60, 1990.

219. SHARLIM, N., HOFFMAN, M.E. The urban complex as a factor in the airtemperature pattern in a Mediterranean coastal region. Energy and Buildings, n.7, 1984, p.149-158.

220. SHEETS, Virgil L., MANZER, Chris D. Affect, cognition, and urban vegetation. Some effects of adding trees along city streets. Environment and Behavior, v.23, n.3, p.285-304, May 1991.

221. SILVA, Francisco A. Gonçalves da. O vento como ferramenta no desenho do ambiente construído. Uma aplicação do nordeste do Brasil. São Paulo, 1999. Tese (Doutorado) - Faculdade de Arquitetura e Urbanismo, Universidade de São Paulo.

222. SIMONDS, John Ormsbee. Garden cities 21. Creating a livable urban environment. United Sates: McGraw-Hill, 1994.

223. SMITH, Herbert. Do Rio de Janeiro a Cuyabá. Notas de um Naturalista. São Paulo: Melhoramentos, 1922. (Com um capítulo de Carlos von den Steinen sobre a capital de Matto Grosso).

224. SPIRN, Anne Whiston. O jardim de granito. São Paulo: EDUSP, 1995.

225. STEEMERS, Koen and YANNAS, Simos (ed.). Architecture, City, Environment. PLEA2000. The $17^{\text {th }}$ International Passive and Low Energy Architecture Conference. Cambridge, July, 2000. Proceedings. London: James \& James, 2000.

226. SUMMIT, Joshua \& SOMMER, Robert. Urban tree-planting programs - a model for encouraging environmentally protective behavior. In: Atmospheric Environment, Oxford, v.32, n.1, p.1-5, 1998.

227. SZOKOLAY, Steven (ed.) Sustaining the future. Energy-ecology-architecture. PLEA'99. The $16^{\text {th }}$ international Passive and Low Energy Architecture Conference. Brisbane, Australia, 22-24 September 1999. Proceedings. Brisbane: University of Queensland, 1999. 2v.

228. TAESLER, Roger. Urban climatological methods and data. In: URBAN CLIMATOLOGY AND ITS APPLICATIONS WITH SPECIAL REGARD TO TROPICAL AREAS. Mexico D.F., 26-30 November 1984. Proceedings. OKE, T. (ed.) Urban Climatology and its Applications with Special Regard to Tropical Areas. Geneva: WMO n.652, 1986, p.199-236.

229. TAHA, Haider et al. Residential cooling loads and the urban heat island - the effects of albedo. Building and Environment, v.23, n.4, p.271-283, 1988. 
230. TAHA, Haider. Night time air temperature and the sky-view factor: a case study in San Francisco, California. Lawrence Berkeley Laboratory, Berkeley CA, LBL- 24009, 1988.

231. TOLEDO, Eustáquio. Ventilação Natural das Habitações. Maceió: EDUFAL, 1999.

232. TREWARTHA, Glenn. An Introduction to Climate. 3.ed. New York: McGrawHill, 1954.

233. TSO, C. P. A survey of urban heat island studies in two tropical cities. Atmospheric Environment, Oxford, v.30, n.3, p.507-519, 1996.

234. UNILIVRE. Cidade, homem e natureza: uma história das políticas ambientais de Curitiba. Curitiba: Unilivre, 1997.

235. UPMANIS, Hillevi. The park has its own climate. Swedish Building Research, n.2, p.8-10, 2000.

236. VILLAS BOAS, Márcio. Environmental criteria and design principles for a new community in Brasilia. In: Environmentally Friendly Cities. Proceedings of PLEA'98. Lisbon: James and James, 1998, p.137-140.

237. VITRUVIO, Marco Lucio. Los Diez Libros de Arquitectura. Barcelona: Iberia, 1997.

238. VIVEIROS, Esther. Rondon conta sua vida. Rio de Janeiro: Livraria São José, 1958.

239. WORLD METEOROLOGICAL ORGANIZATION. Fourth WMO Long-Term Plan 1996-2005. Summary of Objectives, Policies and Strategy. Geneva: WMO n.831, 1996.

240. World Meteorological Organization. Guide to Meteorological Instruments and Methods of Observations. 6.ed. [s.l.]: WMO n.8, [s.d.].

241. WORLD METEOROLOGICAL ORGANIZATION. Technical Conference on Tropical Urban Climates, 1993, Dhaka. Report. Geneva: WCASP-30, WMO/TD n647, 1994.

242. YANNAS, Simos. Living with the city. Urban design and Environmental Sustainability. In: Environmentally Friendly Cities. Proceedings of PLEA’98. Lisbon: James and James, 1998, p.41-48.

243. YEANG, Ken. Designing with nature. The ecological basis for architectural design. United States: McGraw-Hill, 1995. 